\title{
PETROLOGÍA, GEOQUÍMICA Y DIAGÉNESIS DE SEDIMENTITAS Y FÓSILES CARBONÁTICOS DEL JURÁSICO SUPERIOR - CRETÁCICO INFERIOR DE LAS CUENCAS NEUQUINA Y AUSTRAL, ARGENTINA
}

Tesis doctoral 2017

Lic. Alejandro R. Gómez Dacal

Directores:

Dr. Luis A. Spalletti

Dra. Lucía E. Gomez Peral

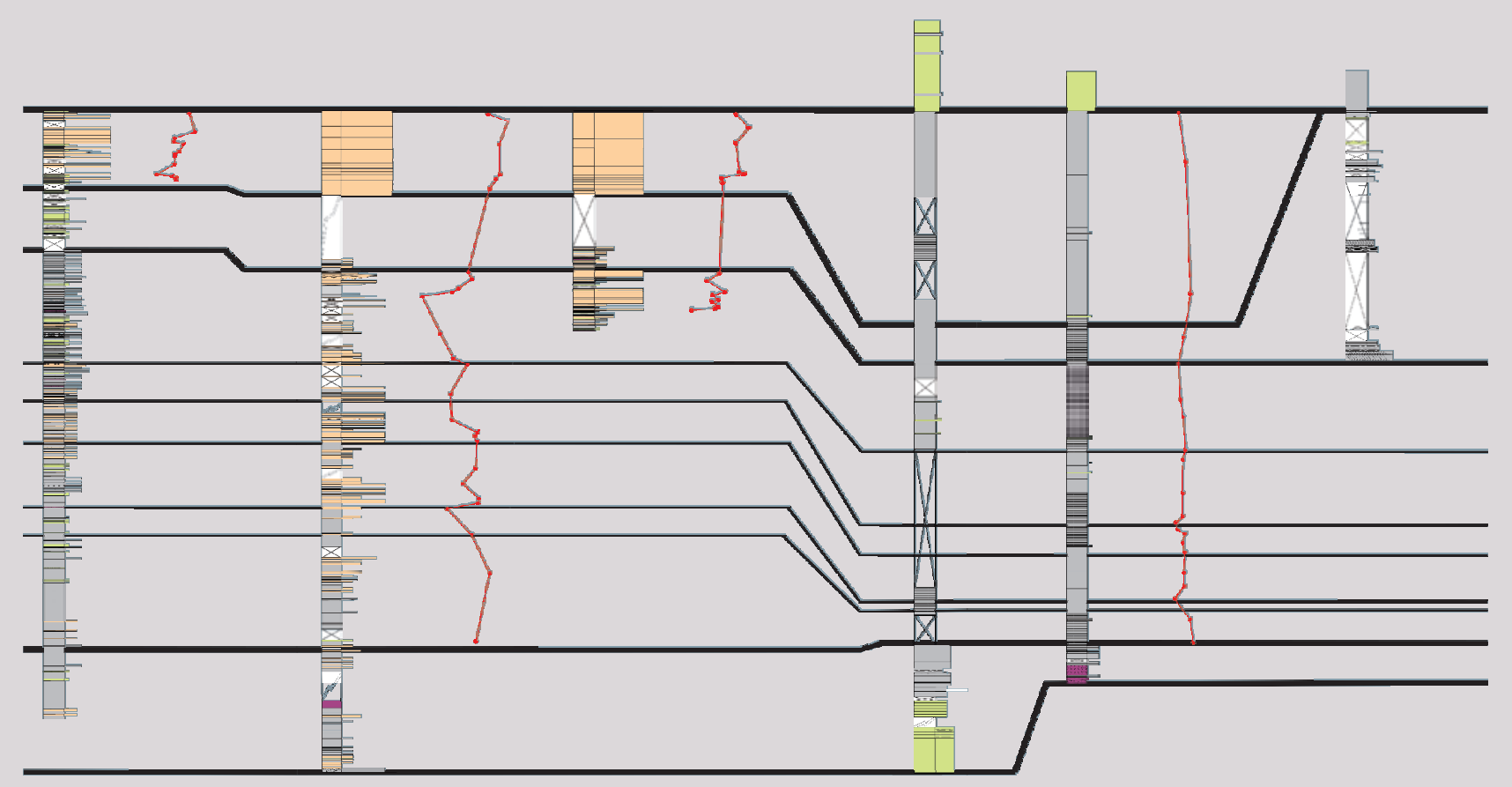




\title{
PETROLOGÍA, GEOQUÍMICA Y DIAGÉNESIS DE SEDIMENTITAS Y FÓSILES CARBONÁTICOS DEL JURÁSICO SUPERIOR - CRETÁCICO INFERIOR DE LAS CUENCAS NEUQUINA Y AUSTRAL, ARGENTINA
}

\author{
Tesis Doctoral \\ Facultad de Ciencias Naturales y Museo \\ Universidad Nacional de La Plata \\ 2017
}

Lic. Alejandro R. Gómez Dacal Directores: Dr. Luis A. Spalletti y Dra. Lucía E. Gómez Peral 
" "No te conformes con el qué, sino que logra saber el porqué y el cómo" "

Lord Baden-Powell 


\section{Índice}

RESUMEN

ABSTRACT

1 INTRODUCCIÓN

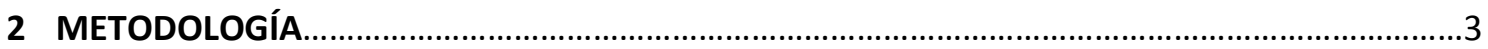

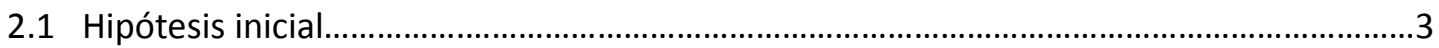

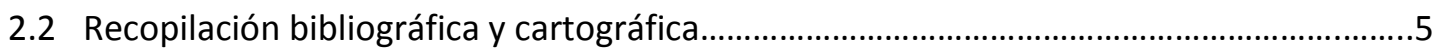

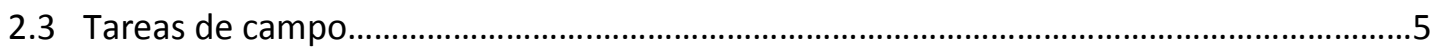

2.3.1 Relevamiento de perfiles sedimentológicos........................................................

2.3.2 Muestreo con criterio quimioestratigráfico............................................................

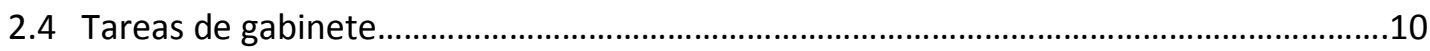

2.4.1 Elaboración de secciones columnares...............................................................10

2.4.2 Análisis de facies y modelos depositacionales....................................................10

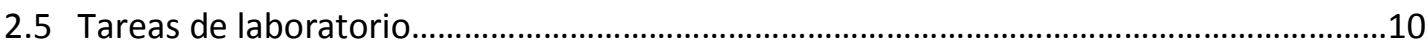

2.5.1 Petrografía......................................................................................................

2.5.2 Tinción de cortes delgados................................................................................12

2.5.3 Microscopía electrónica de barrido.......................................................................12

2.5.4 Microscopía de catodoluminscencia.....................................................................

2.5.5 Micromuestreo................................................................................................13

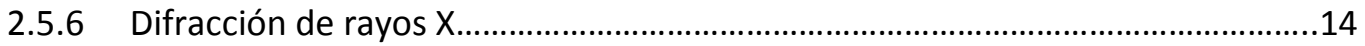

2.5.7 Isotopos estables de carbono en materia orgánica...............................................17

2.5.8 Geoquímica de elementos mayoritarios y minoritarios.........................................18

2.5.9 Geoquímica de elementos traza (ICP-MS) ......................................................19

2.5.10 Isótopos estables de carbono y oxígeno...............................................................19

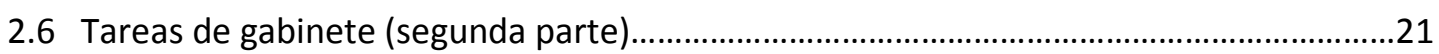

2.6.1 Elaboración de curvas quimioestratigráficas.....................................................21

2.6.2 Calculo de paleotemperaturas y paleosalinidades..............................................21

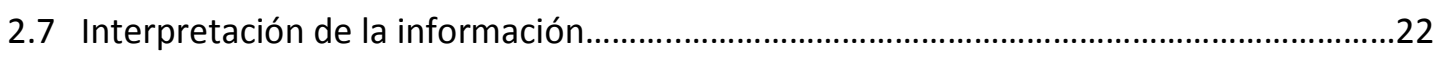

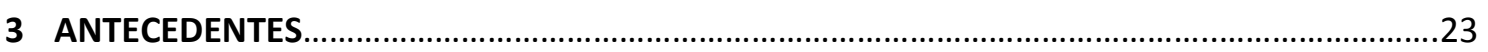

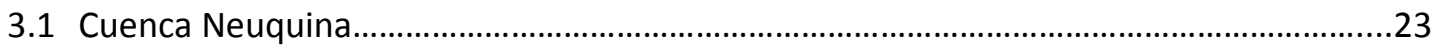

3.1.1 Etapas tectónicas de la Cuenca Neuquina.........................................................24

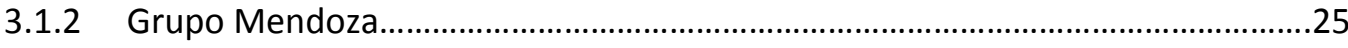

3.1.3 Formación Vaca Muerta.........................................................................................28

3.1.3.1 Generalidades................................................................................28 


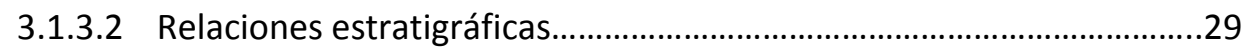

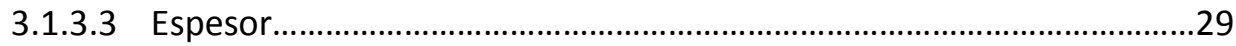

3.1.3.4 Asignación temporal...........................................................................29

3.1.3.5 Litología y biodiversidad.......................................................................30

3.1.3.6 Ambientes de depositación....................................................................30

3.1.3.7 Estudios geoquímicos y diagenéticos...................................................32

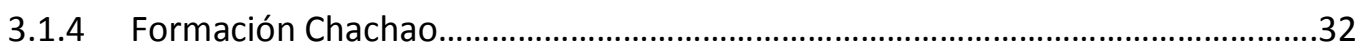

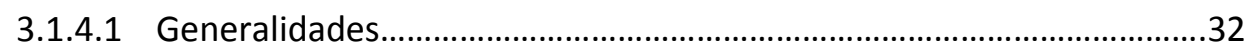

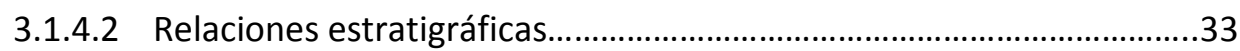

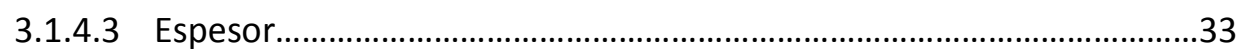

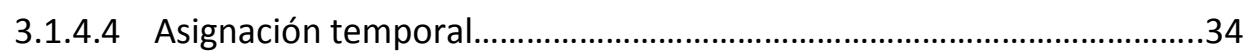

3.1.4.5 Litología y biodiversidad..........................................................................34

3.1.4.6 Ambientes de depositación..................................................................35

3.1.4.7 Estudios geoquímicos y diagenéticos.....................................................35

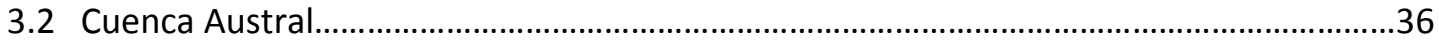

3.2.1 Etapas tectónicas de la Cuenca Austral.................................................................38

3.2.2 Ciclos sedimentarios de la Cuenca Austral..........................................................39

3.2.3 Formación Springhill................................................................................................

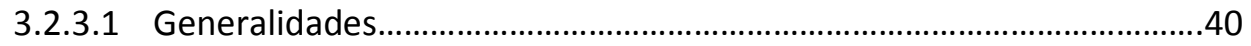

3.2.3.2 Relaciones estratigráficas....................................................................

3.2.3.3 Espesor.............................................................................................

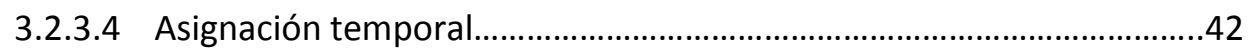

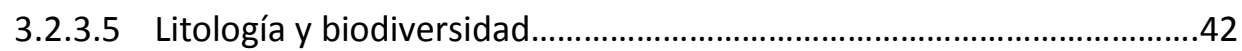

3.2.3.6 Ambientes de depositación.......................................................................43

3.2.3.7 Estudios geoquímicos y diagenéticos....................................................4

3.2.4 Formación Río Mayer........................................................................................4

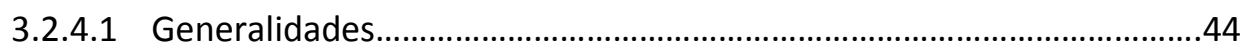

3.2.4.2 Relaciones estratigráficas.....................................................................

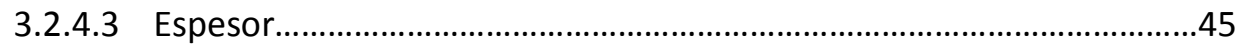

3.2.4.4 Asignación temporal............................................................................45

3.2.4.5 Litología y biodiversidad......................................................................46

3.2.4.6 Ambientes de depositación.....................................................................47

3.2.4.7 Estudios geoquímicos y diagenéticos....................................................47

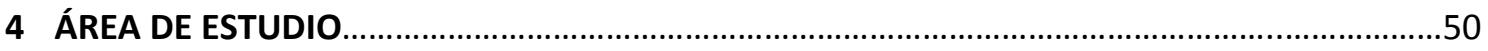

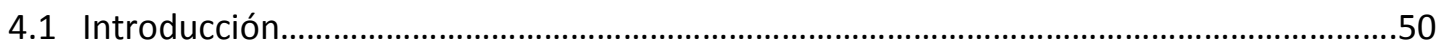


4.2 Plataforma mendocina en la Cuenca Neuquina............................................................51

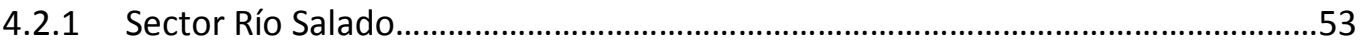

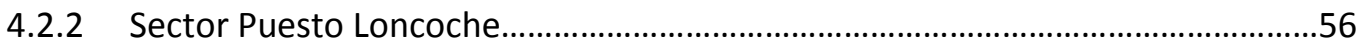

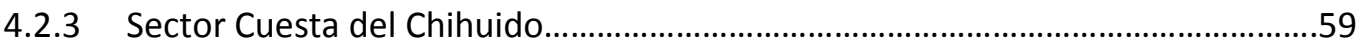

4.3 Entre los lagos Argentino y San Martin en la Cuenca Austral..............................................62

4.3.1 Sector Lago San Martín........................................................................................64

4.3.2 Sector entre los lagos Argentino y Viedma........................................................67

5 ANÁLISIS DE FACIES Y SISTEMAS DE DEPOSITACIÓN.............................................................71

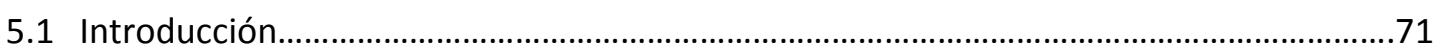

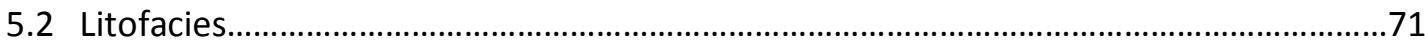

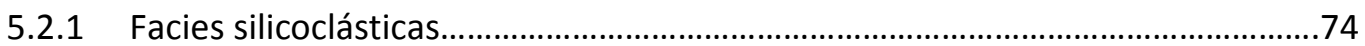

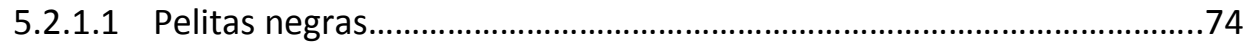

5.2.1.2 Pelitas castañas.....................................................................................74

5.2.1.3 Areniscas masivas..............................................................................

5.2.1.4 Areniscas masivas glauconíticas...............................................................75

5.2.1.5 Areniscas con estratificación horizontal..................................................76

5.2.1.6 Areniscas con estratificación entrecruzada tangencial..........................76

5.2.1.7 Areniscas con estratificación entrecruzada en artesa............................77

5.2.1.8 Areniscas con óndulas.........................................................................77

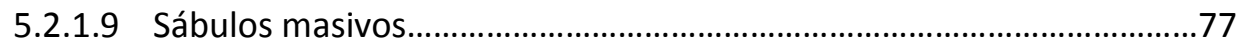

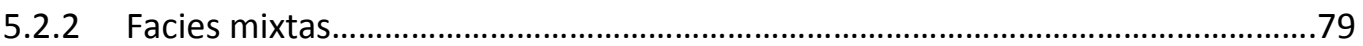

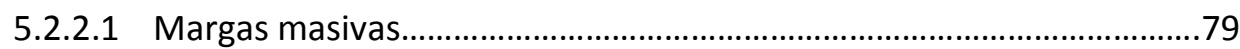

5.2.2.2 Heterolíticas mixtas con estratificación ondulosa.................................79

5.2.2.3 Areniscas mixtas con fango micrítico........................................................80

5.2.2.4 Areniscas mixtas con fango silicoclástico masivas..................................80

5.2.2.5 Areniscas mixtas con fango silicoclástico y estratificación

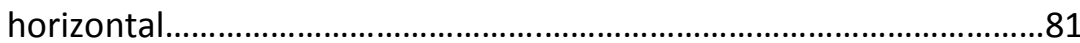

5.2.2.6 Areniscas mixtas con fango silicoclástico y óndulas................................81

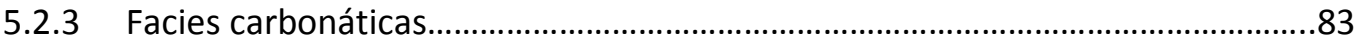

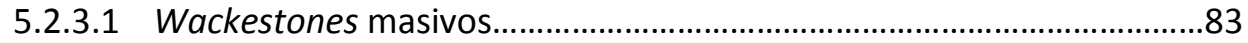

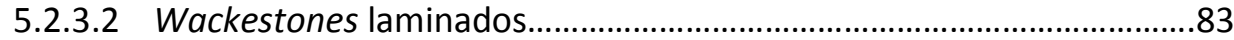

5.2.3.3 Wackestones bioturbados.........................................................................84

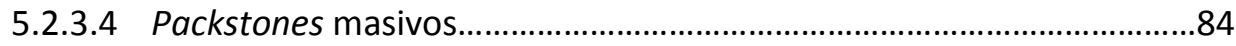

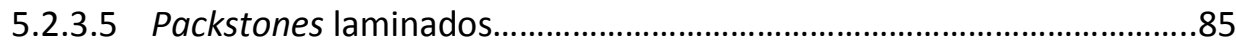

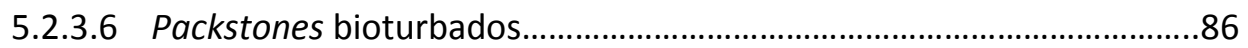


5.2.3.7 Packstones con estructuras monticulares.............................................86

5.2.3.8 Floatstones masivos................................................................................86

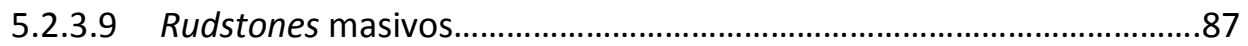

5.2.3.10 Rudstones con estructuras monticulares................................................8

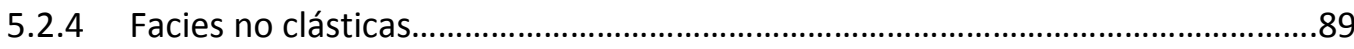

5.2.4.1 Bindstone

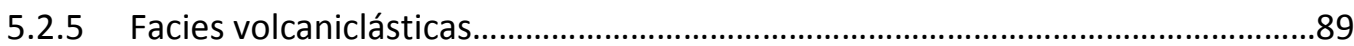

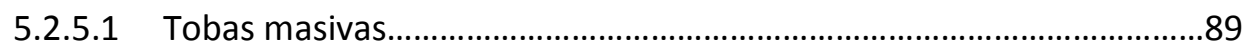

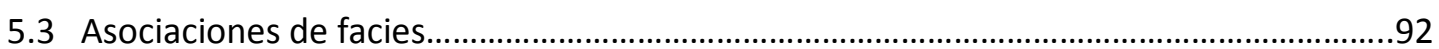

5.3.1 Asociaciones de facies en la Cuenca Neuquina.................................................92

5.3.1.1 Asociación de facies de cuenca............................................................92

5.3.1.2 Asociación de facies de rampa externa distal........................................92

5.3.1.3 Asociación de facies de rampa externa proximal....................................93

5.3.1.4 Asociación de facies de rampa media distal...........................................94

5.3.1.5 Asociacion de facies de rampa media proximal....................................94

5.3.2 Asociaciones de facies en la Cuenca Austral........................................................95

5.3.2.1 Asociación de facies de plataforma externa...........................................95

5.3.2.2 Asociación de facies de plataforma interna............................................96

5.3.2.3 Asociación de facies de shoreface.........................................................96

5.3.2.4 Asociación de facies de foreshore..........................................................97

5.3.2.5 Asociación de facies fluviales................................................................97

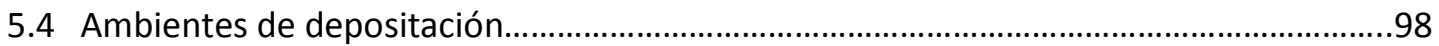

5.4.1 Sistema de rampa carbonática/mixta de la Cuenca Neuquina.............................98

5.4.2 Sistema de plataforma marina silicoclástica/mixta de la Cuenca Austral...........99

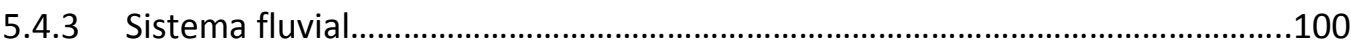

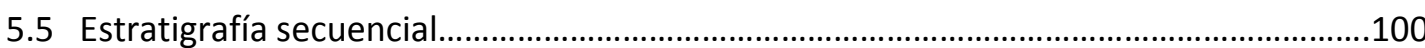

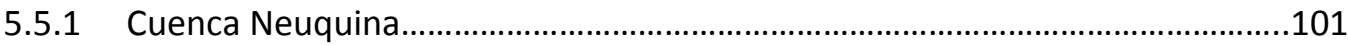

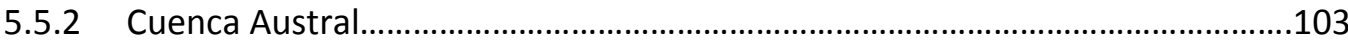

5.5.3 Correlación entre las cuencas y asignación temporal de los cortejos...............106

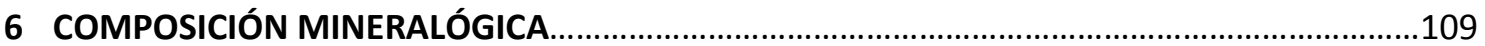

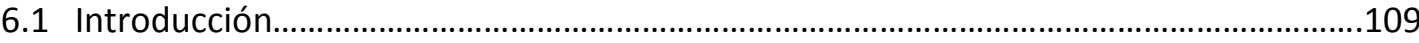

6.2 Análisis composicional de pelitas......................................................................................110

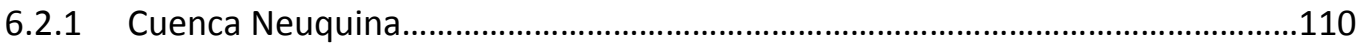

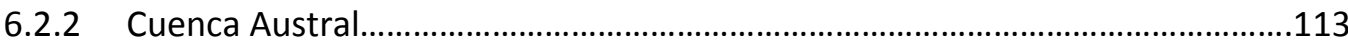

6.3 Análisis composicional de psamitas silicoclásticas (Cuenca Austral)...............................115 


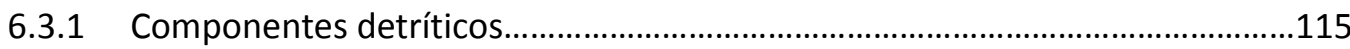

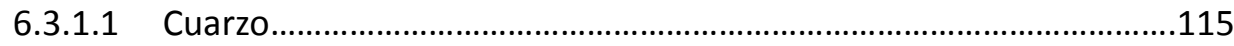

6.3.1.2 Líticos volcánicos............................................................................116

6.3.1.3 Feldespato....................................................................................116

6.3.1.4 Líticos sedimentarios.........................................................................116

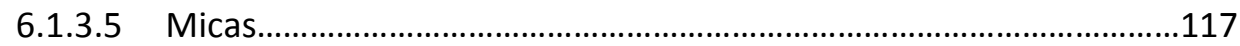

6.1.3.6 Materia orgánica................................................................................117

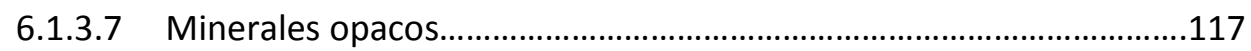

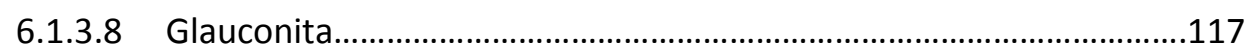

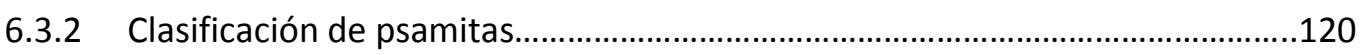

6.4 Análisis composicional de psefitas silicoclásticas............................................................122

6.5 Análisis composicional de carbonatos (Cuenca Neuquina).............................................123

6.6 Análisis composicional de rocas mixtas............................................................................131

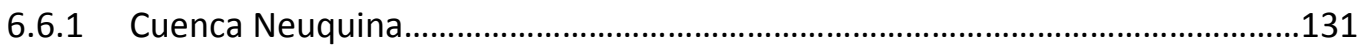

6.6.2 Cuenca Austral...............................................................................................131

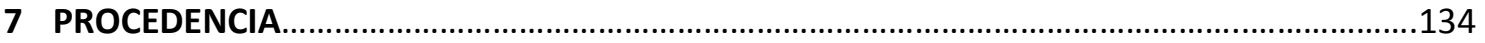

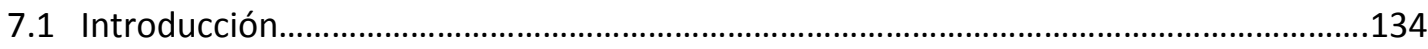

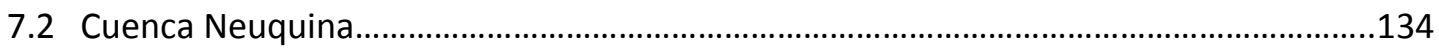

7.2.1 Formación Vaca Muerta......................................................................................134

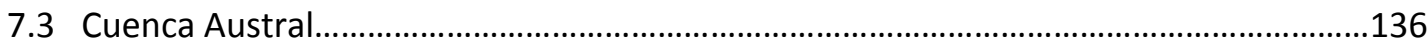

7.3.1 Formación Springhill........................................................................................136

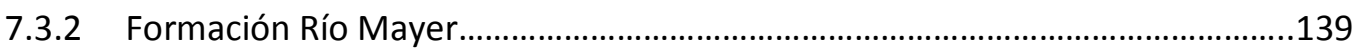

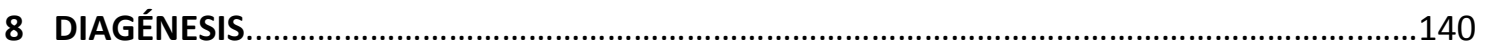

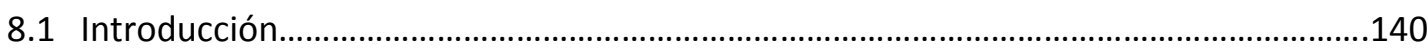

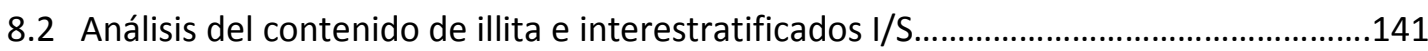

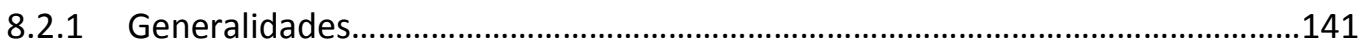

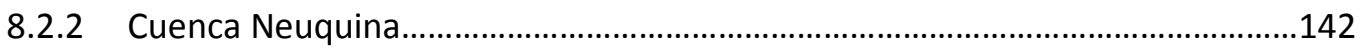

8.2.3 Cuenca Austral................................................................................................146

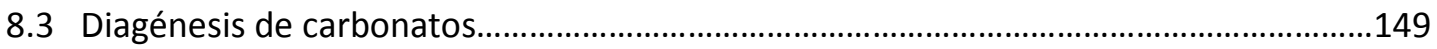

8.3.1 Introducción.........................................................................................................149

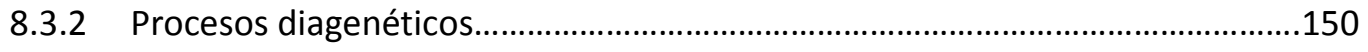

8.3.2.1 Cementación marina............................................................................151

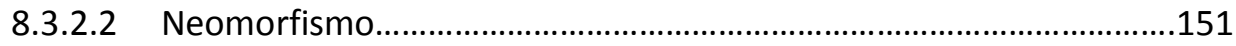

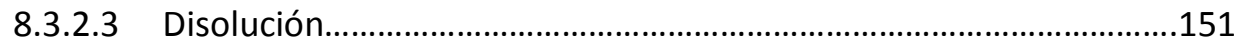

8.3.2.4 Cementación esparítica y subesparítica................................................152 


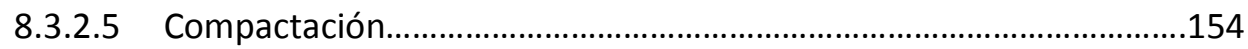

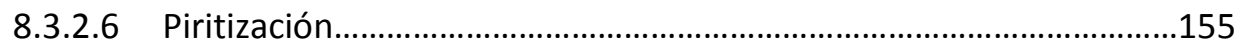

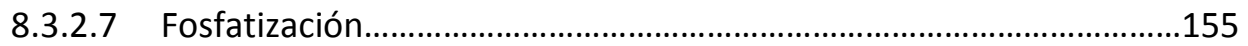

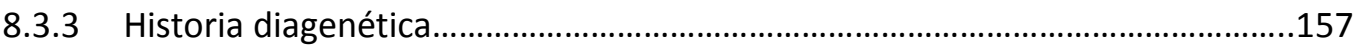

8.4 Diagénesis de psamitas silicoclásticas y mixtas...............................................................161

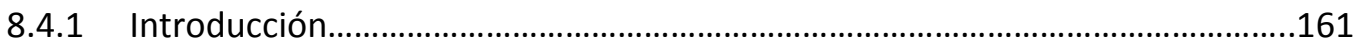

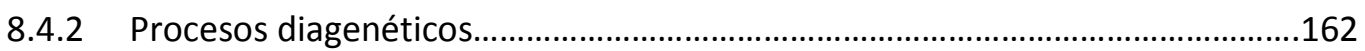

8.4.2.1 Glauconitización.....................................................................................162

8.4.2.2 Cementación carbonática marina.........................................................162

8.4.2.3 Cementación cuarzosa.........................................................................162

8.4.2.4 Autigénesis de arcillas..........................................................................162

8.4.2.5 Cementación carbonática de soterramiento..........................................164

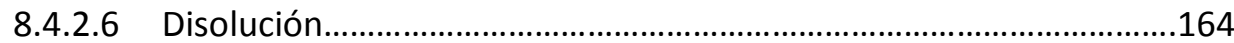

8.4.2.7 Compactación....................................................................................164

8.4.3 Historia diagenética............................................................................................166

8.5 Diagénesis en fósiles.....................................................................................................171

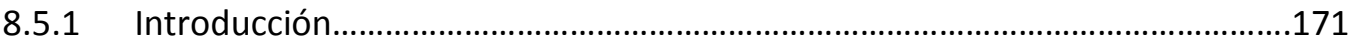

8.5.2 Ostras de la Cuenca Neuquina (Aetostreon sp.)..............................................171

8.5.3 Belemnites de la Cuenca Austral (Belemnopsis sp.).........................................173

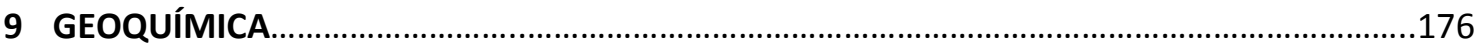

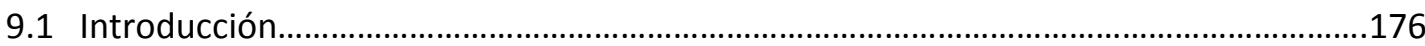

9.2 Cambios en la composición geoquímica durante la diagénesis......................................176

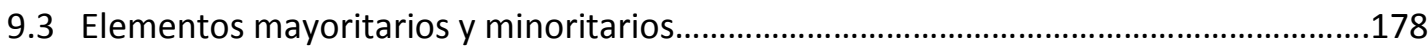

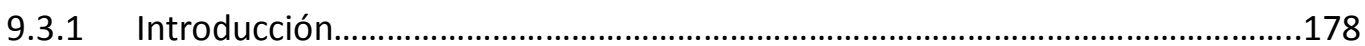

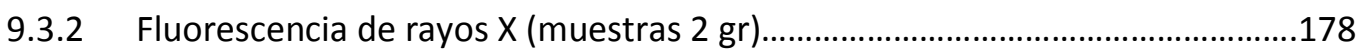

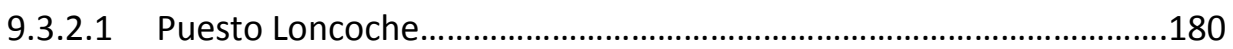

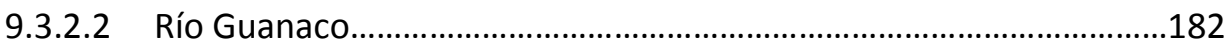

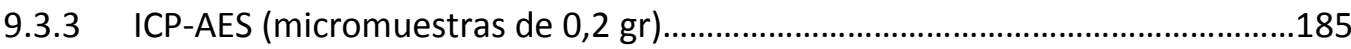

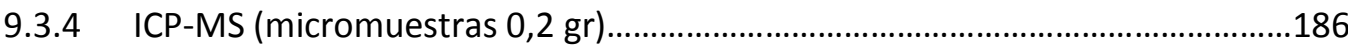

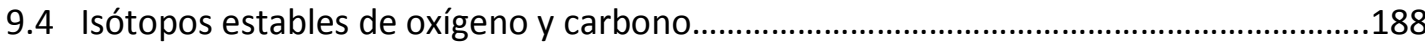

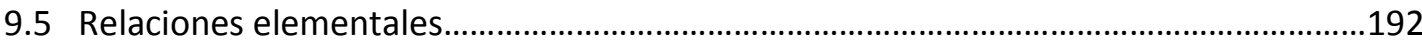

9.5.1 Relaciones $\mathrm{Mg} / \mathrm{Ca}$, $\mathrm{Sr} / \mathrm{Ca}, \mathrm{Na} / \mathrm{Ca}, \mathrm{Mn} / \mathrm{Ca}$, Fe/Ca vs $\delta^{18} \mathrm{O}$ (FRX)........................192

9.5.3 Relaciones Mg/Ca, Mn/Sr, Mn, Sr vs. $\delta^{13} \mathrm{C}$ (FRX) ...........................................195

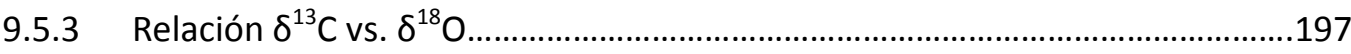

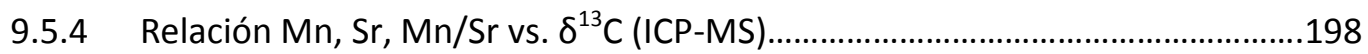




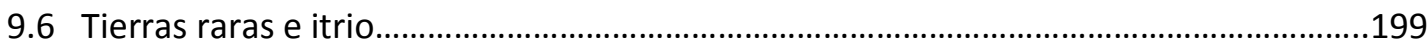

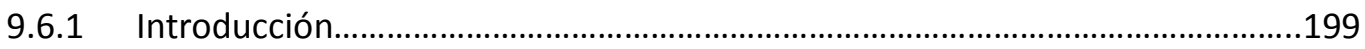

9.6.2 Alteración diagenética......................................................................................202

9.6.3 Niveles de oxigenación......................................................................................203

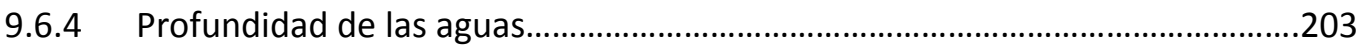

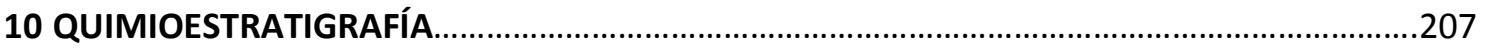

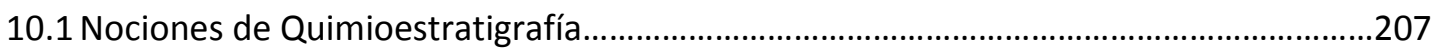

10.2 Curvas quimioestratigráficas de isótopos estables de carbono y oxígeno.......................208

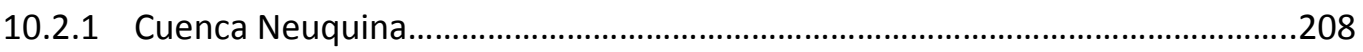

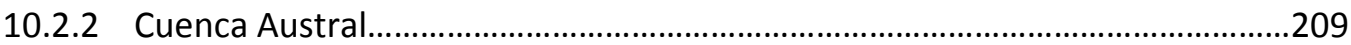

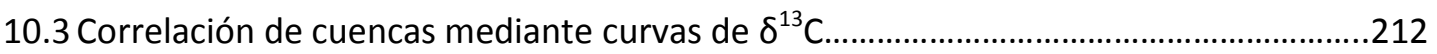

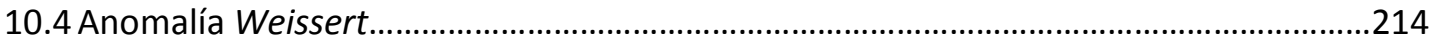

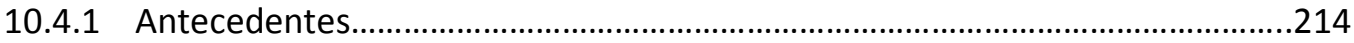

10.4.2 Anomalía Weissert en la Cuenca Neuquina.........................................................215

10.4.3 ¿Anomalía “fantasma” Weissert en la Cuenca Austral?......................................216

10.5 Correlación de secciones mediante curvas de isótopos de C en materia orgánica......217

10.6 Correlaciones quimioestratigráficas con secciones contemporáneas en otras cuencas

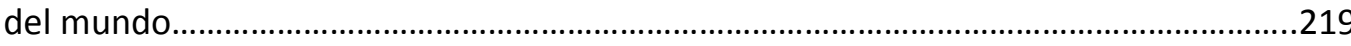

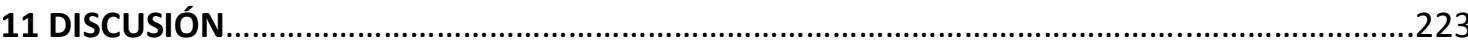

11.1 Introducción.......................................................................................................................22

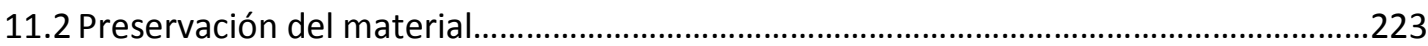

11.3 Caracterización del agua de mar y análisis del paleoclima............................................225

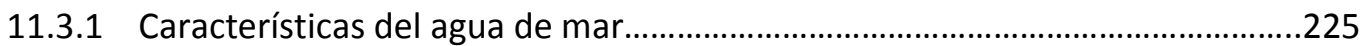

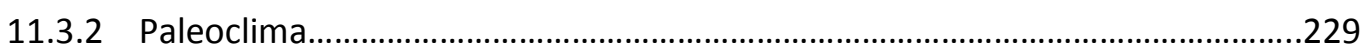

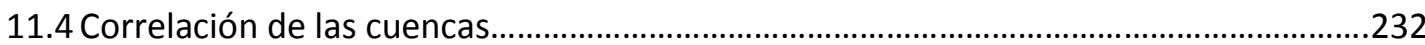

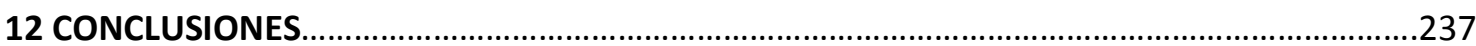

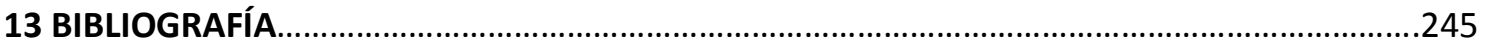

AGRADECIMIENTOS

ANEXOS 


\section{Resumen}

El siguiente trabajo de tesis se construyó a partir de tres objetivos fundamentales. En primer lugar, la descripción desde el punto de vista petrográfico, geoquímico y diagenético de los niveles de sedimentitas y fósiles carbonáticos del Jurásico superior- Cretácico inferior representados en las Cuencas Neuquina (Formaciones Vaca Muerta y Chachao) y Austral (Formaciones Springhill y Río Mayer). En segundo término, el análisis del clima en el intervalo Tithoniano- Valanginiano a partir de datos geoquímicos. En última instancia, la correlación entre las cuencas utilizando distintas herramientas metodológicas como contenido faunístico, estratigrafía secuencial y quimioestratigrafía.

La metodología utilizada consistió en seis etapas de trabajo: recopilación cartográfica y bibliográfica, labores de campo, análisis de laboratorio (representaron el periodo más extenso e innovador), dos instancias de tareas de gabinete y el procesamiento intelectual de la información.

A partir de una minuciosa revisión de antecedentes bibliográficos y cartográficos se seleccionaron dos áreas de estudio: la Plataforma Mendocina, localizada en los alrededores de la ciudad de Malargüe, en el sur de la Provincia de Mendoza, y el sector entre los lagos Argentino y San Martín al sudoeste de la Provincia de Santa Cruz, entre las localidades de El Calafate y Tres Lagos.

Las cuatro formaciones estudiadas (Vaca Muerta, Chachao, Springhill y Río Mayer) fueron asignadas a intervalos temporales. En el caso de la Cuenca Neuquina, sobre la base de las biozonas de amonites y en la Cuenca Austral teniendo en cuenta las asociaciones faunísticas. Este acotamiento temporal permitió esbozar una primera correlación entre las dos cuencas.

Durante las tareas de campo se realizaron seis perfiles sedimentarios de detalle (Río Salado, Puesto Loncoche y Cuesta del Chihuido en la Cuenca Neuquina, y Subida del Chancho, Río Guanaco y Cerro Hobler en la Cuenca Austral). Posteriormente, se definieron veintisiete facies sedimentarias, las cuales se agruparon según su relación vertical y lateral en diez asociaciones de facies, cinco correspondientes a la Cuenca Neuquina y cinco a la Cuenca Austral.

En la Cuenca Neuquina se establecieron las asociaciones de facies de cuenca, rampa externa distal, rampa externa proximal, rampa media distal y rampa media proximal. A partir de ellas se interpretó como ambiente de depositación una rampa carbonática/mixta. Por otro lado, en la Cuenca Austral se definieron las asociaciones de facies de plataforma externa, plataforma interna, shoreface, foreshore y fluvial. A partir de dichas asociaciones se definieron 
dos ambientes de acumulación: sistema de plataforma marina silicoclástica/mixta y sistema fluvial.

A partir del análisis estratigráfico secuencial se concluyó que existen cinco cortejos principales limitados por superficies estratigráficas que pueden ser reconocidas en ambas cuencas. Este análisis permitió una segunda instancia de correlación que resultó coincidente con la primera basada en el contenido faunístico.

Se realizó una descripción composicional, tanto elemental como mineralógica, de las unidades estudiadas. Para esta caracterización se llevaron a cabo, según la granulometría y naturaleza (carbonática, silicoclástica o mixta) de las rocas, análisis petrográficos, de tinción de láminas delgadas $\mathrm{y}$ de difracción de rayos $\mathrm{X}$.

En la Cuenca Neuquina, se estudiaron detalladamente las facies pelíticas, carbonáticas y mixtas. En la fracción pelítica, los minerales más abundantes son cuarzo y calcita, cuya suma siempre supera el $90 \%$ de la muestra. El incremento en el contenido de cuarzo en todos los casos coincide con una disminución en la calcita y viceversa. Entre los argilominerales se reconocieron illita, interestratificado illita/esmectita (I/S) y esmectita, además de cantidades menores de caolinita y clorita.

Las facies carbonáticas son íntegramente esqueletales. Mineralógicamente, están principalmente compuestas por calcita con bajo contenido de magnesio. En cuanto a la preservación tafonómica, es importante destacar que se reconocieron fragmentos de los mismos géneros fósiles desde totalmente fragmentados hasta con las valvas articuladas y en posición de vida. Las rocas mixtas son escasas, y se diferencian de las carbonáticas por la presencia de pequeños porcentajes de elementos terrígenos.

En la Cuenca Austral, se estudiaron detalladamente las facies pelíticas, silicoclásticas y mixtas. La fracción pelítica está compuesta por cuarzo (que constituye el mineral más abundante) y cantidades menores de calcita y arcillas. Entre los argilominerales predominan illita, caolinita y clorita, y en menor medida esmectita e interestratificado I/S. Entre las psamitas y psefitas, la composición es principalmente lítica volcánica. Las rocas mixtas se diferencian de las silicoclásticas por la presencia de bivalvos no ostreidos, algas dasycladáceas y belemnites.

A partir del análisis de los datos composicionales se definieron las áreas de procedencia de los elementos detríticos. En la Formación Vaca Muerta, los aportes detríticos provendrían del arco magmático, de terrenos volcánicos triásicos y jurásicos tempranos y desde los depósitos de la subyacente Formación Tordillo. La Formación Chachao esta íntegramente compuesta por elementos esqueletales, lo que denota su carácter intracuencal. 
La fuente del material terrígeno que compone a las formaciones Springhill y Río Mayer sería el Complejo vulcano- sedimentario El Quemado que las subyace.

El estudio de la diagénesis se dividió en cuatro partes teniendo en cuenta las características composicionales y granulométricas: fracción pelítica (Cuenca Neuquina y Austral), facies carbonáticas (Cuenca Neuquina), facies silicoclásticas (Cuenca Austral) y fósiles (Cuenca Neuquina y Austral).

En la fracción pelítica se determinó el origen detrítico o autigénico de los argilominerales illita e interestratificado I/S. Además, fue posible cuantificar el grado de alteración diagenética de acuerdo al porcentaje de capas expansivas. En la Formación Vaca Muerta (Cuenca Neuquina), una parte de la illita y los interestratificados I/S presentes son consideradas autigénicas. De acuerdo al porcentaje de capas expansivas, los depósitos habrían experimentado mesodiagénesis temprana.

En las formaciones Springhill y Río Mayer (Cuenca Austral), los interestratificados I/S y la mayor parte de la illita son autigénicas. A partir del estudio del porcentaje de capas expansivas, se puede concluir que la Formación Río Mayer habría alcanzado un estadio de mesodiagénesis tardía. En la Formación Springhill, por otro lado, no fue posible cuantificar el grado de alteración diagenética con el empleo de argilominerales.

En los niveles carbonáticos de las Formaciones Vaca Muerta y Chachao, se identificaron rasgos diagenéticos correspondientes a los procesos de cementación, neomorfismo, piritización, fosfatización, disolución y compactación. Estos procesos corresponden a los estadios de eogénesis y mesogénesis temprana. La diagénesis afecta de manera diferencial a las facies profundas y someras. Mientras en las facies profundas la diagénesis se caracteriza por el escaso desarrollo de los procesos de cementación marina y neomorfismo, en las facies someras se observan rasgos tales como la abundancia de disolución y neomorfismo y la precipitación de cemento drusiforme, características de la acción de procesos diagenéticos meteóricos.

En los niveles de psamitas silicoclásticas y mixtas de la Cuenca Austral, se reconocieron rasgos diagenéticos que corresponden a los procesos de: glauconitización, cementación carbonática marina, cementación cuarzosa, autigénesis de arcillas, cementación carbonática de soterramiento, disolución y compactación. Estos procesos se llevaron a cabo durante los estadios de eogénesis, mesogénesis temprana y mesogénesis tardía. Para la Formación Springhill se han establecido sobre la base de los procesos diagenéticos actuantes, tres trenes diagenéticos correspondientes a las facies fluviales, marinas mixtas y marinas silicoclásticas.

El estudio de la diagénesis en fósiles estuvo especialmente enfocado en seleccionar los sectores mejor preservados para realizar estudios geoquímicos y quimioestratigráficos. Se 
llevó a cabo en ejemplares de ostras (Cuenca Neuquina) y belemnites (Cuenca Austral) escogidos sobre la base de sus atributos tafonómicos, tamaño, espaciamiento, abundancia y distribución. A partir de estudios de catodoluminiscencia y microscopía electrónica de barrido, se puede concluir que la diagénesis afecta de manera diferencial a las distintas microtexturas que componen la conchilla de las ostras y belemnites. Los ostras del género Aetostreon sp. reflejan una muy buena preservación en sus capas con crecimiento foliar, mientras que las de crecimiento "chalky" se ven alteradas. Los belemnites del género Belemnopsis sp. muestran una muy buena preservación de los rostros, pero poseen alta luminiscencia en sectores como la línea apical y el alveolo.

Sobre la base del estudio geoquímico de los restos fosilíferos, se definió el potencial de preservación isotópico de las muestras de ambas especies y se caracterizó el agua de mar (temperatura, salinidad, profundidad y oxigenación) en la cual estos organismos vivieron.

Los elementos mayoritarios y minoritarios fueron estudiados mediante fluorescencia de rayos $\mathrm{X}$, ICP-AES e ICP-MS. La mayoría de las muestras analizadas se encuentran dentro de los rangos estipulados para el taxón y la época, aunque existe una cantidad menor que presenta enriquecimientos o empobrecimientos diagenéticos. A pesar de esto, no existen correlaciones entre los elementos o relaciones elementales y los datos isotópicos que puedan ser vinculadas con la diagénesis. De esta forma, se concluye que dichas alteraciones no condicionaron los valores isotópicos.

A partir de los resultados isotópicos se calcularon paleotemperaturas y paleosalinidades, caracterizando a los mares de las dos cuencas como cálidos (con temperaturas entre 24 y $25 \stackrel{\circ}{\circ}$ ) y euhalinos (con salinidades entre 31 y $35 \mathrm{~g} / \mathrm{l}$ ).

Por medio del estudio de las tierras raras e itrio se realizaron importantes observaciones sobre alteraciones diagenéticas, niveles de oxigenación y profundidad de las aguas. A partir del cálculo de enriquecimientos en las MREY, se caracterizó a los valores como primarios (sin alteración diagenética). La anomalía negativa de Ce registrada en todas las muestras de las dos cuencas, refleja que existieron condiciones óxicas en las aguas donde las especies fósiles tuvieron su ciclo de vida. Sobre la base del estudio de los patrones de REY y las anomalías elementales se corroboró que los organismos de la Cuenca Austral vivieron y precipitaron sus conchillas en ambientes más profundos que los de la Cuenca Neuquina.

Con los datos de $\delta^{13} \mathrm{C}, \delta^{18} \mathrm{O}$ y $\delta^{13} \mathrm{C}_{\mathrm{ORG}}$, se confeccionaron curvas quimioestratigráficas. $\mathrm{El}$ análisis de las mismas aportó importante información sobre anomalías isotópicas y facilitó la correlación entre las cuencas.

A partir del análisis de las curvas quimioestratigráficas de $\delta^{13} \mathrm{C}$ se reconoció la excursión isotópica positiva conocida como "anomalía Weissert" (final del Valanginiano 
temprano y comienzo del Valanginiano tardío) en los afloramientos de ambas cuencas. En la Cuenca Neuquina se observó con valores máximos de $\sim 2-3 \%$ VPDB, en los niveles de la Formación Chachao. En la Cuenca Austral, por otro lado, es identificada hacia el tope de la Formación Río Mayer inferior y se presenta con un valor máximo de apenas -0,56\%॰VPB. En este caso, fue definida como "anomalía fantasma" debido al carácter negativo de la misma, (dado por la precipitación de las conchillas en aguas profundas) y a que el evento es reconocible gracias a la correlación entre curvas de $\delta^{13} \mathrm{C}$. El evento Weissert fue restringido en ambas cuencas por su contenido fosilífero y posibilitó la comparación de las secciones estudiadas con otras contemporáneas en diferentes cuencas del mundo.

Sobre la base del análisis de las curvas quimioestratigráficas de $\delta^{13} C_{\mathrm{ORG}}$ se pudo concluir que en las secciones Río Salado y Puesto Loncoche, existe una buena correlación con los resultados obtenidos con el material fosilífero, sobre todo hacia el sector de la curva correspondiente al Tithoniano.

A partir del análisis integrado de los datos composicionales, geoquímicos y quimiestratigráficos se arribó a conclusiones sobre el paleoclima. Durante el periodo Tithoniano- Valanginiano se habría producido un "greenhouse" a nivel global que habría elevado la temperatura de las aguas. Este evento habría extendido el clima ecuatorial más allá de los trópicos, restringiendo las condiciones frías a unas pocas regiones polares y equilibrando la temperatura de las aguas en estas dos cuencas, separadas por unos $2000 \mathrm{~km}$ en sentido norte- sur. El clima durante el intervalo estudiado habría sido cálido y árido, con eventuales períodos con condiciones húmedas denominados "episodios de cambio ambiental". Estos episodios se ven reflejados en las variaciones más importantes de las curvas quimioestratigráficas de $\delta^{13} \mathrm{C}$, pero no en la composición de los depósitos, que tendría como principal factor de control a los cambios relativos en el nivel del mar.

El análisis quimioestratigráfico aporta la tercera herramienta de correlación entre cuencas, ya que existe un marcado paralelismo entre las curvas quimioestratigráficas de $\delta^{13} \mathrm{C}$ de los perfiles sedimentarios Puesto Loncoche (Cuenca Neuquina) y Río Guanaco (Cuenca Austral).

El análisis de las curvas quimioestratigráficas, el contenido fosilífero y las superficies estratigráficas constituyen una herramienta eficiente que permitió establecer la evolución temporal comparada del intervalo Tithoniano- Valanginiano en las cuencas Neuquina y Austral. A modo de conclusión, es posible aseverar que existieron en ambas cuencas historias depositacionales y diagenéticas distintas que compartieron un mismo contexto climático. 


\begin{abstract}
This PhD work has three objectives. First, the description of sedimentary levels and carbonate fossil levels of upper Jurassic-lower Cretaceous from Neuquén basin (Vaca Muerta and Chachao Formations) and Austral basin (Springhill and Río Mayer Formations) through petrography, geochemistry and diagenesis. Second, the analysis of climatic features of the Tithonian-Valanginian interval through geochemistry data. Third, the correlation between the two basins through methodological tools like sequence stratigraphy, chemostatigraphy and fossils content.

This work was done in six methodology steps: cartographic and bibliographic compilation, field activities, laboratory analysis (that is where the most extensive and innovative work has been done), two instances of office activities and intellectual processing of information.
\end{abstract}

From the bibliographic and cartographic data, two areas of study were selected: Mendoza Shelf, near Malargüe city, in the south of the Mendoza Province, and the area between Argentino and San Martín Lakes, between El Calafate City and Tres Lagos City.

The four studied formations (Vaca Muerta, Chachao, Springhill and Río Mayer) were assigned temporal intervals. As for Neuquén Basin, on the basis of ammonite biozones and for Austral Basin, taking into account the fossil associations. These temporal assignations allowed to outline the first correlation between both basins.

During field activities, six detailed sedimentary logs were done (Río Salado, Puesto Loncoche and Cuesta del Chihuido in Neuquén Basin, and Subida del Chancho, Río Guanaco and Cerro Hobler in Austral Basin). Later, twenty-seven sedimentary facies were defined and after that, these facies were grouped according to vertical and lateral relation in ten facies association (five from Neuquén basin and five from Austral Basin).

The facies association of basins, distal outer ramp, proximal outer ramp, distal middle ramp and proximal middle ramp were recognized in Neuquén Basin. A depositional environment of mixed/carbonate ramp was defined through these facies association. On the other hand, in Austral Basin, the facies associations of outer platform, inner platform, shoreface, foreshore and fluvial were defined. Two depositional environments were defined for these facies associations: siliciclastic/mixed platform and fluvial system.

Five system tracks limited by stratigraphic boundaries were recognized in both basins as from sequence stratigraphy analysis. From these analyses, a second correlation in concordance with the first was done. 
The formations were described to know their elemental and mineralogical composition. For this characterization, petrographic analysis, staining of thin sections and $\mathrm{X}$ ray diffraction were done according to grain size and composition (siliciclastic, carbonate or mixed).

In the Neuquén Basin, carbonates, silts and mixed facies were studied in detail. In the pelitic fraction, quartz and calcite are the most abundant minerals; between them they reach $90 \%$ of the sample. The increase in quartz content always coincides with a decrease in calcite and vice versa. In the clay fraction: illite, smectite and interstratified illite/smectite are the most abundant type of clay. In addition, there are smaller amounts of kaolinite and chlorite.

The carbonates facies are composed by skeletal elements. Regarding the mineralogy, they are mainly composed of low-magnesium calcite. In respect of the taphonomic preservation, the fragments of the same fossil genera were recognized from totally fragmented to articulated and in life position. The mixed rocks are scarce, and differ from the carbonates by the presence of small percentages of terrigenous elements.

In the Austral Basin, siliciclastics, silts and mixed facies were studied in detail. In the pelitic fraction, quartz is the most abundant mineral; in addition, there are smaller amounts of calcite and clays. In the clay fraction: illite, kaolinite and chlorite are the most abundant clays, and smectite and interstratified illite/smectite $(\mathrm{I} / \mathrm{S})$ are less abundant. Regarding the sandstones and conglomerates, the lithic composition is the most abundant. Mixed rocks differ from siliciclastic ones due to the presence of not-oysters bivalves, dasycladacean algae and belemnites.

Provenance areas of the detrital elements were defined from the analysis of compositional data. In the Vaca Muerta Formation, the detrital input would come from the magmatic arc, Triassic- early Jurassic volcanic lands and of the underlying Tordillo Formation. The Chachao Formation is integrally composed of skeletal elements, which denote its basinal characteristics. The source of the terrigenous material that makes up the Springhill and Río Mayer formations would be the El Quemado volcano-sedimentary complex.

The study of the diagenesis was divided in four parts taking into account the compositional and grain size characteristics: pelitic fraction (Neuquén and Austral Basins), carbonate facies (Neuquén Basin), siliciclastic facies (Austral Basin) and fossils (Neuquén and Austral Basins).

In the pelitic fraction, the detrital or authigenic origin of the illite and interstratified I/S were determined. In addition, the degree of diagenetic alteration was quantified according to the percentage of expansive layers. In the Vaca Muerta Formation (Neuquén Basin), a part of 
the illite and all the interstratified I/S were considered authigenic. According to the percentage of expansive layers, the deposits would have reached early mesodiagenesis.

In the Springhill and Río Mayer formations (Austral Basin), the interstratified I/S and most of the illite are authigenic. From the study of the percentage of expansive layers, it can be concluded that the Rio Mayer Formation would have reached a stage of late mesodiagenesis. In the Springhill Formation, on the other hand, it was not possible to quantify the degree of diagenetic alteration with the use of clay minerals.

In the carbonate levels of the Vaca Muerta and Chachao Formations, diagenetic features corresponding to the cementation, neomorphism, piritization, phosphatization, dissolution and compaction processes were identified. These processes were carried out during the stages of eogenesis and early mesogenesis. Diagenesis affects differentially the deep and shallow facies. In the deep facies, the diagenesis was characterized by the low development of the processes of marine cementation and neomorphism. On the other hand, the shallow facies were characterized by the abundance of dissolution and neomorphism and precipitation of drusiform cement (these characteristics are typical of the action of meteoric diagenetic processes).

In the siliciclastics and mixed sandstones levels of the Austral Basin, diagenetic features corresponding to the glauconitization, marine carbonate cementation, quartz cementation, clay authigenesis, burial carbonate cementation, dissolution and compaction processes were identified. These processes were carried out during the stages of eogenesis, early mesogenesis and late mesogenesis. For the Springhill Formation, three diagenetic trains corresponding to the fluvial, mixed marine and siliciclastic marine facies were established, on the basis of the active diagenetic processes.

The study of fossil diagenesis was especially focused on selecting the best preserved sectors for geochemical and chemostratigraphic studies. It was carried out on oyster (Neuquén Basin) and belemnites (Austral Basin) specimens selected as from their taphonomic attributes, size, equidistance, abundance and distribution. From studies of cathodoluminescence and scanning electron microscopy, it can be concluded that the diagenesis affects differently the diverse micro textures that compose the shell of oysters and belemnites. The oysters of the genus Aetostreon sp. reflect a very good preservation in their layers with foliated growth, while those of "chalky" growth are altered. In the case of Belemnites of the genus Belemnopsis sp. show a very good preservation of the rostra, but they have high luminescence in sectors such as the apical line and the alveolar groove. 
From the geochemical study of the fossiliferous fragments, the potential of isotopic preservation was defined in both species, and the sea in which these organisms lived was characterized water (temperature, salinity, depth and oxygenation).

Major and minor elements were studied by X-ray fluorescence, ICP-AES and ICP-MS. Most of the analyzed samples are within the stipulated ranges for the taxon and the temporal interval values, although there is a smaller amount that presents diagenetic enrichment or impoverishment. Nonetheless, there are no correlations between elements or elemental relationships and isotopic data that can be linked to diagenesis. In this way, it is concluded that these alterations did not condition the isotopic values.

From the isotopic results, paleotemperatures and paleosalinities were calculated, characterizing the seas of the two basins as warm (with temperatures between 24 and $25 \stackrel{\circ}{ }$ ) and euhaline (with salinity between 31 and $35 \mathrm{~g} / \mathrm{l}$ ).

Through the study of rare earth elements and yttrium, important observations were made on diagenetic alterations, levels of oxygenation and depth of water. From the calculation of enrichments in the MREY, values were characterized as primary (without diagenetic alteration). The waters where the fossil species had their life cycle were defined as oxic given that they present negative anomalies of $\mathrm{Ce}$ recorded in all samples of the two basins. Through the study of REY spiders and elemental anomalies, it was corroborated that the organisms of the Austral Basin lived and precipitated their shells in deeper environments than those of the Neuquén Basin.

Chemostatigraphic curves were made with the data of $\delta^{13} \mathrm{C}, \delta^{18} \mathrm{O}$ y $\delta^{13} \mathrm{C}_{\mathrm{ORG}}$. The analysis of chemostratigraphic curves provides important information about isotopic anomalies and facilitated the correlation between basins.

From the analysis of the chemoestratigraphic curves of $\delta^{13} \mathrm{C}$, the positive isotopic excursion known as "Weissert anomaly" was recognized in the outcrops of both basins. In the Neuquén Basin it was observed with maximum values of $\sim 2-3 \%$ VPDB, in the levels of the Chachao Formation. In the Austral Basin, on the other hand, the anomaly was identified towards the top of the Lower Rio Mayer Formation and it was recognized with a maximum value of only $-0.56 \%$ VPDB. In this case, it was defined as a "ghost anomaly" due to the negative value (given the precipitation of the shells in deep water) and because the event was recognized thanks to the very good correlation between $\delta^{13} \mathrm{C}$ curves. The Weissert event was restricted in both basins from the end of the early Valanginian to the beginning of the late Valanginian through its fossil content. This correlation made it possible to compare the sections studied with other contemporary basins around the world. 
From the analysis of the chemoestratigraphic curves of $\delta^{13} \mathrm{C}_{\mathrm{ORG}}$, it was possible to conclude that in the sections Río Salado and Puesto Loncoche, there is a good correlation with the results obtained with the fossiliferous material, especially towards the section of the curve corresponding to the Tithonian. On the other hand, on the central portion of the Vaca Muerta Formation, in the last levels corresponding to the Tithonian, we defined an anomaly (with less intensity than the Weissert) that can be observed both in the chemostatigraphic curves of $\delta^{13} \mathrm{C}_{\mathrm{ORG}}$, as in those of $\delta^{13} \mathrm{C}$. This event was called "Tithonian anomaly".

Conclusions about the paleoclimate were reached through the integrated analysis of the compositional, geochemical and chemostratigraphic data. During the TithonianValanginian interval there would have been a greenhouse that would have raised the global temperature of the waters. This event would have extended the equatorial climate beyond the tropics, restricting cold conditions to a few polar regions and balancing the temperature of the waters in these two latitudinally distant basins. The climate during the interval studied would have been warm and arid, with short periods of dry conditions called "episodes of environmental change". The most important variations of the chemoestratigraphic curves of $\delta^{13} \mathrm{C}$ were reflected in these episodes. In contrast, the compositions of the deposits do not reflect these changes and it would have been controlled by the relative changes in the level of the sea.

The third correlation tool among basins was provided by the chemostratigraphic analysis since there is a marked parallel between the $\delta 13 \mathrm{C}$ chemostratigraphic curves of the Puesto Loncoche (Neuquén Basin) and Río Guanaco (Austral Basin) sedimentary profiles.

In conclusion, it is possible to assert that there existed in both basins different depositional and diagenetic histories that shared the same climatic context. The analysis of the chemostatigraphic curves, the fossil content and the stratigraphic surfaces constitute an efficient tool that allowed establishing the comparative temporal evolution of the TithonianValanginian interval in the Neuquén and Austral basins. 



\section{Capítulo I - Introducción}

El presente trabajo comprende estudios de detalle de las sedimentitas y fósiles carbonáticos del intervalo Tithoniano- Valanginiano (Jurásico superior - Cretácico inferior) de las Cuencas Neuquina y Austral. El objetivo del mismo, es realizar una comparación de las características petrológicas, geoquímicas y diagenéticas en unidades temporalmente correlacionables representadas en ambas cuencas. A partir de estos estudios se han efectuado interpretaciones referidas a las condiciones paleoambientales y paleoclimáticas imperantes durante la sedimentación, como así también sobre los procesos posteriores a su depositación.

En la Cuenca Neuquina, la región de trabajo elegida se localiza al sur de la provincia de Mendoza, en el sector conocido como Plataforma Mendocina (Doyle et al., 2005). Allí se estudiaron las formaciones Vaca Muerta (Weaver, 1931) y Chachao (Dessanti, 1973). Los estudios previos sobre la sedimentología y ambientes de estas formaciones han sido ampliamente desarrollados (Legarreta y Kozlowski, 1981; Palma y Lanes, 2001; Doyle et al., 2005; entre otros). Asimismo, si bien se registran aportes sobre estudios geoquímicos (Lazo et al., 2008; Aguirre-Urreta et al., 2008; Spalletti et al., 2015) y diagenéticos (Carozzi et al., 1981; Palma et al., 2008) en el sector de estudio, esta información resulta escasa y el empleo de novedosas herramientas metodológicas podría dar importante información para el conocimiento de la principal cuenca de desarrollo hidrocarburífero del país.

En la Cuenca Austral, por otro lado, el sector seleccionado para el trabajo se localiza en el sudoeste de la Provincia de Santa Cruz entre los Lagos Argentino y San Martín y las formaciones elegidas para el estudiado fueron Springhill (Thomas, 1949) y Río Mayer (Hatcher, 1897). El estudio de estas temáticas, resulta particularmente innovador para la Cuenca Austral, en donde existen numerosos estudios sobre sedimentología y paleoambientes sedimentarios (Poiré y Franzese, 2008; Varela, 2011; Richiano, 2012; Cereceda, 2016), pero son escasos los referentes a petrología, geoquímica y diagénesis.

Como objetivo adicional se presenta el estudio de la geoquímica de fósiles calcáreos (ostras en la Cuenca Neuquina y belemnites en la Cuenca Austral), teniendo como especial foco los isótopos estables. Estos estudios representaron la herramienta fundamental para el análisis de las condiciones paleoambientales y de la correlación entre cuencas.

El trabajo de tesis se llevó a cabo en las siguientes etapas:

1) Caracterización de los sectores de estudio y análisis sedimentológico, ambiental y estratigráfico secuencial de las formaciones seleccionadas.

2) Análisis exhaustivo y detallado de la composición de las secciones mediante petrografía (convencional y de catodolumiscencia) y difracción de rayos $\mathrm{X}$. 
3) Estudio de la procedencia y la diagénesis a partir de datos petrográficos y de composición.

4) Selección del material más adecuado (menor alteración diagenética) para la posterior realización de estudios geoquímicos de elementos mayoritarios, minoritarios, trazas e isótopos estables de oxígeno y carbono.

5) Cálculo de paleotemperaturas y paleosalinidades y confección de curvas quimioestratigráficas a partir de los datos de isótopos estables. Estudio de las anomalías isotópicas registradas en las unidades sedimentarias seleccionadas.

6) Integración de los resultados y comparación del registro sedimentario en el intervalo temporal seleccionado entre las cuencas desde el punto de vista paleoambiental, estratigráfico secuencial, composicional, diagenético, geocronológico e isotópico. 


\section{Capítulo II - Metodología}

En el siguiente trabajo de tesis doctoral se han desarrollado una serie de etapas sucesivas que corresponden con el método científico. En primer lugar, se planteó una hipótesis inicial, con aspectos generales y específicos establecidos y en un contexto definido.

Luego, se sucedieron distintas etapas de trabajo con la intención de realizar una aproximación al problema (Fig. 2.1). En primer lugar, se elaboró una recopilación bibliográfica y cartográfica que permitió seleccionar las áreas de trabajo y por otro lado considerar el nivel de conocimiento alcanzado en cada zona. Luego, se realizaron campañas de recolección de datos y se desarrolló la primera etapa de trabajo en gabinete con el objetivo de realizar un análisis sedimentológico de los relevamientos. Posteriormente, se desarrolló una extensa labor de laboratorio para abordar los aspectos petrológicos, geoquímicos y diagenéticos, que culminó con una segunda etapa de trabajos de gabinete. Mediante la integración de todas estas actividades se elaboraron los resultados.

\subsection{Hipótesis inicial}

Los niveles de sedimentitas y fósiles carbonáticos del Jurásico superior - Cretácico inferior representadas en las Cuencas Neuquina (Formaciones Vaca Muerta y Chachao) y Austral (Formaciones Springhill y Río Mayer) se localizan en sectores geográficamente distantes (2000 km.) y no evidencian una génesis ni una historia postdepositacional en común. El estudio comparado de la petrología, geoquímica y diagénesis representa un enfoque innovador, tanto por la aplicación de nuevas metodologías para el desarrollo del conocimiento en ambas cuencas como por la comparación entre sectores distantes.

A partir del desarrollo de estudios de petrología y geoquímica se esbozarán las historias diagenéticas de las sedimentitas y fósiles carbonáticos con la intención de comprobar que estos últimos poseen un estado menor de alteración diagenética. Paralelamente se aspirará a mostrar que dichas metodologías constituyen una herramienta adecuada para descifrar el potencial de preservación isotópico.

Gracias a la combinación de estudios sedimentológicos, composicionales y de isótopos estables se pretende probar que las secuencias sedimentarias estudiadas en ambas cuencas poseen historias depositacionales y diagenéticas distintas pero en un contexto paleoclimático común. Por último, se intentará demostrar que es posible establecer una comparación de gran detalle entre las curvas quimioestratigráficas desarrolladas para las dos cuencas y con otras curvas contemporáneas a nivel global. 


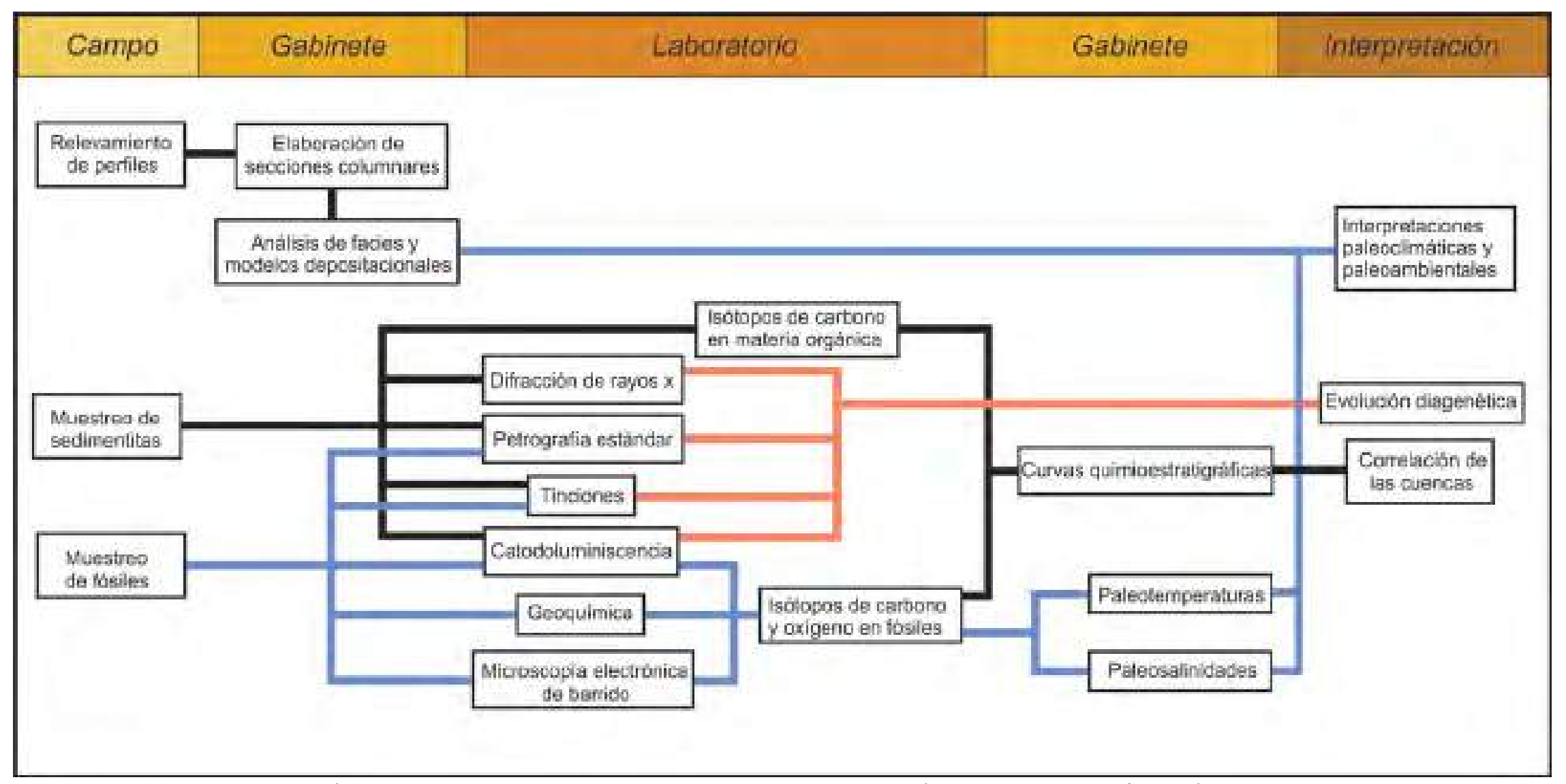

Figura 2.1: Flujo de trabajo, interacción entre las tareas de campo, gabinete, laboratorio y el posterior análisis intelectual de la información. 


\subsection{Recopilación bibliográfica y cartográfica}

Con el objetivo de investigar el estado de conocimiento de las áreas de estudio se realizó una pormenorizada recopilación bibliográfica. En primer término se organizó la información pertinente a los aspectos generales, tales como la evolución tectónica y el desarrollo estratigráfico de las Cuencas Neuquina y Austral. Luego, se recopiló información de detalle sobre los aspectos sedimentológicos, paleontológicos y bioestratigráficos de las formaciones de estudio: Springhill y Rio Mayer (Cuenca Austral), Vaca Muerta y Chachao (Cuenca Neuquina), así como de las unidades equivalentes y adyacentes. Para incorporar un conocimiento geográfico y geológico de la zona de estudio se revisaron los trabajos de mapeo previos, tales como mapas geológicos encontrados en la bibliografía, hojas geológicas, imágenes satelitales LANDSAT y de libre acceso (Google Earth ${ }^{\circledR}$ ).

Posteriormente se revisaron, de modo más específico, trabajos de geoquímica, petrología, diagénesis y quimioestratigrafía realizados sobre dichas formaciones, resultando en algunos casos escasos y en otros nulos. En forma simultánea, se realizó la lectura de bibliografía sobre metodología, que permitió adquirir las herramientas fundamentales para el estudio de las sedimentitas y fósiles carbonáticos. Asimismo, para sustentar las interpretaciones sedimentológicas y geoquímicas se efectuó el análisis crítico de las publicaciones específicas, tanto las clásicas como las más actualizadas, lo que permitió alcanzar un adecuado conocimiento de los avances producidos en las distintas sub-disciplinas de la especialidad.

\subsection{Tareas de campo}

Se realizaron cinco viajes de campo entre los años 2013 y 2015 a las dos zonas de estudio: la Plataforma Mendocina en la Cuenca Neuquina y el sector comprendido entre los Lagos Argentino y San Martin en la Cuenca Austral. Durante un total de 100 días de trabajo se desarrollaron tareas de relevamiento de perfiles sedimentológicos y muestreos sistemáticos de fósiles con criterio quimioestratigráfico.

\subsubsection{Relevamiento de perfiles sedimentológicos}

Con el soporte de mapas e imágenes satelitales se eligieron cuidadosamente los afloramientos en los cuales se relevaron los perfiles, seleccionando las mejores y más completas expresiones de las formaciones de estudio. 
Se relevaron un total de seis perfiles sedimentarios de escala 1:200 (Fig. 2.2), tres en la Cuenca Austral y tres en la Cuenca Neuquina. Para esta tarea se utilizó cinta métrica y brújula geológica y se tomó el posicionamiento satelital (GPS) de la base, el techo y varios puntos intermedios de la sucesión sedimentaria. En cada una de las secciones se describió la geometría, textura, composición, relaciones estratales y estructuras sedimentarias de cada una de las capas. Durante el relevamiento se hizo especial énfasis en la descripción y reconocimiento de la fauna fósil presente en el registro. De manera conjunta se puntualizaron aspectos tafonómicos de cada una de las especies, así como su distribución en sentido vertical.

En paralelo al relevamiento de perfiles se realizó un muestreo sistemático de sedimentitas con el objetivo de realizar estudios de petrografía estándar y catodoouminscencia. Los criterios utilizados para esta tarea fueron el espaciamiento y los cambios litológicos verticales. De modo específico, se muestrearon con mayor espaciamiento las sedimentitas de granulometría pelítica, para llevar a cabo además de los análisis antes mencionados, estudios de rayos $\mathrm{X}$ e isótopos estables de carbono en materia orgánica (ver secciones 2.5 .6 y 2.5 .7$)$. 

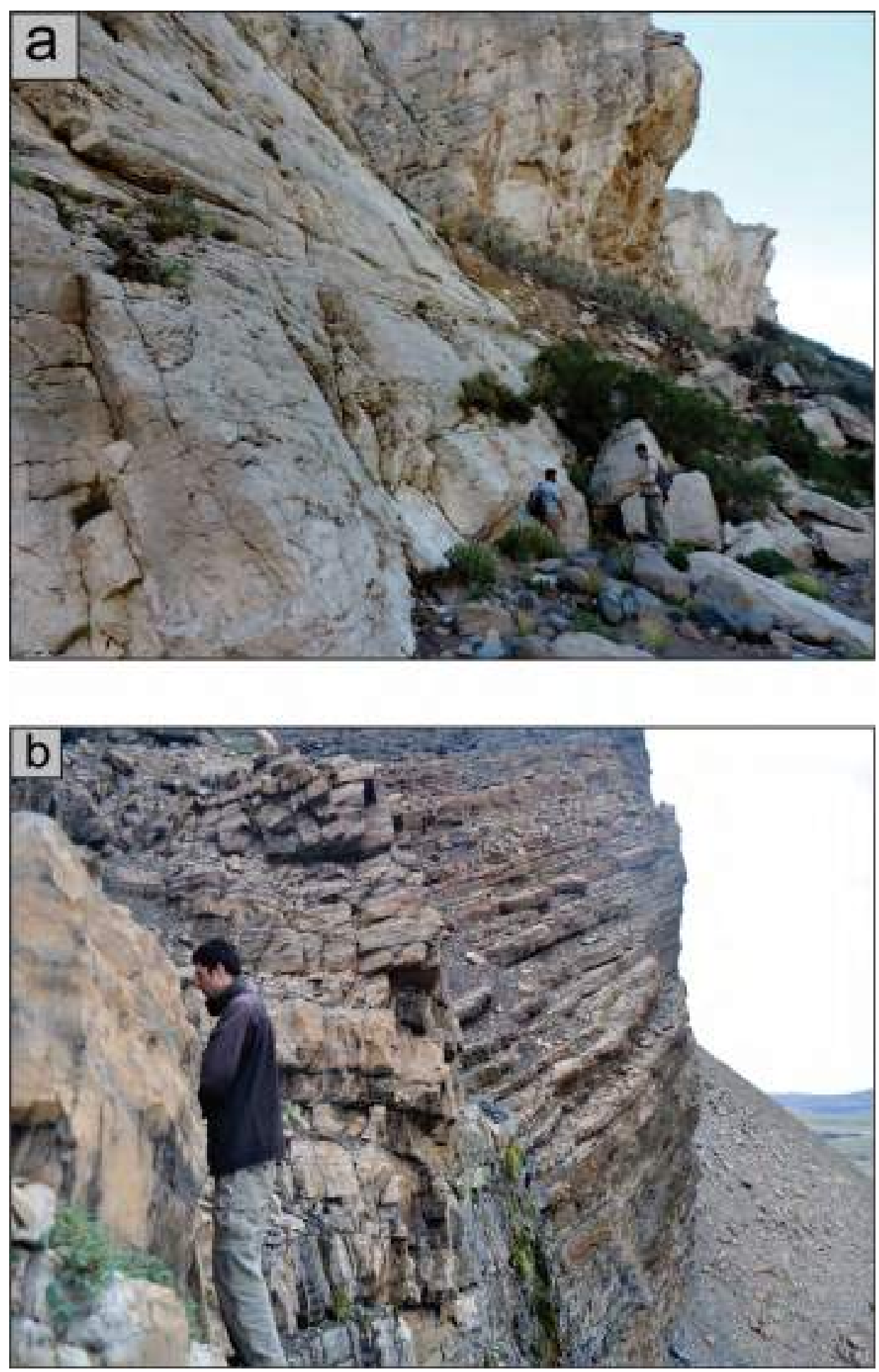

Figura 2.2: Relevamiento de perfiles sedimentarios. a) Formación Chachao en el Perfil Puesto Loncoche, Cuenca Neuquina. b) Formación Río Mayer en el Perfil Río Guanaco, Cuenca Austral. 


\subsubsection{Muestreo con criterio quimioestratigráfico}

Con el objeto de realizar estudios quimioestratigráficos de isótopos estables de C y $\mathrm{O}$ en todas las secciones relevadas, se seleccionaron un total de 57 muestras fósiles del género Aetostreon sp. en la Cuenca Neuquina y 28 muestras del género Belemnopsis sp. en la Cuenca Austral (Fig.2.3).

Dichos taxones fueron escogidos por su presencia en todas las secciones relevadas correspondientes a la misma cuenca y su abundancia en sentido vertical. Los muestreos fueron monoespecíficos con la intención de que los datos de isótopos estables reflejen de forma fiel las características geoquímicas del agua de mar y eliminar errores asociados a su "factor vital". Asimismo, las conchillas de ambos organismos están compuestas por calcita con bajo contenido de magnesio, material menos susceptible a la diagénesis, y existe una extensa bibliografía sobre estudios quimioestratigráficos realizados en ejemplares de estas especies (Pirrie et al., 2004; Aguirre-Urreta et al., 2008; Lazo et al., 2008; Zakharov et al., 2011; Gómez Peral et al., 2012; entre otros).

Los principales criterios de muestreo fueron el espaciamiento (sujeto a la presencia fosilífera), sus características microscópicas y sus aspectos tafonómicos. En el caso de las ostras, se priorizó aquel material con menor grado de fragmentación, bioerosión y corrasión, por otro lado también se seleccionaron ejemplares mayores a $5 \mathrm{~cm}$ teniendo en cuenta observaciones microscópicas que confirmaron que los individuos de mayor tamaño poseían una mejor preservación de sus capas internas. En cuanto a los belemnites, se tuvieron en consideración las mismas características tafonómicas que con las ostras, pero con el cuidado de que se observen las líneas apicales y el crecimiento concéntrico, vinculando estas características con el más alto grado de preservación gracias a observaciones tomadas al microscopio. 


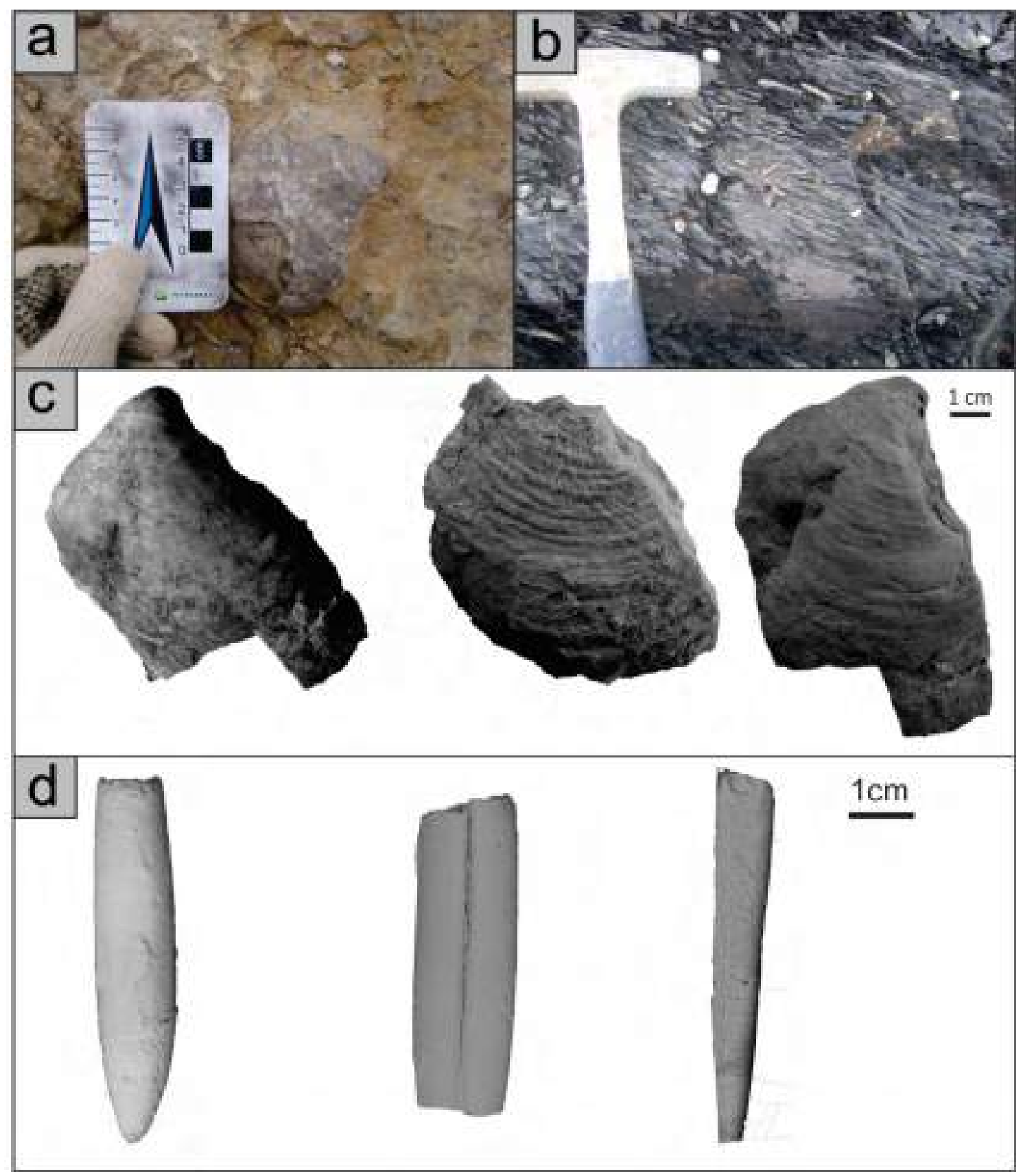

Figura 2.3: Muestreo con criterio quimioestratigráfico. a) Ejemplar fósil del género Aetostreon sp. ubicado en floatstones de la Formación Chachao, b) ejemplares de Belemnopsis sp. ubicados en pelitas negras de la formación Río Mayer, c) Ejemplares fósiles de Aetostreon sp. mayores a $5 \mathrm{~cm}$. seleccionados por su preservación tafonómica., d) Ejemplares fósiles del género Belemnopsis sp. seleccionados por su preservación tafonómica, especialmente de la línea apical y el fragmocono. 


\subsection{Tareas de gabinete}

A partir de los datos obtenidos en las tareas de campo se desarrolló la primera etapa de tareas de gabinete.

\subsubsection{Elaboración de secciones columnares}

Con los datos obtenidos en el campo se realizaron perfiles sedimentarios tipo Selley con una escala de 1:200. En los mismos se reflejó además de la textura y estructura, el contenido fósil, el nivel de bioturbación y los límites formacionales. También se han representado perfiles simplificados a menores escalas, tales como 1:500 y 1:650 con el objetivo de marcar más claramente variaciones verticales, enfatizar aspectos particulares y/o evidenciar correlaciones entre los distintas secciones sedimentarias (figura Anexo Perfiles).

\subsubsection{Análisis de facies y modelos depositacionales}

Para avanzar en la interpretación de los procesos sedimentarios se realizó un análisis de facies. En el mismo se ponderaron las principales características de textura, estructura y composición y se catalogaron en un código de facies con una letra mayúscula para la textura y una o más letras minúsculas para los rasgos texturales y composicionales más distintivos. Posteriormente se elaboraron asociaciones de facies con la finalidad de delinear los principales subambientes sedimentarios. Por último, a partir de la integración de la información se elaboraron los modelos depositacionales.

\subsection{Tareas de laboratorio}

Se desarrollaron durante los años 2014 a 2016 en laboratorios de Argentina, Brasil y Canadá, constituyen la etapa más extensa del presente trabajo de tesis.

\subsubsection{Petrografía}

Un total de 135 secciones delgadas fueron realizadas en el taller de cortes del Centro de Investigaciones Geológicas (UNLP-CONICET) por los técnicos Daniel Mártire y Pablo García. Para su descripción se utilizó un microscopio binocular LEITZ laborlux 12POL (Fig. 2.5a). 
Se observaron psefitas, psamitas, pelitas y fragmentos fósiles. Las psefitas fueron analizadas mediante conteo de clastos en el campo, y posteriormente clasificadas según los criterios de Scasso y Limarino (1997)

El análisis de las areniscas permitió describir tamaño, selección, redondez de los clastos y particularmente composición, característica a partir de la cual se dividió a dichas sedimentitas en carbonáticas, mixtas y silicoclásticas.

Para el estudio de las psamitas silicoclásticas se realizó un análisis estadístico de modas detríticas con el software Rock.ARV2.0, siguiendo la metodología de Gazzi-Dickinson (Ingersoll et al., 1984). Esto incluye el recuento de 400 puntos por sección delgada con el espaciamiento mayor igual al tamaño de grano máximo de la muestra. Posteriormente, estas sedimentitas fueron clasificadas utilizando los modelos de Folk et al. (1970) y Dott (1964) modificado por Pettijohn et al. (1972). Sobre la base de su composición se trabajó con su procedencia, utilizando los diagramas de discriminación tectónica de áreas de aporte de Dickinson et al. (1983) y un diagrama de diferenciación de litoclastos pensado específicamente para el caso de estudio.

Para las psamitas mixtas se utilizó nuevamente el software Rock.ARV2.0 para los análisis estadísticos, y los diagramas propuestos por Álvarez- Trenttini y Schwarz, (2016) para la clasificación. Las muestras psamíticas de composición carbonática, en cambio, fueron descriptas con especial énfasis en la discriminación de microfósiles y se especificaron utilizando la clasificación textural de Dunham (1962) modificada por Embry y Klovan (1972).

En las pelitas se atendió especialmente la composición y granulometría de las muestras analizadas. Así se discriminaron, desde el punto de vista composicional, entre tipos silicoclásticos, mixtos (margas) y carbonáticos. Por su textura, además se reconocieron variedades limolíticas, fangolíticas y arcilíticas. Un mayor refinamiento de los aspectos mineralógicos fue establecido por difracción de rayos $X$ (ver punto 2.5.6).

Los fragmentos fósiles analizados fueron los géneros Aetostreon sp. y Belemnopsis sp. y su estudio se enfocó principalmente en el reconocimiento de microestructuras de crecimiento.

Por último, también se hizo hincapié en las descripciones, clasificaciones y relaciones de elementos tales como cementos, venas, estilolitas, porosidades y relaciones entre clastos, que de manera conjunta con los análisis de catodoluminscencia (ver sección 2.5.4) permitieron estudiar la evolución diagenética de todas las secciones estudiadas. 


\subsubsection{Tinción de cortes delgados}

Con el objetivo de determinar la composición mineralógica de las sedimentitas y fósiles carbonáticos se realizaron tinciones de las láminas delgadas anteriormente descriptas (Fig. 2.5b). Las mismas se efectuaron en el Laboratorio de Geoquímica del Centro de Investigaciones Geológicas (UNLP-CONICET), y consistieron en la aplicación del método de Dickson $(1965,1966)$ sobre el cual se modificaron tiempos y proporciones de forma experimental, hasta generar un correcto teñido adecuado a la composición de los minerales carbonáticos y textura de cada roca.

Para el procedimiento se prepararon tres soluciones: 1) $200 \mathrm{ml} \mathrm{HCl}$ (1\%), 2) $150 \mathrm{ml} \mathrm{HCl}$ + 0,3g alizarina roja, y 3$)(150 \mathrm{ml} \mathrm{HCl}+0,3 \mathrm{~g}$ alizarina roja $)+(150 \mathrm{ml} \mathrm{HCl}+3 \mathrm{~g}$ de ferricianuro de potasio). En primera instancia los cortes delgados fueron sumergidos en la solución 1 aproximadamente 10 segundos (las muestras con mayor contenido de micrita se dejaron 12, y aquellas con mayor proporción de bioclastos se dejaron 8). Luego, fueron retirados y colocados en la solución 2 por 20 segundos. Una vez concluido el paso anterior los cortes se sumergieron en la solución 3 por aproximadamente 40 segundos (aquellas muestras que tardaban más en teñirse de color azul fueron dejadas hasta 60 segundos como máximo). Por último los cortes fueron lavados con agua destilada.

La observación de los cortes teñidos permitió reconocer variables composicionales dentro de los cementos carbonáticos y avanzar en la determinación de la historia diagenética de las secciones de estudio. Por otro lado, también posibilitó la descripción composicional de los fósiles utilizados para los estudios de isótopos estables de carbono y oxígeno y la determinación de su grado de alteración diagenética.

\subsubsection{Microscopía electrónica de barrido}

La microscopía electrónica de barrido fue utilizada para conocer el potencial de preservación isotópica (PPI) de los fósiles seleccionados en el campo.

Se eligieron, sobre la base de observaciones realizadas en láminas delgadas teñidas, aquellas áreas compuestas por calcita con bajo contenido de magnesio. De allí se tomaron esquirlas de las distintas microestructuras de crecimiento de las ostras y belemnites que fueron metalizadas con oro y analizadas con un equipo de microscopía electrónica de barrido (MEB) FEI Quanta 200 SEM con sonda EDAX (Facultad de Ingeniería, UNLP). Con la utilización de este microscopio se definió la composición química de las muestras y se evaluó el grado de 
preservación de las distintas microestructuras originales, vinculando la conservación de las mismas con un menor nivel de alteración diagenética.

\subsubsection{Microscopía de catodoluminiscencia}

Se seleccionaron treinta cortes delgados de sedimentitas y fósiles carbonáticos para ser analizados mediante catodoluminiscencia. Los mismos fueron realizados en el taller de cortes delgados del Centro de Investigaciones Geológicas (CONICET-UNLP) y fueron analizados con un equipo CiTL Technosyn MKIII de la mencionada institución (Fig. 2.5c).

A partir de las observaciones realizadas con el microscopio de catodoluminiscencia se pudieron reconstruir secuencias de cementos en las sedimentitas carbonáticas y ponderar los procesos de alteración diagenética en fósiles, ya que elementos enriquecidos durante la diagénesis, especialmente el $\mathrm{Mn}$, al ser excitados catódicamente inducen un color naranja a diferencias de sectores con mayor preservación que permanecen no luminiscentes. De esta forma, esta técnica posibilitó por un lado la reconstrucción de la historia diagenética de las secuencias, y por otro, aseverar de manera conjunta con la microscopía electrónica de barrido (ver sección 2.5.3) y los indicadores geoquímicos (ver sección 2.5.8) el potencial de preservación isotópica de las muestras fósiles.

\subsubsection{Micromuestreo}

De las muestras de sedimentitas tomadas sistemáticamente durante el relevamiento de perfiles (ver sección 2.3.1) se seleccionaron aquellas de granulometría fina (lutitas, margas y mudstones carbonáticos) de los seis perfiles estudiados para análisis más específicos de composición y geoquímica. Pequeñas porciones de muestra fueron separadas, eliminándose aquellas áreas alteradas o con presencia de venas o recristalizaciones, y posteriormente molidas en mortero de porcelana hasta obtener un polvo impalpable. Por último, se subdividió el material en dos submuestras destinadas a difracción de rayos X (ver sección 2.5.6) e isótopos estables de carbono en materia orgánica (ver sección 2.5.7).

Sobre las muestras tomadas con criterio quimioestratigráfico (ver sección 2.3.2) de Aetostreon sp. y Belemnopsis sp. en ambas cuencas se realizaron micromuestreos de material para realizar análisis geoquímicos. Para este procedimiento fue necesario discriminar las áreas con más alto potencial de preservación isotópica de aquellas con mayor alteración diagenética mediante microscopía electrónica de barrido y catodoluminscencia. Con el empleo de un microtaladro Drillco y fresas con puntas diamantadas (para evitar la contaminación de la 
muestra) del Centro de Investigaciones Geológicas, se perforaron los sectores mejor preservados (Fig. 2.5d). Las micromuestras tomadas fueron posteriormente divididas en tres submuestras las cuales fueron destinadas para geoquímica de elementos mayoritarios $(>0,1 \%)$ y minoritarios (entre 100 ppm y 0,1\%) (ver sección 2.5.8), geoquímica de elementos traza (menos de 100 ppm) (ver sección 2.5.9) e isótopos estables de carbono y oxígeno (ver sección 2.5.10).

\subsubsection{Difracción de rayos $X$}

Ciento treinta y dos submuestras de granulometrías finas (lutitas, margas y mudstones carbonáticos) de todas las secciones de estudio fueron seleccionadas sobre la base de su espaciamiento y preservación para ser analizadas por difracción de rayos $\mathrm{X}$ con el objetivo de describir de manera semicuantitativa sus composiciones mineralógicas.

Las muestras fueron analizadas con un equipo PANalytical, modelo X'Pert PRO, de óptica prealineada de alta resolución y tubo de rayos $\mathrm{X}$ metal- cerámico con ánodo de $\mathrm{Cu}$ en el Laboratorio de Difracción de Rayos X del Centro de Investigaciones Geológicas (Fig. 2.4a).

Del estudio se obtuvieron cuatros difractogramas, su lectura permite el análisis tanto de la roca total como de arcillas orientadas. La metodología utilizada fue la siguiente:

1) La muestra en polvo, ubicada en un porta muestra, fue colocada en el difractómetro de rayos $\mathrm{X}$ que se corrió desde los 3 a los 37 grados lo que dio como resultado la primera lectura que corresponde a la "roca total".

2) Posteriormente, la muestra fue colocada en un vaso rotulado que se completó con agua destilada. La mezcla de sedimento y agua se agitó bien y se la dejó reposar 20 minutos para que decante la fracción más gruesa y concentrar la fracción menor a 40 micrones. Pasado este tiempo, se tomó una muestra de la mezcla con una pipeta, se dividió el contenido de la pipeta en dos portaobjetos de vidrio y se dejó secar para obtener una fina película de sedimento (Fig. 2.4b). Una de estas muestras se analizó con el difractómetro de rayos $X$ desde los 2 grados hasta los 32 grados, y se obtuvo de esta manera la segunda lectura denominada "natural".

3) La misma muestra utilizada para la lectura normal fue posteriormente expuesta a los vapores de etilenglicol por veinticuatro horas para la hidratación de arcillas expansivas. Luego se procesó nuevamente por difracción para contar con la tercera lectura: la muestra "glicolada".

4) Para la cuarta lectura se utilizó la segunda muestra obtenida por pipeteo en el paso 2. Esta fue colocada en una mufla a $550 \circ \mathrm{C}$ durante 2 horas, rompiendo la 
estructura cristalina de las arcillas expansivas y de la caolinita. Este material (denominado muestra calcinada) fue también analizado por difracción de rayos $\mathrm{X}$.

Posteriormente se representaron gráficamente los resultados, para lo cual se utilizó el

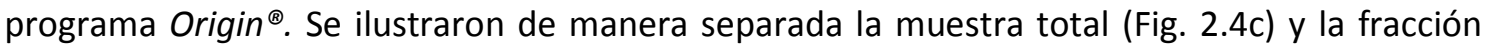
arcilla, en la cual figuran las tres lecturas: natural, calcinada y glicolada (Fig. 2.4d).

Para poder identificar las distintas especies minerales, tanto en roca total como en fracción fina, se consideraron las distintas reflexiones del difractograma que están expresadas en unidades de ángulo $2 \theta$, siendo $\theta$ el ángulo de refracción. Mediante la aplicación de la fórmula de la Ley de Bragg (Brindley, 1961; Brown, 1980) estos valores fueron convertidos a cifras de espaciado (en $\AA$ ) de los planos generadores de las refracciones. Cada especie mineral desarrolla un patrón de reflexiones y espaciados que le es característico, lo que se define por la utilización de patrones estándar ya establecidos.

Luego, se procedió a la semicuantificación de cada una de las especies minerales, realizándose por separado en roca total y en la fracción fina. Para poder visualizar de manera más clara la diferencia de abundancia entre especies minerales se determinaron los siguientes rangos arbitrarios:

Traza: $<0.5 \%$

Muy escaso: $0,5-5 \%$

Escaso: $5-20 \%$

Moderado: $20-40 \%$

Abundante: $40-60 \%$

Muy abundante: $>60 \%$

Para los difractogramas de roca total se utilizó el área del pico principal de cada mineral, en tanto que para los argilominerales esta área no refleja de manera directa la abundancia, razón por la cual se elaboraron las siguientes correcciones:

- Se considera al área correspondiente al pico 001 de illita (10 Å) como unidad entera.

- Debido a que el pico de máxima intensidad de la caolinita y el pico de 002 de la clorita se localizan ambos en $7 \AA$, las proporciones relativas de estas dos especies minerales se determinan sobre la medición de las reflexiones de los picos 002 de la caolinita $(3,57 \AA$ ) y 004 de la clorita $(3,53 \AA$ ) (Lluch y Spalletti, 1976). Ambos picos se dividen por dos.

- El pico de esmectita se encuentra entre 14 y $17 \AA ̊ ̊$ y se divide por cuatro. 
- La cuantificación relativa de las capas de los interestratificados illita/esmectita se calculó a partir de las reflexiones situadas entre 10 y $14 \AA ̊$ y debe dividirse por uno coma cinco.

La totalidad de los resultados fueron expresados en tablas y recalculados a datos porcentuales con el programa Excel. Luego, los valores porcentuales fueron representados paralelamente a los perfiles con el objetivo de reflejar las variaciones verticales.

Posteriormente, se calcularon los índices de cristalinidad y de Esquevin, con el objetivo de caracterizar los interestratificados $\mathrm{I} / \mathrm{S}$ (especialmente los ricos en illita), y de esta manera, aportar nuevos datos sobre procedencia y diagénesis. En última instancia, se calculó el porcentaje de illita en los interestratificados illita/esméctica mediante el método de Moore y Reynolds (1989).

El índice de cristalinidad IC (de la Illita) o índice de Kubler (Kubler, 1967), fue definido como el ancho del pico correspondiente a la reflexión 001 de la illita (medido a la mitad de la altura del pico), expresado en grados $2 \theta$. Este índice permite diferenciar rocas que han sido sometidas a condiciones diagenéticas (IC $>0,42$ ), de aquéllas que han alcanzado un bajo grado de metamorfismo (IC < 0,42), (Kubler, 1967). Mientras que el límite entre la anquizona y la epizona está dado por un valor de IC=0,25 (Kubler, 1967).

También se calcula el índice de Esquevin (IE) (Esquevin, 1969) cuyo valor es dado por la relación entre la intensidad de las reflexiones 002 y 001 de la illita en la fracción fina. Este valor de IE está en función del carácter ferromagnesiano o aluminoso de la illita. Si la relación I 002/I 001 es menor a 0,25 se dice que la illita es ferromagnesiana, mientras que si ese valor es mayor a 0,40 se dice que la misma es aluminosa. Las muestras con valores entre 0,25 y 0,40 de IE se las indica como de carácter intermedio (Gómez Peral, 2008).

Según Moore y Reynolds (1989), es posible establecer el porcentaje de illita en el interestratificado illita/esmectita a partir del análisis directo de los difractogramas de rayos $\mathrm{X}$. Para esto es se establece el parámetro $\Delta 2 \theta$ (la diferencia en grados $2 \theta$ entre el pico 001 y 002 ) en la muestra glicolada ya que el mismo resulta relativamente inalterado ante las variaciones de espesores de la intercapa (Gómez Peral, 2008). 

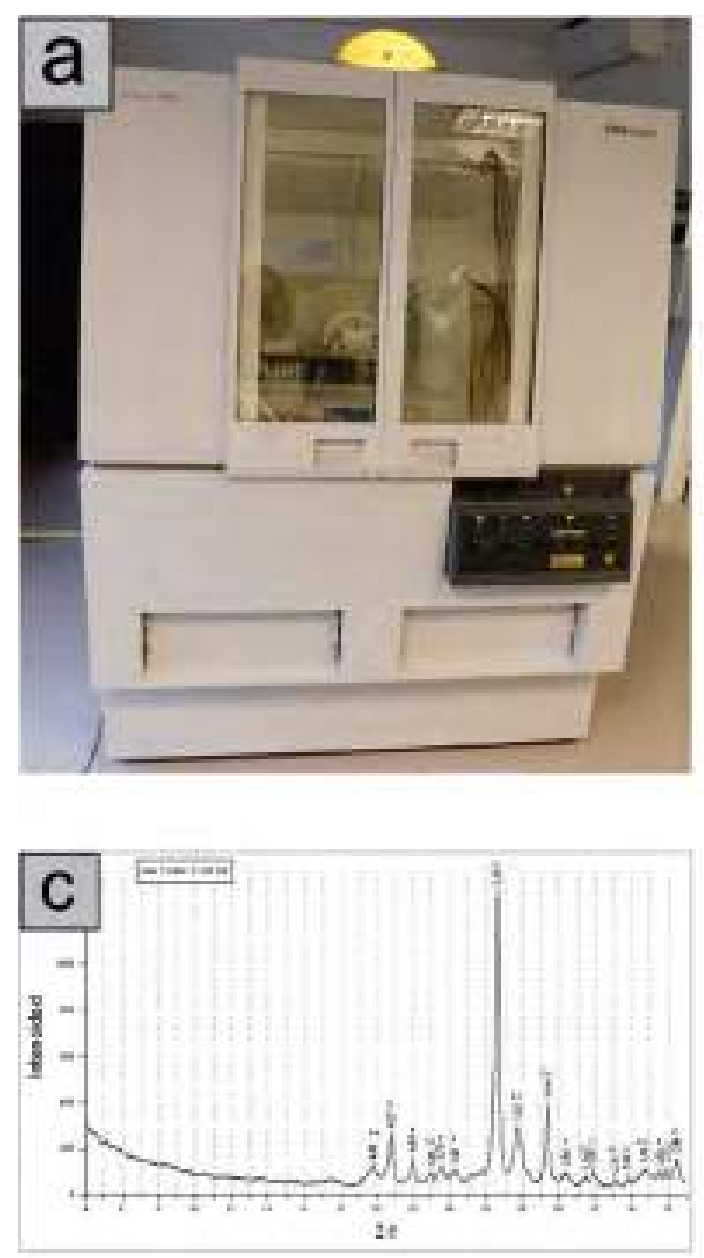

c. Difractograma de rola totat:

Figura 2.4: Difracción de rayos X.

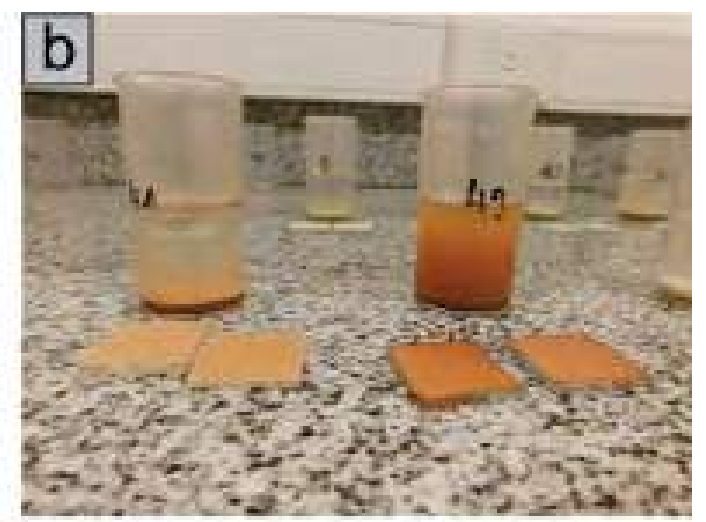

a: Difractometro de havos X Panablyicai modeio $X$ Pot PFO, del Centro de irwestigaxianes Geold gicas.

ti. Vasos rotulados para ia decantacion de codimento fino. fraccion menor a 40 micrones sobre poctaobjetos de vidria.

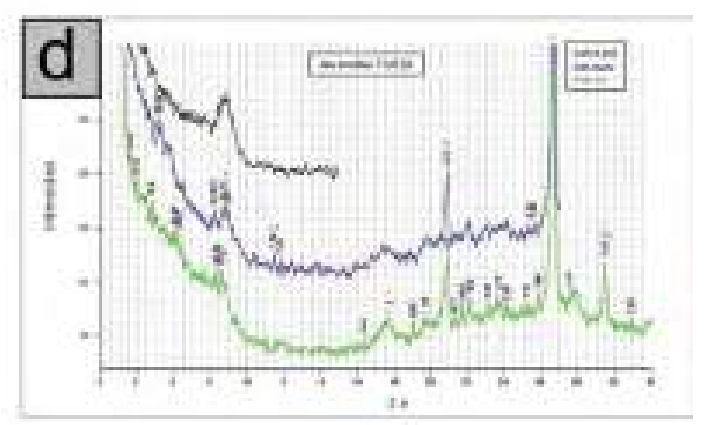

d. Dfractograma de fraccidn arcilla. En verde ta. muestra natural, azia la glicolada y negro la calcnaea.

\subsubsection{Isótopos estables de carbono en materia orgánica}

Cien submuestras de 0,1 gramos de granulometrías finas (especialmente lutitas negras) fueron seleccionadas en base a su espaciamiento y contenido de materia orgánica para realizar estudios de isótopos estables de carbono.

El procedimiento se llevó a cabo en dos partes. En primera instancia, la concentración de materia orgánica se desarrolló en el Laboratorio de Tritio y Radiocarbono (LATYR) con la ayuda de la Licenciada Florencia Mari, del Centro de Investigaciones Geológicas, Universidad Nacional de La Plata, Argentina y consistió en la disolución del carbonato de las muestras, asegurando de ese modo que todo el carbono medido posteriormente corresponda a carbono orgánico. Por otro lado, los isótopos estables fueron realizados en el laboratorio Núcleo de Estudos Geoquímicos - Laboratório de Isótopos Estáveis (NEG- LABISE) del Departamento de Geología, Universidad de Pernambuco en Brasil. 
Para la concentración de materia orgánica, las muestras fueron colocadas en tubos de ensayo con diez mililitros de $\mathrm{HCl}$ al ocho por ciento durante dos horas. Luego, se centrifugaron y se descartó el sobrenadante, se agregó igual cantidad de ácido y se las dejó burbujear durante veinticuatro horas.

Posteriormente, se centrifugó y se descartó el sobrenadante repitiendo nuevamente el proceso de burbujeo durante veinticuatro horas más. Una vez concluido, se las centrifugó de igual forma y se las lavó dos veces con agua destilada. Por último, se las secó en estufa a 60 으 durante veinticuatro horas o hasta que las muestras estuvieron totalmente secas.

Una vez concentrada la materia orgánica, las submuestras fueron analizadas automáticamente en el ECS4010 Elemental Combustion System del NEG-LABISE (Fig. 2.5e) para obtener los isótopos de carbono. El proceso de obtención de los isótopos es descripto con mayor detalle en la sección 2.5.10.

\subsubsection{Geoquímica de elementos mayoritarios y minoritarios}

Los elementos mayoritarios y minoritarios fueron analizados mediante distintas metodologías, con la intención de corroborar no sólo la preservación del material sino también la validez y utilidad de las distintas herramientas. En todos los casos, los resultados fueron procesados en el programa Excel y se recalcularon en porcentajes y partes por millón de cada elemento. Posteriormente, se representaron gráficamente y se calcularon relaciones y correlaciones entre distintos elementos químicos con el objetivo de corroborar el potencial de preservación isotópica del material. En última instancia, se compararon los rangos de valores obtenidos con los recopilados en la bibliografía para muestras fósiles contemporáneas de los mismos géneros.

Veinte submuestras de dos gramos representativas de las Cuencas Neuquina y Austral fueron seleccionadas para realizar estudios geoquímicos de fluorescencia de rayos $\mathrm{X}$ y conocer las concentraciones de elementos mayoritarios y minoritarios. Los análisis fueron efectuados por el laboratorio Bureau Veritas en Vancouver, Canadá.

De las veinte submuestras analizadas se seleccionaron cuatro micromuestras de 0,2 gramos con la intención de focalizar en sectores más puntuales de los ejemplares fósiles y corroborar si existe una relación entre las observaciones de preservación hechas mediante técnicas de microscopía y las realizadas por comparación geoquímica. En esta oportunidad los análisis fueron efectuados mediante ICP-AES, por la empresa Activation Laboratories LSD en Ontario, Canadá. 
Como herramienta adicional, las concentraciones de los elementos minoritarios manganeso y estroncio de cuarenta y nueve submuestras de 0,2 gr fueron analizados mediante ICP-MS. Los detalles de esta técnica se exponen en la sección 2.5.9.

\subsubsection{Geoquímica de elementos traza}

Un total de cuarenta y nueve submuestras de 0,2 gramos de fósiles de ambas cuencas fueron disueltas y analizadas con un equipo Perkin-Elmer ICP-MS equipado con un nebulizador concéntrico Meinhardt. Dichos estudios fueron realizados en el Laboratorio de Geoquímica del Centro de Investigaciones Geológicas con la ayuda del Doctor Marcos Pedemonte y la Licenciada Claudia Cavarozzi.

De los elementos traza analizados se seleccionaron las tierras raras y el itrio (REY) para estudios de detalle. Los valores obtenidos fueron normalizados y graficados con respecto a la post-Archean average Australian sedimentary rock (PAAS) (McLennan, 1989), con el objetivo de poder observar su comportamiento y enriquecimientos relativos. A partir de los resultados se pudo evaluar el efecto diagenético y la química de las aguas oceánicas en equilibrio con la precipitación de los fósiles carbonáticos. Además, se obtuvieron resultados de algunos elementos minoritarios, tales como el $\mathrm{Sr}$ y el $\mathrm{Mn}$ que fueron utilizados para comparar con los reportados en los laboratorios Activation Laboratories y Bureau Veritas.

\subsubsection{Isótopos estables de carbono y oxígeno}

Los estudios de isótopos estables de carbono y oxigeno fueron realizados en Laboratorio Núcleo de Estudos Geoquímicos - Laboratório de Isótopos Estáveis (NEG- LABISE) del Departamento de Geología, Universidad de Pernambuco en Brasil, bajo la dirección del Doctor Alcides Nobrega Sial. Ochenta y dos submuestras de 0,2 gr en polvo fueron pretratadas con ácido ortofosfórico al $100 \%$ a 25 C durante un día. De las mismas, luego se extrajo $\mathrm{CO}_{2}$ en estado gaseoso utilizando una línea de alto vacío. El gas liberado fue analizado con un espectrómetro de masas Delta $V$ Advantage (Fig. 2.5f). Los resultados de isótopos estables de $\mathrm{C}$ y $\mathrm{O}$ obtenidos fueron utilizados para realizar curvas quimioestratigráficas (ver sección 2.6.1) y cálculos de paleotemperaturas y paleosalinidades (ver sección 2.6.2). 


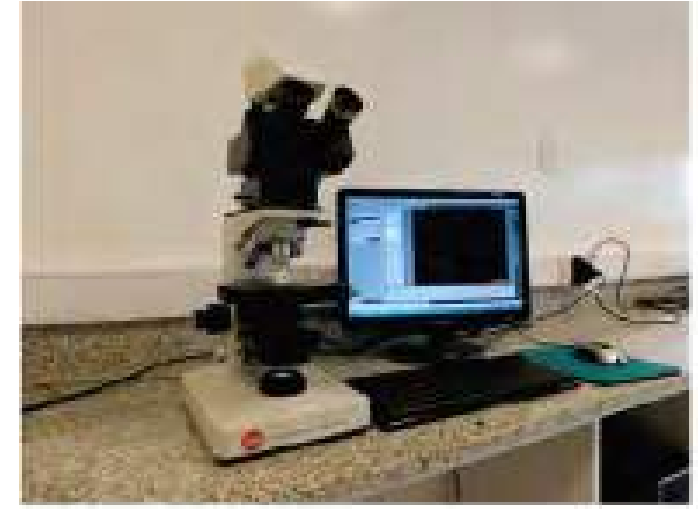

\section{a. Microscopio Linocular Leltz Labortux 12 POL del} Centro de Imestigaciones Geolbigicas

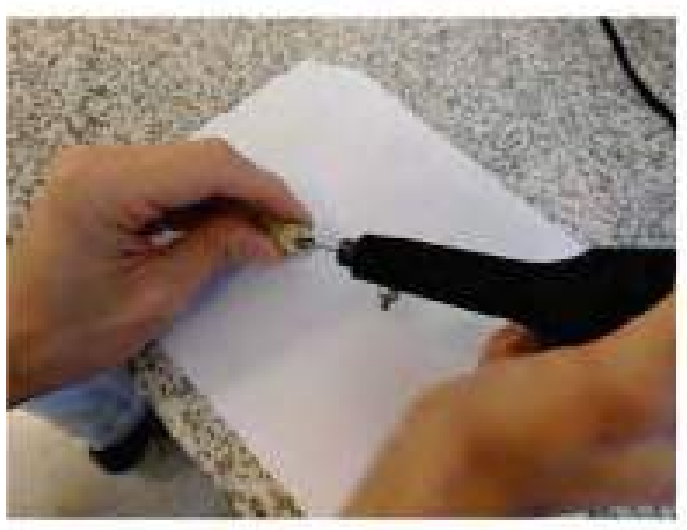

d: Perforación de una muestra fosil con un microtaladro Drillco del Centro do irvestigaciones Gealágicas:

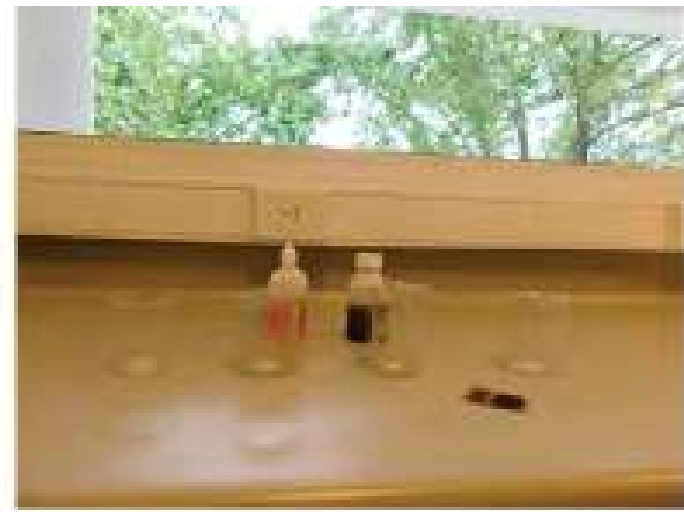

6: Theión de minerales, Soluciones de alizarina rojay ferr clanuro de petsaio.

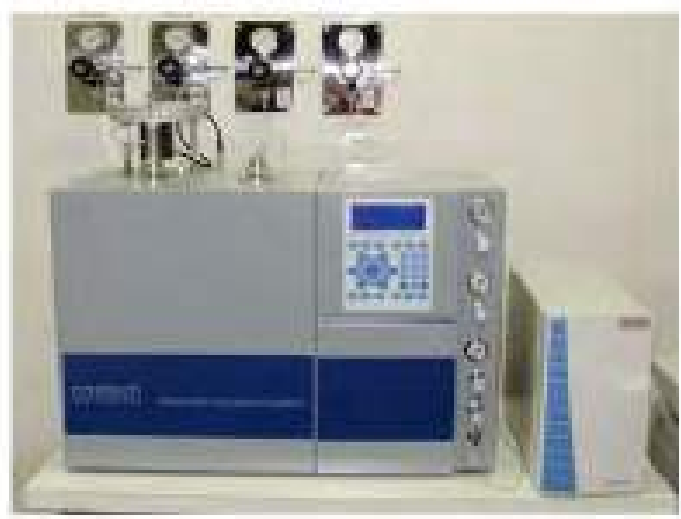

e: Espectrometro de masas ECSA010 Elemental Combuistion Svstem del laboratorio NEG LAAISE

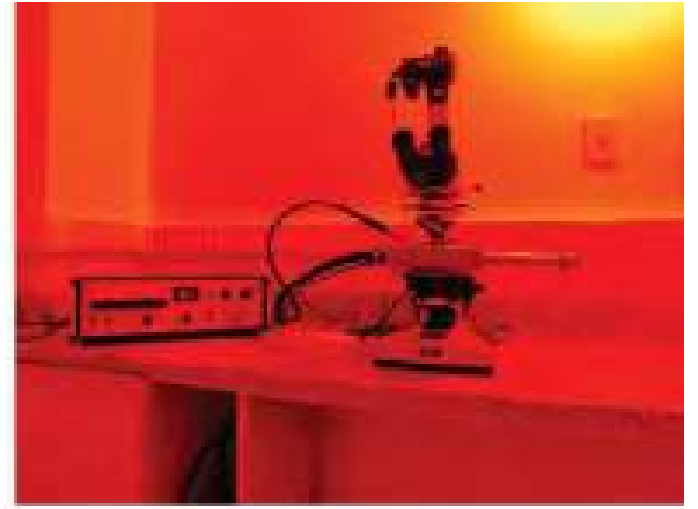

C. Mieroscopio de catodoluminscencia CTL technowy Mxill del Centro de Inwestigacianes Geologicas.

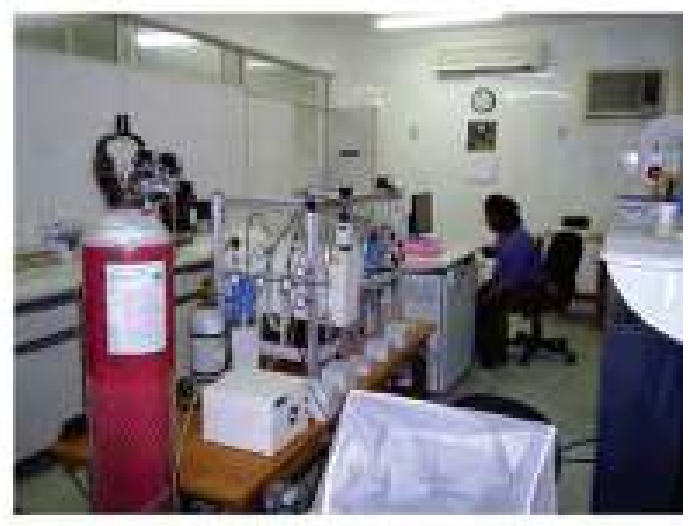

f: Espectrómetro de masas Delta V adventage del laboratonio NEG-LABISE.

Figura 2.5: Tareas de laboratorio, principales metodologías aplicadas en el procesamiento de los datos 


\subsection{Tareas de gabinete (segunda parte)}

Una vez finalizadas las tareas de laboratorio, se llevó a cabo una segunda etapa de tareas de gabinete vinculada a la interpretación de los resultados isotópicos obtenidos.

\subsubsection{Elaboración de curvas quimioestratigráficas}

Los resultados de isótopos estables de carbono y oxígeno fueron llevados a notación delta. El valor delta $(\delta)$ expresa la composición isotópica de un material referida a un estándar determinado (Hoefs, 1997; Gaucher, 2012):

$$
\delta(\%)=\left(R_{\text {muestra- }} R_{\text {estándar }} / R_{\text {estándar }}\right) \times 1000
$$

Donde $\mathrm{R}$ es el cociente entre la concentración del isótopo pesado y el isótopo liviano. El estándar utilizado para este trabajo es la especie Bellemnitella americana de la Formación Pedee (Cretácico de Carolina del Sur), de ahora en más llamado PDB (Peede Belemnite), que equivale a $1,1237 \times 10^{-2}$ (Craig, 1957). Los valores calculados de $\delta^{13} \mathrm{C}, \delta^{18} \mathrm{O}$ y $\delta^{13} \mathrm{C}_{\mathrm{ORG}}$ fueron representados paralelamente a los perfiles sedimentarios generando así curvas quimioestratigráficas, como así también se generaron diagramas comparativos entre éstos valores y otros indicadores geoquímicos de PPI.

\subsubsection{Cálculo de paleotemperaturas y paleosalinidades}

Las paleotemperaturas fueron calculadas a partir de los resultados de los análisis de $\delta^{18} \mathrm{O}$ antes mencionados y utilizando una versión modificada de la ecuación de Craig (Epstein et al., 1953; Anderson y Arthur, 1983; Pirrie et al., 2004):

\section{ToC $=16,0-4,14(\delta c-\delta w)+0,13(\delta c-\delta w)^{2}$}

Donde $\delta c=\delta^{18} \mathrm{O}(\mathrm{VPDB})$ de los análisis efectuados a 25으 y $\delta w=\delta^{18} \mathrm{O}$ (SMOW) del agua en la cual el carbonato fue precipitado relativa al "Standard Mean Ocean Water". Mientras $\delta c$ es medido, $\delta$ w es estimado en $-1,2 \%$, valor estipulado como promedio global para el agua de mar en períodos no glaciales (Shackleton y Kennett, 1975). Para el cálculo de paleotemperaturas sólo fueron tenidos en cuenta los valores mayores a $-5 \%$ o VPDB, tal como se estila en trabajos similares (e.g. Zakharov et al., 2011). 
Los cálculos de paleosalinidades han sido calculados sobre la base de los resultados de análisis de isótopos estables de $\delta^{18} \mathrm{O}$ y sobre los cálculos de paleotemperaturas antes mencionados. Para la obtención de los mismos, se utilizó el modelo de salinidad-temperatura de Railsback et al. (1989). Este modelo supone que es un período no glacial libre de hielos, que el $\delta_{w}=-1,2 \%$ y que la salinidad media del agua de mar es de $34 \mathrm{~g} / \mathrm{l}$ (Lazo et al., 2008).

\subsection{Interpretación de la información}

Para el correcto desarrollo del presente trabajo fueron necesarias distintas instancias de análisis intelectual de la información.

Una primera etapa consistió en elaborar, a partir de la descripción de los perfiles sedimentarios, una interpretación dinámica y ambiental de las facies sedimentarias y de sus asociaciones, para poder generar a partir de ello un modelo de los sistemas depositacionales.

Una segunda etapa fue necesaria para entender la historia diagenética de las secuencias estudiadas a partir de la información petrográfica y geoquímica.

Más adelante, el trabajo se enfocó en la fósil- diagénesis, donde fue posible distinguir las zonas con mejor potencial de preservación isotópica por integración de tres herramientas específicas: catodoluminiscencia, microscopía electrónica de barrido e indicadores geoquímicos.

Sobre la base de la integración de los aspectos sedimentológicos con los resultados isotópicos fue posible arribar a importantes conclusiones sobre aspectos paleoambientales y paleoclimáticos para llevar a cabo en última instancia la correlación y comparación de ambas cuencas entre sí y en un ámbito global. 


\section{Capítulo III - Antecedentes}

\subsection{Cuenca Neuquina}

La Cuenca Neuquina es una amplia región territorial de forma triangular ubicada en el centro-oeste de la República Argentina. Comprende un área que supera los $120000 \mathrm{~km}^{2}$ y presenta un continuo registro estratigráfico de más de $4000 \mathrm{~m}$ de espesor (Howell et al., 2005). Está conformada por la porción extraandina del Neuquén, sur de Mendoza, noroeste de Río Negro y sudoeste de La Pampa (Digregorio y Uliana, 1979) y está limitada al oeste por el cinturón plegado de la Cordillera de los Andes, al noreste por el Bloque de la Sierra Pintada y al sudeste por el Macizo Norpatagónico (Schwarz, 2003)(Fig. 3.1).

La cobertura sedimentaria comprende el lapso entre el Triásico tardío y el Cenozoico temprano e incluye sedimentos silicoclásticos marinos y continentales, carbonatos y evaporitas que se acumulan en una gran variedad de estilos de cuenca (Legarreta y Gulisano, 1989; Legarreta et al., 1993).

Los aspectos paleontológicos han sido particularmente trabajados en esta región. La Cuenca Neuquina contiene uno de los más completos registros del Jurásico y el Cretácico de invertebrados marinos, especialmente amonites. El estudio de estas especies ha permitido la definición de biozonas de gran importancia cronoestratigráfica y la construcción de una carta bioestratigráfica completa y detallada para el oeste de Gondwana (Aguirre-Urreta et al. 1999; Riccardi et al. 1999).

El avanzado grado de conocimiento de las sedimentitas de la Cuenca Neuquina está relacionado con el desarrollo de estudios petroleros en la región. De esta forma, desde la década del 70 hasta la actualidad se llevaron a cabo trabajos de investigación (Marchese, 1971; Leanza et al., 1977; Mitchum y Uliana, 1986; Legarreta y Gulisano, 1989; Legarreta y Uliana, 1996; Spalletti et al., 2000; Sagasti, 2001a; Schwarz et al., 2011a; Kietzmann et al., 2014, entre otros) que han contribuido de manera contundente no sólo al entendimiento de los sistemas petroleros sino al desarrollo de la investigación científica en los campos de la estratigrafía secuencial, bioestratigrafía y sedimentología.

Según Doyle et al. (2005), es posible diferenciar dos extensas áreas depositacionales: al sur el Engolfamiento Neuquino y al norte la Plataforma Mendocina (Fig. 3.1). El Engolfamiento Neuquino, es una región de forma subcircular caracterizada por secuencias sedimentarias espesas y un gran desarrollo hidrocarburífero. La Plataforma Mendocina, se caracteriza por una importante reducción en la amplitud de la cuenca. La generación de esta área se vio 
favorecida por la oblicuidad desarrollada entre el arco magmático y el eje depocentral, de orientación NW-SE (Spalletti et al., 2000; Doyle et al., 2005). Durante el desarrollo de esta tesis se hará especial énfasis en las características de la Plataforma Mendocina, donde se encuentra ubicada la zona de estudio.
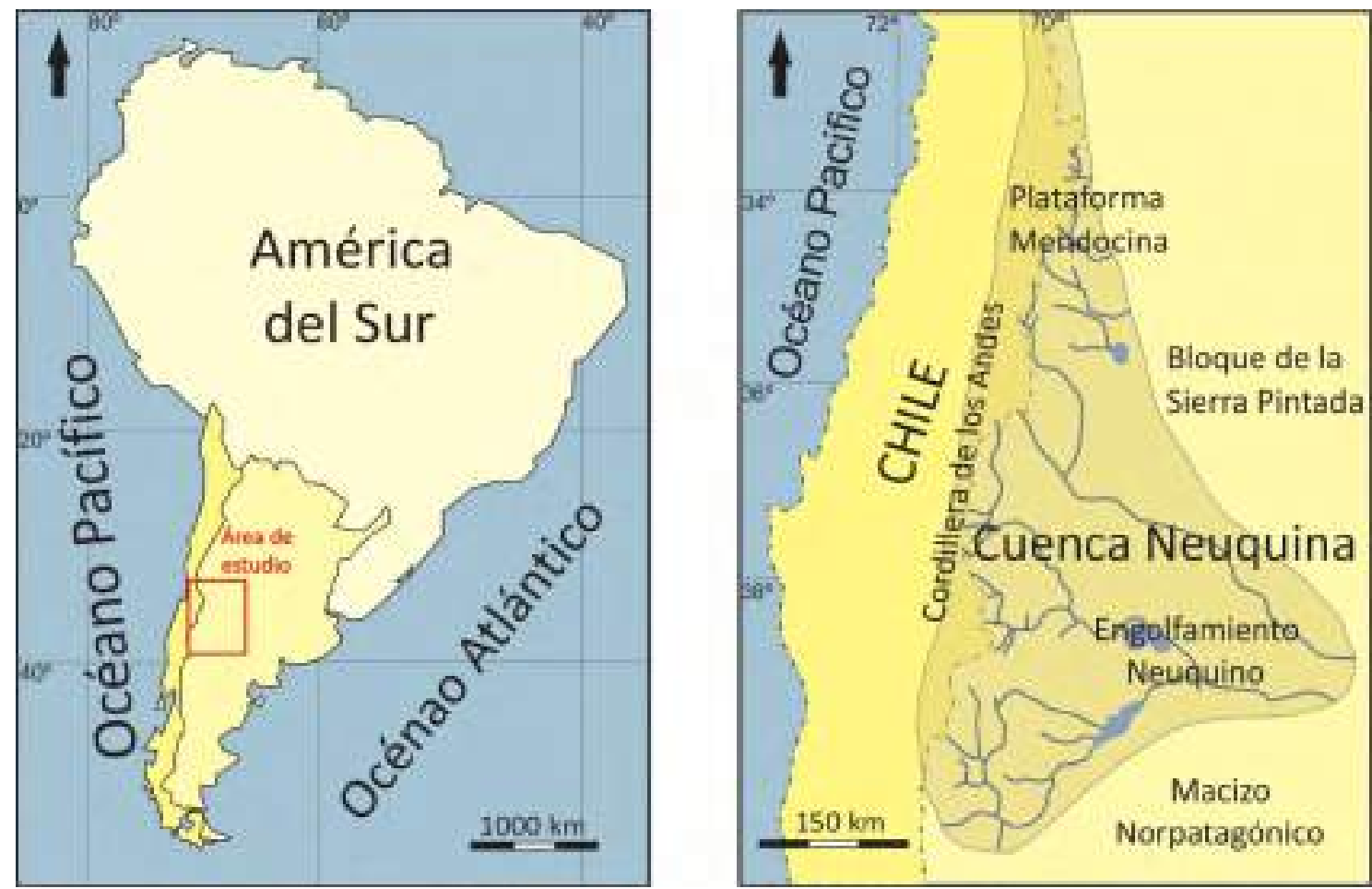

Figura 3.1: Ubicación y contexto geológico de la Cuenca Neuquina.

\subsubsection{Etapas tectónicas de la Cuenca Neuquina}

Legarreta y Gulisano, (1989), Franzese y Spalletti, (2001) y Howell et al. (2005) entre otros autores, proponen que la historia tectónica de la cuenca puede ser visualizada en varias etapas: rift (Triásico tardío- Jurásico temprano); postrift (Jurásico temprano- Cretácico temprano); y subsidencia por carga del arco magmático y tectogénesis andina (Cretácico tardío-Cuaternario temprano) (Fig. 3.7).

Entre el Triásico tardío y el Jurásico temprano se desarrolló, donde hoy está situada la Cuenca Neuquina, un régimen de tectónica extensional. La fase de rift se produjo a partir de la ruptura de una corteza continental previamente engrosada por el magmatismo bimodal del Grupo Choiyoi (ca. 240 Ma.) (Franzese y Spalletti, 2001). Se desarrollaron una serie de hemigrábenes largos de orientación N-S y NO-SE, estrechos y aislados que constituyeron las primeras áreas negativas donde se depositaron sedimentos asociados con flujos de lava (Franzese et al., 2006). 
Durante el Jurásico temprano- Cretácico temprano se desarrolló una etapa de post-rift con una sostenida subsidencia térmica en tres episodios consecutivos: 1) durante el Jurásico temprano y medio se inició el régimen de subducción a lo largo del margen oeste de Gondwana (Franzese et al., 2003), esto generó una importante transgresión marina y la unificación de todos los depocentros anteriormente aislados. 2) Hacia el Jurásico tardío el arco magmático andino se desarrolló casi por completo, aunque la cuenca estuvo por importantes períodos de tiempo conectada con el Protopacífico. 3) Durante el Jurásico tardío- Cretácico temprano se combinó la subsidencia termal con la extensión regional del trasarco y se desarrollaron ciclos transgresivos- regresivos que dieron como resultado la depositación de los Grupos Cuyo, Lotena y Mendoza (Howell et al., 2005), en este último grupo se encuentra el intervalo estratigráfico que es objeto de estudio en el presente trabajo de tesis.

Hacia el intervalo temporal comprendido entre el Cretácico tardío y el Cenozoico se produjo un cambio en el ángulo de subducción de las placas involucradas en el levantamiento Andino. Esto generó el desarrollo de una tectónica compresiva con levantamiento del antepaís (Ramos, 1999b), generándose acortamiento de la corteza, inversión de las estructuras extensionales previas (Vergani et al., 1995) y la migración hacia el este de los depocentros (Franzese et al., 2003). Como resultado de esta etapa se generaron varias fajas plegadas y corridas de piel fina y gruesa (Ramos, 1999b) y se depositaron más de $2000 \mathrm{~m}$ de depósitos continentales correspondientes a los grupos Rayoso y Neuquén (Legarreta y Ulliana, 1996). Hacia finales del Cretácico predominó la sedimentación continental y se registró la primera transgresión marina desde el Océano Atlántico.

\subsubsection{Grupo Mendoza}

El Grupo Mendoza fue definido originalmente como “Mendociano" por Groeber (1946) para describir a las "...facies uniformemente calcáreo-arcilloso-esquistosa de origen marino...", de la Provincia de Mendoza. Se apoya en concordancia sobre depósitos clásticos de la Formación Tordillo y es sobreyacido por la Formación Huitrín mediante una superficie de discordancia erosiva (Schwarz, 2003). En el sur de la Provincia de Mendoza, posee un espesor máximo de 700 m (Legarreta y Gulisano, 1989) y se depositó en el lapso TithonianoBarremiano inferior (Leanza et al., 1977) (Fig. 3.2).

Groeber (1946), dividió el registro sedimentario de la Cuenca Neuquina en tres grandes episodios de acumulación: Jurásico, Ándico y Riográndico, señalando al Mendociano como un ciclo de orden menor dentro del Ándico. Legarreta y Gulisano, (1989) estudiaron el relleno sedimentario de la Cuenca Neuquina desde el punto de vista de la estratigrafía 
secuencial, dividiendo al registro en tres supersecuencias que coinciden parcialmente con los ciclos propuestos por Groeber, (1946). El Grupo Mendoza junto con las Formaciones Tordillo y Huitrín, corresponden según estos autores a la supersecuencia media.

En el sector mendocino de la cuenca, conocido como Plataforma Mendocina (Doyle et al., 2005), la constitución y la denominación del Grupo Mendoza ha sido ampliamente discutida en la bibliografía. Groeber (1946) dividió al Mendociano en cuatro grupos litológicos: Vacamuertense, Quintucoense, Mulichincoense y Agrioense basándose en estudios de Weaver (1931) quien había trabajado en el mismo intervalo temporal pero en la Provincia del Neuquén. Leanza et al., (1977) indicaron que la denominación Grupo Mendoza comenzó a utilizarse en la Plataforma Mendocina, debido a que las Formaciones Vaca Muerta, Quintuco, Mulichinco y Agrio ya estaban definidas en la Provincia del Neuquén (Stipanicic et al., 1968), teniendo en cuenta que las formaciones son homologables en edad.

Por otro lado, Dessanti (1973) propuso llevar la denominación a "Formación Mendoza" para los afloramientos de la provincia homónima, ya que en muchas localidades resultaba imposible la distinción de las formaciones que componen el grupo. Dessanti (1973) y Leanza et al. (1977) proponen la división de la Formación Mendoza en los miembros Vaca Muerta, Chachao y Cienaguitas. Mombrú et al., $(1976,1978)$, comienzan a utilizar la denominación de "Formación" para referirse a los conjuntos litológicos de Vaca Muerta, Chachao y Agrio, elevando nuevamente a la Formación Mendoza a la categoría de Grupo.

Numerosos trabajos (Legarreta y Kozlowski, 1981; Legarreta et al., 1981; Carozzi et al., 1981; Legarreta y Gulisano, 1989; Gulisano y Gutiérrez Pleimling, 1994; entre otros) contribuyeron a dar una visión más completa de la distribución y los límites de las formaciones. Actualmente el Grupo Mendoza se considera compuesto por las facies pelíticas y calcáreas euxínicas de la Formación Vaca Muerta, las calizas de plataforma de la Formación Chachao, las facies clásticas marino marginales correspondientes a la Formación Lindero de Piedra y los depósitos eminentemente pelíticos con participación carbonática y bancos arenosos de la Formación Agrio (Legarreta y Gulisano, 1989). Algunos autores (Leanza y Hugo, 1977; Leanza et al., 1977; Legarreta et al., 1981; Leanza, 1993) consideran además a la Formación Tordillo como la parte basal del Grupo Mendoza. 

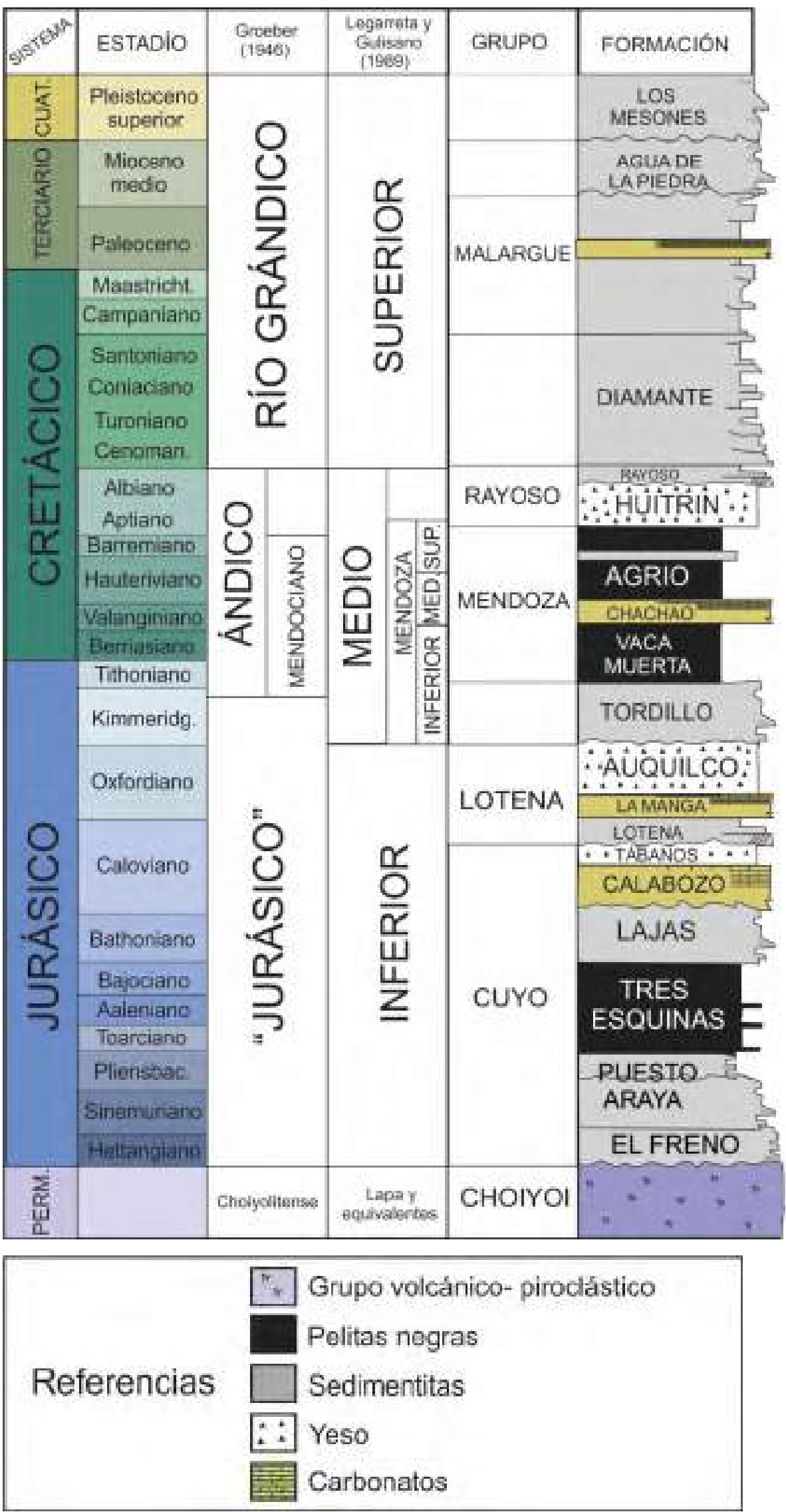

Figura 3.2: Cuadro estratigráfico del relleno de la Cuenca Neuquina (compilado de Groeber, 1946; Legarreta y Gulisano, 1989, Gulisano y Gutiérrez Pleimling, 1994). 


\subsubsection{Formación Vaca Muerta}

\subsubsection{Generalidades}

La Formación Vaca Muerta fue definida originalmente por Weaver (1931) para designar al "...conjunto de estratos Tithonianos constituidos por lutitas calcáreas grises oscuras...". Es denominada en algunos de los trabajos pioneros, tales como Baldwyn (1942) y Herrero Ducloux (1946), como "margas bituminosas del Tithoniano". Fue posteriormente enmendada por Leanza (1972) por ser indiferente, excepto por su contenido de amonites, del "Quintucoense" definido por Weaver (1931). De esta manera los límites de esta formación fueron extendidos hasta la base de la Formación Mulichinco (Leanza et al., 1977).

Esta unidad litoestratigráfica es reconocida desde el sur de la Provincia del Neuquén hasta el norte de la Provincia de Mendoza y su localidad tipo fue definida por Leanza (1973) como el sector occidental de la Sierra de la Vaca Muerta.

En el sector de la cuenca correspondiente al Engolfamiento Neuquino fueron definidos miembros y formaciones contemporáneas a la Formación Vaca Muerta. De esta manera podemos distinguir el Miembro Los Catutos (Leanza y Zeiss, 1990) al noroeste de la localidad de Zapala, Miembro Huncal (Leanza et al., 2003) al este de la localidad de Loncopué, Formación Carrin Curá (Leanza et al., 1978) al noroeste de Piedra del Águila, Formación Picún Leufú (Leanza, 1973) en el arroyo homónimo y la Formación Bajada Colorada (Fossa Mancini et al., 1938) en las barrancas de la Bajada Colorada.

En la zona correspondiente a la Plataforma Mendocina, Doyle et al. (2005) dividieron a la Formación Vaca Muerta en dos secciones estratigráficas formales sobre la base de su contenido litológico: Vaca Muerta inferior y Vaca Muerta superior. Trabajos posteriores en el área, tales como Kietzmann et al. (2008), Kietzmann et al., (2014) y Kietzmann et al. (2015) no registraron la división propuesta por Doyle et al. (2005).

El elevado nivel de conocimiento de estos afloramientos jurásico-cretácicos es debido a su importancia económica. La Formación Vaca Muerta constituye la principal roca madre de la Cuenca Neuquina (Leanza et al., 2011), se calcula que el $75 \%$ de los hidrocarburos descubiertos en el país provienen de sus sedimentitas (Uliana et al., 1999). Sus características, tales como su alto contenido de carbono orgánico total (COT), su moderada profundidad y sus condiciones de sobrepresión lo constituyen como un excelente reservorio de sistemas de tipo shale oil y shale gas (Gulisano et al., 1984; Boyer et al., 2011; Kietzmann et al., 2014). 


\subsubsection{Relaciones estratigráficas}

A lo largo de la Cuenca Neuquina la Formación Vaca Muerta se encuentra sobrepuesta de manera concordante sobre las Formaciones Quebrada del Sapo y Tordillo, siendo esta última la relación más extendida. También suprayace de manera discordante a las Formaciones Lotena, Auquilco, La Manga e incluso a los depósitos precuyanos (Leanza et al., 2011). A la vez, es cubierta en concordancia por las Formaciones Picún Leufú, Quintuco, Mulichinco y Chachao (Leanza et al., 1977).

En la Plataforma Mendocina, la Formación Vaca Muerta se encuentra por sobre los depósitos continentales y clásticos de Tordillo; el límite entre ambas formaciones es el comienzo de la transgresión tithoniana (Leanza, 1981). Sobreyaciendo a dicha formación, se encuentran los carbonatos marinos de la Formación Chachao que conforma, junto a la Formación Vaca Muerta, un registro continuo progradacional (Leanza 1973; 1981b; Leanza y Hugo, 1977; Leanza et al., 1977; Legarreta y Gulisano, 1989; Doyle et al., 2005).

\subsubsection{Espesor}

Los espesores de la Formación Vaca Muerta van desde 11 m en la Comarca de Carrín Curá hasta superar los $1250 \mathrm{~m}$ en áreas depocentrales de la Cuenca como la Sierra de la Vaca Muerta (Leanza et al., 2011). Más allá de las diferencias en su potencia, esta unidad ostenta unos $350 \mathrm{~m}$ de espesor promedio en toda la cuenca (Leanza et al., 1977).

En la zona de estudio, se registra un espesor de $300 \mathrm{~m}$ para el Puesto Loncoche (Kietzmann et al., 2008), $145 \mathrm{~m}$ en el sector de Río Salado (Doyle et al., 2005) y $225 \mathrm{~m}$ en la Cuesta del Chihuido (Kietzmann et al., 2015).

\subsubsection{Asignación temporal}

Su edad es definida tradicionalmente sobre la base de su contenido de amonites (Aguirre-Urreta et al., 2011; Riccardi et al., 2011; Riccardi, 2015; entre otros). La Formación Vaca Muerta se depositó entre el final del Tithoniano temprano (biozona ándica de amonites de Virgatosphinctes mendozanus) (Riccardi, 2015) y el Valanginiano temprano (biozona ándica de amonites de Olcostephanus atherstoni) (Kietzmann et al., 2015). Este rango temporal fue soportado por estudios efectuados en nanofósiles calcáreos (se registró desde el evento de Polycostella beckmanii hasta el de Eiffellithus windii) (Concheyro et al., 2006; Lescano y Kietzmann, 2010; Kietzmann et al., 2015) y calpionélidos (se reconocieron los géneros de 
Tintinnopsella, Crassicollaria y Calpionella) (Fernández-Carmona y Riccardi, 1998; Kietzmann et al., 2015) (Fig. 3.3).

\subsubsection{Litología y biodiversidad}

La Formación Vaca Muerta representa la entidad estratigráfica con mayor extensión areal de la Cuenca Neuquina (Kietzmann y Vennari, 2013) y se caracteriza por su alta uniformidad litológica (Leanza, 1973). Estudios sedimentológicos, tales como los de Leanza et al. (1977), exponen que más del 95\% de su espesor está constituido por pelitas y calizas. Legarreta et al. (1993) definieron a las acumulaciones correspondientes a la Formación Vaca Muerta como facies de pelitas oscuras y mudstone- wackestone esqueléticos que ocurren en bancos medianos a finos, portadores de pelecípodos de valvas finas, amonites, foraminíferos y braquiópodos.

En la última década, nuevos estudios sedimentológicos, petrográficos y geoquímicos pusieron en evidencia la variabilidad composicional de la Formación Vaca Muerta, sobre todo en el sector de la Plataforma Mendocina. Kietzmann et al. (2008), Kietzmann y Palma (2009) y Spalletti et al. (2014), registraron la presencia de una alta variabilidad composicional en los sedimentos finos y textural y tafonómica en los bancos de calizas.

En cuanto a su contenido paleontológico, en los niveles clásticos es posible reconocer amonites, escamas fosfáticas, bivalvos infaunales y epifaunales (ostreidos y lucínidos) y serpúlidos. Por otro lado, los niveles carbonáticos poseen además de la fauna antes mencionada radiolarios, foraminíferos, gastrópodos, briozoos, espículas de esponjas, belemnites y nautiloideos dispersos (Doyle et al., 2005; Kietzmann et al., 2008). En cuanto a su contenido de fósiles vertebrados, es destacable su contenido de reptiles marinos tales como cocodrilos, ictiosaurios y plesiosaurios (Fernández, 1998; Gasparini et al., 1999; Talevi et al., 2012; entre otros)

\subsubsection{Ambiente de depositación}

Leanza et al (1977), sobre la base de su composición litológica propone un ambiente caracterizado por la escasa profundidad del fondo marino de índole litoral a sublitoral cubierto por aguas tranquilas, contraponiéndose al pensamiento de autores anteriores que proponían un ambiente batial en base a su "gran espesor". 
Posteriormente, trabajos como Legarreta et al. (1981), Mitchum y Uliana (1986) y Legarreta et al. (1993) sugieren para el sector mendocino, que el análisis del sistema de acumulación indica una geometría tipo rampa, carente de quiebre de plataforma, donde se depositaron sedimentos finos en condiciones de disaerobia/ anaerobia y baja energía. Legarreta et al. (1993), Spalletti et al. (2000) y Kietzmann et al. (2008), describen esta rampa como mixta, mostrando una alternancia entre intervalos carbonáticos y silicolásticos, conformando ciclos de lutitas- margas- calizas de diferentes órdenes y jerarquías. Estos ciclos fueron estudiados en mayor detalle por Kietzmann et al. (2011) quienes atribuyeron su periodicidad a precisos cambios climáticos impulsados por excentricidad de alta frecuencia.

En la Plataforma Mendocina se realizaron importantes interpretaciones ambientales a partir de estudios sedimentológicos. Doyle et al. (2005) describieron dichas sedimentitas en el Río Salado, donde postularon que ambos miembros se habrían acumulado a partir de decantación suspensiva en un ambiente anóxico a subóxico de cuenca, con evidencia de retrabajo por tormentas hacia el tope.

En el sector del Puesto Loncoche, una interpretación ambiental detallada de los depósitos de la formación Vaca Muerta fue propuesta por Kietzmann et al. (2008). Los autores identificaron de base a techo los subambientes de cuenca, rampa externa distal, rampa externa proximal y rampa media distal. Los afloramientos al sur del Arroyo Loncoche fueron estudiados por Kietzmann et al. (2015). Los autores reconocen una continuidad entre las exposiciones descriptas en el Puesto Loncoche y los afloramientos de la Cuesta del Chiuido, pero con intercalaciones de autoparabiostromas de ostras hacia el sector cuspidal interpretados como una rampa externa dominada por biostromas de ostras. Hacia el sur, en las zonas del Arroyo Rahue y de Bardas Blancas, se observa la desaparición de los autoparabiostromas y un predominio de condiciones ambientales interpretadas como rampa media dominada grainstones retrabajados por tormentas

Desde el punto de vista de la estratigrafía secuencial, la Formación Vaca Muerta forma parte de la Mesosecuencia Mendoza Inferior de Legarreta y Gulisano (1989). El abrupto límite entre las Formaciones Tordillo y Vaca Muerta puede ser interpretado como el resultado de una extendida transgresión Proto- pacífica hacia el Tithoniano temprano (Legarreta y Uliana, 1996). Este fenómeno constituye una inundación catastrófica, caracterizada por una superficie de ravinamiento en la base de la unidad y una intensa deformación sinsedimentaria de muchas de las capas cuspidales de la Fm. Tordillo (Veiga y Spalletti, 2007). A partir de allí pueden ser distinguidos tres ciclos transgresivos -regresivos con límites representados por regresiones forzadas. Estos ciclos, fueron considerados como secuencias depositacionales a partir de 
observaciones sismoestratigráficas realizadas por Mitchum y Uliana (1986) y Legarreta y Uliana (1991) y respaldada por estudios sedimentológicos realizados por Kietzmann et al. (2008).

\subsubsection{Estudios geoquímicos y diagenéticos}

A partir del empleo de nuevas técnicas para el análisis de los sedimentos finos, tales como fluorescencia de rayos $X$, difracción de rayos $X$, espectrometría de masas $y$ caracterizaciones composicionales con ICP-MS, QEMSCAN y Rock Eval, se llegó a un entendimiento mucho más profundo de los aspectos de geoquímica orgánica e inorgánica de la Formación Vaca Muerta.

Desde este punto de vista, y si bien en la Formación Vaca Muerta no se han propuesto subdivisiones estratigráficas formales, en el presente caso resulta apropiado reconocer una sección inferior y otra superior. La sección inferior se caracteriza por altos contenidos de carbono orgánico total (COT), acompañados por valores anormalmente altos de molibdeno, circonio, vanadio, níquel y cromo, indicando que en el ambiente sedimentario del área depocentral persistieron y/o dominaron condiciones sulfhídricas anóxicas (Nawratil et al., 2012; Larriestra y Merino., 2014; Spalletti et al., 2014; Spalletti et al., 2015). Por otro lado, en el sector superior se observa una disminución en la cantidad de COT, rubidio, circonio y molibdeno (Nawratil et al., 2012; Larriestra y Merino, 2014), pudiendo reflejar cambios en las condiciones redox y/o niveles de oxigenación.

En cuanto al estudio de isótopos estables, se registran algunos antecedentes en el área del Engolfamiento Neuquino. Scasso et al. (2002) realizaron análisis sobre muestras de margas y calizas con el objetivo de analizar la diagénesis de estos sedimentos. Posteriormente, Aguirre-Urreta et al. (2008) y Lazo et al. (2008), realizaron estudios sobre ostras fósiles del género Aetostreon sp. para arribar a conclusiones de tipo paleoambiental.

\subsubsection{Formación Chachao}

\subsubsection{Generalidades}

Diversos autores, como Fossa Mancini et al. (1938), habían notado el desarrollo de calizas con abundante cantidad de fósiles del género Exogyra couloni en el sur de la Provincia de Mendoza. Groeber (1946) asignó estas calizas dentro de sus estratos a los que nombró Mendociano, considerando como localidad tipo a la sierra Azul (Leanza et al., 1977). Cuando Dessanti (1973) lleva al Mendociano a la categoría de Formación, las "Calizas de Exogyra" 
pasan a conformar un miembro denominado Chachao. Leanza et al. (1977) proponen como localidad tipo a la sierra de Chachao, al sur de la Cuesta del Chihuido, donde este miembro aparece muy bien expuesto. Finalmente, trabajos posteriores, tales como Mombrú et al. (1976) y Mombrú et al. (1978) denominan como Formación Chachao a la unidad en cuestión.

Los afloramientos de Chachao pueden ser reconocidos en la Provincia de Mendoza desde el Río Diamante hasta el Río Colorado y presentan un doble acuñamiento hacia el borde y hacia el centro de la cuenca (Mombrú et al., 1978).

Legarreta y Kozlowski (1981) dividieron a la Formación Chachao en tres miembros: Inferior, Medio y Superior sobre la base de sus características litológicas y su contenido fósil. Los miembros inferior y medio de esta propuesta, que fue adoptada por Doyle et al. (2005), son denominados en trabajos posteriores (Kietzmann et al., 2008; Kietzmann et al., 2014; Kietzmann et al., 2015; entre otros) como parte cuspidal de la Formación Vaca Muerta por sus características litológicas, su contenido fósil y la presencia de la biozona Lissonia riveroi. En estos términos, el miembro superior, caracterizado por las biozona Olcostephanus (0.) atherstoni, pasó a representar la totalidad de la Formación Chachao para otros autores (Palma y Lanés, 2001; Palma et al., 2008; entre otros).

Hacia el este, la Formación Chachao, se interdigita con la Formación Lindero de Piedra, mientras que en la Provincia del Neuquén engrana con el miembro medio de la Formación Mulichinco (Mombrú et al., 1978, Legarreta y Kozlowski, 1981; Schwarz, 2003).

\subsubsection{Relaciones estratigráficas}

La Formación Chachao se asienta en concordancia sobre la Formación Vaca Muerta y es cubierta en igual relación por la Formación Agrio (Mombrú et al., 1978).

Las Formaciones Vaca Muerta y Chachao conforman una misma secuencia depositacional transgresiva, razón por la que el límite inferior de las calizas de Chachao es difícil de precisar, lo que lleva al problema de nomenclatura citado anteriormente. Por otro lado, el límite superior constituye un contacto neto marcado por la aparición de wackestones y mudstones de textura fina y hábito tabular que corresponden a la base de la Formación Agrio (Mombrú et al., 1978; Sagasti, 2001a). 


\subsubsection{Espesor}

En cuanto a su espesor, fueron registrados valores desde $15 \mathrm{~m}$ en Mallín Redondo hasta 108 m en Cienaguitas (Leanza et al., 1977); constituyendo en promedio secuencias de 35 m de espesor (Palma et al., 1999).

Los espesores en la zona de estudio van desde $76 \mathrm{~m}$ en el Río Salado (Doyle et al., 2005) hasta 37 m en la Cuesta del Chihuido (Palma y Angeleri, 1992). Vale destacar que las mediciones de Palma y Angeleri corresponden a lo que Doyle et al. (2005) consideran como Chachao superior, que en la zona del Río Salado equivale a $23 \mathrm{~m}$ de espesor.

\subsubsection{Asignación temporal}

La Formación Chachao fue depositada durante el Valanginiano temprano y parte del Valanginiano tardío, contiene la biozona ándica de amonites de Olcostephanus atherstoni (Legarreta y Kozlowski, 1981; Palma y Lanés, 2001; Aguirre-Urreta et. al., 2011).

En la mayoría de los depósitos correspondientes a esta formación no es posible distinguir las subzonas de Olcostephanus atherstoni. La edad queda definida no sólo por la presencia de esta biozona sino también por la restricción temporal otorgada por las biozonas presentes en las formaciones Agrio y Vaca Muerta (Aguirre-Urreta y Rawson, 1997) (Fig. 3.3).

\subsubsection{Litología y biodiversidad}

La Formación Chachao está compuesta por wackestones, packstones, grainstones, floatstones y rudstones bioclásticos (Palma y Lanés, 2001). Estas sedimentitas se caracterizan por una gran biodiversidad entre las que se destacan ostreidos grandes del género Aetostreon sp., que en la bibliografía se conocen como Exogyra couloni, ostreidos pequeños (Ceratostreon minos) y otros pelecípodos. Además, se pueden observar gastrópodos, anélidos (principalmente serpúlidos), equinodermos, ocasionalmente corales ramosos y amonites del género Olcostephanus sp. (Legarreta y Kozlowsky, 1981).

Las calizas de Chachao poseen una importante diversidad litológica, producto de una amplia variedad faunística y un alto rango de preservación tafonómica. De esta forma la cantidad de facies reconocidas difiere según los objetivos particulares de cada trabajo. Mombrú et al. (1978) hacen especial énfasis en la textura de las rocas reconociendo hasta cinco variedades de packstones: grueso, mediano, fino, de ostras y briozoarios y paquidérmico. Legarreta y Kozlowsky (1981) trabajaron sobre la biodiversidad, y reconocieron en distintas 
áreas del sur mendocino hasta diez asociaciones de facies que van desde packstones con predominio de distintos géneros de pelecípodos, hasta compuestos casi en su totalidad por corales ramosos y abultamientos domales definidos por Palma et al. (2000) como mudmounds. Palma y Lanés (2001) realizaron un análisis tafofacial de las concentraciones carbonáticas, describiendo los patrones de acumulación en dos tramos, uno inferior con bajo grado de retrabajo de los bancos de ostras y otro superior con progresivo aumento en la intensidad de desarticulación, bioerosión y fragmentación de los restos, acompañado por un incremento en el tenor de matriz.

\subsubsection{Ambientes de depositación}

Mombrú et al. (1978) interpretan originalmente a los depósitos de la Formación Chachao como una barrera arrecifal tomando como base su geometría. Sin embargo, Legarreta y Kozlowski (1981), reconocen la presencia de corales ramosos pero aclaran que estos no llegaron a producir algún tipo de restricción ambiental. En tanto, interpretan estas sedimentitas como depositadas en un ambiente de rampa carbonática con sedimentación por debajo del nivel de ola de buen tiempo. Palma et al. (1999) refuerzan las interpretaciones realizadas por Legarreta y Kozlowski (1981) y observan retrabajo por acción de tormentas hacia el tope.

Palma y Lanés (2001) interpretaron los cuerpos de caliza desde el punto de vista de la bioestratinomía definiendo a los mismos como concentraciones esqueletales autóctonas a parautóctonas. Del análisis de las tafofacies los autores interpretan, en la sección inferior una progresiva profundización marcada por el diseño de superposición de los cuerpos de ostras y en la sección superior la alternancia de bancos depositados bajo condiciones de buen tiempo intercalados con otros con signos de retrabajo por tormentas.

Desde el punto de vista de la estratigrafía secuencial, la Formación Chachao forma parte de la Mesosecuencia Mendoza Media de Legarreta y Gulisano (1989), conformando una misma secuencia depositacional con las formaciones contemporáneas Lindero de Piedra y Mulichinco. Doyle et al. (2005), reconocen esta secuencia en el arreglo vertical de los cuerpos de ostras que son definidos como depositados con tendencia profundizante desde shoreface a proximal offshore en una rampa mixta en ambiente marino abierto. 


\subsubsection{Estudios geoquímicos y diagenéticos}

Desde el punto de vista geoquímico y diagenético son escasos los trabajos realizados en la Formación Chachao. Carozzi et al. (1981) realizan un detallado trabajo de petrografía en el cual describen microfacies y hacen las primeras estimaciones sobre diagénesis. Posteriormente, Palma et al. (1999) realizan estudios geoquímicos y de microscopía electrónica de barrido en los cuales reconocen cambios neomórficos en cementos micríticos y microesparíticos. Por último, Palma et al. (2008) estudian los procesos diagenéticos acontecidos en las calizas y presentan una descripción de los cementos. Además, estos autores dan a conocer los primeros estudios de isótopos estables en el área diferenciando valores contrastantes entre las ostras y la matriz.

Es necesario destacar los estudios de isótopos estables realizados en la Formación Mulichinco (Aguirre-Urreta et al., 2008; Lazo et al., 2008 y Gómez Peral et al., 2012), los cuales tienen importancia debido a la contemporaneidad con la Formación Chachao (ver capítulo 10).

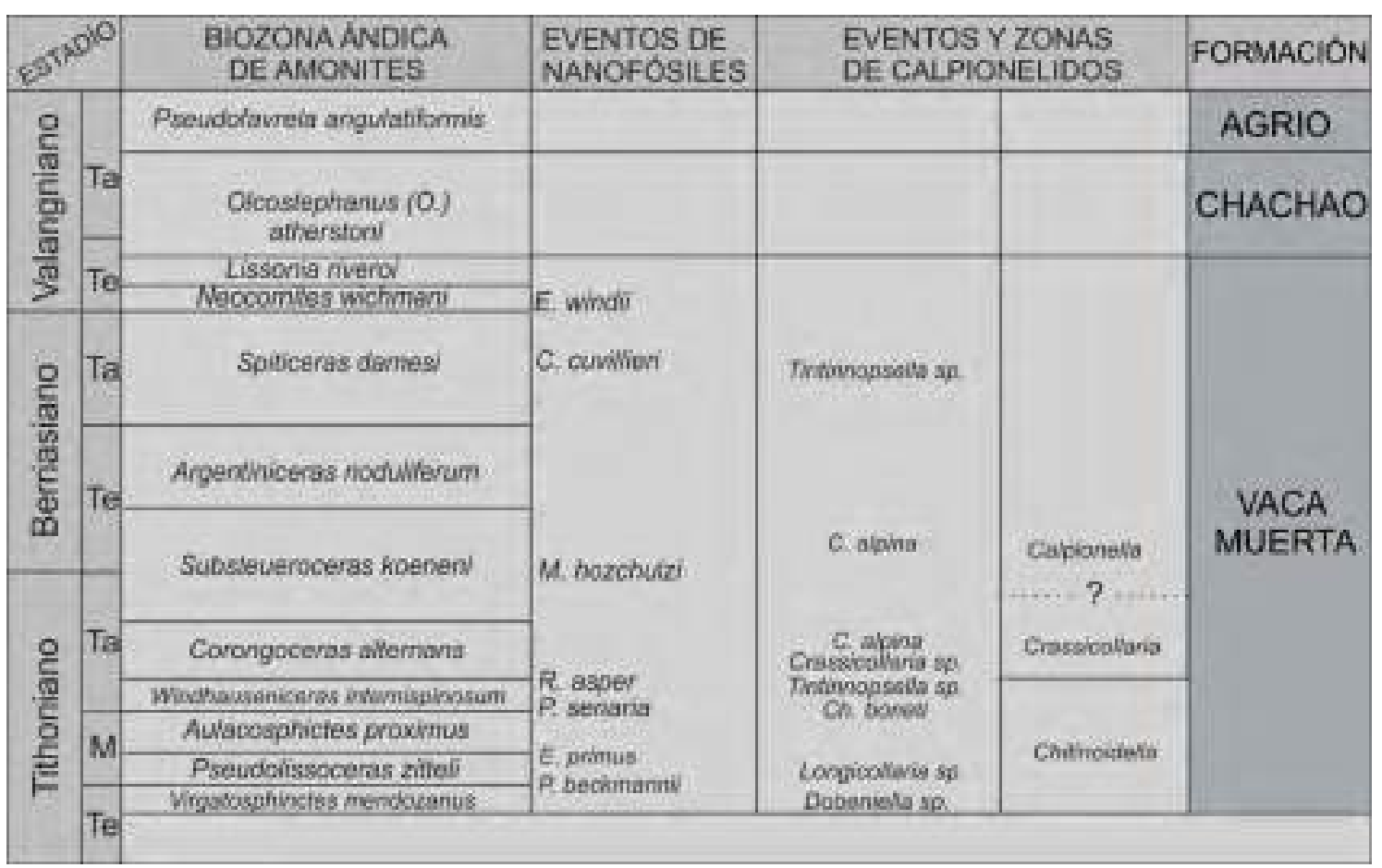

Figura 3.3: Asignación temporal de las Formaciones Vaca Muerta y Chachao sobre la base de su contenido fósil (modificado de Kietzmann et al., 2015, datos de Fernández-Carmona y Riccardi, 1998; Concheyro et al., 2006; Kietzmann y Palma 2009; Lescano y Kietmann, 2010 y Kietzmann et al., 2011) 


\subsection{Cuenca Austral}

La Cuenca Austral o Cuenca de Magallanes, es una extensión de territorio argentino chileno elongado en sentido Norte-Sur, ubicado en el borde suroccidental de la placa Sudamericana. Comprende un área que supera los $230000 \mathrm{~km}^{2}$ y presenta un registro sedimentario de $8000 \mathrm{~m}$ de espesor máximo (Peroni et al., 2002). Está conformada por la isla grande de Tierra del Fuego y el sur de la provincia de Santa Cruz. Limita con el Macizo del Deseado al norte y el Alto del Río Chico o Arco de Dungeness al este, mientras que la Cordillera Patagónica y los Andes Patagónicos Fueguinos conforman sus límites occidental y austral respectivamente (Rodríguez y Miller, 2005) (Fig. 3.4).

Los afloramientos de la Cuenca Austral están presentes en las provincias geológicas de la Cordillera Patagónica Austral, la Patagonia Austral Extraandina y la Cordillera Fueguina. Sus unidades sedimentarias se registran desde el Jurásico tardío al Cenozoico (Russo y Flores, 1972), poseen un potente espesor y están compuestas casi exclusivamente por material silicoclástico marino y continental, limitando la producción carbonática a bancos aislados de escaso desarrollo (Peroni et al., 2002). La cuenca estuvo conectada al Océano Pacífico hacia el oeste, aunque la comunicación estuvo parcialmente restringida por el arco volcánico (Riccardi, 1988; Aguirre-Urreta y Rawson, 1998), razón por la cual las primeras trasgresiones se desarrollaron desde el sector sur. Por su parte, la cuenca estuvo abierta hacia el Océano Atlántico recién a partir del Cretácico inferior alto.

El estudio de la paleontología ha sido importante en esta región, no sólo para la caracterización paleoambiental sino para la asignación temporal de muchas secuencias sedimentarias. En este sentido, trabajos como Riccardi $(1988,1991)$, Aguirre-Urreta y Rawson (1998) realizados sobre amonites, permitieron ubicar cronológicamente las distintas unidades de la cuenca. El nexo entre estos estudios y la descripción de distintas faunas, como las de belemnites, facilitó la vinculación temporal de la Cuenca Austral con la Cuenca Neuquina y con otras cuencas del mundo.

Aunque el nivel de entendimiento de esta cuenca es relativamente bajo con respecto al de la Cuenca Neuquina en materia de recursos hidrocarburíferos, las tareas de exploración en esta área han contribuido de manera sustancial a su conocimiento. Así, se destacan los trabajos pioneros de Feruglio (1950) y Borrello (1956) y más cercanos en el tiempo los trabajos de Arbe y Hechem (1984) y Kraemer (1991).

La estratigrafía del área de estudio ha sido motivo de múltiples controversias representadas en la bibliografía debido a las diferentes nomenclaturas utilizadas en el sector chileno y entre el sector septentrional y austral de la porción argentina. En este trabajo de 
tesis se utilizarán los nombres y límites formacionales propuestos por Poiré et al. (2007), los cuales fueron adoptados en numerosos trabajos tales como los de Varela (2011), Richiano (2012) y Cereceda (2016).
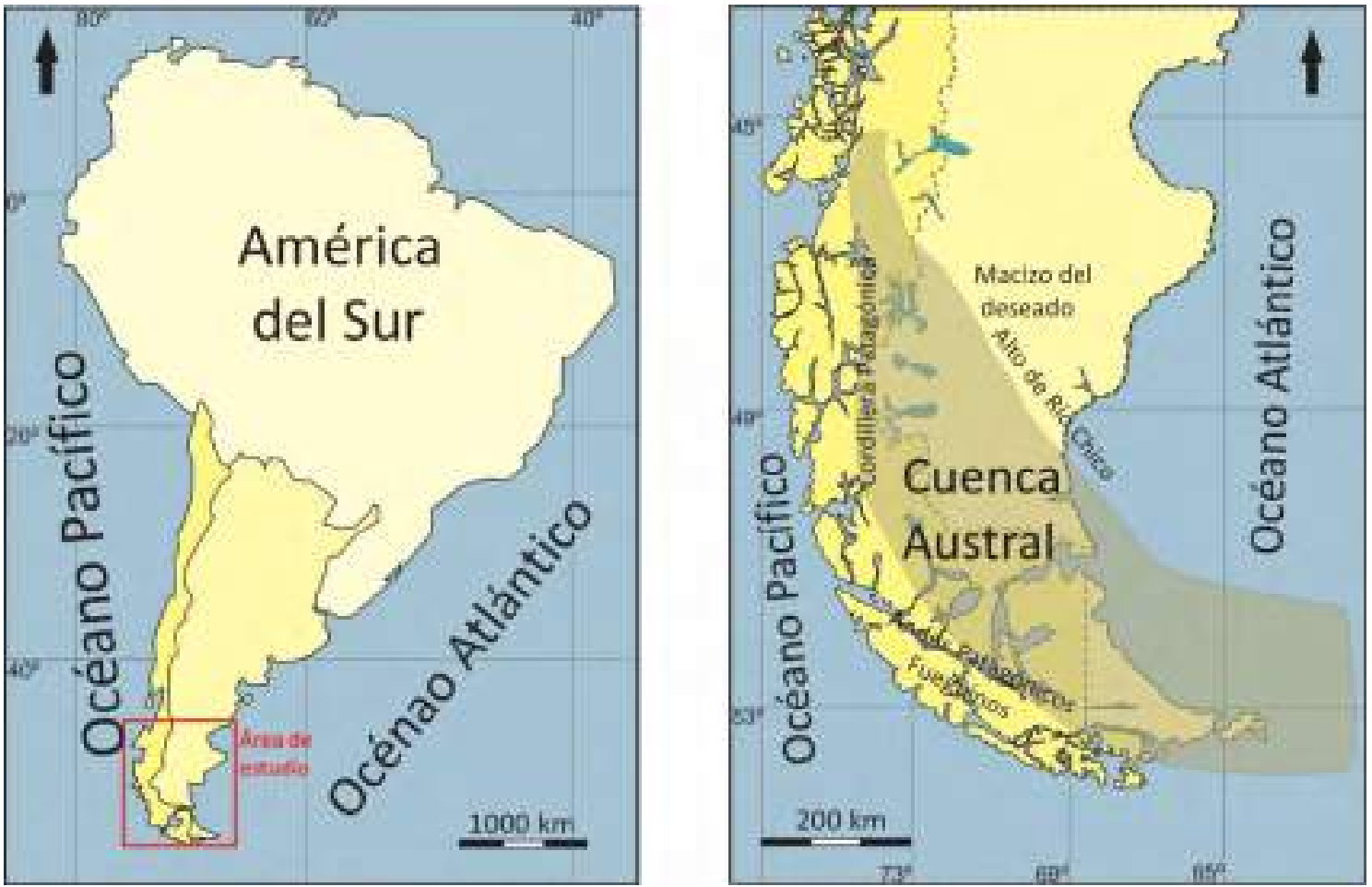

Figura 3.4: Ubicación y contexto geológico de la Cuenca Austral (modificado de Varela, 2011).

\subsubsection{Etapas tectónicas de la Cuenca Austral}

En la génesis de la Cuenca Austral se registran tres etapas tectónicas principales: rift, subsidencia termal y antepaís (Biddle et al., 1986; Robbiano et al., 1996; Ramos, 2002; Kraemer et al., 2002; Peroni et al., 2002; Rodríguez y Miller, 2005; Varela, 2011; Ghiglione et al., 2014) (Fig. 3.7).

La etapa de rift se desarrolla entre el Jurásico medio y el Jurásico tardío (170Ma.) y está vinculada con la ruptura de Gondwana (Pankhurst et al., 2000, Varela et al., 2012). Este evento extensional produce el desarrollo de fallas directas que generaron depocentros de synrift con orientación N-S (Biddle et al., 1986). Los depósitos correspondientes a este período llevan el nombre de Formación Tobífera en Chile y Complejo El Quemado en Argentina, haciéndose más jóvenes hacia el sur y oeste. Los mismos son de origen volcánico (dacitas y andesitas) intercalados con sedimentos de origen piroclástico y epiclástico y su acumulación fue cohetanea con la extensión, dentro de grábenes y hemigrábenes (Uliana y Biddle, 1989). 
Hacia el sur y oeste de la cuenca, sobre el margen continental Pacífico se generó en esta época un estadío caracterizado por desarrollo de fondo oceánico, lo que llevó a la apertura de la Cuenca marginal de Rocas Verdes (Dalziel, 1981, Varela et al., 2012).

En el comienzo de la etapa de hundimiento termal, y como producto de la actividad tectónica se registra una importante transgresión del mar que se inicia con la sedimentación de la Formación Springhill (Tithoniano) y culmina con facies más profundas correspondientes a la Formación Río Mayer que se extienden hasta el Albiano (Kraemer y Riccardi, 1997; Richiano, 2012).

La etapa de antepaís está caracterizada por un cambio en el régimen tectónico, desde uno extensional hacia uno de tipo compresional producto de la convergencia del arco hacia mediados del Cretácico (Varela, 2011). Este importante cambio en las condiciones llevó a la obducción de las ofiolitas de la Cuenca Marginal de Rocas Verdes (Calderón et al., 2012) y la generación de una faja plegada y corrida con desarrollo de una cuenca de antepaís asociada hacia el este, conocida como Cuenca Austral de antepaís (Ramos et al., 1982). Entre el Cenomaniano medio y el Coniaciano inferior (96-84 Ma) se desarrolló un evento de deformación, que habría generado el cierre de la cuenca de Rocas Verdes (Ramos et al., 1982; Biddle et al., 1986), como rasgo de esta etapa compresiva se puede observar el cambio de las direcciones de progradación hacia Este- Oeste en las Formaciones Mata Amarilla, Lago Viedma y en sus correlativas en la República de Chile (Canessa et al., 2005; Fildani et al., 2003; Varela 2011). Los siguientes episodios de deformación están relacionados con el ciclo Andino donde se estructura la actual faja plegada y corrida y se desarrolla el alzamiento definitivo de la cordillera (Ramos, 2002; Kraemer et al., 2002, Ghiglione et al., 2014).

\subsubsection{Ciclos sedimentarios de la Cuenca Austral}

Arbe (2002) dividió al relleno de la Cuenca Austral en "ciclos tectosedimentarios". Estos ciclos constituyen, desde el punto de vista de la estratigrafía secuencial, supersecuencias de segundo orden limitadas por discontinuidades y compuestas a su vez por ciclos de tercer orden o "parasecuencias".

Para el Jurásico- Cretácico, este autor propuso tres ciclos tectosedimentarios con arreglos transgresivos y regresivos: Ciclo Río Mayer (Tithoniano- Aptiano temprano), Ciclo Lago San Martin (Aptiano temprano- Turoniano temprano) y Ciclo Lago Viedma (Turoniano temprano- Maastrichtiano). En este capítulo se desarrollarán las principales características de las Formaciones Springhill y Río Mayer, pertenecientes al Ciclo Río Mayer (Fig. 3.5). 


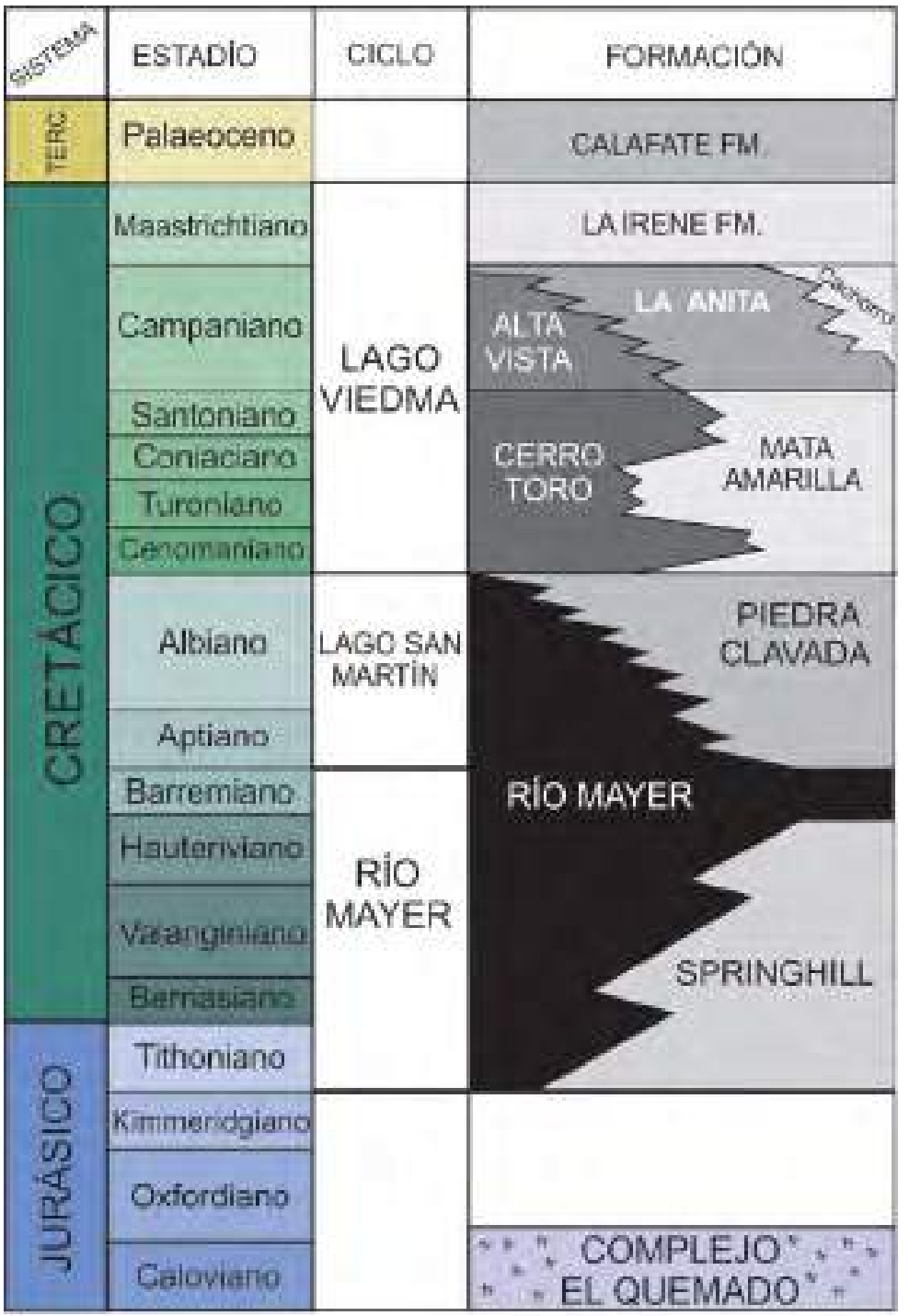

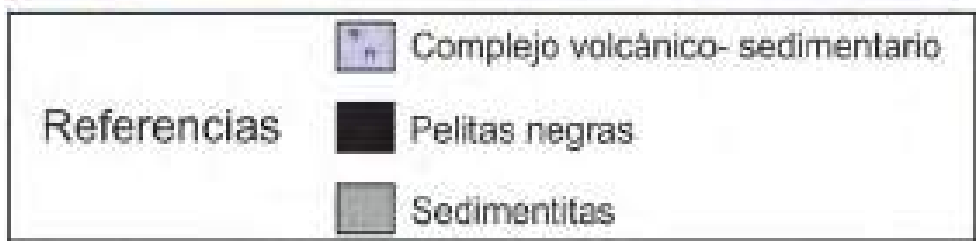

Figura 3.5: Cuadro estratigráfico del relleno de la Cuenca Austral (compilado de Arbe, 2002; Poiré et al. 2007; Varela, 2011; Moyano Paz et al., 2016).

\subsubsection{Formación Springhill}

\subsubsection{Generalidades}

La Formación Springhill fue definida por Thomas (1949) como “... un cuerpo de arenitas de 10 a 30 metros de espesor...compuesta por granos de cuarzo cristalinos..." a partir de un pozo exploratorio de Chile. Sin embargo, esta formación había sido reconocida antes por Halle (1913), Bonarelli y Nágera (1921) y Feruglio (1938) quien la incluyó en su "Complejo 
Tithoniano- Cretácico". Asimismo, fue también denominada como "Manantiales" (Leanza, 1967) y fue elevada a categoría de grupo por Cecioni (1955). Finalmente, es Bianchi (1967) quien la define formalmente como "formación" en territorio argentino.

La Formación Springhill aflora en forma discontinua desde el sur del Lago Buenos Aires hasta el norte del Lago Argentino (Arbe, 2002). La mayor extensión de la formación está desarrollada en subsuelo (Riccardi y Rolleri, 1980).

Cecioni (1955) describe dos formaciones dentro del "Grupo Springhill" para afloramientos en Tierra del Fuego. Cortiñas y Arbe (1981), tomando como base las apreciaciones de Cecioni, describen dos miembros de Springhill en la localidad de Perito Moreno: un miembro inferior continental y otro superior de origen marino. Riccardi (1971) y Kraemer y Riccardi (1997) desestiman la división en miembros para las localidades de Bahía de la Lancha y Río Guanaco. Por otro lado, Robbiano et al. (1996) dividieron a estas sedimentitas en cuatro secuencias depositacionales de tercer orden para el sector offshore de la Cuenca Austral a las que denominaron: Hidra, Argo, Paloma y Carina. Esta división fue adoptada por trabajos posteriores como los de Arbe (2002) y Schwarz et al. (2011).

Es destacable la importancia de la Formación Springhill como roca reservorio, ya que se estima que representa la gran mayoría del total de reservas convencionales probadas y probables de hidrocarburos de la Cuenca Austral en Argentina y Chile (González et al., 1998, Peroni et al., 2002, Schwarz et al., 2011b).

\subsubsection{Relaciones estratigráficas}

La Formación Springhill apoya en paraconcordancia o discordancia sobre las rocas del complejo El Quemado y sobre ella yacen de forma concordante las pelitas de la Formación Rio Mayer (Kraemer y Riccardi, 1997, Richiano, 2012).

\subsubsection{Espesor}

La depositación de la Formación Springhill estuvo principalmente controlada por la topografía previa, razón por la cual se depositó principalmente en las depresiones existentes en el relieve irregular del Complejo El Quemado. El espesor promedio es de 30 a $40 \mathrm{~m}$, aunque se registran espesores desde inferiores a $10 \mathrm{~m}$ hasta $150 \mathrm{~m}$. 


\subsubsection{Asignación temporal}

La Formación Springhill fue depositada a medida que el mar transgredió sobre las áreas emergidas razón por la cual la edad de los depósitos en los distintos sitios de esta extensa cuenca es muy variada (Riccardi y Rolleri, 1980). En términos generales, los depósitos serían más jóvenes hacia el norte lo cual indicaría un período de marcado ascenso eustático de segundo orden (Arbe, 2002)

La edad de Springhill ha sido acotada exclusivamente sobre la base de su contenido fósil. Los afloramientos más antiguos son atribuidos al Oxfordiano- Kimmeridgiano (Riccardi y Rolleri, 1980), aunque esta datación ha sido motivo de controversias, ya que Arbe y Fernández Bell Fano (2002) ubican cronológicamente estas exposiciones como posteriores al evento de levantamiento tectónico Berriasiano.

Nullo (1979) propone una edad de Tithoniano temprano a Tithoniano medio para los afloramientos entre los Lagos Argentino y Viedma fundada en la fauna de cefalópodos presente en el área. Kraemer y Riccardi (1997), describen en el mismo sector distintos géneros de amonites (Choicensisphinctes erinoides- Aulacosphinctoides smithwoodwardi- Aspidoceras andinum) y corroboran las edades antes propuestas. Por último, Richiano (2012) atribuye la misma edad en las nacientes del Río Guanaco.

Hacia el norte, en el sector del lago San Martín, se encuentran los afloramientos más jóvenes correspondientes a Springhill. Kielbowicz et al. (1983) definen la edad de estas sedimentitas como Valanginianas, basándose en su contenido de microfósiles, especialmente foraminíferos de la familia de las Nodociraceas. Estas edades son reforzadas posteriormente en trabajos como Kraemer y Riccardi (1997) y Richiano et al. (2016) (Fig. 3.6).

\subsubsection{Litología y biodiversidad}

Thomas (1949), describió a la formación como una alternancia de carbones, lutitas carbonosas y cuerpos de arena cuarzosa. Trabajos más detallados, tales como los de Riccardi (1971), Cortiñas y Arbe (1981), Kraemer y Riccardi (1997), describen en profundidad estos afloramientos. Las secciones arenosas caracterizadas como bancos de ortocuarcitas con mayor grado de redondeamiento hacia el tope y con abundantes y bien conservados restos de paleofloras en los niveles basales. Por otro lado, las lutitas poseen restos carbonosos en las secciones más cercanas a la base, en algunos casos con troncos carbonizados, y una abundante fauna de invertebrados marinos hacia el tope. 
Richiano et al. (2016) realizaron un estudio sedimentológico de detalle en el norte del Lago San Martín, en el que reconocen tres secciones bien diferenciadas: una basal con escasas tufas intercaladas con lutitas y cuerpos cuarzoarenosos que hacia el tope intercalan con espesos bancos de lutitas masivas, un cuerpo intermedio representado por bancos de carbón, facies heterolíticas y lutitas y uno cuspidal principalmente psamítico con una variada fauna y una intensa bioturbación.

La Formación Springhill posee una amplia biodiversidad: es posible reconocer especies de plantas, principalmente del grupo de las bennettitales (Villar de Seoane, 2001). En cuanto a la paleofauna se reconoció una amplia variedad de cefalópodos entre los que se destacan Belemnopsis sp. y numerosos amonites como Aspidoceras cf. Andinum y Aulacosphinctoides cf. smithwoodwardi (Riccardi, 1971; Riccardi y Rolleri, 1980; Kraemer y Riccardi, 1997). Numerosas especies de foraminíferos y ostrácodos con utilidad estratigráfica y cronológica fueron descriptas por Kielbowicz et al. (1983). También se reconocieron abundantes bivalvos como Inoceramus aff. Anomiaeformis y Aetostreon sp. (Riccardi y Rolleri, 1980).

\subsubsection{Ambientes de depositación}

Thomas (1949) interpretó originalmente a los afloramientos de la Formación Springhill como depositados en un ambiente de shoreface a lagoon. Como se mencionó anteriormente, sobre la base de su contenido litológico y paleontológico, Cecioni (1955) y Cortiñas y Arbe (1981) propusieron una división en un sector inferior continental y uno superior marino.

Trabajos más modernos, tales como Schwarz et al. (2011b) y Richiano et al. (2016) reconocen en zonas muy distantes de la cuenca la misma sucesión ambiental. Hacia la base, estos autores reconocieron un sistema fluvial representado por canales sinuosos con amplias planicies de inundación que hacia el tope pasan a meandrosos. En el sector medio, una planicie costera con desarrollo de paleosuelos con señales de hidromorfismo. El tope de la Formación Springhill fue descripto como un ambiente marino de shoreface, con facies estuarinas, que hacia los sectores más cuspidales es interpretado como un paquete transgresivo desde foreshore a offshore.

Vale destacar, que en el sector entre los Lagos Argentino y Viedma, Kraemer y Riccardi (1997) y Poiré et al. (2007), solo identifican facies correspondientes a ambientes marinos de shoreface.

Desde el punto de vista de la estratigrafía secuencial, la Formación Springhill conforma un subciclo netamente transgresivo junto con el miembro inferior de la Formación Río Mayer. 
Este subciclo puede ser desglosado en secuencias de tercer orden con tendencias transgresivas (Arbe, 2002).

\subsubsection{Estudios geoquímicos y diagenéticos}

Existen pocos registros en la bibliografía sobre estudios geoquímicos y diagenéticos realizados en las sedimentitas de la Formación Springhill, y la mayoría de ellos (ej: Pedrazzini y Cagnolatti, 2002) fueron realizados con la intención de estudiar las características de la Formación Springhill en subsuelo como reservorio.

Spalletti et al. (2005) interpretaron, mediante estudios de petrografía estándar y catodolumiscencia, las principales características diagenéticas de esta formación. Estos autores efectuaron un tratamiento detallado de los procesos diagenéticos de compactación, disolución por presión, cementación silícea, cementación carbonática y autigénesis de argilominerales. También expusieron las principales características sedimentológicas y diagenéticas de la Formación Springhill en ambiente de plataforma y talud.

\subsubsection{Formación Río Mayer}

\subsubsection{Generalidades}

La Formación Río Mayer fue definida por Hatcher (1897) como “... pizarras negras, muy duras pero fracturadas con abundantes amonites...", bajo el nombre de "Mayer River Beds". El hecho de que no abarque en todos sus afloramientos el mismo intervalo temporal y que presente cambios faciales hizo que en los años sucesivos, depósitos de la misma formación fueran nombrados de múltiples maneras en distintos sitios. Entre otras denominaciones, la Formación Río Mayer fue llamada "Meseta Schiefer" (Stolley, 1912), "Serie Infracretácica" (Bonarelli y Nágera, 1921), “Complejo Tithoniano-Cretáceo" (Feruglio, 1938) y “Formación San Martín" (Zambrano y Urien, 1970). El nombre actual de esta unidad litoestratigráfica fue adoptado finalmente en trabajos posteriores en los cuales se desarrolló de modo más detallado sus características sedimentológicas y paleontológicas (Nullo et al., 1981; Riccardi y Rolleri, 1980; Kraemer y Riccardi, 1997; Arbe, 2002; Richiano 2012).

El área tipo de la Formación Río Mayer se encuentra en el río homónimo, y sus afloramientos forman una franja más o menos continua de extensión Norte-Sur desde la Estancia Tucu- Tucu al norte, hasta al límite con Chile al Sur donde pasa a denominarse Formación Zapata (Poiré et al., 2014). Se reconocen afloramientos continuos tanto en 
superficie como en subsuelo, donde lleva el nombre de Formación Palermo Aike (Riccardi y Rolleri, 1980).

La formación ha sido dividida en miembros por distintos autores teniendo en cuenta sus características. Arbe (2002), por ejemplo, dividió esta formación tomando como criterio sus secuencias depositacionales. En el corriente trabajo se adoptará la división propuesta por Richiano (2012) quien reconoce tres miembros sobre la base de sus características litológicas.

\subsubsection{Relaciones estratigráficas}

La Formación Río Mayer se apoya en concordancia sobre las Vulcanitas del Complejo El Quemado en algunos sectores, y en otros lo hace en concordancia o paraconcordancia sobre los niveles clásticos de la Formación Springhill (Kraemer y Riccardi, 1997).

De norte a sur la Formación Río Mayer es cubierta, conformando límites transicionales, por las formaciones Kachaike, Piedra Clavada, Lago Viedma y Cerro Toro (Richiano, 2012).

\subsubsection{Espesor}

Esta formación posee potentes expresiones de variable espesor. Se han reconocido secuencias desde 350 m en pozos de exploración hasta 1200 m en la región del Payne en Chile (Soffia et al., 1988).

En el área de estudio se ha medido un espesor de 700 m para la región del Lago San Martín (Riccardi, 1971), 400 m en las nacientes del Río Guanaco y 450 m en el Cerro Hobler (Kraemer y Riccardi, 1997).

\subsubsection{Asignación temporal}

La Formación Río Mayer posee un extenso rango de edades que va desde el Berriasiano hasta el Albiano, y varía según la región considerada, siendo más joven hacia el norte (Poiré et al., 2014)

Teniendo en cuenta su contenido fósil, principalmente la fauna de amonites, se determinaron las edades para las distintas áreas. En la región localizada entre los lagos Argentino y Viedma, Kraemer y Riccardi (1997) asignaron edad Berriasiana a la base de la formación por la presencia de la asociación faunística de Berriasella cf. behrendseni, Jabronella cf. michaelis, Subthurmannia sp. y Phyllopachyceras aureliae. Richiano (2012) definió como Valanginiano medio al sector superior de la Formación Río Mayer inferior en la región de las 
nacientes del Río Guanaco en base a la presencia de la fauna de Belemnopsis sp. Hacia el sector medio se fijó la edad Valanginana temprana al reconocer amonites de la especie Busnardoites cf. campylotaxus, correlacionables con la región del Tethis. Arbe y Hechem (1984) asignaron edad Albiano al techo teniendo en cuenta la presencia de Mortoniceras cf. arietiforme.

En la región del lago San Martín, Riccardi (1971) asignó a esta secuencia un rango temporal que va desde el Valanginiano en la base, reconocida por la fauna de Belemnopsis patagoniensis, y Albiano en el tope por asociaciones de amonites. Aguirre-Urreta y Rawson (1998), realizaron una correlación entre niveles de las cuencas Neuquina y Austral sobre la base del reconocimiento de ejemplares de amonites del género Olcostephanus. Los niveles vinculados corresponden a la Formación Agrio en la Cuenca Neuquina, posteriormente asignados a la Formación Mulichinco por Schwarz, (2003), y afloramientos de Río Mayer en la Cuenca Austral, posteriormente asignados a Springhill por Richiano (2012) (Fig. 3.6).

\subsubsection{Litología y biodiversidad}

Es destacable la gran uniformidad litológica que presentan los afloramientos de la Formación Río Mayer en su gran extensión areal y a pesar de su amplio rango de edad. Los trabajos pioneros (Stolley, 1912; Halle, 1913) sobre estos afloramientos hablaron incorrectamente de "esquistos". Riccardi (1971), Ricardi y Rolleri (1980), Kraemer y Riccardi (1997), Arbe (2002) entre otros autores concordaron en describir a estas sedimentitas como una potente sucesión de pelitas negras que hacia el tope intercalan con bancos arenosos y calcáreos.

Estudios de mayor detalle fueron realizados por Richiano (2012), quien describió las tres secciones formales de la Formación Río Mayer de la siguiente manera: una sección inferior compuesta casi exclusivamente por pelitas negras, una sección media eminentemente margosa con abundantes trazas fósiles y una sección superior pelítica con intercalación de bancos de areniscas.

Estas sedimentitas contienen restos fósiles, mayormente invertebrados marinos, abundantes en las secciones inferior y superior y escasos en la parte media (Riccardi, 1971). Es justamente en esa sección media donde Richiano (2012) describe un cuantioso y variado desarrollo de trazas fósiles. En cuanto a su contenido faunístico se destaca una abundante fauna de amonites y belemnites y cantidades menores de bivalvos y gasterópodos (Poiré et al., 2014). También es posible distinguir briznas vegetales y madera petrificada. 


\subsubsection{Ambientes de depositación}

Richiano (2012) realizó un detallado análisis de los ambientes de depositación de la Formación Río Mayer en distintas localidades de la Cuenca Austral. De norte a sur observó en el Lago San Martín y en la Estancia La Vega facies de plataforma externa que pasan a prodelta hacia el tope. En la Seccional Río Guanaco por otro lado, la influencia deltaica se presenta de forma distal en los topes de las secuencias, mientras que las características de la base se mantienen inalteradas. Por último, en el Lago Argentino sólo se observan condiciones de plataforma externa.

Desde el punto de vista de la estratigrafía secuencial, Arbe (2002) describe en depósitos de la Formación Río Mayer cuatro subciclos con tendencias transgresivas y regresivas. Posteriormente, Richiano (2012), realiza estudios geoquímicos, petrográficos y sedimentológicos a partir de los cuales define secuencias de tercer orden.

\subsubsection{Estudios geoquímicos y diagenéticos}

Existe escaso material en la bibliografía sobre estudios geoquímicos y diagenéticos realizados en afloramientos de la Formación Río Mayer. Entre lo más destacados se pueden citar los trabajos pioneros de Bowen $(1961,1963)$, que tratan sobre isótopos estables de oxígeno en belemnites calculando paleotemperaturas que ostentan valores de entre 23 y $31^{\circ}$ C. Estudios más recientes realizados por Pirrie et al. (2004), calculan paleotemperaturas en el mismo material y con el mismo método pero acotado a estratos de edad Albiana. En este caso, las temperaturas calculadas dan un promedio de $9^{\circ} \mathrm{C}$.

Estudios geoquímicos realizados en pelitas negras (Richiano, 2012) permitieron conocer procedencia, índices de meteorización y diagénesis de la Formación Río Mayer. Posteriormente, Richiano et al. (2015a) realizaron estudios geoquímicos en términos de analizar la composición y cantidad de materia orgánica de la formación. 


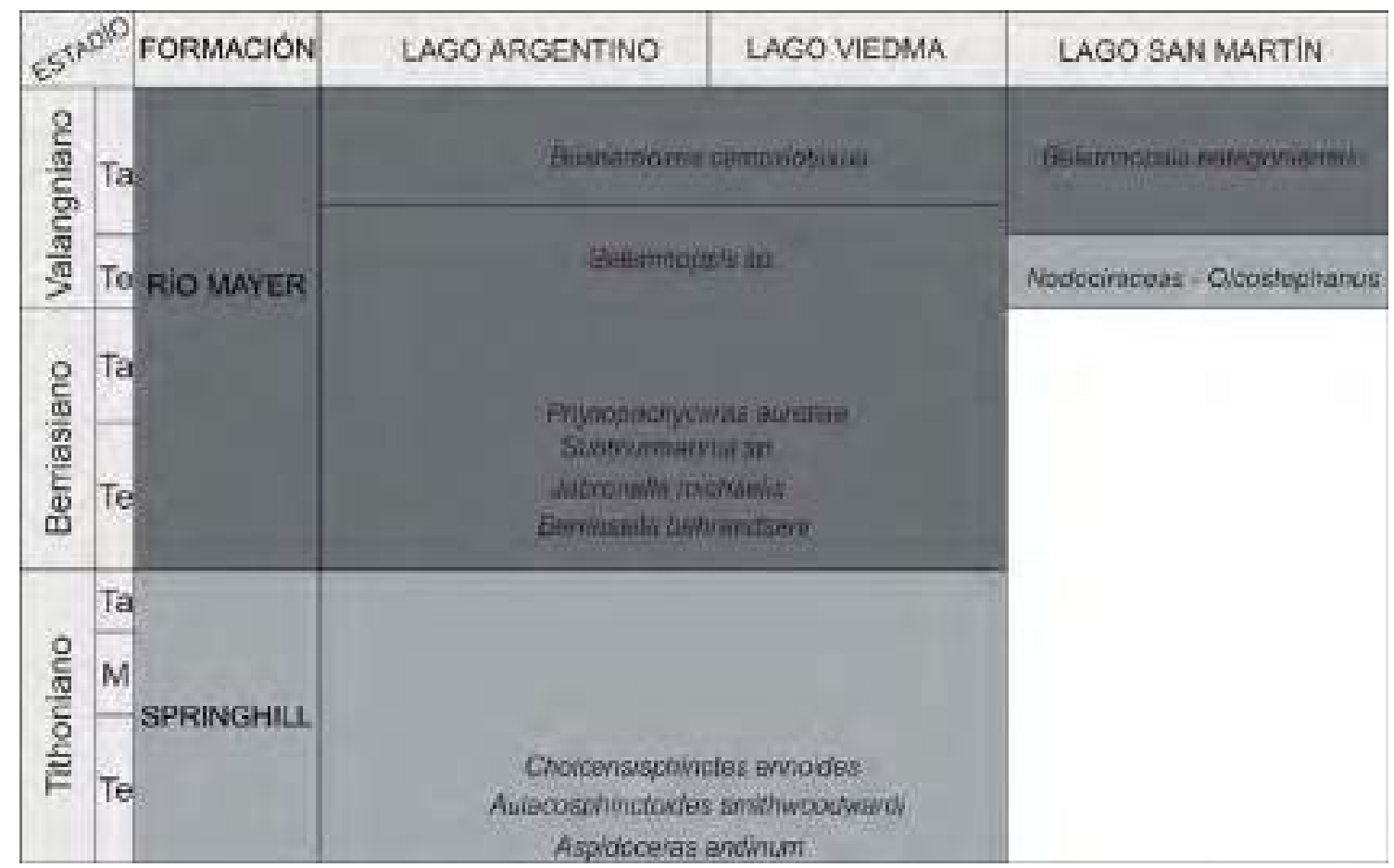

Figura 3.6: Asignación temporal de las Formaciones Springhill y Río Mayer basada en su contenido fósil (compilado de Nullo et al., 1979; Riccardi y Rolleri, 1980; Kielbowicz et al., 1983; Kraemer y Riccardi, 1997; Richiano, 2012 y Richiano et al., 2015). Te: temprano; M: medio; Ta: tardío. 


\section{Cuenca Neuquina}

200Ma.

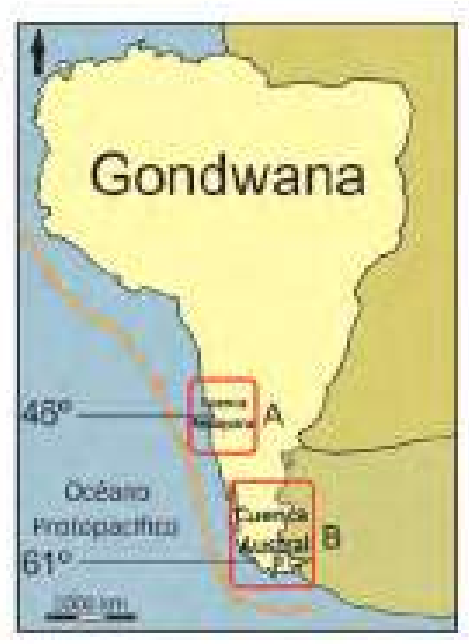

130Ma.

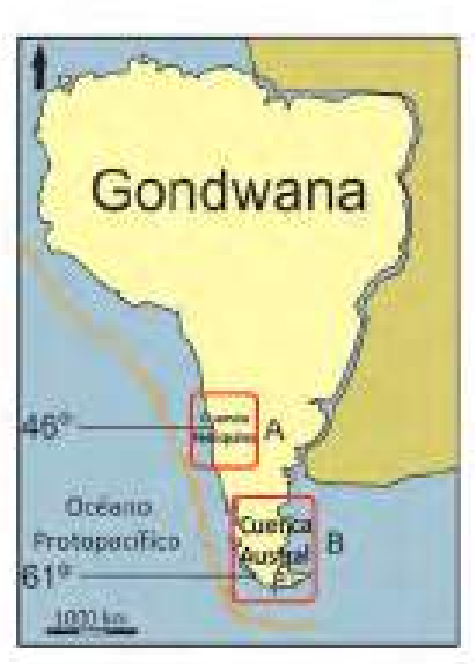

95Ma.

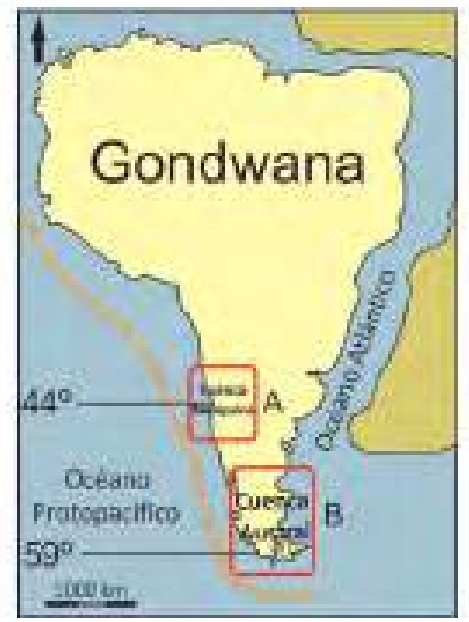

1) Fase de Synrift (Triásico

tardio-Jurásico temprano)

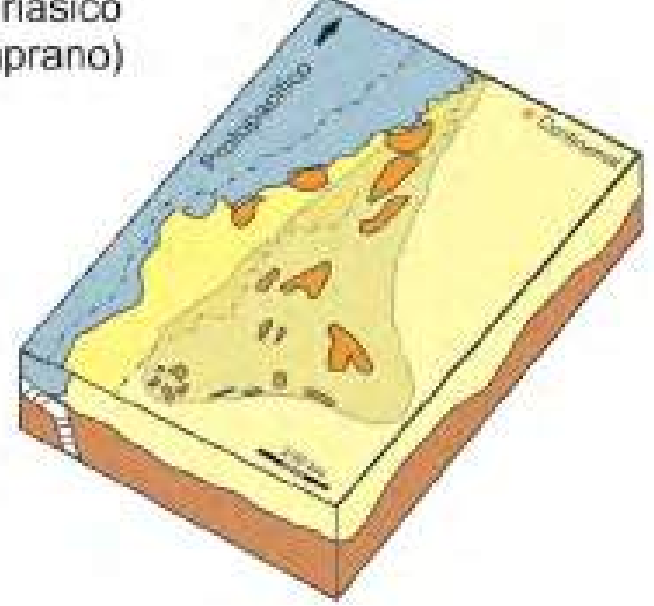

2) Fase de Postrift (Jurásico

temprano- Cretácico temprano)

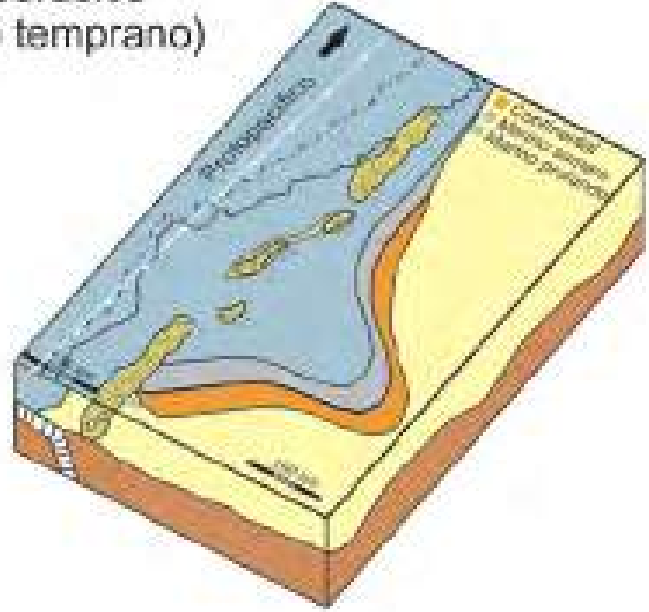

3) Fase de Antepais (Cretácico temprano- Cenozoico)

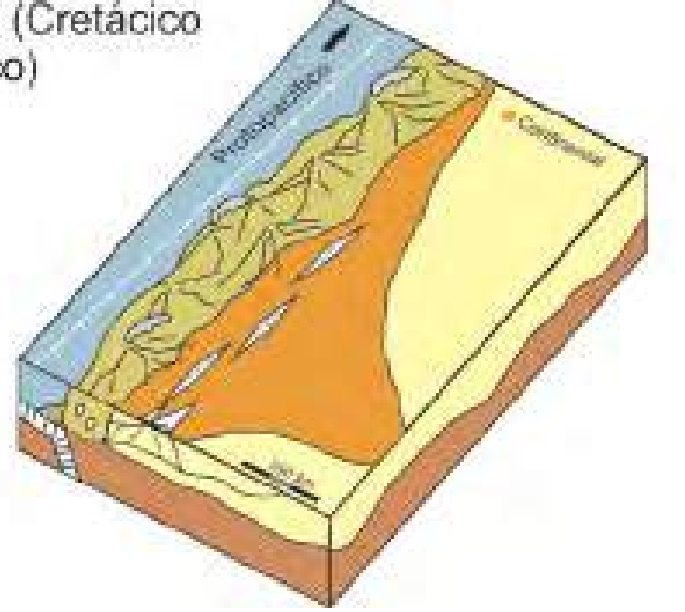

Cuenca Austral
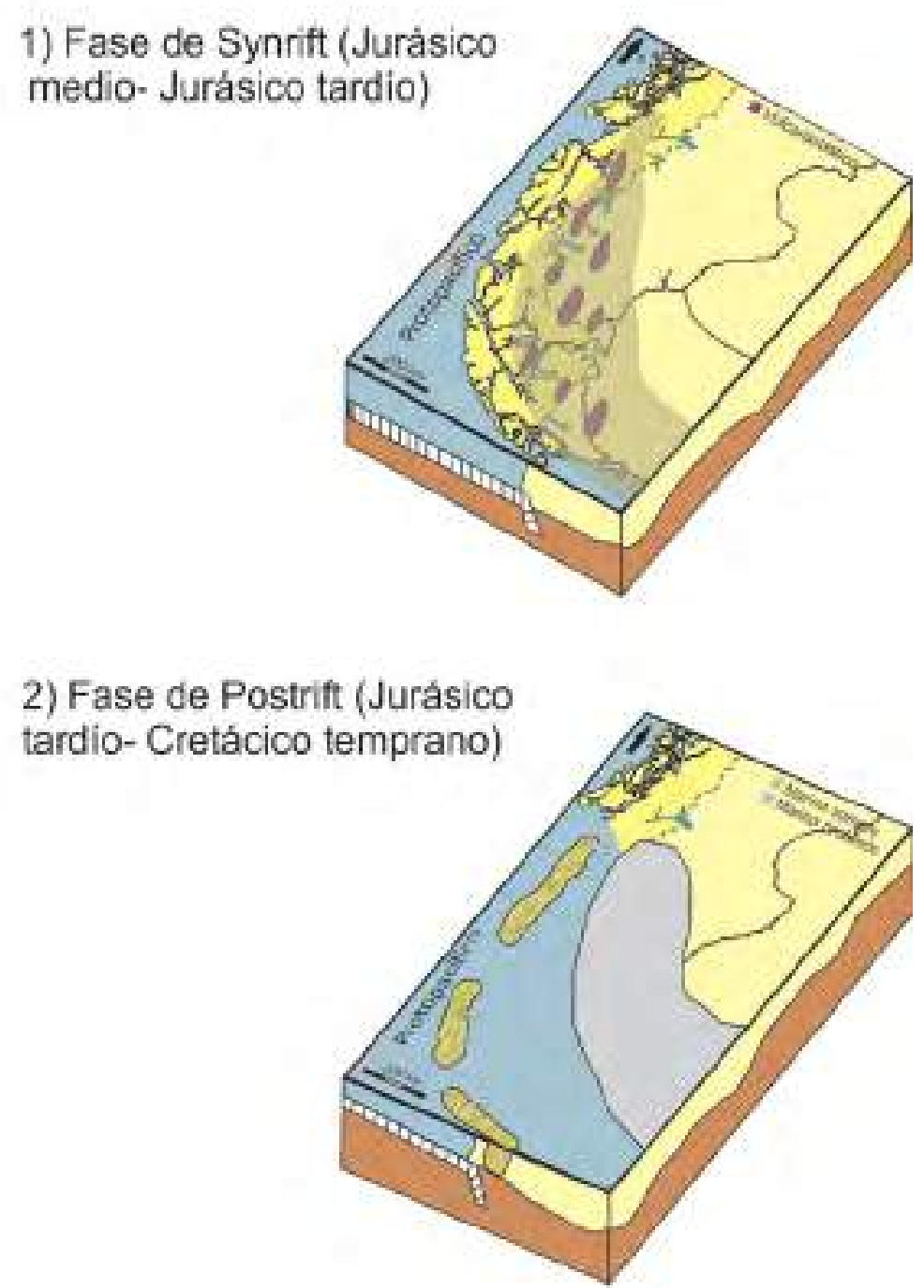

3) Fase de Antepaís (Cretácico temprano- Cenozoico)

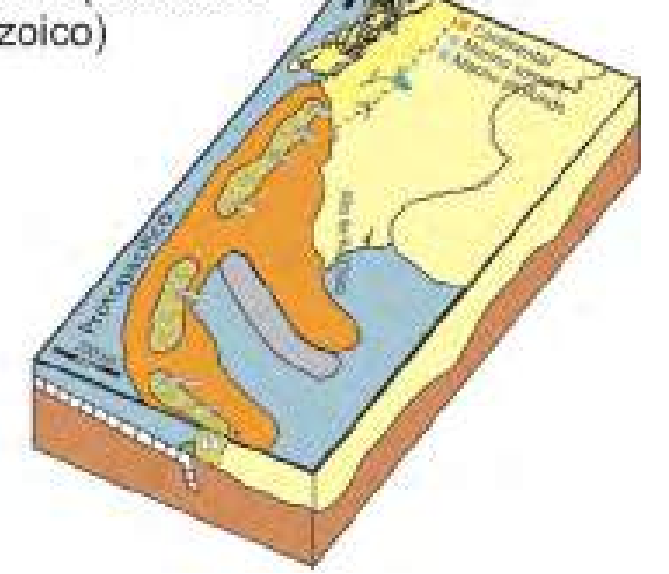




\section{Capítulo IV-Área de estudio}

\subsection{Introducción}

Para el presente trabajo de tesis se han seleccionado dos áreas de estudio ubicadas en las Cuencas Neuquina y Austral respectivamente. La primera está localizada en los alrededores de la ciudad de Malargüe, en el sur de la Provincia de Mendoza y la segunda al sudoeste de la Provincia de Santa Cruz, entre las localidades de El Calafate y Tres Lagos (Fig. 4.1).

Estos sectores de trabajo han sido cuidadosamente seleccionados sobre la base del análisis de imágenes satelitales, mapas geológicos y la lectura de bibliografía específica, teniendo en cuenta como principales criterios la continuidad estratigráfica y la baja deformación tectónica de las formaciones estudiadas.

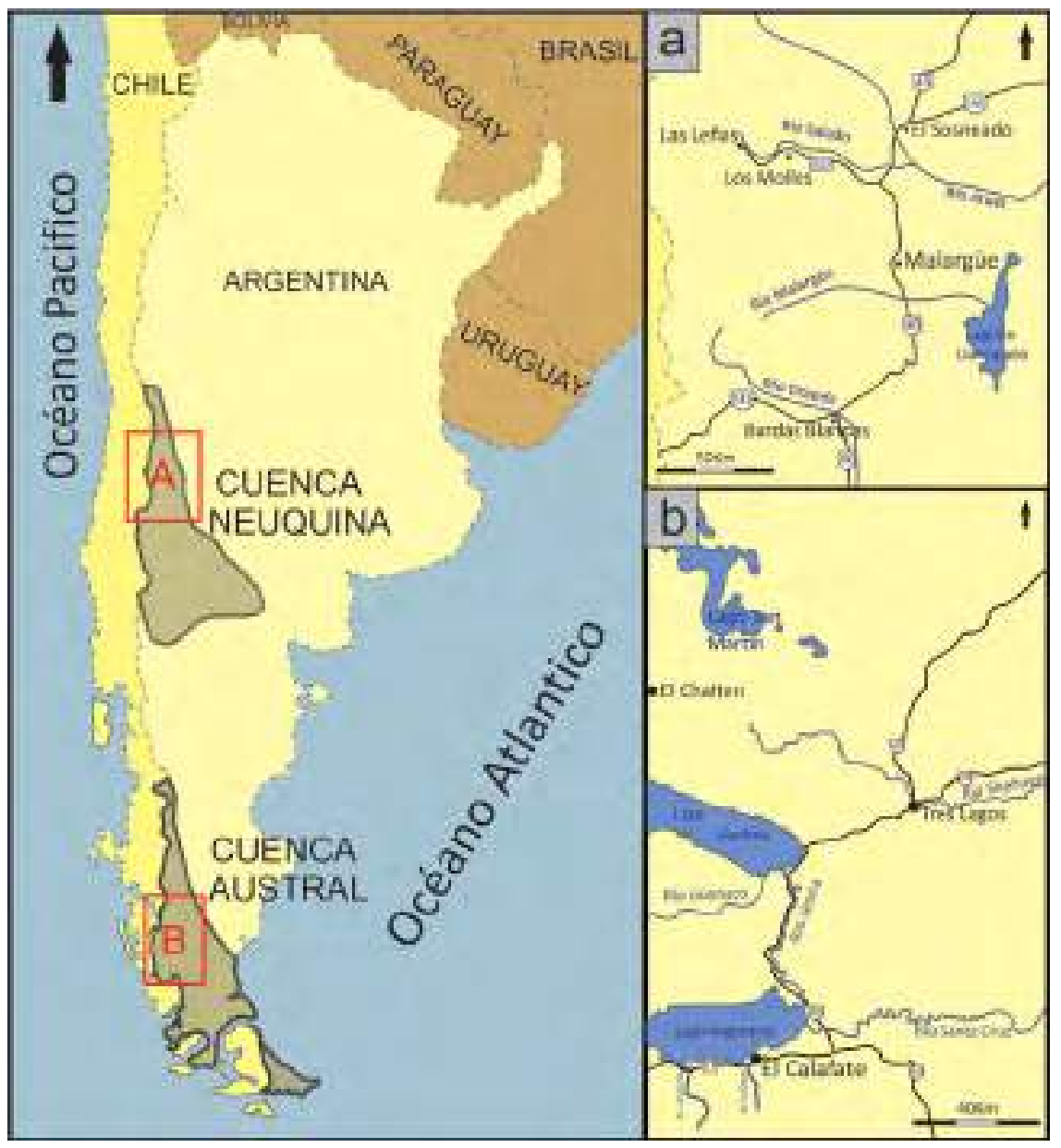

Figura 4.1. Ubicación de las áreas de estudio en la República Argentina. a) Mapa esquemático de la zona de estudio en la Cuenca Neuquina; b) mapa esquemático de la zona de estudio en la Cuenca Austral. 


\subsection{Plataforma mendocina en la Cuenca Neuquina}

La zona de trabajo en esta cuenca se localiza entre los 35 10` y los 350 48` de latitud sur y entre los 69 $30^{\prime}$ y $69^{\circ} 60^{\prime}$ de longitud oeste. Se extiende a lo largo de unos $80 \mathrm{~km}$ de extensión por $40 \mathrm{~km}$ de ancho máximo, representando una superficie total de $3200 \mathrm{~km}^{2}$. Este sector es recorrido por la ruta nacional 40 en dirección norte- sur y la localidad de Malargüe constituye el principal centro urbano del área. El límite norte está definido por el trazo de la ruta provincial 222 que acompaña el curso del Río Salado desde la localidad de Las Leñas, mientras que su límite sur lo marca la Cuesta del Chihuido, al norte del Cerro Mirano (Fig. 4.2).

La red hidrográfica está conformada por los ríos Malargüe, Grande y Salado como principales elementos y una serie de arroyos de menor caudal tales como el Loncoche, Rezago, Las Minas, Negro, Casa de Piedra y Chequen-Co (Dessanti, 1973). Mientras los cursos de agua principales tienen orientación predominante este- oeste los arroyos poseen direcciones variables, siendo más abundantes los cursos de agua permanentes hacia el sector andino y los efímeros hacia el sector oriental.

La provincia geológica de la Cordillera Principal se constituye como la unidad morfoestructural más importante del área, la cual presenta alta deformación en el sector de la Faja Plegada y Corrida de Malargüe, intensa actividad volcánica y migración de la deformación hacia el sector de antepaís, evidenciada por la disminución en las edades de eventos en dirección oeste - este (Arcila Gallego, 2010), la cual varía de $17 \pm 2$ Ma (Nullo et al., 2002) a 5,4 $\pm 0,1 \mathrm{Ma}$ (Silvestro et al., 2006). Desde el punto de vista estructural, los afloramientos están asociados a una serie de anticlinales y corrimientos de orientación meridional que forman parte del sector externo sur de la Faja Plegada y Corrida de Malargüe (Kozlowski et al., 1993). Al sur, la región se ve limitada por el lineamiento Bardas Blancas.

La región seleccionada para el estudio forma parte de la Plataforma Mendocina definida por Doyle et al. (2005). Gracias a su estructuración y la erosión de su extensa red hídrica, posee excelentes exposiciones de toda la secuencia sedimentaria desde su basamento constituido por el Grupo Choiyoi, hasta sedimentitas cuaternarias. La Formación Vaca Muerta es particularmente distinguible en la región por su alternancia de bancos finos compuestos por pelitas negras, margas y calizas. La Formación Chachao se presenta en un espeso banco calcáreo de coloración blanquecina que es cortado numerosas veces por la ruta 40 entre el Río Mendoza y la Cuesta del Chihuido. La calidad de sus afloramientos, la abundancia y estado de preservación de su material fósil y la ausencia de trabajos específicos en materia de geoquímica y diagénesis convirtieron a este sector del sur mendocino en el área perfecta para la realización del presente trabajo. 
Sobre la base del estudio y posterior corroboración en el campo de las características generales del área se seleccionaron tres sectores de estudio donde se elaboraron perfiles sedimentológicos de detalle (Fig. 4.2).

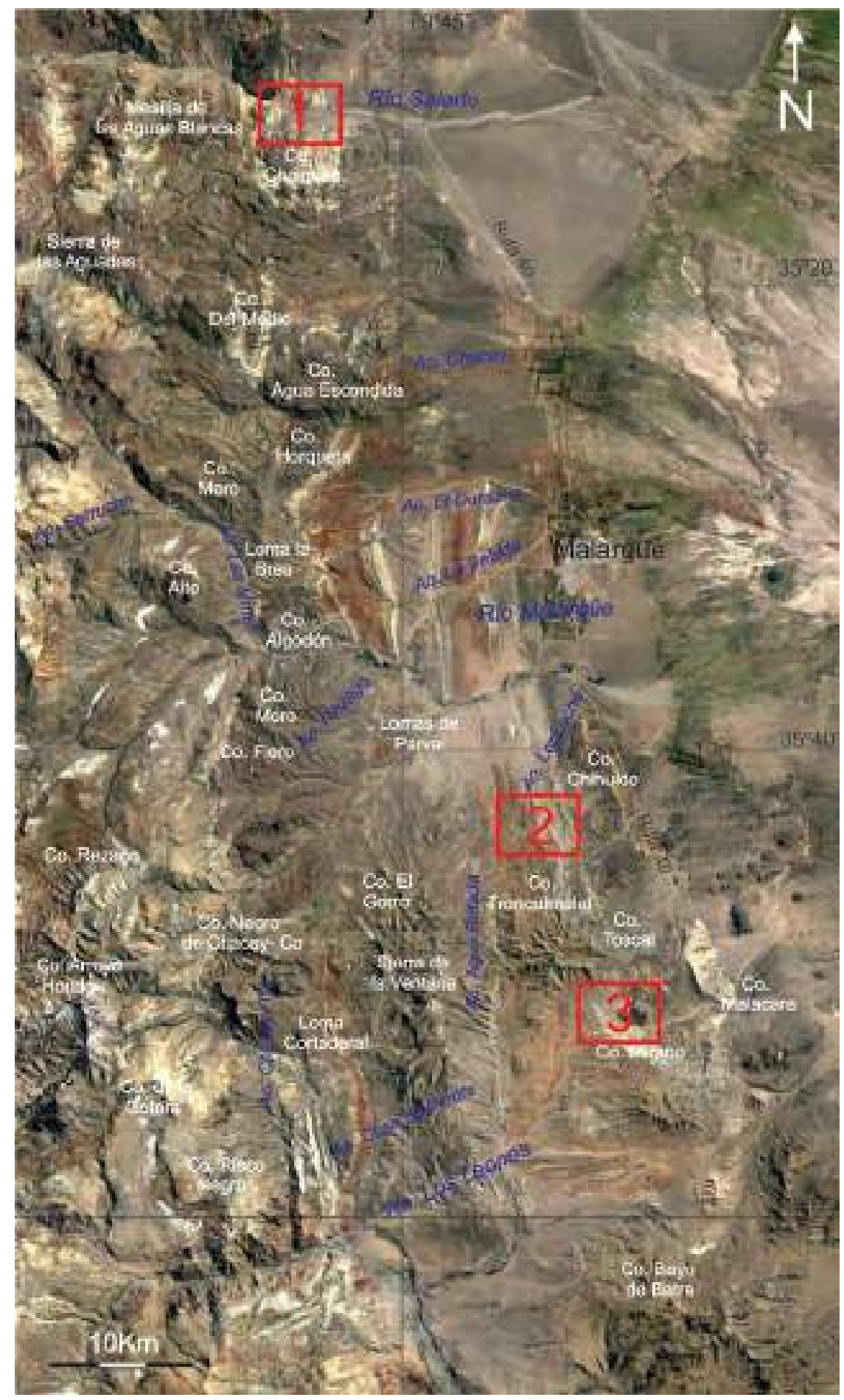

Figura 4.2. Imagen satelital del área de estudio en la Cuenca Neuquina. Se pueden observar los rasgos orográficos en blanco, los hidrográficos en azul y los sectores de estudio en rojo. 


\subsubsection{Sector Río Salado}

El sector Río Salado (350 11' S y 69 46' W) se ubica a $30 \mathrm{~km}$ de la localidad de Malargüe y se accede por la ruta provincial 222 (Fig. 4.3). La erosión del río permite observar en ambas márgenes parte de la cubierta sedimentaria depositada entre el Jurásico superior y el Cretácico inferior. Hacia el sector oriental se reconocen corrimientos y anticlinales de orientación norte- sur. En la región central, se evidencia una sucesión homoclinal con buzamiento hacia el oeste, que expone estratos cada vez más jóvenes en esa dirección. Por otro lado, en el oeste es posible observar una potente colada basáltica de edad cuaternaria y afloramientos sin continuidad estratigráfica de las formaciones Agrio, Vaca Muerta y Tordillo.

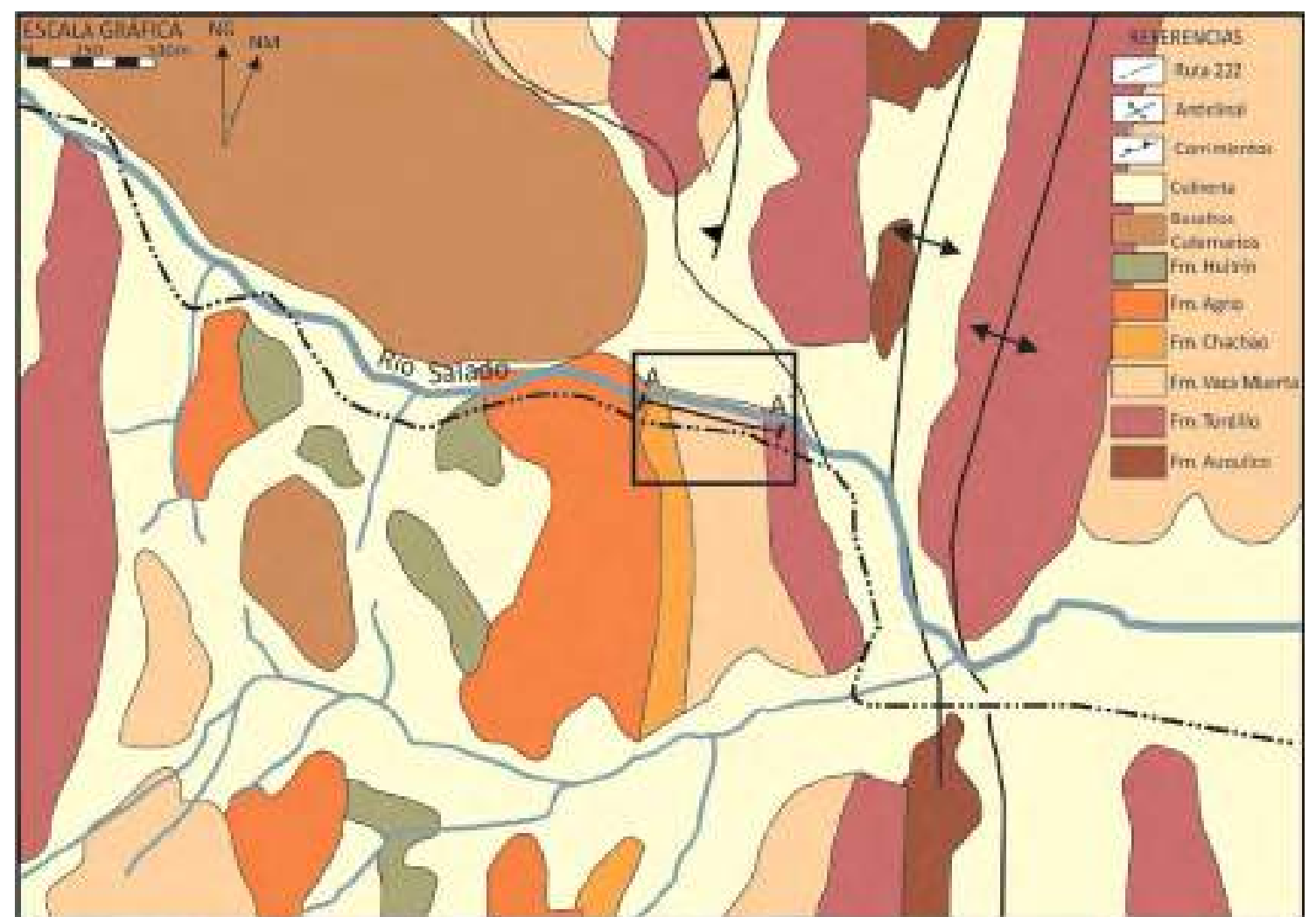

Figura 4.3: Mapa geológico del sector Río Salado. Modificado de Nullo et al. (2004) y Doyle et al. (2005). El recuadro en blanco señala el perfil relevado, mientras que A y A' marcan la base y el techo del perfil respectivamente.

Perfil Río Salado (ver Anexos): se relevó una sucesión mixta de tendencia vertical granocreciente de 176 metros de espesor compuesta por una alternancia de lutitas negras con carbonatos. Los carbonatos se encuentran dispuestos en capas de entre 10 y $70 \mathrm{~cm}$ de wackestones, packstones, floatstones y bioclásticos (Fig. 4.4). La base de la Formación Vaca Muerta no se encuentra expuesta, mientras que el pasaje entre esta y la Formación Chachao es transicional. El límite entre la Formación Chachao y la suprayacente Formación Agrio se 
evidencia en el pasaje brusco de capas de carbonatos granulométricamente gruesos hacia otros de texturas más finas.

Es posible distinguir cinco intervalos en este perfil, diferenciados sobre la base de sus atributos sedimentológicos, icnológicos y fosilíferos. Basándose en estas características, Doyle et al. (2005) Ilamaron a estos intervalos Vaca Muerta inferior y superior y Chachao inferior, medio y superior respectivamente. En el presente trabajo se considerará a la Formación Chachao a partir de la aparición de los primeros floatstontes (Chachao superior según Doyle et al., 2005) según el criterio utilizado por Kietzmann et al. $(2008,2015)$.

El primer segmento tiene un espesor de 75 metros y corresponde al sector basal de la Formación Vaca Muerta. Consiste en una alternancia de bancos de pelitas negras que en ocasiones alcanzan los $7 \mathrm{~m}$ de potencia intercalados con margas, wackestones y areniscas dispuestas en paquetes de entre 10 y $40 \mathrm{~cm}$ de espesor. Las margas se presentan tanto en estratos continuos como nodulares y se pueden reconocer niveles de depósitos piroclásticos de caída hacia el tope de este intervalo. Existe una rica fauna de amonites, gasterópodos, serpúlidos y fragmentos de bivalvos no diferenciados, concentrada principalmente en los niveles carbonáticos de la secuencia. Este sector presenta una rica icnofauna compuesta por los icnogéneros Thalassinoides, Phycodes, Arenicolites, Planolites y Chondrites.

La secuencia continúa con 23 metros de intercalaciones de pelitas negras en bancos de hasta 2 metros de potencia con paquetes de packstones de entre 10 y $40 \mathrm{~cm}$ de espesor. La fauna está representada por amonites, ostras y bivalvos no diferenciados, mientras que es posible reconocer icnogéneros de Entollium y Thalassinoides.

El tercer segmento está compuesto por 37 metros de bancos de pelitas alternados con areniscas, packstones y margas. Presenta el mismo contenido fosilífero que el intervalo anterior, mientras que aumenta la diversidad de icnogéneros, incluyendo Arenicolites, Thalassinoides, Palaeophycus, Gordia, Phycodes y Chondrites.

El cuarto intervalo constituye el tope de la Formación Vaca Muerta y consta de 18 metros caracterizados por la intercalación de pelitas negras y margas con espesores que van desde los 15 hasta los $60 \mathrm{~cm}$. Presenta una fauna consistente en amonites, gasterópodos, bivalvos no diferenciados y escasas ostras del género Aetostreon sp. Disminuye significativamente la icnodiversidad y sólo se reconocen escasas trazas de Entollium y Thalassinoides.

El sector cuspidal corresponde a la Formación Chachao, está compuesto por 23 metros de pelitas negras alternadas con margas, abundantes floatstones y escasos packstones. En cuanto a su contenido fosilífero, existe un incremento en la abundancia de los géneros antes 
descriptos, en especial de las ostras del género Aetostreon sp. El contenido icnológico está representado por Palaeophycus, Entollium, Thalassinoides y Chondrites.

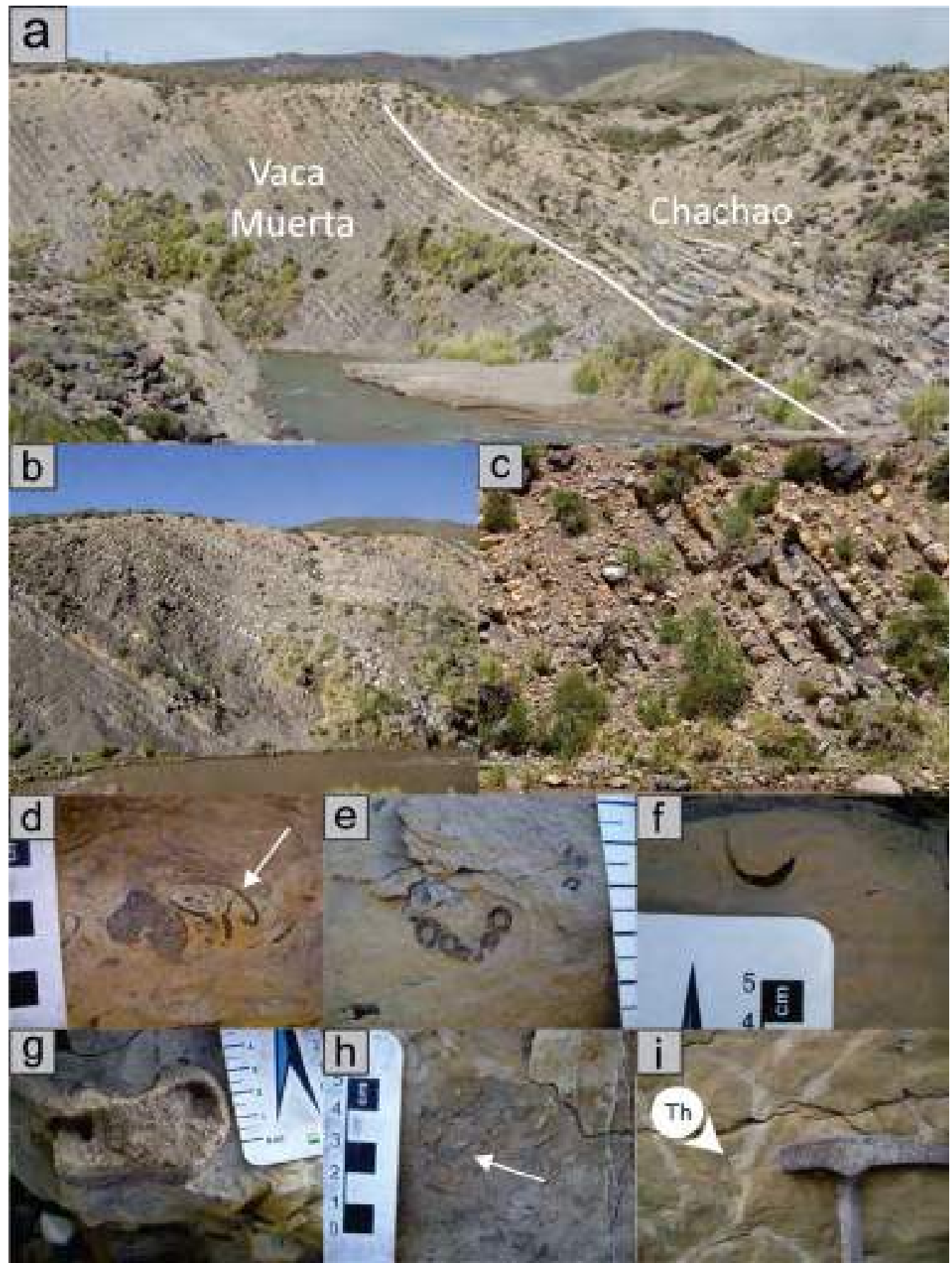

Figura 4.4: a) Vista general del Perfil Río Salado, se observa el contacto entre las formaciones Vaca Muerta y Chachao; b) vista general de la Formación Vaca Muerta; c) vista general de la Formación Chachao. d) Vista en detalle de un floatstone, la flecha indica una ostra del género Aetostreon sp.; e) nivel de floatstone, vista en detalle de un serpúlido; f) nivel de wackestone, vista en detalle de un fragmento de bivalvo no diferenciado; g) amonite recristalizado; h) floatstone de granulometría fina, la flecha indica un gaterópodo; i) vista en detalle de un Thalassinoides. 


\subsubsection{Sector Puesto Loncoche}

El sector Puesto Loncoche (35 $36^{\prime} \mathrm{S}$ y $69^{\circ}$ 37' W) se ubica a $22 \mathrm{~km}$ de la localidad de Malargüe, en el centro geográfico del área de estudio y posee acceso desde la ruta 40 por caminos internos (Fig. 4.5). En este sector, es posible observar una espesa sucesión sedimentaria de edad Triásica hasta Cretácica superior, que es claramente distinguible gracias a la erosión del Arroyo Loncoche que atraviesa dichos afloramientos en dirección sudoestenoreste. El área presenta anticlinales con orientación norte- sur y lineamientos sin direcciones preferenciales ubicados al este del sector, hacia la porción más occidental la secuencia se presenta como homoclinal con buzamiento hacia el oeste.

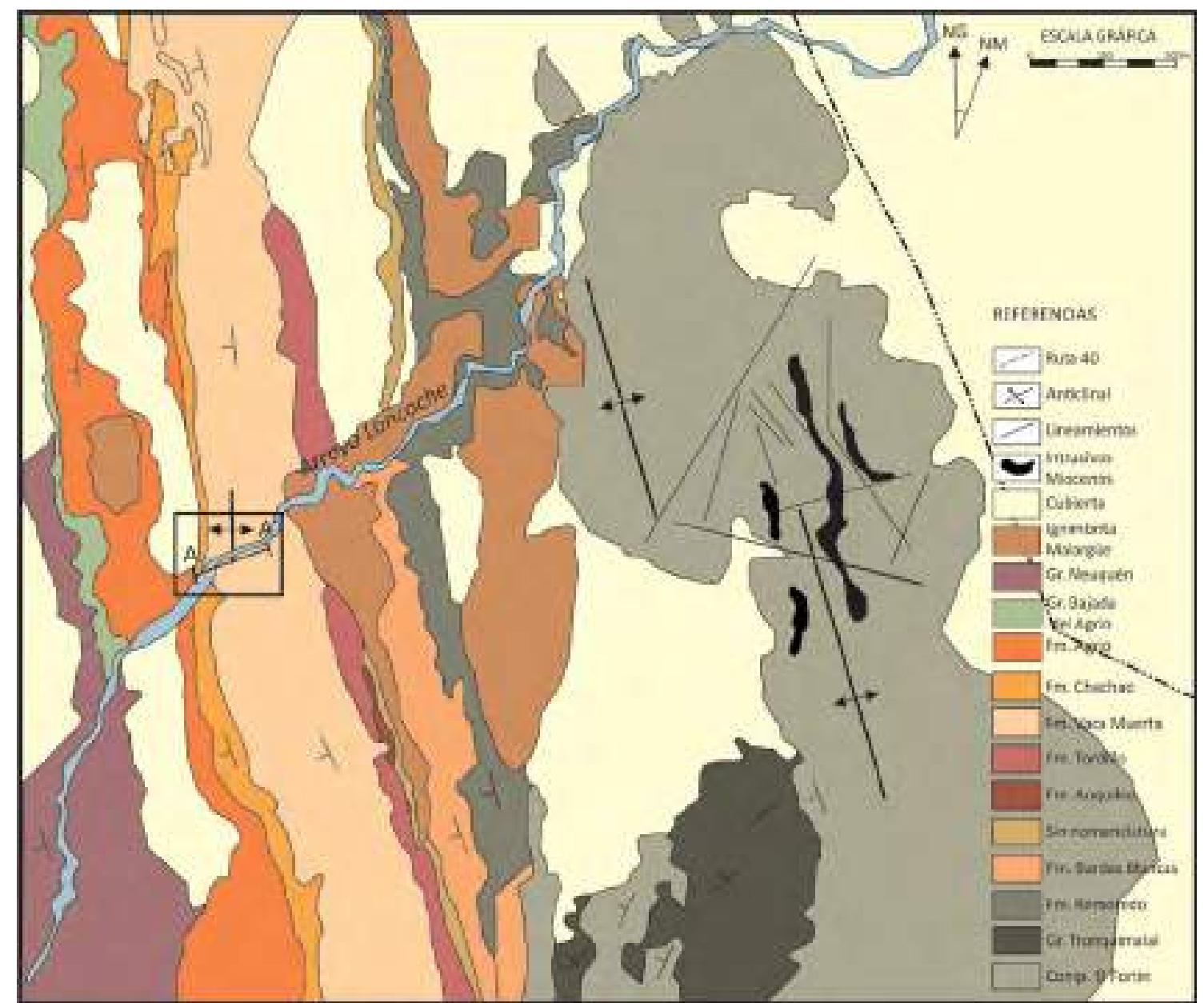

Figura 4.5. Mapa geológico del sector Puesto Loncoche. Modificado de Nullo et al. (2004) y Kietzmann et al. (2008).

El recuadro en negro señala el perfil relevado, mientras que $A^{\prime}$ y $A$ indican la base y el techo del perfil respectivamente.

Perfil Puesto Loncoche (ver Anexos): se reconoció una alternancia de bancos de pelitas negras y carbonatos que alcanzan una potencia total de $200 \mathrm{~m}$. Se observa la misma tendencia vertical granocreciente que en el Río Salado, pero acompañada por un arreglo estratocreciente 
que culmina en un banco de ostras de 25 metros de espesor correspondiente a la Formación Chachao (Fig. 4.6).

Este perfil presenta tres segmentos bien diferenciados, correspondiendo los dos primeros a la Formación Vaca Muerta y el tercero a la Formación Chachao.

El primer segmento expone la base de la Formación Vaca Muerta, mostrando un contacto neto y plano entre esta y la subyacente Formación Tordillo, representada en esta área por conglomerados polimícticos. Se presenta como una alternancia de pelitas y psamitas silicoclásticas en paquetes de hasta $1 \mathrm{~m}$ de espesor que intercalan con bancos de margas, mudstones y escasos packstones carbonáticos de entre 20 y $50 \mathrm{~cm}$ de potencia. Su contenido fosilífero consta de fragmentos de bivalvos ostreidos y otros no diferenciados, amonites y serpúlidos. Presenta trazas fósiles de los icnogéneros Thalassinoides, Skolithos, Palaeophycus y Chondrites.

Luego de un extenso sector cubierto, el perfil continúa con una secuencia mixta de pelitas negras y castañas intercaladas con bancos de wackestones, packstones, floatstones y rudstones, siendo las granulometrías gruesas más comunes hacia los sectores más cuspidales. El contenido fosilífero y también su estado de preservación tafonómica aumentan en el mismo sentido que la granulometría, se reconocieron amonites, fragmentos de bivalvos no diferenciados, gasterópodos, serpúlidos, braquiópodos y ostras del género Aetostreon sp. Por lo contrario, la abundancia y diversidad icnológica disminuye en sentido vertical, identificándose Thalassinoides, Rhizocorallium y Diplocraterion.

El perfil sedimentario culmina con $25 \mathrm{~m}$ de rudstones y floatstones de ostras formando acumulaciones bioclásticas con arreglos verticales y amalgamación lateral de sus cuerpos, dentro de las cuales hay signos de un leve retrabajamiento de los bancos de ostras originales, por lo que pueden caracterizarse como autoparabiostromas de acuerdo a Kershaw (1994). Las ostras son casi exclusivamente del género Aetostreon sp. aunque también se observan del género Ceratostreon sp. Además se reconocieron bivalvos y serpúlidos con un alto grado de preservación tafonómica. Posee trazas fósiles de los icnogéneros Gastrochaenolites, Trypanites y Thalassinoides. El contacto con la suprayacente Formación Agrio es neto y pleno reconociéndose por el restablecimiento de las facies de pelitas. 

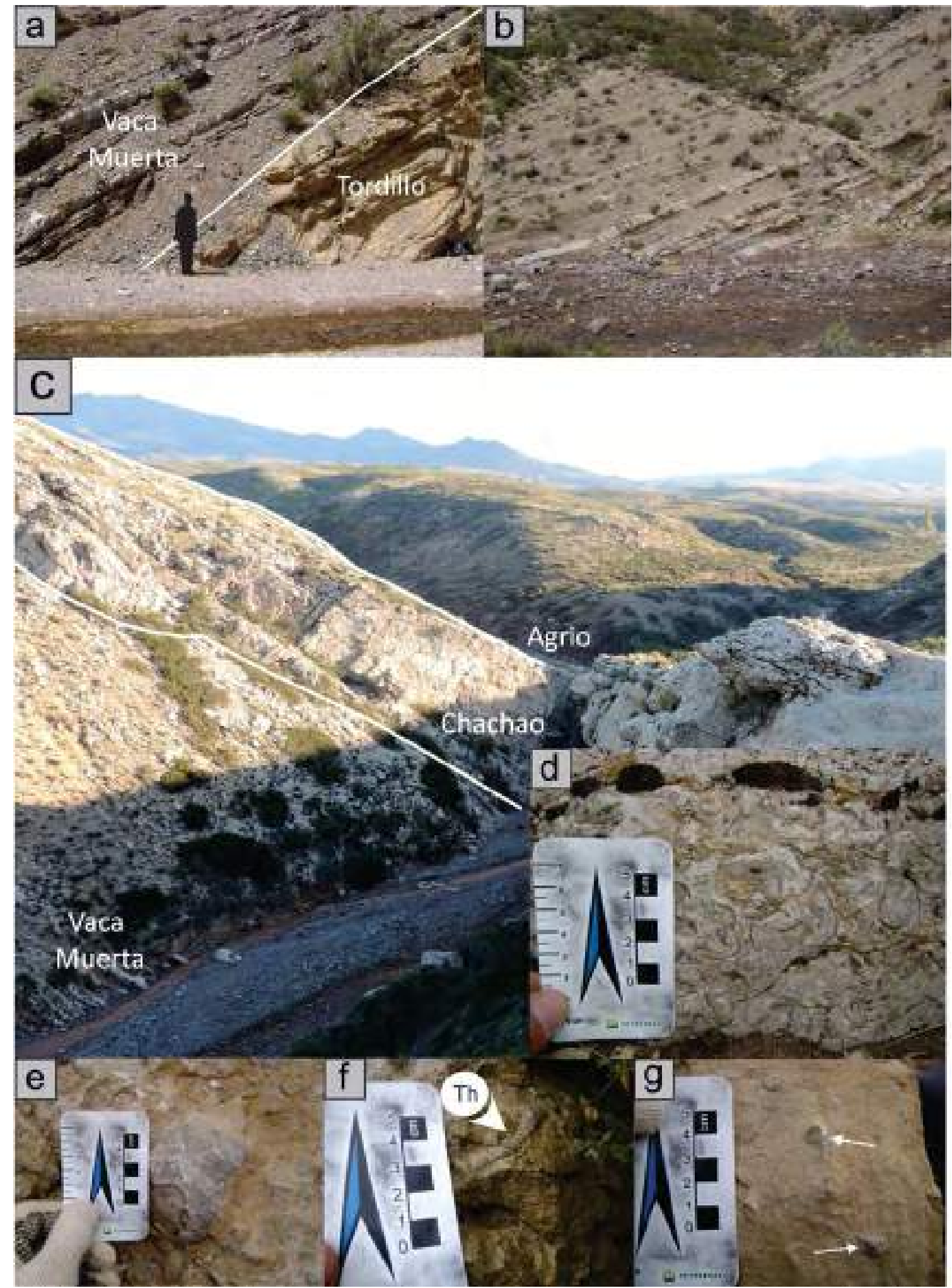

Figura 4.6: a) Contacto entre las formaciones Tordillo y Vaca Muerta; b) niveles de la Formación Vaca Muerta; c) vista panorámica del perfil Puesto Loncoche, contacto entre las formaciones Vaca Muerta, Chachao y Agrio; d) detalle de la Formación Chachao, autoparabiostroma de ostras; e) ostra del género Aetostreon sp.; f) thalassinoides; g) nivel de floatstone de la Formación Vaca Muerta, serpúlido y gaterópodo indicados con flechas. 


\subsubsection{Sector Cuesta del Chihuido}

El sector Cuesta del Chihuido (35 44' S y 69o $34^{\prime} \mathrm{W}$ ), se encuentra a $35 \mathrm{~km}$ de la localidad de Malargüe en el extremo sur del área de estudio (Fig. 4.7). En esta zona se reconoce una espesa cubierta sedimentaria que comprende depósitos desde triásicos hasta cuaternarios. Estas sedimentitas se estructuran en un braquianticlinal de orientación norte sur que fue posteriormente afectado por corrimientos con igual dirección. Esta característica permite observar las capas más antiguas hacia el sector central. La erosión generada por el Arroyo Agua Botada y el trazo de la ruta 40 favorecen perfiles de los afloramientos que permiten estudiar dichas sedimentitas en excelentes exposiciones.

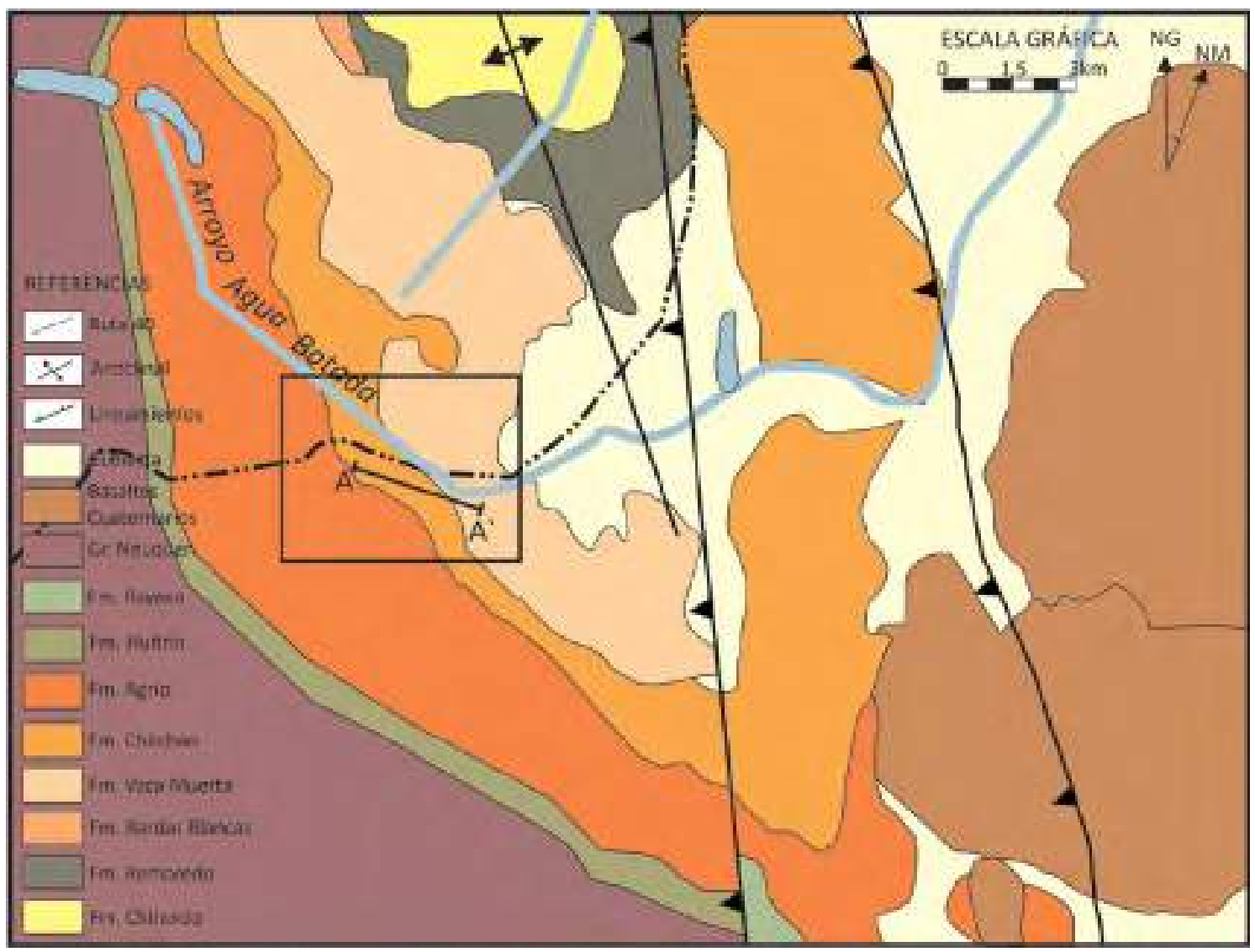

Figura 4.7: Mapa geológico del sector de la Cuesta del Chihuido. Modificado de Nullo et al. (2004) y Arcila Gallego (2010). El recuadro en negro señala el perfil relevado, mientras que $A^{\prime}$ y $A$ indican la base y el techo del perfil respectivamente.

Perfil Cuesta del Chihuido (ver Anexos): este perfil sedimentario sólo expone la parte superior de la Formación Vaca Muerta y la Formación Chachao sumando un espesor total de 63 metros, con un arreglo vertical muy similar al descripto para el Puesto Loncoche (Fig. 4.8). 
Los primeros $25 \mathrm{~m}$ consisten en una intercalación de ostras formando autoparabiostromas constituidos por floatstones y rudstones bioclásticos con bancos decimétricos de pelitas negras, wackestones, packstones y margas. Su contenido fósil es muy abundante y consiste en bivalvos no diferenciados, amonites, gasterópodos, belemnites, serpúlidos, ostrácodos, briozoos y ostras del género Aetostreon sp. Entre los icnogéneros se diferencian Thalassinoides, Chondrites y Ophiomorpha.

El sector superior está formado por un espeso banco de $25 \mathrm{~m}$ con iguales características a las previamente descriptas en Puesto Loncoche. Se trata de cuerpos carbonáticos amalgamados compuestos por floatstones y rudstones ricos en fauna bentónica (serpúlidos, bivalvos, ostreidos, braquiópodos y ocasionales amonites) con un buen estado de preservación tafonómica. Se distinguen icnogéneros de Thalassinoides, Trypanites y Chondrites. 


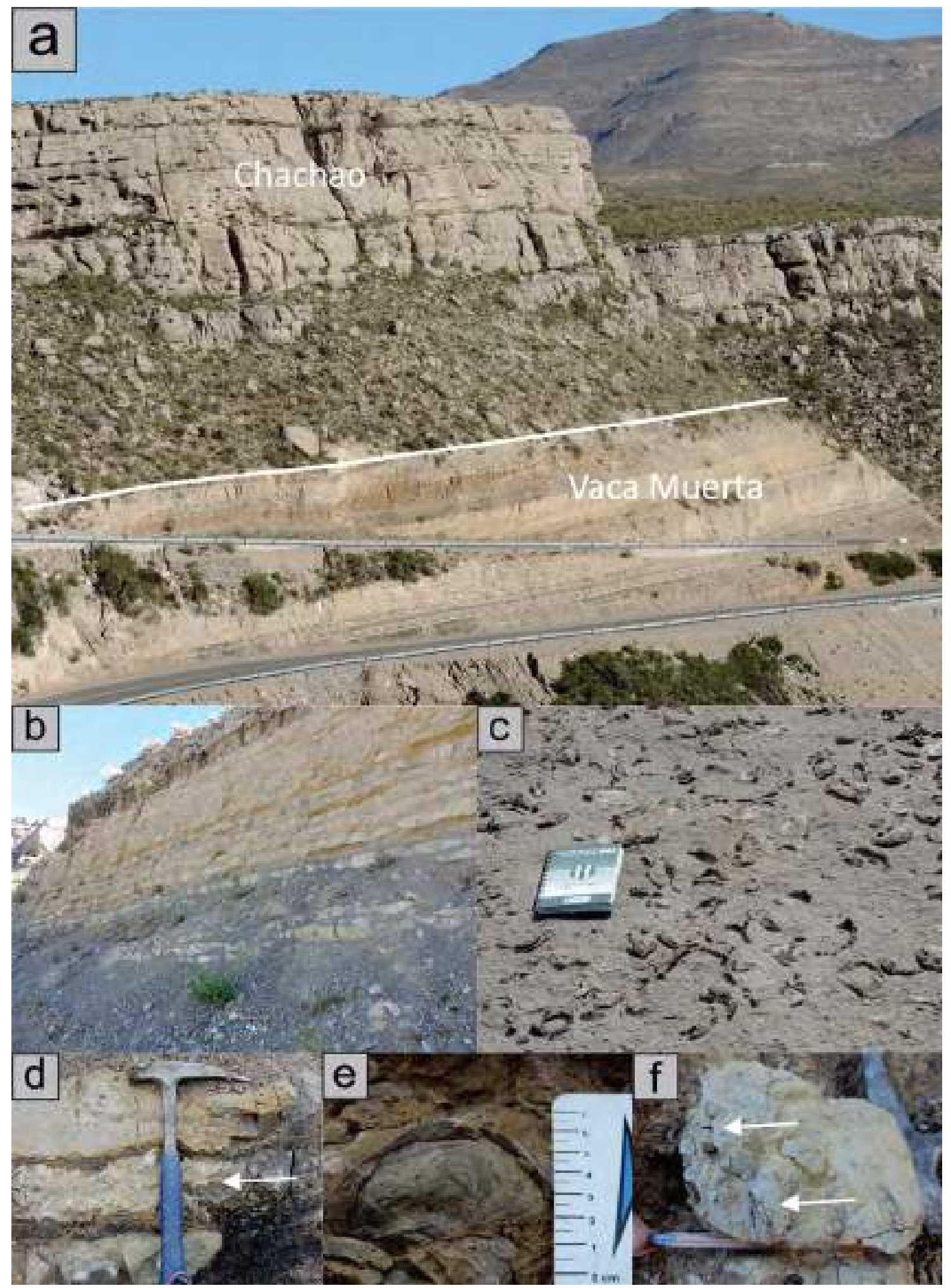

Figura 4.8: a) Vista general de las formaciones Vaca Muerta y Chachao en el perfil Cuesta del Chihuido; b) niveles de la Formación Vaca Muerta; c) pavimento de ostras en el tope de la Formación Chachao; d) intercalación entre niveles de pelitas negras y rudstones conformando autoparabiostromas; e) vista en detalle de un ejemplar de Aetostreon sp. con buen estado de preservación tafonómica; f) floatstone con contenido fosilífero de belemnites y amonites (flechas blancas). 


\subsection{Entre los lagos Argentino y San Martín en la Cuenca Austral}

La zona de trabajo en esta cuenca (distante de la Cuenca Neuquina por unos $2000 \mathrm{~km}$ aproximadamente), se localiza entre los $48^{\circ} 45^{`}$ y los 50 ㅇ $15^{`}$ de latitud sur y entre los $72^{\circ}$ y 73ㅇ de longitud oeste. Se desarrolla a lo largo de unos $150 \mathrm{~km}$ de extensión por $90 \mathrm{~km}$ de ancho máximo, representando una superficie total de $13500 \mathrm{~km}^{2}$. El área de trabajo es recorrida por la ruta nacional 40 en dirección norte- sur, y por seis rutas provinciales $(31,23$, $21,69,19$ y 11) en dirección este- oeste que comienzan en la zona andina y culminan en la ruta 40. Las localidades de El Calafate, El Chalten y Tres Lagos constituyen los principales asentamientos urbanos de la región. El límite norte está definido por el Brazo Chacabuco del Lago San Martín, mientras que su límite sur lo marca el Lago Argentino (Fig. 4.9).

Se destaca en esta zona la presencia de tres extensos lagos de aguas glaciares: San Martín, Viedma y Argentino, que conforman una extensa red hidrográfica. El Lago Argentino recibe en la margen sur a los ríos Mitre y Centinela, además de algunos arroyos poco caudalosos en las cercanías de la localidad de El Calafate. Al este, se encuentran las nacientes del río Santa Cruz, mientras que en la margen norte desaguan los arroyos de montaña de Las Hayas y Horquetas. En el extremo noreste se presenta el delta de la desembocadura del río La Leona que trae las aguas del Lago Viedma. El Lago Viedma, en tanto, recibe desde el norte a los ríos Túnel, Las Vueltas, Blanco y Cangrejo. En la margen sur, el Río Guanaco constituye el principal afluente, aunque también vierten sus aguas el río Cóndor y numerosos arroyos. El Lago San Martín por su parte, recibe por el norte las aguas de los ríos Caracoles, Fósiles y el arroyo El Bolsón. Por el este se conecta con el lago Tar a través del río homónimo y en su margen sur despliega una densa red hídrica con los arroyos Macía, Grande, del Diablo, Elena; y los ríos Grande y Manuel de Rosas.

La zona de estudio se encuentra constituida por la provincia geológica de la Cordillera Patagónica y la Faja Plegada y Corrida de la Patagonia (Riccardi y Rollleri, 1980; Ghiglione et al., 2009; Ghiglione et al., 2014). Ghiglione et al. (2014) dividieron este sector en tres dominios estructurales, incluyendo de oeste a este: el dominio de basamento de piel gruesa y la faja plegada y corrida subdividida en un dominio interno occidental y un dominio externo oriental. El sector de trabajo se desarrolla dentro del área de dominio de basamento y se ve caracterizado por numerosos corrimientos de orientación norte-sur.

La estructuración del área y la escasa vegetación hacen que esta región presente excelentes exposiciones de las unidades objeto de estudio. Es posible distinguir las psamitas cuarzosas de la Formación Springhill rellenando hemigrábenes y espesas sucesiones de pelitas negras que constituyen la Formación Río Mayer constituyendo una faja de orientación norte- 
sur fácilmente accesible desde caminos y estancias. Esta región fue seleccionada para este trabajo por presentarse casi inexplorada en materia de geoquímica y diagénesis, por la calidad de sus ejemplares fósiles (principalmente belemnites) y por su correlación temporal con los afloramientos de la Cuenca Neuquina.

Sobre la base de la información bibliográfica del área y la interpretación de mapas e imágenes satelitales, se seleccionaron dos sectores donde se relevaron tres perfiles sedimentarios de detalle (Fig. 4.9).

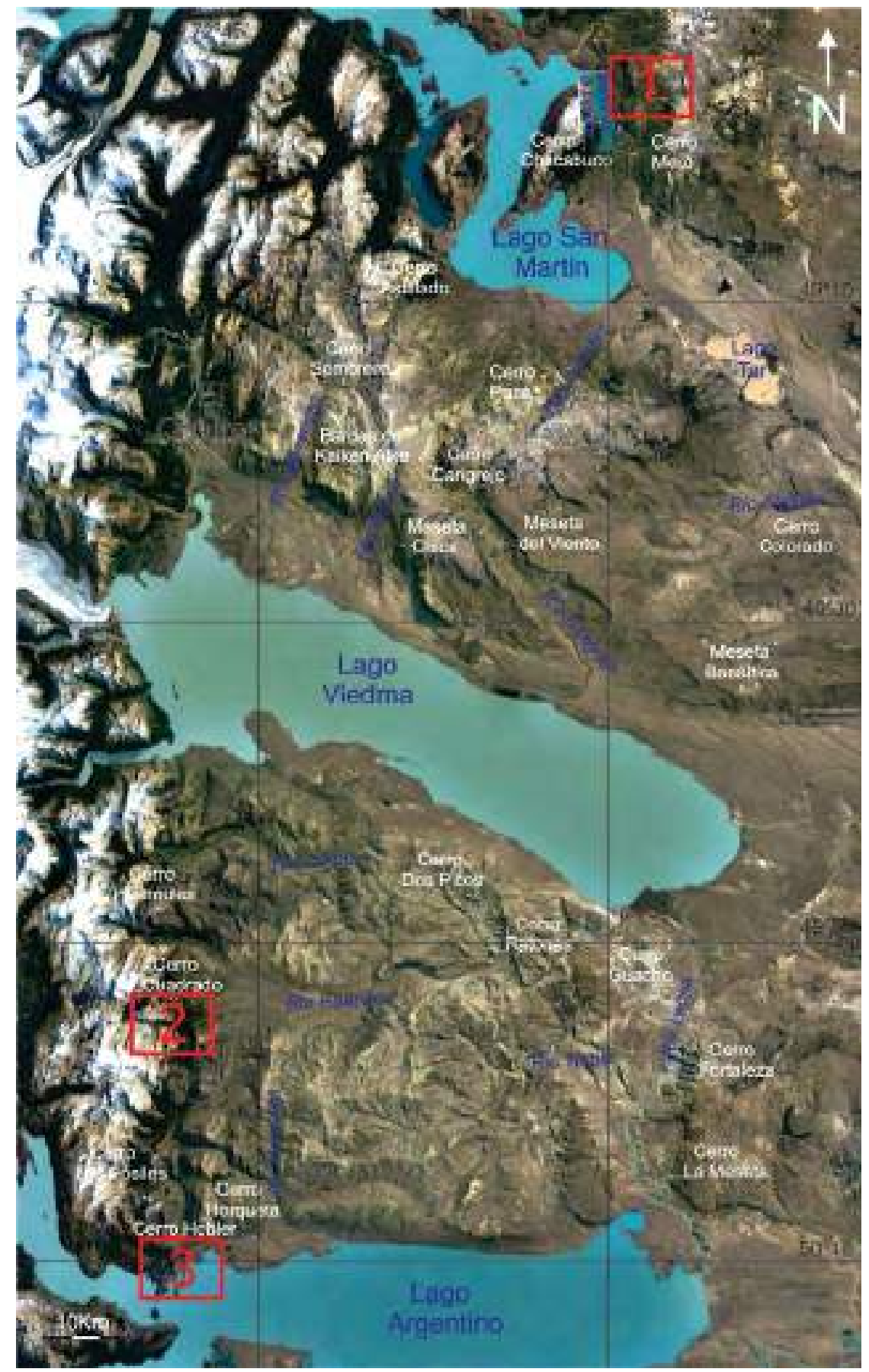

Figura 4.9: Imagen satelital del área de estudio en la Cuenca Austral. Se pueden observar los rasgos orográficos en blanco, los hidrográficos en azul y los sectores de estudio en rojo. 


\subsubsection{Sector Lago San Martín}

El sector Lago San Martín (48은 59’ y 72 12’ W) se ubica aproximadamente a 100 km al noroeste de la localidad de Tres Lagos y se accede por la ruta provincial 31, constituyendo el extremo norte del área de estudio (Fig. 4.10). En esta región se observan predominantemente afloramientos de la Formación Bahía de la Lancha (Borrello, 1967), la cual se compone de rocas meta-sedimentarias de edad paleozoica cubriendo ambas márgenes de dicha bahía. Además se reconocen cuantiosos afloramientos del Complejo El Quemado y aisladas expresiones del conglomerado Arroyo de la Mina (Bianchi, 1967), asignadas por relaciones estratigráficas al Jurásico (Riccardi, 1971). Poseen una gran representación en la zona las rocas de edad Jurásico superior- Cretácico inferior, representadas por las formaciones Springhill, Río Mayer y Kachaike. Además, se registra en el área una cubierta cuaternaria, compuesta por sedimentos continentales de distintos orígenes.

El trabajo se focalizó en una de las bahías del Lago San Martín, conocida como "Bahía de la Lancha". Allí se relevó un perfil sedimentológico de detalle en la denominada "Subida del Chancho", cerro ubicado entre las estancias "La Lila" y "La Federica".

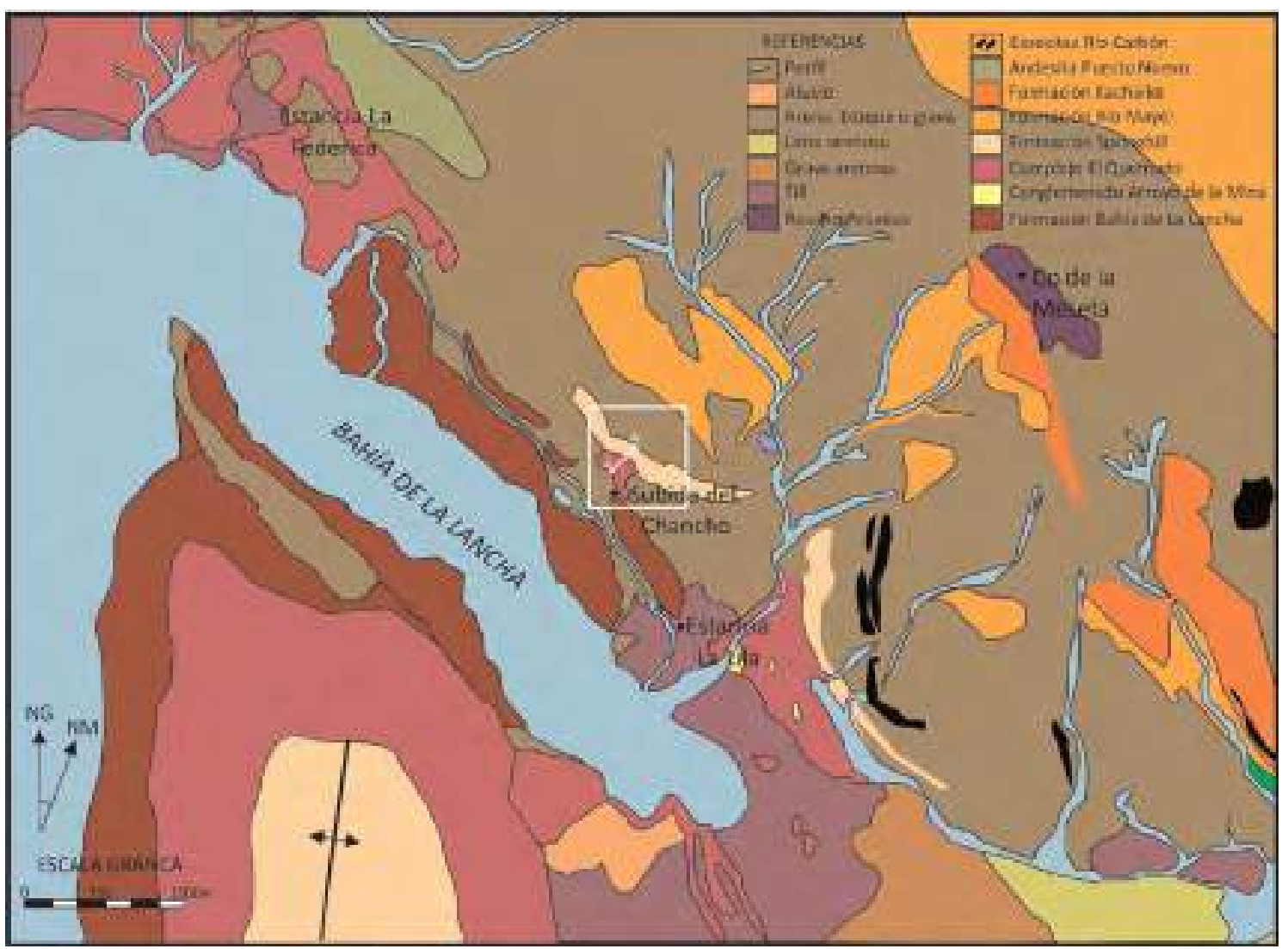

Figura 4.10: Mapa geológico del sector del Lago San Martín. Modificado de Riccardi (1971) y Panza et al. (1994). EI recuadro en blanco señala el perfil relevado, mientras que $A$ y $A^{\prime}$ indican la base y el techo del perfil respectivamente. 
Perfil Subida del Chancho (ver Anexos): el perfil representa la totalidad de la Formación Springhill en el área de estudio. Posee un espesor total de 72 metros con extensos sectores cubiertos (Fig. 4.11).

En los primeros $60 \mathrm{~m}$ se observan niveles de psamitas y psefitas cuarzosas en paquetes amalgamados de entre 4 y $6 \mathrm{~m}$ de potencia que presentan estructuras sedimentarias mecánicas tales como estratificación entrecruzada tangencial y tabular planar. Estos niveles presentan abundantes briznas vegetales y se encuentran intensamente bioturbados en sus topes, reconociéndose los icnogéneros Skolithos isp. y Arenicolites isp. En los extensos sectores cubiertos es posible reconocer pelitas negras masivas y laminadas con abundante contenido de materia orgánica.

En el sector medio se observan packstones masivos compuestos principalmente por fragmentos de bivalvos no identificados y abundantes belemnites. En el sector cuspidal se puede observar arenitas glauconíticas con igual contenido fosilífero que los packstones. 


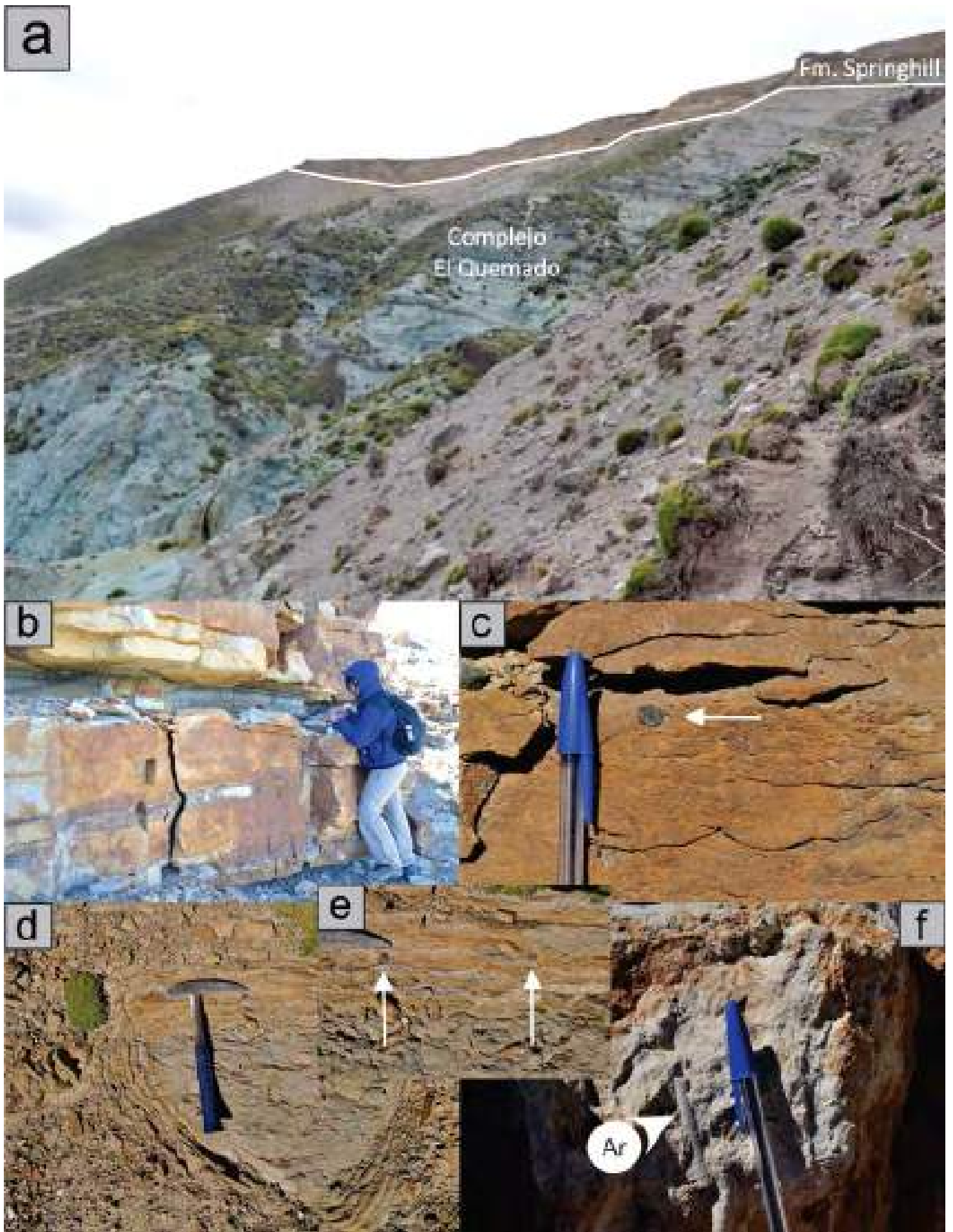

Figura 4.11: a) Vista general del Complejo El Quemado y la Formación Springhill en el perfil "Subida del Chancho"; b) niveles amalgamados de psefitas y psamitas cuarzosas; c) packstones ricos en belemnites y fragmentos de bivalvos; d) arenitas glauconíticas; e) detalle de los belemnites (flechas blancas) del nivel de arenitas glauconíticas; f) arenicolites. 


\subsubsection{Sector entre los lagos Argentino y Viedma}

Este sector se desarrolla entre los $49 \circ 39^{\prime}$ y $50^{\circ} 09^{\prime}$ de latitud sur y los $72^{\circ} 06^{\prime}$ y $72^{\circ}$ $56^{\prime}$ de longitud oeste y es posible acceder por la ruta provincial 69 a la margen norte del Lago Argentino, por la ruta 19 al sector de las nacientes del Río Guanaco y por la ruta 21 a la margen sur del Lago Viedma (Fig. 4.12).

Hacia el sector occidental de la región, se presenta el dominio de basamento de piel gruesa (Ghiglione et al., 2014) donde se pueden reconocer a la Formación Bahía de la Lancha y el Complejo El Quemado estructuradas por múltiples corrimientos de dirección norte- sur y fallas normales conformando hemigrábenes. La Formación Springhill se encuentra rellenando estas estructuras y por encima sobreyace concordantemenre la Formación Río Mayer con potentes espesores de pelitas negras. Hacia el este se pueden observar los dominios interno y externo, fuertemente estructurados, con abundantes anticlinales, sinclinales y corrimientos de orientación norte- sur. Allí se presentan todas las formaciones de la cubierta sedimentaria de la Cuenca Austral más jóvenes que la Formación Río Mayer en orden ascendente de edad en sentido oeste- este.

En este sector se seleccionaron dos áreas para realizar tareas de perfilaje sedimentológico. La primera de ellas en el Cerro Pintado, en las nacientes del Río Guanaco (Fig. 4.12). Es posible acceder por la Ruta Provincial $N^{\circ} 69$ arribando al puesto de guardaparques. La segunda zona seleccionada fue el Cerro Hobler, que se ubica sobre la costa norte del Lago Argentino (Fig. 4.12) cruzando los arroyos de Las Hayas y Horqueta. A este sitio se accede por la Ruta Provincial №19, la cual bordea la costa norte del Lago Argentino, pasando el casco de la Estancia San Ernesto. 


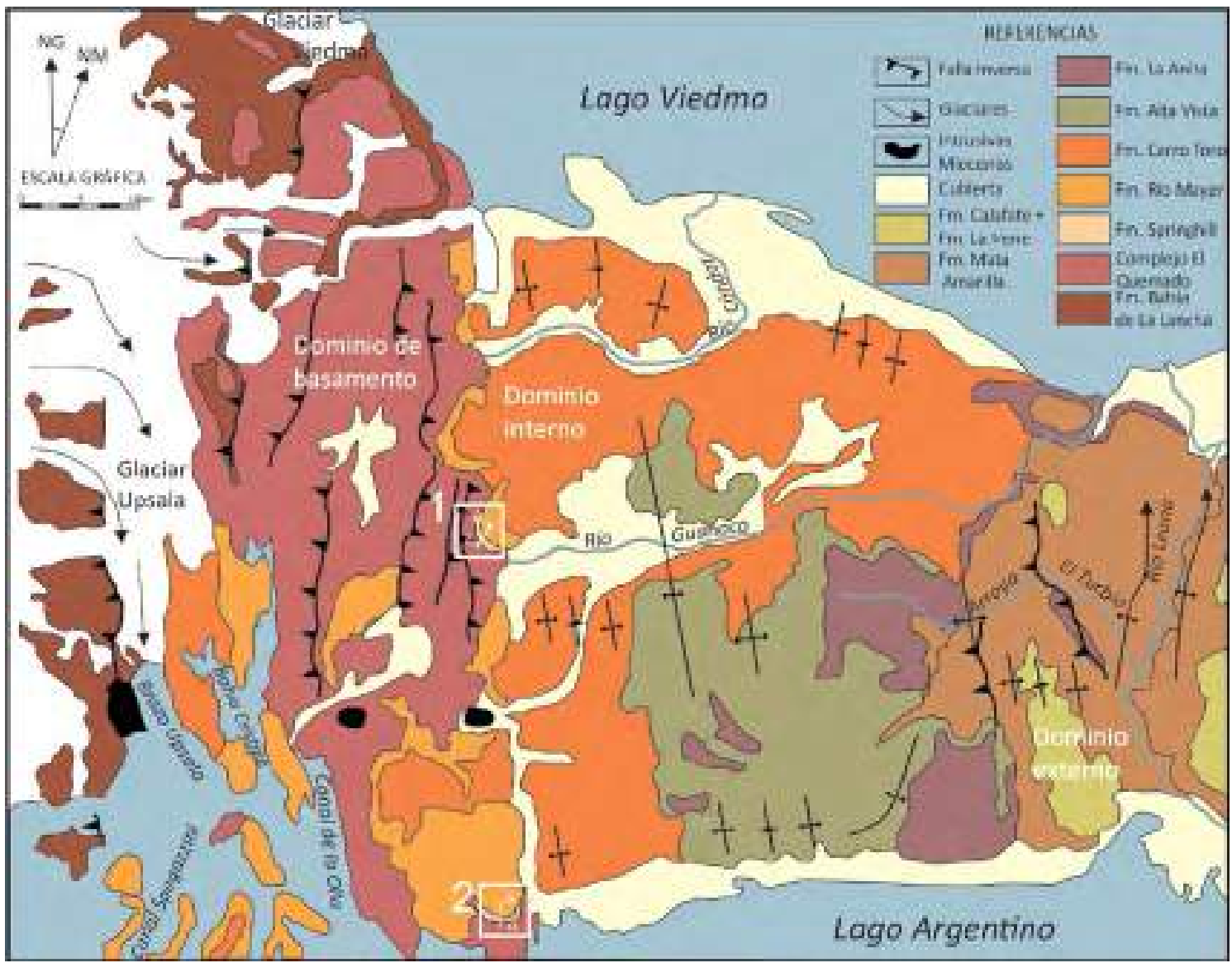

Figura 4.12: Mapa geológico del área entre los lagos Argentino y Viedma. Modificado de Panza et al. (1994), Kraemer y Riccardi (1997) y Ghiglione et al. (2014). Los recuadros en blanco señalan los perfiles relevados, mientras que $A$ y $A^{\prime}$ indican la base y el techo del perfil respectivamente. El número 1 corresponde al sector del Río Guanaco y el 2 al del Cerro Hobler.

Perfil Río Guanaco (ver Anexos): este perfil se encuentra en un hemigraben desarrollado en el Complejo el Quemado. Representa la totalidad de las Formación Springhill y la parte inferior de la Formación Río Mayer alcanzando una potencia total de $175 \mathrm{~m}$. El perfil presenta dos segmentos bien diferenciados correspondientes a las dos formaciones de estudio (Fig. 4.13, recuadro 1).

La Formación Springhill se compone de niveles de arenitas cuarzosas masivas de entre 30 y $60 \mathrm{~cm}$ de potencia ricas en belemnites que intercalan con pelitas negras laminadas. El contacto con el Complejo El Quemado resulta neto y plano, al igual que el límite con la suprayacente Formación Río Mayer.

La Formación Río Mayer está compuesta principalmente por pelitas negras laminadas o masivas intercaladas con ocasionales bancos o concreciones de margas que no superan los $60 \mathrm{~cm}$ de espesor. Presenta bivalvos aislados mal conservados, impresiones de amonites y una abundante cantidad del belemnites. Hacia el tope comienza un potente paquete margoso 
reconocido como Río Mayer medio (Richiano, 2012) rico en belemnites e intensamente bioturbado, del cual sólo fueron relevados los primeros metros.

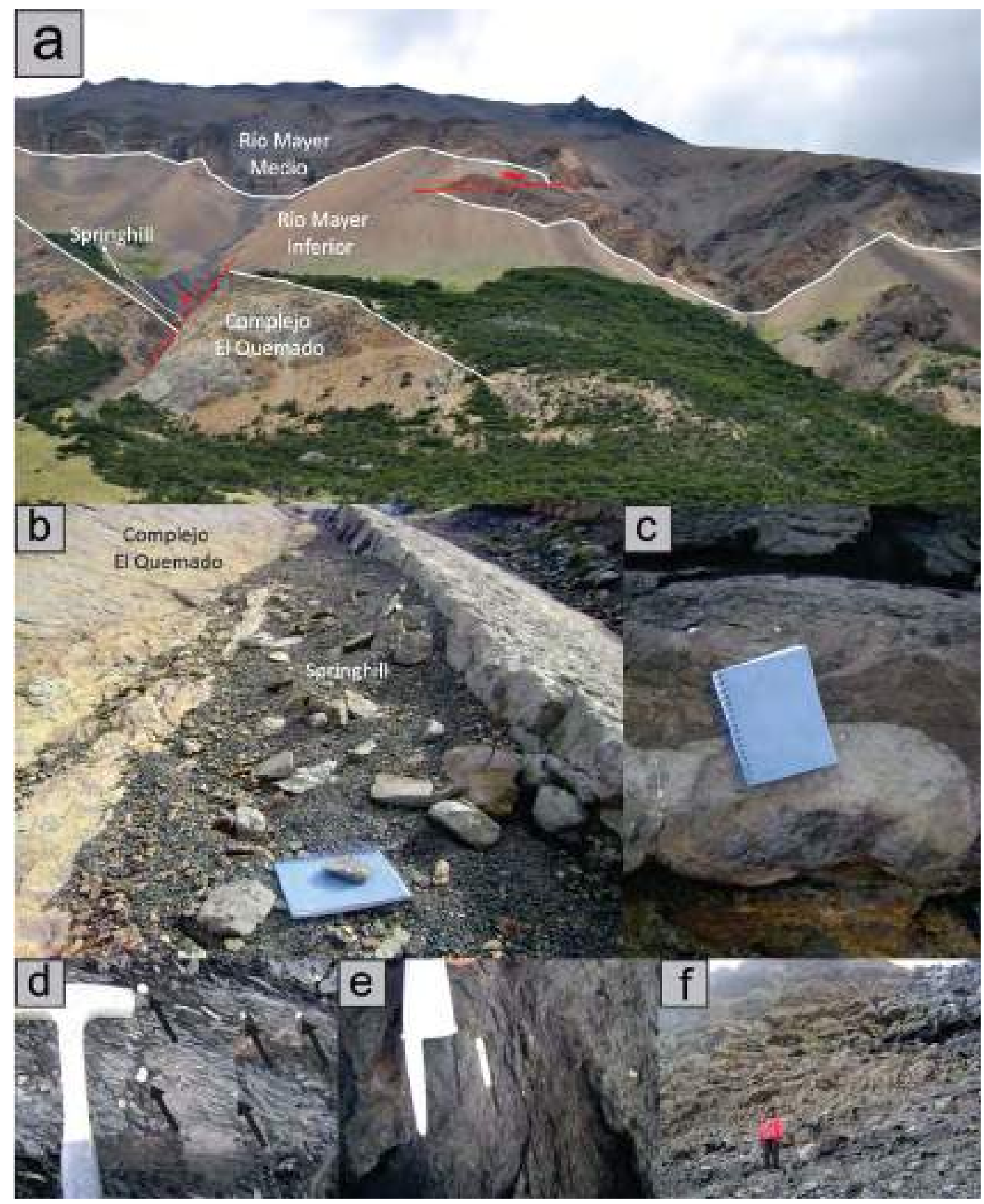

Figura 4.13: a) Vista general del Complejo El Quemado, Formación Springhill y sectores inferior y medio de la Formación Río Mayer en el perfil Río Guanaco; b) contacto entre el Complejo El Quemado y la Formación Springhill; c) niveles de areniscas cuarzosas intercaladas con pelitas negras correspondientes a la Formación Springhill; $d$ y e) niveles de la Formación Río Mayer ricos en fauna de belemnites; f) margas de la sector medio de la Formación Río Mayer. Los límites formacionales se muestrasn con líneas blancas, mientras que las fallas se reflejaron en color rojo (tomado de Kraemer y Riccardi, 1997 y Zefrass et al., 2017) 
Perfil Cerro Hobler (ver Anexos): este perfil se desarrolla sobre la ladera sur del cerro homónimo. Representa la totalidad de la Formación Springhill y la parte inferior de la Formación Río Mayer y alcanza una potencia total de 175 m (Fig. 4.14, recuadro 2). Aunque los contactos se encuentran cubiertos, el perfil presenta dos segmentos bien diferenciados correspondientes a las dos formaciones de estudio.

La Formación Springhill está representada por dos segmentos distintos. En el sector basal se reconocen niveles de packstones y floatstones masivos con abundantes bivalvos indeterminados, belemnites e inocerámidos. Hacia el tope de la formación se presentan arenitas y vaques masivos y laminados con ocasionales fragmentos fósiles.

La Formación Río Mayer posee un potente espesor de pelitas negras laminadas y masivas con intercalaciones de margas y arenitas silicoclásticas dispuestas en bancos de entre 10 y $60 \mathrm{~cm}$ de espesor.

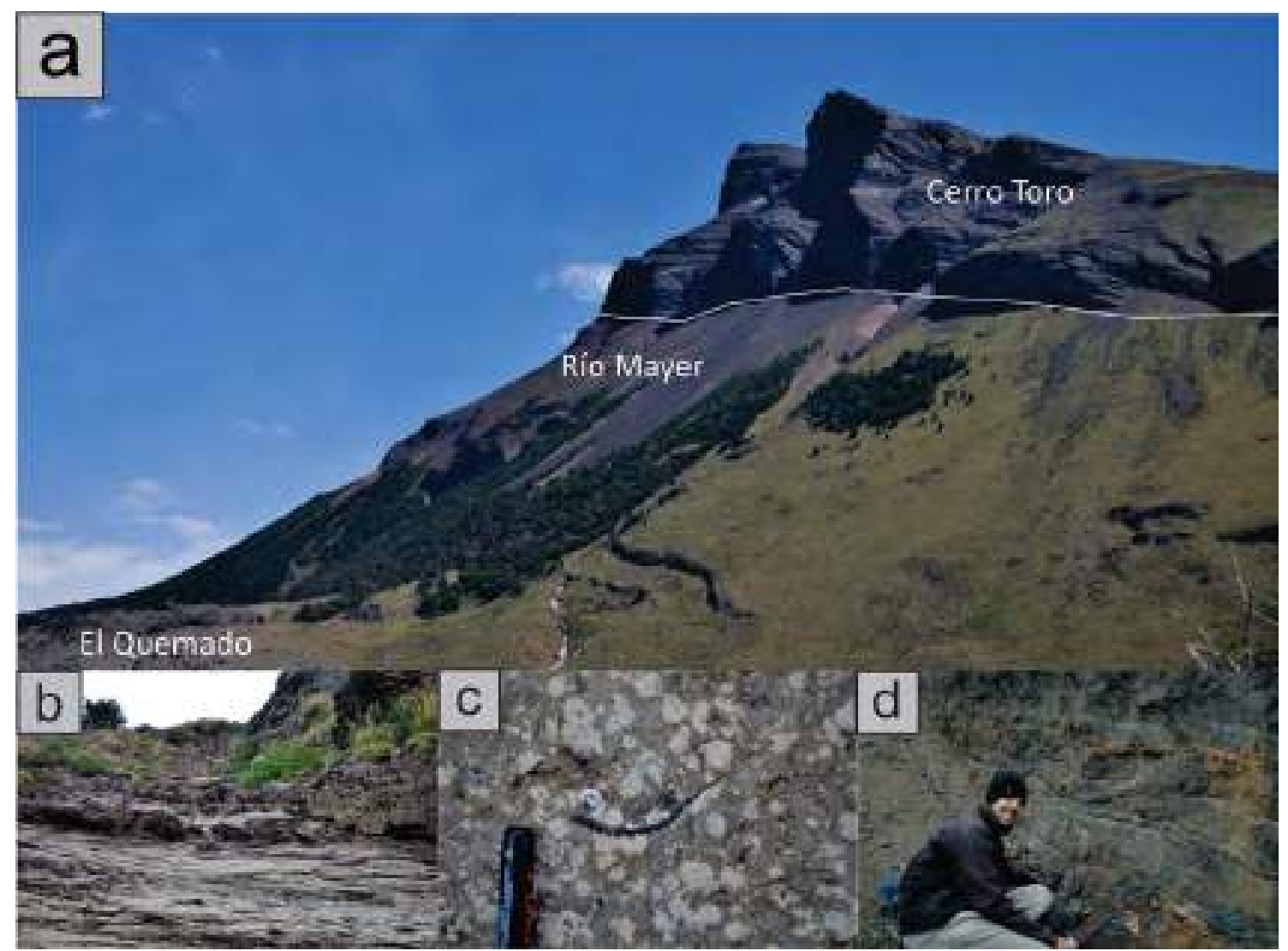

Figura 4.14: a) Vista general del Complejo El Quemado y las formaciones Río Mayer y Cerro Toro en el perfil del Cerro Hobler; b) vista general de niveles de la Formación Springhill; c) detalles de un floatstone de la Formación Springhill donde se observan belemnites e inocerámidos; d) niveles pelíticos de la Formación Río Mayer. 


\section{Capítulo V- Análisis de facies y sistemas de depositación}

\subsection{Introducción}

El análisis de facies constituye una herramienta fundamental para el entendimiento de los procesos sedimentarios y paleoambientes de acumulación (Schwarz, 2003). Para realizar un correcto estudio de las sucesiones sedimentarias y arribar a confiables interpretaciones, es necesario en primer lugar realizar una descripción detallada nivel por nivel de los cuerpos rocosos y describir perfiles sedimentarios (ver capítulo 4 y anexo).

Posteriormente se procede a la descripción facial. El término facies fue introducido formalmente por Gressly (1838) para denominar a la suma total de los aspectos litológicos y paleontológicos de una unidad estratigráfica. Existen numerosos tipos de "facies" según sea la disciplina y el objetivo del estudio. En este trabajo de tesis se definieron "facies sedimentarias observacionales", es decir, basadas en criterios descriptivos y objetivos (Spalletti, 1980). Entre los cuantiosos aspectos reconocibles en los cuerpos de rocas sedimentarias, se han elegido para este análisis los litológicos, definiendo de esta manera "litofacies".

En la continuidad del estudio, las facies fueron interpretadas acorde al proceso sedimentario que le dio origen y agrupadas sobre la base de sus relaciones genéticas, constituyendo asociaciones de facies. Posteriormente, estas asociaciones fueron comparadas con modelos preestablecidos para poder interpretar los paleoambientes de acumulación. Por último, se realizó un breve análisis estratigráfico secuencial de las dos zonas de estudio y se esbozaron los primeros criterios de comparación entre ambas cuencas.

\subsection{Litofacies}

Como criterio para la diferenciación de litofacies se han tenido en cuenta diferentes elementos (Fig. 5.1). En primer término se distinguieron facies de origen clástico de aquellas asociaciones con escaso o nulo transporte denominadas parautóctonas y autóctonas, respectivamente. En segundo lugar se caracterizaron por su composición; dentro de las facies clásticas se reconocieron de origen volcaniclástico (depósitos de caída originados en el arco volcánico), silicoclástico (fragmentos extracuencales tales como cuarzo, feldespato o micas), carbonático (fragmentos intracuencales, principalmente bioclastos) y mixtas (con elementos calcáreos y terrígenos). En tercera instancia se tuvieron en cuenta las características texturales, principalmente la granulometría; se diferenciaron rocas psefíticas (mayoría de los clastos 
mayores a $2 \mathrm{~mm}$ ), psamíticas (entre 2 y $0,062 \mathrm{~mm}$ ) y pelíticas (menores a $0.062 \mathrm{~mm}$ ). En un cuarto nivel de análisis se distinguieron según sus estructuras sedimentarias, tanto mecánicas como orgánicas. Por último, se abordaron algunos elementos de detalle, como la composición a escala microscópica y el color.

Se definieron un total de 27 facies sedimentarias las cuales fueron identificadas mediante un código de facies (Fig. 5.1). 


\begin{tabular}{|c|c|c|c|c|c|}
\hline \multicolumn{2}{|c|}{ FACIES } & TEXTURA & ESTRUCTURA YIO CARACT. & COD. & PERFIL \\
\hline \multirow{26}{*}{$\frac{\infty}{\frac{\infty}{0}}$} & \multirow{10}{*}{ 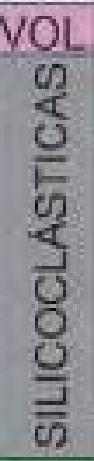 } & tobes & masiva & $\mathrm{Tm}$ & RS \\
\hline & & \multirow{2}{*}{ peliass } & 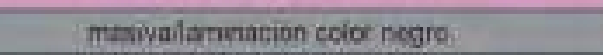 & $\operatorname{Ln}$ & 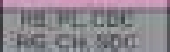 \\
\hline & & & 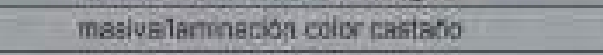 & Lc & RSPL PL \\
\hline & & \multirow{6}{*}{ aranstas } & Inxsivalen nodudos & $\mathrm{Am}$ & FG, $C H, S D C$ \\
\hline & & & masfos camocsidion galuconiticz: & Amg & 500 \\
\hline & & & Estathicarión hatizental & Al & or 500 \\
\hline & & & estrotifcadibn enrecruzada fangendis & Aet & $S D=$ \\
\hline & & & eatratificacionn entrecruzede en arlese & Aea & 800 \\
\hline & & & con Oodules & Ao & 900 \\
\hline & & satuitas & masivalen noduces & $\mathrm{Sm}$ & 900 \\
\hline & \multirow{6}{*}{$\frac{\frac{\infty}{\alpha}}{\frac{x}{2}}$} & mingers & musine & $\mathrm{Mm}$ & माम \\
\hline & & nexorditicais & 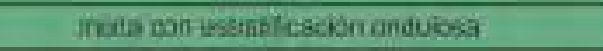 & $\mathrm{Hm}$ & PES $\operatorname{COC}$ \\
\hline & & \multirow{4}{*}{ areniscess } & mixst con fargen miquition. & Amfm & ASI PI \\
\hline & & & mixta con tangp sicoctasbec masivo & Amsm & or \\
\hline & & & 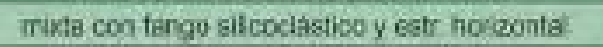 & Amsh & $\mathrm{CH}$ \\
\hline & & & mxta con fango silicodilssec y anditas & Amso & $S D C$ \\
\hline & \multirow{10}{*}{ 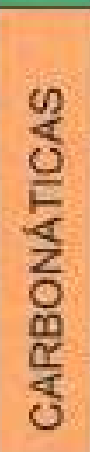 } & \multirow{3}{*}{ wathesticres } & masiva & Wm & F5, Pl, CDC \\
\hline & & & faminacion & WI & FS PL \\
\hline & & & bicurbacikn intensa & Wb & Fi5 \\
\hline & & \multirow{4}{*}{ paccistores } & masiva & $\mathrm{Pm}$ & RSBPL,CDC \\
\hline & & & Eminacion & $\mathrm{P}$ & PESPL \\
\hline & & & bioturtoakon intersa & $\mathrm{Pb}$ & RES \\
\hline & & & estructuras moentioulares & Po & RG, PL CDC \\
\hline & & flaststones: & masiva & $\mathrm{Fm}$ & RES PLCOC \\
\hline & & \multirow{2}{*}{ rudstones } & masiva & $\mathrm{Rm}$ & FS. PL, COC \\
\hline & & & can ondzas & Ro & $\mathrm{PL}$ \\
\hline N.C & & bindstores: & mascke & $\mathrm{Bm}$ & ASS PL CDC \\
\hline
\end{tabular}

Figura 5.1. Facies reconocidas en las áreas de estudio sobre la base de sus características texturales, estructurales y de composición. N.C.= no clásticas, COD. = código de facies, VOL.= volcaniclásticas, $\mathrm{RS}=$ Río Salado, $\mathrm{PL}=$ Puesto Loncoche, $\mathrm{CDC}=$ Cuesta del Chihuido, $\mathrm{SDC}=$ Subida del Chancho, RG= Río Guanaco y $\mathrm{CH}=$ Cerro Hobler. 


\subsubsection{Facies silicoclásticas}

\subsubsection{Pelitas negras (Ln)}

Se compone por fangolitas y limolitas de color negro generalmente masivas (Fig. 5.2a) $y$ en ocasiones finamente laminadas (Fig. 5.2b). Estas sedimentitas están dispuestas en paquetes de geometrías tabulares. El espesor de los niveles resulta variable entre 20 y $300 \mathrm{~cm}$ y extraordinariamente hasta 8 metros en el perfil Río Guanaco. Presentan contactos netos, planos o irregulares.

Poseen un alto contenido de materia orgánica y se identifican escasos fósiles, generalmente bien preservados, de serpúlidos, belemnites (fauna de Belemnopsis sp.), bivalvos e impresiones de amonites. No se registra bioturbación.

Esta facies conforma la tipología más habitual de la Formación Río Mayer, intercala con margas masivas y carbonatos de granulometrías finas en el sector basal de la Formación Vaca Muerta y se encuentra ocasionalmente en las formaciones Chachao y Springhill. Es posible diferenciar la facies "Ln" en los perfiles Río Salado y Puesto Loncoche en la Cuenca Neuquina y en todos los perfiles relevados en la Cuenca Austral.

Interpretación: la textura de esta facies y la preservación de la materia orgánica, en conjunto con la laminación y la escasa presencia tanto de material fosilífero como icnológico, permite inferir que se trata de sedimentos depositados por decantación en un ambiente anóxico (Crame, 1991).

\subsubsection{Pelitas castañas (LC)}

Está constituida por fangolitas y limolitas de color castaño a gris, masivas, con fisilidad o laminadas (Fig. 5.2c). Constituyen niveles de geometrías tabulares y eventualmente con un ligero acuñamiento en una dirección, cuyo espesor varía entre 20 y $220 \mathrm{~cm}$. Presentan contactos netos, planos o irregulares.

Incluyen escasos fósiles generalmente bien preservados de serpúlidos, bivalvos, gasterópodos e impresiones de amonites. No se registra bioturbación.

Esta facies se encuentra muy difundida en la Formación Vaca Muerta, e intercalada con carbonatos de granulometrías gruesas en la Formación Chachao. Es posible diferenciar la facies "Lc" en todos los perfiles relevados en la Cuenca Neuquina.

Interpretación: con igual criterio que la facies de "lutitas negras", se permite inferir que se trata de sedimentos depositados por decantación. La disminución en las cantidades de 
materia orgánica y la coloración más clara sugiere que las aguas serían subóxicas a disóxicas (Sagasti, 2001b; Kietzmann et al., 2008).

\subsubsection{Areniscas masivas (Am)}

Se compone de vaques $y$ areniscas desde finas a muy gruesas de composiciones cuarzosas y líticas (ver capítulo 6) dispuestas en estratos con espesores entre 10 y $180 \mathrm{~cm}$ (Fig. 5.2d). En general poseen geometría tabular pero excepcionalmente pueden disponerse en niveles nodulares (Fig. 5.2e) como en el perfil Río Guanaco de la Formación Springhill. Sus contactos son netos y en general planos.

Poseen escaso material fósil representado principalmente por belemnites, aunque también se reconocen restos de bivalvos muy fragmentados y briznas vegetales. El nivel de bioturbación es muy variable, desde niveles sin bioturbación (Río Guanaco) hasta intensamente bioturbados (Subida del Chancho). Richiano et al. (2016) reconocieron los icnogéneros de Ophiomorpha isp., Skolithos isp., Arenicolites isp., Rosselia isp. y Cylindrichnus isp. en la Subida del Chancho.

Esta facies se reconoció sólo en la Cuenca Austral, donde representa a un importante porcentaje de la litología de la Formación Springhill y constituye niveles aislados de granulometrías finas a medianas en la Formación Río Mayer.

Interpretación: esta facies es interpretada como depósitos generados a partir de la desaceleración de flujos gravitatorios subácueos hiperconcentrados (Miall, 1978; Collinson et al., 2006), por lo que se interpretan como de origen primario.

\subsubsection{Areniscas masivas glauconíticas (Amg)}

En esta facies se reconocen vaques y areniscas desde finas a medianas de composición glauconítica. Se agrupan en niveles de geometría tabular o nodulares de un espesor de entre 50 y $115 \mathrm{~cm}$ con contactos netos y planos (Fig. 5.2f).

Su contenido fósil consiste en bivalvos no identificados con un buen estado de preservación (baja fragmentación) y belemnites de la fauna de Belemnopsis sp. Los depósitos se encuentran escasamente bioturbados.

La facies "Amg" se reconoció únicamente en el tope de la Formación Springhill en el perfil de la Subida del Chancho.

Interpretación: se infiere que esta facies fue generada por la pérdida de capacidad de transporte de un flujo subácueo de alta densidad. La glauconita es un producto de 
cristalización temprana en el medio marino con aguas relativamente agitadas, de escasa a moderada profundidad y salinidad normal (Cloud, 1955; Pettijohn, 1957; Odin y Matter, 1981). Según Spalletti et al. (2005), la geometría nodular puede estar relacionada con intervalos estratigráficos condensados o con superficies transgresivas.

\subsubsection{Areniscas con estratificación horizontal (Al)}

Estas facies está formada por vaques y areniscas finas a medianas de composición cuarzosa a lítica (ver capítulo 6) con estratificación horizontal (Fig. 5.2g). Los cuerpos se disponen en niveles tabulares de entre 35 y $100 \mathrm{~cm}$ de espesor y sus contactos son netos y planos tanto en la base como en el techo.

No se registra contenido fosilífero ni icnológico. Esta facies se concentra en la Formación Springhill en los perfiles Cerro Hobler y Subida del Chancho.

Interpretación: se la interpreta como depósitos generados bajo condiciones de alto régimen de flujo (Fielding, 2006). Se infiere un flujo subácueo poco profundo, no canalizado, que transporta sedimentos por tracción (Collinson et al., 2006).

\subsubsection{Areniscas con estratificación entrecruzada tangencial (Aet)}

Esta facies está compuesta por vaques y areniscas desde muy finas a areniscas conglomerádicas de composición cuarzosa a lítica (ver capítulo 6) con estratificación entrecruzada tangencial (Fig. 5.2h). Se presenta en estratos agrupados de geometrías tabulares que van desde 35 a $70 \mathrm{~cm}$. Poseen tendencias generales granodecrecientes; mientras las bases son netas y levemente erosivas, los techos suelen ser transicionales y planos.

Entre el contenido fosilífero sólo se registran briznas vegetales y a nivel microscópico algunos fragmentos bioclásticos no identificados. No se observa bioturbación en estos niveles.

La facies "Aet" se encuentra restringida al sector basal de la Formación Springhill en el perfil Subida del Chancho.

Interpretación: se interpretan como depósitos de dunas bidimensionales arenosas a areno-gravosas generadas por flujos tractivos en ambientes subácueos (Schwarz, 2003). La variación en la granulometría de los depósitos se encuentra asociada a la profundidad y la velocidad del agente de transporte (Southard y Boguchwal, 1990). 


\subsubsection{Areniscas con estratificación entrecruzada en artesa (Aea)}

Está formada por vaques y areniscas desde muy finas a areniscas conglomerádicas de composición cuarzosa a lítica (ver capítulo 6) con estratificación entrecruzada en artesa. Se caracteriza por estratos agrupados de geometrías tabulares o lenticulares con espesores que van desde 35 a $50 \mathrm{~cm}$. Poseen tendencias generales granodecrecientes, y mientras las bases son netas y levemente erosivas los techos suelen ser transicionales y planos.

Tanto el contenido faunístico e icnológico como la ubicación en los perfiles es el mismo que el de la facies "Aet", ya que ambas facies se encuentran íntimamente relacionadas.

Interpretación: esta facies se atribuye a la migración de megaóndulas tridimensionales arenosas a areno- gravosas depositadas por flujos tractivos en ambientes subácueos (Spalletti, 1994; Schwarz, 2003). La variación en la granulometría de los depósitos se encuentra asociada a la profundidad y la velocidad del agente de transporte (Southard y Boguchwal, 1990).

\subsubsection{Areniscas con óndulas (Ao)}

Son vaques y areniscas medianas con óndulas levemente asimétricas tridimensionales en su tope. Esta facies se encuentra coexistiendo con las facies "Aet" y "Aea" con las que comparte sus características texturales, contenido faunístico e icnológico y posición en los perfiles.

Interpretación: esta facies representa la acumulación durante la migración de óndulas 3D debido a corrientes ácueas combinadas en un bajo régimen de flujo (Bridge y Demico, 2008; Collinson et al., 2006; Olivo, 2016).

\subsubsection{Sábulitas masivas $(\mathrm{Sm})$}

Esta facies está representada por sabulitas masivas de composición lítico- cuarzosa (ver capítulo 6) que conforman un estrato tabular de $22 \mathrm{~cm}$ con base erosiva y neta y techo neto y plano (Fig. 5.3a). No se registra contenido faunístico ni icnológico. Se encuentra asociado a facies de "Am", "Aet”, "Aea” y “Ao" en la Formación Springhill en el perfil Subida del Chancho.

Interpretación: se interpreta como la pérdida de capacidad de transporte de un flujo subácueo de baja fluidez y alta descarga. Su origen estaría relacionado con el de la facies "Am" siendo esta granulometría la más habitual en los depósitos. 


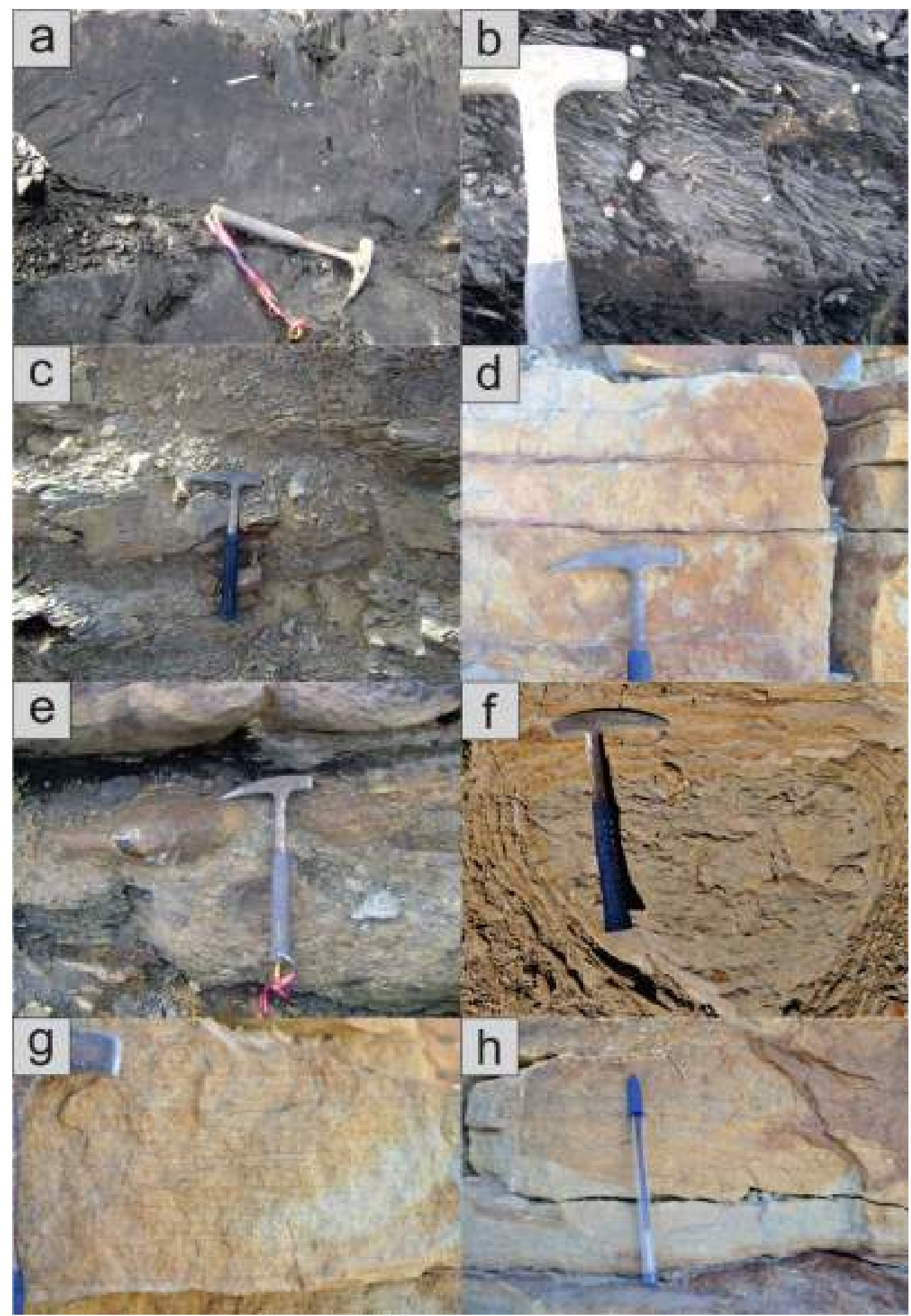

Figura 5.2. Facies sedimentarias silicoclásticas. a y b) facies de pelitas negras masivas y laminadas; c) facies de pelitas castañas; d y e) facies de areniscas masivas tabulares y en nódulos; f) facies de areniscas masivas glauconíticas; g) facies de areniscas con estratificación horizontal; h) facies de areniscas con estratificación entrecruzada tangencial. 


\subsubsection{Facies mixtas}

\subsubsection{Margas masivas (Mm)}

Se trata de fangolitas y limolitas de coloración castaña a amarillenta, que poseen una débil reacción carbonática. Estas sedimentitas constituyen niveles endurecidos que pueden presentarse en paquetes de geometría tabular (Fig. 5.3b) o bien nodulares (Fig. 5.3c) como se observa en el sector basal de la Formación Vaca Muerta en el perfil Río Salado. Su espesor oscila entre los 10 y $50 \mathrm{~cm}$ y excepcionalmente constituye registros métricos en el sector medio de la Formación Río Mayer. Sus contactos son netos y planos.

Estos niveles son en general poco bioturbados, y poseen un escaso material fosilífero constituido principalmente por bivalvos, serpúlidos y gasterópodos. En la Cuenca Austral concentran la mayor abundancia y diversidad de icnogéneros (Richiano, 2012), y es habitual la presencia de belemnites.

La facies de "margas masivas" se puede distinguir en la Formación Vaca Muerta alternando con facies clásticas y calcáreas en todos los perfiles de la Cuenca Neuquina, así como en la Formación Chachao en el perfil Río Salado. En la Cuenca Austral se puede encontrar en niveles discretos intercalando con pelitas negras en el sector inferior de la Formación Río Mayer y como constituyente esencial del sector medio de la misma formación en los perfiles Río Guanaco y Cerro Hobler.

Interpretación: la acumulación de facies de margas masivas sería a partir de la decantación de material fino tanto calcáreo como silicoclástico. La coloración y su contenido fosilífero indica condiciones óxicas a subóxicas. La generación de niveles nodulares está relacionada con procesos de redistribución del carbonato en estadios diagenéticos tempranos (Ricken y Eder, 1991).

\subsubsection{Heterolíticas mixtas con estratificación ondulosa $(\mathrm{Hm})$}

Está facies consiste en pelitas negras a castañas mixtas que intercalan con areniscas finas de color amarillento con laminación entrecruzada difusa (Fig. 5.3d) (Reineck y Wunderlich, 1968). Se encuentra en paquetes poco potentes de entre 10 y $60 \mathrm{~cm}$, y tanto su base como su techo son en todos los casos netos y planos. Los depósitos muestran leve reacción carbonática. En ellos se identificó una microfauna compuesta por foraminíferos (principalmente Epistomínidos) y radiolarios (ver capítulo 6). 
Esta facies se ha reconocido alternando con facies clásticas, mixtas y calcáreas de granulometrías finas en la Formación Vaca Muerta en los perfiles Río Salado y Cuesta del Chihuido.

Interpretación: se infiere como la alternancia de cuerpos psamíticos con óndulas 3D producto de flujos unidireccionales de bajo régimen de flujo con material fino, tanto calcáreo como clástico, depositado por decantación (Tessier et al., 1995; Spalletti et al., 2000).

\subsubsection{Areniscas mixtas con fango micrítico (Amfm)}

Esta facies se encuentra formada por equivalentes proporciones de tres componentes: bioclastos, componentes terrígenos (ambos de granulometría psamítica) y fango calcáreo (Fig. 5.3e) (Álvarez- Trenttini y Schwarz, 2016) (ver capítulo 6). Se dispone en niveles masivos muy poco potentes, de entre 2 y $30 \mathrm{~cm}$ de espesor; sus contactos son netos y planos y la geometría tabular.

El contenido fosilífero está dado por fragmentos de bivalvos (pectínidos y lucínidos), serpúlidos, ostreidos (Aetostreon sp.) y moldes de amonites, además de una microfauna compuesta por foraminíferos, radiolarios y calciesferas. Se encuentran intensamente bioturbados y se pueden reconocer los icnogéneros Thalassinoides, Phycodes, Gordia, Paleophycus.

Esta facies se localiza en la Formación Vaca Muerta en los perfiles Río Salado y Puesto Loncoche.

Interpretación: la formación de esta facies está relacionada con la intercalación entre estadios de baja energía, donde la depositación se da por decantación de material fino calcáreo, y estadios tractivos de material bioclástico alóctono y clástico transportado durante tormentas (Schwarz, 2003). Los icnogéneros encontrados sugieren una icnofacies Cruziana y condiciones de buena oxigenación (Kietzmann et al., 2008).

\subsubsection{Areniscas mixtas con fango silicoclástico masivas (Amsm)}

Son areniscas medianas hasta muy gruesas, masivas, compuestas por mayor proporción de fragmentos bioclásticos que silicoclásticos (Álvarez- Trenttini y Schwarz, 2016). Constituyen estratos tabulares de entre $70 \mathrm{~cm}$ y $1 \mathrm{~m}$ de espesor, con contactos netos y planos (Fig. 5.3f). 
Su contenido fosilífero está representado por belemnites, inocerámidos y bivalvos con un alto grado de fragmentación. A nivel microscópico se observan numerosos fragmentos de algas dasycladáceas (ver capítulo 6).

Esta facies constituye, junto con la facies que se describirá a continuación ("Amseh"), el sector basal de la Formación Springhill en el perfil Cerro Hobler.

Interpretación: se interpreta como depósitos de flujos tractivos de alta densidad con pérdida de su capacidad de transporte. Los restos fragmentados de algas dasycladaceas indican que se trataría de un ambiente marino somero, de buena oxigenación y aguas cálidas (Vaamonde y Poiré, 2006).

\subsubsection{Areniscas mixtas con fango silicoclástico y estratificación horizontal (Amseh)}

Se caracteriza por areniscas muy gruesas compuestas por mayor proporción de individuos bioclásticos que silicoclásticos (Fig. 5.3g). Los depósitos se presentan en estratos tabulares de entre 80 y $150 \mathrm{~cm}$ de espesor con límites netos y planos. Su contenido fosilífero y ubicación en los perfiles es el mismo que "Amsn".

Interpretación: se infiere un flujo supercrítico subácueo no canalizado que transporta sedimentos por tracción generando formas de lecho de capa plana. Las condiciones ambientales interpretadas para "Amsn" son también válidas para "Amseh" ya que comparten la misma asociación fosilífera.

\subsubsection{Areniscas mixtas con fango silicoclástico y óndulas (Amso)}

Esta facies está compuesta por areniscas muy finas a medianas con óndulas levemente asimétricas en el tope (Fig. 5.3h). Se encuentran agrupadas en niveles de entre 50 y $100 \mathrm{~cm}$ de potencia con límites netos y planos.

Presenta belemnites (fauna de Belemnopsis) y bivalvos no identificados, mientras que no se identifican bioturbaciones. Se localiza en el sector cuspidal de la Formación Springhill en el perfil de la Subida del Chancho.

Interpretación: esta facies representa la acumulación de componentes terrígenos y bioclásticos durante la migración de óndulas 3D debido a corrientes ácueas combinadas en bajo régimen de flujo (Bridge y Demico, 2008; Collinson et al., 2006; Olivo, 2016). 


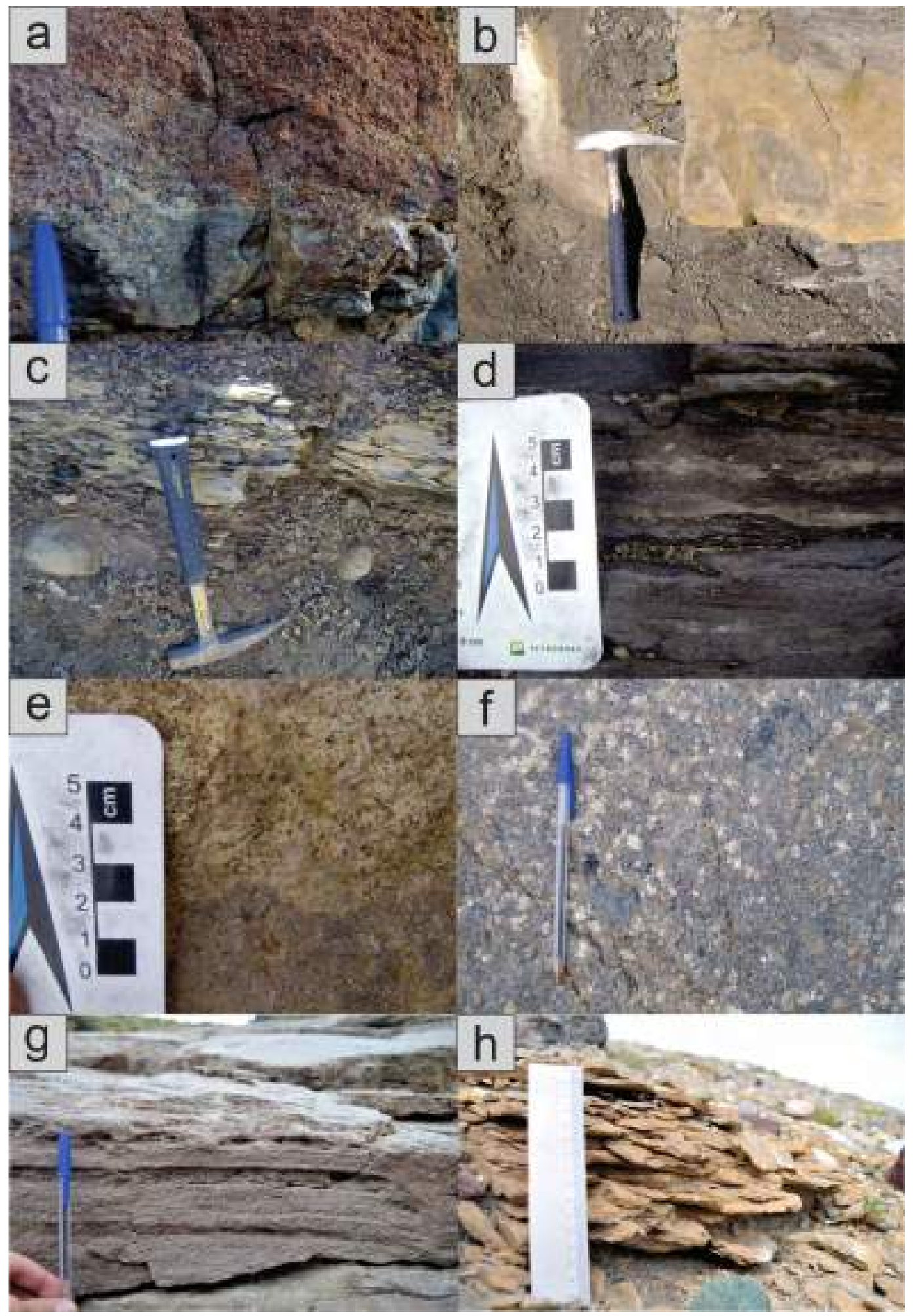

Figura 5.3. Facies sedimentarias mixtas. a) facies de sabulitas masivas; b y c) facies de margas masivas tabulares y en nódulos; d) facies heterolítica con estratificación ondulosa; e) facies de areniscas mixtas con fango micrítico; f) facies de areniscas mixtas con fango silicoclástico masivas; g) facies de areniscas mixtas con fango silicoclástico y estratificación horizontal; g) facies de areniscas mixtas con fango silicoclástico y óndulas. 


\subsubsection{Facies carbonáticas}

\subsubsection{Wackestones masivos $(\mathrm{Wm})$}

Son wackestones castaños a grises con una amplia diversidad fosilífera (Fig. 5.4a). Se encuentran dispuestos en paquetes de geometría tabular de entre 5 y $53 \mathrm{~cm}$. Los techos son en ocasiones netos y en otras transicionales a facies de packstones principalmente y en menor medida a facies de wackestones laminados y wackestones bioturbados; en todos los casos el contacto entre paquetes es plano.

A mesoescala se observan bivalvos lucínidos, pectínidos (Posidonotis principalmente) e indeterminados, también se registran moldes de amonites, gasterópodos y serpúlidos bien preservados y fragmentos de ostras del género Ceratostreon sp. A nivel microscópico se observan foraminíferos (Epistomina sp.), ostrácodos, calciesferas y radiolarios (ver capítulo 6). El material bioclástico presenta grados de preservación y fragmentación muy variables; en ocasiones los fragmentos se encuentran muy dispersos, mientras que por sectores forman empaquetamientos densos. Muchos de los niveles están bioturbados en el tope; se reconocen los icnogéneros de Phycodes, Arenicolites, Planolites, Chondrites y Thalassinoides de distintos diámetros.

Esta facies se encuentra en la Formación Vaca Muerta, sobre todo en los niveles basales, y en la Formación Chachao en todos los perfiles de la Cuenca Neuquina.

Interpretación: la microfauna presente, junto con las características texturales sugieren condiciones tranquilas de sedimentación por decantación en aguas profundas (Sagasti y Ballent, 2002; Kietzmann et al., 2008). La asociación de trazas puede asignarse a la icnofacies Cruziana lo cual respalda las condiciones de baja energía del agente.

\subsubsection{Wackestones laminados (WI)}

Esta facies está compuesta por wackestones laminados grises a castaños con una amplia diversidad fosilífera. Se presentan como paquetes de geometría tabular con un espesor de 15 a $40 \mathrm{~cm}$ (Fig. 5.4b). Sus techos son en algunas ocasiones netos y en otras transicionales hacia facies de margas masivas, mientras que en todos los casos el contacto es plano.

Las observaciones sobre la diversidad composicional a meso y microescala de las facies de wackestones masivos también son válidas para las facies de wackestones laminados, a excepción de la presencia de belemnites bien preservados en niveles aislados. No se observa bioturbación, salvo algunos Thalasssinoides de diámetro reducido. 
Esta facies se encuentra en la Formación Vaca Muerta en los perfiles Río Salado y Puesto Loncoche.

Interpretación: al igual que la facies "Wm", es posible interpretar estos niveles como producto de la sedimentación por decantación en aguas profundas. La presencia de laminaciones podría inferir condiciones menos energéticas que en el caso anterior, mientras que la escasez de bioturbación estaría vinculada a un déficit en el contenido de oxígeno, lo que generaría condiciones menos favorables para la actividad orgánica.

\subsubsection{Wackestones bioturbados $(\mathrm{Wb})$}

Son wackestones castaños de aspecto craquelado que se agrupan en niveles muy poco espesos de entre 4 y $20 \mathrm{~cm}$ de geometría tabular, con contactos netos y planos.

Poseen la misma diversidad y abundancia fosilífera que las facies de "Wm" y "Wl" pero una bioturbación mucho más intensa que no permite distinguir la textura a escala mesoscópica y dificulta la identificación de las estructuras sedimentarias orgánicas. Se reconoció el género Thalassinoides.

Esta facies fue identificada en la Formación Vaca Muerta en el Perfil Río Salado.

Interpretación: se asume el mismo origen que la facies "Wm", pero con menor aporte sedimentario y mayores niveles de oxigenación permitiendo el desarrollo de actividad biológica.

\subsubsection{Packstones masivos (Pm)}

Son packstones masivos de colores grises a castaños con una amplia diversidad fosilífera (Fig. 5.4d). Se encuentran dispuestos en paquetes de geometría tabular de entre 15 y $80 \mathrm{~cm}$. Sus techos son en general netos y en algunos casos transicionales hacia facies de wackestones y floatstones masivos; en todos los casos los límites son planos.

A mesoescala se observan, en tamaños que no superan los $2 \mathrm{~mm}$, bivalvos pectínidos y lucínidos, serpúlidos, foraminíferos y gasterópodos. También se reconocen ostras, exogiras y belemnites de mayores dimensiones. Los amonites se ven recristalizados y enteros, en fragmentos y como moldes de tamaño superior a los $10 \mathrm{~cm}$ en los techos de los cuerpos. A nivel microscópico se pueden distinguir calciesferas, serpúlidos, gasterópodos y foraminíferos del género Epistomina sp., también fragmentos de braquiópodos, bivalvos indeterminados y ostreidos. Hacia niveles cuspidales se reconocieron poríferos. 
El material bioclástico presenta grados de preservación y fragmentación muy variables; las valvas de los bivalvos pueden encontrarse desde separadas y desorientadas hasta orientadas con su sector cóncavo hacia arriba, en ocasiones los fragmentos se encuentran muy dispersos mientras que por sectores forman empaquetamientos densos. Es habitual en el techo de los paquetes la presencia de Thalassinoides de distintos diámetros y abundante bioturbación. Otros icnogéneros reconocidos en esta facies son Arenicolites, Palaeophycus, Gordia, Phycodes y Chondrites.

Esta facies se encuentra en niveles de la Formación Vaca Muerta en los tres perfiles de estudio de la Cuenca Neuquina, también se localiza en la Formación Chachao en el perfil Río Salado.

Interpretación: es posible interpretar esta facies a partir de sus características tafonómicas como generada a partir de flujos subcríticos, relacionados a episodios de tormenta (Kietzmann et al., 2008). Kietzmann y Palma (2009), describen detalladamente las variaciones tafonómicas de los distintos sectores de estos niveles. Estos autores interpretan que la alta desarticulación y fragmentación está dada por episodios de depositación rápida y fricción con el sustrato durante los eventos de tormenta (Simpson, 1987; Kidwell, 1991). Por otro lado, el material que se presenta con su porción cóncava hacia arriba puede ser vinculado a la redepositación por suspensión a partir de corrientes de retorno de los mismos eventos (Kidwell y Bosence, 1991).

Su relación con facies de wackestones masivos y laminados y el desarrollo de la icnofacies de Cruziana hacia el techo de los paquetes, asumen a estos episodios de tormenta como eventuales dentro de un ambiente de baja energía.

\subsubsection{Packstones laminados (PI)}

Está constituida por packstones laminados de color castaño a gris, se encuentran dispuestos en paquetes de geometría tabular que no superan los $20 \mathrm{~cm}$ de espesor con límites planos y netos. La diversidad icnológica y fosilífera tanto a mesoescala como a microescala es similar a la de las facies de packstones masivos.

Son facies muy poco abundantes registradas en la Formación Vaca Muerta en los perfiles Río Salado y Puesto Loncoche.

Interpretación: se infiere un transporte por un flujo supercrítico que genera formas de lecho de capa plana, su origen también estaría relacionado a flujos de retorno durante episodios de tormenta (Myrow y Southard, 1996). 


\subsubsection{Packstones bioturbados $(\mathrm{Pb})$}

Son packstones castaños de aspecto craquelado que se agrupan en niveles muy poco espesos de entre 2 y $16 \mathrm{~cm}$, de geometría tabular, y contactos netos y planos (Fig. 5.4e).

Poseen la misma diversidad y abundancia fosilífera que las facies de "Pm" y "PI", pero una bioturbación mucho más intensa que no permite distinguir la textura a escala mesoscópica y dificulta la identificación de las estructuras sedimentarias orgánicas. Esta facies fue identificada en los niveles cuspidales de la Formación Vaca Muerta en el Perfil Río Salado.

Interpretación: se asume el mismo origen que la facies "Pm" pero con altos niveles de oxigenación y pausas en la sedimentación que permiten el desarrollo de una intensa actividad biológica.

\subsubsection{Packstones con estructuras monticulares (Po)}

Facies compuesta por packstones con montículos simétricos sin preservación de estructuras internas (Fig. 5.4f). Su coloración es de gris a castaña y posee una amplia diversidad fosilífera. Se encuentran dispuestos en paquetes de entre 10 y $23 \mathrm{~cm}$ de espesor con bases erosivas y techos netos y fuertemente irregulares. Las características composicionales tanto a micro como mesoescala son similares a la de las litofacies de packstones masivos, siendo ricas en amonites, bivalvos, ostras, exogiras y serpúlidos.

Esta facies se encuentra en niveles cuspidales de la Formación Vaca Muerta en todos los perfiles de la Cuenca Neuquina.

Interpretación: esta facies se interpreta como desarrollada a partir de flujos combinados dominados por oscilación que generan formas de lecho dómicas durante episodios de tormenta (Dumas y Arnott, 2006, Perillo et al., 2014).

\subsubsection{Floatstones masivos $(\mathrm{Fm})$}

Facies con un alto tenor de matriz y esqueleto bioclástico con individuos de hasta 10 cm de tamaño, con una amplia diversidad fosilífera, icnológica y tafonómica de colores castaños a grises. Se disponen en cuerpos tabulares de entre 13 y $120 \mathrm{~cm}$ de espesor con bases netas y erosivas y techos planos e irregulares (Fig. $5.4 \mathrm{~g}$ ).

A mesoescala se observan bivalvos lucínidos y pectínidos de valvas finas con un tamaño promedio inferior a los $2 \mathrm{~mm}$ constituyendo en muchos casos la matriz $\mathrm{y}$ eventualmente de hasta $2 \mathrm{~cm}$ de tamaño máximo formando parte del esqueleto. Se reconocen 
ostras y exogiras de hasta $10 \mathrm{~cm}$ de tamaño, muchas de ellas con un muy buen estado de preservación y en posición de vida, también belemnites y gasterópodos. Los amonites se ven recristalizados y enteros, en fragmentos y como moldes de tamaño superior a los $10 \mathrm{~cm}$ en los techos de los cuerpos. Los serpúlidos se encuentran dispersos o en asociación sobre los amonites. Al microscopio se observa una microfauna compuesta por calciesferas, foraminíferos indeterminados y foraminíferos de tipo Epistomina sp. Además se observan bivalvos ostreidos y no ostreidos, braquiópodos, gasterópodos, serpúlidos y briozoos que aumentan su tamaño y disminuyen su fragmentación de base a techo. En el sector cuspidal del perfil se reconocen equinodermos.

Muchos de los techos de los estratos se encuentran bioturbados, se reconocieron los icnogéneros Palaeophycus, Entollium, Trypanites, Ophiomorpha, Chondrites y Thalassinoides de distintos diámetros. El estado de preservación de los bioclastos es muy variable y se encuentran desde altamente fragmentados hasta articulados y en posición de vida.

Esta facies se encuentra representada en la Formación Vaca Muerta en los perfiles Puesto Loncoche y Cuesta del Chihuido y en la Formación Chachao en el perfil Río Salado.

Interpretación: Kietzmann et al. (2008) interpretan a partir de elementos tomados de esta facies y del grado de articulación, fragmentación y tipo de fábrica como depósitos tempestíticos proximales desarrollados en el sector de rampa media distal o rampa externa proximal. La presencia de la icnofacies Cruziana junto con la relación de alternancia existente con las facies de pelitas castañas confirma la eventualidad de estos procesos tempestíticos en una ambiente de energía baja.

\subsubsection{Rudstones masivos (Rm)}

Esta facies se compone por rudstones masivos, con esqueletos bioclásticos con individuos de hasta $12 \mathrm{~cm}$ de tamaño, con alta variabilidad tafonómica, fosilífera e icnológica de colores castaños a grises y con escaso contenido de matriz. Se disponen en cuerpos de geometría tabular de entre 18 y $60 \mathrm{~cm}$, con bases netas y planas o erosivas, y techos netos y planos (Fig. 5.4h).

A mesoescala se observan bivalvos pectínidos y lucínidos de valvas finas con un tamaño promedio inferior a los $2 \mathrm{~mm}$ constituyendo en muchos casos la matriz $y$ eventualmente de hasta $2 \mathrm{~cm}$ de tamaño máximo formando parte del esqueleto. Se reconocen ostras y exogiras de hasta $12 \mathrm{~cm}$ de tamaño, encontrándose desde desorientadas hasta en posición de vida, muchas de ellas con un muy buen estado de preservación y otras con abundantes perforaciones. También se registran escasos belemnites y gasterópodos bien 
preservados. Los amonites se ven recristalizados y enteros, en fragmentos y como moldes de tamaño superior a los $10 \mathrm{~cm}$ en los techos de los cuerpos. Los serpúlidos se encuentran dispersos o en asociación sobre los amonites. A nivel microscópico se reconocen bivalvos ostreidos y no ostreidos, braquiópodos y serpúlidos y hacia el techo del perfil se identificaron equinodermos.

Muchos de los techos de los estratos se encuentran bioturbados, reconociéndose Palaeophycus, Entollium, Chondrites y Thalassinoides. El tamaño de los fósiles es variable y aumenta hacia el tope de la secuencia. El material presenta diversidad de estados de preservación tafonómica.

Esta facies se encuentra representada en la Formación Vaca Muerta en los perfiles Puesto Loncoche y Cuesta del Chihuido y en la Formación Chachao en el perfil Río Salado.

Interpretación: al igual que "Fm", esta facies se asigna a depósitos tempestíticos distales sobre la base del grado de articulación y fragmentación de sus componentes. Se observa mayor grado de articulación, incrustación y bioerosión de las ostras por lo que se asumen mayores periodos de exposición en la interfase agua- sedimento. La presencia de la icnofacies Cruziana permite interpretar la eventualidad del proceso formador de la facies "Rm", tal como se explicó anteriormente para la facies "Fm".

\subsubsection{Rudstones con estructuras monticulares (Fo)}

Está formada por facies de rudstones, de características similares a "Rm", con montículos simétricos sin preservación de estructuras internas. Posee coloraciones castañas a grises y se dispone en cuerpos de geometría tabular de entre 19 y $23 \mathrm{~cm}$ de espesor con bases erosivas y techos netos y fuertemente irregulares. Sus asociaciones faunísticas e icnológicas tanto meso como microscópicas son las mismas que la de las facies de rudstones masivos. Desde el punto de vista tafonómico aumentan los niveles de fragmentación y disminuyen los de articulación generando empaquetamientos densos.

La facies "Ro" se identificó en niveles de la Formación Vaca Muerta en el perfil Puesto Loncoche.

Interpretación: como se mencionó anteriormente en Pm, esta facies puede ser interpretada como desarrollada a partir de flujos combinados dominados por oscilación que generan formas de lecho dómicas durante episodios de tormenta (Dumas y Arnott, 2006, Perillo et al., 2014). 


\subsubsection{Facies no clásticas}

\subsubsection{Bindstone (B)}

Esta facies está conformada principalmente por ostras formando acumulaciones bioclásticas de entre 30 y $450 \mathrm{~cm}$ de espesor, con arreglos verticales y amalgamación lateral (Fig. 5.4i). Dentro de los bancos se registran signos de un leve retrabajamiento de los bindstones de ostras originales, por lo que pueden caracterizarse como autoparabiostromas de acuerdo a Kershaw (1994).

Desde el punto de vista composicional se observaron ostras del género Aetostreon sp. y Ceratostreon sp., serpúlidos (principalmente Parsimonia sp.), pelecípodos (Eryphila sp., Ptychomya sp., Pecten sp., Pinna sp., Trigonia sp., Cucullaea sp.) y escasos amonites (Olcostephanus). Palma y Lanés (2001) realizaron un análisis tafofacial de estos cuerpos carbonáticos describiendo los patrones de acumulación en dos tramos, uno inferior con bajo grado de retrabajamiento de los bancos de ostras y otro superior con progresivo aumento en la intensidad de desarticulación, bioerosión y fragmentación de los restos, acompañado por incremento en el tenor de matriz.

La facies de bindstone constituye la totalidad de la Formación Chachao en los perfiles de Puesto Loncoche y Cuesta del Chihuido.

Interpretación: se trata de bioconstrucciones desarrolladas en plataforma media proximal con un bajo grado de retrabajo. De la alta variabilidad faunística descripta anteriormente, se interpreta que los organismos epifaunales serían los fijadores de estos montículos, mientras que la culminación del desarrollo de los mismos estaría dada por la acción de los pelecípodos infaunales (Legarreta y Kozlowski, 1981).

\subsubsection{Facies Volcaniclásticas}

\subsubsection{Tobas masivas (Tm)}

Consiste en delgados niveles de coloración castaña, generalmente alterados a arcillas. Estos estratos rara vez superan los $3 \mathrm{~cm}$ y sus límites son difíciles de distinguir debido a la intensa meteorización. Intercalan con pelitas negras en niveles basales de la Formación Vaca Muerta en el perfil Río Salado. 
Interpretación: se interpretan como niveles piroclásticos de caída que fueron depositados en una ambiente de baja energía con condiciones anóxicas a subóxicas (asociación con pelitas negras). 


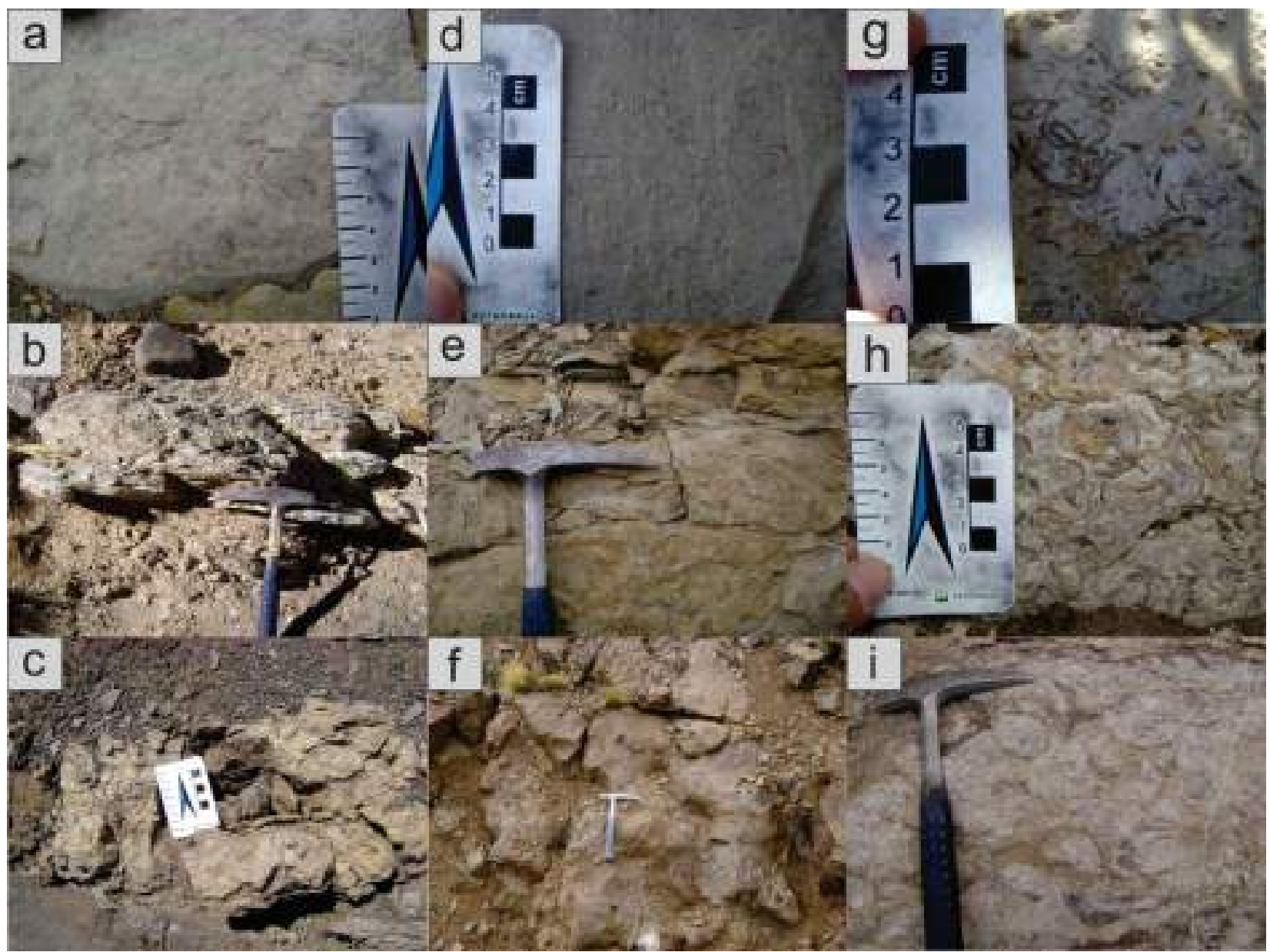

Figura 5.4. Facies sedimentarias carbonáticas y no clásticas. a) Facies de wackestones masivos; b) facies de wackestones laminados; c) facies de wackestones bioturbados; d) facies de packstones masivos; e) facies de packstones bioturbados; f) facies de packstones con estructuras monticulares; g) facies de floatstones masivos; h) facies de rudstones masivos; i) facies de bindstones. 


\subsection{Asociaciones de facies}

\subsubsection{Asociaciones de facies en la Cuenca Neuquina}

\subsubsection{Asociación de facies de cuenca}

Esta asociación esta integrada por las facies de pelitas negras y wackestones, margas (tabulares y nodulares) y tobas masivas. Se relacionan en arreglos de carácter rítmico sin tendencias verticales definidas y las relaciones entre estratos estan dadas por límites netos y planos.

La fauna de esta asociación es mayoritariamente planctónica, compuesta por foraminíferos (principalmente Epistomina Sp.), radiolarios calcitizados, ostrácodos, calciesferas y restos muy fragmentados de bivalvos pectínidos. También se observan escasos serpúlidos y gasterópodos y moldes de amonites. El nivel de bioturbación es escaso y sólo se reconocen algunos icnogéneros como Chondrites y Thalassinoides.

Constituye esencialmente el sector basal de la Formación Vaca Muerta en los perfiles Río Salado y Puesto Loncoche.

Las facies de cuenca son interpretadas como originadas en un ambiente marino anóxico a subóxico de baja energía en donde predominan los procesos de decantación. La disponibilidad de carbonato es variable por lo que se generan facies que van desde fangolitas, hasta margas e incluso mudstones. Las facies de wackestones masivos son interpretadas como material bioclástico muy fragmentado que es trabajado durante las tormentas y trasladado posteriormente como plumas hemipelágicas que se depositan por decantación interrumpiendo la sedimentación de material fino (Kietzmann et al., 2008). Las tobas masivas representan eventos de intensa actividad del arco volcánico en el que se generan fenómenos piroclásticos de caída que depositan cenizas que son incorporadas al registro sedimentario por decantación en el ambiente marino.

\subsubsection{Asociación de facies de rampa externa distal}

Constituida principalmente por facies de lutitas castañas, margas masivas y wackestones masivos, laminados y bioturbados. Posee un carácter rítmico muy similar al de las facies de cuenca pero con paquetes de pelitas negras menos espesos, no se observan tendencias verticales generales y los límites entre estratos suelen ser planos y netos. 
La asociación faunística e icnológica es la misma que para las facies de cuenca, pero se observa mayor cantidad de fragmentos de valvas de pectínidos y lucínidos. Es posible reconocer esta asociación en la Formación Vaca Muerta en todos los perfiles de la Cuenca Neuquina.

Se interpreta un ambiente marino de baja energía donde predominan los procesos de decantación, mientras que el cambio en la coloración de los componentes finos sugiere mayor contenido de oxígeno en el fondo marino. Al igual que en el subambiente de cuenca, también es posible observar un contenido calcáreo variable en el segmento fino y el desarrollo de la icnofacies de Cruziana confirma la condición de baja energía. La presencia de wackestones tanto masivos como laminados se hace más habitual hacia este intervalo de la secuencia, acompañada por la disminución del espesor de los bancos de pelitas negras. Este arreglo refleja una mayor cercanía al origen de las plumas hemipelágicas que dan origen a las facies bioclásticas. Por último, la aparición de bancos muy poco potentes de wackestones intensamente bioturbados indica periodos de una alta actividad biológica en condiciones muy poco energéticas.

\subsubsection{Asociación de facies de rampa externa proximal}

Compuesta por las facies de lutitas castañas, margas masivas, wackestones masivos, laminados y bioturbados, packstones masivos, laminados y bioturbados y ocasionales areniscas mixtas con fango micrítico, heterolíticas ondulosas y floatstones masivos. Los límites entre estratos suelen ser erosivos en la base de packstones y floatstones, y netos y planos en los demás casos. Las facies se presentan en secuencias rítmicas con arreglos verticales grano y estratocrecientes.

Se desarrolla una abundante y variada fauna, foraminíferos y calciesferas de concentran en las fracciones finas mientras que gasterópodos, bivalvos, serpúlidos, braquiópodos, amonites, briozoos y ostras (Aetostreon Sp.) se concentran en los carbonatos esqueletales. Se observa un gran número de icnogéneros, Arenicolites, Palaeophycus, Gordia, Phycodes y Chondrites, componentes de la icnofacies Cruziana.

Es posible reconocer esta asociación en la Formación Vaca Muerta en todos los perfiles de la Cuenca Neuquina.

Las facies de pelitas castañas y margas masivas, así como la presencia de la icnofacies Cruziana apoyan la continuidad de la decantación en un ambiente marino de baja energía y buena oxigenación. Estas condiciones se ven interrumpidas por tempestitas distales que generan depósitos bioclásticos con bases erosivas. La presencia de facies heterolíticas mixtas 
con estratificación ondulosa confirman la ya mencionada allternancia entre condiciones de buen tiempo (donde se deposita el material fino) y de tormentas (con formación de óndulas). Los arreglos verticales grano y estratocrecientes pueden ser caracterizados como parasecuencias y se interpretan como resultado de reiteradas oscilaciones relativas en la posición del nivel del mar (pequeños ciclos transgresivo-regresivos).

Composicionalmente, las facies mixtas tales como $\mathrm{Amfm}$ y $\mathrm{Hm}$ corroborarían la alternancia en la disponibilidad de carbonato observadas también en los sedimentos finos. Los niveles poco espesos de wackestones y packstones bioturbados permiten inferir lapsos de interrupcíon en el aporte extracuencal de clásticos.

\subsubsection{Asociación de facies de rampa media distal}

Integrada por facies de lutitas castañas, margas masivas, packstones masivos, packstones y rudstones con estructuras monticulares, floatstones masivos y rudstones masivos. Los límites entre estratos son erosivos e irregulares en la base de las facies carbonáticas clásticas, y netos y planos en los demás casos. Las facies se presentan en secuencias rítmicas con arreglos verticales grano y estratocrecientes.

Las características tanto fosilíferas como icnológicas son las mismas que en la asociación de rampa externa proximal pero con un aumento en la proporción de ostras, principalmente del género Aetostreon Sp. Esta asociación se desarrolla en el sector cuspidal de la Formación Vaca Muerta en los tres perfiles correspondientes a la Cuenca Neuquina.

Las ya mencionadas condiciones de energía baja y buena oxigenación interpretadas a partir de las facies de pelitas castañas, margas y wackestones masivos e icnofacies de Cruziana son interrumpidas por tempestitas proximales. Estos depósitos son originados durante episodios de tormenta y se caracterizan por la presencia de estructuras monticulares, bases erosivas y el aumento en la proporción de facies bioclásticas gruesas por sobre las finas. Como se mencionó anteriormente, los arreglos verticales grano y estratocrecientes pueden ser caracterizados como parasecuencias y se interpretan como ciclos transgresivo-regresivos.

\subsubsection{Asociacion de facies de rampa media proximal}

Integrada por la facies de bindstone que conforman la totalidad de la Formación Chachao en los perfiles Cuesta del Chihuido y Puesto Loncoche.

Esta facies esta compuesta por organismos tanto sésiles como coloniales y oportunistas, las características tafonómicas cambian drasticamente con respecto a los otros 
subambientes de rampa, ya que se observan abundantes valvas articuladas y en posición de vida. También es apreciable el alto grado de bioerosión e incrustación. Sus características composicionales fueron desarrolladas anteriormente (ver sección 5.2.4.1).

Se interpretan como densas bioconstrucciones acumuladas en ambientes marinos de escasa energía sin influencia importante de corrientes de fondo (Schwarz, 2003). Legarreta y Kozlowski, (1981) postulan una iniciación de estos abultamientos a partir de montículos extendidos de origen hidrodinámico, que posteriormente son fijados por epifaunales cementantes (algas, serpúlidos y ostreidos principalmente) y culminados por la acción de pelecípodos infaunales. La intensa actividad de excavadores y perforadores sugiere un ambiente situado por debajo de la línea de olas de buen tiempo. Uliana et al. (1978) recalcan, sobre la base del análisis regional de las facies, que estos abultamientos nunca llegaron a generar una restricción ambiental.

\subsubsection{Asociaciones de facies en la Cuenca Austral}

\subsubsection{Asociación de facies de plataforma externa}

Formado por las facies de pelitas masivas y laminadas, margas masivas y areniscas masivas. Se distribuyen en sucesiones finas homogéneas interrumpidas por episódicos bancos de areniscas y margas masivas poco espesos, sin arreglos verticales aparentes.

No se regstraron trazas fósiles ni evidencias de bioturbación. La fauna está compuesta por belemnites del género Belemnopsis sp., escasos bivalvos indeferenciados y moldes de amonites. Esta asociación comprende el sector inferior de la Formación Río Mayer, representada en el tope de los perfiles Río Guanaco y Cerro Hobler.

Es posible intepretar esta asociación como generada en un ambiente marino de baja energía sin influencia del oleaje. Los elementos finos son acumulados por depositación hemipelágica, es decir, son trasnsportados en suspensión y posteriormtene decantan formando cuerpos de pelitas negras masivas y laminadas. En cuanto a los niveles episódicos, aquellos con mayor contenido carbonático (margas masivas) son generados por una combinación entre mayor productividad de carbonatos y concomitante dilución de los aportes silicoclásticos, mientras que las areniscas masivas serían generadas a partir de corrientes de turbidez diluidas (Richiano, 2012). 


\subsubsection{Asociación de facies de plataforma interna}

Esta integrada por las facies de areniscas masivas y pelitas negras. Sus contactos son en todos los casos planos y netos y representa una suceción rítmica sin arreglos verticales aparentes.

No se observa bioturbación y el contenido fósil se ve restringido sólo a la presencia de belemnites. Esta asociación constituye la totalidad de la Formación Springhill en el perfil Río Guanaco.

El origen de estos depósitos se vincula a la acumulación de sedimentos finos por decantación en un ambiente de baja energía sin influencia del oleaje. Esta sedimentación es interrumpida por corrientes de turbidez interpretadas como proximales debido al espesor de los paquetes y la frecuencia de la alternancia.

\subsubsection{Asociación de facies de shoreface}

Se denomina shoreface al sector de la playa que se encuentra entre el nivel de marea baja y el de olas de buen tiempo. Los límites entre los diferntes niveles son en general erosivos, aunque también se observan netos. No se reconocen arreglos verticales definidos. Sobre la base de sus características faciales, los depósitos fueron divididos en upper shoreface y lower shoreface. Desde el punto de vista composicional, se registraron depósitos netamente silicolásticos y otros con un importante porcentaje de material bioclástico.

El upper shoreface está representado en la Formación Springhill en los perfiles Cerro Hobler y Subida del Chancho, se compone de areniscas masivas, con estratificación tangencial y con estratificación horizontal. No se observaron evidencias de bioturbación. En la mitad inferior del perfil Cerro Hobler se reconoció abundante contenido fosilífero: algas dasycladáceas, inocerámidos, belemnites y bivalvos fragmentados indiferenciados. Por otro lado, en el perfil Subida del Chancho y el tope del perfil Cerro Hobler no se reconocieron ejemplares fósiles. Se interpreta como un ambiente marino dominado por corrientes combinadas, con estructuras mecánicas generadas tanto en alto como en bajo régimen de flujo. La presencia de algas dasycladáceas permite inferir condiciones climáticas cálidas, aguas claras y bien oxigenadas (Poiré et al., 2002, 2006; Vaamonde y Poiré, 2006).

El lower shoreface está representado en la Formación Springhill en el perfil Subida del Chancho, se encuentra formado por areniscas mixtas con fango silicoclástico y óndulas y glauconíticas. Su contenido fósil consiste en bivalvos no identificados con un buen estado de preservación (baja fragmentación) y belemnites de la fauna de Belemnopsis sp. Los depósitos 
se encuentran escasamente bioturbados. Se interpreta como un ambiente marino dominado por corrientes combinadas de bajo régimen de flujo. La presencia de las facies glauconíticas reflejan condiciones de mayor profundidad (ver sección 5.2.4.1).

\subsubsection{Asociación de facies de foreshore}

Se denomina foreshore al sector de la playa desarrollado entre el nivel de marea alta y el de marea baja. Está representado en la Formación Springhill en el perfil Subida del Chancho, y constituido por areniscas masivas o con estratificación entrecruzada, fuertemente bioturbadas en los topes.

No se reconoció contenido fosilífero, mientras que el contenido icnológico fue descripto por Richiano et al. (2016), quienes describieron los icnogéneros Ophiomorpha isp., Skolithos isp., Arenicolites isp., Rosselia isp. y Cylindrichnus isp. que constituyen la icnofacies Sholithos. Estos autores, interpretaron estos depósitos como foreshore a partir de su icnofacies que es característica de este subambiente, y se describe como desarrollada en un sustrato marino limpio, oxigenado y de alta energía (Buatois y Mángano, 2001).

\subsubsection{Asociación de facies fluvial}

Se encuentra constituida por las facies de pelitas masivas, areniscas masivas, con estratificación entrecruzada y estratificación horizontal, y sábulitas masivas. Estas facies constituyen cuerpos principalmente arenosos amalgamados y con geometrías generalmente cóncavo-planas, aunque también se reconocen tabulares. Son más habituales los límites erosivos que los netos.

No se reconocieron trazas fósiles, mientras que se identificaron abundantes briznas vegetales. Esta asociación está ubicada en la base de la Formación Springhill en el perfil Subida del Chancho.

La asociación de facies descripta ha sido interpretada como el relleno de canales fluviales y planicies de inundación. Este relleno habría estado representado principalmente por barras, las cuales habrían sido construidas a partir de la migración de megaóndulas y óndulas sobre el lecho del canal (Olivo, 2016). Por otro lado, las planicies de inundación se ven representadas por las pelitas depositadas por decantación durante los eventos de crecida. Richiano et al. (2016) identificaron paleosuelos en vinculación con estas litologías e interpretaron como canales meandrosos que se interdigitan con planicies costeras. 


\subsection{Ambientes de depositación}

\subsubsection{Sistema de rampa carbonática/mixta de la Cuenca Neuquina}

Este sistema ha sido reconocido en la zona de la Plataforma Mendocina y está integrado por asociaciones de facies que se agrupan en sucesiones somerizantes de decenas de metros de espesor (Fig. 5.5a). La depositación comienza con facies de cuenca, de composición principalmente silicoclástica, donde dominan procesos de decantación en un medio anóxico que son interrumpidos esporádicamente por corrientes hemipelágicas que transportan material bioclástico con un alto grado de fragmentación. Esta asociación es sucedida por las facies de rampa externa distal, donde la decantación continúa siendo el principal proceso, pero se observa un cambio en la oxigenación del medio y en la frecuencia de depósitos calcáreos de mayor granulometría.

La sucesión continúa con la asociación de rampa externa proximal, donde las facies finas se encuentran alternadas con bancos calcáreos y mixtos de mayor granulometría transportados por corrientes vinculadas a tormentas distales. Hacia la rampa media distal, la acción de las tormentas se torna mucho más frecuente en el registro, observándose los primeros niveles gruesos junto a la aparición de estructuras monticulares y bases erosivas.

La asociación más somera registrada en los perfiles de la Plataforma Mendocina es la de rampa externa proximal, donde se desarrollan potentes bioconstrucciones. Estos bindstones representan un aumento en la cantidad y diversidad de la fauna presente en el área y un cambio hacia condiciones de mayor preservación tafonómica.

Es posible reconocer la misma sucesión somerizante en los tres perfiles relevados en la Cuenca Neuquina y una composición que intercala niveles finos carbonáticos o silicoclásticos con niveles netamente bioclásticos. Los cambios en la estratigrafía representan superficies contemporáneas, debido a que las transgresiones marinas se daban en dirección oeste -este, mientras que los perfiles relevados están ubicados en sentido norte-sur. El perfil Río Salado, el más septentrional relevado en el área, posee asociaciones de facies más profundas, contrariamente a los perfiles Puesto Loncoche y Cuesta del Chihuido que presentan condiciones más someras donde es posible elaborar un modelo estratigráfico secuencial de mayor resolución (ver 5.5.1). 


\subsubsection{Sistema de plataforma marina silicoclástica/mixta de la Cuenca Austral}

El sistema de plataforma marina se desarrolla en el sector entre los lagos Argentino y San Martin en la Cuenca Austral, donde las asociaciones de facies silicoclástica y mixta se vinculan, evidenciando condiciones cada vez más profundas hacia el tope (Fig. 5.5b). Las facies de foreshore se caracterizan por su asociación icnológica Skolitos, que se dispone en bancos de arenas silicoclásticas intensamente bioturbadas y representan episodios de exposición subaérea entre las mareas. Esta asociación es cubierta por facies de shoreface representadas por areniscas bioclásticas y silicoclásticas que son depositadas por flujos unidireccionales bajo condiciones de alto régimen de flujo.

Cubriendo los depósitos antes mencionados se deposita la asociación de facies de plataforma interna, donde se registran procesos de decantación de material silicoclástico interrumpidos por corrientes de turbidez interpretadas como proximales. Los depósitos más profundos corresponden a la asociación de facies de plataforma externa, ambiente de baja energía donde domina la decantación con episódicos depósitos generados por corrientes de turbidez diluídas.

Los depósitos más someros se registraron en el perfil Subida del Chancho (ubicado hacia el norte), donde interactúan con depósitos fluviales anteriores a la instalación del sistema. Los perfiles Cerro Hobler y Río Guanaco poseen una suceción de facies más profundas, ya que se ubican en sectores más centrales de la cuenca para el intervalo de tiempo estudiado. 

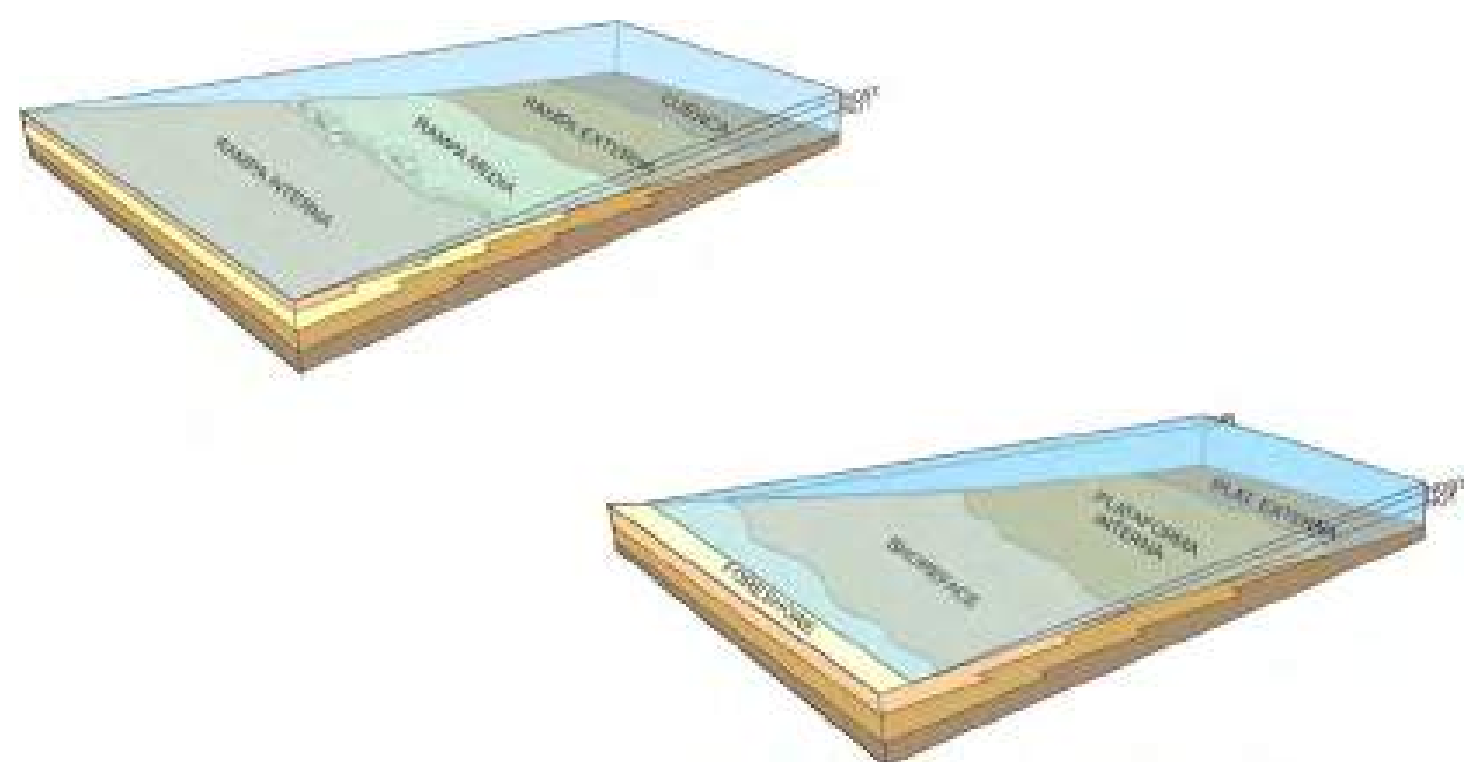

Fig. 5.5. a) Disposición de las asociaciones de facies dentro de un sistema de rampa carbonática/mixta. B) Disposición de las asociaciones de facies, dentro de un sistema de plataforma marina silicoclástica/mixta LMB: línea de marea baja, NOBT: nivel de olas de buen tiempo, , NOT: nivel de olas de tormenta.

\subsubsection{Sistema fluvial}

Por otra parte, el sistema fluvial está representado en el sector basal de la Formación Springhill en la Subida del Chancho. La correspondiente asociación de facies posee muy escaso desarrollo dentro de las secciones relevadas, y sus características fueron mencionadas anteriormente (ver 5.3.9). Se interpreta como el relleno de canales fluviales meandrosos intercalado con planicies de inundación costeras.

\subsection{Estratigrafía secuencial}

La estratigrafía secuencial es la disciplina que estudia cómo unidades estratigráficas, facies y elementos depositacionales se relacionan unos con otros dentro de una cuenca sedimentaria (Catuneanu, 2005). Esta disciplina consiste en la subdivisión de las sucesiones sedimentarias en paquetes contemporáneos limitados por superficies de erosión o no depositación que se conocen como secuencias (Vail et al., 1977). Estas secuencias son divididas en cortejos sedimentarios que son controlados por cambios relativos en el nivel del mar.

Con el objetivo de entender la génesis y factores que controlaron la depositación de los sistemas antes estudiados y enmarcarlos dentro de un contexto cronológico y evolutivo, se desarrolla a continuación un breve análisis estratigráfico secuencial de las sucesiones estudiadas. 
En última instancia se generará a partir del análisis estratigráfico secuencial y del estudio de ambientes depositacionales contemporáneos, una primera correlación entre las cuencas estudiadas.

\subsubsection{Cuenca Neuquina}

La historia evolutiva de la zona estudiada comienza con un importante evento transgresivo en el cual el mar se instala en gran parte de la cuenca. Este acontecimiento queda registrado en la base del perfil Puesto Loncoche (Fig. 5.6), y pone en contacto conglomerados polimícticos de origen fluvial correspondientes al tope de la Formación Tordillo (Gulisano y Gutierrez Pleimling, 1994) con la asociación de facies de cuenca de la base de la Formación Vaca Muerta. En sentido vertical, es posible observar en primera instancia una tendencia inicial de profundización o retrogradación que progresivamente se vuelve progradante (Kietzmann et al., 2008), indicando un límite entre el cortejo transgresivo (TST) y el cortejo de mar alto (HST).

El cortejo de mar alto queda registrado en los tres perfiles relevados en la Plataforma Mendocina (Fig. 5.6), aunque se expresa de diferente modo según la posición paleogeográfica de las distintas localidades dentro de la cuenca. En el perfil Puesto Loncoche es posible observar dentro del HST, arreglos transgresivos- regresivos interpretados como tres secuencias de menor orden. En este sector se ponen en contacto de forma alternada las asociaciones de facies de rampa externa proximal y rampa media distal, constituyendo una tendencia progradacional que hacia el tope se vuelve agradacional. Estas interpretaciones coinciden con la evolución ambiental propuesta por Kietzmann et al. (2015) y las observaciones sismoestratigráficas realizadas por Mitchum y Uliana (1986) y Legarreta y Uliana (1991). En la Cuesta del Chihuido no se observa la base del perfil, por lo que sólo es identificada la última secuencia del HST. En el perfil Río Salado se registran facies más profundas, razón por la cual no se distinguen secuencias internas de orden menor y sólo es posible definir un arreglo netamente somerizante que pone en contacto a las asociaciones de facies de cuenca con las de rampa externa distal y a éstas con las de rampa externa proximal.

Por encima del HST se depositan sedimentos marinos de mayor profundidad que permiten definir un nuevo evento transgresivo. Así, se ponen en contacto facies de rampa media distal (en el caso de los perfiles Puesto Loncoche y Cuesta del Chihuido) y de rampa externa proximal (en el caso del perfil Río Salado) con la asociación de facies de rampa externa distal. Estos últimos depósitos se asignan a un nuevo TST que instala nuevamente las condiciones observadas cerca de la base de la formación. 
El contacto entre las formaciones Vaca Muerta y Chachao, sólo es observado en el perfil Río Salado, donde se aprecia una abrupta somerización que dispone los bancos de floatstone y rudstone masivos correspondientes a la rampa media distal por sobre las margas masivas y pelitas negras de la rampa externa distal. En los perfiles Puesto Loncoche y Cuesta del Chihuido, dicho contacto se encuentra cubierto, pero inmediatamente se encuentran los potentes autoparabiostromas desarrollados en la rampa media proximal. Esta sucesión es interpretada como un nuevo cortejo de mar alto (HST), en un marco de escaso a nulo aporte silicoclástico. La falta de aporte terrígeno permitió el desarrollo de una extensa biota, la cual se acumula formando facies de bindstone con un patrón de apilamiento progradante.

Por encima de la Formación Chachao se encuentran las pelitas castañas y calizas micríticas de la Formación Agrio (Sagasti, 2001a). El contacto entre ambas unidades representa una nueva superficie transgresiva, comparable en jerarquía a la de la base de la Formación Vaca Muerta, con el consecuente restablecimiento de las facies de cuenca (Sagasti y Ballent, 2002). 


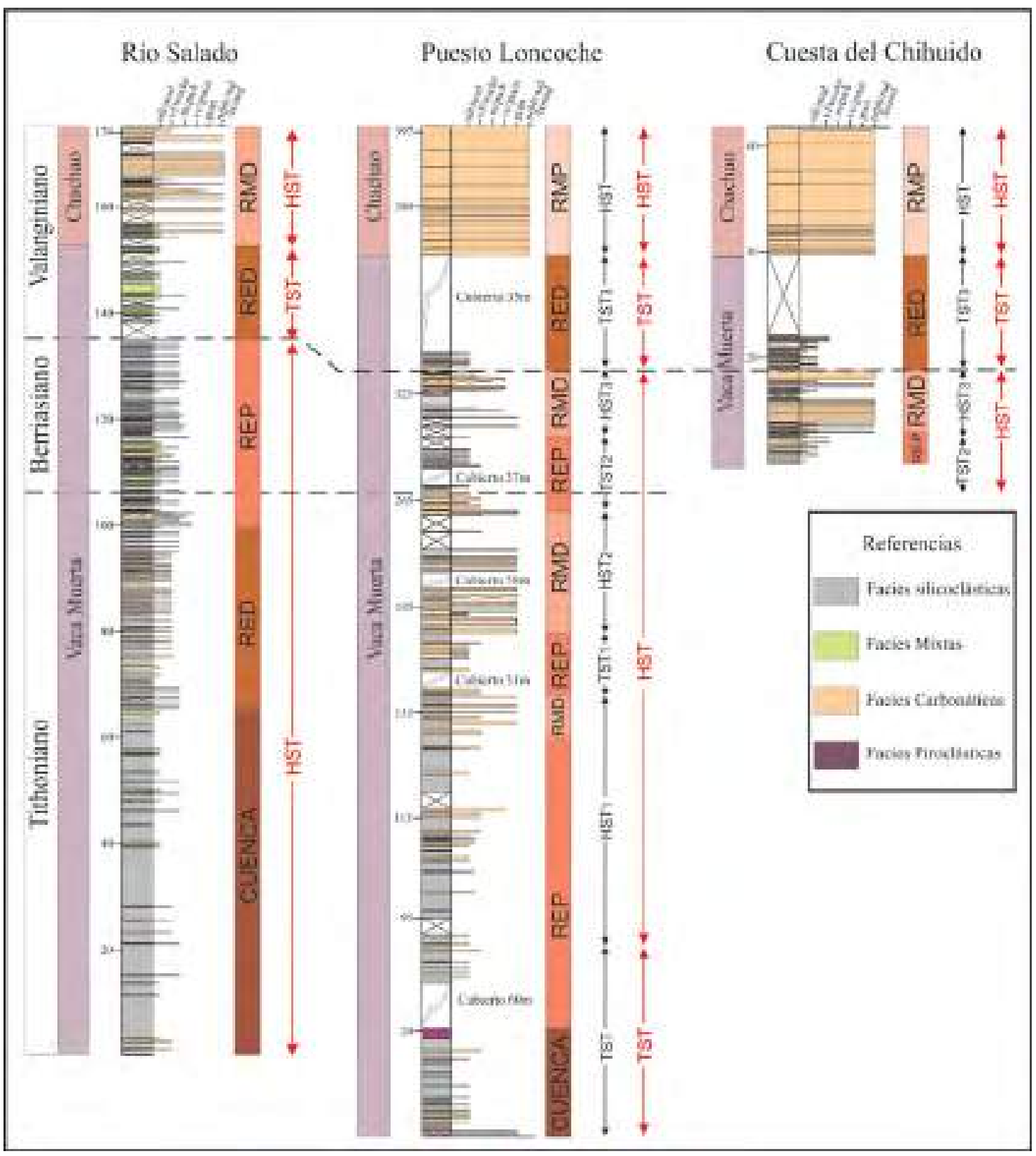

Figura 5.6. Comparación de perfiles simplificados de la Cuenca Neuquina. Se observan las asociaciones de facies y el modelo estratigráfico secuencial. TST: cortejo transgresivo, HST: cortejo de mar alto, RED: rampa externa distal, REP: rampa externa proximal, RMD: rampa media distal, RMP: rampa media proximmal.

\subsubsection{Cuenca Austral}

Para un correcto entendimiento de la historia estratigráfica secuencial del sector entre los Lagos Argentino y San Martín en la Cuenca Austral (Fig. 5.7) es necesario tener en cuenta dos importantes factores. En primer lugar que la Cuenca Austral se encontraba conectada con el Océano Protopacífico en su sector sur hacia finales del Jurásico y principios del Cretácico. Esta situación generó que las regresiones y transgresiones registradas en este período se dieran en dirección norte-sur (ver sección 3.2.1). En segundo término, los perfiles 
sedimentarios están ubicados en la misma dirección que las variaciones del nivel del mar y existe una gran distancia entre ellos. Esta situación trae como consecuencia que la misma formación se vea representada por diversos ambientes sedimentarios y posea diferentes edades en distintos sectores de la misma cuenca.

El desarrollo de las formaciones estudiadas comienza con una importante transgresión que pone en contacto facies marinas someras (correspondientes a la Formación Springhill) con el basamento representado por el Complejo El Quemado. En el perfil Río Guanaco la Formación Springhill corresponde a la asociacion de facies de plataforma interna. Por otro lado, en el perfil Cerro Hobler, la misma formación es representada por el subambiente de shoreface, dividido composicionalmente en una mitad superior silicoclástica y una mitad basal de composición mixta, este último interpretado como más somero por la presencia de algas dasycladáceas (Poiré et al., 2002, 2006; Vaamonde y Poiré, 2006). Dentro del mismo evento transgresivo se encuentra además, el contacto con la Formación Río Mayer. En el perfil Río Guanaco el pasaje entre formaciones es abrupto hacia facies de plataforma externa. En Cerro Hobler, el contacto entre ambas formaciones se encuentra cubierto, razón por la cúal se desconoce si existe el desarrollo de facies de plataforma interna también en este perfil. Esta sucesión fue definida como un cortejo transgresivo (TST), que culmina con una superficie de máxima inundación, desarrollada dentro del registro de la Formación Río Mayer, y que fue asociada al máximo porcentaje de carbono orgánico total (COT) en el perfil Río Guanaco por Richiano (2012) (Fig. 5.7).

A continuación se definió un cortejo de mar alto (HST), que está representado por la asociación de facies de plataforma externa en los perfiles Cerro Hobler y Río Guanaco. Al estar compuesta por potentes depósitos de pelitas negras de ambiente marino profundo, no es posible apreciar mediante herramientas sedimentológicas la presencia de variaciones significativas en el nivel del mar durante la depositación de este tramo de la Formación Río Mayer.

En el perfil Subida del Chancho se observa a la Formación Springhil apoyada sobre el Complejo El Quemado. La sucesión está compuesta por depósitos fluviales que mediante un arreglo retrogradante pasan a niveles de foreshore, upper shoreface y lower shoreface. Estos subambientes constituyen un cortejo transgresivo (TST) que culmina con facies ricas en glauconita y material bioclástico que constituyen la máxima inundación.

El final de la sucesión se ve representado por una nueva transgresión de mayor jerarquía que da comienzo a un nuevo cortejo transgresivo (TST). Esta superficie pone facies de plataforma externa por sobre facies de shoreface en el perfil Subida del Chancho marcando una dramática profundización. En los perfiles Cerro Hobler y Río Guanaco este evento se ve 
representado por un cambio en la composición hacia facies margosas. Este aumento del contenido carbonático estaría relacionado con la disminución de las contribuciones silicoclásticas, como resultado de la retrogradación en la ubicación de las áreas de aporte (que se habrían localizado en sectores más distantes de la ubicación de los perfiles) como consecuencia del significativo avance marino.

En la zona de la Subida del Chancho se encuentran en contacto dos cortejos transgresivos sin evidencias de superficies erosivas de importancia regional. Habría existido entre ambos TST, una regresión de tipo normal que generaría condiciones erosivas en el sector del Lago San Martín y un HST en el área de los lagos Argentino y Viedma, cuyos límites no estarían bien definidos debido a la profundidad de los depósitos. 


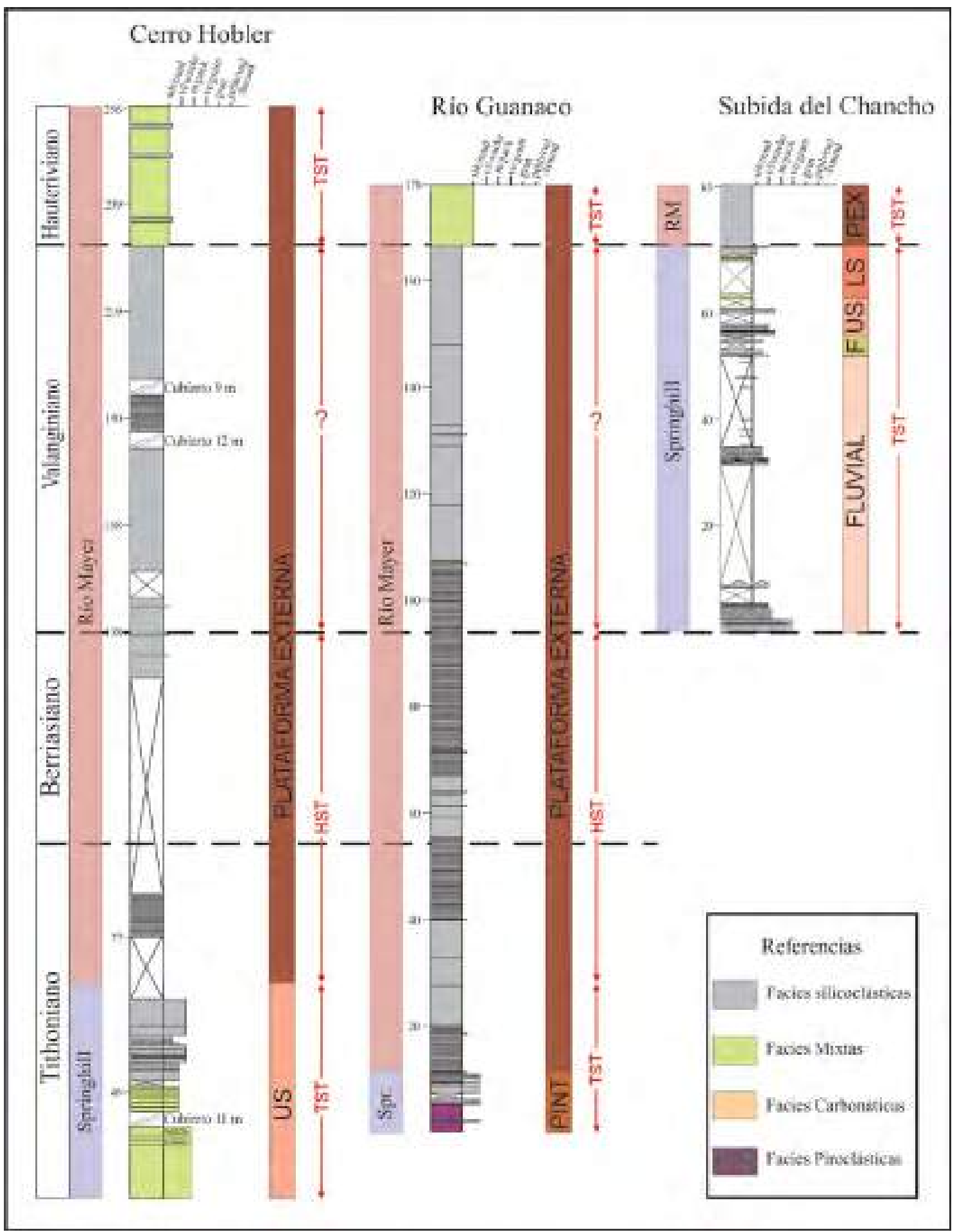

Figura 5.7. Comparación de perfiles simplificados de la Cuenca Austral. Se observan las asociaciones de facies y el modelo estratigráfico secuencial. TST: cortejo transgresivo, HST: cortejo de mar alto, PINT: plataforma interna, LS: lower shoreface, US: upper shoreface, F: foreshore.

\subsubsection{Correlación entre las cuencas y asignación temporal de los cortejos}

De lo expuesto anteriormente se puede interpretar que existen cinco cortejos principales limitados por superficies que es posible reconocer en ambas cuencas, los cuales 
respaldan las correlaciones temporales esbozadas por distintos autores (mencionados abajo) sobre la base del contenido fosilífero de las formaciones (Fig. 5.8) (ver secciones 3.1.3.4, 3.1.4.4, 3.2.3.4 y 3.2.4.4).

La transgresión con el que da inicio la depositación de las formaciones Vaca Muerta y Springhill puede ser ubicada al final del Tithoniano temprano. En la Cuenca Neuquina fue restringida por Riccardi (2015) al reconocerse la biozona ándica de amonites de Virgatosphinctes mendozanus, mientras que en los perfiles Cerro Hobler y Río Guanaco de la Cuenca Austral se asignó en base a su fauna de cefalópodos (Nullo, 1979; Kraemer y Riccardi, 1997; Richiano, 2012).

EI HST que representa la mayor parte del desarrollo de las formaciones Vaca Muerta y Río Mayer se habría depositado entre el Tithoniano medio y el Berriasiano. Su acotamiento temporal fue postulado por biozonas de amonites en la Cuenca Neuquina (Kietzmann et al., 2015) y corroborado por los eventos de nanofósiles y calpionelidos (Fernández-Carmona y Riccardi, 1998; Concheyro et al., 2006; Lescano y Kietzmann, 2010). En el sector entre los lagos Argentino y Viedma se realizó sobre la base de la asociación faunística de Berriasella cf. behrendseni, Jabronella cf. michaelis, Subthurmannia sp. y Phyllopachyceras aureliae postulada por Kraemer y Riccardi (1997).

La acumulación del TST se habría dado hacia el comienzo del Valanginiano temprano. Fue relacionado con la biozona de amonites de Spiticeras damesi por Kietzmann et al. (2015) en la Plataforma Mendocina y a la presencia del género Olcostephanus sp. en la zona de la subida del Chancho (Aguirre-Urreta y Rawson, 1998; Richiano, 2012).

El HST en la cual se depositan los sedimentos correspondientes a la Formación Chachao en la Cuenca Neuquina fue asignado al final del Valanginano temprano y comienzo del Valanginano tardío. Este acotamiento temporal fue realizado en base a la presencia de la biozona ándica de amonites de Olcostephanus atherstoni (Legarreta y Kozlowski, 1981; Palma y Lanés, 2001; Aguirre-Urreta et. al., 2011). No se encontraron equivalentes en la Cuenca Austral de este periodo tan acotado de tiempo, pero puede restringirse sobre la base de los cortejos depositados anterior y posteriormente.

El evento transgresivo que da comienzo a la depositación de la Formación Agrio en la Plataforma Mendocina, los depósitos de la Formación Río Mayer medio entre los lagos Argentino y Viedma y de Río Mayer inferior en el Lago San Martín se habría desarrollado hacia finales del Valanginano tardío. En la Cuenca Neuquina fue definido por la presencia de la biozona ándica de amonites de Pseudofavrela angulatiformis (Sagasti, 2001a), mientras que en la Cuenca Austral fue definido por la presencia del microfósil Watznaueria británica (Richiano, 2012). 


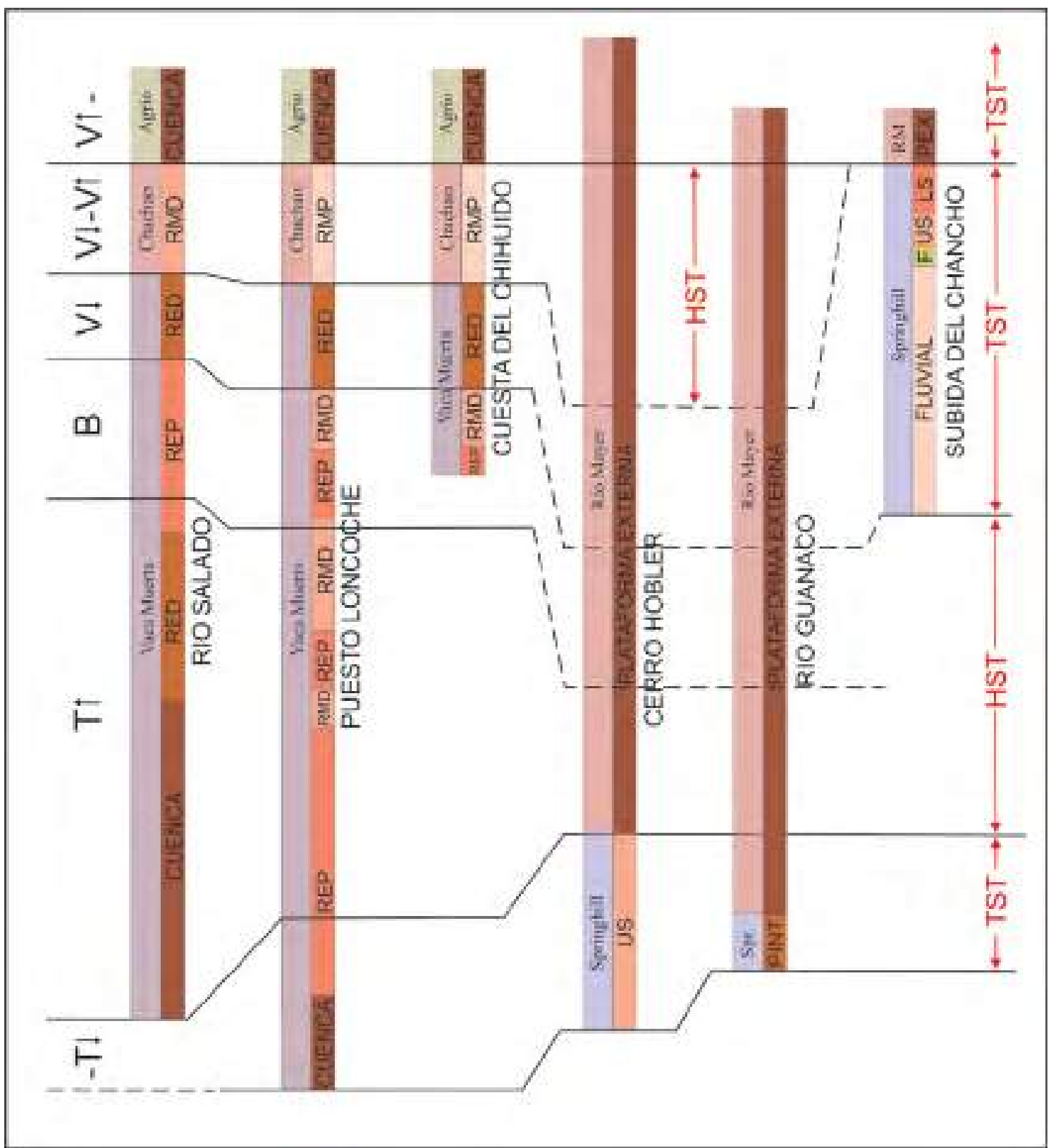

Figura 5.8. Correlación temporal y estratigráfico secuencial entre las cuencas Neuquina y Austral. T: Tithoniano, B: Berriasiano y V: Valanginiano. Las flechas hacia arriba y abajo indican temprano y tardío. Las líneas rellenas aluden a superficies comprobadas mientras que las punteadas son aparentes. 


\section{Capítulo VI- Composición mineralógica}

\subsection{Introducción}

El presente capítulo tiene como objetivo la descripción composicional de las unidades estudiadas. Para esta caracterización se llevaron a cabo, según la granulometría y naturaleza (carbonática, silicoclástica o mixta) de las rocas, análisis petrográficos, de tinción de láminas delgadas $\mathrm{y}$ de difracción de rayos $\mathrm{X}$.

Para el análisis de las facies pelíticas y mixtas se ha tratado de modo separado las correspondientes a la Cuenca Neuquina y Austral. Por otro lado, el análisis de las psamitas y psefitas silicoclásticas es exclusivo de la Cuenca Austral y los carbonatos han sido estudiados en la Cuenca Neuquina.

La fracción pelítica, tanto carbonática como silicoclástica, fue analizada mediante difracción de rayos $X$. Ciento treinta y dos muestras de todos los perfiles fueron especialmente elegidas y analizadas según los procedimientos descriptos en la sección 2.5.6, obteniéndose como resultado la semicuantificación de cada una de las especies minerales presentes.

Las psamitas silicoclásticas y mixtas fueron estudiadas mediante veintitrés láminas delgadas, a partir de la cuales se caracterizó detalladamente a los distintos componentes detríticos y se realizó un análisis estadístico de modas con el software Rock.ARV2.0, (ver sección 2.5.1). Posteriormente, aquellas de composición silicoclástica fueron clasificadas utilizando los triángulos composicionales propuestos por Folk et al. (1970) y Dott (1964) modificados por Pettijohn et al. (1972), mientras que para las mixtas se utilizó la clasificación de Álvarez- Trenttini y Schwarz (2016).

El único nivel psefítico presente en las secciones estudiadas corresponde a una sabulita (entre 2 y $4 \mathrm{~mm}$ ). Su composición fue detallada en los afloramientos, donde se realizó un conteo estadístico de clastos. Posteriormente fue clasificada según Scasso y Limarino (1997).

Las rocas carbonáticas fueron estudiadas mediante análisis petrográfico a partir de la descripción de más de sesenta láminas delgadas. Se llevó a cabo una caracterización de los distintos componentes esqueletales con reconocimiento de las especies fósiles presentes y su grado de preservación tafonómica. Adicionalmente, con el objetivo de determinar la composición mineralógica de cada elemento, se realizaron tinciones de las láminas delgadas descriptas (ver sección 2.5.2). Por último, se especificaron los tipos litológicos utilizando la clasificación textural de Dunham (1962) modificada por Embry y Klovan (1972). 
A partir del análisis detallado de la composición de las sedimentitas fue posible el estudio de la procedencia del material que las constituye, tema que se tratará en el capítulo 7. Asimismo, la compleja evolución diagenética de las formaciones estudiadas será abordada de modo especial en este trabajo de tesis. Por esta razón, los elementos tales como cementos, venas, estilolitas y porosidades (obtenidas a partir del análisis petrográfico), la caracterización de interestratificados I/S, el cálculo de índices de Esquevin (IE) y de cristalinidad de la illita (IC) (obtenidos a partir de difracción de rayos $\mathrm{X}$ ) serán presentados en el capítulo 8 .

\subsection{Análisis composicional de pelitas}

\subsubsection{Cuenca Neuquina}

Las noventa muestras analizadas fueron tomadas en los tres perfiles relevados en la Cuenca Neuquina, y corresponden a las facies pelitas negras y pelitas castañas (ver secciones 5.2.1.1 y 5.2.1.2). La semicuantificación de las especies minerales obtenidas a partir de este estudio es representada de forma gráfica en la figura 6.2 donde es posible observar importantes cambios composicionales tanto en roca total como en la fracción arcilla, los cuales se detallan a continuación.

En los estudios de roca total se reconocieron cantidades variables de cuarzo, calcita, feldespato, plagioclasa y arcillas. Los minerales más abundantes son cuarzo y calcita, cuya suma siempre supera el $90 \%$ de la muestra. El incremento en el contenido de cuarzo en todos los casos coincide con una disminución en la calcita y viceversa. Las plagioclasas se encuentran en escasas cantidades en los tres perfiles estudiados, con proporciones constantes de base a techo. El feldespato potásico es muy escaso en la base y el sector medio y no se registra hacia el tope de los perfiles Puesto Loncoche y Cuesta del Chihuido, mientras que en el perfil Río Salado está ausente o en proporciones traza. Los argilominerales se hallan como trazas en los tres perfiles estudiados, registrándose eventualmente sectores con proporciones muy escasas. Otros minerales encontrados en porcentajes inferiores al $5 \%$ son pirita, siderita, yeso y dolomita. Mientras la siderita y la pirita se encuentran presentes en casi la totalidad de las muestras de los tres perfiles, el yeso y la dolomita se concentran en niveles aislados de todas las secciones.

A partir del análisis detallado de la fracción arcilla se reconocieron las especies minerales de illita, interestratificado de illita esmectita (I/S), clorita, caolinita y esmectita. Las cantidades de illita e I/S disminuyen de forma progresiva en dirección norte-sur, siendo muy abundantes en el perfil Río Salado, abundantes a moderadas en el perfil Puesto Loncoche y 
moderadas a escasas en la Cuesta del Chihuido. El contenido de clorita permanece constante, tanto entre las distintas secciones como de base a techo dentro de cada perfil, oscilando sus cantidades desde escasas hasta trazas.

La caolinita se encuentra en general en escasas proporciones con sectores de abrupto aumento que llegan a ser abundantes en los perfiles Río Salado y Cuesta del Chihuido y muy abundantes en el Puesto Loncoche. En el Río Salado las mayores proporciones se localizan cerca de la base, en el sector medio en el perfil Puesto Loncoche y cerca del tope en la Cuesta del Chihuido.

La esmectita se localiza en cantidades escasas y en sectores puntuales en los perfiles Río Salado y Puesto Loncoche, mientras que en la Cuesta del Chihuido aumenta notablemente su continuidad y abundancia (Fig. 6.1). 
Río Salado

Roca Total

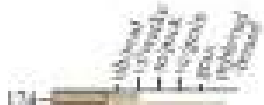

$0,20,40,60,80,100$

E

E

此

辟

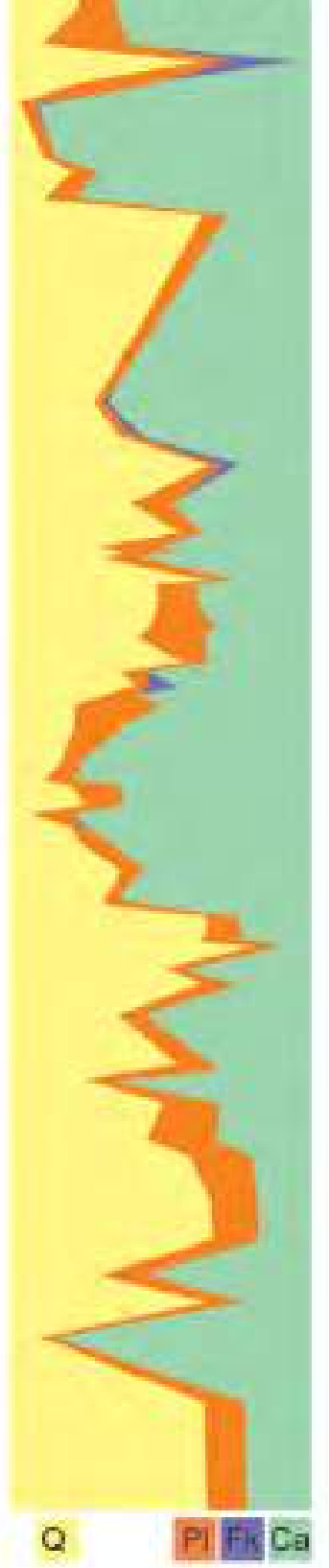

Argilominerales

$0,20,40,60,80,100$

Puesto Loncoche

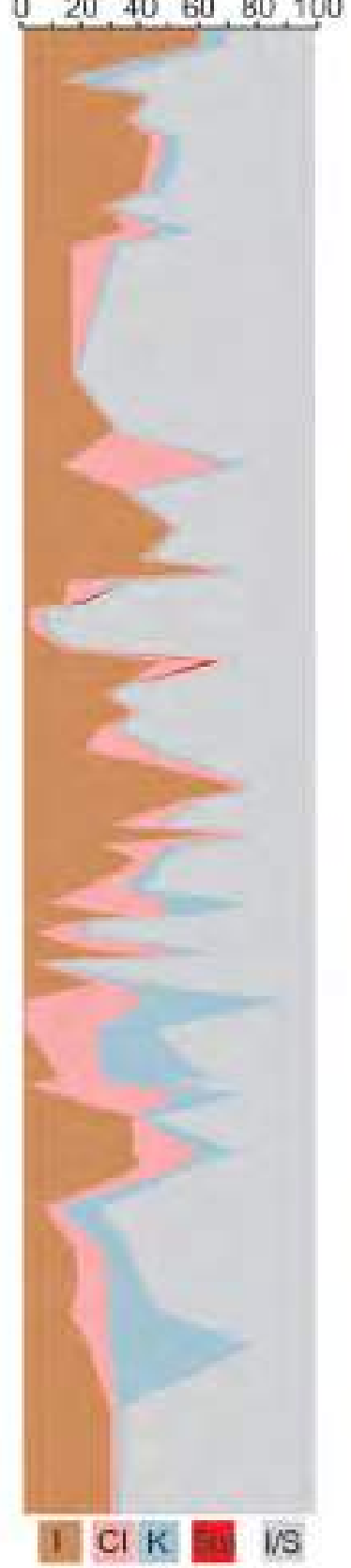

Roca Total

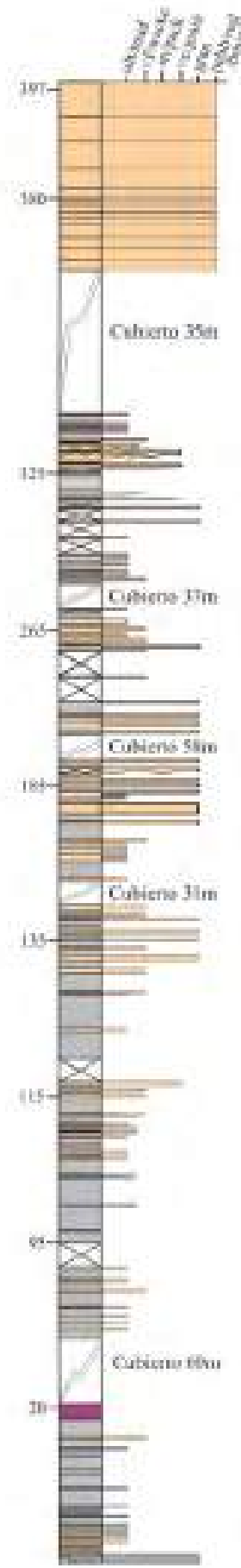

Argilominerales

$0,20,40,60,80,100 \quad 0,20,40,60,80,100$
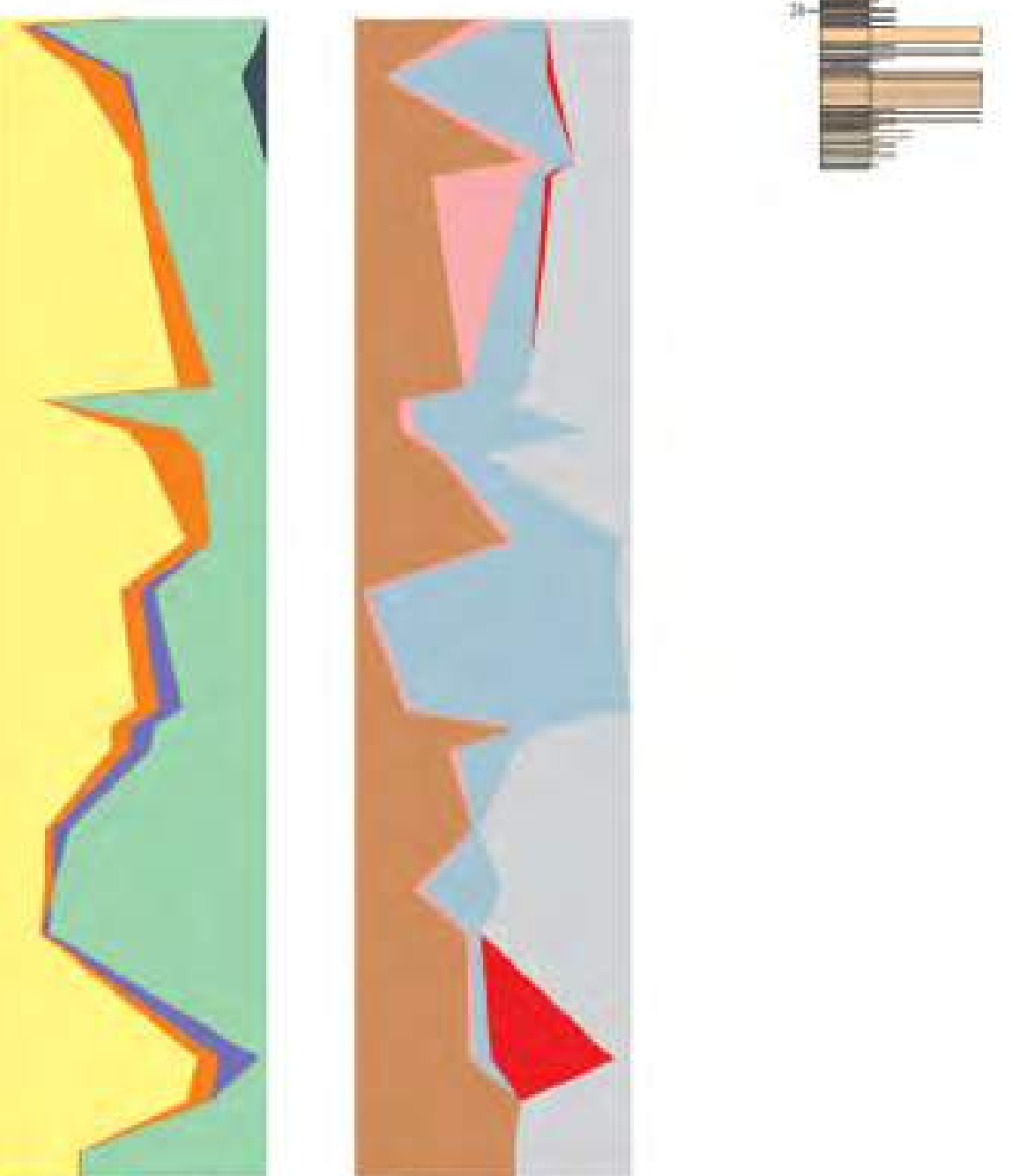

Q PIFI Ca
Cuesta del Chihuido

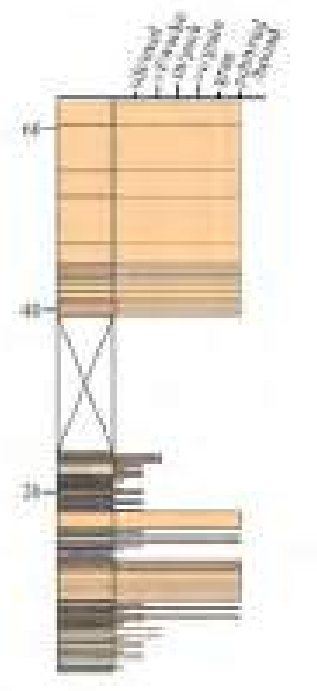

Roca Total

Argilominerales

$\begin{array}{lllllllllll}20 & 40 & 60 & 80 & 100 & 0 & 20 & 40 & 60 & 80 & 100\end{array}$
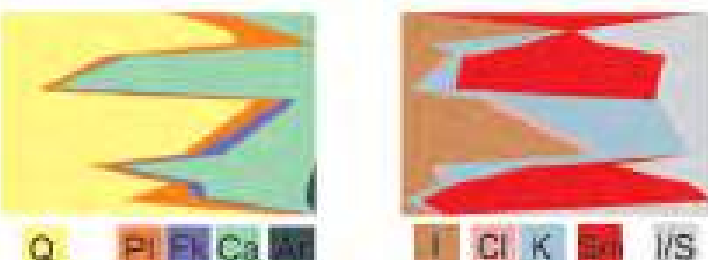

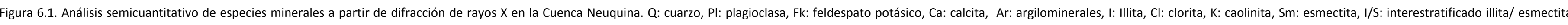




\subsubsection{Cuenca Austral}

Las treinta y cinco muestras analizadas fueron tomadas de los tres perfiles representativos de la Cuenca Austral, y corresponden a las facies pelitas negras (ver sección 5.2.1.1). La semicuantificación de las especies minerales obtenidas a partir de este estudio es representada de forma gráfica en la figura 6.2. La descripción composicional y la comparación entre los perfiles se detalla a continuación.

En los estudios de roca total se reconocieron proporciones variables de cuarzo, calcita, feldespatos alcalinos, plagioclasas y arcillas. El cuarzo es el mineral más abundante en todos los niveles de los tres perfiles. El contenido de plagioclasa disminuye en dirección sur-norte siendo muy escaso en la base del perfil Cerro Hobler y escaso en el tope, muy escaso a trazas en el perfil Río Guanaco y de trazas a ausente en la sección Subida del Chancho. El feldespato potásico solo se encuentra en proporciones de muy escasas a trazas, se reconoce en el perfil Cerro Hobler, donde aumenta su contenido hacia el tope desde trazas a muy escaso, y en ciertos niveles de los otros perfiles.

La calcita se encuentra en proporciones escasas a muy escasas en los perfiles Cerro Hobler y Río Guanaco, y aumenta en relación proporcional inversa respecto al contenido de cuarzo. De la misma manera que la calcita, las arcillas son más abundantes en las muestras con menor contenido de cuarzo en el perfil Subida del Chanco alcanzando concentraciones escasas hacia la base de la sección. En Cerro Hobler y Subida del Chancho las arcillas se encuentran en cantidades desde muy escasas a trazas. Otros minerales encontrados como trazas son pirita, yeso y siderita que se concentran en niveles aislados de los perfiles Cerro Hobler y Río Guanaco.

Entre los argilominerales se reconocieron illita, I/S, clorita, caolinita y esmectita. Existe una gran similitud composicional entre Cerro Hobler y Río Guanaco, ambos poseen contenidos moderados a abundantes de illita y clorita, moderados de $\mathrm{I} / \mathrm{S}$, y muy escasos a trazas de caolinita. Las principales diferencias entre ambas secciones radican en la abundancia de la esmectita, -que se encuentra en mayores proporciones en el perfil Cerro Hobler-y la tendencia al incremento de la illita y pérdida del I/S que se aprecia hacia la base del perfil Río Guanaco.

El perfil Subida del Chancho posee proporciones muy abundantes de caolinita que disminuyen a moderadas hacia el tope, acompañadas por el incremento de illita, que pasa de muy escaso a escaso y de $\mathrm{I} / \mathrm{S}$ que aumenta desde niveles muy escasos a muy abundantes. La clorita se presenta como trazas en todo el perfil mientras que la esmectita se concentra en niveles puntuales en proporciones muy escasas a moderadas (Fig. 6.2). 
Subida del Chancho

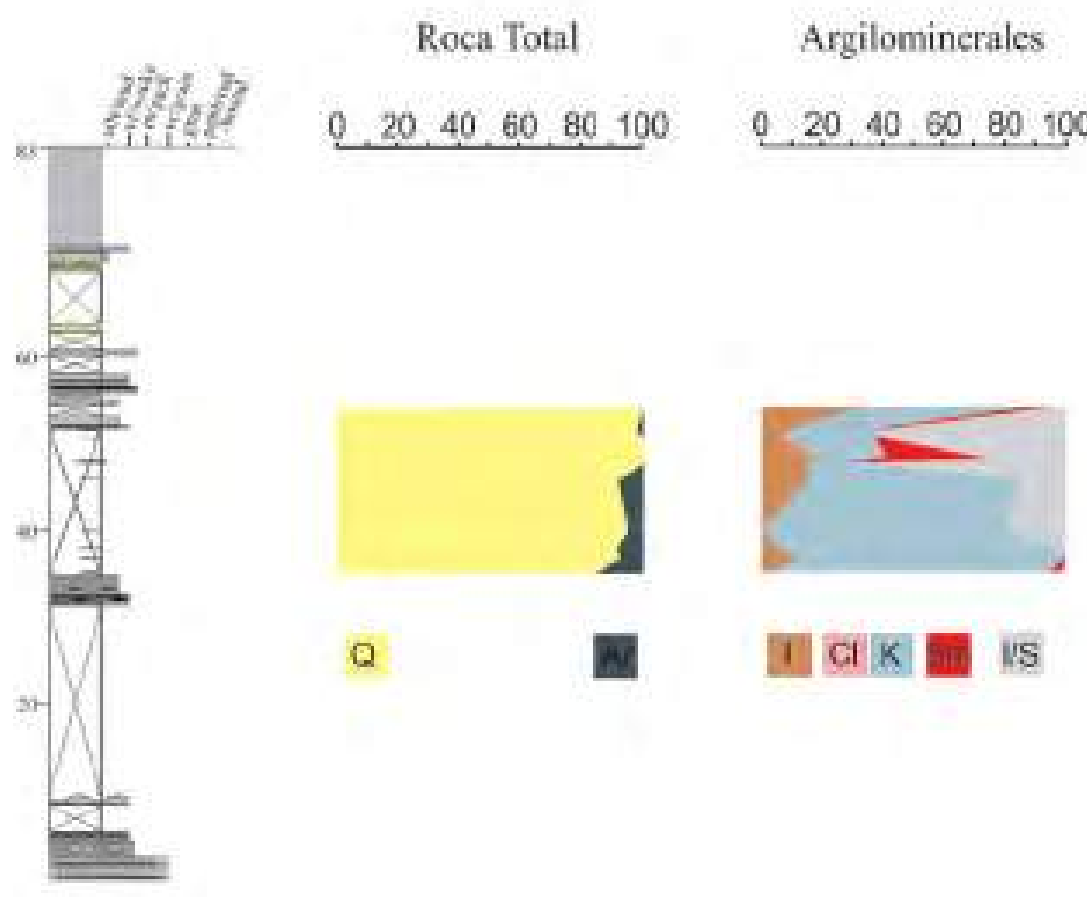

Rio Guanaco

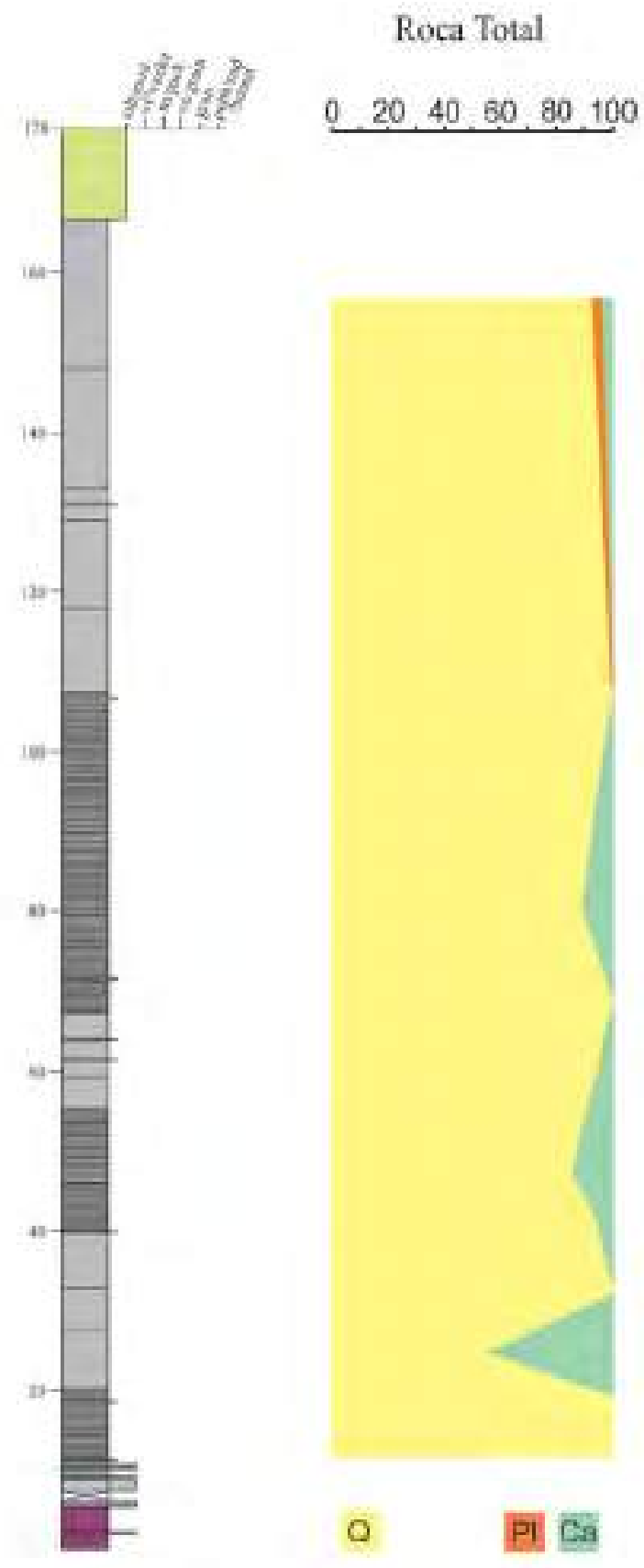

Cerro Hobler

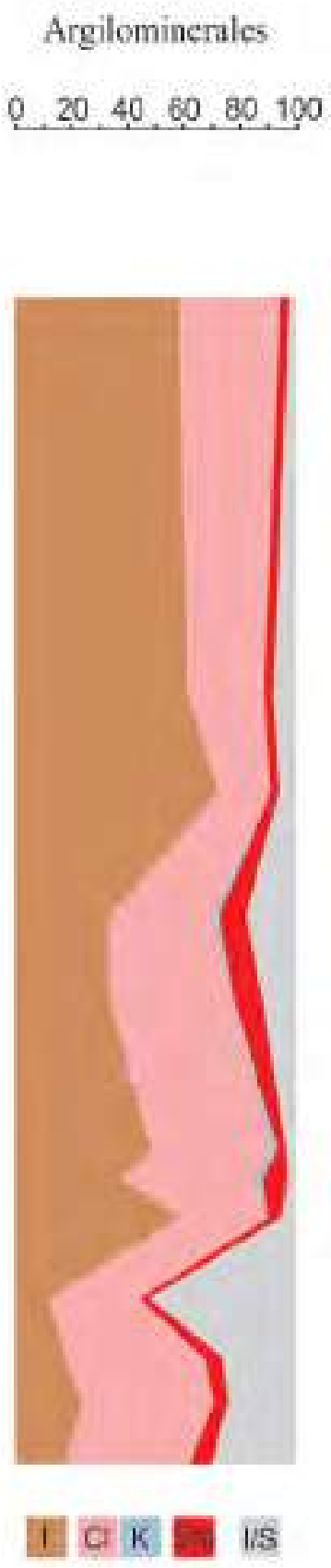

Roca Total

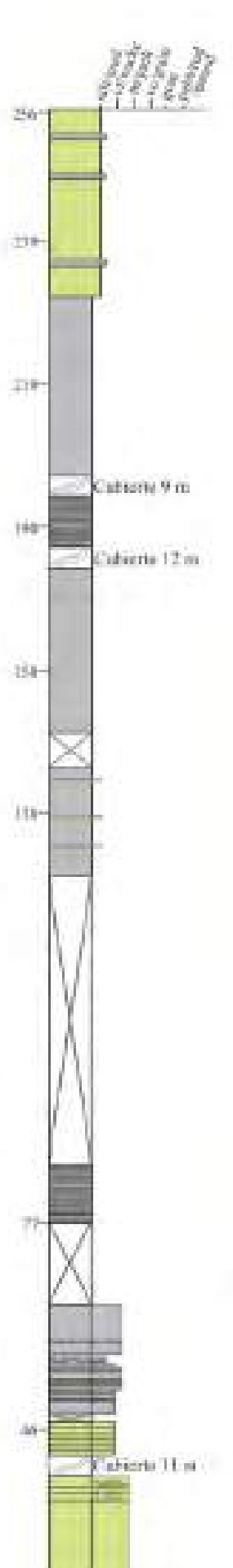

Argilominerales

$0.20,40,60,80.100$

$0.20 .40 \quad 60.80 .100$

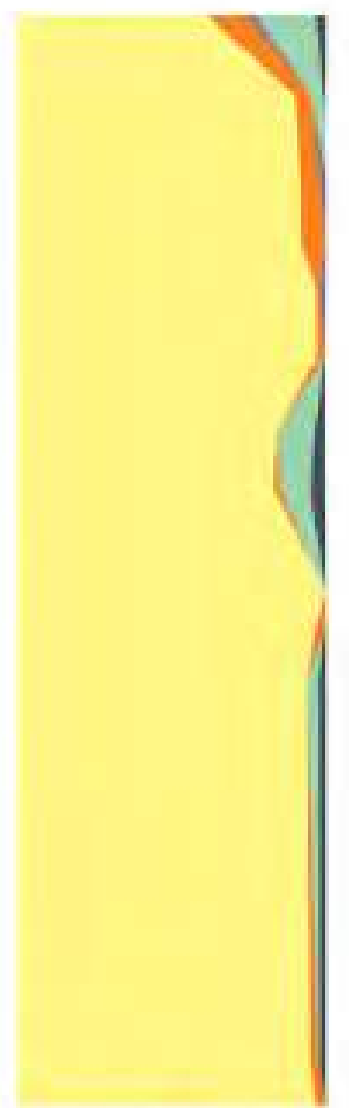

Q PIECa

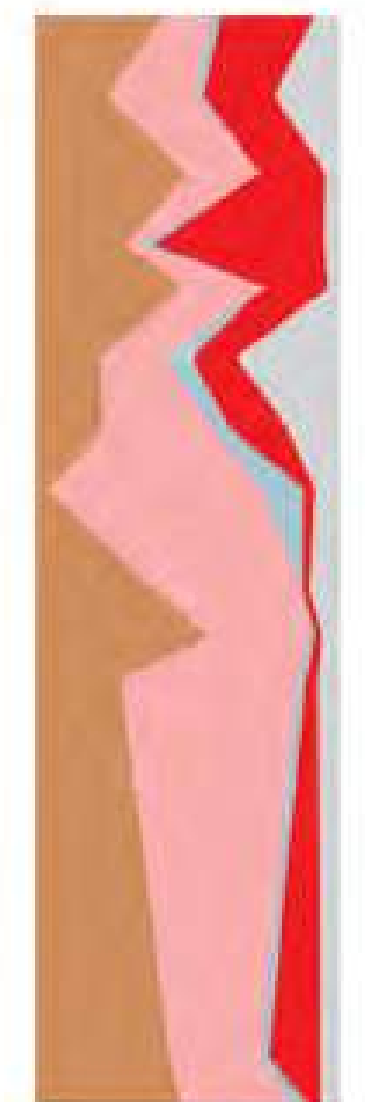

I C K E. I/ 


\subsection{Análisis composicional de psamitas silicoclásticas (Cuenca Austral)}

Para el análisis composicional de las psamitas silicoclásticas se describen en detalle trece secciones delgadas de muestras de areniscas y vaques correspondientes a los tres perfiles representativos de la Cuenca Austral (tres de Cerro Hobler, cinco de Río Guanaco y seis de la Subida del Chancho). Estas muestras forman parte de las facies de areniscas masivas, con estratificación horizontal, con estratificación entrecruzada tangencial, con estratificación entrecruzada en artesa y con óndulas (ver secciones 5.2.1.3, 5.2.1.5, 5.2.1.6, 5.2.1.7 y 5.2.1.8). A partir de estos estudios, las psamitas fueron clasificadas y se caracterizaron los componentes detríticos que las forman.

Es importante destacar que las muestras $\mathrm{SCH} 23 \mathrm{a}$ y $\mathrm{SCH} 23 \mathrm{c}$ poseen abundantes cantidades de granos de glauconita. Por esta razón, no serán clasificadas como el resto de las psamitas silicoclástica y su origen será discutido en el capítulo 8.

\subsubsection{Componentes detríticos}

Se han reconocido un total de siete componentes detríticos principales en las areniscas y vaques analizados: cuarzo monocristalino (Fig. 6.3 a y b), líticos volcánicos (Fig. 6.3 c y d), feldespato (Fig. 6.3 e y f), líticos sedimentarios (Fig. 6.3 g y h), mica (Fig. 6.4 a y b), materia orgánica (Fig. $6.4 \mathrm{c} \mathrm{y} \mathrm{d}$ ), minerales opacos (Fig. 6.4 e y f) y glauconita (Fig. $6.4 \mathrm{~g} \mathrm{y} \mathrm{h}$ ). A continuación se desarrollan las principales características de cada uno de los componentes.

\subsubsection{Cuarzo}

El cuarzo es el componente más abundante de las rocas estudiadas (Fig. 6.3 a y b), se presentan en cantidades de entre $6 \%$ y $67 \%$, con un promedio de $35 \%$. Se observaron clastos de cuarzo exclusivamente de tipo monocristalino, con formas angulosas y circulares en sección. Los granos presentan características típicas de origen volcánico, tales como extinción neta (no ondulatoria), superficies libres de inclusiones, formas bipiramidales, presencia (parcial) de caras cristalinas y perímetros con engolfamientos (Pettijohn et al., 1987; Tucker, 1988; Blatt, 1992). 


\subsubsection{Líticos volcánicos}

Estos clastos presentan una abundancia de entre $17 \%$ y $63 \%$ con un promedio de $29,44 \%$. Sus formas son muy poco circulares en sección y van desde subredondeados a subangulosos, (Fig. $6.3 \mathrm{c} \mathrm{y} \mathrm{d}$ ). Composicionalmente, existe un dominio de los componentes ácidos, la mayoría de los fragmentos líticos presentan texturas microcristalinas generadas por desvitrificación, también abundan los clastos compuestos íntegramente por pastas felsíticas. En menor medida también se registraron fenocristales de feldespatos potásico y cuarzo inmersos en una pasta afanítica (composición riolítica).

\subsubsection{Feldespato}

Se encuentran casi en la totalidad de las muestras en cantidades que oscilan entre $0,5 \%$ y $16 \%$, con un valor promedio de $6 \%$. Se aprecia como clastos con formas variadas, con secciones muy poco circulares a circulares y desde angulosas a subangulosas (Fig. 6.3 e y f). Se reconocieron tanto plagioclasas como feldespatos potásicos. Las plagioclasas son menos abundantes y composicionalmente se trata de variedades sódicas del tipo de la oligoclasa y andesina (Richiano, 2012). Además, se reconocieron maclas polisintéticas rectas, vinculadas a un origen ígneo (Blatt, 1992). Los feldespatos potásicos en tanto, son más abundantes y están compuestos casi en su totalidad por ortosa; se encuentran en general corroídos o presentando alteración argílica (de modo disperso o siguiendo planos de maclas). En ocasiones se observan maclas de Carlsbad. Menos frecuentemente muestran maclas en enrejado y cuneiforme, por lo que se caracterizan como granos de microclino.

\subsubsection{Líticos sedimentarios}

Corresponden a areniscas con cantidades variables de matriz (Fig. $6.3 \mathrm{~g} \mathrm{y} \mathrm{h}$ ). Se encuentran en proporciones de entre $0,5 \%$ y $10 \%$ (3,04\% en promedio) y presentan formas circulares y angulosas en sección. Composicionalmente presentan cuarzo monocristalino y feldespato potásico. 


\subsubsection{Micas}

Se encuentran muy distribuidas entre las muestras pero en proporciones muy escasas, entre $0,25 \%$ y $0,75 \%$ con un valor promedio de $1,75 \%$. La muestra $\mathrm{SCH} 16$ posee un valor anómalo de 7,75\%. Los clastos presentan secciones laminares y muy angulosas (Fig. 6.4 a y b).

Se reconocieron tanto biotita como muscovita, siendo las primeras más frecuentes. Ambas presentan clivaje y extinción paralela. Mientras la muscovita se presenta incolora con luz normal y con colores de interferencia brillantes de segundo orden con nicoles cruzados, la biotita posee color castaño con pleocroismo con luz trasmitida y menor birrefringencia con luz polarizada (Tucker et al., 1988).

\subsubsection{Materia orgánica}

Los restos de materia orgánica se presentan dispersos tanto en la matriz como en los bordes de los granos. Su abundancia varía entre $0,25 \%$ y $2 \%$ con un promedio de $0,67 \%$ (Fig. 6.4 c y d). Se trata de fragmentos de materia orgánica opacos y con tamaños y formas variadas, desde equidimensionales hasta en láminas. Si bien se trata de material detrítico, no se descarta que en parte la materia orgánica pueda tener origen autóctono.

\subsubsection{Minerales opacos}

Se trata de minerales opacos a la luz polarizada, tales como óxidos y sulfuros. Se encuentran dispersos en la matriz y en los bordes de minerales y su abundancia nunca supera el 0,5\% de la muestra. El principal componente reconocido es la pirita que presenta una forma angulosa y circular en sección (Fig. 6.4 e y f).

\subsubsection{Glauconita}

La glauconita sólo se encuentra en dos muestras correspondientes al tope del perfil Subida del Chancho, con una abundancia del $46 \%$ y $48 \%$ respectivamente. Se presenta en granos de color verde con o sin analizador de formas subangulosas a bien redondeadas y muy circulares en sección (Fig. 6.4 g y h). 

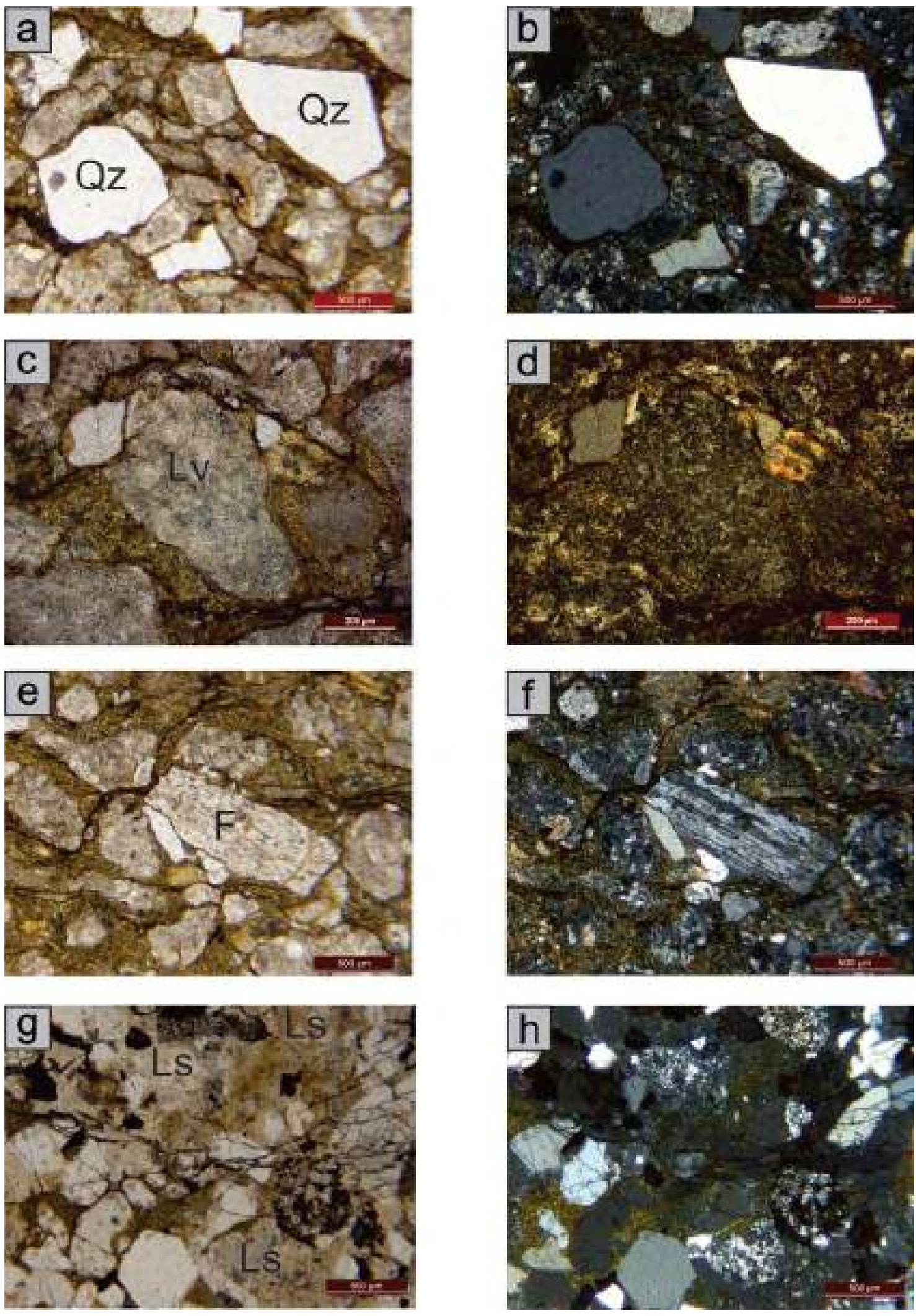

Figura 6.3. Microfotografías de componentes detríticos, en todos los casos se muestran con y sin nicoles. A y b: cuarzo monocristalino, c y d: lítico volcánico, e y f: feldespato, g y h: lítico sedimentario. 

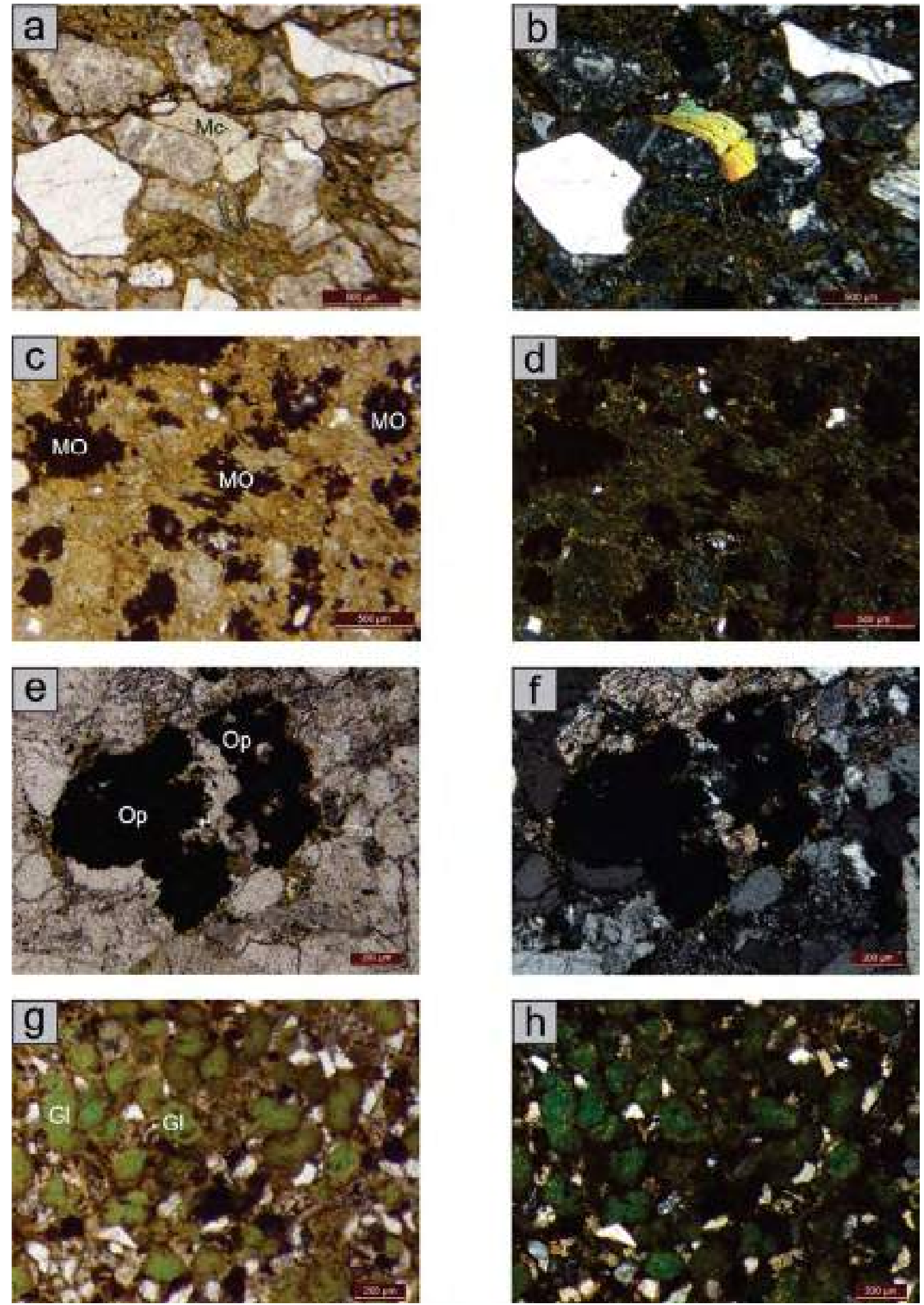

Figura 6.4. Microfotografías de componentes detríticos, en todos los casos se muestran con y sin nicoles. A y b: mica, c y d: materia orgánica, e y f: opaco, g y h: glauconita. 


\subsubsection{Clasificación de psamitas}

Las muestras de psamitas analizadas para la Cuenca Austral se ubican en el campo de las litoarenitas, con la excepción de una muestra del perfil Río Guanaco que se trata de una litoarenita feldespática según la clasificación de Folk et al. (1970) (Fig. 6.5). También se utilizó la clasificación de Dott (1964) modificada por Pettijhon et al. (1972), la cual discrimina por el contenido de matriz, en arenitas y vaques. En este caso, dos muestras de Río Guanaco y dos de Subida del Chancho se ubican en el campo de los vaques líticos, mientras que el resto de las muestras analizadas corresponden a las arenitas líticas (Fig. 6.6).

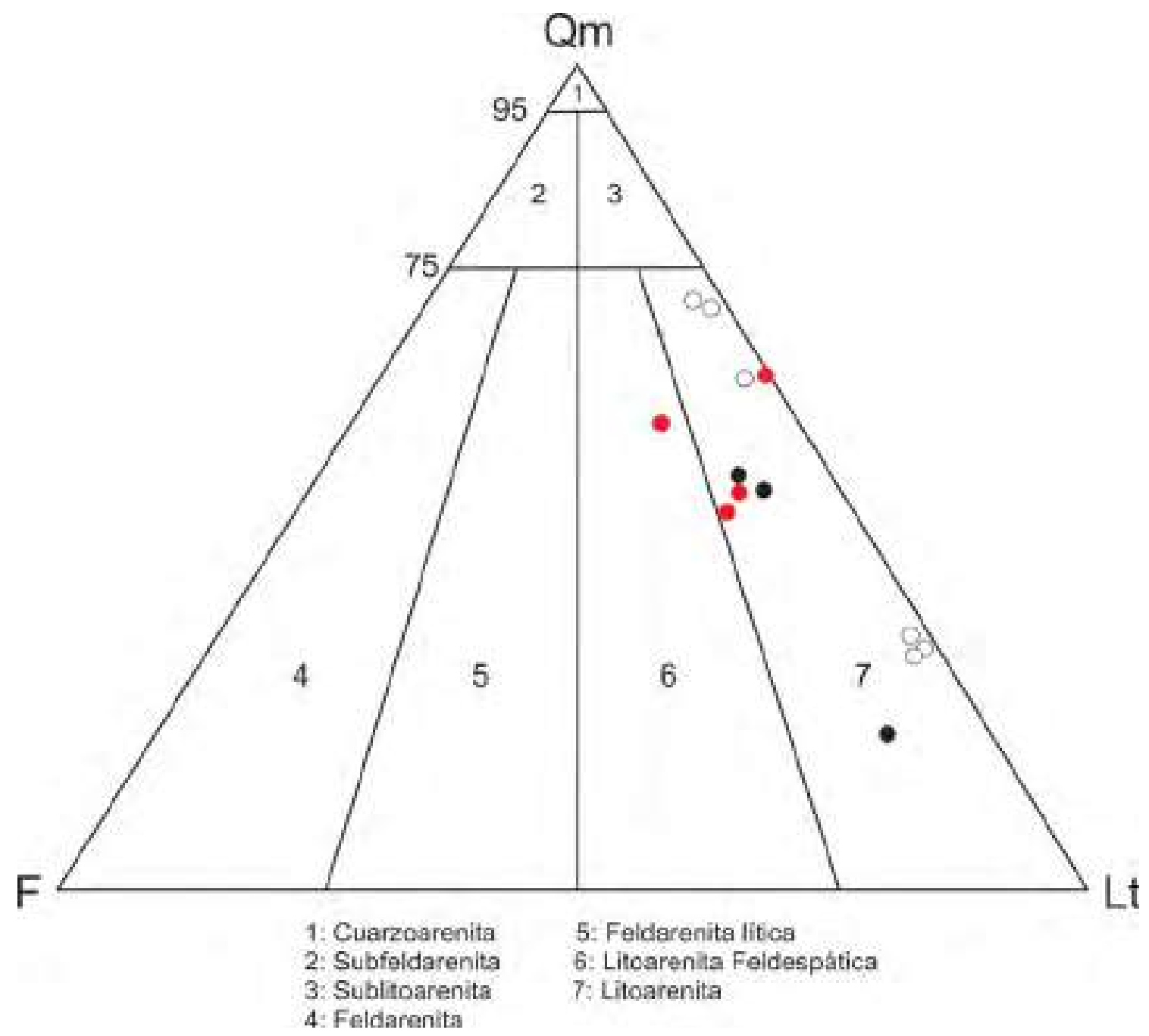

Figura 6.5. Clasificación de psamitas según Folk et al. (1970). Qm: cuarzo monocristalino, F: feldespato, Lt: líticos totales. Las muestras de color negro corresponden al perfil Cerro Hobler, las de color rojo a Río Guanaco y las de color blanco a Subida del Chancho. 

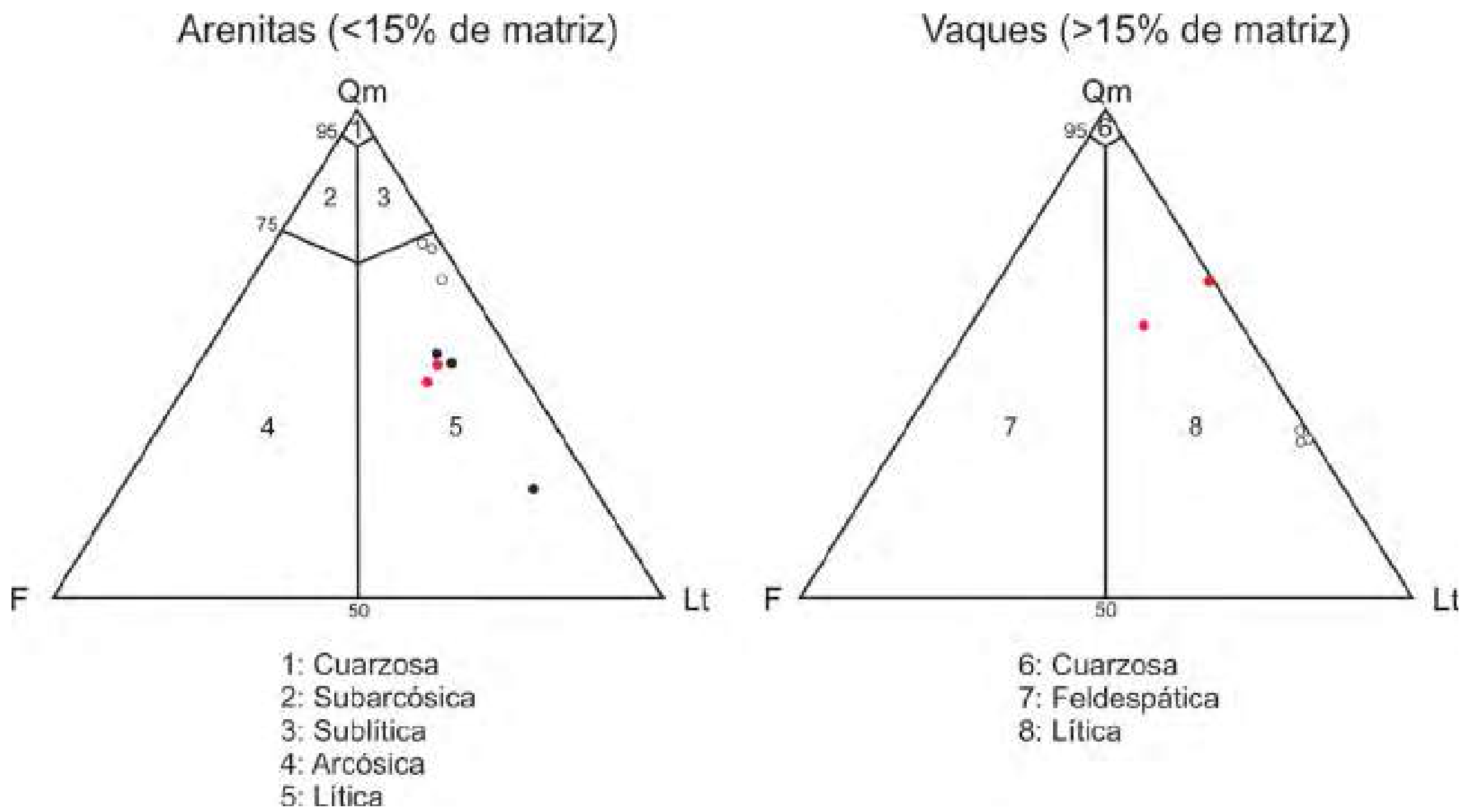

Figura 6.6. Clasificación de psamitas según Dott (1964) modificada por Pettijohn et al. (1972). Qm: cuarzo monocristalino, F: feldespato, Lt: líticos totales. Las muestras de color negro corresponden al perfil Cerro Hobler, las de color rojo a Río Guanaco y las de color blanco a Subida del Chancho. 


\subsection{Análisis composicional de psefitas silicoclásticas}

Las psefitas constituyen la granulometría menos abundante en las áreas seleccionadas para este estudio, sólo están representadas por una facies correspondiente a la Formación Springhill en el perfil Subida del Chancho.

La facies de sábulitas masivas (ver sección 5.2.1.9) fue analizada mediante conteo de clastos en el campo, en orden de abundancia se registraron líticos volcánicos, cuarzo monocristalino y líticos sedimentarios. Texturalmente posee matriz arenosa, y fue clasificada según los criterios de Scasso y Limarino (1997) como clasto ortoconglomerados líticos (Fig. $6.7)$.

ORTOCONGLOMERADO

(MATRIZ ARENOSA)

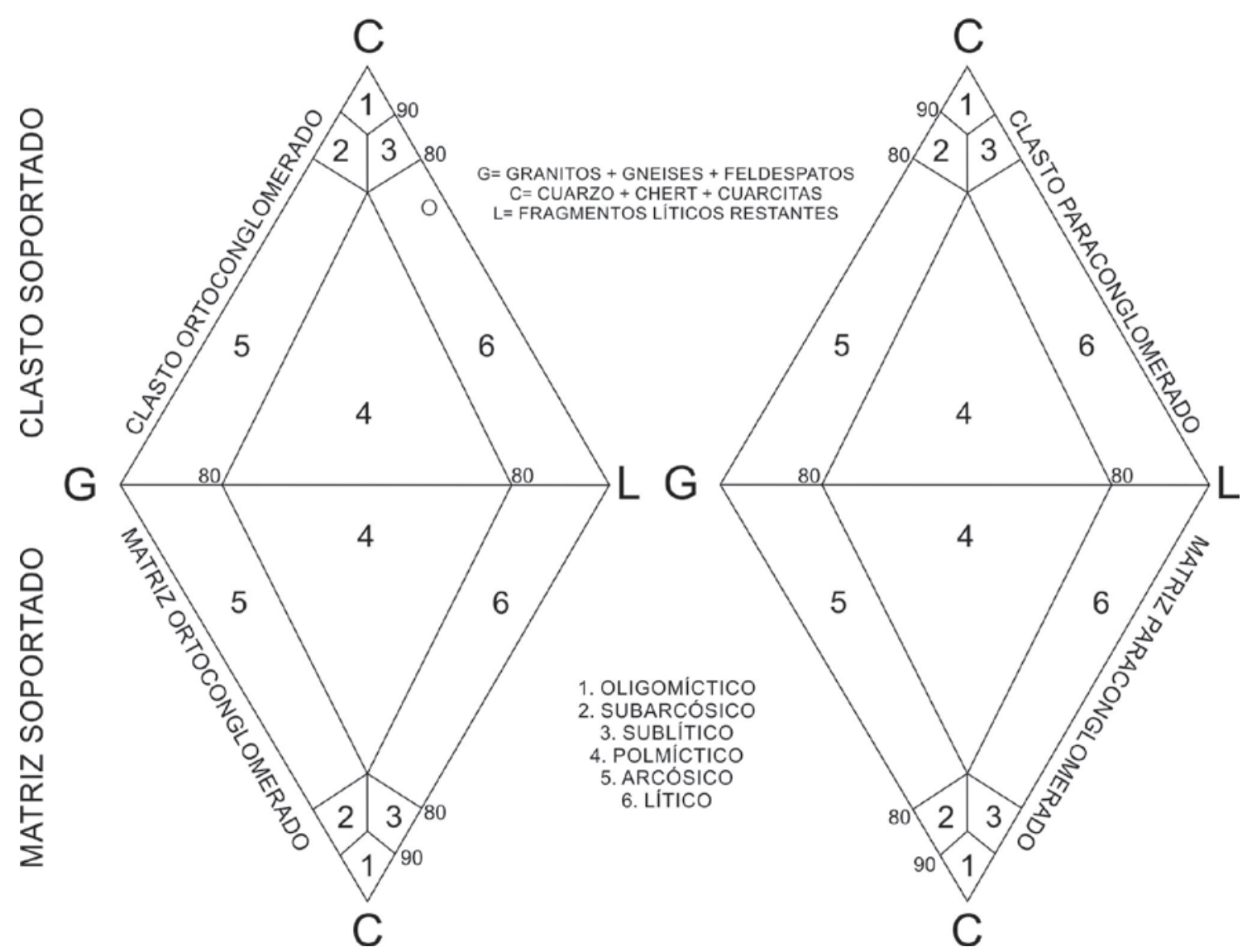

Figura 6.11: Clasificación de psefitas según Scasso y Limarino (1997). El círculo de color blanco indica la ubicación de la muestra correspondiente a las psefitas del perfil Subida del Chancho. 


\subsection{Análisis composicional de carbonatos (Cuenca Neuquina)}

Para el estudio composicional de los niveles carbonáticos se analizaron sesenta y una muestras de los tres perfiles representativos de la Cuenca Neuquina (veinticinco de Río Salado, veintiuna de Puesto Loncoche y quince de la Cuesta del Chihuido). Estas muestras forman parte de las facies de wackestones masivos, wackestones laminados, packstones masivos, packstones laminados, packstones con estructuras monticulares, floatstones masivos, rudstones masivos, rudstones con estructuras monticulares y bindstones masivos (ver secciones 5.2.3.1, 5.2.3.2, 5.2.3.4, 5.2.3.5, 5.2.3.6, 5.2.3.7, 5.2.3.8, 5.2.3.9 y 5.2.4.1).

A partir del exhaustivo análisis de las láminas delgadas y teniendo en cuenta criterios texturales, tales como el tamaño de los componentes y la presencia de fango, se corroboraron a escala microscópica las clasificaciones realizadas inicialmente en los afloramientos. Tanto para las observaciones de campo como para las de laboratorio se utilizó la clasificación de Dunham (1961) modificada por Embry y Klovan (1972).

Sobre la base del estudio de las láminas delgadas se caracterizó la composición de las rocas carbonáticas, la cual resulta íntegramente esqueletal. Se reconocieron un total de once componentes: foraminíferos (Fig. 6.8 a y b), radiolarios (Fig. 6.8 c y d), bivalvos no ostreidos (Fig. 6.8 e y f), bivalvos ostreidos (Fig. $6.8 \mathrm{~g}$ y h), braquiópodos (Fig. 6.9 a y b), gasterópodos (Fig. 6.9 c y d), briozoos (Fig. 6.9 e y f), serpúlidos (Fig. 6.9 g y h), poríferos (Fig. 6.10 a y b), equinodermos (Fig. $6.10 \mathrm{c} \mathrm{y} \mathrm{d}$ ) y amonites.

Otro elemento caracterizado a escala microscópica es la composición mineralógica de los distintos restos fosilíferos. Todos estos elementos están compuestos por calcita con bajo contenido de magnesio (LMC) que una vez teñidos se observan de color rojo (Fig. 6.11 a, b y d), a excepción de algunos radiolarios (originalmente habrían sido silíceos y posteriormente sustituidos por calcita), foraminíferos y bivalvos no ostreidos compuestos por calcita ferrosa, por lo que se observaron teñidos de color azul (Fig. 6.11 c). Estos últimos, corresponden a niveles ubicados en la base de la Formación Vaca Muerta en el perfil Río Salado.

Por último, se puso especial énfasis en la caracterización del grado de preservación tafonómica de los restos fosilíferos. En este sentido, es importante destacar que se analizaron fragmentos de los mismos géneros fósiles desde totalmente fragmentados constituyendo wackestones hasta con las valvas articuladas y en posición de vida formando parte de bindstones. En la tabla 6.2 se compendian las principales características generales, tafonómicas y mineralógicas de cada uno de los componentes esqueletales. 


\begin{tabular}{|c|c|c|c|c|}
\hline Bioclastos & Características & Composición & Tafonomía & Abundancia \\
\hline Foraminíferos & $\begin{array}{l}\text { Principalmente Epistomina Sp., y otros más escasos } \\
\text { no determinados. Ejemplares de entre } 50 \text { y } 200 u m \\
\text { de tamaño }\end{array}$ & $\begin{array}{l}\text { LMC/ Calcita } \\
\text { Ferrosa }\end{array}$ & $\begin{array}{l}\text { Buena preservación } \\
\text { tafonómica }\end{array}$ & $\begin{array}{l}\text { Muy abundantes } \\
\text { en facies de Lc, } \\
\text { Wm, WI, Pm, PI. } \\
\text { Moderado en } \\
\text { facies Fm y Rm }\end{array}$ \\
\hline Radiolarios & Ejemplares de entre 50 y $200 u m$. & $\begin{array}{l}\text { LMC/ Calcita } \\
\text { Ferrosa }\end{array}$ & $\begin{array}{l}\text { Buena preservación } \\
\text { tafonómica }\end{array}$ & $\begin{array}{l}\text { Muy abundantes } \\
\text { en facies de Lc, } \\
\text { Wm, WI, Pm, PI. } \\
\text { Moderado en } \\
\text { facies Fm y Rm }\end{array}$ \\
\hline $\begin{array}{l}\text { Bivalvos no } \\
\text { ostreidos }\end{array}$ & $\begin{array}{l}\text { Fragmentos de entre } 300 \text { y } 800 \text { um de tamaño. } \\
\text { Mesoscópicamente se reconocieron ejemplares de } \\
\text { Eryphila sp., Ptychomya sp., Pecten sp., Pinna sp., } \\
\text { Trigonia sp. y Cucullaea sp. }\end{array}$ & $\begin{array}{l}\text { LMC/ Calcita } \\
\text { Ferrosa }\end{array}$ & $\begin{array}{l}\text { Su grado de preservación es } \\
\text { muy variable. Se observan } \\
\text { ejemplares con alto grado de } \\
\text { fragmentación en facies de } \\
\text { Pm, Pl, Wm, Wl; y altos niveles } \\
\text { de articulación y bioerosión en } \\
\text { facies de Bm. }\end{array}$ & $\begin{array}{l}\text { Desde moderado a } \\
\text { muy abundantes } \\
\text { en todas las facies. }\end{array}$ \\
\hline
\end{tabular}




\begin{tabular}{|c|c|c|c|c|}
\hline $\begin{array}{l}\text { Bivalvos } \\
\text { ostreidos }\end{array}$ & $\begin{array}{l}\text { Se observan fragmentos de entre } 200 u m \text { y } 2 \mathrm{~mm} \text {. } \\
\text { Mesoscópicamente se reconocieron Ceratostreon sp. } \\
\text { y Aetostreon sp. de hasta } 10 \mathrm{~cm} \text {, siendo este último } \\
\text { más frecuente en las facies más gruesas }\end{array}$ & $\begin{array}{l}\text { LMC/ Calcita } \\
\text { Ferrosa }\end{array}$ & $\begin{array}{l}\text { Su grado de preservación es } \\
\text { muy variable. Se observan } \\
\text { ejemplares con alto grado de } \\
\text { fragmentación en facies de } \\
\text { Pm, Pl, Wm, Wl; y altos niveles } \\
\text { de articulación, incrustación y } \\
\text { bioerosión en facies de Rm, } \\
\text { Fm y Bm. }\end{array}$ & $\begin{array}{l}\text { Abundantes en } \\
\text { facies de Fm, Rm, } \\
\text { Ro y Bm. De } \\
\text { moderados a } \\
\text { escasos en facies } \\
\text { de Pm, Pl y Po }\end{array}$ \\
\hline Braquiópodos & $\begin{array}{l}\text { Se reconocieron ejemplares desde } 200 u m \text { hasta } \\
2 \mathrm{~mm} \text { y se reconocieron especies punctuadas e } \\
\text { impuctuadas y otras altamente ornamentadas. } \\
\text { Mesoscópicamente se identificaron ejemplares de } \\
\text { varios centímetros de tamaño }\end{array}$ & LMC & $\begin{array}{l}\text { En las facies Pm, Pl, Wm y WI, } \\
\text { se aprecian con altos niveles } \\
\text { de fragmentación. En facies } \\
\text { Rm y Fm se observan desde } \\
\text { fragmentados hasta } \\
\text { articulados. Se apreciaron } \\
\text { ejemplares en perfecta } \\
\text { conservación en las facies Bm. }\end{array}$ & $\begin{array}{l}\text { Moderados en } \\
\text { facies de Fm y Rm }\end{array}$ \\
\hline Gasterópodos & Se observan ejemplares desde $200 u m$ hasta $2 \mathrm{~cm}$. & LMC & Poseen un alto grado de & Moderados en \\
\hline
\end{tabular}




\begin{tabular}{|c|c|c|c|c|}
\hline & $\begin{array}{l}\text { Generalmente monoseriados y muy ornamentados. } \\
\text { Se reconoció Dicroloma sp. }\end{array}$ & & $\begin{array}{l}\text { preservación, la } \\
\text { fragmentación es baja y posee } \\
\text { varabiable grado de } \\
\text { redondeamiento observable } \\
\text { en la ornamentación }\end{array}$ & facies de Fm y Rm \\
\hline Briozoos & Se identifican valvas que varían entre 1 y $3 \mathrm{~mm}$. & LMC & $\begin{array}{l}\text { Bajo grado de preservación } \\
\text { tafonómica. Altos niveles de } \\
\text { fragmentación. }\end{array}$ & $\begin{array}{l}\text { Escasos en facies } \\
\text { de Fm }\end{array}$ \\
\hline Serpúlidos & $\begin{array}{l}\text { Se reconocieron ejemplares desde } 200 \text { um hasta } 3 \mathrm{~cm} \\
\text { de tamaño. Principalmente Rotularia sp. y } \\
\text { Parsimonia sp. }\end{array}$ & LMC & $\begin{array}{l}\text { Alto grado de fragmentación } \\
\text { en } \mathrm{Fm}, \mathrm{Rm} \text { y } \mathrm{Pm} \text {. } \\
\text { Eventualmente se registran } \\
\text { ejemplares bien preservados } \\
\text { adheridos a ostras del género } \\
\text { Aetostreo } \mathrm{Sp} \text {. en facies Bm }\end{array}$ & $\begin{array}{l}\text { Abundantes a muy } \\
\text { abundantes en } \\
\text { facies de Fm y Rm, } \\
\text { escasos en Pm. } \\
\text { Asociados a la } \\
\text { aparición de } \\
\text { Aetostreon } \mathrm{Sp} \text {. }\end{array}$ \\
\hline Poríferos & $\begin{array}{l}\text { Se reconocieron fragmentos de ejemplares de 600um } \\
\text { de tamaño promedio. }\end{array}$ & LMC & $\begin{array}{l}\text { Muy bajo grado de } \\
\text { preservación. Altos niveles de } \\
\text { fragmentación y }\end{array}$ & $\begin{array}{l}\text { Escasos en facies } \\
\text { de Fm y Rm }\end{array}$ \\
\hline
\end{tabular}




\begin{tabular}{|c|c|c|c|c|}
\hline & & & redondeamiento. & \\
\hline Equinodermos & $\begin{array}{l}\text { Fragmentos de entre } 400 \text { y } 600 \text { um promedio que } \\
\text { eventualmente pueden llegar hasta } 1000 u m \text {. }\end{array}$ & LMC & $\begin{array}{l}\text { Poseen un bajo grado de } \\
\text { preservación. Las placas } \\
\text { poseen altos niveles de } \\
\text { fragmentación, no hay } \\
\text { conservación de espinas. }\end{array}$ & $\begin{array}{l}\text { Moderados a } \\
\text { abundantes en } \\
\text { facies de Fm, Rm, } \\
\text { Ro, Po y Bm }\end{array}$ \\
\hline Amonites & $\begin{array}{l}\text { Solo se observan a escala mesoscópica. Según } \\
\text { Kietzmann et al. (2015) se reconocen } \\
\text { Virgatosphinctes mendozanus, Pseudolissoceras } \\
\text { zitteli, Aulacospichtes proximus, Windhauseniceras } \\
\text { internispinosum, Corongoceras alternans, } \\
\text { Substeuroceras koeneni, Argentiniceras noduliferum, } \\
\text { Spiticeras damesi, Neocomites wichmani, Lissonia } \\
\text { riveroi, Olcostephanus (O.) atherrstoni y } \\
\text { Pseudofavrela angulatiformis }\end{array}$ & LMC & $\begin{array}{l}\text { El nivel de conservación es } \\
\text { muy variable y se registran } \\
\text { ejemplares recristalizados y } \\
\text { enteros, en fragmentos y } \\
\text { como moldes de tamaño } \\
\text { superior a los } 10 \mathrm{~cm} \text { en los } \\
\text { techos de los cuerpos }\end{array}$ & $\begin{array}{l}\text { Abundantes en } \\
\text { facies de Wm, Wl, } \\
\text { Pm, Pl, Po, Fm, Rm, } \\
\text { Ro y Bm. }\end{array}$ \\
\hline
\end{tabular}

Tabla 6.2: Características generales, tafonómicas y mineralógicas de cada una de los componentes esqueletales. LMC: calcita con bajo contenido en magnesio 

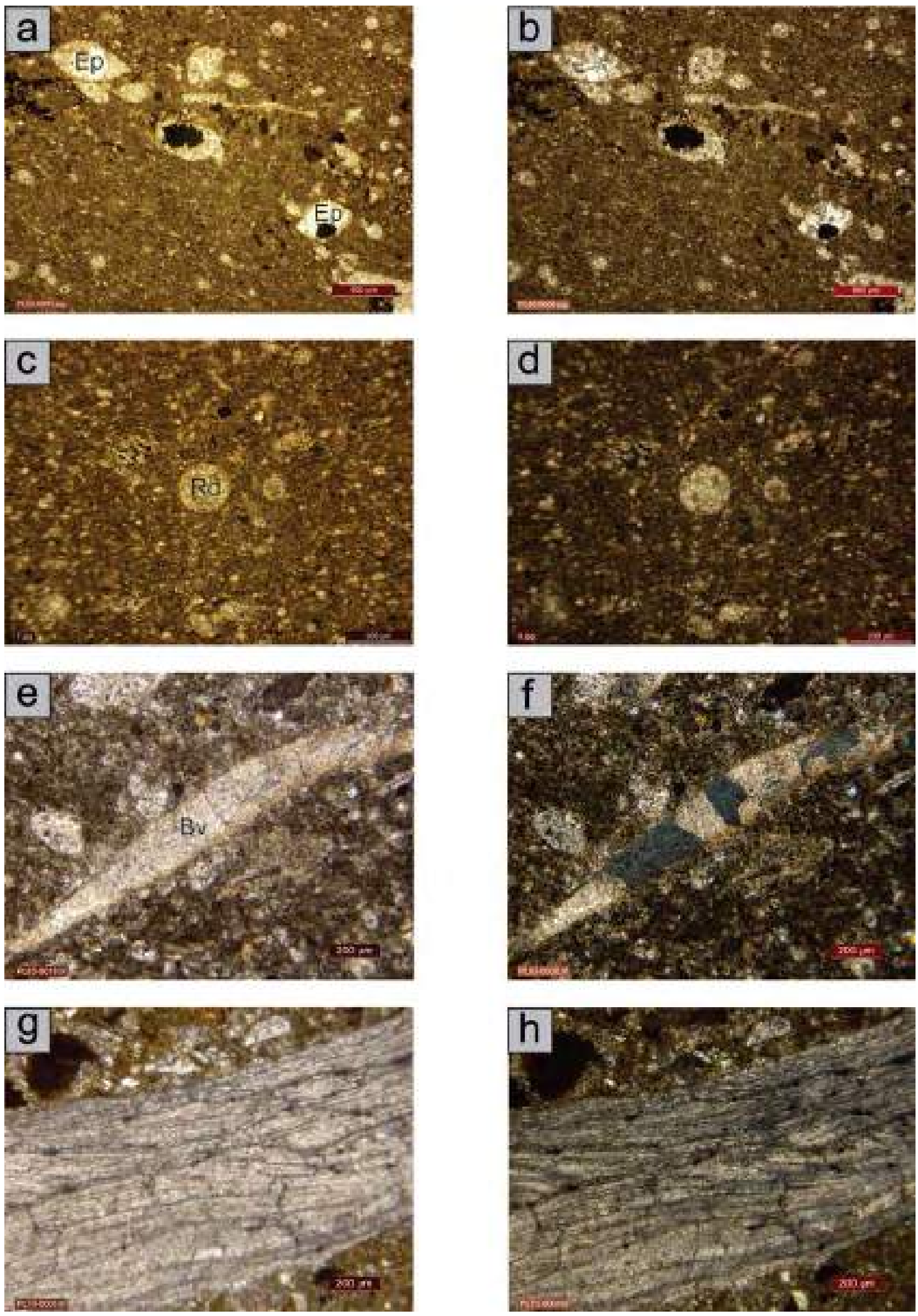

Figura 6.8. Microfotografías de componentes esqueletales, en todos los casos se muestran con y sin nicoles. A y b: foraminíferos epistomínidos, c y d: radiolarios, e y f: bivalvos no ostreidos, $\mathrm{g}$ y h: bivalvos ostreidos. 

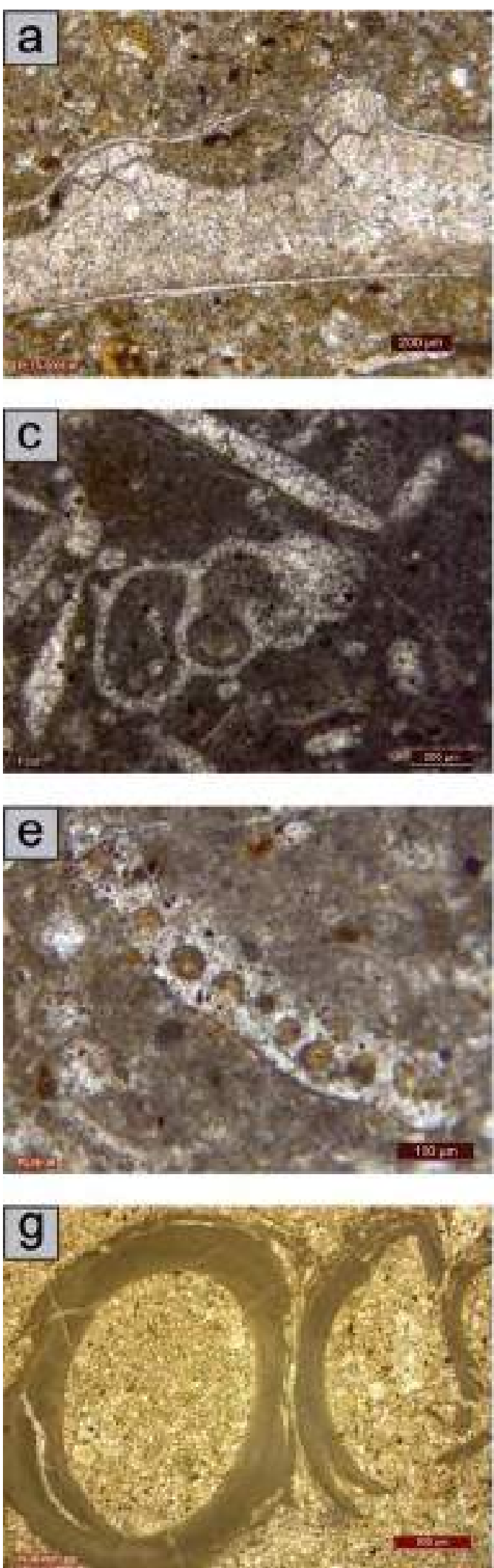

Figura 6.9. Microfotografías de componentes esqueletales, en todos los casos se muestran con y $\sin$ nicoles. A y b: braquiópodos, c y d: gasterópodos, e y f: briozoos, g y h: serpúlidos.
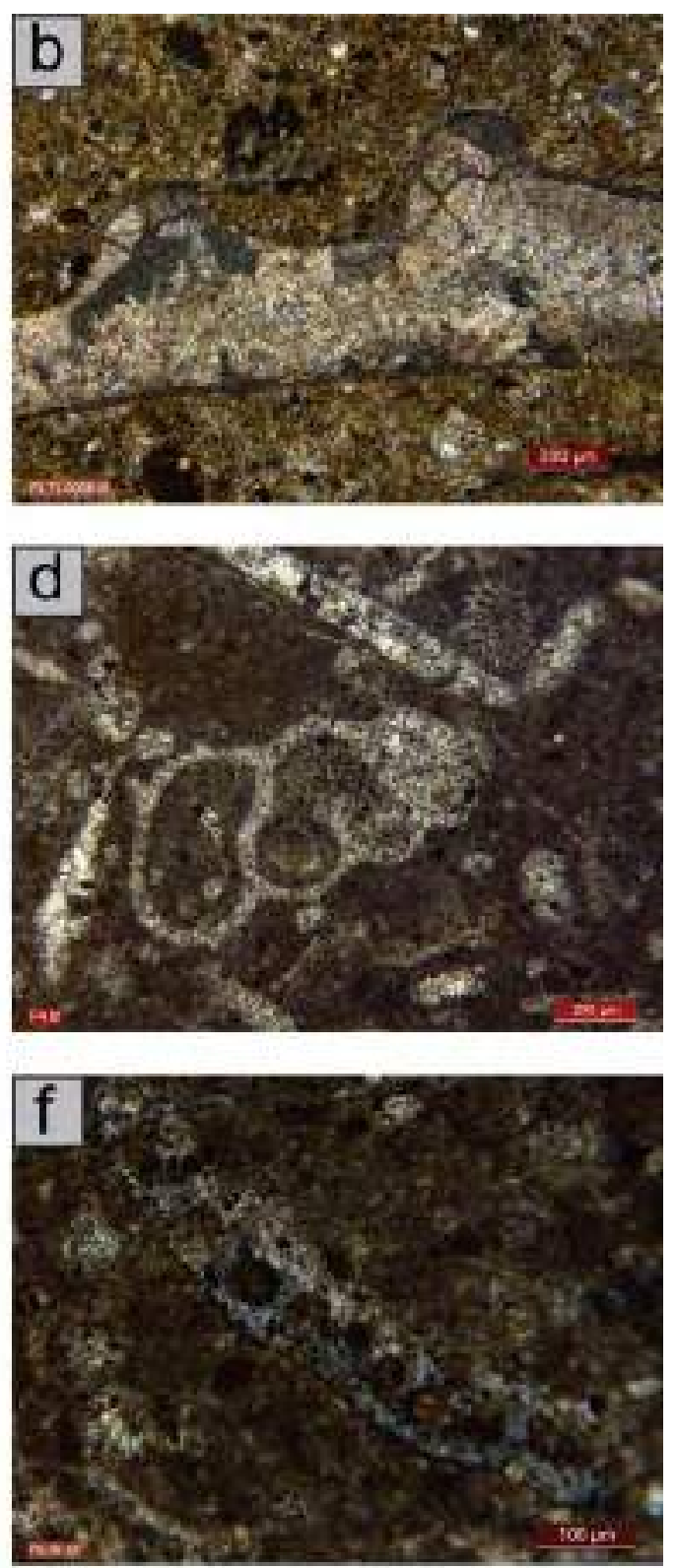

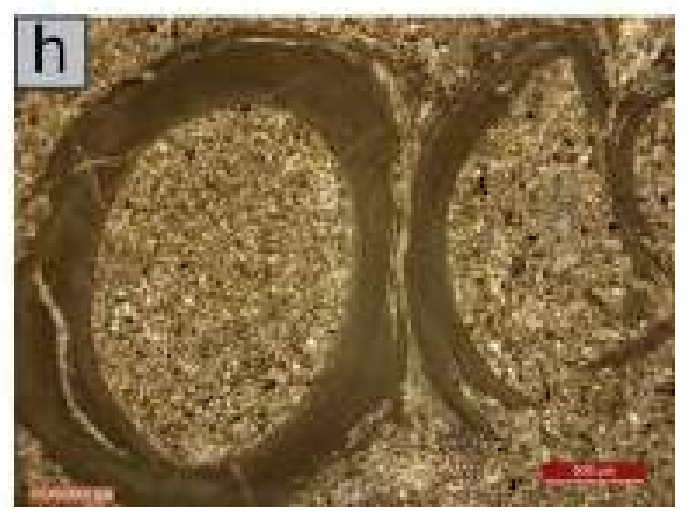



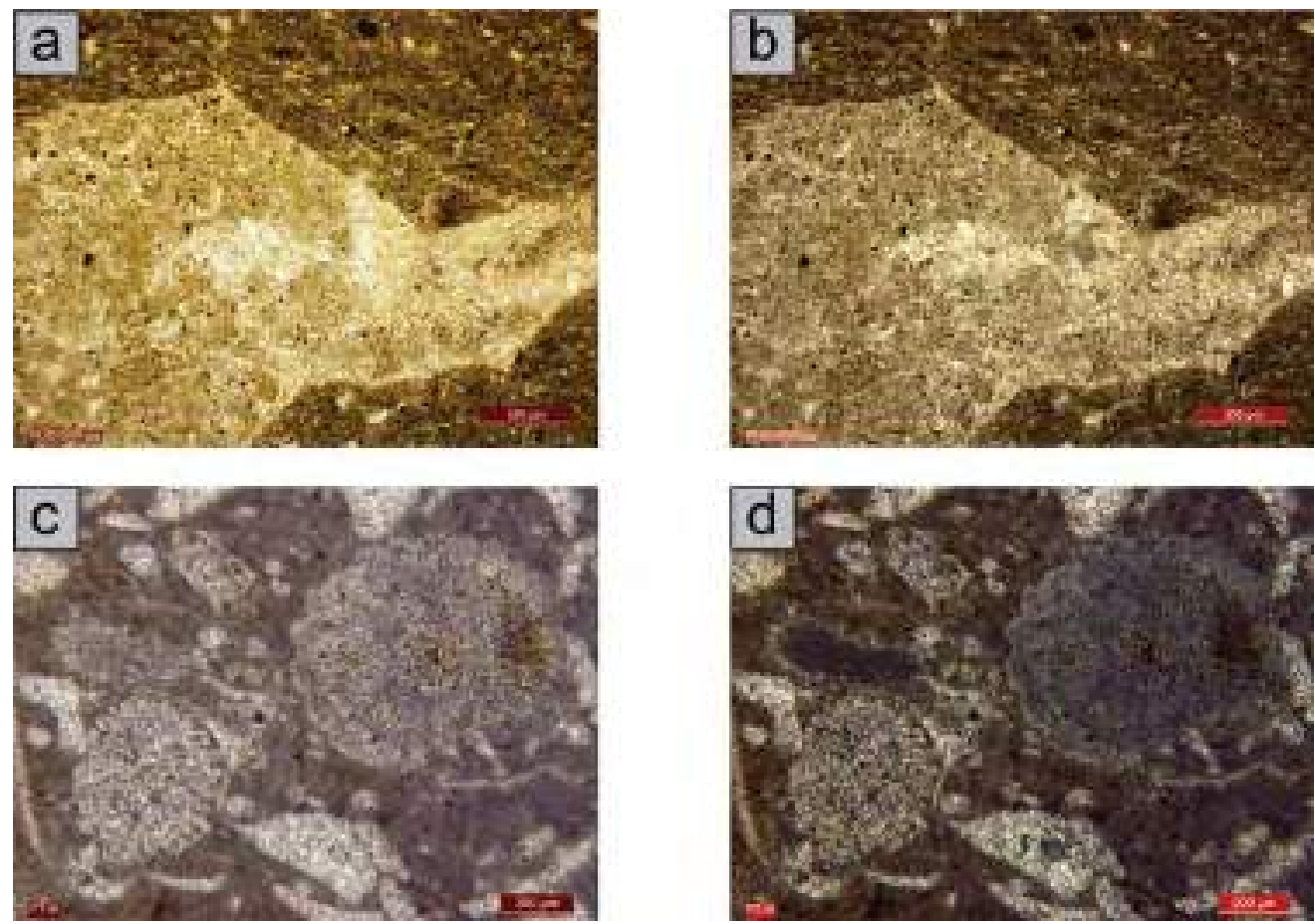

Figura 6.10. Microfotografías de componentes esqueletales, en todos los casos se muestran con y sin nicoles. A y b: poríferos, c y d: placas de equinodermos.
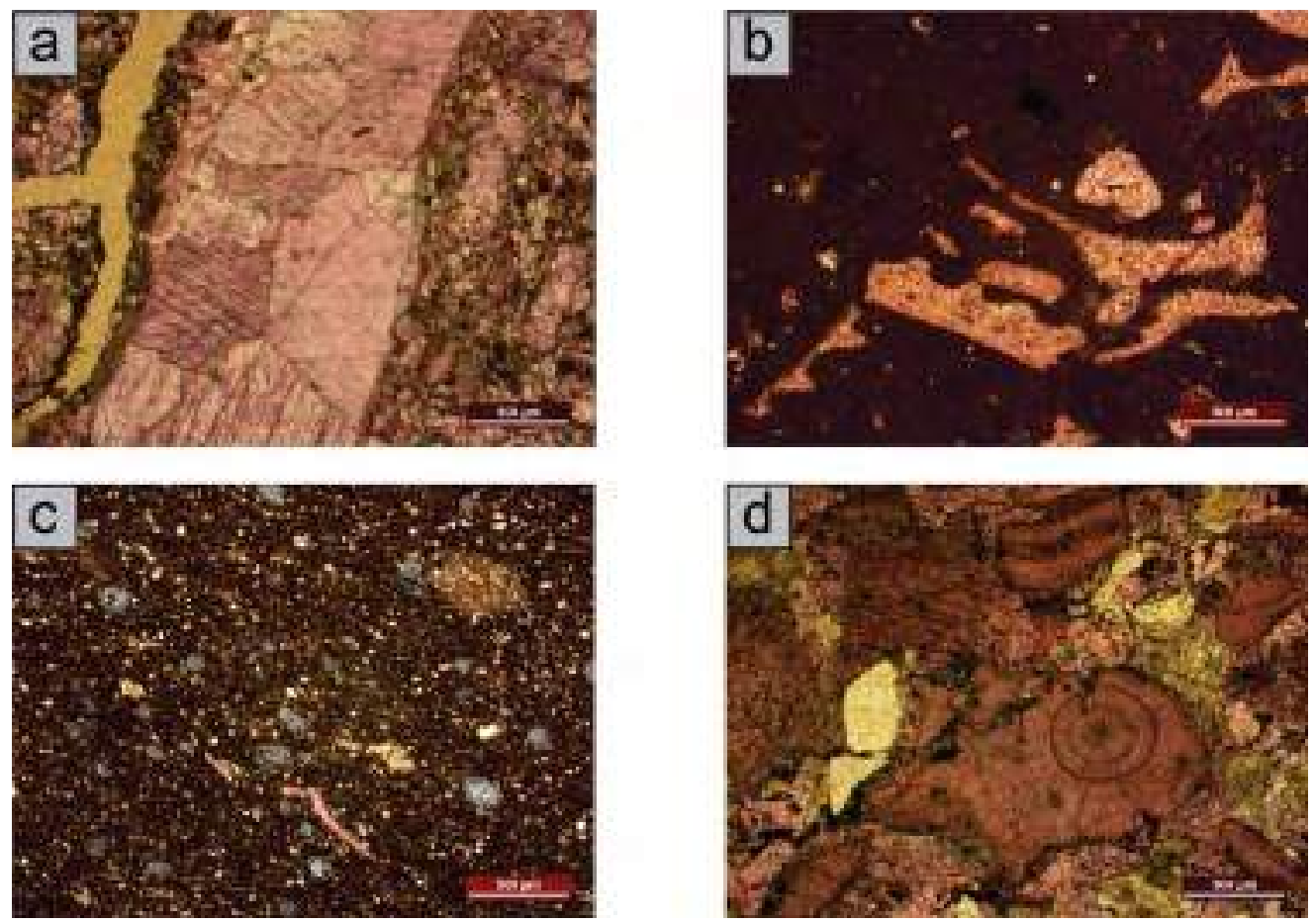

Figura 6.11. Microfotografías de componentes esqueletales teñidos. A: Fragmento de bivalvo correspondiente a facies de rudstone masivo compuesto por LMC (calcita con bajo contenido de magnesio), b: braquiópodos, bivalvos y foraminíferos correspondientes a facies de packstone masivo compuestos por LMC, c: fragmentos de bivalvos (LMC) y foraminíferos (calcita ferrosa) de facies de wackestone masivo y d: algas dasycladáceas y belemnites de LMC de facies de areniscas mixtas con fango silicoclástico. 


\subsection{Análisis composicional de rocas mixtas}

\subsubsection{Cuenca Neuquina}

Se analizaron cinco muestras (tres de Río Salado y dos de Puesto Loncoche) correspondientes a la facies areniscas mixtas con fango micrítico (ver sección 5.2.2.3). Se reconocieron elementos detríticos de tamaño psamítico, principalmente feldespatos (predominan las plagioclasas sobre el feldespato potásico) y en menor medida líticos sedimentarios y micas. También se identificaron componentes esqueletales entre los que se distinguen: foraminíferos epistomínidos, radiolarios, bivalvos no ostreidos y braquiópodos. La matriz es abundante y está formada por fango micrítico.

Las muestras analizadas correspondientes al perfil Río Salado se ubican en el campo de las areniscas mixtas fangosas carbonáticas según la clasificación de Álvarez- Trenttini y Schwarz, (2016), (Fig. 6.13). Por otro lado, las muestras del perfil Puesto Loncoche corresponden al campo de las fangolitas micríticas aloquímicas de la misma clasificación debido al incremento del fango carbonático y el consecuente decrecimiento de los componentes psamíticos silicoclásticos.

\subsubsection{Cuenca Austral}

De la Cuenca Austral se analizaron nueve muestras (tres de Cerro Hobler, una de Río Guanaco y cinco de la Subida del Chancho) correspondientes a las facies de areniscas mixtas con fango silicoclástico masivos, areniscas mixtas con fango silicoclástico y estratificación horizontal y areniscas mixtas con fango silicoclástico y óndulas (ver secciones 5.2.2.4, 5.2.2.5 y 5.2.2.6). Entre los elementos detríticos se reconoció cuarzo monocristalino, feldespatos, líticos sedimentarios, líticos volcánicos, micas y materia orgánica. Entre los componentes esqueletales se distinguieron bivalvos no ostreidos, algas dasycladáceas (Fig. 6.12 a y b) y belemnites (Fig. 6.12 c y d). Mineralógicamente, todos los fragmentos fósiles están compuestos por calcita con bajo contenido de magnesio (LMC) ya que al ser teñidos se observaron de color rojo (Fig. 6.11 d). La matriz está compuesta por fango silicoclástico en cantidades moderadas a escasas.

Las muestras fueron clasificadas según los criterios de Álvarez- Trenttini y Schwarz, (2016), (Fig. 6.13). Las correspondientes al perfil Subida del Chancho se ubican casi exclusivamente en el campo de las areniscas mixtas aloquímicas, presentan escaso contenido de fango silicoclástico y más componentes carbonáticos aloquímicos (principalmente algas 
dasycladáceas) que silicoclásticos. El ejemplar correspondiente al perfil Río Guanaco se encuentra en el campo de las areniscas mixtas fangosas silicoclásticas y posee cantidades equivalentes de los tres componentes. Por último, las muestras del perfil Cerro Hobler se reparten entre los campos de las areniscas fangosas silicoclásticas y las fangolitas arenosas silicoclásticas estando constituidas por un escaso tenor de fragmentos esqueletales y cantidades variables de clastos y fango silicoclásticos.
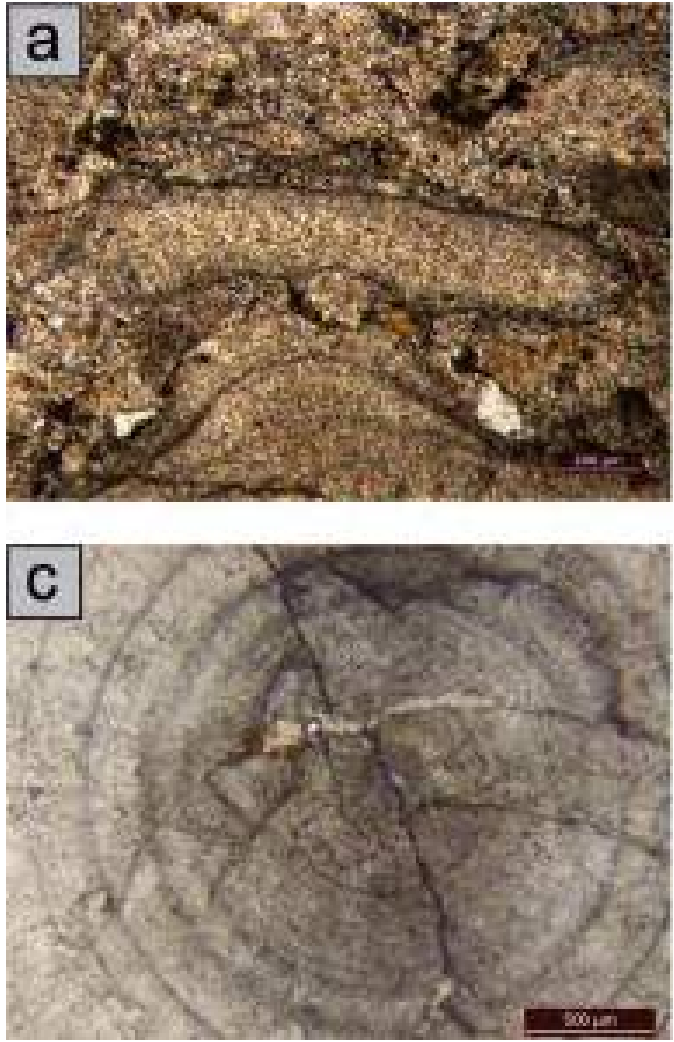

Figura 6.12. Microfotografías de componentes carbonáticos esqueletales en rocas mixtas, en todos los casos se muestran con y sin nicoles. A y b: algas dasycladáceas, c y d: belemnite.
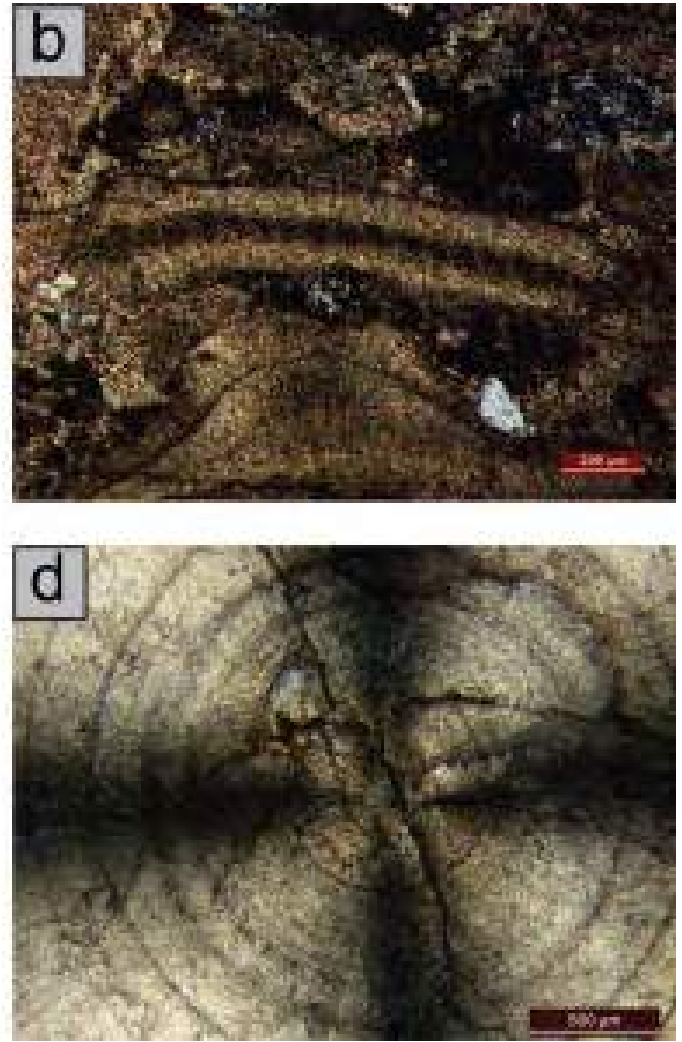


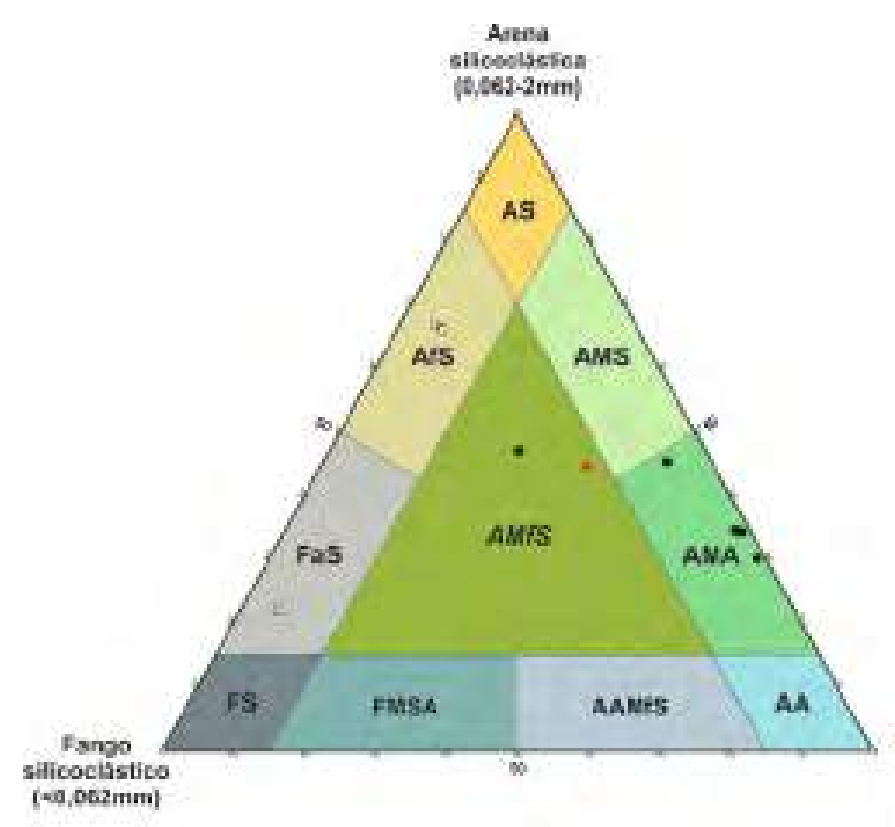

\section{Clasificación textural y composicional}

\section{Rocas Silicoclásticas}

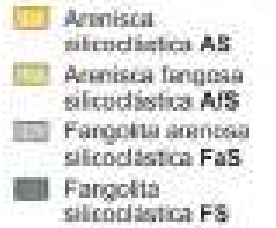

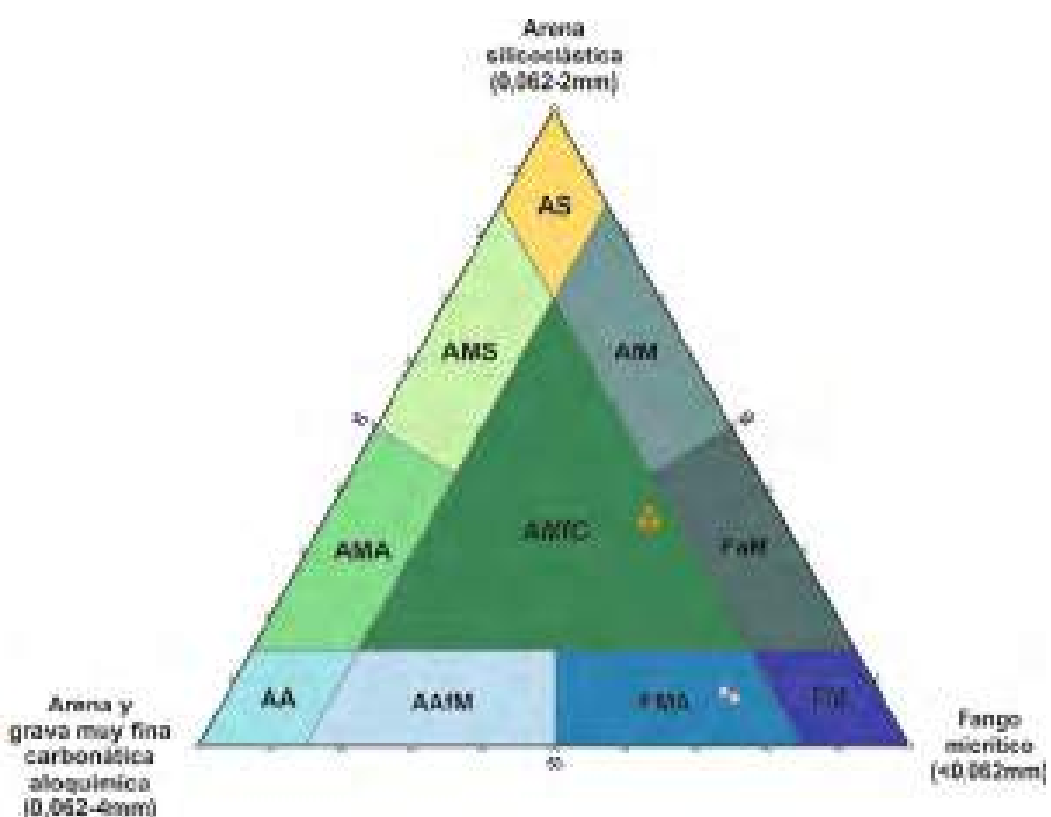

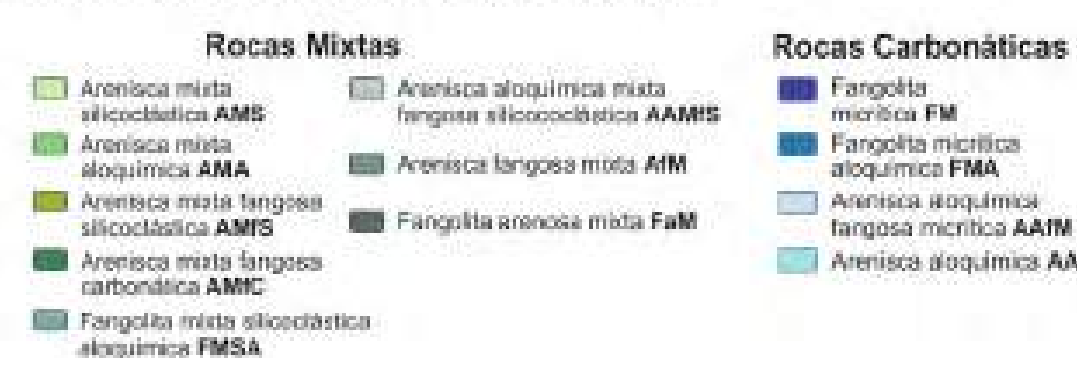

Figura 6.13. Clasificación textural y composicional de Álvarez- Trenttini y Schwarz, (2016). Las muestras de color negro corresponden al perfil Cerro Hobler, las de color rojo a Río Guanaco, las de color blanco a Subida del Chancho, las de color naranja de Río Salado y las de color rosa de Puesto Loncoche. 


\section{Capítulo VII - Procedencia}

\subsection{Introducción}

A partir de los datos composicionales expuestos en el capítulo 6 fue posible realizar un análisis de la procedencia de los elementos detríticos. El mismo se presentará de forma diferenciada por cada cuenca y específicamente por cada formación. Es importante destacar que la Formación Chachao no será desarrollada en este capítulo por estar compuesta íntegramente por rocas carbonáticas de origen intracuencal.

Para que el estudio de la fracción arcilla sea eficiente en términos de análisis de procedencia, es importante distinguir entre aquellas de origen detrítico y las autigénicas. Para poder arribar a esta diferenciación el microscopio electrónico de barrido constituye la herramienta más eficiente. En el presente trabajo, las diferenciaciones en el origen de los argilominerales se realizaron a partir de datos previos consultados en la bibliografía y cálculo de índices, razón por la cual estudios de mayor detalle serán necesarios para validar las apreciaciones a continuación desarrolladas.

\subsection{Cuenca Neuquina}

\subsubsection{Formación Vaca Muerta}

En la Formación Vaca Muerta, los niveles de composición silicoclástica aparecen de forma cíclica y están representados sólo en la fracción fina. Las escasas rocas mixtas que representan los únicos componentes detríticos de tamaño psamítico de la unidad poseen más de $80 \%$ de carbonatos por lo que no es posible realizar conteos representativos para un análisis de procedencia.

A partir de los estudios de difractometría de rayos $\mathrm{X}$ se reconocieron valores abundantes de cuarzo y calcita (el aumento en la cantidad de uno siempre marca el descenso de la abundancia del otro) y cantidades escasas de feldespatos potásicos, plagioclasas y arcillas. En la fracción arcilla, por otro lado, la illilta y el interestratificado I/S se encuentran en abundantes proporciones, mientras que la clorita, la caolinita y la esmectita lo hacen con contenidos cambiantes según el perfil (ver sección 6.2.1). 
Sobre la base del cálculo de cristalinidad (IC), cuyos resultados se desarrollarán en el capítulo 8 , se determinó para la illita un origen principalmente detrítico, aunque existen proporciones menores y aisladas de illita diagenética.

Spalletti et al. (2015) estudiaron mediante DRX la composición de las pelitas de la Formación Vaca Muerta. Estos autores proponen a la clorita como producto tanto de aportes detríticos como de concentración autígena. En tal sentido, la clorita alotígena tiende a concentrarse en los ambientes marinos más profundos donde el ritmo de acumulación sedimentaria es menor, razón por la cual existen mayores proporciones en el perfil Río Salado; su preservación se ve favorecida por la estratificación de aguas, con bajas temperaturas y un ambiente anaeróbico en el fondo (Spalletti et al., 2015). Por otro lado, la generación autígena de la clorita puede darse en estos mismos ambientes acompañando al proceso de piritización.

La caolinita por su parte sería detrítica, y su origen estaría relacionado a ambientes continentales (Chamley, 1989). La presencia de este argilomineral en ambientes marinos se explica mediante un aumento de la humedad en climas cálidos que genera un incremento del aporte continental (Duchamp-Alphonse et al., 2011).

La esmectita, por otro lado, se genera a partir de sustratos volcánicos en climas templados (Potter et al., 2005), y sus mayores concentraciones coinciden con el perfil Cuesta del Chihuido, que es el que mayor cantidad de niveles volcaniclásticos posee (ver "Perfil Cuesta del Chihuido" en Anexo).

Spalletti et al. (2014) determinaron a partir de estudios de geoquímica inorgánica que la procedencia del material terrígeno para la Formación Vaca Muerta sería a partir de rocas ígneas corticales ácidas a intermedias.

A partir de estas apreciaciones, se puede concluir que los aportes detríticos provendrían del arco magmático que flanqueaba a la cuenca por el oeste, así como desde terrenos volcánicos triásicos y jurásicos tempranos ubicados en las regiones del margen pasivo (suroriental) de la cuenca. Tampoco se descarta la contribución desde los depósitos de la subyacente Formación Tordillo, incorporados a los sedimentos de la Formación Vaca Muerta durante el proceso transgresivo (Spalletti et al., 2014). La composición final de los elementos detríticos se habría visto controlada principalmente por el clima, en especial por los cambios en la humedad que limitaron el aporte continental. 


\subsection{Cuenca Austral}

\subsubsection{Formación Springhill}

La procedencia de esta formación ha sido estudiada a partir de tres herramientas: conteo estadístico de clastos de psefitas, análisis petrográficos de muestras de areniscas y difracción de rayos $X$ en pelitas. Mientras los perfiles Cerro Hobler y Río Guanaco fueron analizados mediante petrografía, la alta variabilidad granulométrica del perfil Subida del Chancho permitió la implementación de todas las técnicas antes mencionadas.

El estudio composicional realizado sobre las psamitas (secciones 6.3 .1 y 6.3.2) y psefitas (sección 6.4) ha permitido determinar que los principales componentes detríticos son el cuarzo y los fragmentos líticos.

Las muestras de areniscas analizadas han sido representadas en los triángulos de Dickinson et al. (1983) (Fig. 7.1). En el diagrama QFL las muestras se ubican en el campo orógeno reciclado, a excepción de una muestra correspondiente al perfil Cerro Hobler que se encuentra en arco no disectado. En cuanto al diagrama QmFLt las muestras se distribuyen entre los campos orógeno reciclado cuarzoso, transicional y lítico, reflejando la variedad en la abundancia de cuarzo y líticos totales.

Ya que las clasificaciones de Dickinson et al. (1983) no reflejan la naturaleza de los fragmentos líticos se realizó un diagrama de discriminación de los mismos (Fig. 7.2). En el mismo se observa preponderancia de los líticos volcánicos por sobre los sedimentarios y la ausencia total de líticos plutónicos y metamórficos. Además, los cristaloclastos de cuarzo poseen características texturales que corroboran el origen volcánico, como la extinción neta (no ondulatoria), superficies libres de inclusiones, presencia (parcial) de caras cristalinas y perímetros con engolfamiento (Pettijohn et al., 1987; Tucker, 1988; Blatt, 1992).

El estudio de semicuantificación de especies minerales a partir de difractometría de rayos $\mathrm{X}$ evidenció para la Formación Springhill en el perfil Subida del Chancho, una composición casi exclusivamente cuarzosa con cantidades menores de arcillas. En los análisis de argilominerales se pudieron observar altos niveles de caolinita e I/S y escasos tenores de illita y esmectita (ver sección 6.2.2). Richiano et al. (2015b) postulan, a partir de estudios realizados mediante microscopía electrónica de barrido (MEB), que la mayor parte de la illita y en menor medida los interestratificados $\mathrm{I} / \mathrm{S}$ de este perfil serían de origen detrítico, tendencia que se ve parcialmente respaldada por los cálculos de Índice de Cristalinidad (ver capítulo 8), mientras que la esmectita sería de origen diagenético. Por otro lado, las altas cantidades de caolinita se encuentran en coincidencia con los menores contenidos de feldespato registrado 
en areniscas. Dicho fenómeno podría explicar el origen de esta arcilla a partir de la meteorización in situ de los feldespatos (Raigemborn, 2007). La abundancia en caolinita, sumado a las escasas cantidades de illita y clorita evidenciarían un ambiente cálido y húmedo. Bajo estas circunstancias, probablemente el clima haya promovido la meteorización química y la hidrólisis requeridas para el desarrollo de asociaciones ricas en caolinita (Chamley, 1989).

A partir de estos estudios se puede concluir que la principal fuente de material de la unidad sería el Complejo vulcano- sedimentario El Quemado y equivalentes, que durante el periodo Tithoniano- Valanginiano es la unidad que mayor superficie abarca en esta región de Gondwana, y sobre la cual se desarrolla el resto de las unidades del inicio de la cuenca Austral (formaciones Springhill y Río Mayer) (Richiano et al., 2012). Este complejo forma parte de la Provincia Magmática de Chon Aike y está conformado por ignimbritas, riolitas, tobas, brechas y lavas andesíticas (Pankhurst et al., 2000) generadas durante un gran episodio volcánico que se extendió en todo el sector sur patagónico asociado a un fenómeno de extensión cortical. De esta forma, se desestiman los resultados obtenidos a partir del diagrama de Dickinson et al. (1983), ya que el origen orogénico que se desprende como conclusión a partir de los triángulos composicionales, no coincide con las evidencias antes expuestas que relacionan la proveniencia de la formación con el vulcanismo generalizado que se extendió en la Patagonia en el marco de un tectonismo de carácter netamente extensional. 


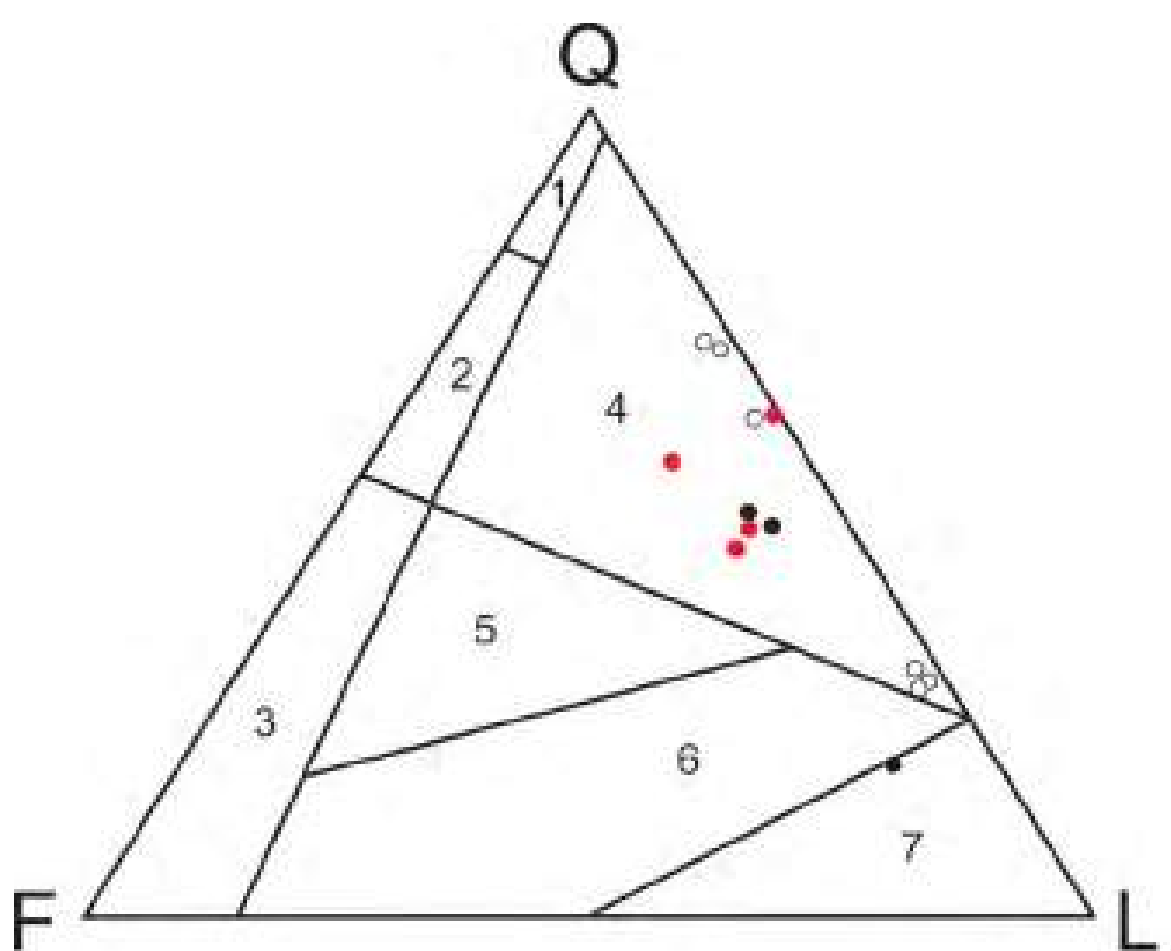

1: Interior cratónico

2: Continental transicional

3: Basamento elevado

4: Orógeno reciclado

\section{5: Arco disectado}

6: Arco transicional

7: Arco no disectado

8: Orógeno reciclado cuarzoso

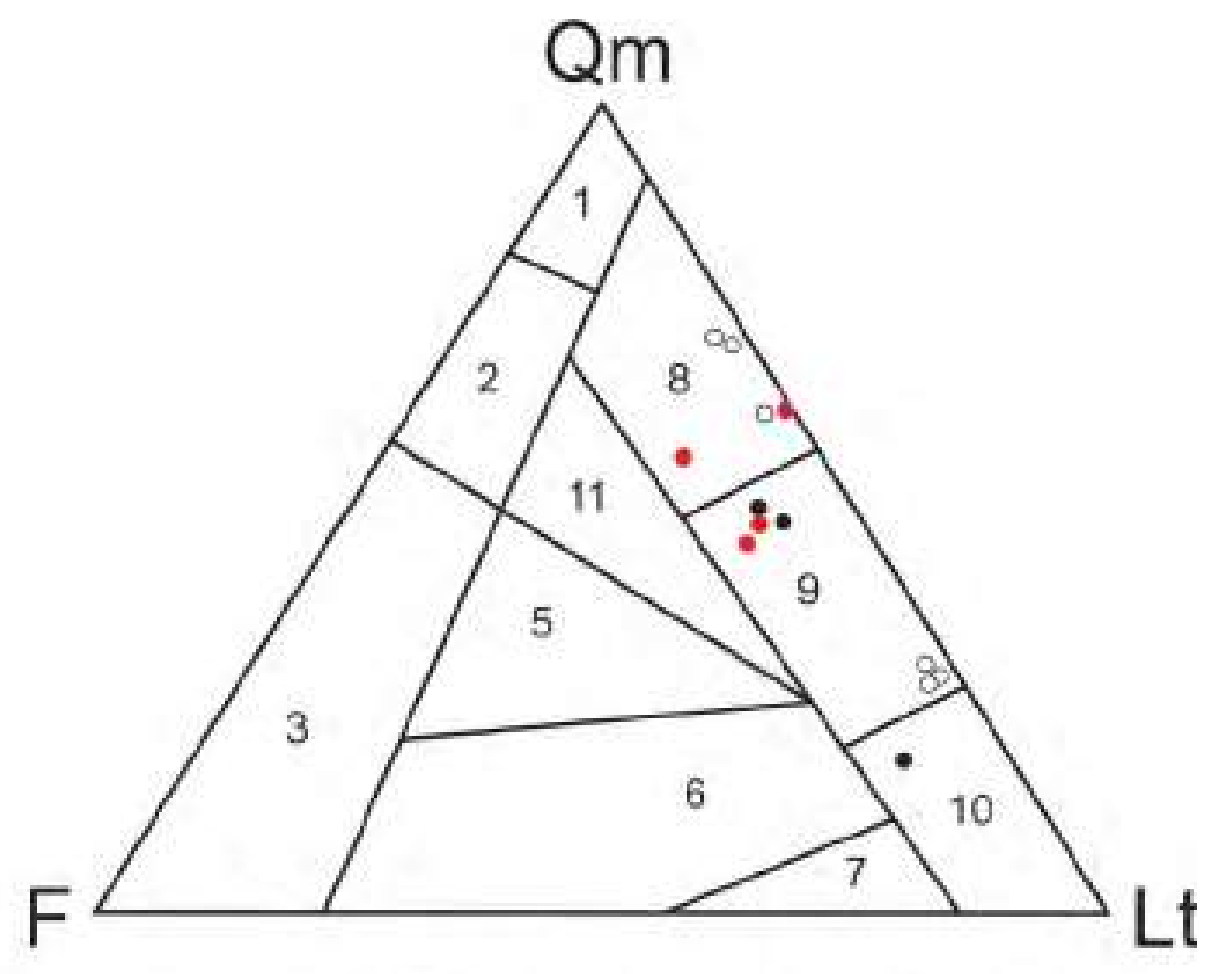

9: Orógeno reciclado transicional 10: Orógeno reciclado lítico

11: Mezcla

Figura 7.1. Diagrama de discriminación tectónica de áreas de aporte de Dickinson et al. (1983). Q: cuarzo total, Qm: cuarzo policristalino, F: feldespato y L: líticos. Las muestras de color negro corresponden al perfil Cerro Hobler, las de color rojo a Río Guanaco y las de color blanco a Subida del Chancho. 


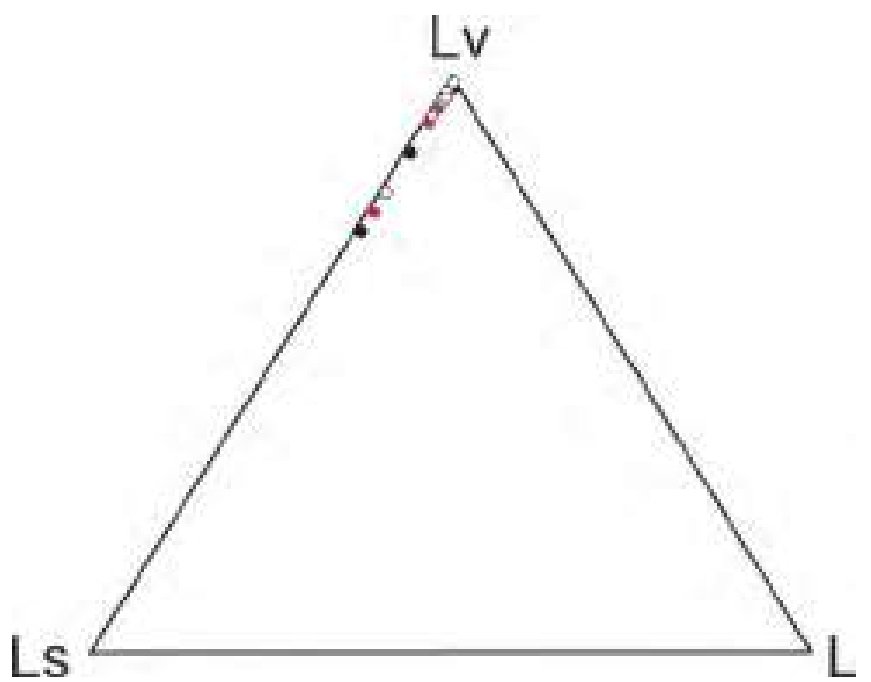

Figura 7.2. Diagrama de discriminación de litoclastos. Lv: líticos volcánicos, Ls: líticos sedimentarios, L: líticos plutónicos más líticos metamórficos. Las muestras de color negro corresponden al perfil Cerro Hobler, las de color rojo a Río Guanaco y las de color blanco a Subida del Chancho.

\subsubsection{Formación Río Mayer}

La Formación Río Mayer está compuesta casi en su totalidad por rocas pelíticas, razón por la cual fue estudiada mediante difracción de rayos X (ver capítulo 6) en los perfiles Cerro Hobler y Río Guanaco. A partir de estos análisis se distinguieron abundantes cantidades de cuarzo, cantidades moderadas y aisladas de calcita y escasas de plagioclasa, feldespato potásico y arcillas. En la fracción arcilla se reconocieron cantidades moderadas a abundantes de illita y clorita, moderadas de I/S y muy escasas a traza de caolinita (ver sección 6.2.2).

Richiano et al. (2015b) estudiaron mediante microscopía electrónica de barrido las distintas arcillas de la Formación Río Mayer en el área de estudio. Estos autores, determinaron signos de retrabajo en la illita lo cual indicaría para este argilomineral un origen detrítico, tendencia que se corrobora parcialmente mediante el cálculo del Índice de Cristalinidad (ver capítulo 8). Por otro lado, tanto la Illita como el interestratificado I/S fueron reconocidos como crecimientos en forma de escamas en poros, razón por la cual se le asignó un origen diagenético. De todas formas, la naturaleza detrítica de estos minerales no fue descartada por los autores.

Estudios geoquímicos de detalle realizados por Richiano (2012) postularon como procendecia de las pelitas de la Formación Río Mayer a rocas con afinidad ácida.

Sobre la base de estos datos se infiere como fuente del material al Complejo El Quemado, que conformaba una de las principales áreas elevadas para el momento de la depositación de la Formación Río Mayer. 


\section{Capítulo VIII- Diagénesis}

\subsection{Introducción}

La diagénesis involucra todos los procesos que afectan a los sedimentos luego de la depositación, y hasta que sufren los efectos incipientes del metamorfismo (Choquette y Pray, 1970; Burley y Worden, 2003). Para un correcto entendimiento de la diagénesis de los niveles estudiados, se realizó un análisis de las formaciones desde distintos enfoques, teniendo en cuenta la composición y granulometría de cada una de ellas.

A partir del estudio mediante difracción de rayos $X$ se determinaron los contenidos de illita e interestratificado illita - esmectita (I/S) en las rocas pelíticas. Posteriormente, teniendo en cuenta los cálculos de índice de cristalinidad (IC) e índice de Esquevin (IE) realizados sobre las illitas, se analizó el origen (diagenético o detrítico) de estos argilominerales así como su composición (ferromagnesiana o aluminosa). Por último, se reconoció el grado de evolución diagenética tomando como base el porcentaje de capas expansivas en los interestratificados I/S: eodiagénesis ( $>75 \%)$, mesodiagénesis temprana (75\%-50\%), mesodiagénesis tardía (50\%$25 \%)$ y telodiagénesis $(<25 \%)$.

En la Cuenca Neuquina se analizaron de manera detallada la diagénesis de las rocas carbonáticas. Gracias al estudio mediante microscopía convencional y de catodoluminiscencia fue posible identificar los procesos y productos postdepositacionales, y se propuso una historia diagenética para el área de estudio.

En la Cuenca Austral por otro lado, se estudiaron las psamitas silicoclásticas y mixtas con las mismas herramientas metodológicas que para los carbonatos. En el apartado 8.4 se exponen la totalidad de los procesos postdepositacionales reconocidos así como la evolución diagenética de las secciones de la región.

Con el objetivo de tomar muestras para realizar estudios geoquímicos y quimioestratigráficos se estudiaron en detalle los procesos diagenéticos en especies fósiles. Para esto se seleccionaron ostras en la Cuenca Neuquina y belemnites en la Cuenca Austral, ya que por su composición original y sus características tafonómicas podrían tener menor influencia de los procesos postdpositacionales. La diagénesis de los restos fósiles (fósildiagénesis) fue estudiada mediante catodoluminiscencia y microscopía electrónica de barrido y los resultados se presentan en el apartado 8.5. 


\subsection{Análisis del contenido de illita e interestratificados $\mathrm{I} / \mathrm{S}$}

\subsubsection{Generalidades}

El interestratificado I/S constituye el tipo más abundante, diversificado y de mayor distribución dentro de las rocas sedimentarias (Gómez Peral, 2008). Este grupo de argilominerales varía su posición en los difractogramas de acuerdo al número de capas expansivas que posee la muestra. Estas capas, decrecen en abundancia con el incremento de la profundidad, lo que provoca un desplazamiento del pico en la muestra glicolada que varía desde los $14 \AA ̊$ con $100 \%$ de esmectita, hasta $10 \AA ̊$ con un $100 \%$ de capas de illita (Decastelli e Iñiguez Rodriguez, 1984).

Reynolds (1980), definió tres formas de interestratificados I/S utilizando la notación de "Reichweite" ( $R)$ : desordenada $(R=0)$, de bajo grado de ordenamiento $(R=1)$ y de alto grado de ordenamiento $(R=3)$, donde el porcentaje de illita del interestratificado es de $20 \%$ para $R=0$, $65 \%$ para $\mathrm{R}=1$ y $90 \%$ para $\mathrm{R}=3$.

Las muestras del grupo $\mathrm{R}=3$ poseen un alto porcentaje de Illita (Fig. 8.1a), razón por la cual, se han tratado como "Illita" en los capítulos anteriores y se realizaron sobre ellas los cálculos de Índice de cristalinidad (IC) e Índice de Esquevin (IE). La metodología con la cual se llevaron a cabo dichos cálculos se encuentra desarrollada en la sección 2.5.6, y los resultados se representaron gráficamente asociando las muestras de la Cuenca Neuquina (Fig. 8.2) y las de la Cuenca Austral (Fig. 8.3).

Aquellos sectores donde se observa un predominio de la forma R=1 (Fig. 8.1b), han sido citados en los capítulos anteriores como "interestratificados I/S". Este grupo se caracteriza por la falta de picos definidos y baja cristalinidad. A raíz de estas características, sólo fue posible la cuantificación del porcentaje de capas expansivas en un grupo pequeño de muestras donde los picos se encuentran mejor definidos. 

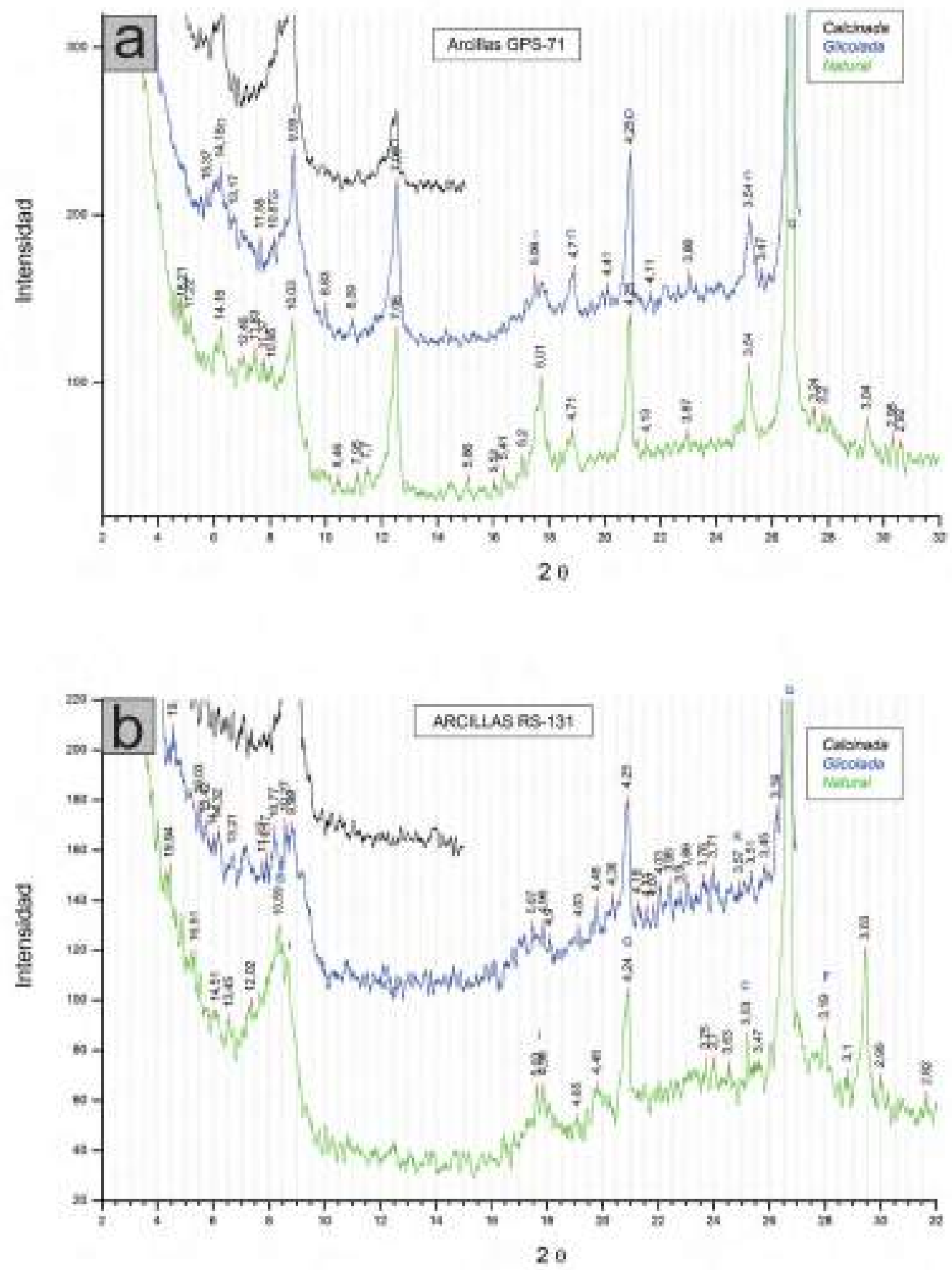

Figura 8.1. Difractogramas de muestras de pelitas. A) Muestra con alta concentración de illita, obsérvese el pico de $10 \AA$ en la muestra glicolada. B) Muestra con interestratificado I/S con pico entre 10 y $12 \AA$.

\subsubsection{Cuenca Neuquina}

Las muestras analizadas en la Cuenca Neuquina corresponden a la Formación Vaca Muerta, donde los interestratificados $\mathrm{I} / \mathrm{S}$ conforman el grupo de argilominerales más abundante y están presentes en todos los niveles estudiados. Se han reconocido formas del 
tipo $R=1$ y $R=3$, siendo el primer grupo más abundante en el perfil Río Salado, mientras que en las secciones Puesto Loncoche y Cuesta del Chihuido las proporciones son similares.

Como se mencionó anteriormente, se han calculado los índices de cristalinidad (IC) y de Esquevin (IE) para el grupo $\mathrm{R}=3$ (Tabla 8.1). Todas las muestras analizadas poseen IE mayores a 0,4 con la excepción de dos muestras cercanas al tope del perfil Cuesta del Chihuido donde los valores son menores a 0,2. A partir de esta apreciación se puede indicar el carácter predominantemente aluminoso de este grupo de argilominerales.

Por otro lado, los valores de IC, son muy variables para los distintos sectores de cada perfil. En el diagrama de covariación de IC versus IE, es posible observar a las muestras repartidas en los campos de la diagénesis, anquizona y rocas ígneas y metamórficas (Fig. 8.2, Tabla 8.1). En el perfil Río Salado se identifica mayor cantidad de muestras del campo de las rocas ígneas y metamórficas en la base, mientras que hacia el techo predominan las del campo de la diagénesis. En la sección Puesto Loncoche, por otro lado, no existe una relación aparente entre los campos del IC y su posición en el perfil sedimentario. En tanto que para el perfil Cuesta del Chihuido existe un claro predominio de las altas cristalinidades correspondientes a rocas ígneas y metamórficas.

Los interestratificados $\mathrm{R}=1$ se caracterizan por la baja cristalinidad, y la presencia de múltiples picos que no permiten, en la mayoría de los casos, la cuantificación de las capas expansivas (Tabla 8.1). En aquellas muestras en donde fue posible la medición, se reconocieron valores de entre 40 y $60 \%$ de esmectita por el método de Moore y Reynolds (1989) (ver sección 2.5.6).

Del total de datos analizados, es posible concluir que las illitas presentes en las pelitas de la formación Vaca Muerta no presentan un origen común, tal como refleja la variación de su IC. Una importante proporción de ellas pueden asociarse a un origen detrítico (muestras del campo de las rocas ígneas y metamórficas y la anquizona, IC entre 0 y 0,4 ) mientras que otras son consideradas autigénicas (campo de la diagénesis, IC entre 0,4 y 1 ), estas últimas se asocian a un origen a partir de la transformación de esmectita durante la diagénesis, la cual resulta un argilomineral muy abundante en rocas volcánicas y volcaniclásticas como producto de la alteración del vidrio volcánico (Raigemborn et al., 2014). Los altos estándares de aluminio registrados pueden ser explicados gracias al estudio de proveniencia del material detrítico, principalmente aportado de las rocas ígneas corticales ácidas a intermedias, que conforman el basamento de la región de estudio (Spalletti et al., 2015). Finalmente, tal como muestra el estudio de los interestratificados $\mathrm{R}=0$ (Tabla 8.1), los depósitos habrían experimentado mesodiagénesis temprana (de acuerdo al porcentaje de las capas expansivas), proceso durante el cual se habrían formado los interestratificados $\mathrm{I} / \mathrm{S}$ de origen diagenético. 


\begin{tabular}{|c|c|c|c|c|c|c|c|c|c|c|c|}
\hline \multicolumn{4}{|c|}{ Diosyads } & \multicolumn{4}{|c|}{ Pueves Lanciche } & \multicolumn{4}{|c|}{ Coves del Chinido } \\
\hline Muestra & $x$ & 11 & $\mathrm{ksm}$ & Muestra & ic. & II & $x 5=$ & Muestra & ic & E & $\mathrm{s5m}$ \\
\hline RSY & 030 & 2.50 & ND & P16 & aso & $2 \pi$ & NO & $\operatorname{KDC2}$ & 0.20 & 2 & no \\
\hline B512A & $0 \neq 0$ & 259 & ND & pis & SAEN & 1.61 & 30 & $\cos 7$ & 0,1 & 1 & ND \\
\hline B515 & 010 & 100 & MD & PLIS & Q50 & 2.00 & 40 & cocils & 020 & 0.71 & 42 \\
\hline $1 \mathrm{BS312 \textrm {A }}$ & $020^{\circ}$ & 0.28 & ND & P(I) & 6.20 & c.2u & No & $6 \times 13$ & a. 7 & 169 & 50 \\
\hline BSEDA & 0.50 & 200 & 40 & PLII & 2.30 & 100 & no & $\operatorname{coc} 20$ & 0.20 & 2 & WD \\
\hline nSIIA & a.d & 1,00 & MD & PLIA & Qsक & 3.2 & NO & $\operatorname{coc} 23$ & a.10 & 1 & No \\
\hline PSTISA & 035 & 1.50 & 50 & PL36 & Q.EO & 1.75 & NO & $\operatorname{coc} 26$ & 810 & 0.11 & No \\
\hline R525A & 0.30 & 1.50 & MD & PL32 & 0.30 & as & NO & रा० 28 & 0.10 & 017 & ND \\
\hline R530 & 050 & 3.29 & ND & PLIA & a.d & $\operatorname{san}$ & NO & $\operatorname{coc}>3$ & 0.5 & das & No \\
\hline ns: & 900 & 200 & AD & PLAS & 0.70 & 1.00 & ND & cocst & 0.20 & 1 & 86 \\
\hline Rs 35 & $n \times a$ & $a n$ & ND & Pis! & Q. & 1.8 & NO & & & & \\
\hline$n S B$ & d9d & 1.25 & ND & PL56 & $0.40^{\circ}$ & $4.40^{1}$ & NO & & & & \\
\hline RSAO & 0.30 & 1.II & AD & FLEA & 0.40 & 2.67 & 50 & & & & \\
\hline KSE3 & 0.20 & 150 & AD & PLS & Q.10 & 1.67 & NO & & & & \\
\hline R5ESA & 0.39 & 100 & $A B$ & FLES & Q.5n & 0.9 & NO & & & & \\
\hline RSETA & 020 & 1.67 & AD & PLA & Q.20 & $\operatorname{Lag}$ & NO & & & & \\
\hline BS54 & 050 & 1. 15 & ND & PLS & 030 & IEI & NO & & & & \\
\hline 7855 & 040 & 2.29 & 50 & PLues & 0.20 & 100 & 40 & & & & \\
\hline isss & 0.20 & $25 x$ & MD & PLIS & and & 063 & NO & & & & \\
\hline R5SA & $a 10$ & 1.50 & ND & & & & & & & & \\
\hline RSEO & 060 & 200 & ND & & & & & & & & \\
\hline BSEA & 0.10 & 100 & ND & & & & & & & & \\
\hline RSER & 0.00 & 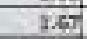 & ND & & & & & & & & \\
\hline BSPO & ifac & 1.49 & 20 & & & & & & & & \\
\hline 10573 & $a 3$ & 1.75 & ND & & & & & & & & \\
\hline $\mathrm{RS} \pi$ & 030 & $2 \pi 1$ & $M D$ & & & & & & & & \\
\hline R5:79 & 0.20 & 2.00 & MD & & & & & & & & \\
\hline RSE9 & 030 & 2.87 & $\infty, 60$ & & & & & & & & \\
\hline RSE5 & $0 \times 0$ & 4.50 & 0,50 & & & & & & & & \\
\hline BSES & 9.9 & $3 . \mathrm{F}$ & ND & & & & & & & & \\
\hline KSSI & 0.20 & 2.09 & MD & & & & & & & & \\
\hline ASDD & 090 & 2.60 & No & & & & & & & & \\
\hline R5121 & 0.32 & 1.17 & ND & & & & & & & & \\
\hline R5126 & 035 & 3.00 & AD & & & & & & & & \\
\hline BSISE & 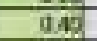 & 343 & ND & & & & & & & & \\
\hline RS113 & 070 & 2.50 & AD & & & & & & & & \\
\hline B5115 & 0.45 & a.t. & ND & & & & & & & & \\
\hline 185125 & aso & 1.20 & $30-50$ & & & & & & & & \\
\hline R5III & 0.80 & 205 & 40 & & & & & & & & \\
\hline A513SA & 0,0 & 3.00 & 40 & & & & & & & & \\
\hline R5138 & 050 & 300 & ND & & & & & & & & \\
\hline R5349 & 030 & 2,33 & ND & & & & & & & & \\
\hline B515? & 0.70 & 2.25 & 50 & & & & & & & & \\
\hline KSISS & $4 \times 0$ & 3,00 & AD & & & & & & & & \\
\hline BS163 & 0.50 & 4.50 & MD & & & & & & & & \\
\hline $\mathrm{R} 5173$ & $a .70$ & 2.00 & so & & & & & & & & \\
\hline R5155 & 0 so & 1.17 & $\theta \pi$ & & & & & & & & \\
\hline BS190 & 945 & 1.29 & AD & & & & & & & & \\
\hline RS120 & 0.00 & 3.8 & $\infty$ & & & & & & & & \\
\hline $85 \times 91$ & 940 & $2 \times 0$ & ND & & & & & & & & \\
\hline 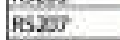 & a.4d & 2.53 & ND & & & & & & & & \\
\hline RSIn & 0.25 & 2.50 & AD & & & & & & & & \\
\hline A5sas & 105) & 189 & ND & & & & & & & & \\
\hline 85737 & 840 & 3.67 & AD & & & & & & & & \\
\hline R5225 & aso & $2 \mathrm{M}$ & ND & & & & & & & & \\
\hline 85229 & 040 & 159 & ND & & & & & & & & \\
\hline KSs2s & $a x^{0}$ & 0.70 & $\pi 00$ & & & & & & & & \\
\hline Assio & 0.50 & $x .67$ & MD & & & & & & & & \\
\hline PS245 & 050 & 2.40 & ND & & & & & & & & \\
\hline
\end{tabular}

Tabla 8.1. Valores de porcentaje de capas expansivas, índice de cristalinidad y de Esquevin de los perfiles de la

Cuenca Neuquina ordenadas de base a techo. En color rosa se observan las muestras del campo de las rocas ígneas y metamórficas, verde para la anquizona y naranja para la diagénesis. En color azul se distinguen las muestras ferromagnesianas y en gris las aluminosas. ND: no determinado. 

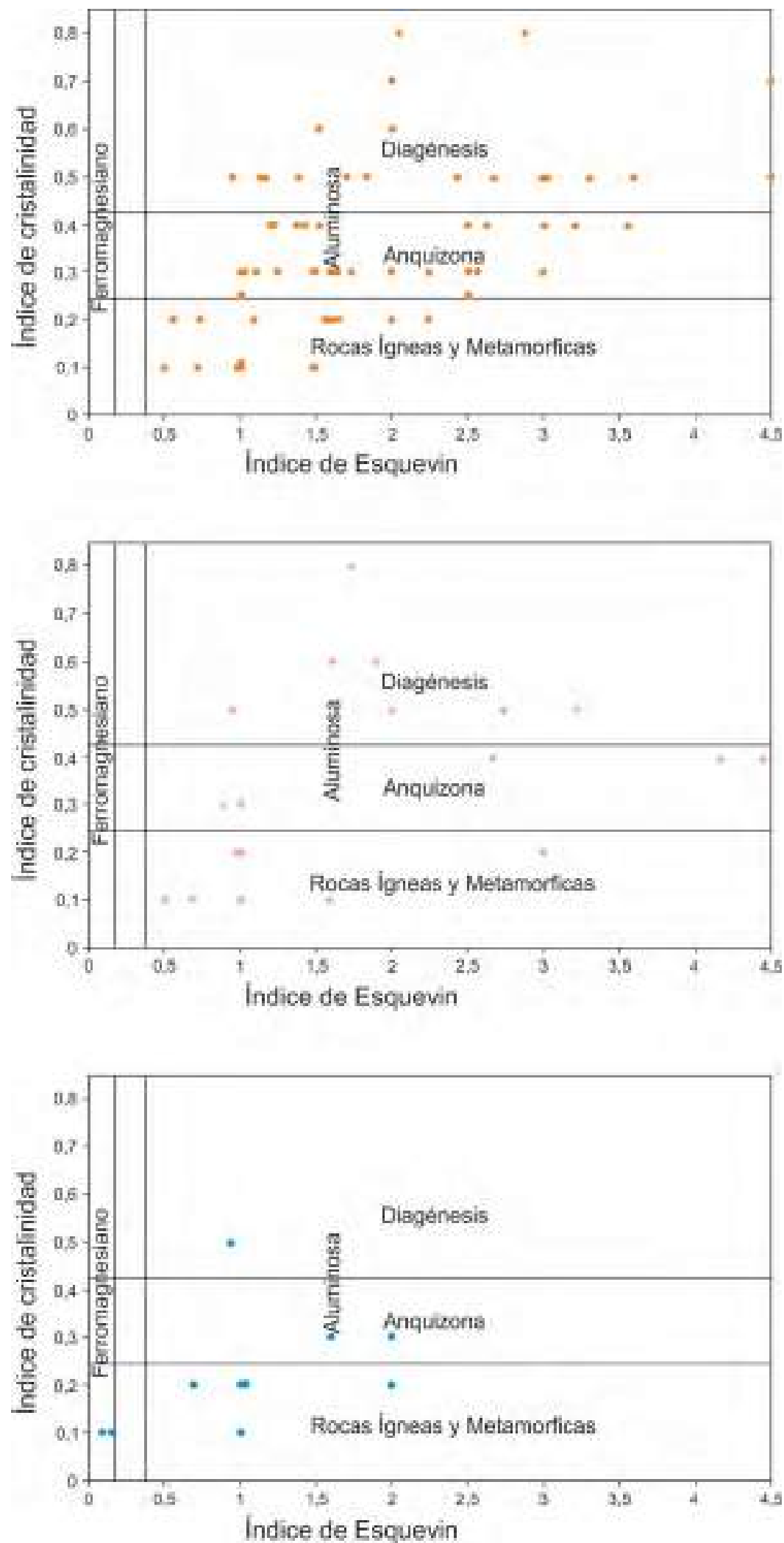

Figura 8.2. Representación de los Índices de Esquevin y de cristalinidad de illita de la Cuenca Neuquina. En naranja las correspondientes al perfil Río Salado, en rosa las de Puesto Loncoche y en azul las de la Cuesta del Chihuido. 


\subsubsection{Cuenca Austral}

Las muestras analizadas en la Cuenca Austral corresponden a la Formación Springhill en el perfil Subida del Chancho, y a la Formación Río Mayer en los perfiles Cerro Hobler y Río Guanaco, donde los interestratificados I/S están presentes en todos los niveles. Se reconocieron formas del tipo $\mathrm{R}=0$ y $\mathrm{R}=3$, mientras el primer grupo es más abundante en la formación Springhill, el segundo predomina en la formación Río Mayer.

En los argilominerales del tipo $\mathrm{R}=3$ se calcularon lo índices de cristalinidad y Esquevin (Tabla 8.2). Todas las muestras presentan valores de IE mayores a 0,4 , con lo cual es posible definir un carácter aluminoso común para todas las illitas de la región de estudio. Por otro lado, los valores de IC, son muy variables para los distintos sectores de cada perfil. En las tres secciones es posible observar muestras repartidas en los campos de la diagénesis, anquizona y rocas ígneas y metamórficas, siendo el campo de la diagénesis el que presenta mayor volumen de datos (Fig. 8.3 y Tabla 8.2). En el perfil Cerro Hobler las muestras del campo de la anquizona y las rocas ígneas y metamórficas se acumulan hacia el sector central del perfil, en la sección Río Guanaco las muestras del campo de la diagénesis se acumulan al tope mientras que en la Subida del Chancho se encuentran concentradas en la base.

En los interestratificados desordenados se han reconocido valores bajos de cristalinidad y presencia de múltiples picos que dificultaron, en muchos casos, la cuantificación de las capas expansivas. En este sentido, sólo fue posible obtener valores en algunos niveles de la Formación Río Mayer, los cuales oscilan entre 30 y 70\% de esmectita (Tabla 8.2).

Del total de datos analizados, es posible concluir que las illitas presentes en las pelitas de las formaciones Springhill y Río Mayer no presentan un origen común, tal como se refleja en la variación de su IC. Un porcentaje menor de ellas tienen un origen detrítico (muestras del campo de las rocas ígneas y metamórficas y la anquizona), mientras que la mayoría son autigénicas (campo de la diagénesis).

Los altos estándares de aluminio registrados en las muestras de illita pueden ser explicados gracias al estudio de proveniencia del material detrítico y las condiciones de humedad. En la Formación Springhill del perfil Subida del Chancho, la illita aluminosa se ve acompañada de altos niveles de caolinita y esmectita los cuales reflejarían condiciones ambientales de alta humedad, generando meteorización química del material parental (rocas del Complejo El Quemado, principalmente vulcanitas ácidas) y una alta concentración de alúmina en el medio con la consecuente generación de illitas ricas en este elemento (Chamley, 1989; Steinke et al., 2008). La composición aluminosa de la Formación Río Mayer en los perfiles Cerro Hobler y Río Guanaco puede ser explicada por los mismos fenómenos que la 
Formación Springhill, ya que las asociaciones argílicas marinas habitualmente reflejan las condiciones ambientales que prevalecían en el continente (Biscaye, 1965; Grousset et al., 1983; Petschick et al., 1996).

Finalmente, tal como muestra el estudio de los interestratificados $\mathrm{R}=0$, la Formación Río Mayer en las regiones de Río Guanaco y Cerro Hobler presenta estadios de mesodiagénesis tardía (calculado según el porcentaje de capas expansivas). En la Formación Springhill, por otro lado, no fue posible cuantificar el grado de alteración diagenética.

\begin{tabular}{|c|c|c|c|c|c|c|c|c|c|c|c|}
\hline \multicolumn{4}{|c|}{ Cinetstiker } & \multicolumn{4}{|c|}{ Ao Quanuse } & \multicolumn{4}{|c|}{ Sabida de Chanche } \\
\hline Murestas & $x$ & Vaiar & $\mathrm{NSm}$ & muestris & ic & Valer & $\mathrm{KSm}$ & Muestra & II & Vaior & Xsm \\
\hline CHO 14 & e.7 & 2.29 & ND & AG 85 & a.3 & a.81 & 4060 & sors: & 03 & {$[43$} & 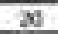 \\
\hline $\mathrm{CH}+15$ & 0.8 & 2.75 & 70 & AG 37 & $a \in$ & 092 & No & $\mathrm{BCH} 9$ & 0.4 & 0.85 & ND \\
\hline C60 18 & C5 & 1.00 & ND & AC 39 & an & 110 & NO & 50150 & 05 & 10 & Nb \\
\hline$D+200$ & of & $2.5 \mathrm{~F}$ & ND & moss & arg & $x \%$ & 40.6 & $\mathrm{SOH} 21$ & a! & 10 & 300 \\
\hline $0+022$ & es & 200 & MD & net 7 & at & $1 \mathrm{ma}$ & NO & 50122 & od & 600 & Nh \\
\hline $\mathrm{CHO} 24$ & 0.4 & $16 \pi$ & ND & A6. 3 & 0.3 & 120 & NO & $50+132$ & 09 & 100 & 200 \\
\hline $\mathrm{CH} 025$ & 0.2 & 3.00 & $A D$ & AG $\pi$ & $a, 3$ & $14 \pi$ & No & $30 \mathrm{H} 13 \mathrm{~b}$ & 28 & 125. & 100 \\
\hline C4028 & a. & 200 & 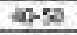 & As 7 & as & 128 & No & sorit & 02 & 1.20 & ND \\
\hline CHO32 & 0, & 3.09 & $2,-62$ & A679 & 02 & 077 & 30 & 50415 & 07 & 079 & 1200 \\
\hline C.60 22 & a) & 200 & ND & Abs & ae & 1.24 & NO & $\operatorname{sol} 37$ & a7 & 271 & ND \\
\hline CHO 34 & 0.5 & 2.67 & ND & A683 & 0.4 & IIs & 60 & & & & \\
\hline Oto 35 & of: & 2.5. & 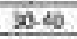 & noss & ad & 18 & No & & & & \\
\hline $\mathrm{CH}+39$ & d5 & 1.56 & ND & & & & & & & & \\
\hline
\end{tabular}

Tabla 8.2. Valores de porcentaje de capas expansivas, índice de cristalinidad y de Esquevin de la Cuenca Austral ordenados de base a techo. En color rosa se observan las muestras del campo de las rocas ígneas y metamórficas, verde para la anquizona y naranja para la diagénesis. En color azul se distinguen las muestras ferromagnesianas y en gris las aluminosas. ND: no determinado. 

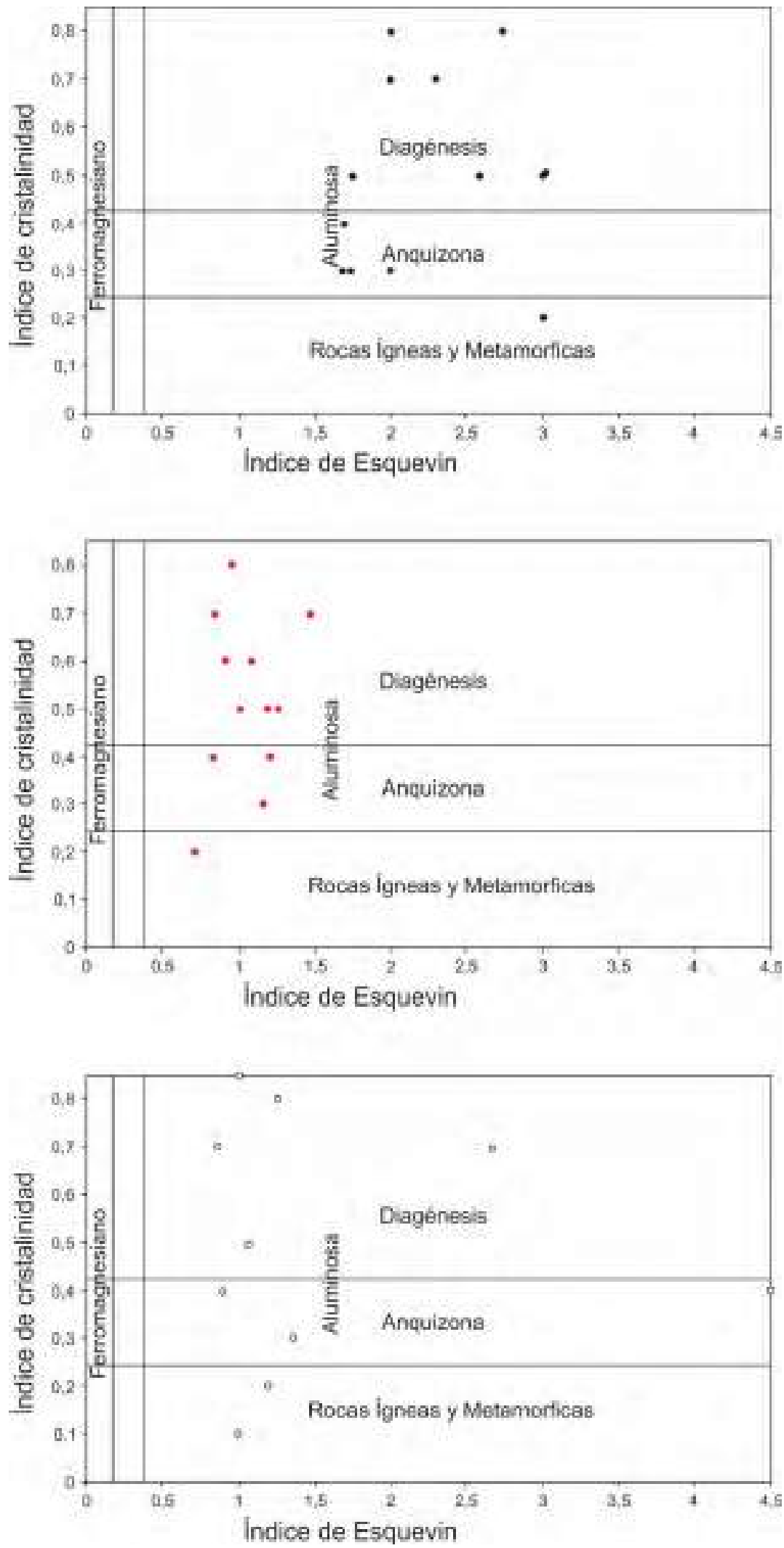

Figura 8.3.Representación de los Índices de Esquevin y de cristalinidad de illita de la Cuenca Austral. En negro las correspondientes al perfil Cerro Hobler, en rojo las de Río Guanaco y en blanco las de la Subida del Chancho. 


\subsection{Diagénesis de carbonatos}

\subsubsection{Introducción}

En esta sección se tratará el conjunto de eventos postdepositacionales que afectaron a los niveles carbonaticos de las formaciones Vaca Muerta y Chachao en la Cuenca Neuquina. Se desarrolla de forma específica un apartado que explica la evolución de los procesos y productos postdepositacionales, así como el ambiente diagenético en el cual éstos tuvieron lugar.

La diagénesis de las rocas carbonáticas depende de su mineralogía original, de la composición química del agua poral y del ambiente de formación (Tucker y Bathurst, 1990). Los carbonatos compuestos por aragonita y calcita con alto contenido de magnesio son más susceptibles a los cambios diagenéticos que los de calcita con bajo contenido de magnesio.

Se reconocen tres ambientes principales donde se lleva a cabo la diagénesis de los carbonatos: marino, meteórico y de soterramiento (Tucker, 2001). Por otro lado, Choquette y Pray (1970) proponen la denominación de los estadios diagenéticos como eodiagénesis (desde la sedimentación al enterramiento muy somero), mesodiagénesis (enterramiento somero a profundo) y telodiagénesis (post ascenso tectónico). En este trabajo se propone una combinación de las etapas antes mencionadas ya que los cambios relativos en el nivel del mar hacen que los estadios se desarrollen en más de un ambiente diagenético.

Cada ambiente diagenético se caracteriza por el tipo y magnitud de los procesos involucrados de los cuales, los más importantes son la cementación, la disolución, la compactación y el neomorfismo.

Cementación: es el proceso a través del cual un sedimento calcáreo se litifica, y ocurre cuando los fluidos porales están sobresaturados con respecto a la composición química del sedimento y no existen factores cinéticos que inhiban la precipitación (Tucker y Bathurst, 1990). Puede ser de tipo intergranular, en poros y fracturas tensionales como oquedades y venas, o intragranular, en espacios generados por disolución en el interior de bioclastos u otros comoponentes.

Compactación: es la pérdida de espacio poroso por presión de carga, y se da por razones físicas o químicas. La compactación física se observa por incipientes laminaciones mientras que la química está representada por estilolitas. Las estilolitas son superficies donde se concentra la disolución por presión en sedimentos con desarrollo de cementos (Gómez Peral, 2008). Flügel (2004), indica que estas superficies pueden generarse desde decenas a cientos de metros de profundidad y que en general se desarrollan perpendicularmente a la 
dirección principal de estrés. Debido a que las estilolitas son zonas preferenciales de disolución dentro del sedimento, algunos pequeños fragmentos o los minerales menos solubles tienden a acumularse a lo largo de estas superficies (Tucker, 1988). La composición calcítica con bajo contenido de magnesio, la presencia de materia orgánica y, en el caso de las facies más profundas, el tamaño de grano fino son factores que favorecen el amplio desarrollo de las estilolitas (Flügel, 2004). En ocasiones, los planos de debilidad generados por las estilolitas son aprovechados por fluidos cementantes, dando lugar al desarrollo de venas.

Disolución: es el proceso en el cual minerales son destruidos por la convivencia con fluidos subsaturados en cavidades (Burley y Worden, 2003). Se da con mayor frecuencia en ambientes meteóricos, y afecta de preferencia a las composiciones aragoníticas y de calcita con alto contenido de magnesio, mientras que las de bajo contenido de magnesio son más resistentes (Tucker y Bathurst, 1990).

Neomorfismo: término propuesto por Folk (1965) para designar las transformaciones entre un mineral (carbonato) y él mismo, o un polimorfo, sin pasar por el estadio intermedio de porosidad visible. Los procesos neomórficos incluyen: recristalización (variación del tamaño y/o forma de los cristales) e inversión polimórfica de aragonita a calcita (calcitización) (Tucker, 2001).

A partir del estudio petrográfico y geoquímico (ver capítulo 9) de los procesos y productos diagenéticos se pudo establecer un orden de generación cronológico relativo de cada uno de ellos, permitiendo reconstruir la historia diagenética de las sedimentitas de la Cuenca Neuquina.

\subsubsection{Procesos diagenéticos}

A partir del estudio petrográfico convencional y mediante catodoluminiscencia (cátodo frío) de los niveles calcáreos de las formaciones Vaca Muerta y Chachao fue posible la identificación y caracterización de los siguientes procesos diagenéticos. Vale destacar que la catodoluminiscencia representa una herramienta fundamental para el entendimiento de la diagénesis, ya que su activación está dada por la cantidad de $\mathrm{Mn}$, elemento que se enriquece durante los procesos postdepositacionales. Así, los cristales pueden ser luminiscentes, de luminscencia baja (dull) o no luminiscentes, de acuerdo a la cantidad de Mn que éstos posean (Ullmann y Korte, 2015). 


\subsubsection{Cementación marina}

Se presenta en forma de halos isópacos de aproximadamente $20 \mu \mathrm{m}$ de espesor que cubren de forma irregular los bordes de los bioclastos, principalmente los de mayor tamaño como bivalvos no ostreidos y braquiópodos (fig. 8.4 a, b y c). Los cristales poseen formas aserradas e irregulares y los halos suelen desarrollarse sólo en una cara de los bioclastos. Con luz polarizada se observan con extinción ondulosa y poseen colores naranjas brillantes bajo catodolouminscencia en frío.

Esta cementación es común en las facies someras (asociaciones de facies de rampa media distal y rampa media proximal) y se da de manera excepcional en las facies más profundas (asociaciones de facies de cuenca, rampa externa distal y rampa externa proximal).

\subsubsection{Neomorfismo}

Se presenta en los niveles estudiados como la recristalización de la matriz micrítica a cristales anhedrales de microesparita de aproximadamente $10 \mu \mathrm{m}$ de tamaño que se observan de color naranja brillante bajo catodoluminiscencia (Fig. 8.4 d, e y f). Palma et al. (2008) postularon la pérdida de $\mathrm{Sr}^{+2}$ y Na${ }^{+1}$ y el enriquecimiento en $\mathrm{Mn}^{+2}$ producido durante este fenómeno como el origen de la alta luminiscencia.

La intensidad del neomorfismo es muy variada en los distintos niveles, siendo más abundante en las facies más someras. Se puede presentar como cristales de subesparita aislados, formando pequeños mosaicos o bien conformando una matriz totalmente neoformada. El contacto gradual entre la micrita turbia y los cristales de microesparita sustenta el origen neomórfico de estos cristales (Bathurst, 1975).

\subsubsection{Disolución}

Es un proceso muy extendido y frecuente tanto en las calizas someras como en las profundas que afecta sólo a los bioclastos. En las facies más someras se identificó la disolución preferencial de los aloquemes compuestos originalmente por aragonita y calcita con alto contenido de magnesio, mientras que los de calcita de bajo contenido de magnesio (bivalvos ostreidos, equinodermos y algunos foraminíferos) se encuentran bien preservados (ver sección 8.5.2). La incipiente porosidad móldica generada por la disolución localizada es obliterada por la precipitación de cementos de calcita con bajo contenido de magnesio (ver capítulo 6). 
En las facies profundas, por otro lado, se observa también un fenómeno de disolución que se limita a la escasa variedad de bioclastos registrada en estos niveles (foraminíferos bentónicos, radiolarios, calciesferas y bivalvos ostreidos y no ostreidos), sin registrarse evidencias de disolución de la matriz. Al igual que en las facies someras, estos aloquemes compuestos por aragonita, calcita de alto contenido de magnesio y sílice (en el caso de los radiolarios), generan porosidad móldica y posterior precipitación de cementos calcíticos de bajo contenido de magnesio.

\subsubsection{Cementación esparítica y subesparítica}

Consta de la precipitación de cemento de calcita con bajo contenido de magnesio en los espacios intragranulares generados por la disolución. Presenta características disimiles en las facies someras y profundas.

En las facies más someras se observa el desarrollo de cementos de tipo granular y drusiforme precipitados tempranamente. El cemento granular es luminiscente bajo luz catódica, generalmente reemplaza a los radiolarios y calciesferas (fig. 8.4 f) y consiste en la precipitación de cristales ecuantes de calcita de tamaño subesparítico.

Por otro lado, el cemento drusiforme (el más extendido) (fig. $8.4 \mathrm{~g} \mathrm{y} \mathrm{h)} \mathrm{precipita}$ obliterando parcial o totalmente los espacios porales en estadios consecutivos con distintas luminiscencias definidas por una compleja relación del contenido de $\mathrm{Fe}^{+2}$ y $\mathrm{Mn}^{+2}$.

La cementación comienza hacia el centro de los espacios porales con la precipitación de un cemento con luminiscencia de tipo dull con el cual intercalan delgadas bandas brillantes que se encuentran más concentradas hacia el centro de los bioclastos (fig. 8.5 a y b).

En las facies profundas, en tanto, se observa cemento subesparítico granular y esparítico en bloque, ambos rellenando los espacios porales generados durante la disolución.

Contemporáneamente, se genera tanto en facies someras como profundas, cemento calcítico esparítico y subesparítico de color naranja brillante bajo catodoluminscencia en frío como relleno de fracturas tensionales que cortan la laminación primaria. Se trata de venas de carbonato con bajo contenido de magnesio, de espesores muy variados, anastomosadas y no anastomosadas, generalmente desorientadas, que atraviesan tanto la matriz como el esqueleto bioclástico (fig. 8.6 a y b). 

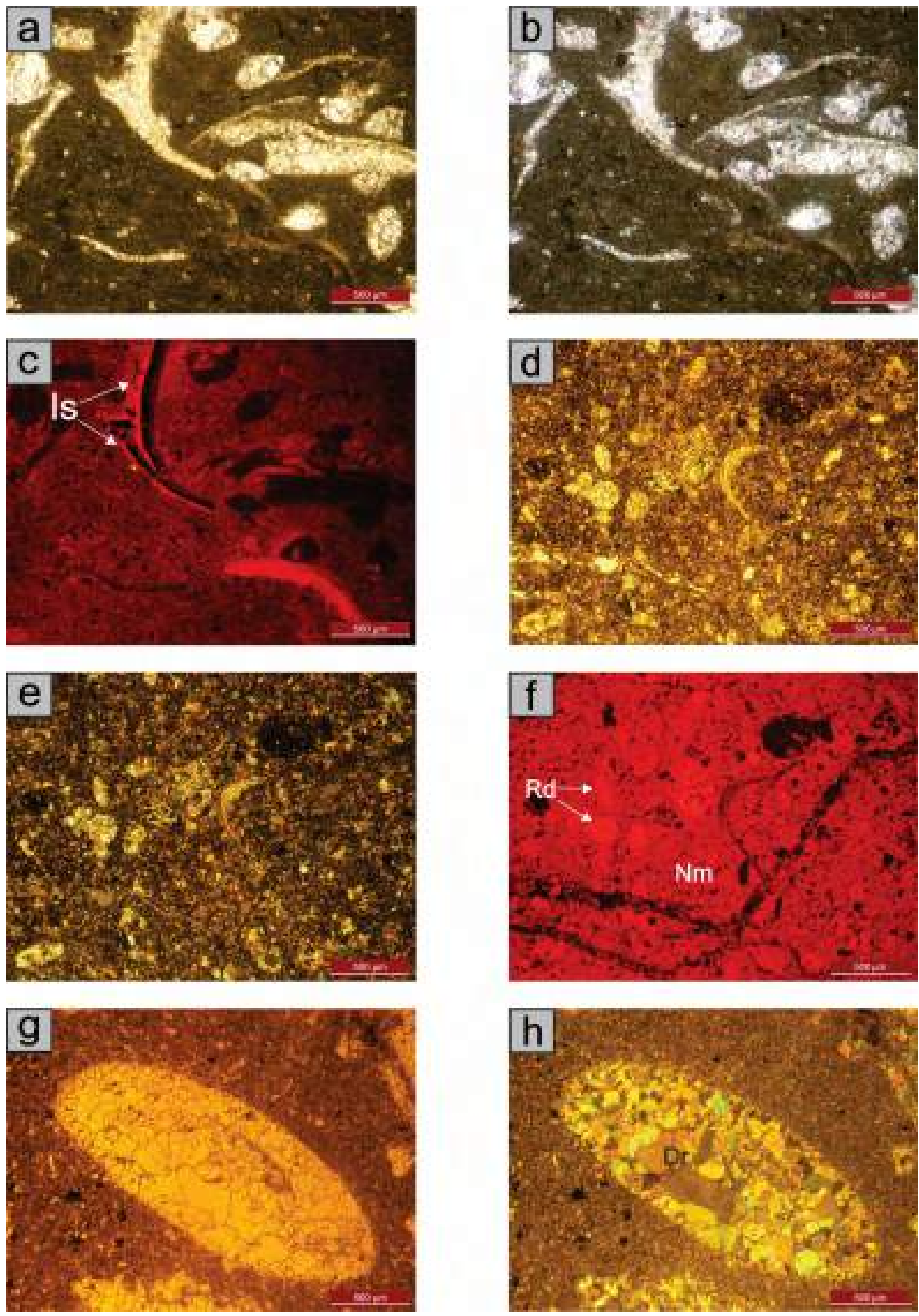

Figura 8.4. Rasgos diagenéticos en carbonatos. A, b y c: cemento en halo isópaco con y sin nicoles y bajo catodoluminscencia. D, e y f: matriz micrítica neoformada a subesparita y radiolarios disueltos con precipitación posterior de cemento de calcita con bajo contenido de magnesio, las imágenes se observan con y sin nicoles y bajo catodoluminscencia. G y h: Cemento drusiforme precipitado en facies someras con y sin nicoles. Is: cemento en halo isópaco, Rd: radiolario, $\mathrm{Nm}$ : neomorfismo y Dr: cemento drusiforme. 


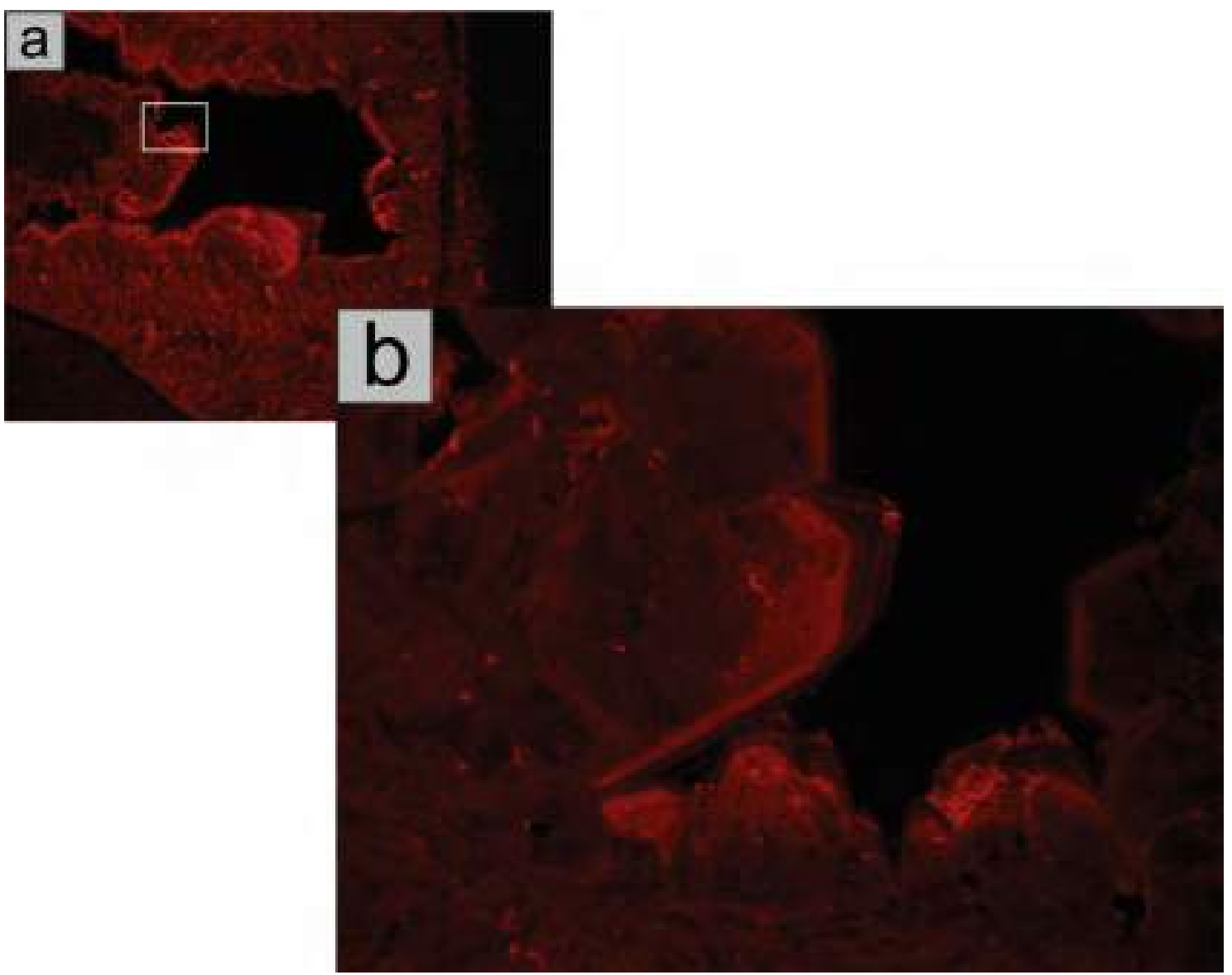

Figura 8.5. A: Cemento drusiforme visto bajo catodoluminiscencia en frío, b: vista en detalle del sector marcado en blanco en la figura a. Se observan cristales de cemento con luminiscencia de tipo dull con el cual intercalan delgadas bandas brillantes que se encuentran más concentradas hacia el centro de los bioclastos.

\subsubsection{Compactación}

Se desarrolla de la misma manera tanto en las facies profundas como en las someras, siendo más habitual en las primeras. Se trata de un proceso que se caracteriza por un predominio de la compactación química en una etapa tardía, representada por el desarrollo de estilolitas y venas, mientras que la compactación física inicial es subordinada y estaría representada por la presencia de laminación irregular y tenue, más visible en las rocas con abundante micrita.

La compactación química en los niveles de las formaciones Vaca Muerta y Chachao se llevó a cabo en tres estadios consecutivos definidos por las relaciones de corte.

Venas carbonáticas: el primer proceso de desarrollo de estilolitas se ve seguido por la posterior precipitación de cemento calcítico esparítico y subesparítico de color naranja brillante bajo catodoluminscencia en frío. Este relleno constituye venas de carbonato con bajo contenido de magnesio de espesores muy variados, anastomosadas y no anastomosadas, que 
atraviesan tanto la matriz como el esqueleto bioclástico (fig. 8.6 d y e). Estas venas carbonáticas acompañan la incipiente laminación generada durante la compactación física.

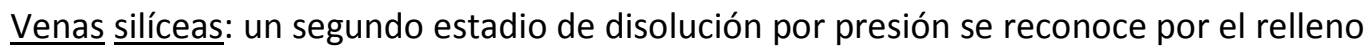
de estilolitas con cemento silíceo. Esta material puede ser tanto cuarzo microcristalino como chert, y precipita formando venas no orientadas que pueden o no estar anastomosadas (fig. 8.6 c). El momento en que estas estilolitas se rellenaron es reconocido gracias a las relaciones de corte establecidas con los otros eventos de compactación.

Estilolitas: en segundo término se reconocieron estilolitas con anchos inferiores a 15 $\mu \mathrm{m}$ y amplitudes muy bajas (rara vez superan los $30 \mu \mathrm{m}$ ). Son generalmente anastomosadas y se desarrollan en segmentos de $400 \mu \mathrm{m}$ como máximo que se disponen consecutivamente (fig. 8.6 d). Las estilolitas atraviesan tanto la matriz como los bioclastos que conforman el esqueleto, y cortan además las venas carbonáticas y silíceas (fig. 8.6 e). Usualmente, sobre estas estructuras se identifican restos de materia orgánica.

\subsubsection{Piritización}

Se observan cristales subhedrales a euhedrales desde 5 a $15 \mu \mathrm{m}$ aislados o formando pirita framboidal (fig. 8.6 f). Son abundantes tanto en facies profundas como someras y se encuentran en todos los perfiles estudiados. Las piritas framboidales se presentan reemplazando parcial o totalmente bioclastos como foraminíferos, calciesferas y bivalvos no ostreidos. Por otro lado, la pirita aislada se encuentra frecuentemente dispersa en la matriz y asociada a venas y estilolitas (fig. $8.6 \mathrm{~g}$ ).

\subsubsection{Fosfatización}

Es un proceso que se registra de modo frecuente tanto en facies someras como profundas. Se trata de apatitas en cristales con texturas equigranulares que no superan los 4 $\mu \mathrm{m}$; se reconoce por colores típicamente castaños sin nicoles, e isótropo con nicoles cruzados. Aparece como un proceso generalizado en todas las muestras analizadas, reemplazando parcial o totalmente valvas de foraminíferos, calciesferas, braquiópodos y bivalvos no ostreidos y en ocasiones diseminada en la matriz (fig. 8.6 h). 

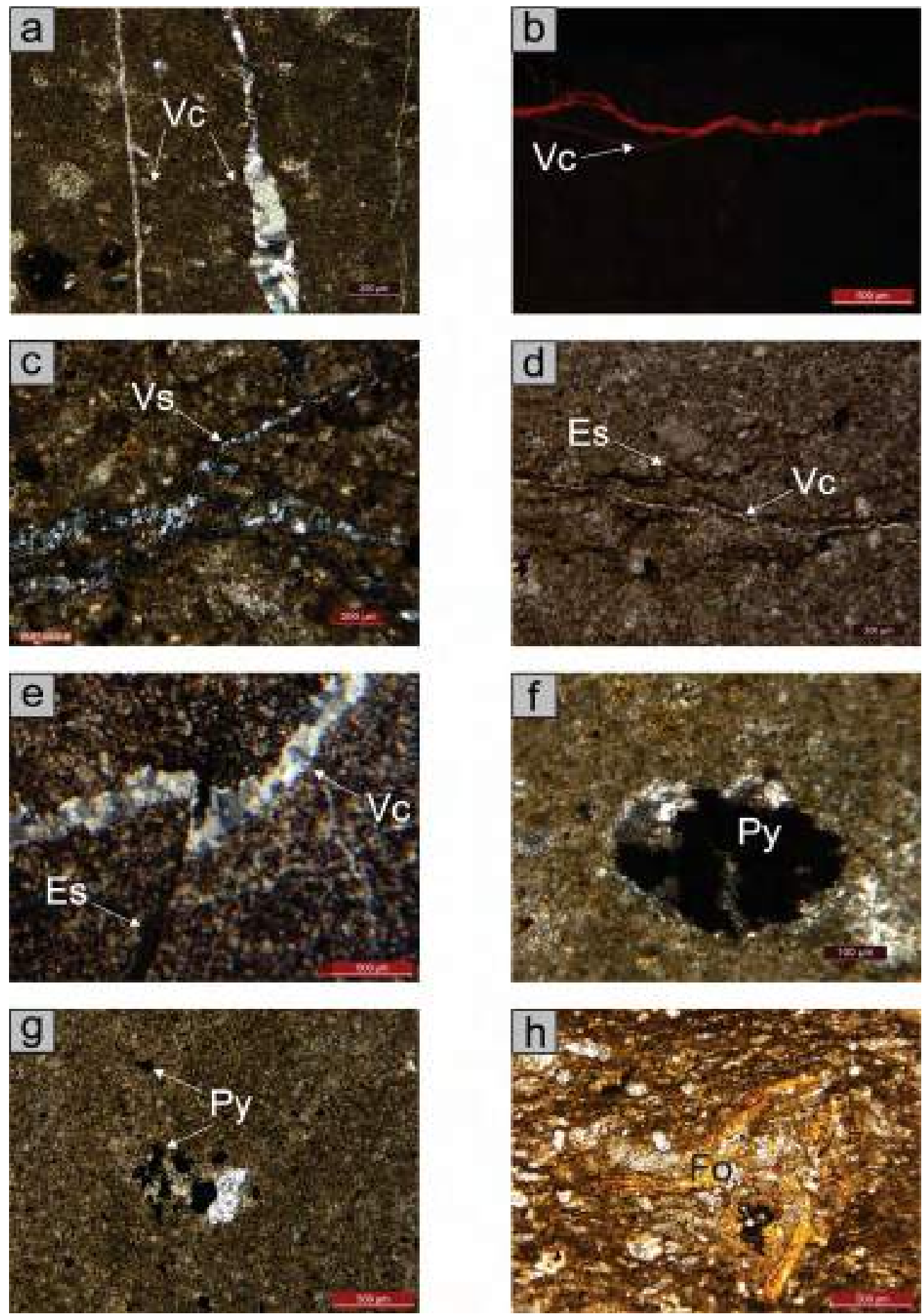

Figura 8.6. Rasgos diagenéticos en carbonatos. A: venas de carbonato con bajo contenido de magnesio, no anastomosadas y orientadas vistas con nicoles, b: venas de carbonato con bajo contenido de magnesio vistas bajo catodoluminiscencia de color naranja brillante anastomosadas, c: venas silíceas compuestas por cuarzo microcristalino anastomosadas vistas con nicoles, $\mathrm{d}$ : estilolitas no orientadas y anastomosadas vistas con nicoles, e: relación de corte entre venas calcíticas y estilolitas, f: pirita framboidal precipitada en un foraminífero vista con nicoles, g: piritización afectando esqueleto y matriz vista con nicoles, h: fosfatización de bivalvos no ostreidos vista sin nicoles. Vc: venas carbonáticas, Vs: venas silíceas, Es: estilolitas, Py: piritización, Fo: fosfatización. 


\subsubsection{Historia diagenética}

El conjunto de procesos diagenéticos que se observaron en las secciones de estudio de la Cuenca Neuquina permiten reconocer dos historias diagenéticas distintas, una para las facies someras y otra para las facies profundas (Gómez Dacal, 2014a).

Facies profundas (fig. 8.7): incluyen a los depósitos correspondientes a las asociaciones de facies de cuenca, rampa externa distal y rampa externa proximal de la base de la Formación Vaca Muerta. Las sedimentitas se caracterizan por su abundante matriz micrítica y un esqueleto representado mayormente por bioclastos de foraminíferos, calciesferas y bivalvos no ostreidos (compuestos originalmente de calcita con alto contenido de magnesio y aragonita), bivalvos ostreidos (calcita con bajo contenido de magnesio) y radiolarios (sílice).

En la etapa de eogénesis marina temprana se produce la precipitación de cementos en halo isópacos recubriendo de manera diferencial los bordes de los bioclastos de mayor tamaño. Los halos isópacos indican precipitación en un ambiente freático marino donde todos los poros están rellenos con agua de mar (James y Choquette, 1990; Palma et al., 2008).

El proceso generalizado de fosfatización también se asocia a los fluidos típicos del ambiente y el enterramiento incipiente. La precipitación autigénica de apatitas puede ser un proceso generalizado, como el que se observa tanto en las facies someras como profundas que reemplaza a diversos componentes carbonáticos, el cual se asocia a condiciones climáticas cálidas y húmedas y al aumento en los procesos de meteorización (Pufahl et al., 2003).

La precipitación de pirita framboidal se lleva a cabo acompañando de los procesos de fosfatización y cementación en halo y es favorecida por la alta cantidad de materia orgánica presente en el medio y por las condiciones de óxido-reducción. Posteriormente, se habría producido el neomorfismo de parte de la matriz micrítica como proceso ya involucrado a un enterramiento somero.

En una etapa de mesogénesis temprana se produce la disolución de los bioclastos compuestos por sílice, aragonita y calcita con alto contenido de magnesio y la inmediata precipitación de cementos de calcita con bajo contenido de magnesio subesparíticos a esparíticos de tipo intragranulares. El proceso de disolución de calcita, en este caso, corresponde al soterramiento y estaría vinculado a la descomposición de la materia orgánica y la consecuente acidificación del medio (Champ et al., 1979). El proceso de cementación ocurrió inmediatamente a posteriori de la disolución de los bioclastos, impidiendo que se produzca la compactación de las cavidades móldicas (Sagasti, 2001a).

Dentro de la compactación física inicial se reconoce desarrollo de laminación incipiente e irregular. La cementación que continúa aparece cortando dicha laminación, con venas 
tensionales de calcita, previa fracturación oblicua o pseudovertical respecto a la planaridad de la roca. También durante la mesogénesis temprana, pero de modo posterior a los procesos de disolución y cementación, se habría llevado a cabo la compactación química con desarrollo de estilolitas que en ocasiones fueron rellenadas por fluidos cementantes generados durante la disolución de los bioclastos (Gómez Dacal, 2014a). En orden temporal, primero se habrían desarrollado las venas calcáreas paralelas a la laminación, seguido por las venas silíceas y en último lugar las estilolitas con presencia de materia orgánica en sus planos irregulares. Se estima que el fluido saturado en sílice estaría disponible como producto de la disolución de radiolarios originalmente silíceos, y por esta razón el desarrollo de venas sería más abundante en las facies profundas donde existe mayor abundancia de estos géneros (Sagasti, 2001a).

Según Gómez Peral (2008) la caracterización de estas estilolitas poco aserradas, de baja amplitud vertical y con escasa continuidad lateral, corresponden a rasgos de presióndisolución que las relacionan a procesos de diagénesis temprana, más aún cuando abunda la micrita asociada a materia orgánica diseminada como en los ejemplos reconocidos en este estudio (eogénesis a mesogénesis temprana).

El proceso de piritización aislada se habría producido desde una etapa de mesogénesis temprana, siendo el último en culminar. La piritización se desarrolla a partir de fluidos porales euxínicos. Berner (1984) postula que la degradación de la abundante materia orgánica presente en el sedimento generaría condiciones reductoras locales en las aguas porales, que inducirían a la precipitación de pirita. 


\begin{tabular}{|c|c|c|c|}
\hline $\begin{array}{l}\text { Proces } \\
\text { produr }\end{array}$ & $\begin{array}{ll}\text { os y } & \\
\text { tos } & \text { Etapas } \\
\text { diagenéticas }\end{array}$ & Eogénesis & Mesogenesis temparana \\
\hline \multicolumn{2}{|r|}{ Cemento isópaco } & $m=-m=n=0$ & \\
\hline \multicolumn{2}{|r|}{ Fosfatización } & - & \\
\hline \multicolumn{2}{|r|}{ Neomorfismo } & $m--m=m$ & \\
\hline \multicolumn{2}{|r|}{ Disolución } & & \\
\hline \multicolumn{2}{|c|}{ Cemento granular } & & $=$ \\
\hline \multicolumn{2}{|c|}{ Compactación física } & & \\
\hline \multicolumn{2}{|c|}{$\begin{array}{c}\text { Venas carbonáticas } \\
\text { tensionales }\end{array}$} & & \\
\hline \multirow{3}{*}{ 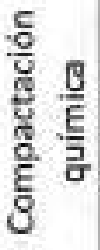 } & Venas carbonáticas & & $\longrightarrow$ \\
\hline & Venas siliceas & & - \\
\hline & Estilolitas & & $\Longrightarrow$ \\
\hline \multicolumn{2}{|r|}{ Piritización } & 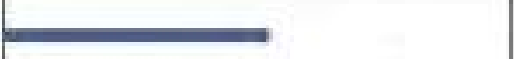 & \\
\hline
\end{tabular}

Figura 8.7. Historia diagenética de las facies profundas. La líneas llenas indican que el proceso está ampliamente representado y las líneas cortadas procesos con menor representación.

Facies someras (fig. 8.8): incluyen a los depósitos correspondientes a las asociaciones de facies de rampa media distal y rampa media proximal del tope de la Formación Vaca Muerta y la Formación Chachao. Las sedimentitas se caracterizan por una matriz micrítica abundante y un esqueleto representado mayormente por bioclastos de foraminíferos, calciesferas, braquiópodos, briozoos, serpúlidos, poríferos y bivalvos no ostreidos (composición original de aragonita y calcita con alto contenido de magnesio), bivalvos ostreidos y equinodermos (calcita con bajo contenido de magnesio) y radiolarios (sílice).

Durante la etapa de eogénesis marina temprana se reconocen los mismos procesos que en las facies profundas pero con mayor intensidad. Se identificó abundante cemento en halo isópaco en los fósiles de mayor tamaño, precipitación de pirita framboidal y fosfatización de los bioclastos y la matriz. El neomorfismo en tanto, es mucho más prominente que en las facies profundas, favorecido por el cambio hacia un ambiente diagenético meteórico.

El alto potencial de agradación de los carbonatos, así como los cambios relativos en el nivel del mar favorecieron la emersión de dichos depósitos, los que quedaron sometidos a la acción de procesos diagenéticos meteóricos durante breves intervalos de tiempo. Durante la 
eogénesis meteórica se desarrolló la disolución de los organismos compuestos por calcita de alto contenido de magnesio y aragonita y la inmediata precipitación de cementos con bajo contenido de magnesio, de tipo granular y drusiforme. Por su carácter extensivo, se vincula a la disolución como un proceso relacionado al ambiente meteórico durante la etapa de diagénesis temprana.

El cemento drusiforme es el más extendido en las facies someras, en el que se reconocieron estadios consecutivos con distintas luminiscencias según los contenidos $\mathrm{de} \mathrm{Fe}^{+2}$ y $\mathrm{Mn}^{+2}$ (Machel, 2000) y que obedecerían a las condiciones de óxido-reducción de los fluidos porales (Boggs y Krinsley, 2006). La intercalación de cemento tipo dull con delgadas bandas brillantes es interpretada como consecuencia del decrecimiento en el potencial de óxidoreducción o redox (Eh), bajo condiciones de progresivo enterramiento en un ambiente diagenético meteórico- freático (Palma et al., 2008).

La compactación física y el desarrollo de venas calcáreas tensionales es menos frecuente en las facies someras que en las profundas. Por otro lado, la compactación química en las facies someras también involucra el desarrollo de estilolitas y venas calcáreas y silíceas asociadas a una etapa de mesogénesis temprana. A diferencia de las facies profundas, las venas silíceas son menos frecuentes posiblemente debido a la menor proporción de radiolarios, cuya disolución sería la fuente de los fluidos cementantes. Finalmente, también se observaron procesos de piritización aislada, vinculada a la etapa de mesodiagénesis temprana. 


\begin{tabular}{|c|c|c|c|}
\hline $\begin{array}{l}\text { Froces } \\
\text { prodis }\end{array}$ & tos Es Etapas & Eoginesis & Mesogénesis temparana \\
\hline \multicolumn{4}{|c|}{ Cemervto isopaco } \\
\hline \multicolumn{4}{|c|}{ Fosfatizaciän } \\
\hline \multicolumn{2}{|r|}{ Neornorfismo } & $=$ & \\
\hline \multicolumn{2}{|r|}{ Disclución } & & \\
\hline \multicolumn{2}{|r|}{ Cemento granulat } & & $=$ \\
\hline \multicolumn{2}{|c|}{ Comenta drusiforme } & & $=$ \\
\hline \multicolumn{2}{|c|}{ Compactacięn fisica } & & $=m=$ \\
\hline \multicolumn{2}{|c|}{$\begin{array}{c}\text { Venas carbonaticas } \\
\text { tensionales }\end{array}$} & & $=-\infty$ \\
\hline \multirow{3}{*}{$\begin{array}{l}\delta \\
8 \\
\frac{8}{8} \\
\frac{6}{6} \\
\text { है } \\
\text { है }\end{array}$} & Venes carbonaticas & & \\
\hline & Venas siliteess & & $=$ \\
\hline & Estiblitas & & \\
\hline \multicolumn{2}{|r|}{ Pintizacion } & - & \\
\hline
\end{tabular}

Figura 8.8. Historia diagenética de las facies someras. Las barras en verde indican procesos correspondientes a la diagénesis meteórica y en negro los de diagénesis marina y de soterramiento. La líneas llenas indican que el proceso está ampliamente representado y las líneas cortadas procesos con menor representación.

\subsection{Diagénesis de psamitas silicoclásticas y mixtas}

\subsubsection{Introducción}

A continuación se tratarán los procesos y productos postdepositacionales que afectaron a las psamitas silicoclásticas y mixtas de las Formación Springhill. En la sección 8.2.3 se realizó un análisis similar sobre la fracción pelítica que conforma parte de esta formación y casi la totalidad de la Formación Río Mayer, de manera que el estudio de las areniscas podrá dar una idea acabada de la totalidad de los eventos diagenéticos acontecidos en el área de estudio de la Cuenca Austral.

Múltiples factores tales como la composición inicial, la naturaleza de las aguas porales y el contenido de materia orgánica intervienen en la diagénesis de las rocas silicoclásticas (Tucker, 2001). El estudio mediante petrografía convencional y de catodoluminiscencia permitió entender los procesos y factores generadores, así como desarrollar una cronología relativa de los eventos diagenéticos acontecidos permitiendo armar la historia diagenética. 


\subsubsection{Procesos diagenéticos}

\subsubsection{Glauconitización}

Es el proceso de cristalización temprana de la glauconita en poros de sustratos de naturaleza muy diversa (cuarzo, feldespatos, fragmentos líticos, bioclastos) contemporánea a la disolución progresiva de los mismos (Odin y Matter, 1981). En el área de estudio, la glauconita se presenta formando nódulos de textura microcristalina de entre 150 y $200 \mu \mathrm{m}$ de tamaño de formas subangulosas a bien redondeadas y muy circulares (fig. 8.9 a y b).

\subsubsection{Cementación carbonática marina}

La cementación carbonática marina se ve representada por halos isópacos que contornean bioclastos y otros clastos detríticos (fig. 8.9 c y d). Mientras los halos se ven continuos y con cristales de hasta $20 \mu \mathrm{m}$ de tamaño en los bioclastos de algas dasycladáceas, se observan irregulares y con cristales de $10 \mu \mathrm{m}$ como máximo en bivalvos y como sombras incipientes en cristaloclastos de cuarzo. Con luz polarizada poseen extinción ondulosa y colores naranjas brillantes bajo catodolouminscencia en frío.

\subsubsection{Cementación cuarzosa}

Este cemento se observa como sobrecrecimiento de los granos de cuarzo en continuidad óptica y cristalográfica, y su límite suele reconocerse por la presencia de arcillas (fig. 8.9 e y f). Bajo catodoluminiscencia, los sobrecrecimientos son no luminiscentes, razón por la cual se habrían formado a menos de 150 C según Marshall (1988), lo que ubicaría este proceso durante la mesogénesis.

\subsubsection{Autigénesis de arcillas}

En los poros entre los granos es posible observar cementos de arcillas con cristales inferiores a $4 \mu \mathrm{m}$ (fig. $8.9 \mathrm{~g}$ y h). Según Spalletti et al. (2005), el principal argilomineral en precipitar en los poros de las areniscas de la Formación Springhill es la caolinita y en menor medida la illita por reemplazo pseudomórfico de la caolinita. La cuantificación propuesta coincide con las interpretadas por Richiano et al. (2015b) y con las del análisis de fracción fina de este trabajo (ver sección 6.2.2). 

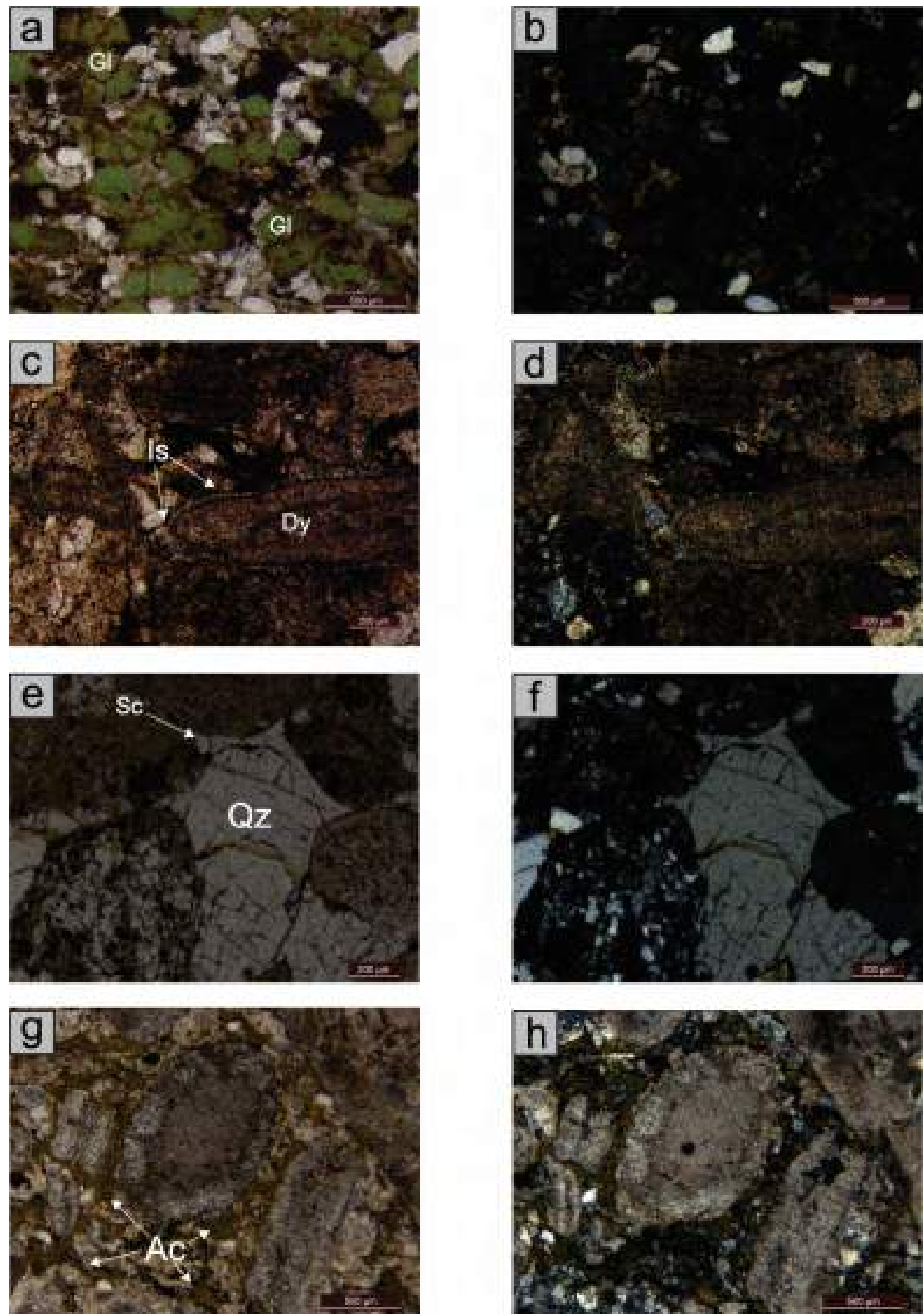

Figura 8.9. Rasgos diagenéticos en rocas silicoclásticas y mixtas. A y b: nódulos de glauconita, observados con y sin nicoles. C y d: cemento en halo isópaco con y sin nicoles. E y f: sobrecrecimientos de cuarzo con y sin nicoles. G y h: autigénesis de arcillas con y sin nicoles. Gl: glauconita, Dy: alga dasycladácea, Is: cemento isópaco, Qz: cuarzo, Sc; sobrecrecimiento, Ac: arcillas. 


\subsubsection{Cementación carbonática de soterramiento}

Se distinguen cristales esparíticos a subesparíticos inequigranulares de calcita con bajo contenido de magnesio, que con frecuencia alcanzan buen desarrollo de los individuos y aparecen como cemento poiquilotópico, es decir, rellenando los espacios porales entre los elementos que conforman el esqueleto (fig. 8.10 a y b). Bajo catodoluminiscencia en frío, se observan colores naranjas a rojos brillantes (fig. 8.10 c y d), denotando en su composición contenidos altos de $\mathrm{Mn}^{+2}$ (Spalletti et al., 2005).

El cemento carbonático de soterramiento en los perfiles estudiados sólo se encuentra en niveles de rocas mixtas o aledaños a ellos, donde existe un mayor porcentaje de material bioclástico carbonático.

\subsubsection{Disolución}

Se observan importantes procesos de disolución que generaron porosidad secundaria. Particularmente, se registraron abundantes fracturas y cavidades porales en la asociación de facies fluvial de la base de la Formación Springhill en el perfil Subida del Chancho (fig. 8.10 e y f).

Las fracturas poseen hasta $10 \mu \mathrm{m}$ de espesor, gran continuidad y no están rellenas ni anastomosadas. Las cavidades, por otro lado, pueden alcanzar los $3 \mathrm{~mm}$ de ancho.

\subsubsection{Compactación}

De la misma forma que en las facies carbonáticas de la Cuenca Neuquina, se reconocieron evidencias de compactación química, mientras que la compactación física resulta mucho menos evidente y se ve representada por la presencia de granos fracturados (fig. 8.9 e y f). Se observaron estilolitas con anchos de hasta $20 \mu \mathrm{m}$ y amplitudes que no superan los 50 $\mu \mathrm{m}$. Predominan las formas simples por sobre las anastomosadas y frecuentemente se observan concentraciones de materia orgánica (fig. $8.10 \mathrm{~g}$ y h). La presencia de contactos cóncavo-convexos y suturados más concomitante disolución parcial de los granos sugiere una evolución de la compactación química importante durante el soterramiento.

La mayor abundancia de estilolitas coincide con los mayores tenores de materia orgánica que se dan en la asociación de facies fluvial de la base de la Formación Springhill en la Subida del Chancho. 

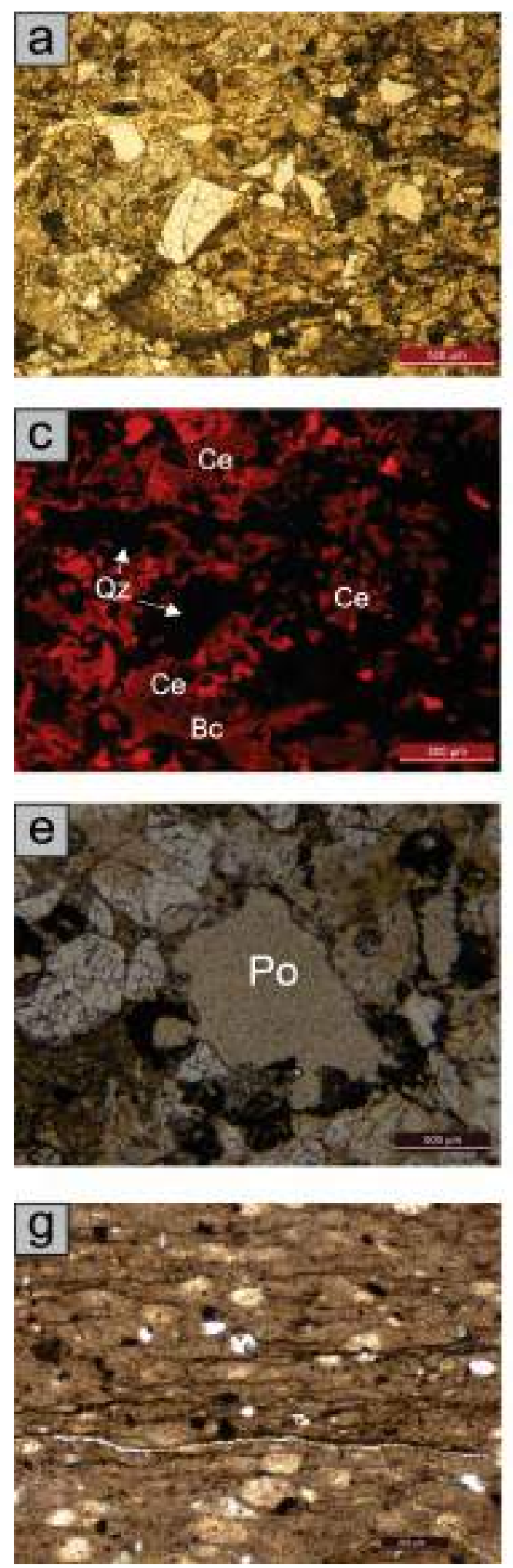
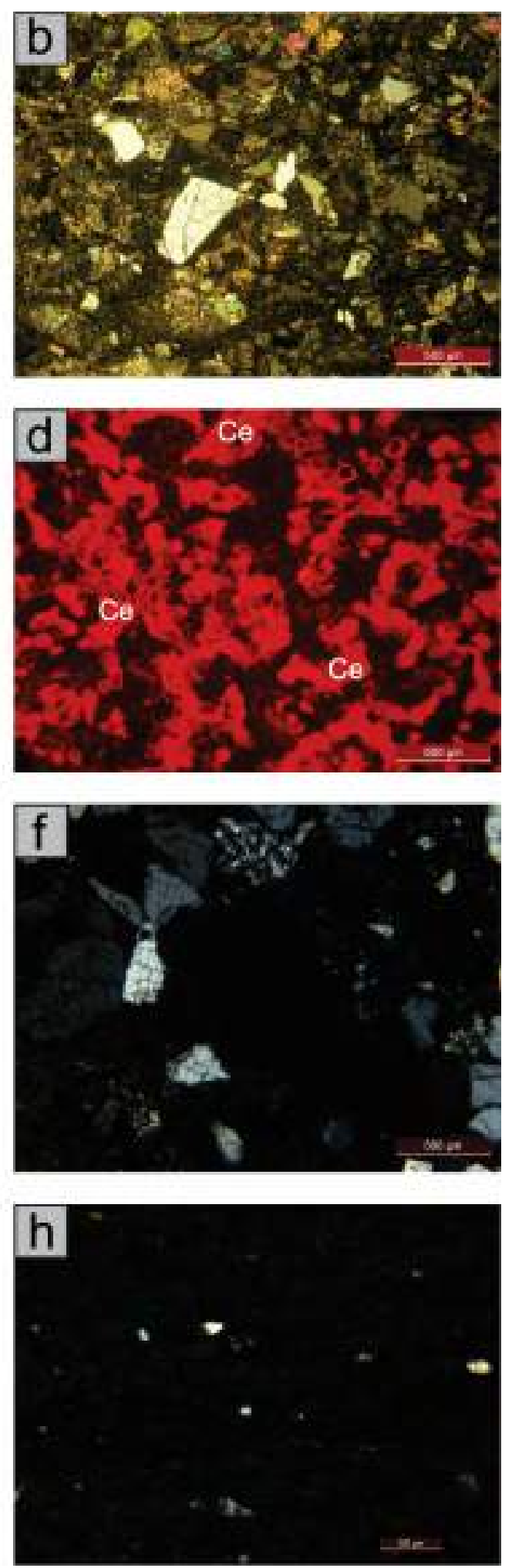

Figura 8.10. Rasgos diagenéticos en rocas silicoclásticas y mixtas. A y b: cemento carbonático poiquilotópico visto con y sin nicoles. C y d: cemento carbonático poiquilotópico visto con catodoluminiscencia. E y f: porosidad secundaria con y sin nicoles. G y h: Microestilolitas anastomosadas vistas con y sin nicoles. Qz: cuarzo, Bc: bioclasto, Ce: cemento esparítico poiquilotópico, Po: porosidad secundaria. 


\subsubsection{Historia diagenética}

Los procesos diagenéticos reconocidos pudieron ser ordenados temporalmente sobre la base de las relaciones de corte observadas petrográficamente y las condiciones de presión y temperatura en las que éstos se llevan a cabo. De esta forma, se propone una historia diagenética ideal para toda la zona de estudio (fig. 8.11). La aparición y magnitud de los procesos depende principalmente de la composición, asociada principalmente a la presencia y cantidad de materia orgánica y de bioclastos. Para la Formación Springhill se han establecido tres trenes diagenéticos correspondientes a las facies fluviales, marinas mixtas y marinas silicoclásticas.

Facies marinas mixtas (fig. 8.12 a): incluyen parte de la asociación de facies de shoreface en los perfiles Cerro Hobler y Subida del Chancho. Están formadas por una matriz silicoclástica y un esqueleto conformado por bioclastos de belemnites, bivalvos ostreidos, equinodermos y belemnites, además de cuarzo y líticos volcánicos.

La eogénesis comienza con el proceso de cementación carbonática marina, donde se generan cementos en halo isópacos en torno a los bioclastos, y de forma más incipiente, en los clastos de cuarzo y líticos volcánicos. Es importante destacar que la cementación carbonática marina sólo se registró en psamitas mixtas. Este proceso se lleva a cabo en un ambiente freático marino donde todos los poros están rellenos con agua de mar (James y Choquette, 1990; Palma et al., 2008).

De modo contemporáneo, en el perfil Subida del Chancho, se aprecia una glauconitización en nódulos. Múltiples autores (p.e. Cloud, 1955; Pettijohn, 1957; Odin y Matter, 1981) postulan que este proceso se lleva a cabo en un medio marino de aguas relativamente agitadas, de escasa a moderada profundidad y salinidad normal. Además, Amorosi (1995) y Spalletti et al. (2005), hacen referencia a que la geometría nodular puede estar relacionada a superficies transgresivas con bajas tasas de sedimentación. La presencia y origen de este componente es advertida por varios autores (Spalletti et al., 2005; Schwarz et al, 2011b; Richiano et al., 2016). Los niveles glauconíticos se concentran sólo donde las características ambientales para su formación habrían sido las adecuadas, en este caso un lower shoreface desarrollado en un cortejo transgresivo (ver sección 5.3.2.4).

La mesogénesis comienza con la compactación física, que se ve representada por los granos fracturados. Durante la mesogénesis temprana, la cementación cuarzosa es poco frecuente, no así la autigénesis de arcillas, principalmente de caolinita a partir de feldespatos, proceso que se reconoce en la totalidad de las muestras tomadas en estas facies. 
La precipitación de la caolinita en el ambiente diagenético se habría producido en medios ácidos y con bajos tenores de potasio, y pudo haberse visto favorecida por la descomposición de materia orgánica (Spalletti et al., 2005).

Por último, el estadio mesogenético se ve caracterizado por una intensa cementación carbonática de tipo poiquilotópica. La fuente de los fluidos cementantes sería los mismos fragmentos esqueletales del nivel, ya que no se reconoció este proceso en facies marinas silicoclásticas ni fluviales. Según Tucker (2001), este tipo de cemento es el más frecuente en areniscas clasto-soportadas y se generaría en profundidad por incremento del pH junto con la temperatura. Spalletti et al. (2005) ubican este proceso diagenético en el área como acontecido con posterioridad a la autigénesis de arcillas y con anterioridad a los procesos de disolución y compactación química.

La compactación química se ve representada por unas pocas estilolitas no anastomosadas con poca continuidad.

Facies marinas silicoclásticas (fig. 8.12 b): incluye a las asociaciones de facies de shoreface del perfil Cerro Hobler, la plataforma interna del perfil Río Guanaco y los subambientes de upper shoreface y foreshore del perfil Subida del Chancho. Están formadas por areniscas líticas con matriz limosa.

No se reconocen procesos de eogénesis, mientras que la mesogénesis temprana se ve representada por la fracturación de granos (compactación física), una abundante cementación cuarzosa (que se da casi con exclusividad en estas facies) y la autigénesis de arcillas que se prolonga hasta la mesogénesis tardía.

El origen del cemento cuarzoso ha sido ampliamente debatido en la bibliografía (Tucker, 2001; Gluyas et al., 2000; Worden y Morad, 2000), y para el caso de las areniscas de la formación Springhill Spalletti et al. (2005) proponen como fuente de los fluidos cementantes la alteración de trizas de vidrio volcánico a esmectita (de unidades del sustrato e incluso de niveles piroclásticos de la misma Formación Springhill) y la transformación diagenética de argilominerales esmectíticos a illíticos que ha ocurrido con mayor frecuencia e intensidad en la formación Río Mayer (ver sección 8.2.3). Este proceso estaría asociado a profundidades mayores dentro de la mesogénesis, donde las temperaturas alcanzarían los 120-150 ㄷ (Surdam et al., 1989). Sin embargo, debe tenerse en consideración que a medida que aumenta la profundidad se requieren concentraciones cada vez más altas de sílice disuelta en las aguas porales para que el cuarzo pueda precipitar (Worden y Morad, 2000). La autigénesis de arcillas, por otro lado, se generaría a expensas de la descomposición de los feldespatos (ver sección 7.3.1). 
Entre los procesos mesogenéticos terminales se destaca una intensa compactación química representada por estilolitas anastomosadas y no anastomosadas orientadas. Estas acumulaciones son interpretadas como el principal factor que favorece los procesos de disolución por presión en el área de estudio (Flügel, 2004). Las estilolitas cortan tanto a la matriz como al esqueleto y los cementos, siendo el último proceso de la secuencia diagenética en llevarse a cabo. Por otro lado, la morfología de las mismas sustenta que este proceso se haya llevado a cabo durante la mesogénesis (Gómez Peral, 2008).

Cabe agregar que los procesos de disolución y cementación carbonáticos son muy poco frecuentes y se ven reducidos a sectores aislados.

Facies fluviales (fig. 8.12 c): se reconocieron en el sector basal del perfil Subida del Chancho y están representados por vaques líticos con matriz fangosa. Los procesos que se reconocen en esta secuencia están vinculados a la abundante cantidad de materia orgánica presente en estas facies, que produjo la acidificación del medio y potenció el desarrollo de la disolución y la compactación química durante la mesogénesis temprana a tardía.

Sobre el proceso de disolución, Liermann et al. (2011) proponen que con la incursión de fluidos ácidos, algunos minerales como los feldespatos y la calcita se disuelven más drásticamente originando la porosidad secundaria. Este proceso comenzaría durante la eogénesis tardía, pero se acentuaría durante la mesogénesis posteriormente a los fenómenos de cementación. 


\begin{tabular}{|c|c|c|c|}
\hline $\begin{array}{l}\text { Procesos y } \\
\text { productos Etapas } \\
\text { diagenéticas }\end{array}$ & Eogénesis & Mesogénesis temprana & Mesogénesis tardia \\
\hline \multicolumn{4}{|l|}{ Glauconitizoción } \\
\hline \multicolumn{4}{|l|}{$\begin{array}{c}\text { Cementación } \\
\text { carbonática marina }\end{array}$} \\
\hline \multicolumn{4}{|l|}{ Compactación fisica } \\
\hline \multicolumn{4}{|l|}{ Cementación cuarzosa } \\
\hline \multicolumn{4}{|l|}{ Autigenesis de arcillas } \\
\hline \multicolumn{4}{|l|}{$\begin{array}{l}\text { Cementación } \\
\text { carbonática }\end{array}$} \\
\hline \multicolumn{4}{|l|}{ Disolución } \\
\hline Compactación quimica & & 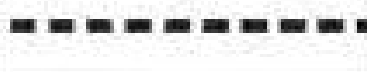 & 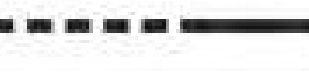 \\
\hline
\end{tabular}

Figura 8.11. Historia diagenética ideal para el sector de estudio en la Cuenca Austral. 


\begin{tabular}{|c|c|c|c|}
\hline $\begin{array}{l}\text { Procesasy } \\
\text { protuogy Etapss }\end{array}$ & Eoctresis & Mesegtnesia temprars & Mesoptneik torda \\
\hline Giacoenstizasion & ang & & \\
\hline \multicolumn{4}{|l|}{$\begin{array}{c}\text { Gementabsn } \\
\text { cartentees nariva }\end{array}$} \\
\hline \multicolumn{4}{|l|}{ Compoctacien fhira } \\
\hline Cementeciln cuarroia & & $\mathrm{n}=\mathrm{m}=\mathrm{n}$ & 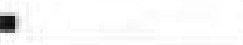 \\
\hline \multicolumn{4}{|l|}{ Autginess de ardiss } \\
\hline \multicolumn{4}{|l|}{$\begin{array}{l}\text { Comencacion } \\
\text { carbonitica }\end{array}$} \\
\hline \multicolumn{4}{|l|}{ Dsotwitn } \\
\hline Compactadon a-isica & & & $= \pm$ \\
\hline $\begin{array}{l}\text { Frocesest } \\
\text { productoge Eapas } \\
\text { dagentron }\end{array}$ & Exglnesis & Mesogenesis tonprara & Mesopinesis tanth \\
\hline \multicolumn{4}{|l|}{ Glauscontizacior } \\
\hline \multicolumn{4}{|l|}{$\begin{array}{l}\text { Cemertadón } \\
\text { arbensica marina }\end{array}$} \\
\hline \multicolumn{4}{|l|}{ Compactacion tista } \\
\hline \multicolumn{4}{|l|}{ Cencertatian aarasss } \\
\hline \multicolumn{4}{|l|}{ Autginab de erollan } \\
\hline $\begin{array}{l}\text { Ceminticiln } \\
\text { Cabonitia }\end{array}$ & & & $= \pm$ \\
\hline Dasolveitin & & & $m= \pm$ \\
\hline Compsctadisn quformica & & $m=m=0$ & $=m$ \\
\hline 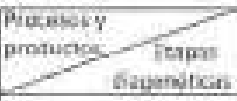 & Estatresa & Mescestnos temarare & Mesogtneib tenas. \\
\hline \multicolumn{4}{|l|}{ cisubcritizucish } \\
\hline \multicolumn{4}{|l|}{$\begin{array}{c}\text { Comentakish } \\
\text { carbenatca marisa }\end{array}$} \\
\hline \multicolumn{4}{|l|}{ Compoctadion fiva } \\
\hline \multicolumn{4}{|l|}{ Cenertadiln cuarioa } \\
\hline \multicolumn{4}{|l|}{ Autigeno is de arsilas } \\
\hline \multicolumn{4}{|l|}{$\begin{array}{l}\text { Commentsodin } \\
\text { carbonatia }\end{array}$} \\
\hline Dsotooen & & & = \\
\hline Compscradon quatica & & $m=-m=$ & 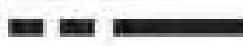 \\
\hline
\end{tabular}

Figura 8.12. Historias diagenéticas. A) Facies marinas mixtas, b) Facies marinas silicoclásticas y c) Facies fluviales. La barra de color rojo indica que el proceso se localiza solo en el perfil Subida del Chancho. La línea llena indica que el proceso está ampliamente representado; la línea cortada indica que el proceso tiene menor representación. 


\subsection{Diagénesis en fósiles}

\subsubsection{Introducción}

La composición química original de los carbonatos constituye un factor clave en la respuesta ante los procesos diagenéticos. Por esta razón, fósiles compuestos por calcita con bajo contenido de magnesio, como ostras, equinodermos, foraminíferos y belemnites, poseen mayor potencial de preservación de sus estructuras originales.

Otro factor que juega un rol importante en la fósil- diagénesis es la tafonomía. Fósiles con menor grado de fragmentación, bioerosión y corrasión suelen verse menos afectados ante los procesos diagenéticos.

Para poder evaluar el grado de alteración diagenética, los fósiles fueron analizados mediante microscopía electrónica de barrido y catodoluminiscencia. Sobre la base de esta información y con el objetivo de realizar estudios geoquímicos e isotópicos que puedan reflejar las características ambientales originales en las cuales estas especies vivían, se seleccionaron los fósiles con mejor preservación en cada cuenca.

\subsubsection{Ostras de la Cuenca Neuquina (Aetostreon sp.)}

En los niveles carbonáticos de la Cuenca Neuquina, se seleccionaron fósiles del género Aetostreon sp. Su composición de calcita con bajo contenido de magnesio, su bajo grado de alteración tafonómica observada en las tareas de campo, su abundancia y amplia distribución, y su utilización en trabajos previos como Aguirre-Urreta et al. (2008) y Lazo et al. (2008), fueron los criterios utilizados para la selección de este taxón.

Cincuenta y siete muestras de ostras fósiles (once de Río Salado, veintinueve de Puesto Loncoche y diecisiete de Cuesta del Chihuido) fueron elegidas de los perfiles para su estudio petrográfico.

A escala microscópica, es posible observar en las valvas tres tipos de microestructuras: prismática, foliada y "chalky", las cuales se combinan de diferentes maneras para conformar las capas de crecimiento de la ostra. Las láminas prismáticas, están compuestas por gruesos cristales de calcita elongados en forma perpendicular a la superficie de la capa; las foliadas poseen cristales escamosos de calcita empaquetados de modo oblicuo a horizontal a la superficie de la valva, y las capas chalky, están integradas por una masa de granos pequeños de carbonato sin orientación preferencial definida. 
Detallados estudios de Cuitiño (2011) y Cuitiño et al. (2015) indican que en las capas chalky existe una fábrica abierta con presencia de poros y cristales euhedrales de calcita que sugiere que el relleno del espacio poral y recristalización del material original se formó durante la diagénesis. Por otro lado, las capas foliadas y prismáticas muestran una fábrica cerrada sin espacios porales que limitarían la circulación de los fluidos diagenéticos.

En las imágenes tomadas mediante microscopía de catodoluminiscencia se observaron áreas luminiscentes y no luminiscentes, siendo las primeras coincidentes con las capas de tipo chalky y las últimas correspondientes al crecimiento de tipo foliado de las ostras (fig. 8.13 a y b). La ausencia de luminiscencia en las capas foliadas indica cantidades bajas de $\mathrm{Mn}$ (elemento activador de la luminiscencia), las cuales se correlacionan con valores primarios para ostras del Jurásico- Cretácico (Jones et al., 1994; Wierzbowski y Joachimski, 2007). La preservación de las cantidades originales de Mn evidenciaría el carácter primario de estas texturas.

Por otro lado, mediante el uso de un microscopio electrónico de barrido (MEB) se observó en detalle el crecimiento foliado de las ostras (fig. 8.13 c y d). En las microfotografías es posible apreciar la preservación de las microtexturas originales (superficies smoothtextured), hecho que se correlaciona con un alto grado de preservación de los restos fósiles (Korte y Hesselbo, 2011; Ullmann y Korte, 2015). 

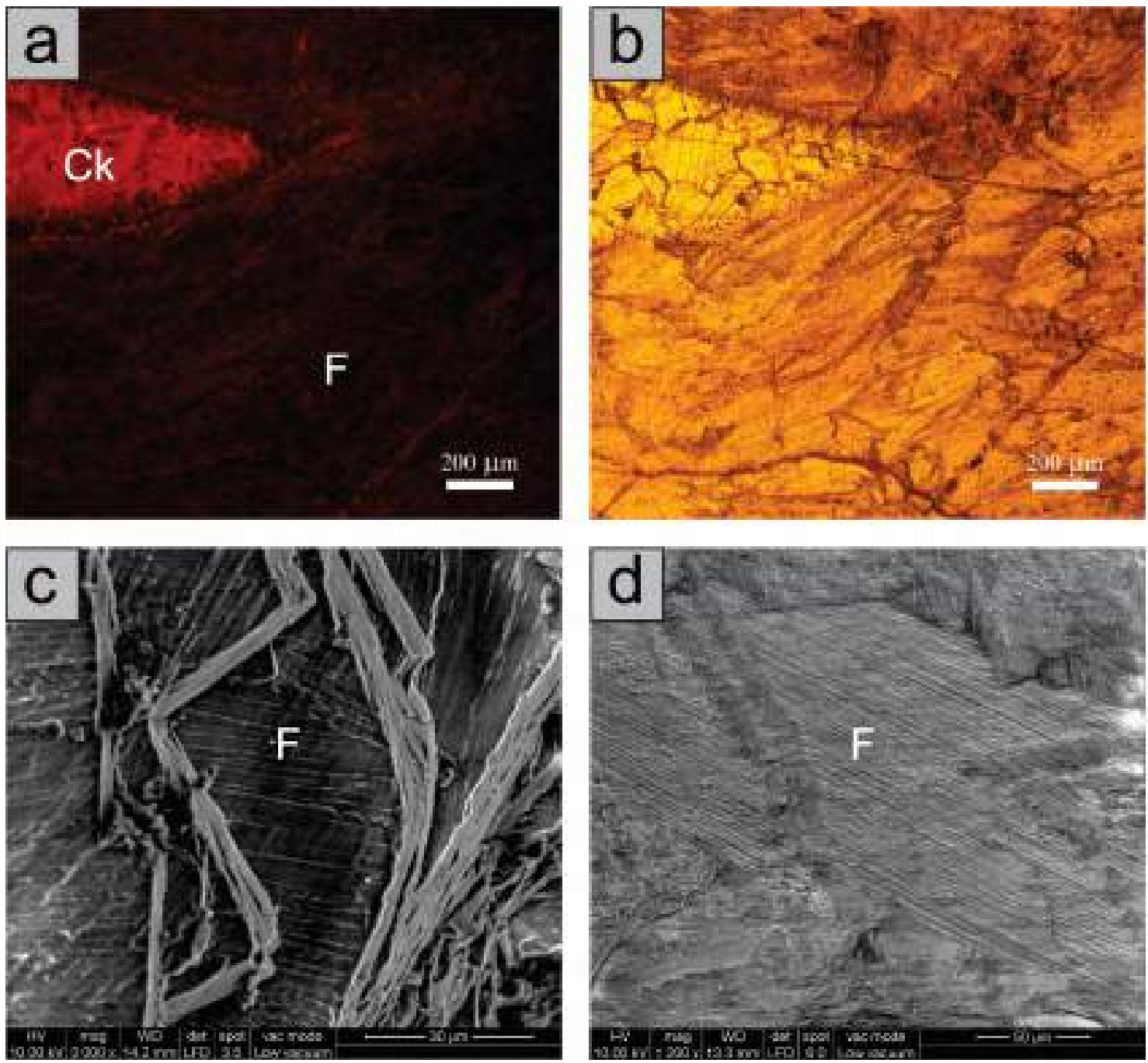

Figura 8.13. Ostras del género Aetostreon sp. A y b: Fotografías tomadas con microscopio de catodoluminiscencia donde se observan sectores luminiscentes y no luminiscentes. $C$ y d: Fotografías tomadas con microscopio electrónico de barrido donde se aprecia la preservación de las microtexturas originales. Ck: microestructura chalky, F: microestructura foliosa.

\subsubsection{Belemnites de la Cuenca Austral (Belemnopsis sp.)}

En los niveles silicoclásticos de la Cuenca Austral, se seleccionaron para este estudio ejemplares fósiles del género Belemnopsis sp. Su composición de calcita con bajo contenido de magnesio, su bajo grado de alteración tafonómica observada en las tareas de campo, su abundancia y amplia distribución, y su utilización en trabajos previos como el de Pirrie et al. (2004), fueron los criterios utilizados para la selección de este taxón.

Veinticuatro muestras de belemnites fósiles (veintiuna de Río Guanaco y tres de Subida del Chancho) fueron elegidas de los perfiles para su estudio petrográfico. 
En los belemnites se destacan dos tipos de microtexturas principales: granular y prismática (Zakharov et al., 2011). Ambas se caracterizan por sus fábricas cerradas, razón por la cual estos géneros poseen baja susceptibilidad ante los procesos diagenéticos y han sido utilizadas extensamente en la bibliografía para estudios isotópicos (Li et al., 2013; Mc Arthur et al., 2004; Price y Mutterlose, 2004; Price y Nunn, 2010; Ullmann et al., 2015).

En las microfotografías tomadas por catodoluminiscencia se observan sectores no luminiscentes y otros con una luminiscencia de color amarillo a naranja brillante. Casi la totalidad de los rostros de los belemnites son no luminiscentes (fig. $8.14 \mathrm{c} \mathrm{y} \mathrm{d),} \mathrm{pero} \mathrm{presentan}$ áreas con alta luminiscencia. Entre estas áreas suele encontrarse la línea apical y el alveolo (fig. 8.14 a y b), mientras que eventualmente se observan estilolitas y venas rellenas de calcita de bajo contenido de magnesio. La falta de luminiscencia se asocia a valores originales bajos de $\mathrm{Mn}$ (elemento activador) en este caso concordantes con los reportados en los belemnites del Jurásico- Cretácico (Li et al., 2013; Mc Arthur et al., 2004; Price y Nunn, 2010). La preservación dada por la baja concentración original de $\mathrm{Mn}$ en las valvas comprobaría la preservación de estos sectores de los efectos diagenéticos.

Mediante la utilización del microscopio electrónico de barrido (MEB), se observaron en detalle los sectores no luminiscentes. En las fotografías con alta definición es posible notar la preservación de las microtexturas granulares originales (fig. 8.14 e y f), hecho que se correlaciona con el más bajo grado de alteración diagenética (Korte y Hesselbo, 2011; Zakharov et al., 2011; Ullmann y Korte, 2015). 

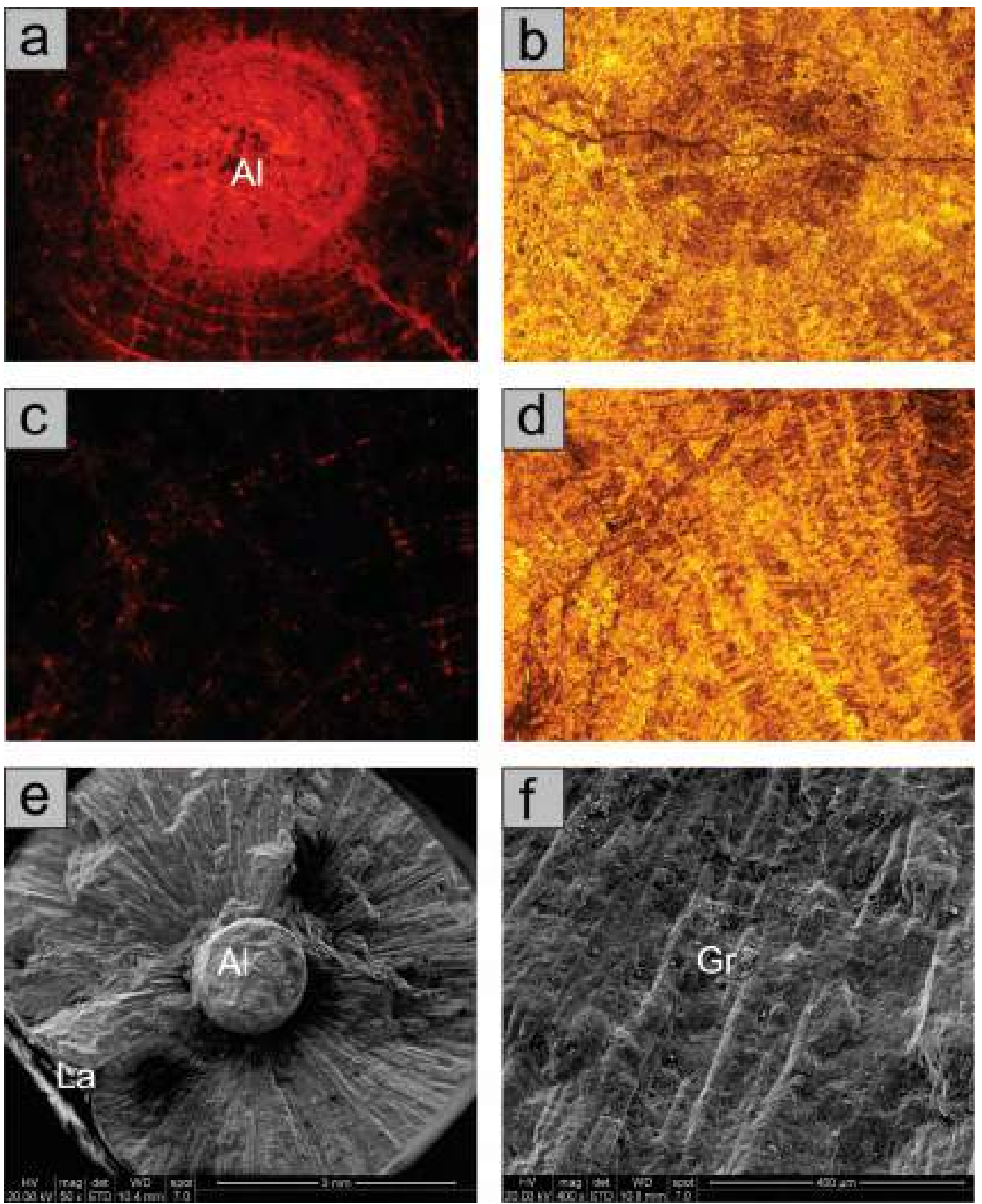

Figura 8.14. Belemnites del género Belemnopsis sp. A y b: fotografías tomadas con microscopio de catodoluminiscencia donde se observa el sector alveolar luminiscente. $\mathrm{C}$ y d: sector externo de mismo belemnite sin luminiscencia. E y f: fotografías tomadas con microscopio electrónico de barrido donde se observa la preservación de las microtexturas originales. Av: sector alveolar, La: línea apical, Gr: microtextura granular. 


\section{Capítulo IX - Geoquímica}

\subsection{Introducción}

El análisis geoquímico constituye una herramienta fundamental para el estudio sedimentológico ya que provee valiosa información tanto de la composición y procedencia, como de los procesos ocurridos durante la diagénesis.

Los estudios geoquímicos resultan indispensables para realizar la caracterización de los depósitos, definir el potencial de preservación isotópica (PPI) e identificar el intercambio con los fluidos durante la diagénesis. En el caso particular de las secuencias carbonáticas y fosilíferas estudiadas, se han seleccionado para este tipo de análisis, ostras de la especie Aetostreon sp. de la Cuenca Neuquina y belemnites de la especie Belemnopsis sp. de la cuenca Austral, cuyos criterios de muestreo y selección del material fosilífero han sido desarrollados en las secciones 2.3 .2 y 8.5 .

En el presente capítulo se describe de manera detallada la composición química de los fósiles desde varios puntos de vista. En primer lugar se analizaron los elementos mayoritarios y minoritarios gracias a estudios efectuados en muestras y micromuestras mediante fluorescencia de rayos $\mathrm{X}$, ICP-AES e ICP-MS.

En segundo término se realizaron estudios de isótopos estables de carbono y oxígeno con el empleo de espectrometría de masas. A partir de estos datos se realizaron determinaciones de parámetros de valor paleoambiental, tales como paleotemperaturas y paleosalinidades. Con los resultados elementales e isotópicos obtenidos se llevaron a cabo cálculos de correlación entre variables, para ser utilizados como indicadores del carácter primario de los datos isotópicos.

En última instancia se trabajó con elementos del grupo de las tierras raras y el itrio (REY) cuyos contenidos fueron obtenidos mediante el uso de un ICP-MS. Estos resultados corroboraron el grado de preservación del material y contribuyeron a nuevas interpretaciones ambientales, tales como la oxigenación y la profundidad de las aguas.

\subsection{Cambios en la composición geoquímica durante la diagénesis}

Existen diferentes reacciones durante la diagénesis, capaces de modificar la composición elemental e isotópica original de los fósiles. Una de las más importantes causas de este cambio, está dada por los procesos de disolución-reprecipitación, que desencadenan 
reacciones entre el sedimento/roca sedimentaria y la fase fluida. Esta última puede ser agua de mar, incorporada durante los primeros estadios de diagénesis, agua de formación asociada a la diagénesis de enterramiento o agua meteórica introducida generalmente en una etapa telogenética. La magnitud de dichos cambios puede deberse a innumerables causas, pero la más importante se debe a la diferencia composicional entre el agua y la roca/fósil, y la duración de la reacción (Brand y Veizer, 1981; Gómez Peral, 2008).

Según Brand y Veizer (1981), Veizer (1983 a,b) y Marshall (1992) el incremento o disminución de la concentración de elementos durante la diagénesis está en gran medida controlado por la diferencia en la disponibilidad del elemento entre el ambiente de depositación y el ambiente diagenético. Así, ciertos elementos y razones isotópicas con altas concentraciones en el agua de mar pero bajas en las aguas diagenéticas tenderán a decrecer con el aumento progresivo de la diagénesis, mientras que los elementos y relaciones isotópicas que están enriquecidos en las aguas diagenéticas producirán un consecuente incremento de los mismos en la roca que está sujeta a cambios postdeposicionales (Fig. 9.1).

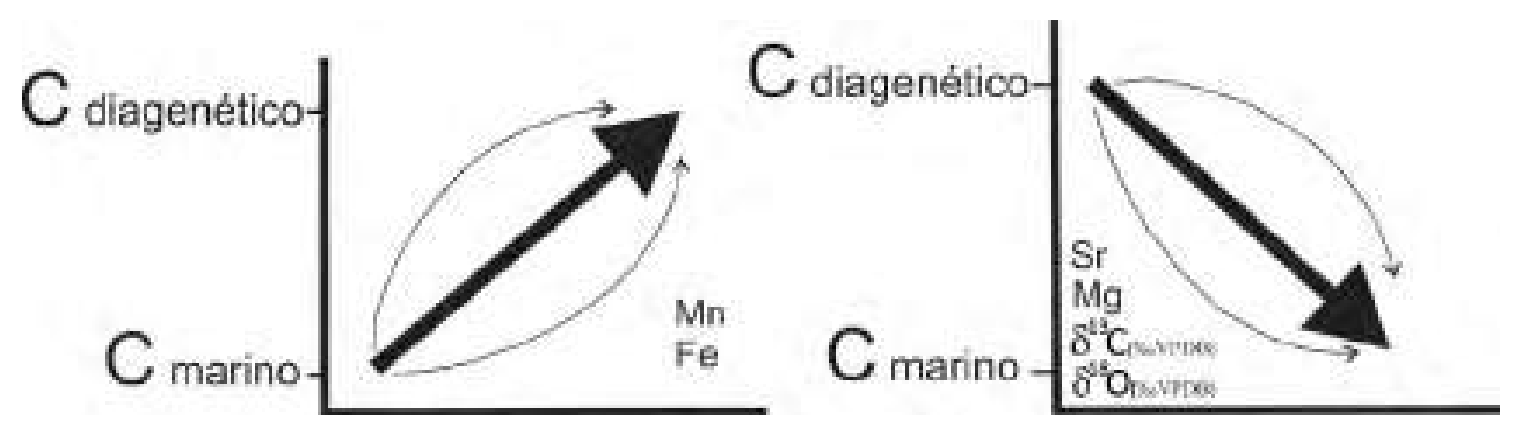

Figura 9.1. Modificado de Marshal (1992), comportamiento de los elementos durante la diagénesis. Las flechas de color negro indican incremento de las concentraciones de los elementos durante la diagénesis.

Para poder estudiar los fenómenos geoquímicos acontecidos durante la diagénesis y para conocer el potencial de preservación de las especies fósiles, es necesario conocer en primera medida el contenido de cada elemento y compararlo con las cantidades originales de dicha especie. Es importante destacar que la composición química de los fósiles cambia según la especie, fenómeno llamado "factor vital" (Gaucher, 2012). Otro importante aspecto a tener en cuenta, es que los valores originales no son los mismos en todas las épocas, ya que la precipitación de las conchillas carbonáticas tanto internas como externas se realiza en equilibrio con el agua de mar, y esta ha sufrido importantes cambios a lo largo del tiempo geológico.

En última instancia, es necesario correlacionar los valores elementales obtenidos con los de $\delta^{13} \mathrm{C}$ y $\delta^{18} \mathrm{O}$ de manera de comprobar si posibles alteraciones diagenéticas registradas en 
los elementos puedan condicionar los resultados isotópicos. Gaucher (2012) postula que las correlaciones entre elementos e isótopos constituye una medida mucho más confiable de la preservación isotópica que los valores absolutos considerados de forma aislada.

\subsection{Elementos mayoritarios y minoritarios}

\subsubsection{Introducción}

Se realizaron estudios de fluorescencia de rayos X (ver sección 2.5.8), con el fin de obtener la cuantificación de elementos mayoritarios y minoritarios. Para ello se seleccionaron como representativas de los sectores de estudio, 10 muestras de $2 \mathrm{gr}$ de Aetostreon sp. del perfil Puesto Loncoche en la Cuenca Neuquina y 10 muestras de igual peso de Belemnopsis sp. del perfil Río Guanaco en la Cuenca Austral.

Posteriormente, con el objetivo de corroborar la viabilidad de la metodología utilizada para obtener los elementos mayoritarios y minoritarios (ver sección 2.5.5), se efectuaron estudios más detallados en cuatro de las muestras analizadas (RG 9, RG 18, PL 116 y PL 111, Río Guanaco y Puesto Loncoche, respectivamente), utilizando ICP-AES en los laboratorios Actlab en Canadá. En estos, se utilizaron $0,2 \mathrm{gr}$ de material en polvo contra 2 gr que fueron necesarios para efectuar los primeros.

Por último, con el empleo de un equipo ICP-MS (ver sección 2.5.9) fue posible calcular las concentraciones de los elementos minoritarios $\mathrm{Mn}$ y $\mathrm{Sr}$ en cuarenta y nueve submuestras de $0,2 \mathrm{gr}$ de las dos cuencas (seis de Río Salado, doce de Puesto Loncoche, diez de Cuesta del Chihuido, diecinueve de Río Guanaco y dos de la Subida del Chancho). Estos análisis permitieron tener resultados de los elementos más sensibles a la alteración diagenética en cinco de los seis perfiles de estudio.

Es importante destacar que todos los resultados de elementos mayoritarios fueron obtenidos en óxidos, y posteriormente recalculados a porcentajes elementales. Por otro lado, los resultados de elementos minoritarios y traza fueron adquiridos en partes por millón.

\subsubsection{Fluorescencia de rayos $X$ (muestras de $2 \mathrm{gr}$ )}

Los datos obtenidos por este método en restos fósiles de ostreidos y belemnites son presentados en la tabla 9.1 y se encuentran representados en la figura 9.2. Adicionalmente, en la figura 9.3 se muestran nuevamente los datos expresados en partes por millón (ppm) 
excluyendo Si y $\mathrm{Ca}$, de manera de visualizar aquellos elementos que se presentan en bajas concentraciones $(<1 \%)$.

\begin{tabular}{|c|c|c|c|c|c|c|c|c|c|c|c|c|}
\hline \multicolumn{13}{|c|}{ POACEMTANE EUCMESTTAL } \\
\hline & ses & $3 *$ & recone & MOo & Msionen & not $\operatorname{son} 0$ & Klagei & $7100=1$ & Wragn & Plano & 3000 & Ba cosei \\
\hline 5010 & 8550 & ass & ise & 12009 & Nos: & 2305 & 2003 & ma & 1345 & 1527 & $4=$ & 1000 \\
\hline 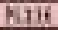 & 0335 & Q4P & 1720 & 14855 & 1063 & tit] & 413 & 539 & 388 & 304 & 36 & 00005 \\
\hline nIII & 1111 & ans & 3290 & 1850 & 2002 & EII & 200,9 & 39 & $294 \mathrm{~K}$ & 232.2 & 34 & 10000 \\
\hline Ause & 2225 & ash & $\operatorname{lin} 2$ & 10236 & 1504 & sक्या & $\triangle C E E \mid$ & 2199 & 140 & 6516 & 100 & $100 \pi$ \\
\hline 726 & 1500 & 0.04 & 1004 & 19029 & 1608 ] & 3 Nor & $428]$ & $\mathrm{xa}$ & 1340 & IEII & $42 \pi$ & 10011 \\
\hline Fiss & 1323 & $0<\infty$ & 1 1): & 1064 & 4063 & anger & {$[\mathrm{Bb}]$} & 190 & 5002 & 9265 & $2 \pm 0$ & 1001 \\
\hline$k(z)$ & 609 & $n>0$ & 1630 & Peat & $\sin x-4$ & $\operatorname{sen}$ & कात & 2007 & $P A$ & म42a & 1201 & $3 \times 000$ \\
\hline$F 68$ & 2334 & ass & inat & PQD3: & क्ये & कint & 200 & 299 & 724 & $13 \times 3$ & 31 & 1007 \\
\hline FLG & पno & aves & 455: & 2511 & 12003 & 2201 & 2200 & $300]$ & $\pi$. & 327 & 44 & $100 \mathrm{n}$ \\
\hline 720 & 500 & 0,09 & 1342. & $34 \times 64$ & $1621 \mathrm{c}$ & 12972 & cI2A) & 2287 & TIE & joss: & 53 & $100 \mathrm{cin}$ \\
\hline \multicolumn{13}{|c|}{ POECONARE EIEMTETAL } \\
\hline & $55 i$ & $\mathrm{MBI}$ & Feipeni & $\mathrm{sc}$ & Meipanal & Walsamel & Glpen] & Tilesal & Mnlapos] & Pirem] & Grigan & Elaeni \\
\hline ingt: & tมx & ninte & 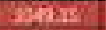 & $2 \mathrm{ng}$ & 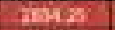 & Dares. & ogy & 1022 & 1920 & tortua & 3510 & sail \\
\hline 9631 & Atent: & nats. & thas? & $A$ ESA & Mris & $3: 4$. & $428 \mathrm{r}$. & $144: 24$ & stas: & $24 \mathrm{ne}$ & At 12 & \pm \\
\hline जint: & asro & non & osyte & Indes & IStes: & 445 & 43.5t: & 2025 & 305 & Ex. & 8.15 & At. \\
\hline 4021 & 758 & 858 & $2652 x$ & 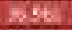 & $203 n$ & 450 & anis & $78 x 2$ & 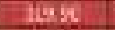 & Ieger & megr & ISt. \\
\hline $\sin 24$ & at3e & $0 \times 3$ & Whas & X612 & rager. & Fors & als & $275^{\circ}$ & 4996 & Font & 9041 & 44 \\
\hline 963. & atso & ast & 1300 & 2415 & Jeare: & $\operatorname{anc} x$ & xeat & $204:$ & 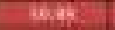 & 34.8 & Jik-is & 100. \\
\hline Sals & abs & nos & (5).15) & any & 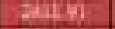 & Iesta: & exin & $m=$ & 2035 & B 39 & a) 34 & 33 \\
\hline 1612 & 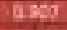 & 020 & 244.0 & 305 & $\operatorname{san} x$ & 25192 & $\sin$ & He:ne & 3215 & cese. & as. 45. & 11 \\
\hline no: & asa & Dop & $204 \times 3$ & 202 & $254=$ & 3200 & Ans & 720: & oses: & twat & 3082 & 48. \\
\hline HEB & $0 \times 1$ & tisting & 74.2. & से & $\log 2 x$ & IIIII & 1203 & $72=$ & 9025 & 108 in & 185 & ing \\
\hline
\end{tabular}

Tabla 9.1. Valores de porcentajes elementales de $\mathrm{Si}$, Al y Ca y cantidades en parte por millón de $\mathrm{Fe}, \mathrm{Mg}, \mathrm{Na}, \mathrm{K}, \mathrm{Ti}$, $\mathrm{Mn}, \mathrm{P}, \mathrm{Sr}$ y Ba. Arriba, resultados de las muestras de Aetostreon sp. del perfil Puesto Loncoche (Cuenca Neuquina) y abajo, muestras de Belemnopsis sp. correspondientes al perfil Río Guanaco (Cuenca Austral). 

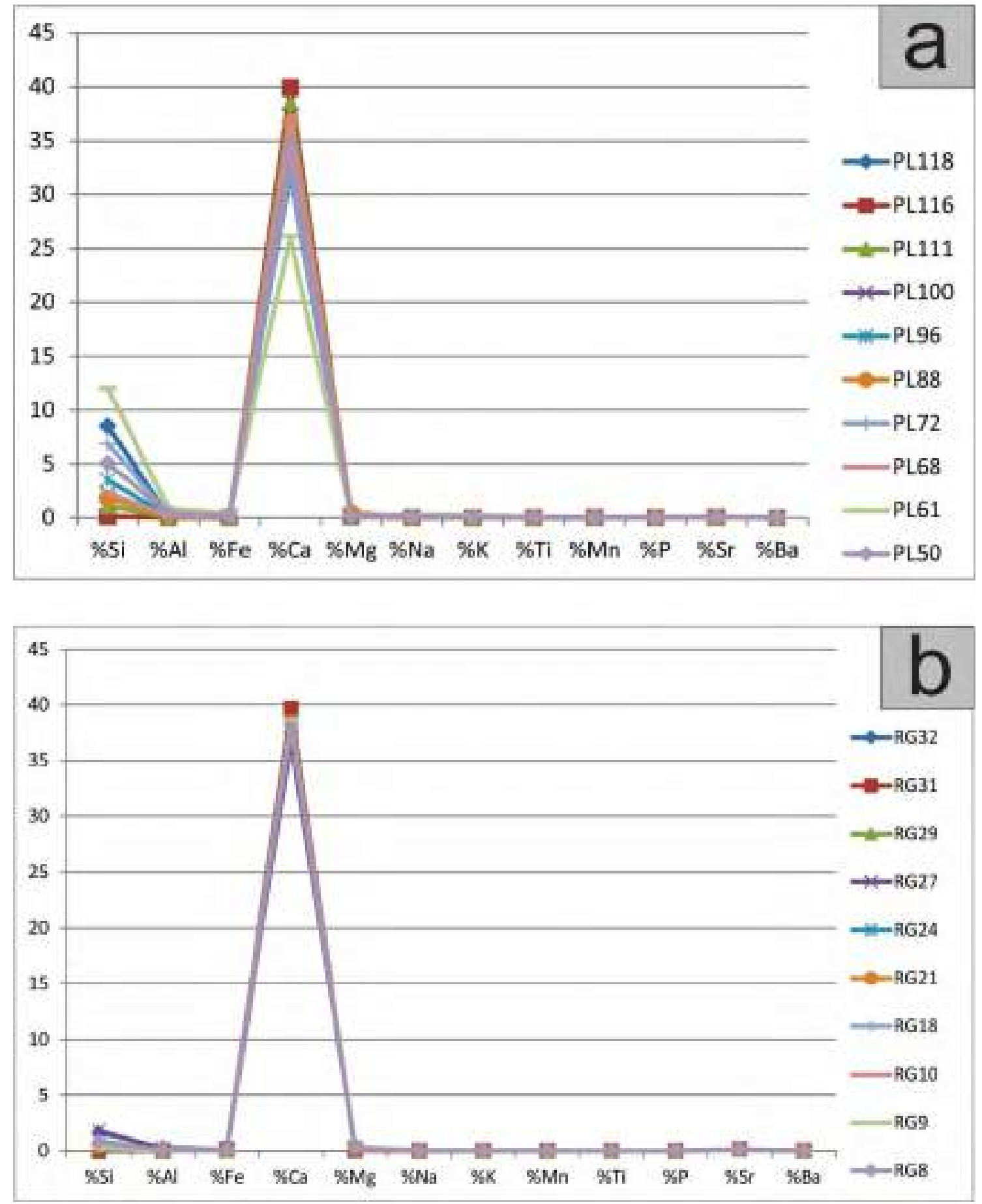

Figura 9.2. Cuantificación de los elementos mayoritarios y minoritarios, indicados en porcentajes elementales. a) Muestras de Aetostreon sp. del perfil Puesto Loncoche (Cuenca Neuquina) y b) muestras Belemnopsis sp. del perfil Río Guanaco (Cuenca Austral).

\subsubsection{Puesto Loncoche}

Se observan porcentajes de calcio (Ca) de entre $32 \%$ y $39 \%$ para las muestras de Aetostreon sp. en Puesto Loncoche, con un valor anómalo de $26 \%$ correspondiente a la muestra PL61 (fig. 9.2 a). La abundancia de silicio (Si) es inversamente proporcional a la 
cantidad de calcio presente en la muestra; así se definen contenidos entre 0,13\% y 8,55\% para el Puesto Loncoche, salvo en la muestra PL61 en la que alcanza 12,04\% (fig. 9.2 a). Vale destacar, que los valores altos de Si podrían corresponder a venas rellenas con cemento silíceo generadas durante la mesogénesis temprana que han sido nítidamente observadas por vía microscópica (ver sección 8.3.2.5). El resto de los elementos se encuentran en cantidades menores al $1 \%$.

En el caso del aluminio, los valores oscilan entre $0,02 \%$ y $0,44 \%$, observándose el mayor contenido en la muestra PL61 (0,87\%). Dichos contenidos de Al coinciden con las mayores concentraciones de $\mathrm{Si}$ y las menores concentraciones de $\mathrm{Ca}$, lo cual podría corresponder a la presencia de aluminosilicatos (Tabla 9.1 y Fig. 9.2 a).

Otros valores a tener en cuenta son los correspondientes al hierro ( $\mathrm{Fe}$ ) y manganeso $(\mathrm{Mn})$, ya que representan una medida del grado de alteración diagenética (Price y Mutterlose, 2004; Mc Arthur et al., 2004; Stouber et al., 2005; Nunn y Price, 2010; Price y Nunn, 2010 y Li et al., 2013) (Tabla 9.1 y Fig. 9.3 a). En el caso del hierro las muestras ostentan contenidos de entre 174 ppm hasta 1783 ppm con un promedio de 1433 ppm y un dato anómalo de 4651 ppm correspondiente a la muestra PL61; en cuanto al manganeso las concentraciones correspondientes a la base del perfil son inferiores a los $77 \mathrm{ppm}$, mientras que hacia el sector del techo las mismas ascienden a valores de entre 154 ppm y 309 ppm con un valor promedio para todo el perfil de 163 ppm.

Korte et al. (2009) y Korte y Hesselbo (2011) establecieron 250 ppm como límite para los valores de $\mathrm{Mn}$ en bivalvos de edad Jurásica, con este criterio, todas las muestras con excepción de PL 88 y PL 116 estarían dentro de los rangos estipulados como primarios. Por otro lado, Wierzbowski y Joachimski (2007) proponen 250 ppm como límite para el Fe en bivalvos jurásico-cretácicos. Teniendo esto en cuenta, todas las muestras salvo PL 116 estarían por encima de los límites establecidos por estos autores, razón por la cual se podría concluir que existió enriquecimiento en este elemento durante la diagénesis.

Otro elemento que reviste especial atención en la bibliografía es el estroncio (Sr). Wierzbowski y Joachimski (2007), Korte et al. (2009) y Korte y Hesselbo (2011) coinciden en establecer en 400 ppm el contenido mínimo para este elemento en las ostras Jurásicas. Las muestras analizadas en este trabajo poseen cantidades que superan las $400 \mathrm{ppm}$ de $\mathrm{Sr}$, con excepción de los ejemplares PL 88, 111 Y 116.

También se utilizan como límites de referencia para la alteración diagenética las concentraciones del Mg y Na (Tabla 9.1 y Fig. 9.4 a). En las muestras analizadas el Mg presenta una alta variabilidad, encontrándose valores desde 904 hasta 2592 ppm con un promedio de 
1863 ppm. El Na también presenta un amplio rango de contenidos, desde 111 hasta 2966 ppm con una media de 771 ppm.

No se ha registrado en la bibliografía una referencia clara sobre las concentraciones de $\mathrm{Mg}$ y $\mathrm{Na}$ a partir de las cuales una ostra del Mesozoico se consideraría alterada diagenéticamente. En comparación con los trabajos sobre belemnites de Li et al. (2013) se observaría un empobrecimiento en las cantidades de $\mathrm{Mg}$ y $\mathrm{Na}$ de las muestras del Puesto Loncoche durante la diagénesis, aunque es importante aclarar que los valores límites pueden cambiar considerablemente al tratarse de especies distintas.

\subsubsection{Río Guanaco}

En las muestras analizadas de Belemnopsis sp. se observan valores de Ca entre $36 \%$ y $39 \%$, mientras que el tenor de Si posee un promedio de $0,74 \%$ y alcanza un máximo de $1,81 \%$ (fig. 9.2 b). Por otro lado, las concentraciones del Al no superan el 0,25\%, mientras que el resto de los elementos analizados tampoco llegan a 0,3\% (Tabla 9.1 y Fig. 9.2 b). Estos datos muestran con claridad la ausencia de reemplazos por aluminosilicatos y/o cementos silíceos asociados.

Los valores de Fe en los belemnites analizados oscilan entre 209 y 1398 ppm con un promedio de 723 ppm. Por su parte, el Mn en la muestra RG 32 presenta un valor anómalo de 387 ppm, en las muestras RG 31, RG 27 e RG 10 es de 154 ppm, y el resto posee menos de 77 ppm, no apreciándose el valor exacto porque está por debajo del límite de detección del método (Tabla 9.1 y Fig. 9.3 b).

En el caso del $\mathrm{Sr}, \mathrm{Mg}$ y $\mathrm{Na}$ los resultados obtenidos de los análisis están en el orden de 1094 a 1511 ppm de Sr, 663 a 3075 ppm de Mg y 37 a 444 ppm de Na (Tabla 9.1 y Fig. 9.3 b).

Existe una amplia variedad de datos geoquímicos sobre belemnites en la bibliografía (Li et al., 2013; McArthur et al., 2004; Price y Nunn, 2010; Nunn y Price, 2010; Price y Mutterlose, 2004 entre otros). En este trabajo se han seleccionado aquellas reseñas correspondientes al lapso Tithoniano- Valanginiano para comparar los valores límite de $\mathrm{Fe}, \mathrm{Mn}, \mathrm{Sr}, \mathrm{Mg}$ y $\mathrm{Na}$ con los obtenidos en este estudio para Río Guanaco (Tabla 9.2). 


\begin{tabular}{|c|c|c|c|c|c|c|c|}
\hline & & Uet a. $|2013|$ & $\begin{array}{c}\text { Mcarthur et al. } \\
\text { [2004] }\end{array}$ & $\begin{array}{c}\text { Price y Nunn } \\
\text { [2010! }\end{array}$ & $\begin{array}{c}\text { Numn v Price } \\
(2010)\end{array}$ & $\begin{array}{c}\text { Price y } \\
\text { Mutteriose (2004) }\end{array}$ & Este tratajo \\
\hline \multirow{2}{*}{$\begin{array}{l}\text { Contenida } \\
\text { limite en apm }\end{array}$} & Fen & 100 & 150 & 200 & 150 : & 150 & $200-1328$ \\
\hline & $\mathrm{Mn}$ & 20 & 50 & 50 & 100 & 100 & a7-154 \\
\hline \multirow{3}{*}{$\begin{array}{l}\text { Raness velores } \\
\text { primanios an pom }\end{array}$} & St & $110-1500$ & $900-1400$ & & & $358 \cdot 1758$ & 1094-1510 \\
\hline & $M_{\mathrm{g}}$ & 17003500 & $500-1300$ & & & 263.2238 & $663-3075$ \\
\hline & $\mathrm{Na}$ & 13002300 & $500-110$ & & & & 37.444 \\
\hline
\end{tabular}

Tabla 9.2. Contenidos límite en ppm y rangos de valores primarios en ppm de $\mathrm{Fe}, \mathrm{Mn}, \mathrm{Sr}, \mathrm{Mg}$ y $\mathrm{Na}$ para belemnites valanginianos según Li et al. (2013); McArthur et al. (2004); Price y Nunn (2010); Nunn y Price (2010) y Price y Mutterlos (2004) y comparación con los resultados de este trabajo.

Al comparar los contenidos de Fe de este trabajo con los antes mencionados, se puede concluir que se aprecia un enriquecimiento diagenético en este elemento con respecto a los valores sugeridos por los estudios mencionados. Por otra parte, los valores de $\mathrm{Mn}$ se encuentran enriquecidos en el caso de las muestras RG 32, RG 31, RG 27 y RG 10 e inalterados en el del resto de las muestras según los criterios de Price y Mutterlose (2004) y Nunn y Price (2010), no pudiendo precisar en el caso de los criterios de Li et al. (2013), Mc Arthur et al. (2004) y Price y Nunn (2010) porque no lo permite la definición de la herramienta de medición. Los valores de $\mathrm{Sr}$ y $\mathrm{Mg}$ se encuentran dentro de los estándares estipulados en Price y Mutterlose (2004), Mc Arthur et al. (2004) y Li et al. (2013), mientras que se observa un empobrecimiento diagenético en $\mathrm{Na}$ con respecto a los valores primarios. 

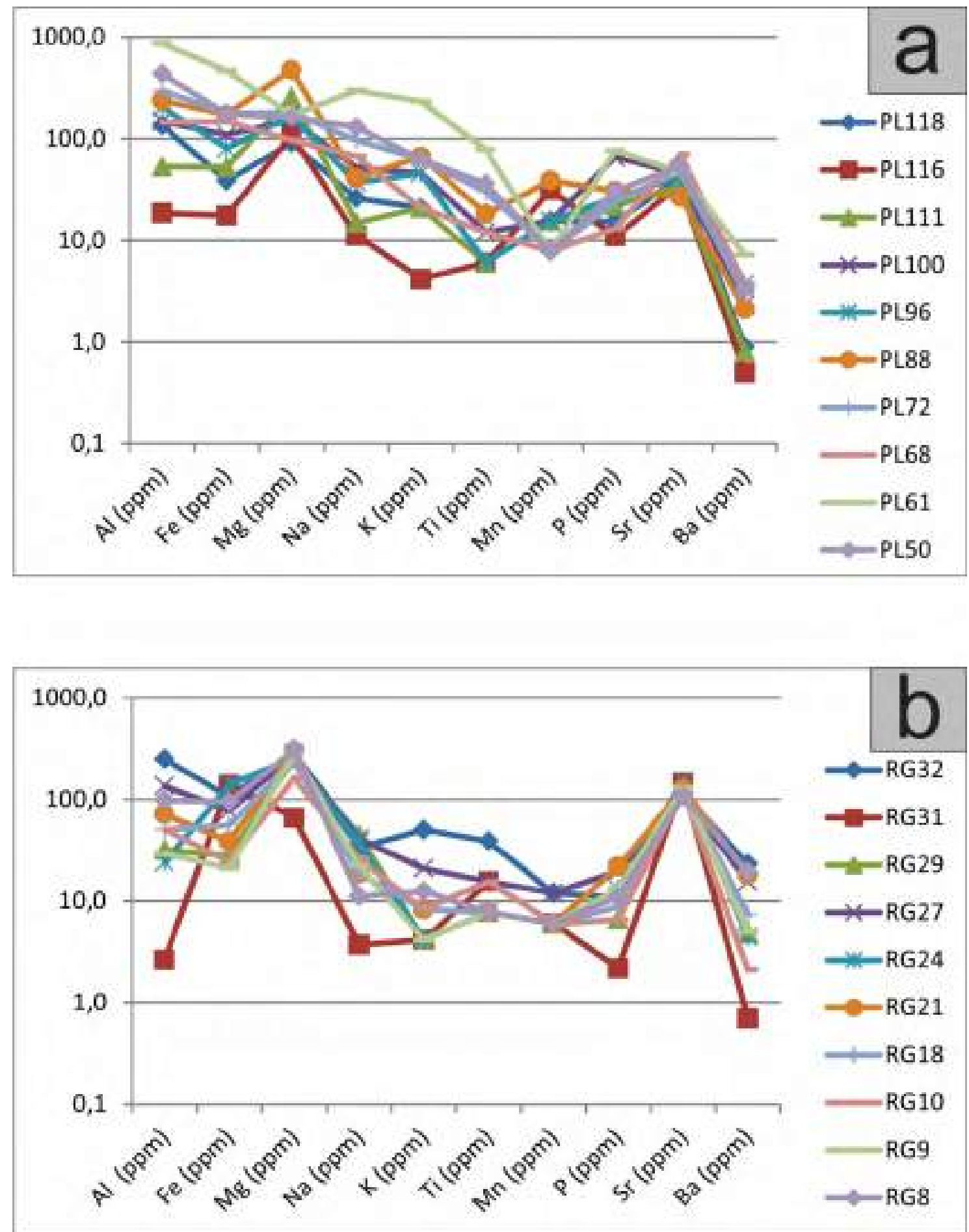

Figura 9.3: Cuantificación de los elementos en cantidades menores a 1\% expresados en partes por millón (ppm). Arriba, las muestras de Aetostreon sp. del perfil Puesto Loncoche y abajo las muestras de Belemnopsis sp. del perfil Río Guanaco. 


\subsubsection{ICP-AES (micromuestras de $0,2 \mathrm{gr}$ )}

La importante reducción en la cantidad de material de este método, permitió que se pudiera seleccionar de forma cuidadosa las áreas a muestrear, pudiendo distinguir y separar las distintas texturas de las ostras y excluir sectores con presencia de venas carbonáticas y silíceas y secciones con alta luminiscencia en ostras y belemnites.

Los resultados obtenidos (Tabla 9.3) para las muestras de Belemnopsis sp. en la Cuenca Austral reflejan valores elevados de $\mathrm{Ca}$, $\mathrm{Na}$ y $\mathrm{Sr}$, acompañado de tenores bajos de $\mathrm{Si}, \mathrm{Al}, \mathrm{Fe}, \mathrm{Mg}$ y Mn (Fig. 9.4 a y b). Estos resultados ubican a las muestras dentro de los rangos definidos para belemnites primarios del Cretácico (Tabla 9.2).

En la Cuenca Neuquina por otro lado, se tomaron muestras de ostras de dos texturas distintas. La muestra PL 111 corresponde a una preponderancia de crecimientos de tipo foliado y evidencia elevadas concentraciones de Ca y Sr y bajos valores de Si, Al, Mg y Mn, por lo que estos datos son comparables a las cifras estipuladas para las ostras de la misma edad (Fig. 9.4 c). La muestra PL 116 en tanto, corresponde a una preponderancia de crecimientos de tipo "chalky" y muestra un comportamiento elemental opuesto al anteriormente descripto. Esta cuantificación elemental comprueba las observaciones realizadas mediante catodoluminiscencia (sección 8.5.2), indicando que texturas foliadas son más resistentes a la alteración diagenética que las de tipo "chalky" (Fig. 9.4 d).

\begin{tabular}{|c|c|c|c|c|c|c|c|c|c|c|c|c|}
\hline \multicolumn{13}{|c|}{ 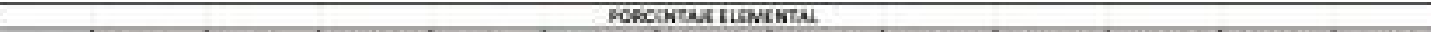 } \\
\hline & $\mathrm{sq}$ & Sw & Aakght & $\mathrm{sa}$ & ㅂyternt & Hajegene & Klogm: & Dipeni & Magend & Pifpnl & $5 \mathrm{lgg}$ & Doipery \\
\hline ค111 & EIII & $\operatorname{acs} 8$ & 2381 & 3509 & Enes & 143 & ints & 89 & 1105 & $218 \pi$ & 123 & 00003 \\
\hline 6116 & 6.41 & 0.60 & $\mathrm{PM}$ & CWa & insts & 110 & 0,3 & जि & Whe & Def & 146 & alosh. \\
\hline KG9 & $a m$ & $10 \times 0$ & xing & ECO & $210 \%$ & 2210 & as! & 1204 & $3 x$ & 12311 & Fon & iI \\
\hline mait & Dengi & aeon & arss & 1072 & $2 \sin 31$ & 10,3in & $\min$ & $\pi 4:$ & 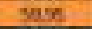 & $m, 2$ & Eris & $n$ \\
\hline R.16m & 6.9.4 & Hase & 587 & nut & Iove: & Iats & in & 100 & $14 \pi$ & 100 & 23 & in \\
\hline A:Ti6n & हत्ड & $\operatorname{ass}$ & 5003 & AON & 10654 & 502 & Fan & 1563 & 60 & 157 & 445 & II \\
\hline $\operatorname{man}$ & ani & 000 & 曹 & 43360 & सा17 & स्वा & 40 & 60 & 115 & Inal & 1900 & II \\
\hline Ecinn & son & aeg & 120 & moss & 2304 & 193 & 414 & CO & 212 & 173 & 1911 & C4 \\
\hline
\end{tabular}

Tabla 9.3. Valores de porcentajes elementales de Si, Al y Ca y cantidades en parte por millón de Fe, Mg, Na, K, Ti, $\mathrm{Mn}, \mathrm{P}, \mathrm{Sr}$ y Ba. En naranja resultados de muestras y en celeste resultados de micromuestras sobre los mismos ejemplares fósiles (PL: Aetostreon sp en Puesto Loncoche, Cuenca Neuquina; RG: Belemnopsis sp. En Río Guanaco, Cuenca Austral). 

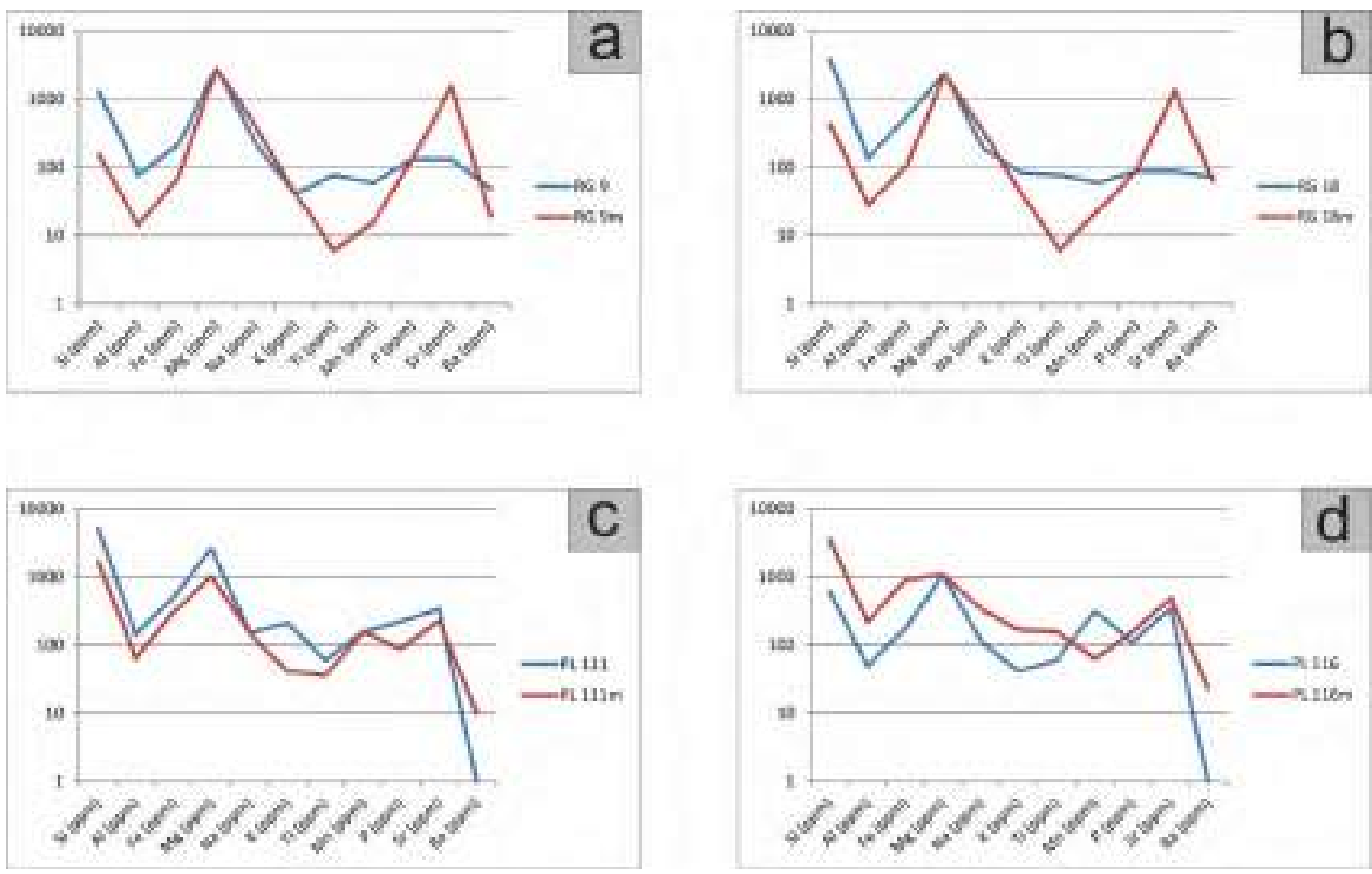

Figura 9.4. Relación entre muestras y micromuestras de los mismos ejemplares. a) Muestra RG 9, b) muestra RG 18, c) muestra PL 111, d) muestra PL 116. Las muestras terminadas en " $m$ " hacen referencia a micromuestras de 0,2 gr.

\subsubsection{ICP-MS (micromuestras de $0,2 \mathrm{gr}$ )}

La cantidad de material necesaria para poder efectuar los análisis con ICP-MS, así como las facilidades para acceder a esta metodología posibilitó realizar mayor cantidad de análisis y elegir los sectores de muestreo con mayor precisión. Los valores obtenidos por este método se presentan en la tabla 9.4 y se ven representados en la figura 9.5. En el caso de las muestras PL 111 y PL 116, fue posible comparar las distintas metodologías utilizadas en micromuestras (ICP-MS y e ICP-AES), observándose una gran similitud en los resultados.

En la Cuenca Neuquina, las muestras de Aetostreon sp. del perfil Río Salado y las de Puesto Loncoche (con excepción de PL 88, PL 111 y PL 119) presentan valores inferiores a 250 ppm de Mn (fig. 9.5 a) e inferiores a 400 ppm de Sr (fig. 9.5 b), límite propuesto como indicador de alteración diagenética por Korte et al. (2009) y Korte y Hesselbo (2011). En la sección Cuesta del Chihuido en tanto, se puede observar enriquecimiento en $\mathrm{Mn}$ y empobrecimiento en Sr en siete de las diez muestras analizadas.

Por otro lado, en la Cuenca Austral, las muestras de Belemnopsis sp. correspondientes al perfil Subida del Chancho y Río Guanaco (con excepción de RG 19, RG 22 y RG 28) presentan valores por debajo de 100 ppm de Mn (fig. 9.5 c) y entre 358 y 1758 ppm de Sr (fig. 9.5 d), 
rango propuesto por Price y Mutterlose (2004) y Nunn y Price (2010) para belemnites cretácicos.

\begin{tabular}{|c|c|c|}
\hline Muestra & $\mathrm{Mn}$ & $\mathrm{Sr}$ \\
\hline RS 2488 & 13,260 & 686,732 \\
\hline RS 2378 & 30,184 & 531,348 \\
\hline R5 2328 & 91,469 & 423,923 \\
\hline RS 2288 & 26,828 & 515,504 \\
\hline RS 2278 & 26,690 & 564,949 \\
\hline RS $223 C$ & 89,160 & 506,919 \\
\hline PL 119 & 95,86 & 350,66 \\
\hline PL116 & 63,33 & 586,70 \\
\hline PL111 & 154,75 & 360,33 \\
\hline PL110B & 99,11 & 429,98 \\
\hline PL89B & 98,68 & 394,48 \\
\hline PL88 & 382,47 & 251,36 \\
\hline PL68 & 71,78 & 476,29 \\
\hline PL65 & 60,54 & 374,63 \\
\hline PL61B & 43,11 & 546,15 \\
\hline PL61 & 76,49 & 467,22 \\
\hline PL50 & 44,46 & 598,03 \\
\hline PL 44B & 44,94 & 498,77 \\
\hline $\operatorname{CDC} 40$ & 117,230 & 249,251 \\
\hline CDC 39 & 56,178 & 486,934 \\
\hline $\operatorname{CDC} 38$ & 478,939 & 85,779 \\
\hline CDC 36 & 163,381 & 273,747 \\
\hline $\mathrm{CDC} 35$ & 314,202 & 53,014 \\
\hline CDC 23 & 282,364 & 284,038 \\
\hline $\mathrm{CDC} 18$ & 18,077 & 374,309 \\
\hline $\mathrm{CDC} 16$ & 163,200 & 134,601 \\
\hline $\mathrm{CDC} 12$ & 65,724 & 443,021 \\
\hline $\mathrm{CDC} 10$ & 221,045 & 234,550 \\
\hline
\end{tabular}

\begin{tabular}{|c|c|c|}
\hline Muestra & Mn & Sr \\
\hline RG 33 & 21.856 & 918.876 \\
\hline RG 32 & 12.912 & 984.344 \\
\hline RG 31 & 65.964 & 1160.991 \\
\hline RG 29 & 17.093 & 1241.921 \\
\hline RG 28 & 210.960 & 803.970 \\
\hline RG 27 & 58.067 & 936.711 \\
\hline RG25 & 52.107 & 1391.028 \\
\hline RG 25 & 30.174 & 1267.065 \\
\hline RG 24 & 10.294 & 1259.194 \\
\hline RG23 & 41.020 & 933120 \\
\hline RG22 & 397.864 & 945.269 \\
\hline RG 21 & 57.224 & 1159.766 \\
\hline RG 20 & 122.476 & 1179.027 \\
\hline RG19 & 1342.285 & 687.231 \\
\hline RG17 & 67.675 & 1108.016 \\
\hline RG 10 & 34.397 & 906.110 \\
\hline RG 8 & 52.197 & 714.287 \\
\hline RG 6 & 108.914 & 828.674 \\
\hline RG 4 & 42.001 & 854.714 \\
\hline SCH1981 & 9.145 & 1153.731 \\
\hline SCH21B2 & 23.649 & 1253.186 \\
\hline
\end{tabular}

Tabla 9.4. Valores de Sr y Mn obtenidos con ICP-MS en micromuestras de 0,2 g. En naranja se observan los datos del perfil Río Salado, en rosa los de Puesto Loncoche, en amarillo los de Cuesta del Chihuido para Aetostreon sp.; en rojo los de Río Guanaco y en gris los de la Subida del Chancho para Belemnopsis sp. 

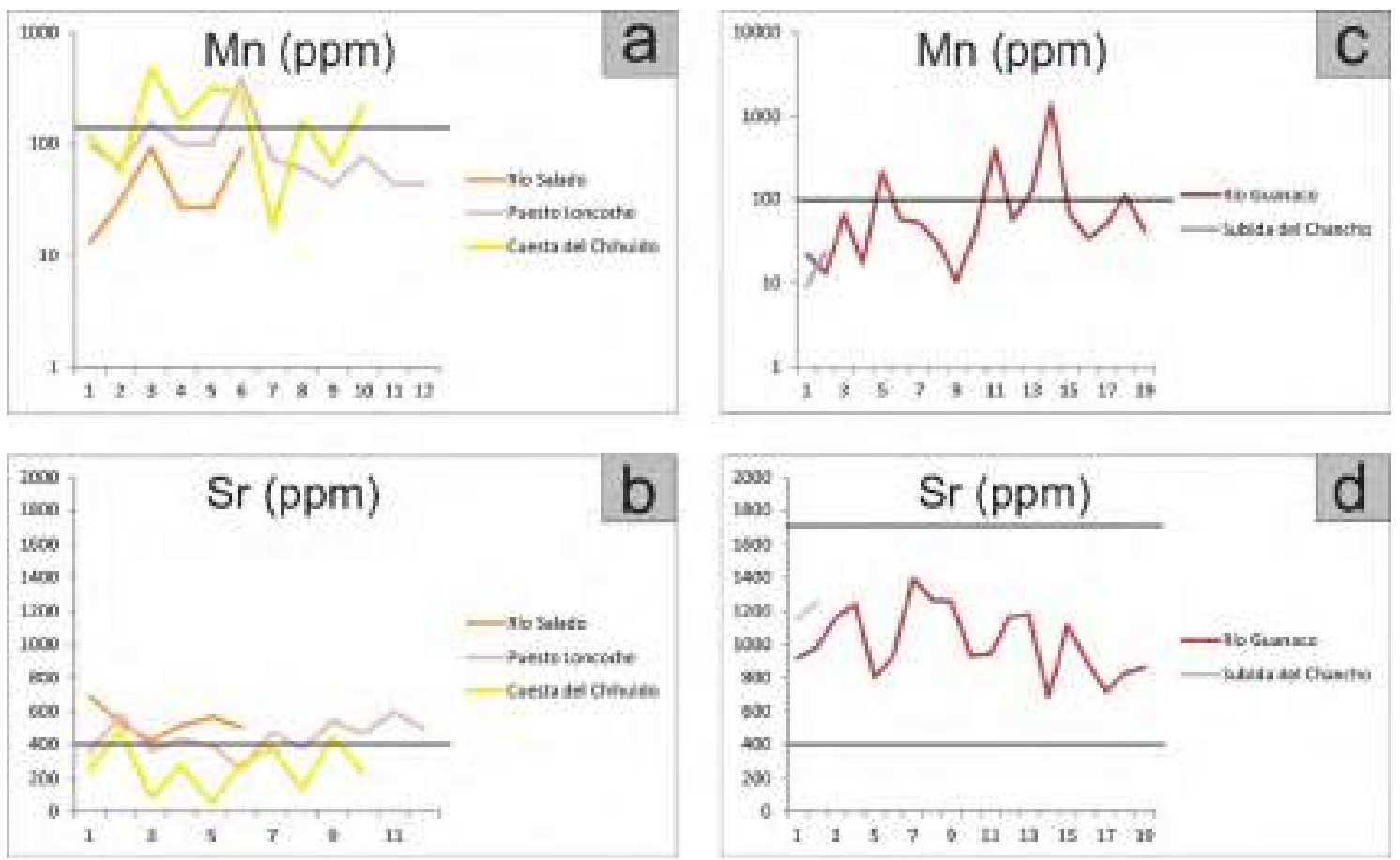

Figura 9.5. Valores de Sr y Mn obtenidos mediante ICP-MS. a) Valores de Mn en ostras de la Cuenca Neuquina, b) valores de Sr en ostras de la Cuenca Neuquina, c) valores de Mn en belemnites de la Cuenca Austral y d) valores de Sr en belemnites de la Cuenca Austral. Las líneas de color negro representan los límites para cada elemento según las especies seleccionadas y la edad de las mismas.

\subsection{Isótopos estables de oxígeno y carbono}

Se realizaron un total de cincuenta y siete análisis de isótopos estables de C y $\mathrm{O}$ en muestras de ostras de la Cuenca Neuquina (veintinueve de Puesto Loncoche, once de Río Salado y diecisiete de Cuesta del Chihuido) y veinticuatro en belemnites de la Cuenca Austral (veintiuno en Río Guanaco y tres en Subida del Chancho). La metodología utilizada para la medición y cálculo de las relaciones isotópicas se detalla en la sección 2.5.10, mientras que los resultados se presentan en las tablas 9.4 y 9.5 .

Los valores de $\delta^{13} \mathrm{C}$ para las ostras de Cuenca Neuquina (Tabla 9.5) son mayormente negativos, con tenores mínimos de -5\% VPDB, para el sector correspondiente a la Formación Vaca Muerta y valores positivos con máximos de 2,66\% VPDB para la Formación Chachao. En los belemnites de la Cuenca Austral, por otro lado, los resultados de $\delta^{13} \mathrm{C}$ (Tabla 9.6) son siempre negativos con un estrecho rango de entre -2 y $-0,5 \%$ VPDB correspondiente a las formaciones Río Mayer y Springhill.

Los valores de $\delta^{18} \mathrm{O}$ en tanto, se presentan como negativos en los fósiles determinados para ambas cuencas y sus mínimos pueden llegar hasta -11\% VPDB. Para el cálculo de paleotemperaturas y paleosalinidades (metodología en la sección 2.6.2) sólo se tuvieron en 
cuenta los valores mayores a $-5 \%$. VPDB, tal como se estila en trabajos similares, por considerarse primarios (e.g. Zakharov et al., 2011). Un análisis más detallado de los resultados isotópicos y sus tendencias generales se presenta en el capítulo 10.

Los resultados de paleotemperaturas obtenidos en la Cuenca Neuquina (Tabla 9.5) dan en promedio $25^{\circ} \mathrm{C}$ para el agua de mar (26ㄷ en Río Salado, $25^{\circ} \mathrm{C}$ en Puesto Loncoche y $25^{\circ} \mathrm{C}$ en Cuesta del Chihuido); esta estimación coincide con los valores estipulados para la Cuenca Neuquina según interpretaciones realizadas por Lazo et al. (2008) basándose en estudios isotópicos y por Lazo et al. (2005), a partir de asociaciones fosilíferas del miembro Pilmatué de la Formación Agrio en el sector neuquino de la cuenca. En la Cuenca Austral (Tabla 9.6), por otro lado, el promedio de paleotemperaturas obtenidas de los belemnites es de $24,5 \circ \mathrm{C}$ ( 25 ㅇ $\mathrm{C}$ en Río Guanaco y 24 ㄷ en Subida del Chancho), estos datos no son contrastables, ya que no se han encontrado referencias en la bibliografía con respecto a la temperatura en esta latitud en el lapso Tithoniano-Valanginiano.

Las paleosalinidades fueron calculadas sobre la base de los valores de paleotemperaturas e isótopos estables de oxígeno anteriormente mencionados (Tabla 9.5, Tabla 9.6 y Fig. 9.6) y oscilan entre 31 y $35 \mathrm{~g} / \mathrm{l}$ para las formaciones estudiadas en ambas cuencas. Estos resultados ubican a las muestras dentro del campo de las aguas euhalinas, es decir, una salinidad normal para el agua de mar. 


\begin{tabular}{|c|c|c|c|c|}
\hline Muestra & $513 C x_{e}$ VPDE & 513 OK6 VPOB & $T(P C)$ & Sal. $[\{1]$ \\
\hline 1152.481 & 2.19 & -240 & 21.7 & 22.3 \\
\hline HS $2411 \mathrm{H}$ & 2.53 & -4.43 & 2091 & 32.2 \\
\hline H15.2378 & 0.93 & 9.15 & 24.78 & 32,3 \\
\hline As $234 \mathrm{~A}$ & 0.86 & 382 & 27.47 & 33,4 \\
\hline AS 23218 & 2.24 & 397 & 2807 & 33.2 \\
\hline HS $228 \mathrm{BH}$ & 1. 31 & 3.38 & $25 . \pi$ & 33 \\
\hline AS 2274 & 0.94 & -285 & 23.62 & 31.5 \\
\hline AS $226 \mathrm{C}$ & 0,94 & 330 & 25.38 & 33,6 \\
\hline HS $223 C$ & 039 & 3.15 & 24.78 & 32.5 \\
\hline 115271 & 0.41 & -417 & 29.61 & 33,5 \\
\hline AS 2200 & 1,14 & 400 & 2851 & 33,3 \\
\hline PL. 139 & 0.91 & 269 & 22.54 & 33,2 \\
\hline PL.116 & 2.66 & 292 & 23.86 & 32.2 \\
\hline A.112 & 1.87 & +37 & 2962 & 32,3 \\
\hline PL 111 & $1: 96$ & 355 & 26.38 & 32,9 \\
\hline Pr. 11200 & 1.66 & 312 & 24.66 & 32.2 \\
\hline A 106E & 1.16 & -5.80 & 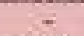 & $=$ \\
\hline D. 100 & -0.35 & -2.28 & 21.29 & 33,4 \\
\hline EQB & 0.43 & +192 & 19.85 & 33,1 \\
\hline FCag8 & -151 & 205 & 2039 & 33.1 \\
\hline PL $8 B C$ & 2.91 & -262 & 22.65 & 34 \\
\hline FL g8 & 451 & -285 & 23.58 & 34.2 \\
\hline PLB3 & -321 & 476 & 3124 & 328 \\
\hline PL78 & -2.11 & -432 & 29.47 & 31,7 \\
\hline$P 176$ & 0.84 & 3.46 & 25.02 & 33 \\
\hline PL 728 & 493 & -197 & 2000 & 33.5 \\
\hline F. 72 & -2.14 & $-3 \sqrt{9}$ & 27.35 & 328 \\
\hline PLEB & 2.08 & +32 & 2947 & 33,1 \\
\hline PL 65 & -4.54 & -194 & 19.93 & 32.9 \\
\hline pL 61A & 0.12 & .210 & 2057 & 32,5 \\
\hline PLEL & 0.12 & -3.52 & 26.26 & 32,3 \\
\hline PL 600 & 0.04 & 235 & 21.57 & $32 x$ \\
\hline$P 154$ & 0.15 & -241 & 2181 & 32,7 \\
\hline FLSO & -1.18 & 2.58 & 22.49 & 32,8 \\
\hline PL 448 & 0.33 & -210 & 20.57 & 32.5 \\
\hline P. 44 & 0.04 & -279 & 23.34 & 32.9 \\
\hline$P L 42 B$ & 258 & 270 & 22.98 & 33,4 \\
\hline PL 38 & 0.45 & 273 & 25.10 & 33,3 \\
\hline PL 338 & 0.99 & -406 & 2843 & 33.5 \\
\hline PL.22C & -0.20 & -370 & 2699 & 34,2 \\
\hline $\operatorname{CDC} 41$ & 0.89 & -768 & 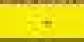 & 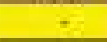 \\
\hline $\operatorname{coc} 40$ & 2.13 & -717 & $\because$ & - \\
\hline $\operatorname{cDC} 39$ & 0.91 & -594 & it. & 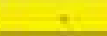 \\
\hline $\operatorname{CoC} 38$ & 1.33 & -7.34 & + & 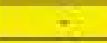 \\
\hline $\operatorname{coc} 37$ & 1.67 & $-7,14$ & - & - \\
\hline $\operatorname{cDC} 36$ & -0.33 & -14.56 & + & + \\
\hline $\operatorname{CDC} 35$ & 0.18 & 378 & 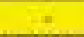 & 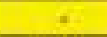 \\
\hline $\operatorname{coc} 24$ & -0.41 & -296 & 2402 & 33,2 \\
\hline $\mathrm{CDC} 23$ & 208 & 72 & 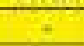 & 4 \\
\hline $\operatorname{CDC} 22$ & 1.51 & -352 & 26.26 & 32,9 \\
\hline CDC 18 & 0.04 & -263 & 2269 & 33,1 \\
\hline $\operatorname{Coc} 17$ & -0.58 & -305 & 24.38 & 32.6 \\
\hline $\mathrm{CDC} 1 \mathrm{~A}$ & 0.53 & 2.85 & 23.58 & 33 \\
\hline $\operatorname{coc} 31$ & -1.10 & $-3 \leq 4$ & 26,34 & 31,6 \\
\hline $\operatorname{CDC} 12$ & -0.53 & -279 & 23.34 & 32,4 \\
\hline $\operatorname{CoC} 11 \mathrm{~B}$ & 0.78 & -279 & 23.34 & 32,4 \\
\hline $\operatorname{cDC} 10$ & -284 & 3.38 & 29.47 & 34.7 \\
\hline
\end{tabular}

Tabla 9.5. Valores de $\delta^{13} \mathrm{C}, \delta^{18} \mathrm{O}$, paleotemperaturas y paleosalinidades para la Cuenca Neuquina. En naranja se observan los datos del perfil Río Salado, en rosa los de Puesto Loncoche y en amarillo los de Cuesta del Chihuido. 


\begin{tabular}{|c|c|c|c|c|}
\hline Muestra & $\delta 13 C \%$ VPDB & $8180 \%$ VPDB & $\mathrm{T}(\stackrel{\circ}{ } \mathrm{C})$ & Sal. $(g / 1)$ \\
\hline AG 33 & -1.39 & -1.72 & 19.0 & 33.2 \\
\hline 1632 & -096 & $-4,39$ & 29.8 & 32.9 \\
\hline A6 31 & -0.56 & 2.01 & 20.2 & 33 \\
\hline AG 29 & -1.11 & 2.74 & 23.1 & 34.5 \\
\hline RG 28 & -1.48 & 7.35 & $=$ & $=$ \\
\hline RG 27 & -1.09 & -8.61 & $=$ & 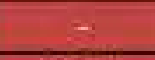 \\
\hline fG 26. & -1.03 & -4.31 & 29.4 & 32.7 \\
\hline RG 25. & -0.88 & -5.26 & . & 8 \\
\hline 2624 & -1.07 & -2.42 & 21.9 & 32.8 \\
\hline fig.23 & -1.22 & -6.48 & 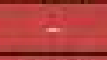 & 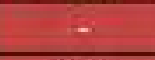 \\
\hline 8622 & -1.14 & $-2,92$ & 23.9 & 32.9 \\
\hline AG 21 & -1.77 & $-9,64$ & - & - \\
\hline AG 20 & -1.56 & -9.03 & e & 8 \\
\hline AG 19 & -0.94 & -3.73 & 27.1 & 32.9 \\
\hline RG 18 & -1.05 & $-4,32$ & 29.5 & 33.2 \\
\hline FG 17 & -0.85 & -6.77 & 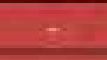 & 3 \\
\hline RG 10 & -0.93 & -5.61 & 7 & 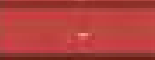 \\
\hline $8 G 9$ & -1.05 & -6.71 & $=$ & 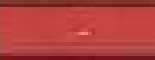 \\
\hline RG 8 & -1.74 & -9.57 & $=$ & 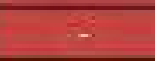 \\
\hline RG 6. & -0.46 & -5.34 & $=$ & $=$ \\
\hline RG 4. & .0 .33 & -6.37 & $=$ & 8 \\
\hline $5 \mathrm{CH} 23$ & -0.57 & -2.69 & 22.9 & 33.5 \\
\hline $5 \mathrm{CH} 21$ & -0.98 & -2.28 & 21.3 & 33.2 \\
\hline SCH 19 & -1.58 & -3.94 & 28.0 & 33.9 \\
\hline
\end{tabular}

Tabla 9.6. Valores de $\delta^{13} \mathrm{C}, \delta^{18} \mathrm{O}$, paleotemperaturas y paleosalinidades para la Cuenca Austral. En rojo se observan los datos del perfil Río Guanaco y en gris los de la Subida del Chancho. 


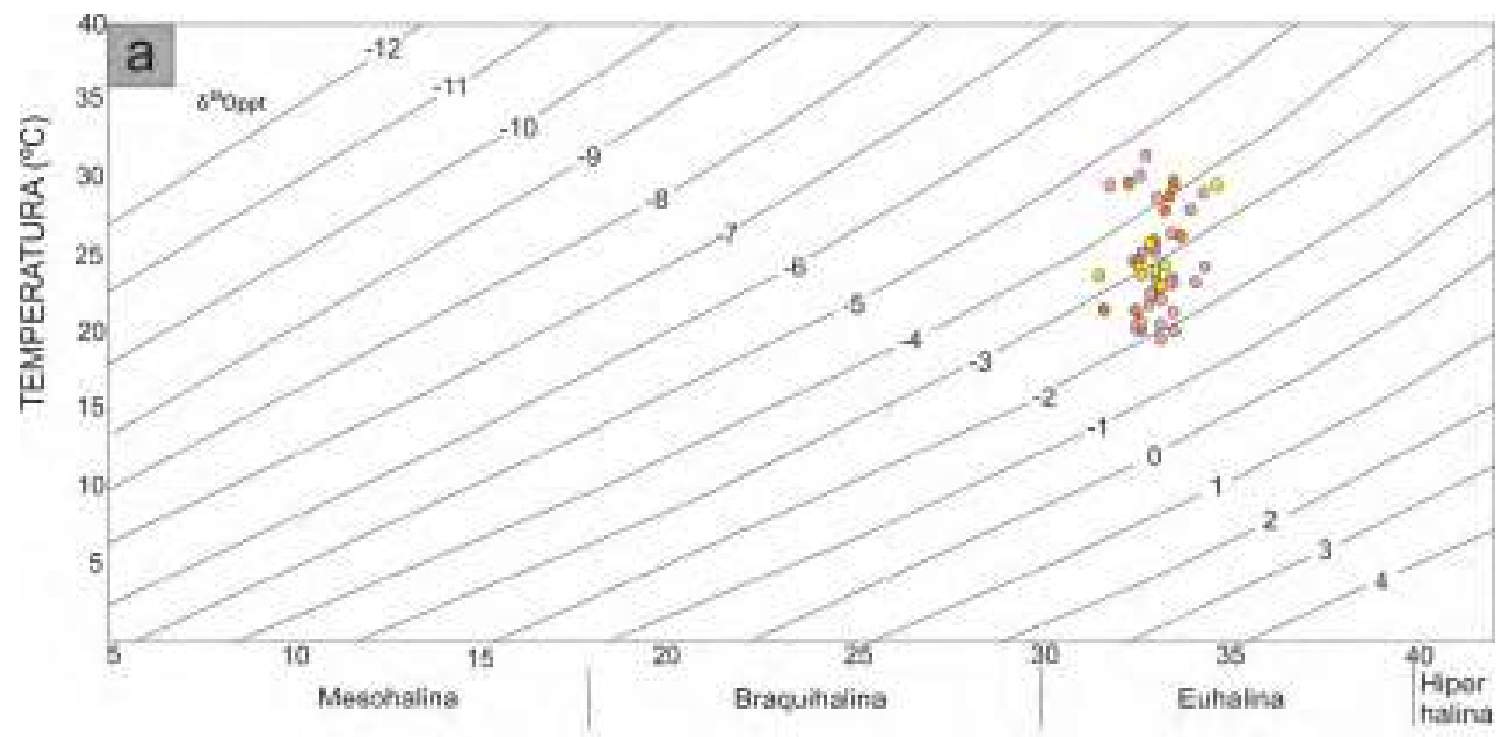

SALINIDAD (g/)

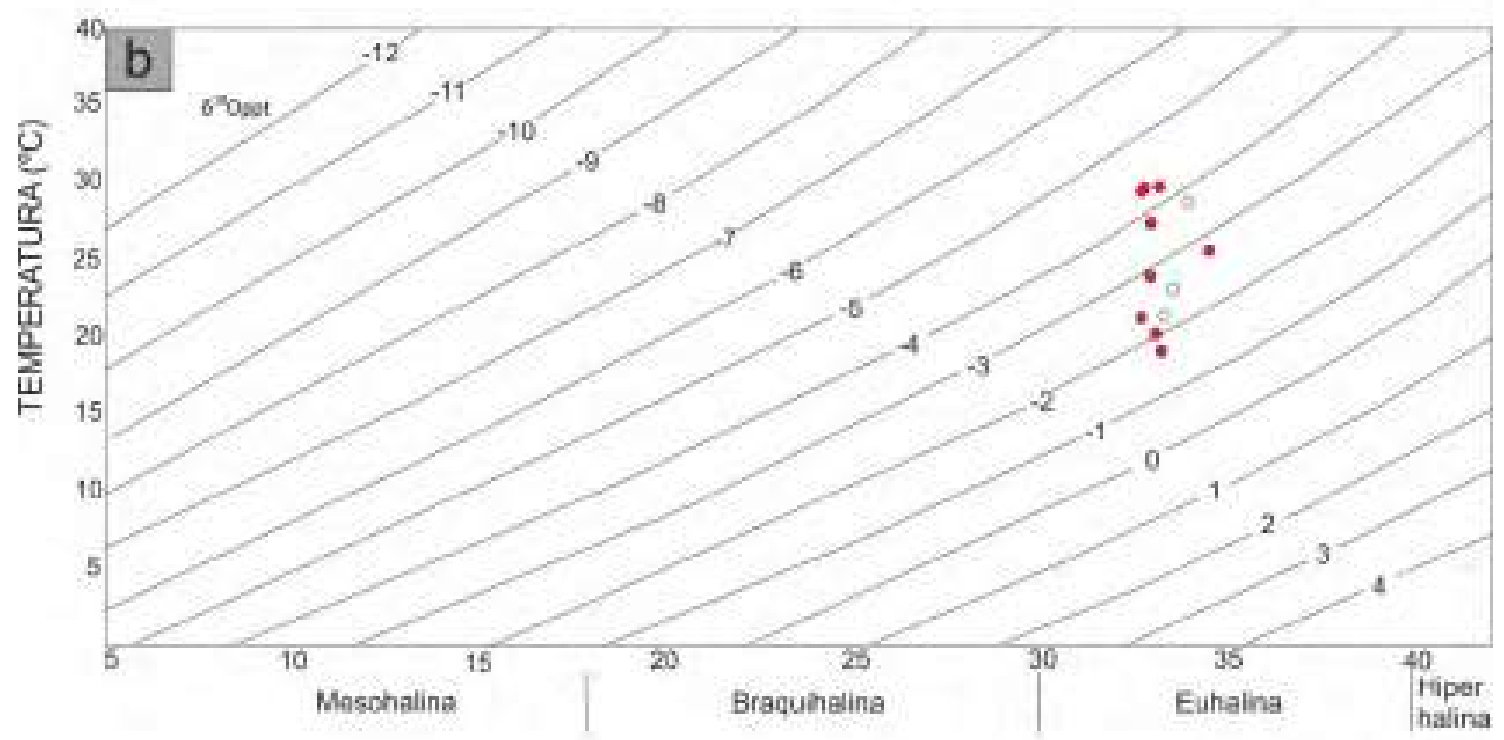

SALINIDAD (g/)

Figura 9.6. Cálculo de paleosalinidades a partir de datos de paleotemperaturas e isótopos estables de O (Modificada de Railsback et al., 1989). a) datos de la Cuenca Neuquina: en naranja se observan los correspondientes al perfil Río Salado, en rosa los de Puesto Loncoche y en amarillo los de Cuesta del Chihuido; b) datos de la Cuenca Austral: en rojo se observan los obtenidos en el perfil Río Guanaco y en blanco los de la Subida del Chancho.

\subsection{Relaciones elementales}

\subsubsection{Relaciones $\mathrm{Mg} / \mathrm{Ca}, \mathrm{Sr} / \mathrm{Ca}, \mathrm{Na} / \mathrm{Ca}, \mathrm{Mn} / \mathrm{Ca}, \mathrm{Fe} / \mathrm{Ca}$ vs $\delta^{18} \mathrm{O}$ (FRX)}

Las concentraciones de ciertos elementos mayoritarios obtenidas a partir de la utilización de fluorescencia de rayos $\mathrm{X}$, fueron utilizadas para calcular las relaciones de $\mathrm{Mg}$, $\mathrm{Sr}$, 
$\mathrm{Na}, \mathrm{Mn}$ y Fe con respecto a la cantidad de Ca. Estas relaciones, a partir de ahora llamadas relaciones $\mathrm{El} / \mathrm{Ca}$, fueron confrontadas con respecto al valor de $\delta^{18} \mathrm{O}$ (Fig. 9.7) con el objeto de determinar si los procesos de enriquecimiento o empobrecimiento diagenéticos tuvieron influencia directa sobre los isótopos estables de oxígeno.

Para el perfil Puesto Loncoche (Cuenca Neuquina) sólo se observa una correlación ( $r$ ) positiva en el caso de la relación $\mathrm{Sr} / \mathrm{Ca}$ vs. $\delta^{18} \mathrm{O}$ (Fig. 9.7 b), aunque con valores moderados de $r$ de 0,37 . Para el resto de las relaciones, la correlación es baja donde $r$ apenas alcanza valores de 0,16 como máximo.

La casi ausencia de correlación existente entre $\mathrm{Fe} / \mathrm{Ca}-\mathrm{Mn} / \mathrm{Ca}$ y $\delta^{18} \mathrm{O}(\mathrm{r}=0,07$ y 0,16 respectivamente) (Fig. 9.7 e y 9.7 d) corroboran que el enriquecimiento diagenético en Fe y $\mathrm{Mn}$ observado en algunas muestras del perfil Puesto Loncoche no habría tenido influencia en el valor primario de los isótopos estables del oxígeno. Por otro lado, los potenciales empobrecimientos diagenéticos en $\mathrm{Sr}$, $\mathrm{Na}$ y $\mathrm{Mg}$ enunciados anteriormente tampoco habrían afectado dicha signatura primaria, ya que poseen una pobre correlación positiva respecto a los valores de $\mathrm{Sr} / \mathrm{Ca}$ (Fig. 9.7 b), con un $\mathrm{r}=0,37$, y prácticamente nula para el caso de $\mathrm{Mg} / \mathrm{Ca}$ y $\mathrm{Na} / \mathrm{Ca}$ (Fig.9.7 a y $9.7 \mathrm{c}$ ) ( $r=0,04$ y 0,05 respectivamente).

Por otro lado, las muestras del perfil Río Guanaco (Cuenca Austral) muestran falta de correlación en el caso de las relaciones $\mathrm{Na} / \mathrm{Ca}$ vs $\delta^{18} \mathrm{O}$ (fig. $9.7 \mathrm{~h}$ ), $\mathrm{Mn} / \mathrm{Ca}$ vs $\delta^{18} \mathrm{O}$ (Fig. 9.7 i) y $\mathrm{Fe} / \mathrm{Ca}$ vs $\delta^{18} \mathrm{O}$ (Fig. $9.7 \mathrm{j}$ ) con valores de $\mathrm{r}$ de 0,$02 ; 0,02$ y 0,12, respectivamente. En el caso de $\mathrm{Sr} / \mathrm{Ca}$ vs $\delta^{18} \mathrm{O}$ existe correlación positiva con un $\mathrm{r}=0,58$ (Fig. 9.7 g). La proporción $\mathrm{Mg} / \mathrm{Ca}$ (Fig. $9.8 \mathrm{f})$ posee una baja correlación negativa con el $\delta^{18} \mathrm{O}(\mathrm{r}=-0,34)$.

De lo expuesto anteriormente, se puede concluir, que la falta de correlación en las relaciones $\mathrm{Mn} / \mathrm{Ca}, \mathrm{Na} / \mathrm{Ca}$ y $\mathrm{Fe} / \mathrm{Ca}$ con $\delta^{18} \mathrm{O}$ demuestran que el enriquecimiento en $\mathrm{Fe}$, empobrecimiento en $\mathrm{Na}$ y parcial enriquecimiento en $\mathrm{Mn}$ observados no condicionan los valores primarios de $\delta^{18} \mathrm{O}$.

En otro aspecto, la correlación positiva expuesta para $\mathrm{Sr} / \mathrm{Ca}$ vs. $\delta^{18} \mathrm{O}$ demuestra un ligero condicionamiento diagenético $(r=0,58)$ entre ambos parámetros. Con todo, no estaría afectada la preservación primaria ya que los valores de Sr y de la relación Sr/Ca se encuentran dentro de los tenores normales para los belemnites valanginianos (Li et al., 2013; McArthur et al., 2004; Price y Mutterlose, 2004; Price y Nunn, 2010; Nunn y Price, 2010).

Por último, la correlación negativa entre el $\mathrm{Mg} / \mathrm{Ca}$ y el $\delta^{18} \mathrm{O}$ marca una dependencia entre ambos valores, aunque dicha relación no sería diagenética sino dada por el mismo factor vital del organismo (Mc Arthur et al., 2007). Cabe destacar, que ante una influencia de la diagénesis se esperaría una correlación positiva, es decir opuesta a la observada. 

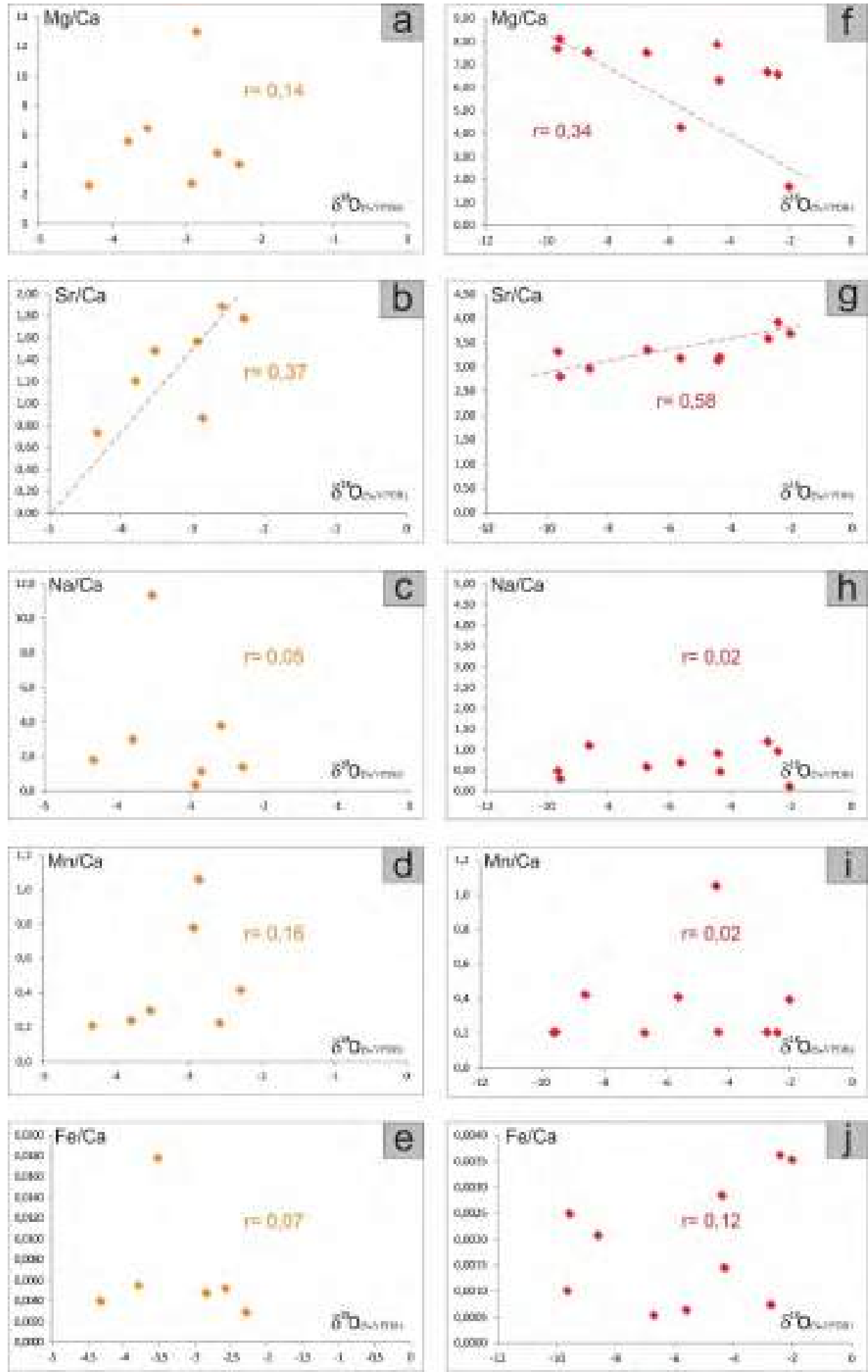

Figura 9.7: Relaciones El/Ca vs. $\delta^{18} \mathrm{O}$. Datos del perfil Puesto Loncoche (Cuenca Neuquina): a) $\mathrm{Mg} / \mathrm{Ca}$ vs. $\delta^{18} \mathrm{O}, \mathrm{b}$ ) $\mathrm{Sr} / \mathrm{Ca}$ vs. $\delta^{18} \mathrm{O}$ con correlación positiva, c) $\mathrm{Na} / \mathrm{Ca}$ vs. $\delta^{18} \mathrm{O}$, d) $\mathrm{Mn} / \mathrm{Ca}$ vs. $\delta^{18} \mathrm{O}$, e) Fe/Ca vs. $\delta^{18} \mathrm{O}$. Datos del perfil Río Guanaco (Cuenca Austral): f) Mg/Ca vs. $\delta^{18} \mathrm{O}$ con correlación negativa, g) $\mathrm{Sr} / \mathrm{Ca}$ vs. $\delta^{18} \mathrm{O}$ con correlación positiva, h) $\mathrm{Na} / \mathrm{Ca}$ vs. $\left.\delta^{18} \mathrm{O}, \mathrm{i}\right) \mathrm{Mn} / \mathrm{Ca}$ vs. $\delta^{18} \mathrm{O}, \mathrm{j}$ ) Fe/Ca vs. $\delta^{18} \mathrm{O}$. 


\subsubsection{Relaciones $\mathrm{Mg} / \mathrm{Ca}, \mathrm{Mn} / \mathrm{Sr}, \mathrm{Mn}, \mathrm{Sr}$ vs. $\delta^{13} \mathrm{C}$ (FRX)}

Para poder determinar si los análisis en carbonatos reflejan la composición isotópica de carbono de la solución a partir de la cual precipitó, existen varios indicadores petrográficos, geoquímicos e isotópicos (Marshall, 1992). Habiéndose abordado dicho tema desde el punto de vista petrográfico en capítulos anteriores, se desarrollará a continuación desde el punto de vista geoquímico.

Con el avance de la diagénesis y la circulación de fluidos formacionales, el Sr se lixivia y el $\mathrm{Mn}$ se incorpora, aumentando la relación $\mathrm{Mn} / \mathrm{Sr}$ tanto en rocas como en fósiles de composición carbonática. Por esta razón, tanto los valores absolutos de $\mathrm{Mn}$ y $\mathrm{Sr}$ (tratados anteriormente en este capítulo) como la relación $\mathrm{Mn} / \mathrm{Sr}$ han sido usados en la bibliografía como valores límite de la alteración diagenética. En este sentido, la ausencia de alteración diagenética quedaría expresada por contenidos de la relación $\mathrm{Mn} / \mathrm{Sr}$ menores a 1,5 (Asmerom et al., 1991; Kaufman et al, 1997) o bien menores a 1 (según Derry et al., 1992).

Los valores de la relación $\mathrm{Mn} / \mathrm{Sr}$ correspondientes tanto a Río Guanaco como a Puesto Lonche se encuentran por debajo de 1 a excepción de la muestra PL88, por lo cual se asumen inalteradas siguiendo los criterios de Asmerom et al. (1991), Derry et al. (1992) y Kaufman et al. (1997).

Las relaciones $\mathrm{Mg} / \mathrm{Ca}, \mathrm{Mn} / \mathrm{Sr}$ y los valores absolutos de $\mathrm{Mn}$ y $\mathrm{Sr}$, fueron confrontados con respecto al valor de $\delta^{13} \mathrm{C}$ (Figs. 9.8) con el objeto de determinar si los procesos de enriquecimiento o empobrecimiento acontecidos durante la diagénesis tuvieron una influencia directa sobre el isótopo estable de carbono.

Para el perfil Puesto Loncoche (Cuenca Neuquina) se observa una correlación negativa respecto de la relación $\mathrm{Mg} / \mathrm{Ca}$ vs. $\delta^{13} \mathrm{C}$ con un $\mathrm{r}=-0,49$ (Fig. 9.8 a). Por otro lado, para el caso de las relaciones $\mathrm{Mn} / \mathrm{Sr}$ vs. $\delta^{13} \mathrm{C}$ (Fig. 9.8 b), Mn vs. $\delta^{13} \mathrm{C}$ (Fig. 9.8 c) y Sr vs. $\delta^{13} \mathrm{C}$ (Fig. 9.8 d) no se observan correlaciones, mostrando valores de $r$ muy cercanos a $0(r=0,04, r=0,005$ y $r=0,0004$ respectivamente).

A partir de lo expuesto anteriormente se puede concluir que la falta de correlación en las relaciones $\mathrm{Mn}$ vs. $\delta^{13} \mathrm{C}$ y $\mathrm{Sr}$ vs. $\delta^{13} \mathrm{C}$ evidencian que el enriquecimiento en $\mathrm{Mn}$ y el potencial empobrecimiento en $\mathrm{Sr}$, observado en algunas muestras, no condicionan los valores primarios de $\delta^{13} \mathrm{C}$. Por otro lado, la relación $\mathrm{Mn} / \mathrm{Sr}$ vs. $\delta^{13} \mathrm{C}$ tampoco posee correlación reforzando el carácter inalterado de los valores de $\delta^{13} \mathrm{C}$.

Por otro lado, la relación $\mathrm{Mg} / \mathrm{Ca}$ vs. $\delta^{13} \mathrm{C}$ posee una correlación negativa representando una dependencia entre los valores de uno y el otro. Dicha relación, en contraposición con la correlación positiva, no sería producto de la alteración diagenética sino una correlación natural 
entre $\mathrm{Mg} / \mathrm{Ca}$ (independiente de la salinidad y correlacionado positivamente con la temperatura) y el $\delta^{13} \mathrm{C}$ (influenciado por la salinidad y correlacionado negativamente con la temperatura) (Nunn y Price, 2010)

En el caso del perfil Río Guanaco (Cuenca Austral) se observa una correlación negativa en el caso de la relación $\mathrm{Mg} / \mathrm{Ca}$ vs. $\delta^{13} \mathrm{C}$ (Fig. 9.8 e) con un $\mathrm{r}=-0,49$. Por otro lado, para el caso de las relaciones $\mathrm{Mn} / \mathrm{Sr}$ vs. $\delta^{13} \mathrm{C}$ (Fig. 9.8 f), Mn vs. $\delta^{13} \mathrm{C}$ (Fig. $9.8 \mathrm{~g}$ ) y Sr vs. $\delta^{13} \mathrm{C}$ (Fig. $9.8 \mathrm{~h}$ ) no se evidencian correlaciones y los valores de $r$ son cercanos a $0(r=0,09, r=0,14$ y $r=0,19$ respectivamente).

Nuevamente se puede concluir que la falta de correlación en las relaciones $\mathrm{Mn}$ vs. $\delta^{13} \mathrm{C}$ y $\mathrm{Sr}$ vs. $\delta^{13} \mathrm{C}$ evidencian que el parcial enriquecimiento en $\mathrm{Mn}$ y los valores inalterados de $\mathrm{Sr}$ no condicionan los valores primarios de $\delta^{13} \mathrm{C}$. Por otro lado, la relación $\mathrm{Mn} / \mathrm{Sr}$ vs. $\delta^{13} \mathrm{C}$ tampoco posee correlación reforzando el carácter inalterado de los valores de $\delta^{13} \mathrm{C}$.

Finalmente, la relación $\mathrm{Mg} / \mathrm{Ca}$ vs. $\delta^{13} \mathrm{C}$ posee una correlación negativa que representa la covarianza natural entre ambos valores. 

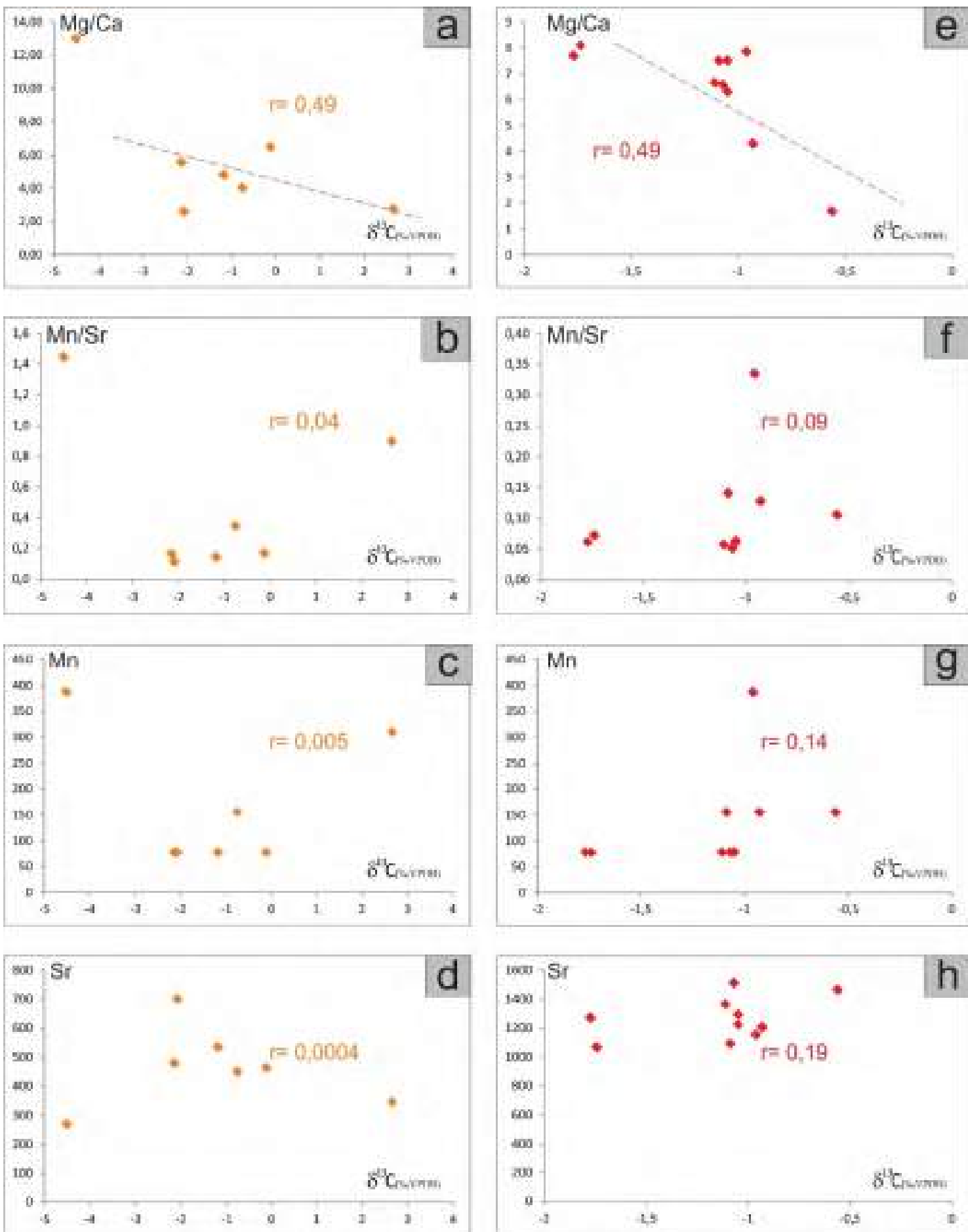

Figura 9.8. Relaciones El/Ca vs. $\delta^{13} \mathrm{C}$. Datos del perfil Puesto Loncoche (Cuenca Neuquina): a) $\mathrm{Mg} / \mathrm{Ca}$ vs. $\delta^{13} \mathrm{C}$ con correlación negativa, b) $\mathrm{Mn} / \mathrm{Sr}$ vs. $\left.\delta^{13} \mathrm{C}, \mathrm{c}\right) \mathrm{Mn}$ vs. $\delta^{18} \mathrm{O}$, d) $\mathrm{Sr}$ vs. $\delta^{13} \mathrm{C}$. Datos del perfil Río Guanaco (Cuenca Austral): e) $\mathrm{Mg} / \mathrm{Ca}$ vs. $\delta^{13} \mathrm{C}$ con correlación negativa, f) $\mathrm{Mn} / \mathrm{Sr}$ vs. $\left.\delta^{13} \mathrm{C}, \mathrm{g}\right) \mathrm{Mn}$ vs. $\left.\delta^{18} \mathrm{O}, \mathrm{h}\right) \mathrm{Sr}$ vs. $\delta^{13} \mathrm{C}$.

\subsubsection{Relación $\delta^{13} \mathrm{C}$ vs. $\delta^{18} \mathrm{O}$}

En la figura 9.9 se calculó la correlación existente entre $\delta^{13} \mathrm{C}$ y $\delta^{18} \mathrm{O}$. Para la Cuenca Neuquina (fig. 9.9 a) se observa una baja correlación en el caso de la sección Cuesta del 
Chihuido, mientras que no existe correlación para los perfiles Río Salado y Puesto Loncoche. Estos resultados demuestran la ausencia de condicionamientos entre ambos valores isotópicos, lo que se condice con lo esperado para valores primarios o inalterados.

Por otro lado, para la Cuenca Austral, el perfil Río Guanaco muestra una pobre correlación positiva entre los valores de $r=0,20$ (Fig. 9.9 b), descartándose condicionamientos diagenéticos. En la Subida del Chancho no se ha obtenido el factor de correlación, ya que la escasa cantidad de valores isotópicos no permite realizar cálculos confiables.

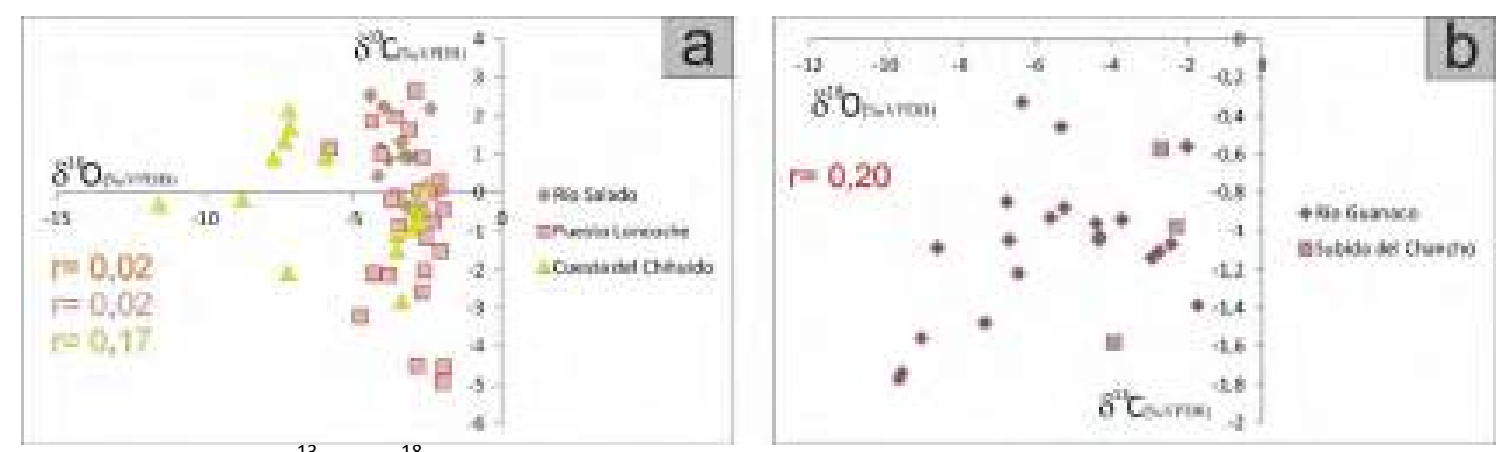

Figura 9.9. Relación $\delta^{13} \mathrm{C}$ vs. $\delta^{18} \mathrm{O}$. a) Valores correspondientes a la Cuenca Neuquina, b) valores correspondientes a la Cuenca Austral.

\subsubsection{Relación $\mathrm{Mn}, \mathrm{Sr}, \mathrm{Mn} / \mathrm{Sr}$ vs. $\delta^{13} \mathrm{C}$ (ICP-MS)}

A partir de los datos de $\mathrm{Mn}$ y Sr (tabla 9.4) fue posible calcular la relación Mn/Sr. Como se mencionó anteriormente, cuando los valores de esta relación son mayores a 1,5 se considera que existió cierta alteración diagenética (Asmerom et al., 1991; Kaufman et al., 1997). En los perfiles estudiados, sólo cuatro muestras (PL 88, CDC 35, CDC 38 y RG19) presentan valores superiores a 1,5. En las muestras correspondientes a la Cuenca Neuquina esta relación suele ser menor a 1, mientras que en las de Cuenca Austral apenas supera 0,5.

Con el objetivo de terminar de validar los resultados isotópicos de $\delta^{13} \mathrm{C}$, se realizó el cálculo de la correlación con $\mathrm{Mn}, \mathrm{Sr}$ y $\mathrm{Mn} / \mathrm{Sr}$ (fig. 9.10). Los valores obtenidos son, en todos los casos, inferiores a 0,10.

Con lo anteriormente expuesto es posible concluir que no sólo no existen enriquecimientos o empobrecimientos diagenéticos en $\mathrm{Mn}$ y $\mathrm{Sr}$, sino que lo que es más importante, éstos no provocaron condicionamientos entre los estos valores y los de $\delta^{13} \mathrm{C}$. 

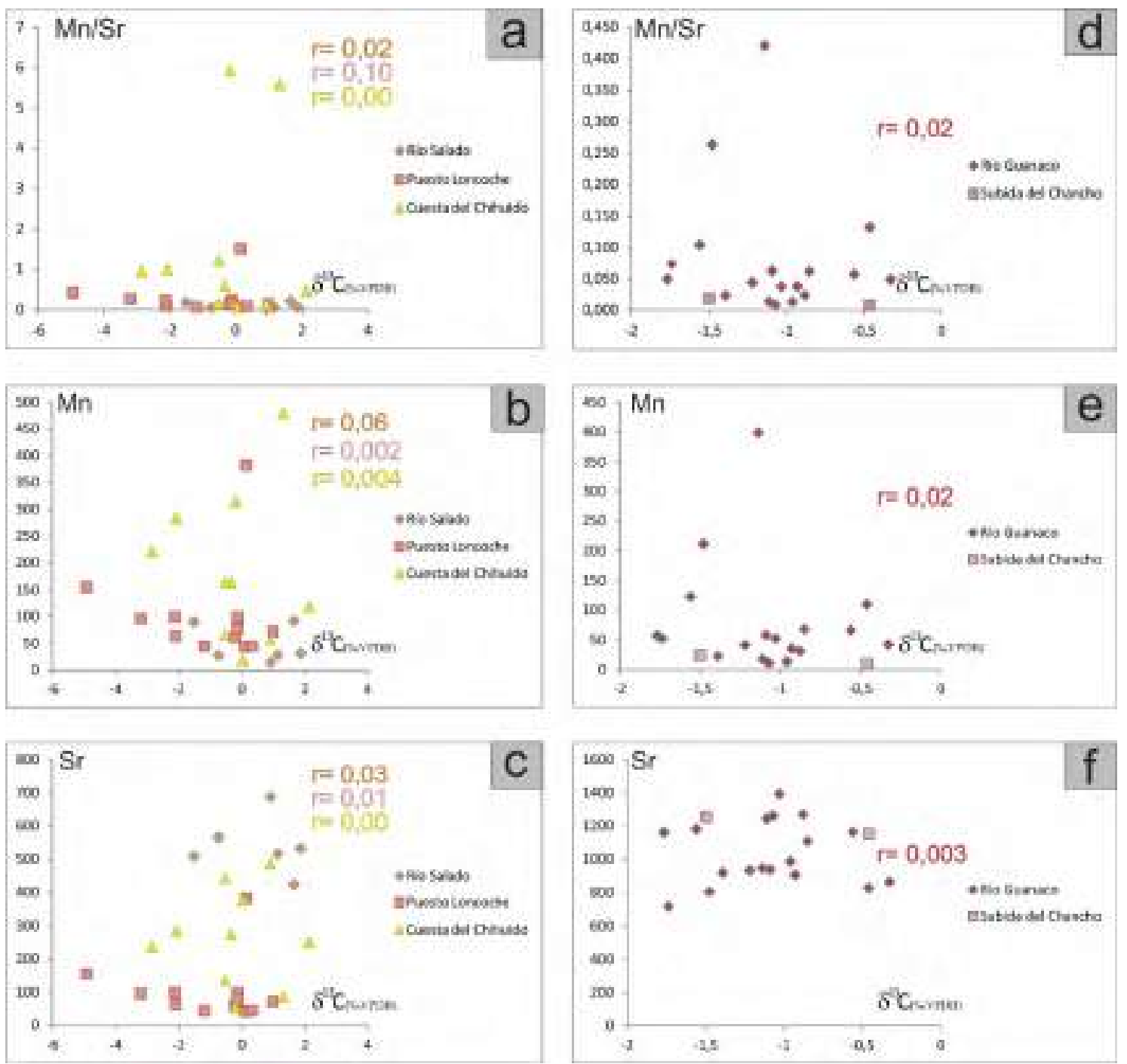

Figura 9.10. Relación $\mathrm{Mn}, \mathrm{Sr}, \mathrm{Mn} / \mathrm{Sr}$ vs. $\delta^{13} \mathrm{C}$ calculado con ICP-MS. a) $\mathrm{Mn} / \mathrm{Sr}$ vs $\delta^{13} \mathrm{C}$, b) $\mathrm{Mn}$ vs $\delta^{13} \mathrm{C}$ y c) $\mathrm{Sr}$ vs $\delta^{13} \mathrm{C}$ e perfiles de la Cuenca Neuquina. d) $\mathrm{Mn} / \mathrm{Sr}$ vs $\delta^{13} \mathrm{C}$, e) $\mathrm{Mn}$ vs $\delta^{13} \mathrm{C}$ y f) $\mathrm{Sr} v \mathrm{vs} \delta^{13} \mathrm{C}$ en perfiles dela Cuenca Austral.

\subsection{Tierras raras e itrio}

\subsubsection{Introducción}

Se denomina Tierras Raras (ETR ó REE en inglés) a los elementos de transición del Grupo IIIB (Grupo 3) Sc, La y los elementos de transición interna desde el Ce hasta Lu (Holser, 1997). Según la nomenclatura geoquímica los ETR se refieren a los lantánidos (La, Ce, Pr, Nd, $\mathrm{Pm}, \mathrm{Sm}, \mathrm{Eu}, \mathrm{Gd}, \mathrm{Tb}, \mathrm{Dy}, \mathrm{Ho}, \mathrm{Er}, \mathrm{Tm}, \mathrm{Yb}$ y Lu), y en algunos casos también se incluye al itrio (Y) debido a que presenta propiedades químicas muy similares al holmio $(\mathrm{Ho})$; cuando esto sucede se designa al grupo entero como tierras raras e itrio (REY) (Tostevin et al., 2016). En geoquímica se suele subdividir a los REE en, Tierras Raras Ligeras (LREE - La hasta Eu) y Tierras 
Raras Pesadas (HREE - Gd hasta Lu). Puede incluirse una subdivisión que considera a las Tierras Raras Medianas (MREE - Nd hasta Tb) (Garbán, 2016).

Los elementos que constituyen las REY presentan características muy similares entre ellos (alta coherencia química), son generalmente trivalentes a excepción del Ce (que puede presentarse también como $\mathrm{Ce}^{+4}$ ) y el $\mathrm{Eu}$ (puede presentarse también como $\mathrm{Eu}^{+2}$ ), en el ambiente exógeno se comportan como elementos inmóviles y aunque son un grupo con una alta coherencia química, sufren fraccionamiento.

Como se explicó en la sección 2.5.9 los valores obtenidos con ICP-MS en muestras de material fósil fueron normalizados con respecto a la lutita patrón PAAS, y son presentados en la tabla 9.7 y figura 9.11. A partir de estos resultados se interpretó el grado preservación de las muestras, el nivel de oxigenación y la profundidad de las aguas. Vale destacar que no fue posible la cuantificación y el análisis de las REY del perfil Subida del Chancho debido a la escasa concentración de los elementos químicos. 


\begin{tabular}{|c|c|c|c|c|c|c|c|c|c|c|c|c|c|c|}
\hline Wata & $\mathbf{L}^{*}$ & $\mathrm{Co}^{\circ}$ & $p^{2}$ & $40^{\circ}$ & $\operatorname{sen}{ }^{2}$ & $\mathrm{CH}^{+}$ & 2 & $\pi^{2}$ & or & $\pi$ & $160^{\circ}$ & $E$ & $7 m^{2}$ & $\sigma^{\prime}$ \\
\hline काइ10 & 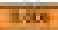 & Tiniा & 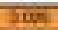 & वर्क & एuा & हका & क्षली & Dali & 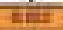 & iहज & क्जि & क्या? & 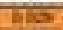 & 7. \\
\hline wate & 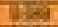 & Data & 70 & प्रक्ष & con & Eú: & 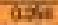 & 219 & EA & $06 \%$ & ชือ? & Jiti & 110 & 060 \\
\hline किख्यू & tix & II & है⿴囗十介 & प्रक्ष & Cमि & Eम & वाश & If & 2115 & 024 & व्यद्ह & in & 120 & का \\
\hline कारि & 800 & हका & हलक & $60 x$ & Bon & Dका & करा & 290 & son: & 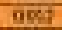 & ane & कबने & $8 \pi$ & तिक्ल \\
\hline बटा क & 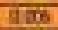 & tini & $\pi{ }^{2}$ & पक & हैo & DहC & ax & 700 & 6श & वका & प्षक & 29 & 520 & Tus \\
\hline ज्वक्ज & ats & 0.18 & वि? & $00+4$ & 604 & 60 & ass & 7003 & 306 & 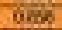 & 000 & 10 & 300 & .0.0. \\
\hline mang & W/15 & 006 & oc & das & coll & 8021 & 2004 & Iaf & क्रा6 & 0004 & ooli & $2 m$ & $\frac{185}{802}$ & 00 \\
\hline pristi & 1000 & एक & 2000 & oven & $c 00 t$ & DCE & ase & 100 & $2 \infty$ & 0.04 & $00 \mathrm{Ca}$ & 200 & BXI & 0000 \\
\hline Whe & 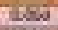 & iftin & We & 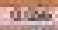 & 100 & 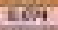 & wet & owin & 67 & wini & wail & the & Itw? & tos \\
\hline$\pi \omega$ & 78 & $0 \mathrm{CH}$ & Doir & 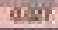 & 0.86 & GES & 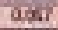 & 2.00 & 605 & DEA & Que & 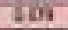 & 7. & $200 \mathrm{at}$ \\
\hline ग158 & क्रूर & किख्य & बin & कासा & हम? & EDe & $\alpha=$ & 225 & कम & प्रत्य & क्य. & क्या & यू & क्रां \\
\hline DAlE & कल & तिक & SलA & 004 & लिu & Dलि! & $a m$ & 1025 & Din & 000 & and & काin & $80 \%$ & nimo \\
\hline Fut & iss & 000 & काजी & $a x^{2}$ & 60 & Don & $a 0^{2}$ & 2109 & क्रो & $02 n$ & 000 & करू & 205 & 008 \\
\hline मब & 75 & 605 & हलe & $60 \%$ & का & $8 x$ & बis & 150 & $6 \%$ & 035 & a11 & 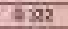 & 1156 & एकी \\
\hline 74 & 1215 & 050 & $\partial \pi$ & $a z_{2}$ & 0108 & 019 & as & 228 & 210 & 013 & $a s$ & $2 \times 4$ & 5404 & Q 40 \\
\hline ncto & $a=$ & 021 & DCu & adil & $\cos 1$ & tos & assi & 2014 & 2001 & 000 & 000 & 208 & 850 & 000 \\
\hline Kon & T.xe & tax & wata & ast & Ein & 60 & 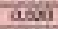 & $x a n$ & Eस & híke & Exiा & in & 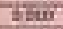 & times \\
\hline kil & $20-2$ & ante & Drert & वath & $\cos \pi$ & 8005 & कब्यो & Tas & 2 Eat & Tusen & tow & 152 & 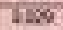 & 000 \\
\hline $\mathrm{FMl}$ & $70 \mathrm{n}$ & 006 & Dिa & प्रवा & हान & EN & वकल & por & लाय & प1100 & प्राय & oni & 2101 & 7100 \\
\hline हला & Q35 & $8 \times 4$ & Dest & $0 \mathrm{ng}$ & $\mathrm{Cole}$ & Eक & 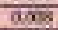 & 700 & थल & 005 & $00 x$ & 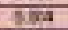 & Dका & 0. \\
\hline कराभ & ED & 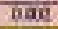 & 800 & क्जि & conit & 805 & $a b$ & Iका & हकब & 000 & $00 \mathrm{a}$ & हक & 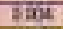 & Q10द्य \\
\hline 또국 & 200 & 300 & कon & $a 07$ & 000 & 8061 & $a p^{\circ}$ & 100 & 6000 & 030 & acs & $2 \infty 0$ & 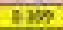 & 000 \\
\hline $\cos c 12$ & g8es & 005 & Dल & 0,000 & Cong & $D \times 61$ & $a x_{5}$ & 2045 & $B M$ & 0.121 & 005 & DII & 857 & एवes \\
\hline $\cos 65$ & 9on & Dow & 000 & onf & COIS & 000 & ando & 2011 & 9002 & ans & oral & aifs & 2500 & 0,03 \\
\hline $\mathrm{Coc}$ & $2 x$ & taxil & 300 & $\sec$ & $\cos$ & 60 & was & $r \times$ & dix & oferi & $\alpha \omega^{2}$ & If26 & thes & $a x$ \\
\hline Coc2 & 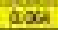 & Gowe & $\operatorname{cose}$ & 200 & sint & 6256 & 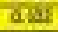 & Tan & 8187 & 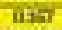 & $\alpha \sin ^{2}$ & 2725 & 756 & $\cos x$ \\
\hline cocas & 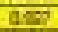 & IIIII & प्रि & प्जin & EIII & एका & प्या & adi? & हूय & $0 \times 9$ & inils & 120 & DxA & $\mathrm{ONO}$ \\
\hline$c \times C^{2}$ & 906 & $0 \times 10$ & Doge & Dogr & Con & $0 \mathrm{CH}$ & aक & Sas & 803 & $0 \infty$ & acss & 204 & 806 & 000 \\
\hline $\mathrm{csca}$ & $10 \times 5$ & ene & कात & क्जि & की & 600 & aक & Im & $C \infty \overline{5}$ & कराए & 000 & ति & Dext & ands \\
\hline cals & 120 & 090 & 300 & कबा & 5001 & किक & and & का & $8 \mathrm{~mol}$ & om & $a x$ & 200 & 800 & 0000 \\
\hline $\mathrm{Cr}_{\mathrm{CAI}}$ & 703 & 0010 & $D \cos$ & $a \in$ & $\mathrm{Cg} / \mathrm{s}$ & Der & $a_{001}$ & 2017 & 207 & 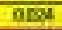 & $0,0 B$ & Enin & 2066 & Q10s \\
\hline 0 & 780 & Dof & 200 & ant & tong & {$[(x)$} & Ya6s & 292 & 1510 & 002 & $0 \mathrm{~min}$ & $\mathrm{~nm}$ & 100 & tom \\
\hline 82 & axw & ads & 50 & $\mathrm{eros}$ & 201 & Bats & act & Iat & $8 \mathrm{se}$ & Taen & wons & tent & 280 & 7 atos \\
\hline 108 & 105 & bits & 0000 & 200 & 062 & $(n+2)$ & 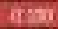 & $6 x 6$ & $\mathrm{~kg}$ & 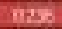 & WRe & rath & 125 & 46: \\
\hline net: & dass & प्रक्य & 508 & 609 & Cas & 634 & 048 & 1008 & tots & 0.86 & $\mathrm{seng}$ & ents & $\tan 2$ & ans \\
\hline Net & ats & $\mathrm{nax}$ & 20 & ast & Ens. & 860 & 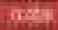 & Ding & $\mathrm{Bnt}$ & $\operatorname{arch}$ & ain: & exi: & $=8 t r$ & nits \\
\hline 8 & 100 & tan & bier & $\mathrm{aga}$ & Eoi & $\mathrm{cms}$ & $\alpha=0$ & 309 & $\mathrm{DEI}$ & cosy & 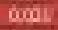 & teis & ast & twos \\
\hline $\mathrm{min}$ & 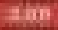 & atas & tofer & ade & tas & Exte & agi & 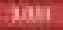 & EFE & intas & 000 & Exts: & 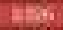 & nim \\
\hline knts & 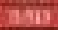 & $\mathrm{nax}$ & 300 & anil & raic & end & 60 & $\sin$ & Ant & 006 & 000 & 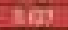 & 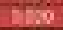 & mas \\
\hline 5610 & 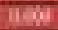 & mat & the & 69 & 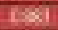 & ENW & $8 x^{2}$ & $7 w$ & $2 \times$ & $50 \times$ & 89 & 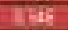 & 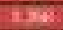 & 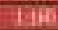 \\
\hline $\mathrm{max}$ & 101 & $\mathrm{DE}$ & $D E x$ & cail & cose & 500 & 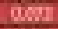 & 2017 & 801 & $0 \times 0$ & cont & \pm 2 & DIP & IIIs \\
\hline $\mathrm{min}$ & ag: & uine & Intas & ond & 600 & Dit: & nind & I09. & Dnes & $20=2$ & $\operatorname{tin}$ & anit & tas & Now \\
\hline $10 \mathrm{st}$ & 764 & nes & 7 arr & $\cos$ & $(0 \times 2)$ & $\tan$ & $a{ }^{2}=$ & 100 & 285 & $0 \mathrm{nz}$ & 0000 & sall & Ian & this \\
\hline $\mathrm{xed}$ & 70 & 20 & Ditas & 00 & con & ED: & 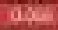 & 179 & 79 & 000 & ani & 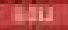 & 210 & 20 \\
\hline $\mathrm{Ten}$ & $8 \pi$ & $\mathrm{Dg}$ & abe & aen & conit & Ecsi & aney & Ialle & sese & orae & $\mathrm{moz}$ & 592 & $\mathrm{sing}$ & 0 obe \\
\hline${ }^{4}+8$ & $7 a y$ & $\cos$ & 2001 & and & $\mathrm{cy}$ & $\mathrm{cm}$ & $0 \mathrm{se}$ & Tets & tin & 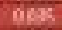 & $a x^{2}$ & 182 & 180 & 009 \\
\hline Whit & Hate & $\cos$ & 60 & $80 \%$ & 620 & reat & 000 & 1021 & $=0$ & $0 \times 80$ & wast & $\cosh$ & 1801 & cow \\
\hline marr & $d x$ & $\tan$ & oide & 60 & ENe & $E 69$ & 202 & Tase & 381 & and & 608 & $=0$ & DESI & 70 \\
\hline $\mathrm{km}^{2}$ & Hen & Dear & nowa & 000 & tand & Band & aodr & yast & $\mathrm{cm}$ & atong & ans & 25 & 150 & 100 \\
\hline mist & 250 & $60 \%$ & Tuat & catid & Eur & Eut & Qyou & 204 & Eera. & ats & wove & =a: & 20 & 4 \\
\hline 50 & atas. & 800 & ming & ads & ton & 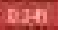 & 2008 & vars & $\operatorname{ses}$ & 00 iो & ation & 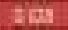 & 223 & 0 \\
\hline ISIII & 70 & $\cos$ & tion & $\mathrm{ang}$ & $\cos$ & 100 & 7DI & 200 & 28 & $08 t 0$ & 008 & 2014 & 28a & $\tan$ \\
\hline $\mathrm{mas}$ & $-3 \times 2$ & $\cos 2$ & $3 \mathrm{sen}$ & $x=$ & Cons & $t e 0$ & $\infty=$ & 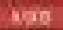 & $\mathrm{ces}$ & ont & aidi & $=28$ & 790 & Ming \\
\hline स्म & $5 \pi$ & usa & War & 7004 & 60 & Eera & ares & $\operatorname{an}$ & 250 & 00 & tom? & 210 & 11 & 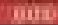 \\
\hline
\end{tabular}

Tabla 9.7. Valores de REY en partes por millón determinados en muestras de ostras y belemnites. En naranja se observan los datos del perfil Río Salado, en rosa los de Puesto Loncoche, en amarillo los de Cuesta del Chihuido (Cuenca Neuquina) y en rojo los de Río Guanaco (Cuenca Austral). 

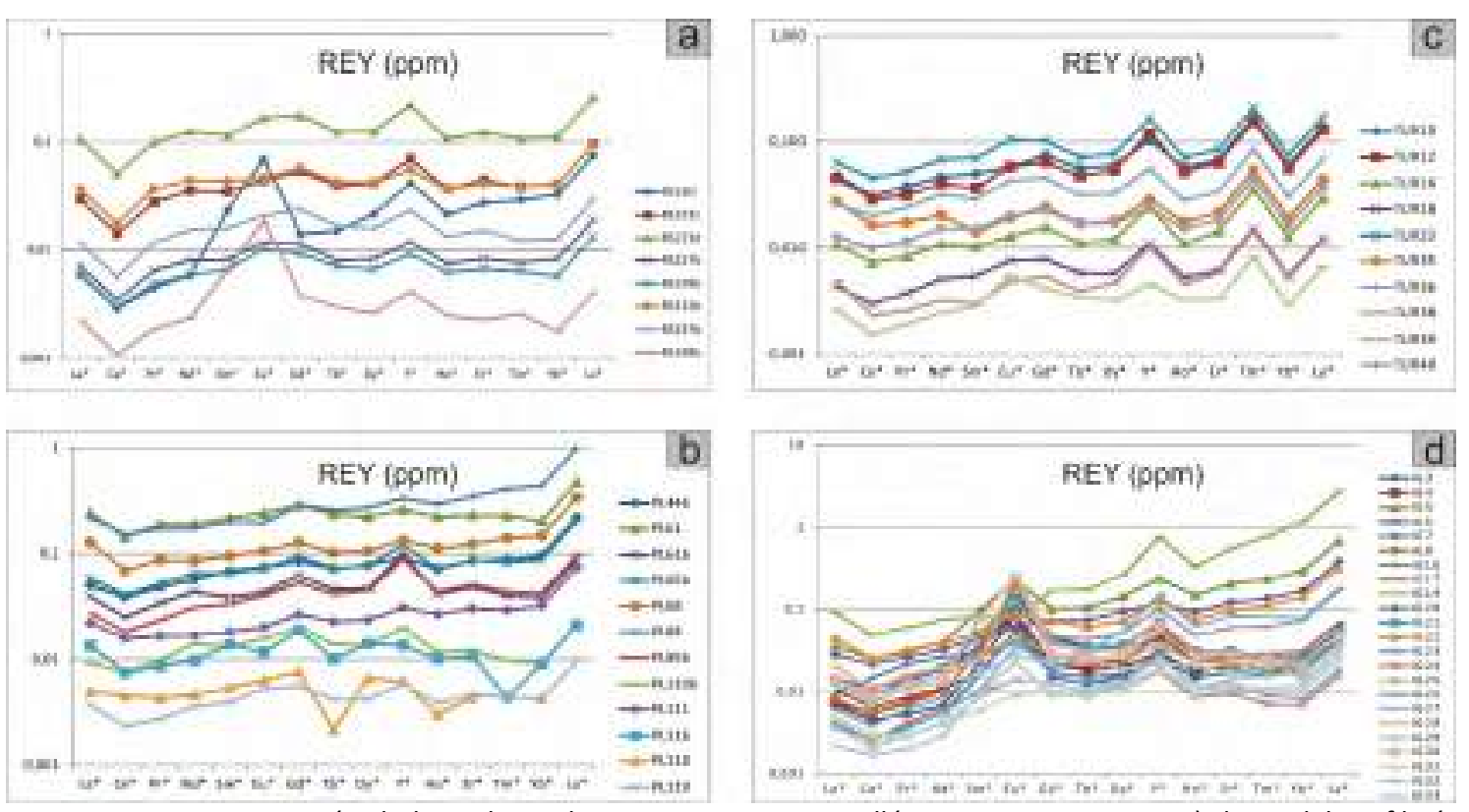

Figura 9.11. Representación de los valores de REY en partes por millón. Cuenca Neuquina: a) datos del perfil Río

Salado; b) datos del perfil Puesto Loncoche; c) datos del perfil Cuesta del Chihuido y Cuenca Austral: d) datos del perfil Río Guanaco.

\subsubsection{Alteración diagenética}

Para poder realizar interpretaciones sobre las condiciones paleoambientales es necesario garantizar que los valores estudiados sean primarios, ya que las concentraciones originales de las REY pueden sufrir modificaciones durante la diagénesis. El efecto más habitual consiste en un enriquecimiento de las MREY, generando patrones llamados de tipo "sombrero" (Holser, 1997). Para poder evaluar este efecto de modo empírico se realiza una comparación entre las MREY y las LREY y HREY a partir de la siguiente ecuación:

\section{MREY $/($ LREY+HREY $)=2 \mathrm{Gd} /(\mathrm{La}+\mathrm{Lu})$}

Si este cálculo resulta mayor a 1 se trata de un enriquecimiento diagenético, mientras que si es menor a 1 los valores serían primarios. En la tabla 9.8 se observan los resultados de las muestras de los cinco perfiles estudiados. A partir de estos datos se puede concluir que todas las muestras analizadas, exceptuando RS 237b, RS 248b, PL 110b, PL 116, PL 118, reflejan cantidades primarias en los patrones de REY normalizados. 


\subsubsection{Niveles de oxigenación}

A partir del estudio de anomalías de cerio (Ce) es posible indagar sobre antiguas condiciones redox del agua de mar (Tostevin et al., 2016). El Ce es el único elemento de las REY que puede existir tanto en el estado de oxidación +3 como en el +4 . En presencia de oxígeno, el Ce (III) se oxida parcialmente a Ce (IV), siendo adsorbido por oxihidróxidos de hierro y manganeso o partículas de materia orgánica (Holser, 1997). Este fenómeno deja el agua de mar residual empobrecida en Ce con respecto al resto de las REY, generando una "anomalía negativa" (German y Elderfield, 1990). Este fraccionamiento de Ce sólo ocurre bajo condiciones óxicas, de manera que el valor negativo indicaría condiciones oxidantes.

Las anomalías de Ce pueden ser calculadas de forma empírica sobre la base de la comparación con sus elementos vecinos, con la siguiente fórmula utilizada por Tostevin et al. (2016):

\section{$\mathrm{Ce} / \mathrm{Ce}^{*}=2 \mathrm{Ce} \mathrm{e}^{*} /\left(\mathrm{La}^{*}+\mathrm{Pr}^{*}\right)$}

Siendo $\mathrm{Ce}^{*}, \mathrm{La}^{*}$ y $\mathrm{Pr}^{*}$ los valores de los elementos normalizados con respecto a la lutita patrón PAAS. La fórmula relaciona el contenido de Ce con la suma de las cantidades de sus elementos vecinos La y Pr. Si este cálculo resulta mayor a 1, la anomalía de Ce es positiva, indicando ambientes anóxicos. Por el contrario, si los resultados son menores a 1, la anomalía de Ce en negativa, evidenciando ambientes óxicos. En la tabla 9.8 se observan los resultados de las muestras de los perfiles estudiados, donde se puede observar que todos las muestras poseen anomalías de Ce negativas que se corresponden a condiciones óxicas del ambiente en el que las especies fósiles tuvieron su ciclo de vida.

\subsubsection{Profundidad de las aguas}

Todas las muestras analizadas en las dos cuencas presentan patrones de REY típicos de ambientes oceánicos, tales como enriquecimiento en las HREY, anomalías positivas de $\mathrm{La}, \mathrm{Eu}, \mathrm{Y}$ y Gd y negativa de Ce (Nothdurft et al., 2004; Lawrence et al., 2006; Tostevin et al., 2016). Los ambientes continentales, por otro lado, se caracterizan por patrones de REY de tipo "flat", es decir con cantidades muy similares de LREY y HREY y con anomalías poco pronunciadas.

Las REY llegan a las cuencas oceánicas a través de los ríos, razón por la cual, ambientes costeros como estuarios, deltas o playas poseen mayores concentraciones de REY que los sectores marinos profundos. Nothdurft et al. (2004) comprobaron que el pasaje desde 
patrones típicos de ríos a patrones de mar se da de forma progresiva y que es posible observar un descenso paulatino en el valor de REY en una transecta desde el continente hacia el océano abierto, sumado a un enriquecimiento relativo en las HREY y la acentuación de las anomalías elementales.

Considerando que los organismos estudiados precipitaron sus conchillas externas e internas en equilibrio con el ambiente, y las muestras tomadas de sus restos fósiles no presentan evidencias de una alteración diagenética significativa, el estudio de sus patrones de REY permite representar la profundidad a la cual vivieron y se desarrollaron estos organismos.

Para poder evaluar de forma objetiva los patrones de REY, se calculó el enriquecimiento en HREY a partir de la relación La/Lu (Tabla 9.8). La anomalía de Y fue cuantificada en base a su proporción sin normalizar entre este elemento y el holmio ( $\mathrm{Y} / \mathrm{Ho})$ (Tostevin et al., 2016), mientras que el resto de las anomalías elementales de La, Eu y Gd fueron calculadas según los criterios de Frimmel (2009):

$$
\begin{gathered}
\mathrm{La} / \mathrm{La}^{*}=\mathrm{La} /(3 \mathrm{Pr}-2 \mathrm{Nd}) \\
\mathrm{Eu} / \mathrm{Eu}^{*}=\mathrm{Eu} /(0.67 \mathrm{Sm}+0.33 \mathrm{~Tb}) \\
\mathrm{Gd} / \mathrm{Gd}^{*}=\mathrm{Gd} /(2 \mathrm{~Tb}-\mathrm{Dy})
\end{gathered}
$$

Siendo La*, Eu* y Gd* los valores de los elementos normalizados con respecto a la lutita patrón PAAS. Las anomalías fueron calculadas en una escala lineal, asumiendo que las diferencias en las concentraciones entre pares vecinos es constante (Frimmel, 2009). Los valores obtenidos figuran en la tabla 8. En todos los casos los resultados mayores a 1 indican anomalías positivas y los menores a 1 anomalías negativas. 


\begin{tabular}{|c|c|c|c|c|c|c|c|}
\hline Muestra & $2 G d /(L a+L u)$ & $2 \mathrm{Ce} /(\mathrm{La}+\mathrm{Pr})$ & $\mathrm{La} / \mathrm{Lu}$ & $\mathrm{Y} / \mathrm{Ho}$ & $\mathrm{La} /(3 \mathrm{Pr}-2 \mathrm{Nd})$ & $\mathrm{Eu} /(0,67 \mathrm{Sm}+0,33 \mathrm{~Tb})$ & $G d /(2 T b-D y)$ \\
\hline AS230 & 0.35 & 0.54 & 0.06 & 53.37 & 3.12 & 334 & 160 \\
\hline $95223 \mathrm{c}$ & 0.86 & 0.49 & 0.31 & 51.94 & 2.34 & 123 & 144 \\
\hline 852236 & 0.97 & 0.50 & 0,41 & 57.00 & 227 & 143 & 1.44 \\
\hline $\mathrm{R} 5227 \mathrm{n}$ & 0.87 & 0.50 & 0.38 & 43,08 & 2.14 & 146 & 1.69 \\
\hline 152282 & 0.95 & 0.53 & 0.45 & 40.38 & 221 & 153 & 1.23 \\
\hline R52320 & 0.83 & 0.48 & D.39 & 41.26 & 1.64 & 108 & 1.33 \\
\hline $\mathrm{R} 5237 \mathrm{~b}$ & 1.17 & 0.48 & 0.39 & 48.27 & 2.70 & 128 & 1.37 \\
\hline R5248: & 1.20 & 0.52 & 0.55 & 46.93 & 233 & 350 & 1.15 \\
\hline PLAab & 0.62 & 0.78 & 0.23 & 35.56 & 167 & 000 & 176 \\
\hline PL61 & 0.80 & 0.65 & 0,52 & 31.64 & 130 & 393 & 1.13 \\
\hline PL61b & 0.99 & 0.69 & 0.45 & 67.75 & 2.55 & 595 & 1.40 \\
\hline PL65b & 0.72 & 0.74 & 0.28 & 45.14 & 221 & Q63 & 139 \\
\hline PL68 & 0.54 & 0.54 & 0.37 & 32.33 & 139 & 074 & 1.90 \\
\hline PL88 & 0.48 & 0.77 & 0.22 & 30.98 & 127 & 0.48 & 1.19 \\
\hline PL89b & 0.86 & $0, \pi$ & 0.78 & 56.27 & 309 & 553 & 1.43 \\
\hline PLIIot & 1.31 & 0.78 & 0.44 & 46.08 & 507 & 296 & 138 \\
\hline p(111 & 0.56 & 0.81 & 0.30 & 31.46 & 1.35 & 080 & 1.21 \\
\hline PL116 & 1.09 & 0.68 & 0.54 & 36.67 & 2.16 & 160 & 3.01 \\
\hline$P(118$ & 3,10 & 0.97 & 0,00 & 57.03 & 1.37 & 269 & $-3,30$ \\
\hline PL119 & 0.85 & 0.73 & 0,38 & 42.83 & 3.54 & 160 & 138 \\
\hline $\mathrm{CDC} 10$ & 0.80 & 0.71 & 0.15 & 48.44 & 235 & 111 & 1.42 \\
\hline $\mathrm{CDC} 12$ & 0.75 & 0.74 & 0.35 & 62.36 & 3.16 & 1.45 & 1.59 \\
\hline $\mathrm{CDCl} 15$ & 0.79 & 0.7 & 0.36 & 61.40 & 351 & 122 & 1.55 \\
\hline CDC18 & 0.93 & 0.73 & 0.35 & 36.14 & 4.28 & 135 & 1.32 \\
\hline $\operatorname{coc} 23$ & 0.85 & 0.78 & 0.37 & 64.23 & 333 & 147 & 1.53 \\
\hline $\mathrm{CoC} 35$ & 0.68 & 0.74 & 0.62 & 43.96 & 237 & 128 & 1.69 \\
\hline coc36 & 0.96 & 0.81 & 0.37 & 54.07 & 3.26 & 1.45 & 148 \\
\hline $\mathrm{CDC} 38$ & 0.65 & 0,61 & 0.42 & 59.87 & 392 & 145 & 170 \\
\hline CDC39 & 0.89 & 0.67 & 0.39 & 38.57 & 282 & 1.80 & 208 \\
\hline CDC40 & 0.90 & 0.81 & 0.34 & 42,38 & 3.15 & 130 & 1.34 \\
\hline RES & A.32. & 0.24 & $\mathrm{Ba}$ & 34.51 & 264 & 4.10 & 157 \\
\hline B54 & 0.38 & 0.74 & D.24 & 45,59 & A5 & 330 & 1.29 \\
\hline RES & 0.14 & 0.76 & 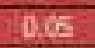 & 4379 & 349 & 223 & $1 \pm 5$ \\
\hline 855 & 054 & 0.20 & 925 & 61:02 & 545 & 412 & 134 \\
\hline 1767 & 0.37 & i. 70 & 0.68 & 4706 & 767 & 331 & 190 \\
\hline 1058 & 0.42 & 0.12 & 0.14 & 45.48 & 34.48 & $b_{1}>0$ & 1.82 \\
\hline घंघ10 & 062 & 0856 & 0.27 & 39.01 & 073 & 351 & 10 \\
\hline Rु 17 & 2218 & 0.69: & 0.25 & 34.15 & 246 & 298 & 146 \\
\hline R619 & 005 & $0: 34$ & 608 & 61.86 & 308 & 068 & 2.15 \\
\hline Rozo & 0.18 & 0.5 & 087 & 35,25 & 210 & $199^{\circ}$ & 137 \\
\hline 8621 & 0.57 & $D 3$ & 0.75 & 69.37 & $4: 2$ & 307 & 730 \\
\hline$R E 22$ & 020 & 0.65 & D.82: & 4652 & 209 & 167 & I.t. \\
\hline 9623 & 0.65 & a. 54 . & D.32. & $67 \geq 0$ & 5.00 & 272 & 1.90 \\
\hline BG2A & 063 & 0.20 & 0.27 & $56 a y$ & 2003 & 140 & 125 \\
\hline 3025 & as 59 & D.57 & n 34 & A1ET & 412 & 158 & 128 \\
\hline BG26 & 0.25 & 0.23 & 0.68 & 56,92 & 357 & 120 & 135 \\
\hline$A 627$ & 032 & 0.50 & 06 & 66,46 & 22,27 & 203 & $2-42$ \\
\hline 8028 & $0,5.2$ & 0.58 & 0.10 & 65.89 & 204 & 10.32 & 135 \\
\hline He29 & 0.45 & 0.5 & 0.49 & 24.03 & 180 & 145 & 0.71 \\
\hline 8530 & 044 & 0,34 & 0.30 & 6163 & 192 & 407 & 130 \\
\hline AGS1 & 0.20 & 0.19 & 0.18 & 52.97 & 11.82 & 1354 & 1.97 \\
\hline 8632 & 022 & 0.80 & 0.06 & 45,02 & 77.55 & 236 & 123 \\
\hline $\operatorname{Ros} 39$ & 0.44 & 0.65 & 0.15 & 61.54 & 1294 & 160 & 185 \\
\hline
\end{tabular}

Tabla 9.8. Valores de anomalías de Ce, Y, La, Gd y Eu y enriquecimientos relativos en HREY Y MREY. En naranja se observan los datos del perfil Río Salado, en rosa los de Puesto Loncoche (Cuenca Neuquina), en amarillo los de Cuesta del Chihuido y en rojo los de Río Guanaco (Cuenca Austral). 
En todas las muestras estudiadas se observa un enriquecimiento en $\mathrm{HREY}$ con respecto a las LREY. En el perfil Río Guanaco de la Cuenca Austral este enriquecimiento es aún mayor, ya que los valores de la relación La/Lu son menores a 0,20. En la Cuenca Neuquina en tanto, los valores de La/Lu se encuentran entre 0,20 y 0,60, marcando un enriquecimiento en HREY aunque de menor escala que el de la Cuenca Austral.

Los valores de $\mathrm{Y} / \mathrm{Ho}$ oscilan entre 30 y 70 en todos los perfiles estudiados. Aunque los resultados obtenidos son similares, es posible observar mayor cantidad de valores superiores a 60 en el perfil Río Guanaco.

En el caso del La* y el Eu* existen anomalías positivas en todos las secciones estudiadas. En el caso de la Cuenca Neuquina los resultados oscilan entre 1 y 3 para La* y entre 1 y 2 para Eu*. Para la Cuenca Austral, estas anomalías son más evidentes, con valores que llegan hasta 20 en La* y 10 en Eu*. La anomalía de Gd, por último, presenta valores entre 1 y 2 en los cuatro perfiles estudiados.

Sobre la base de los resultados obtenidos es posible concluir que el perfil Río Guanaco de la Cuenca Austral posee un enriquecimiento superior en HREY y mayores valores de $\mathrm{Y} / \mathrm{Ho} \mathrm{y}$ de las anomalías en La, Eu y Gd representativas de las aguas oceánicas que los perfiles de la Cuenca Neuquina. Estas tendencias corroboran que los organismos de la Cuenca Austral vivieron y precipitaron sus conchillas en ambientes más profundos que los de la Cuenca Neuquina. 


\section{Capítulo X- Quimioestratigrafía}

\subsection{Introducción}

La quimioestratigrafía, o estratigrafía química, es una rama de la estratigrafía en la que se hace uso de atributos químicos para caracterizar y analizar una secuencia sedimentaria (Garbán, 2016). Según la International Commission on Stratigraphy (ICS), se puede definir como "el estudio de la variabilidad geoquímica (temporal y espacial) de rocas estratificadas con el fin de establecer unidades mapeables, definidas en términos de una composición geoquímica única, relaciones isotópicas, relaciones elementales (o de óxidos elementales) o la combinación de todas ellas". Esta disciplina tiene múltiples aplicaciones; es utilizada para correlaciones estratigráficas, análisis paleoclimáticos, identificación de áreas fuente e historias postdepositacionales. Puede asimismo ser una herramienta para acompañar a la interpretación de procesos sedimentarios y condiciones del ambiente de depositación (Hoefs, 1997). Es considerada muy útil para el estudio de secuencias sedimentarias que poseen un pobre control bioestratigráfico, litoestratigráfico o cronoestratigráfico, así como importantes complicaciones estructurales debido a la sensibilidad de los atributos químicos (Andersson et al., 2004).

Los estudios quimioestratigráficos pueden subdividirse según el tipo de análisis que se utilicen en: 1) aquellos que utilizan abundancias relativas de elementos (mayoritarios o trazas) y relaciones entre elementos, y 2) variaciones de isótopos estables. En este capítulo se hará especial énfasis en el análisis isotópico, de uso común en rocas carbonáticas, fósiles y materia orgánica.

A partir de los resultados de isótopos estables de carbono y oxígeno obtenidos en fósiles de ostras y belemnites (ver capítulo 9) y de isótopos de carbono analizados en muestras de materia orgánica se confeccionaron curvas quimioestratigráficas con las que se realizaron interpretaciones paleoclimáticas, se identificaron anomalías y se correlacionaron cronoestratigráficamente las dos cuencas sedimentarias estudiadas. 


\subsection{Curvas quimioestratigráficas de isótopos estables de carbono y oxígeno}

\subsubsection{Cuenca Neuquina}

Los valores de $\delta^{13} \mathrm{C}$ y $\delta^{18} \mathrm{O}$ fueron representados en curvas paralelamente a los perfiles sedimentarios para comparar los segmentos de igual edad en las tres secciones estudiadas (fig. 10.1). A partir de esto se observa que las curvas isotópicas correspondientes al sector de Río Salado sólo presentan mediciones en la sección del perfil correspondiente a la Formación Chachao por razones de presencia y preservación fosilífera. Por otro lado, en el perfil Puesto Loncoche no se registran mediciones en el sector basal de la Formación Vaca Muerta por ausencia de fósiles del género Aetostreon.

Los valores del $\delta^{13} \mathrm{C}$ para el intervalo Tithoniano temprano (biozona ándica de amonites de Virgatosphinctes mendozanus) hasta Valanginiano temprano (biozona ándica de amonites de Neocomites wichmanni) corresponden a la Formación Vaca Muerta, y van desde negativos a $\sim 0 \%$ VPDB, con un solo valor que alcanza un valor positivo de $1 \%$. Hacia la zona correspondiente al Valanginiano inferior y principio del Valanginiano tardío (biozona ándica de amonites de Olcostephanus atherstoni) (Formación Chachao) se registra una excursión positiva con valores que oscilan entre 0,9 y 2,6\% VPDB para la sección de Río Salado, 1,2 y 2,7\%॰VPDB para la de Puesto Loncoche y entre 0,9 y 2,1\%oVPDB para el perfil Cuesta del Chihuido. Hacia el sector cuspidal de los perfiles se observa un marcado descenso en la proporción de $\delta^{13} \mathrm{C}$, retomando a los valores característicos del sector inferior.

Las curvas representadas por los valores de $\delta^{18} \mathrm{O}$, por otro lado, se encuentran entre 0 y $-5 \%$ ॥PDB para el tramo del perfil correspondiente a la Formación Vaca Muerta, donde además se observan tendencias verticales que copian el comportamiento de las curvas de $\delta^{13} \mathrm{C}$. En el sector cuspidal, que corresponde a la Formación Chachao, el comportamiento de la curva es diferente para los tres perfiles. En las secciones Río Salado y Puesto Loncoche los valores oscilan entre 0 y $-5 \%$ VPDB, mientras que en Cuesta del Chihuido pueden alcanzar hasta $10 \%$ VPDB. En todos los casos, el comportamiento de la curva no coincide con el mostrado por el $\delta^{13} \mathrm{C}$, ya que no se observan tendencias positivas hacia el sector de la biozona de Olcostephanus atherstoni. 

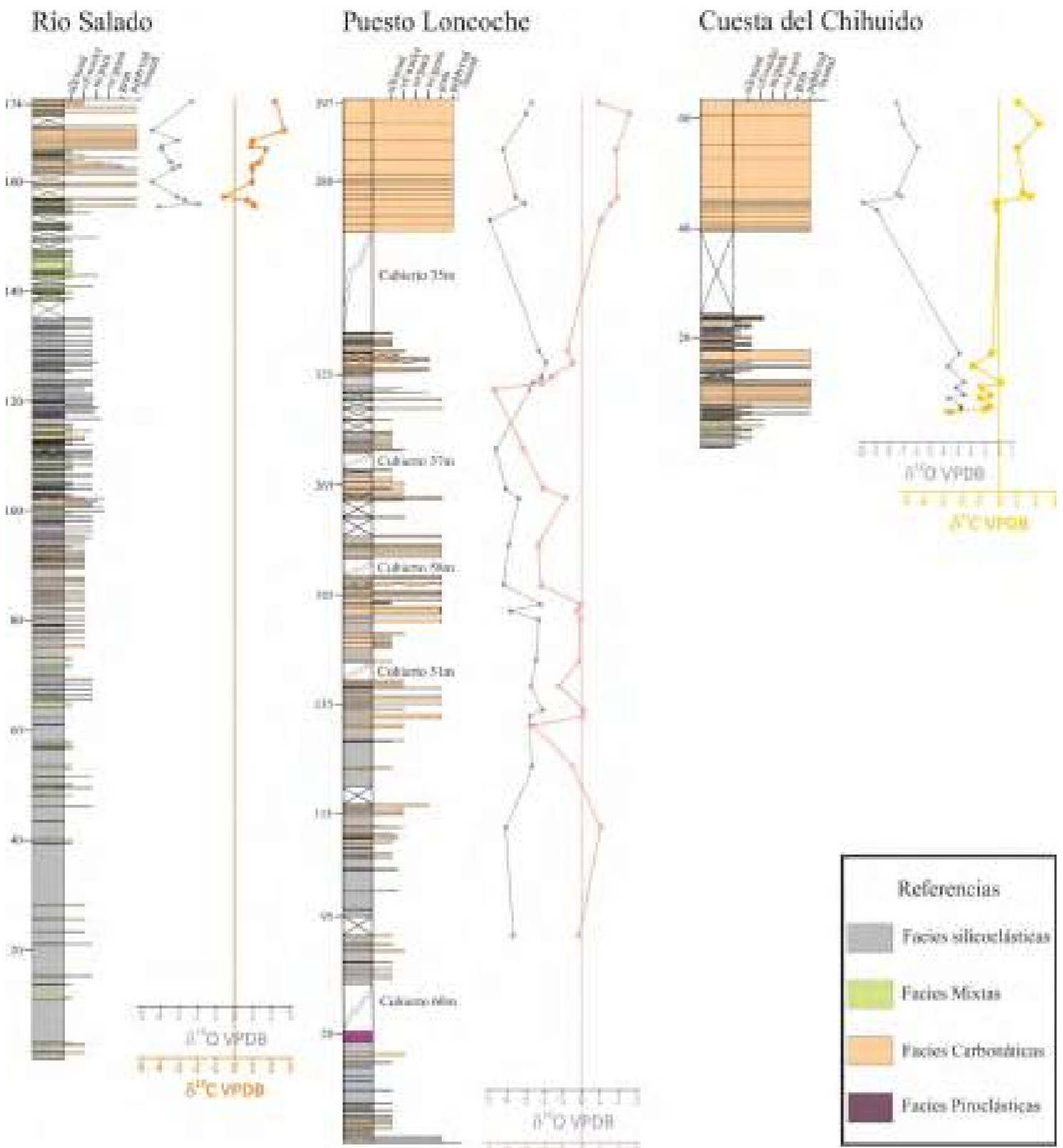

Figura 10.1. Curvas quimioestratigráficas de $\delta^{13} \mathrm{C}$ y $\delta^{18} \mathrm{O}$ para los tres perfiles de la Cuenca Neuquina.

\subsubsection{Cuenca Austral}

En los sectores de estudio en la Cuenca Austral también se representaron los valores de $\delta^{13} \mathrm{C}$ y $\delta^{18} \mathrm{O}$ en curvas paralelamente a los perfiles sedimentarios (fig. 10.2). En el perfil Cerro Hobler no se registraron ejemplares de Belemnopsis sp. con buen estado de preservación, en la sección de la Subida del Chancho sólo tres belemnites pudieron ser utilizados para realizar análisis isotópicos, mientras que en la sección Río Guanaco se pudo generar una curva continua que refleja las variaciones observables en las formaciones Springhill y Río Mayer. Ya 
que la presencia de múltiples valores en sentido vertical resulta esencial para poder trabajar con quimioestratigrafía, sólo se tendrán en cuenta los datos del perfil Río Guanaco.

Los valores de $\delta^{13} \mathrm{C}$ oscilan entre $-0,3$ y $-2 \%$ VPDB, con una tendencia a valores de $0,5 \%$ VPDB hacia el tope de la sección (Valanginiano inferior y principio del Valanginiano tardío).

Los valores de $\delta^{18} \mathrm{O}$, por otro lado, oscilan entre 0 y $-10 \%$ VPDB, siendo más amplio el rango de los mismos en el sector inferior que en el superior. Las tendencias generales observadas en las curvas de $\delta^{18} \mathrm{O}$ acompañan el comportamiento de las de $\delta^{13} \mathrm{C}$. 


\section{Cerro Hobler}
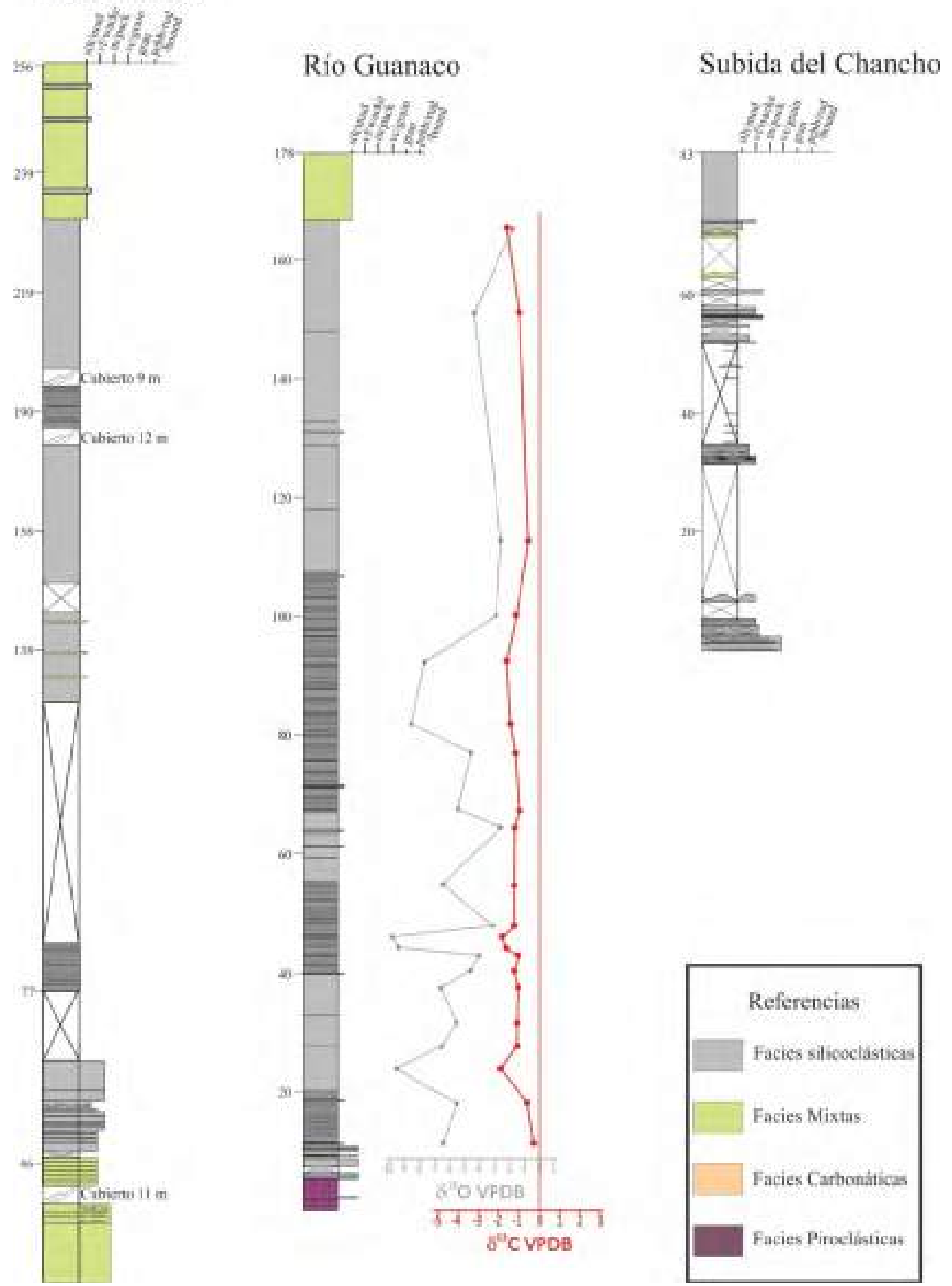

Figura 10.2. Perfiles de la Cuenca Austral ajustados temporalmente y curvas quimioestratigráficas de $\delta^{13} \mathrm{C}$ y $\delta^{18} \mathrm{O}$ para el perfil Río Guanaco. 


\subsection{Correlación de cuencas mediante curvas de $\delta^{13} \mathrm{C}$}

Gracias a su mayor potencial de preservación isotópica (PPI) (Ver capítulo 9), los isótopos de carbono, constituyen los parámetros más confiables a la hora de establecer correlaciones entre las cuencas estudiadas.

Por su continuidad vertical y cantidad de valores analizados, los perfiles sedimentarios Puesto Loncoche (Cuenca Neuquina) y Río Guanaco (Cuenca Austral) fueron los escogidos para comparar los segmentos de igual edad en ambas cuencas (fig. 10.1 y 10.2). A partir de esto se observa que la curva de $\delta^{13} \mathrm{C}$ correspondiente a la Cuenca Neuquina posee forma aserrada, con una fuerte oscilación en las cifras, desde $-4,9$ a 2,6\% VPDB. Por otro lado, la curva de $\delta^{13} \mathrm{C}$ de la Cuenca Austral posee una forma similar pero con oscilaciones menos pronunciadas debido a que el rango de valores es más estrecho (desde $-1,7$ a - $-0,6 \%$ VPDB).

Como se mencionó en la sección 5.5.3, existen dos superficies, desde el punto de vista de la estratigrafía secuencial, que pueden ser reconocidas y acotadas temporalmente en las dos cuencas: la superficie de máxima inundación que da comienzo al HST durante el cual se depositan las formaciones Vaca Muerta y Springhill (Tithoniano temprano) y la superficie transgresiva que marca el inicio de la depositación de la Formación Agrio en la Plataforma Mendocina, los depósitos de la Formación Río Mayer medio entre los lagos Argentino y Viedma, y del tramo inferior de la Formación Río Mayer en el Lago San Martín (finales del Valanginano tardío). Los datos quimioestratigráficos de ambos perfiles, estarían comprendidos en el intervalo temporal representado entre estas superficies. En la figura 10.3 a, se observan las curvas de $\delta^{13} \mathrm{C}$ de los dos perfiles (Río Guanaco y Puesto Loncoche) con sus límites temporales y estratigráfico secuenciales. Al analizar el desarrollo vertical de las curvas se observan similitudes en cuanto a las tendencias de los valores isotópicos. Las flechas azules indican incrementos en la relación $\delta^{13} \mathrm{C}$ VPDB, mientras que las flechas verdes indican decrecimientos de la misma, de esta manera, siempre que se detecta una reducción o un incremento en la relación isotópica en el área de Puesto Loncoche se aprecia también un fenómeno semejante en el área del Río Guanaco, pero de menor intensidad. Nótese que en la figura $10.3 \mathrm{~b}$ se ha exagerado cuatro veces la escala horizontal de los valores de $\delta^{13} \mathrm{C}$ VPDB para el perfil Río Guanaco, de manera de observar las coincidencias en la variación de las tendencias con mayor facilidad. 


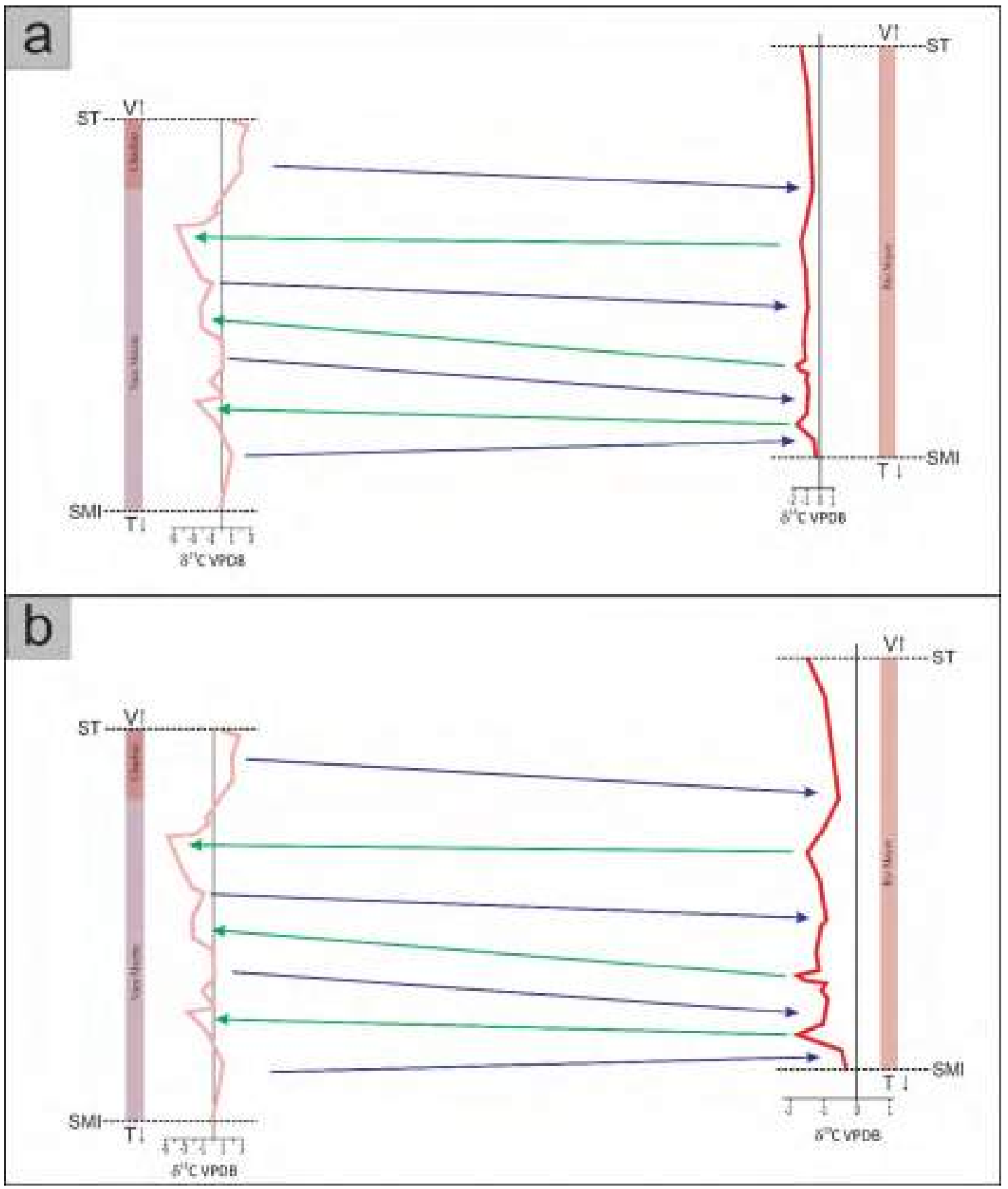

Figura 10.3. a) Similitudes en las tendencias de las curvas de $\delta^{13} \mathrm{C}$ de Puesto Loncoche (rosa) y Río Guanaco (rojo), las flechas azules indican incrementos en la relación $\delta^{13} \mathrm{C}$ VPDB, mientras que las flechas verdes indican decrecimientos de la misma. b) Similitudes en las tendencias de las curvas de $\delta^{13} \mathrm{C}$ de Puesto Loncoche (rosa) y Río Guanaco (rojo), con una exageración de cuatro veces en la escala horizontal de la segunda. T: Tithoniano temprano, V: Valanginiano superior, SMI: superficie de máxima inundación y ST: superficie transgresiva.

Cabe considerar que las diferencias en los valores absolutos de $\delta^{13} \mathrm{C}$ podrían estar controladas por las condiciones de profundidad de las aguas marinas. Así entonces, las curvas quimioestratigráficas de $\delta^{13} \mathrm{C}$ de la Cuenca Austral poseen menor variabilidad en sus datos debido a que provienen de sectores de aguas más profundas. Jarvis (1980) postula que los 
belemnites vivían en profundidades de entre 120 y 330 m, mientras que las ostras lo hacen desde la zona intermareal hasta los 30 m como máximo (Hernández-Ocaña et al., 2015). Esta diferencia en la profundidad del hábitat de las especies es respaldada por la diferencia en los patrones de REY expuestos anteriormente (ver sección 9.6.4).

La mayor parte de la productividad primaria ocurre en la superficie del océano. El carbono allí generado es exportado desde la superficie hacia el océano profundo mediante un mecanismo conocido como "bomba biológica de carbono" (Hilting et al., 2008). El océano profundo se convierte en un depósito para la producción primaria exportada, o flujo de carbono orgánico, que en su mayoría se remineraliza, enriqueciendo las profundidades del océano en ${ }^{12} \mathrm{C}$.

Los valores de la Cuenca Austral registrados en los belemnites serían siempre negativos producto de la precipitación de carbonato en condiciones profundas, lo cual generaría una curva de $\delta^{13} \mathrm{C}$ con tenores negativos y cambios sutiles. En la Cuenca Neuquina, en tanto, los valores obtenidos de las ostras provienen de sectores más someros donde la mayor productividad primaria condiciona los datos isotópicos, generando curvas de $\delta^{13} \mathrm{C}$ con mayor amplitud en sus valores absolutos.

\subsection{Anomalía Weissert}

\subsubsection{Antecedentes}

Se conoce como anomalía Weissert a una excursión positiva de $\delta^{13} \mathrm{C}$ registrada en el Valanginiano medio. Fue reconocida por primera vez por Cotillon y Rio (1984) en el golfo de México (DSDP Site 535) y fue posteriormente descripta por numerosos autores en distintas cuencas en todo el hemisferio norte (cf. Lini et al., 1992; Melinte y Mutterlose, 2001; Bartoini, 2003) y posteriormente también en la Cuenca Neuquina (Aguirre-Urreta et al., 2008; Gómez Peral et al., 2012) en el hemisferio sur. Fue ubicada temporalmente por Lini et al. (1992) sobre la base de nanofósiles calcáreos. La excursión comienza hacia el final de la Busnardoites compylotaxus Zone y termina en la Saynoceras Verricosum Zone (Weissert et al., 1998; Hennig et al., 1999; Van de Schootbrugge et al., 2000; Föllmi, 2012).

El origen y características de esta anomalía han sido motivo de grandes controversias. Lini et al. (1992) y Erba et al. (2004) la vinculan con un aumento en el $\mathrm{CO}_{2}$ de la atmósfera producto de emisiones volcánicas de los basaltos de Paraná-Etendeka, lo cual habría generado un calentamiento a nivel global. Esta teoría se ve soportada por estudios mineralógicos de Duchamp-Alphonse et al. (2011) quienes definen en los depósitos sedimentarios un aumento 
en el contenido de caolinita al que relacionan con un clima cálido y húmedo. Contrariamente, Van de Schootbrugge et al. (2000), Pucéat et al. (2003) y Price y Muterlosse, (2004) proponen un clima frío para dicha anomalía basándose en paleotemperaturas calculadas a partir de $\delta^{18} \mathrm{O}$ en belemnites y peces. Se toman como sustento a esta alternativa la presencia de nódulos de glendonita (Kemper, 1987; Tarduno et al., 2002) y de dropstones, así como la naturaleza de nanofósiles calcáreos (Melinte y Muterlosse, 2001).

Erba et al. (2004) vinculan la excursión positiva de $\delta^{13} \mathrm{C}$ con la presencia de lutitas negras ricas en carbono orgánico en el sur de los Alpes y en el océano Pacífico, reinterpretando la anomalía valanginana como un ocean anoxic event (OAE), al que llama Evento Weissert. Westermann et al. (2010) postulan que las condiciones anóxicas estarían circunscriptas solo a unas pocas regiones. Finalmente, Föllmi (2012) interpreta la anomalía del Valanginiano medio como un cambio de condiciones que llevaron el clima, en un contexto cálido, de árido a húmedo por un corto periodo de tiempo, catalogando al evento Weissert como un episode of environmental change (EEC).

\subsubsection{Anomalía Weissert en la Cuenca Neuquina}

Aguirre-Urreta et al. (2008) localizaron la anomalía positiva de carbono con análisis efectuados sobre ostras ubicadas en la localidad de Cerro La Parva (2-3\%॰VPDB), caracterizados por las subzonas de amonites de Olcostephanus (O.) atherstoniKarakaschiceras attenuatum (biozona de amonites de Olcostephanus atherstoni). Posteriormente, Gómez Peral et al. (2012) registraron en estudios efectuados en ostras y micrita una curva con valores de $\delta^{13} \mathrm{C}$ que en promedio son de 1,6\% VPDB con una anomalía positiva en $2,9 \%$ VPDB, los cuales corresponde a los depósitos caracterizados por la subzona de Karakaschiceras attenuatum de la región de Buta Ranquil (Schwarz et al., 2011a).

Los valores isotópicos positivos registrados en la Formación Chachao en los tres perfiles estudiados (ver sección 10.2.1 y fig. 10.4) constituyen una anomalía en los valores de $\delta^{13} \mathrm{C}$ que puede ser asignada al evento Weissert, ya que coinciden con los registrados en la bibliografía (Weissert et al., 1998; Hennig et al., 1999; Van de Schootbrugge et al., 2000; Föllmi, 2012). Además, los depósitos de la Formación Chachao en la Plataforma Mendocina han sido asignados a la biozona ándica de amonites de Olcostephanus atherstoni por Legarreta y Kozlowski (1981) y Aguirre-Urreta et. al. (2011), razón por la cual dichos valores positivos se encuentran acotados temporalmente al final del Valanginiano inferior $y$ principio del Valanginiano tardío, coincidiendo cronológicamente con el desarrollo de la anomalía (Gómez Dacal 2014b, 2016). 


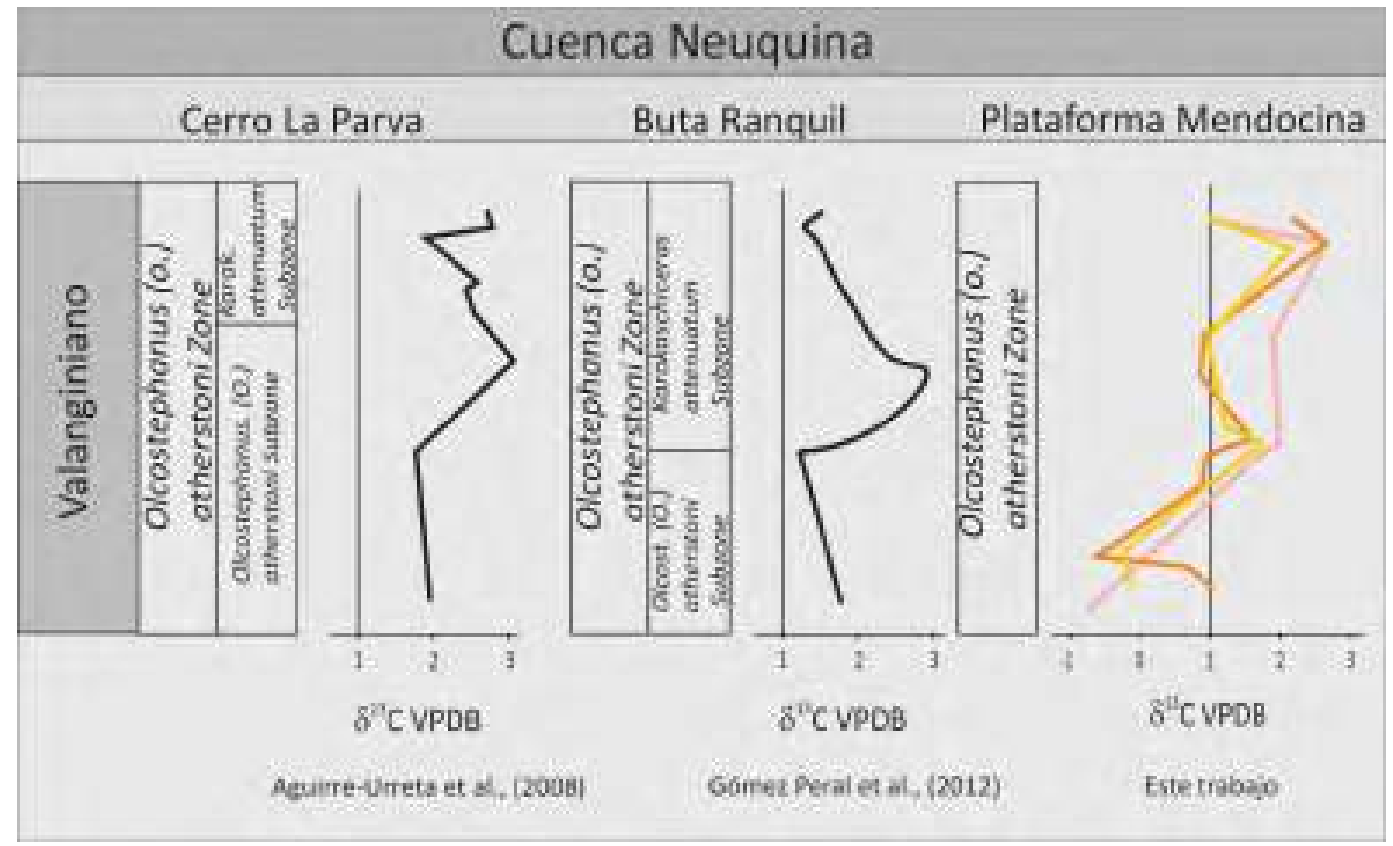

Figura 10.4. Correlación entre curvas de $\delta^{13} \mathrm{C}$ y biozonas en la Cuenca Neuquina: Cerro La Parva (Aguirre-Urreta et al., 2008), Buta Ranquil (Gómez Peral et al., 2012) y la Plataforma Mendocina en Río Salado (naranja), Puesto Loncoche (rosa) y Cuesta del Chihuido (amarillo).

\subsection{3 ¿Anomalía "fantasma" Weissert en la Cuenca Austral?}

En la Cuenca Austral la anomalía "positiva", sería identificada hacia el tope del perfil Río Guanaco y se presentaría con un valor máximo de apenas -0,6\%॰VPDB. El evento sería reconocible gracias a la correlación entre las curvas de $\delta^{13} \mathrm{C}$ de ambas cuencas (fig. 10.5). Este sector del perfil ha sido acotado temporalmente al final del Valanginiano temprano y comienzo del Valanginiano tardío sobre la base de estudios de Kraemer y Riccardi (1997) quienes identificaron la asociación faunística de Berriasella cf. behrendseni, Jabronella cf. michaelis, Subthurmannia sp. y Phyllopachyceras aureliae.

Se define como anomalías "fantasma" a sutiles variaciones en los tenores de $\delta^{13} \mathrm{C}$ que son definidas por la correlación entre curvas antes que por la ponderación de sus valores absolutos. El origen de estas anomalías es el mismo que el de sus correlativas pero evidencian un cambio en alguna de las condiciones iniciales, como la profundidad de las aguas. De esta forma, sería posible definir a la anomalía Weissert en la Cuenca Austral como una anomalía fantasma de $\delta^{13} \mathrm{C}$. 


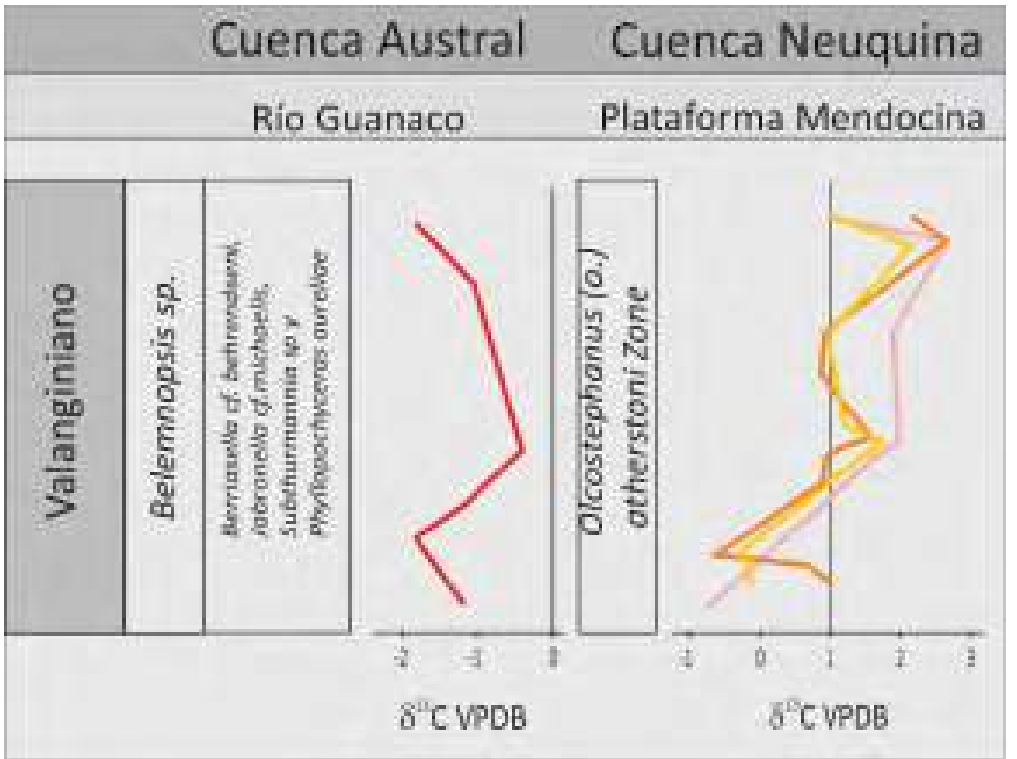

Figura 10.5. Correlación entre curvas de $\delta^{13} \mathrm{C}$ y biozonas de las Cuencas Austral y Neuquina: Río Guanaco (rojo), Río Salado (naranja), Puesto Loncoche (rosa) y Cuesta del Chihuido (amarillo).

\subsection{Correlación de secciones mediante curvas de isótopos de C en materia orgánica}

Mediante el empleo de la metodología descripta en la sección 2.5.7, se obtuvieron datos isotópicos de carbono en materia orgánica. En los perfiles de la Cuenca Austral y en la Cuesta del Chihuido, los valores obtenidos se encuentran fuera del margen de los valores primarios, razón por la cual no fueron tenidos en cuenta para posteriores interpretaciones. En las secciones sedimentarias del Río Salado y Puesto Loncoche (tabla 10.1) de la Cuenca Neuquina, por otro lado, los resultados fueron representados paralelamente a los perfiles y las curvas de isótopos estables obtenidas del material fosilífero (fig. 10.6).

En el perfil Río Salado, los isótopos del carbono registrados en la materia orgánica oscilan entre $-31 \%$ y $-26 \%$ VPDB, con valores anómalos de hasta $-21 \%$ VPDB, y permitieron cubrir los sectores del perfil donde no se contaba con datos isotópicos por falta de material fosilífero. En el perfil Puesto Loncoche, por otro lado, los valores del isótopo de carbono en materia orgánica se encuentran entre $-32 \%$ y $-28 \%$ VPDB con cifras excepcionales de hasta 24\% VPDB, guardando una buena correlación con los resultados obtenidos con el material fosilífero, sobre todo hacia el sector de la curva correspondiente al Tithoniano.

La anomalía Weissert no pudo ser identificada mediante esta técnica, ya que debido a la preponderancia de los carbonatos, sólo se pudo tomar una muestra de pelita negra en dicho intervalo temporal. 


\begin{tabular}{|l|l|l|l|}
\hline Muestra & $\delta^{13} \mathbf{C}_{\text {VPD }}$ & Muestra & $\delta^{13} \mathbf{C}_{\text {VDD }}$ \\
\hline RS 237 & $-37,178$ & PL 105 & $-26,901$ \\
\hline RS 217 & $-28,544$ & PL 97 & $-25,004$ \\
\hline RS 207 & $-39,028$ & PL 85 & $-25,607$ \\
\hline RS 246 & $-27,139$ & PL 84 & $-29,58$ \\
\hline RS 190 & $-27,139$ & PL 66 & $-28,381$ \\
\hline RS 163 & $-33,68$ & PL 58A & $-29,407$ \\
\hline RS 149 & $-29,871$ & PL 56 & $-29,927$ \\
\hline RS 131 & $-29,302$ & PL 49 & $-28,76$ \\
\hline RS 113 & $-21,565$ & PL 43 & $-27,838$ \\
\hline RS 101 & $-31,126$ & PL 34 & $-28,321$ \\
\hline RS 89 & $-31,126$ & PL 32 & $-24,118$ \\
\hline RS 79 & $-39,609$ & PL 30 & $-32,811$ \\
\hline RS 70 & $-35,004$ & PL 24 & $-26,608$ \\
\hline RS 60 & $-39,308$ & PL 21 & $-25,796$ \\
\hline RS 51 & $-29,191$ & PL 18 & $-25,469$ \\
\hline RS 407 & $-23,196$ & PL 15 & $-25,534$ \\
\hline RS 36 & $-29,209$ & PL 97 & $-26,233$ \\
\hline RS 30 & $-25,11$ & PL 6 & $-26,551$ \\
\hline RS 21A & $-22,438$ & & \\
\hline RS 16 & $-25,647$ & & \\
\hline RS 7 & $-26,296$ & & \\
\hline \hline & & \\
\hline & &
\end{tabular}

Tabla 10.1. Valores de isótopos de carbono en materia orgánica en los perfiles Río Salado y Puesto Loncoche 


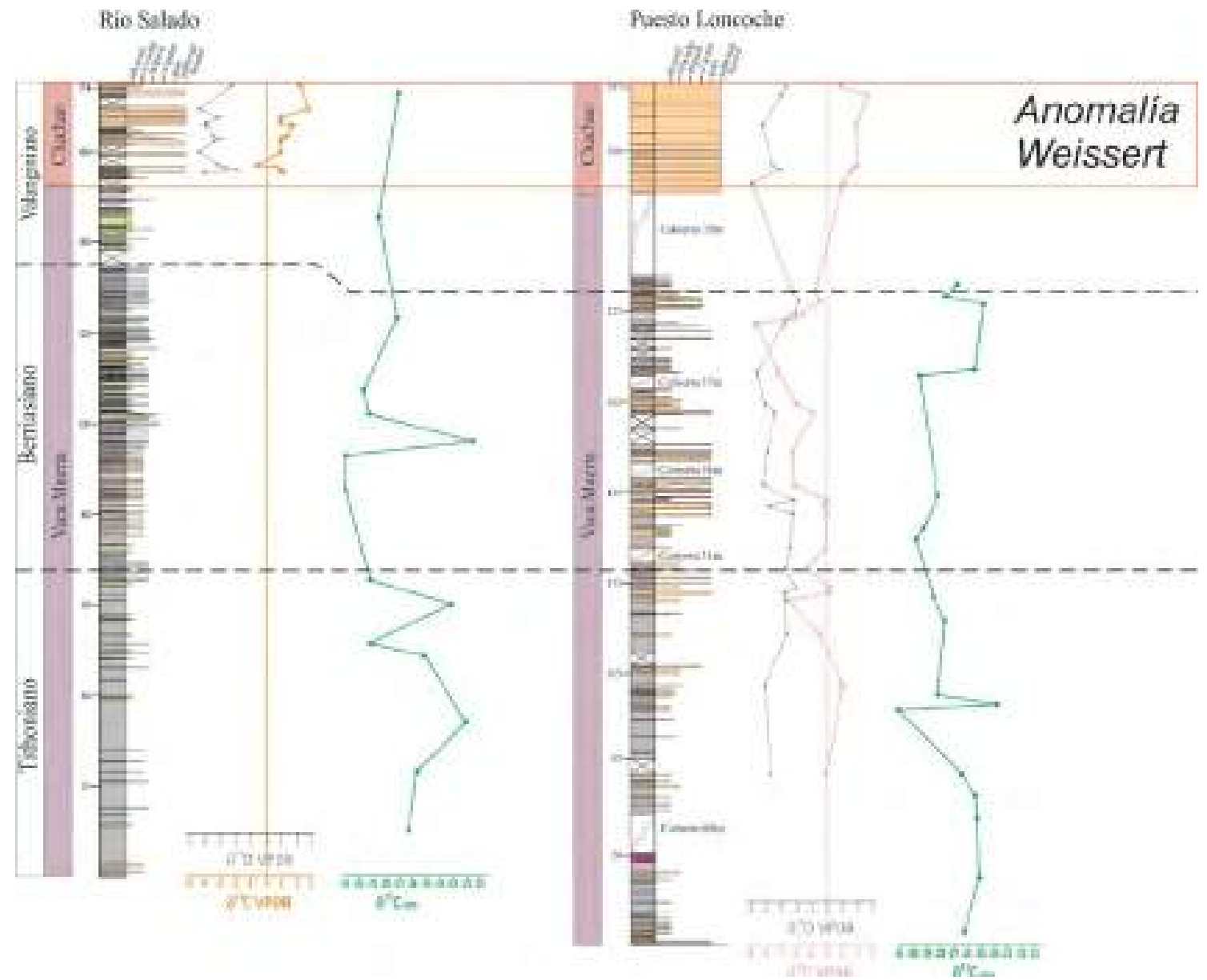

Figura 10.6. Curvas de isótopos de C en materia orgánica para los perfiles Río Salado y Puesto Loncoche.

10.6 Correlaciones quimioestratigráficas con secciones contemporáneas en otras cuencas del mundo

Los valores isotópicos anómalos reconocidos correspondientes al Valanginiano y la abundante bibliografía existente sobre esta temática hacen que el mapeo de la anomalía Weissert constituya la herramienta más atinada para la correlación de las secciones estudiadas con distintas cuencas sedimentarias alrededor del mundo. En la figura 10.7 y la tabla 10.2 se compendian los principales registros de esta anomalía, junto con los valores máximos alcanzados y el material utilizado para los análisis.

Aunque este evento fue citado por vez primera en el Golfo de México (Cotillón y Río, 1984), su estudio ha sido más detallado en el continente europeo (Linni et al., 1992; Hennig et al., 1999; Duchamp-Alphonse et al., 2011; Charbonnier et al., 2013; entre otros), que hacia el Valanginiano medio constituía el sector norte del Océano Tethys (fig. 10.7). En esta zona se presentan excelentes exposiciones con abundante material fósil y una detallada biozonación 
de amonites, razón por la cual, los sucesivos trabajos en distintas cuencas cretácicas del mundo establecieron correlaciones con estas secuencias europeas.

Para la Cuenca Neuquina, Aguirre-Urreta y Rawson (1997) y Aguirre-Urreta et al. (2005), vincularon temporalmente las subzonas de Olcostephanus (0.) atherstoniKarakaschiceras attenuatum (zona de Olcostephanus atherstoni) antes citadas, con las biozonas de Busnardoites campylotoxus y Saynoceras verrucosum de la zona del Thetys donde la anomalía fue registrada por Linni et al., 1992 y Hennig et al., 1998. En la región de la Plataforma Mendocina, donde la anomalía es reconocida en este trabajo, se identificó la zona de Olcostephanus atherstoni en la Formación Chachao (Legarreta y Kozlowski, 1981; Palma y Lanés, 2001; Aguirre-Urreta et. al., 2011), pudiendo de esta manera vincular temporalmente las secciones estudiadas con los afloramientos europeos. Las correlaciones entre cuencas realizadas con isótopos de carbono (sección 10.3), la identificación de la anomalía "fantasma" (sección 10.4.3) y el acotamiento temporal realizado sobre la base del contenido fósil de las formaciones Springhill y Río Mayer (secciones 3.2.3.4 y 3.2.4.4) permitieron extender esta correlación también a los afloramientos de la Cuenca Austral.

Los sectores correspondientes a las secciones de edad Tithoniana y Berriasiana son más difícilmente correlacionables, ya que los valores están dentro de los tenores medios para el carbono. De esta forma, las correlaciones isotópicas dependen en gran medida de la cantidad de datos empleados en los estudios y la definición que otorgue el material utilizado para realizar los análisis. 


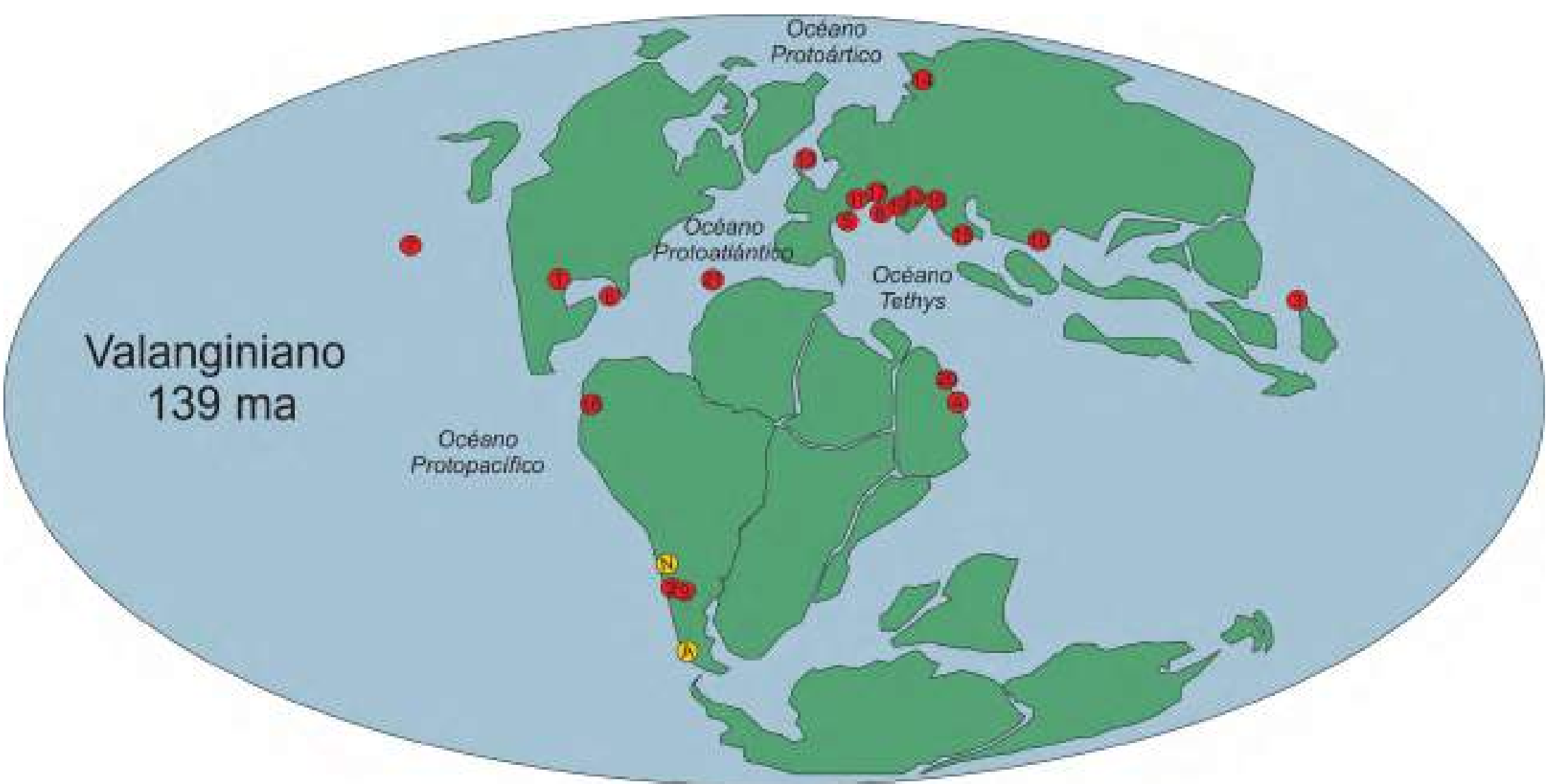

Figura 10.7. Principales registros de la anomalía Weissert para el Valanginiano. 1) Adatte et al., 2001; 2) Aguirre-Urreta et al., 2008; 3) Bartolini, 2003; 4) Celestino et al., 2017; 5) Charbonnier et al., 2013; 6) Cotillon y Rio, 1984; 7) Douglas y Savin, 1973; 8) Duchamp- Alphones et al., 2011; 9) Gómez Peral et al., 2012; 10) Gröcke et al., 2005; 11) Hennig et al., 1999; 12) Linni et al., 1992; 13) Meissner et al., 2015; 14) Price y Mutterlose., 2004; 15) Pucéat et al., 2003; 16) Silva-Tamayo et al., 2016; 17) Van de Schootbrugge et al., 2000; 18) Weissert, 1998; 19) Westermann et al., 2010; 20) Wohlwend et al., 2017; 21) Wortmann y Weisert, 2000; N) registros de las secciones estudiadas en la Cuenca Neuquina; A) registro de la sección Río Guanaco en la Cuenca Austral. 


\begin{tabular}{|c|c|c|c|c|}
\hline Númerd & Trabajo & Valor de anomalia (VPDB) & Material & Lugar \\
\hline 1 & Adatte et al., 2001 & Entre $2 \times 3$ & Roca total & Sierra Madre oriental (Mexico) \\
\hline 2 & Aguirre-Urreta et al, 2008 & Entre $2 y 4$ & Ostras & Cuenca Neuquina (Argentina) \\
\hline 3 & Bartolini, 2003 & Entre $3 y_{4}$ & Roca total & Nadezhda Basin (Japón) \\
\hline 4 & Celestino et al., 2017 & Entre 2 y 3 & Roca total & Central Oman Mountains (Omán) \\
\hline 5 & Charbonnier et al., 2013 & Entre 1y 2 & Roca total & Vocontian Basin (Francia) \\
\hline 6 & Cotillon y Rio, 1984 & Entre $2 y^{3}$ & Roca total & Site 535 (Océano Atlántico) \\
\hline 7 & Douglas y Savin, 1973 & Entre 2 y 3 & Foraminiferos & Site 167 (Océano Pacifico) \\
\hline 8 & Duchamp-Alphones et al., 2011 & Entre $2 \gamma^{3}$ & Roca total & Vocontian Basin (Francia) \\
\hline 9 & Gómez Peral., 2012 & Emtre 2 y 3 & Micritay ostras & Cuenca Neuquina (Argentina) \\
\hline 10 & Gröcke et al., 2005 & Entre $-23 \mathrm{y}-22$ con una excursión de -18 & Plantas & Crimean Peninsula (Ucrania) \\
\hline 11 & Hennig et al., 1999 & Emtre 2 y 3 & Roca total & Vocontian Basin (Francia) \\
\hline \multirow[t]{2}{*}{12} & Linniet al., 1992 & Entre $2 y^{3}$ & Roca total & Southern Alpine (Italia) \\
\hline & Linni et al., 1992 & Entre $-25 y-23$ & Materia orgánica & Southern Alpine (italia) \\
\hline 13 & Meissner et al., 2015 & Entre $2 y^{3}$ & Belemnites & Lower Saxony Basin (Alemania) \\
\hline 14 & Price y Mutterlose., 2004 & Entre 2 r 3 & Belemnites & Yatira River (Siberia) \\
\hline 15 & Puceat et al., 2003 & Calculado en oxigeno & Escamas de peces & Plataforma oeste del Thetys \\
\hline 16 & Silva Tamayo et al., 2016 & Entre 1 y 2 & Roca total & Cuenca de la baja Guajira (Colombia) \\
\hline \multirow[t]{2}{*}{17} & Van de Schootbrugge et al, 2000 & Entre 1 y 2 & Belemnites & Vocontian Basin (Francia) \\
\hline & Van de Schootbrugge et al., 2000 & Entre 2 y 3 & Roca total & Vocontian Basin (Francia) \\
\hline 18 & Weissert, 1998 & Entre 2 y 3 & Roca total & Valle de Mis (Italia) \\
\hline 19 & Westermann et al., 2010 & Entre 0 y 1 & Roca total (rock Eval) & Vergol (Francia) \\
\hline 20 & Wohlwend et al, 2017 & Entre $2 y^{3}$ & Roca total & Oman Mountains (Omán) \\
\hline \multirow[t]{2}{*}{21} & Wortmann y Weisert, 2000 & Entre $2 y^{3}$ & Roca total & Site 416 (Océano Atlántico) \\
\hline & Wortmann y Weisert, 2000 & Entre $-24 y-26$ & Materia orgánica & Site 416 (Océano Atlántico) \\
\hline
\end{tabular}

Tabla 10.2. Principales registros de la anomalía Weissert a lo largo del mundo, junto con los valores máximos alcanzados y el material utilizado para los análisis. 


\section{Capítulo XI - Discusión}

\subsection{Introducción}

El objetivo del presente capítulo es la discusión sobre los puntos en común existentes entre las Cuencas Neuquina y Austral, con motivo de correlacionar y comparar estas distantes regiones que han sido descriptas desde distintos puntos de vista en los capítulos anteriores. Por esta razón, temáticas en las que los resultados no evidencien una relación directa entre ambas cuencas, tales como el análisis ambiental o la procedencia, no serán tenidos en cuenta en la discusión y las interpretaciones que de ellos se desprendan serán abordadas en el capítulo de conclusiones.

Se han seleccionado tres ejes temáticos. En primer lugar, la preservación de los materiales elegidos para los análisis de isótopos estables, que son fruto del minucioso análisis tafonómico, diagenético y geoquímico que se realizó tanto durante las tareas de campo como las de laboratorio en niveles carbonáticos y fosilíferos de ambas cuencas sedimentarias. Posteriormente, se desarrollará un análisis del paleoclima reinante durante el intervalo Tithoniano-Valanginiano y sus implicancias en la composición mineralógica e isotópica y en la geoquímica de las aguas. En último lugar, se procederá a realizar una correlación estratigráfica y temporal sobre la base del contenido fosilífero, las superficies estratigráficas y el análisis quimioestratigráfico.

\subsection{Preservación del material}

Durante las tareas de campo se tomaron muestras tanto de roca como de material fosilífero. El principal objetivo de dicho muestreo fue, en el caso de las rocas, reconocer los distintos procesos diagenéticos y postular una historia diagenética para las sucesiones sedimentarias. Para el caso del material fosilífero, se intentó averiguar en qué medida los procesos identificados afectaron la estructura interna de los ejemplares.

Los taxones elegidos fueron fósiles del género Aetostreon sp. en la Cuenca Neuquina y del género Belemnopsis sp. en la Cuenca Austral. Dichos taxones fueron escogidos por su presencia en todas las secciones relevadas correspondientes a la misma cuenca y su abundancia en sentido vertical. Los principales criterios de muestreo fueron el espaciamiento (sujeta a la presencia fosilífera), sus características microscópicas, sus aspectos tafonómicos y 
su utilización en trabajos previos (Pirrie et al., 2004; Aguirre-Urreta et al., 2008; Lazo et al., 2008).

Al analizar las muestras de roca tomadas mediante petrografía estándar y de catodoluminiscencia se identificaron los procesos diagenéticos de cementación, neomorfismo, piritización, glauconitización, autigénesis, fosfatización, disolución y compactación. En la Cuenca Neuquina se reconocieron dos historias diagenéticas distintas, una para los niveles someros y otra para los profundos, ambas con un desarrollo diagenético que alcanza la mesogénesis temprana. En la Cuenca Austral, en tanto, se reconocieron tres trenes diagenéticos distintos, correspondientes a las facies marinas silicoclásticas, facies marinas mixtas y facies fluviales, con una evolución diagenética que alcanza la mesogénesis tardía.

Con respecto al material fosilífero, fue estudiado mediante petrografía estándar, de catodoluminiscencia, electrónica de barrido (MEB) y geoquímica. Al analizar los ejemplares mediante microscopía estándar con cortes teñidos, pudo observarse que todos ellos estaban formados por calcita con bajo contenido de magnesio y se distinguieron distintos tipos de microestructuras de crecimiento para las ostras (prismática, foliada y chalky) y los belemnites (granular y prismática).

Al analizar las muestras fósiles mediante microscopía de catodoluminiscencia (ver sección 8.5) se pudieron distinguir sectores luminiscentes y no luminiscentes. La ausencia de luminiscencia indica cantidades bajas de $\mathrm{Mn}$ (elemento activador), las cuales se correlacionan con el mayor grado de preservación de los procesos diagenéticos (Korte y Hesselbo, 2011; Ullmann y Korte, 2015). Los sectores mejor preservados corresponden a las capas de tipo foliado en las ostras y a los rostros de los belemnites, mientras que los sectores más afectados (luminiscentes) serían los crecimientos de tipo prismático y chalky en el caso de las ostras y las áreas cercanas a la línea apical y el alveolo en los belemnites.

Las observaciones realizadas con microscopio electrónico de barrido confirmaron las interpretaciones obtenidas anteriormente (ver sección 8.5). Los sectores no luminiscentes presentan además preservación de las microtexturas originales (superficies smoothtextured), hecho que nuevamente correlaciona a estos sectores con el menor grado de alteración diagenética (Korte y Hesselbo, 2011; Ullmann y Korte, 2015).

Los sectores interpretados mediante métodos ópticos como "mejor preservados" fueron muestreados y analizados mediante técnicas geoquímicas. Los resultados de elementos mayoritarios y minoritarios (ver sección 9.3) obtenidos mediante ICP-AES e ICP-MS mostraron que la gran mayoría de las muestras (con excepción de PL 88, 111, 119, RS 19, 22 y 28) presentan una composición química similar a los valores estipulados para las mismas especies de igual edad (Li et al., 2003; Mc Arthur et al., 2004; Price y Mutterlose, 2004; Wierzbowski y 
Joachimski, 2007; Korte et al., 2009; Nunn y Price, 2010; Korte y Hesselbo, 2011; entre otros), con lo cual pueden ser interpretadas como primarias. Adicionalmente se confeccionaros correlaciones entre los elementos y las relaciones isotópicas de $\delta^{13} \mathrm{C}$ y $\delta^{18} \mathrm{O}$, en las cuales se pudo observar que en las muestras que poseían enriquecimientos o empobrecimientos elementales producto de la diagénesis, estas modificaciones no condicionaron los valores isotópicos originales.

Finalmente se realizaron comprobaciones de la alteración diagenética utilizando datos de REY (ver sección 9.7.2). Los ejemplares analizados muestran que no existen enriquecimientos en las MREY, hecho que puede ser relacionado con la mejor preservación de los valores originales.

Es posible concluir a partir de los múltiples estudios realizados, que la diagénesis afecta de manera diferencial a los distintos elementos que componen los depósitos sedimentarios, dependiendo de sus características texturales y estructurales. Así, es posible distinguir desde rocas carbonáticas y silicoclásticas con evidencias de múltiples procesos diagenéticos hasta sectores de fragmentos fósiles con excepcional preservación coexistiendo en los mismos niveles y habiendo experimentado la misma historia postdepositacional.

\subsection{Caracterización del agua de mar y análisis del paleoclima}

Gracias al estudio geoquímico de los fósiles de ostras y belemnites (ver capítulo 9), fue posible inferir las principales características de las aguas de mar en las que los individuos vivieron, tales como temperatura, salinidad y oxigenación. Esta información, en conjunto con la información composicional y quimioestratigráfica permitió dar una idea bastante acabada del clima durante el intervalo temporal Tithoniano- Valanginiano. A su vez, y de forma recíproca, las características climáticas parecen ser el principal factor de control sobre la composición mineralógica y geoquímica y las principales variaciones de las curvas quimioestratigráficas.

\subsubsection{Características del agua de mar}

En primer término, es importante destacar la importancia que tiene el modo de vida de los organismos muestreados en el análisis de las características del agua de mar. En la Cuenca Neuquina se trabajó con el género Aetostreon sp., organismos bentónicos adaptados a condiciones de profundidad de las aguas relativamente bajas (Hernández-Ocaña et al., 2015). En la Cuenca Austral, por otro lado, se muestrearon fósiles de Belemnopsis sp., organismos 
nadadores que se desplazaban libremente por las aguas oceánicas y desarrollaban parte de su ciclo vital a mayores profundidades (Jarvis, 1980). Esta diferencia en el modo de vida, se vio reflejada en la distribución de las REY (ver sección 9.7.4) y la amplitud de las curvas quimioestratigráficas (ver sección 10.3) y evidencia la importancia del modo de vida en el análisis de los datos. Mientras las temperaturas, salinidades y condiciones de óxido reducción (redox) calculadas en la Cuenca Neuquina representan los valores del sector más somero, las de la Cuenca Austral corresponden a las aguas más profundas.

Las paleotemperaturas calculadas (Ver sección 9.4) indican un promedio de 25C para la Cuenca Neuquina y $24^{\circ} \mathrm{C}$ para la Cuenca Austral, sin variaciones significativas durante todo el intervalo temporal (Fig. 11.1). Mientras las paleotemperaturas en la Cuenca Neuquina concuerdan con los datos aportados por Lazo et al. $(2005,2008)$, las de la Cuenca Austral no son contrastables, ya que no se han encontrado referencias en la bibliografía. Estas elevadas temperaturas implicarían una diferencia de aproximadamente $10^{\circ} \mathrm{C}$ y $17^{\circ} \mathrm{C}$ en promedio con los registros de temperaturas superficiales actuales de las aguas del Océano Pacífico para la misma latitud de las Cuencas Neuquina y Austral respectivamente (fuente: world sea temperature). A partir de estos datos, es posible observar una predominancia de las condiciones cálidas en el hemisferio sur y un gradiente de temperaturas con un patrón plano. Estas tendencias ya había sido reconocidas por Fluteu et al. (2007), quienes las vincularon con eventos tectónicos y cambios en el nivel del mar.

Los datos de paleosalinidades (ver sección 9.4) oscilan entre 31 y $35 \mathrm{~g} / \mathrm{l}$ para las formaciones estudiadas en ambas cuencas (Fig. 11.1). Estos resultados ubican a las muestras dentro del campo de las aguas euhalinas, es decir, una salinidad normal para el agua de mar, razón por la cual es posible descartar la falta de circulación de las aguas como factor de control de la temperatura de las mismas.

Los estudios redox (ver sección 9.7.3) muestran que existieron en ambas cuencas condiciones óxicas (relación $\mathrm{Ce} / \mathrm{Ce} \mathrm{e}^{*} 1$ ) durante la depositación de las formaciones Springhill, Río Mayer y Chachao, así como en el sector superior de la Formación Vaca Muerta (Fig. 11.1). Es importante destacar que aunque en los mares había condiciones óxicas, lo que permitió el desarrollo de los organismos que fueron analizados, esto no implica necesariamente que en la interfase sedimentaria el potencial redox haya sido siempre óxico. Con estos datos es posible descartar la posibilidad de que las aguas fueran anóxicas como justificación de la diferencias quimioestratigráficas entre ambas cuencas.

El análisis de las características de las aguas permite concluir que las aguas de las dos cuencas en el intervalo temporal estudiado serían cálidas, óxicas y euhalinas. Además, el conocimiento de la temperatura de las aguas permite hacer consideraciones sobre las 
características climáticas generales, ya que la temperatura del agua se ve condicionada por el entorno externo. En este sentido, es posible afirmar, que durante el periodo TithonianoValanginiano se habría producido un "greenhouse" (Duchamp-Alphonse et al. 2011; Föllmi 2012) que habría elevado la temperatura global de las aguas. Beerling (2000), propone que durante los óptimos climáticos del Mesozoico, las temperaturas ecuatoriales se habrían extendido más allá de los trópicos, restringiendo las condiciones frías a unas pocas regiones polares. Este hecho podría explicar la similitud de las temperaturas de las aguas en estas dos cuencas latitudinalmente tan distantes. 


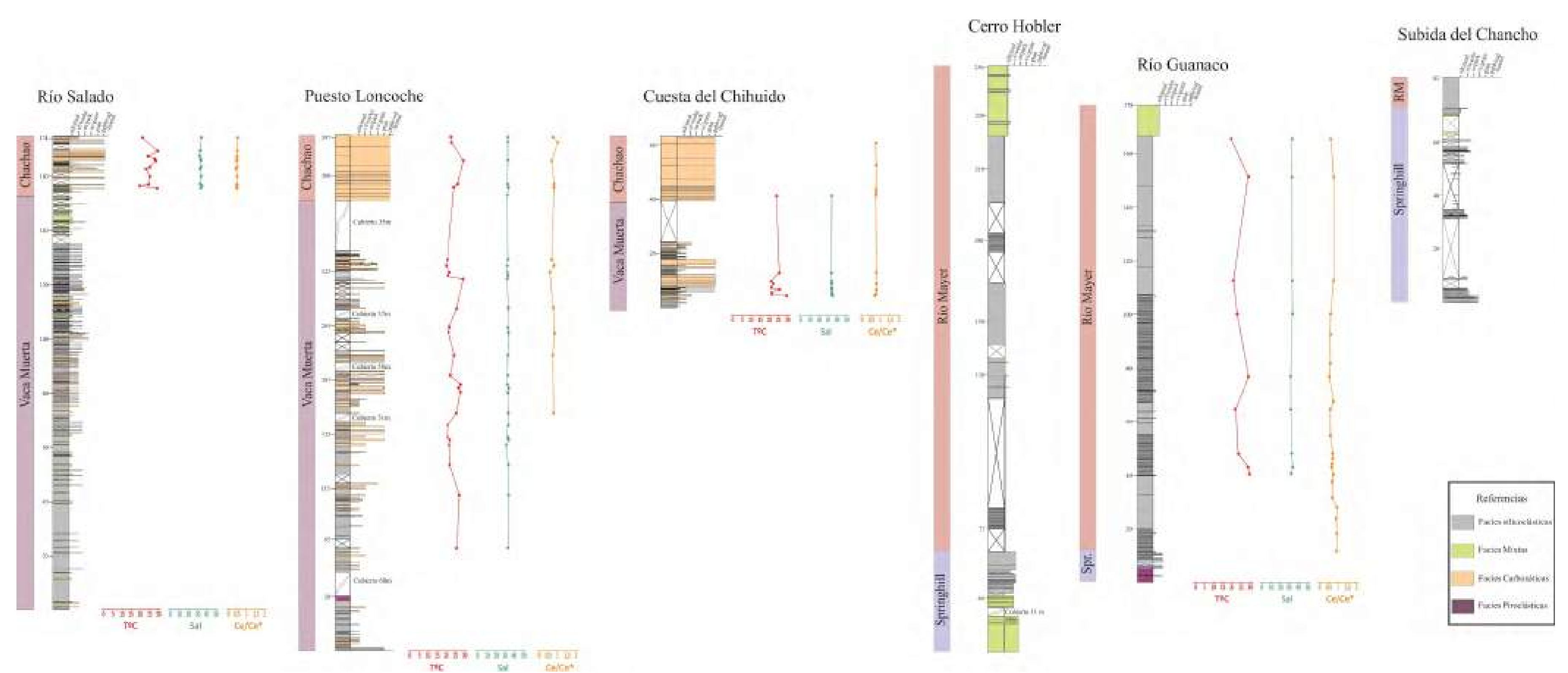

Figura 11.1. Comparación de los perfiles Río Salado, Puesto Loncoche, Cuesta del Chihuido, Cerro Hobler, Río Guanaco y Subida del Chancho. Se puede observar las curvas de paleotemperaturas, paleosalinidades y paleoxigenación (relación Ce/Ce*). 


\subsubsection{Paleoclima}

El análisis del paleoclima parte de la premisa concluida en la sección 11.3.1, es decir, que los mares eran cálidos, óxicos y euhalinos, y que mantuvieron sus características principales durante todo el intervalo Tithoniano-Valanginiano. A partir de esto, es posible descartar cambios importantes en alguna de estas variables como origen de las anomalías positivas en las curvas quimioestratigráficas. En este sentido, Föllmi (2012) postula como origen de las variaciones más drásticas en la curva de $\delta^{13} \mathrm{C}$ (anomalías positivas), cambios de corta duración (menos de $1 \mathrm{Ma}$ ) en el clima Cretácico desde cálido y árido a cálido y húmedo.. A estos cambios en el régimen de humedad se los llamó episodios de cambio ambiental (ECA) (Föllmi, 2012), y habrían estado activos desde el Jurásico superior hasta el comienzo del Cretácico superior. Entre los ECA más destacados se encuentra el evento Weissert (ver sección 10.4) muy estudiado en la bibliografía (Lini et al., 1992; Weissert et al., 1998; Hennig et al., 1999; Van de Schootbrugge et al., 2000; Melinte y Mutterlose, 2001; Bartoini, 2003; Föllmi, 2012; entre otros).

Duchamp-Alphonse et al. (2011) relacionaron el incremento del contenido de caolinita con las variaciones climáticas y del nivel del mar. El aumento en la proporción de este mineral (de origen continental), estaría directamente vinculado con un incremento del aporte de los ríos. Estos autores proponen que este fenómeno estaría vinculado al aumento de la humedad durante los ECA y a los cambios relativos en el nivel del mar durante los periodos cálidos y áridos.

En los perfiles Puesto Loncoche y Cuesta del Chihuido es posible observar cómo, durante la depositación de la Formación Vaca Muerta, los mayores contenidos de caolinita coinciden con los cortejos de mar alto (HST). En la Formación Chachao (afloramientos correspondientes a la anomalía Weissert), no fue posible realizar apreciaciones sobre cómo se comportan los niveles de caolinita ante los cambios en la humedad, ya que no se realizaron análisis de rayos $\mathrm{X}$ debido a la ausencia de material pelítico. En el caso de las secciones relevadas en la Cuenca Austral, existe una gran proporción de caolinita en los niveles continentales correspondientes a la Formación Springhill en el Subida del Chancho, mientras que los perfiles Cerro Hobler y Río Guanaco presentan contenidos mínimos de esta arcilla debido a la connotación netamente marina y principalmente profunda de estos afloramientos.

Westermann et al. (2010), propusieron que el cambio hacia las condiciones de mayor humedad, tiene como consecuencia un ahogamiento (drowning) de los cuerpos carbonáticos por el aumento del contenido de componentes terrígenos. En el caso estudiado, se observa que la relación calcita/cuarzo-feldespato-plagioclasa es independiente de las variaciones de las 
curvas quimioestratigráficas, como así también de los cambios relativos en el nivel del mar en los afloramientos de ambas cuencas. Además, en el periodo caracterizado como de mayor humedad (Valanginiano medio), se desarrolló en la Cuenca Neuquina un importante bindstone carbonático, lo cual terminaría por descartar, la relación entre la humedad y el drowning de los carbonatos.

A modo de conclusión, es posible afirmar que el clima durante el intervalo estudiado habría sido cálido y árido, con eventuales períodos con condiciones húmedas, hecho que se ve reflejado en las variaciones más importantes de las curvas quimioestratigráficas de $\delta^{13} \mathrm{C}$. En este contexto, no se encontraron evidencias suficientes para vincular dicha variación climática con los cambios en el contenido de caolinita. Por el contrario, las variaciones en los valores de este mineral estarían vinculadas a cambios relativos en el nivel del mar, al menos para los depósitos de la Formación Vaca Muerta. Por último, la relación entre el contenido de componentes carbonáticos y silicoclásticos no habría estado controlada por los cambios en la humedad ni por los del nivel del mar. 


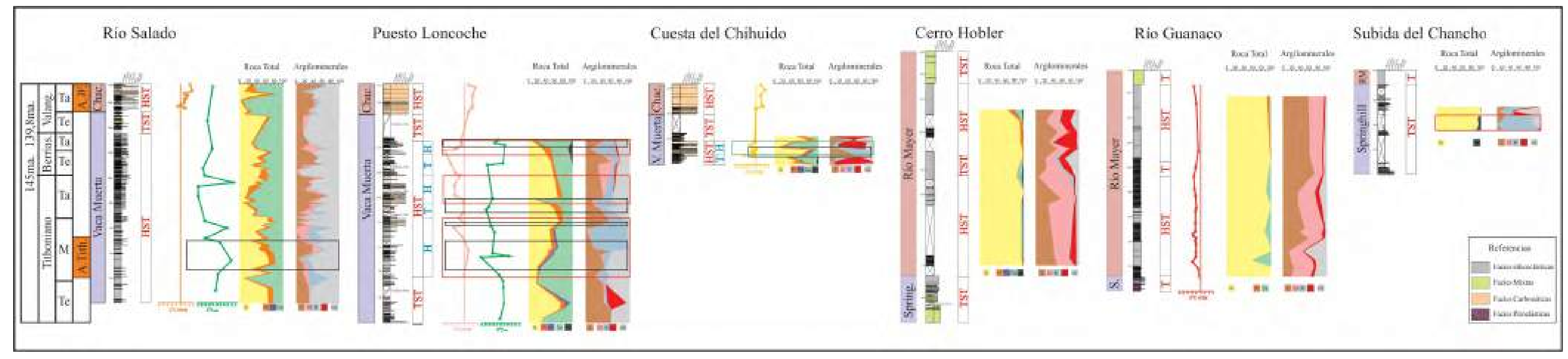

Figura 11.2. Comparación de los perfiles Río Salado, Puesto Loncoche, Cuesta del Chihuido, Cerro Hobler, Río Guanaco y Subida del Chancho. Se reflejaron paralelamente a los perfiles, tres elementos de comparación: las variaciones estratigráficas secuenciales, las curvas

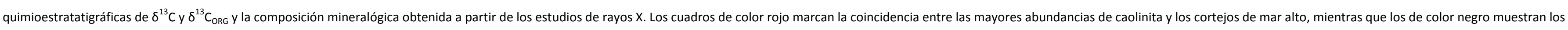
sectores con valores más positivos de $\delta^{13} \mathrm{C}$ y $\delta^{13} \mathrm{C}$ ORG. A.W: anomalía Weissert; A. Tith: anomalía del Tithoniano medio; Te: temprano: M: medio; Ta: tardío. 


\subsection{Correlación de las cuencas}

El primer elemento de correlación que ha sido tenido en cuenta es el análisis del contenido fósil. Utilizando como principal herramienta el estudio de las biozonas de amonites en la Cuenca Neuquina y las asociaciones faunísticas en la Cuenca Austral pudo esbozarse una primera comparación temporal entre las unidades de ambas cuencas (ver secciones 3.1.3.4, 3.1.4.4, 3.2.3.4 y 3.2.4.4).

A esta comparación inicial se le sobreimpusieron datos quimioestratigráficos (ver secciones 10.3 y 10.5) y de superficies estratigráficas (ver sección 5.5.3), los cuales validaron las primeras aproximaciones hechas con asociaciones fósiles y le otorgaron un mayor grado de detalle a la correlación. A continuación se presenta un modelo de evolución temporal teniendo en cuenta los datos de todas las fuentes (Fig. 11.3):

-Final del Tithoniano temprano: se registra un importante evento transgresivo con el que da inicio la depositación de las formaciones Vaca Muerta y Springhill (Fig. 11.3). En la Cuenca Neuquina, la Formación Vaca Muerta, fue restringida por Riccardi (2015) al reconocerse la biozona ándica de amonites de Virgatosphinctes mendozanus, mientras que en los perfiles Cerro Hobler y Río Guanaco de la Cuenca Austral se asignó la misma edad a la Formación Springhill sobre la base de la asociación de cefalópodos Choicensisphinctes erinoides- Aulacosphinctoides smithwoodwardi- Aspidoceras andinum (Nullo, 1979; Kraemer y Riccardi, 1997; Richiano, 2012).

-Tithoniano medio: inicia con el evento de máxima inundación que marca el final del cortejo transgresivo (TST) y el comienzo del cortejo de mar alto (HST) observado en los perfiles Río Salado, Puesto Loncoche, Cerro Hobler y Río Guanaco (Fig. 11.3). En la Cuenca Austral este evento marca el comienzo de la depositación de la Formación Río Mayer entre los Lagos Argentino y Viedma. Vale destacar que anteriormente había sido ubicado dentro de la Formación Río Mayer (ver sección 5.5.2) a partir del contenido de COT (Richiano, 2012), pero las similitudes en el comportamiento de las curvas quimioestratigráficas permitió reubicar esta superficie en el límite entre las Formaciones Springhill y Río Mayer (Fig. 11.3).

Por encima de esta superficie estratigráfica se observa un pico positivo en las curvas quimioestratigráficas del $\delta^{13} \mathrm{C}$ de los perfiles Río Salado y Puesto Loncoche de la Cuenca Neuquina (Kietzmann et al., 2015). Allí la curva alcanza valores de $1 \%$ VPDB de $\delta^{13} \mathrm{C}$ y entre $22 \%$ y $-24 \%$ VPDB de $\delta^{13} \mathrm{C}_{\mathrm{ORG}}$. Este evento se encuentra restringido a la totalidad de la biozona de Pseudolissoceras zitteli y la parte inferior de la de Aulacosphictes proximus. En la Cuenca Austral, en tanto, dicha tendencia fue registrada en el perfil Río Guanaco, alcanzando 
valores de entre $-0,33 \%$ y $-0,46 \%$ VPDB y posibilitando la correlación con las secciones de la Plataforma Mendocina (Fig. 11.3).

Hacia finales de este intervalo, se observa un pico negativo en la curva quimioestratigráfica del $\delta^{13} \mathrm{C}$ en el perfil Puesto Loncoche, que se acota a la parte final de la biozona de Aulacosphictes proximus y que se corresponde con un cambio hacia el subambiente de rampa media distal. Este evento encuentra su paralelismo en el perfil Río Guanaco en la Cuenca Austral donde también se observa la misma tendencia en la curva del $\delta^{13} \mathrm{C}$ (Fig. 11.3).

-Tithoniano tardío: durante este intervalo se registran tres superficies de correlación producto de la comparación de curvas quimioestratigráficas. Estos cambios isotópicos corresponden a dos picos positivos y un pico negativo de $\delta^{13} \mathrm{C}$ y permiten comparar los perfiles Puesto Loncoche y Río Guanaco (Fig. 11.3).

En la Cuenca Neuquina las superficies de correlación se acotan al intervalo representado por la totalidad de las biozonas de Windhauseniceras internispinosum y Corongoceras alternans y la parte inferior de la biozona de Substeuroceras koeneni (Kietzmann et al., 2015). Los picos positivos coinciden con cambios estratigráficos de menor orden, tales como variaciones subambientales y de cortejo. En la cuenca Austral se define un perfecto paralelismo en las tendencias de las curvas quimioestratigráficas, aunque no se reconoció material fosilífero que pueda acotar la edad ni se registraron cambios estratigráfico secuenciales ni ambientales que puedan dar mayor definición a las observaciones realizadas en la Cuenca Neuquina. Por otro lado, el espesor total representado por este intervalo temporal es mucho menor en la Cuenca Austral que en la Cuenca Neuquina debido al carácter más profundo de las facies.

-Berriasiano: la correlación de este intervalo temporal ha sido realizada estrictamente por su contenido fósil. En la Cuenca Neuquina se reconocen en los tres perfiles estudiados la última porción de la biozona de Substeuroceras koeneni y las biozonas de Argentiniceras noduliferum y Spiticeras damesi (Kietzmann et al., 2015). En la Cuenca Austral, por otro lado, el intervalo queda definido en los perfiles relevados entre los Lagos Argentino y Viedma (Cerro Hobler y Río Guanaco) por la presencia de la asociación faunística de Berriasella cf. behrendseni, Jabronella cf. michaelis, Subthurmannia sp. y Phyllopachyceras aureliae (Kraemer y Riccardi, 1997). En todos los perfiles, los niveles del Berriasiano representan el final del cortejo de mar alto (HST) y aunque no se distinguen picos positivos o negativos bien definidos, es posible reconocer las mismas tendencias en las curvas quimioestratigráficas de $\delta^{13} \mathrm{C}$ de los perfiles Río Guanaco y Puesto Loncoche (Fig. 11.3).

-Comienzo del Valanginiano temprano: es definido en ambas cuencas en primer término por su contenido faunístico. En la Cuenca Neuquina, el intervalo temporal 
corresponde a las biozonas de Neocomites wichmani y Lissonia Riveroi (Kietzmann et al., 2015), que se encuentran representadas en los tres perfiles estudiados. En la Cuenca Austral, el comienzo del Valanginino temprano pudo ser reconocido por la presencia de foraminíferos de la familia de las Nodociraceas (Kielbowicz et al., 1983) y amonites del género Olcostephanus (Aguirre-Urreta y Rawson, 1998; Richiano, 2012) en la zona del Lago San Martin.

En la Cuenca Neuquina este intervalo representa un cortejo transgresivo (TST), que marca el final de la depositación de la Formación Vaca Muerta. Por otro lado, en la región del Lago San Martín (Cuenca Austral), se reconoce un pasaje transicional desde un subambiente fluvial hasta un lower shoreface que también representa un TST (Fig. 11.3). Entre los Lagos Argentino y Viedma no se reconocen cambios faciales significativos y la correlación se fundamenta en el contenido fosilífero.

Las curvas quimioestratigráficas no registran valores para este intervalo temporal en la Cuenca Neuquina, mientras que apenas se cuenta con un solo resultado para el perfil Río Guanaco en la Cuenca Austral. A pesar de la falta de datos, este segmento queda perfectamente restringido por la buena correlación que se observa entre las curvas quimioestratigráficas de $\delta^{13} \mathrm{C}$ de los perfiles Puesto Loncoche y Río Guanaco por encima y por debajo de este segmento.

-Final del Valanginiano temprano y comienzo del Valanginiano tardío: en la Cuenca Neuquina está representado por la Formación Chachao, que constituye un nuevo cortejo de mar alto, que es extendido al sector entre los Lagos Argentino y Viedma de la Cuenca Austral, Formación Río Mayer (sector inferior), por comparación quimioestratigráfica, aunque no se observan cambios faciales significativos debido al carácter profundo de las facies representadas. En el sector del Lago San Martín, en tanto, no se registran evidencias de este cortejo.

Las secciones han sido acotadas temporalmente sobre la base de su contenido fósil; en la Cuenca Neuquina por la presencia de la biozona de Olcostephanus (O.) atherstoni (Kietzmann et al., 2015) y en la Cuenca Austral por la de la fauna de Belemnopsis sp. (Richiano, 2012).

Las curvas quimioestratigráficas de $\delta^{13} \mathrm{C}$, muestran un alto grado de correlación, ya que en ambas cuencas ha sido identificada la anomalía Weissert (Fig. 11.3). En la Cuenca Neuquina, se registran valores positivos de entre $2 \%$ y $3 \%$ VPDB $\delta^{13} \mathrm{C}$ y en la Cuenca Austral los valores alcanzan -0,5\% VPDB $\delta^{13} \mathrm{C}$, constituyendo en este último caso una "anomalía fantasma".

En último término, se desarrolla el evento transgresivo que da comienzo a la depositación de la Formación Agrio en la Plataforma Mendocina, los depósitos de la Formación Río Mayer (sector medio) entre los lagos Argentino y Viedma, y de Río Mayer inferior en el 
Lago San Martín. En la Cuenca Neuquina fue definido por la presencia de la biozona ándica de amonites de Pseudofavrela angulatiformis (Sagasti, 2001b), mientras que en la Cuenca Austral está caracterizado por la presencia del microfósil Watznaueria británica (Richiano, 2012), ambos ubicados cronológicamente hacia finales del Valanginiano. Este evento constituye la única superficie de correlación que puede ser seguida en los seis perfiles estudiados. 


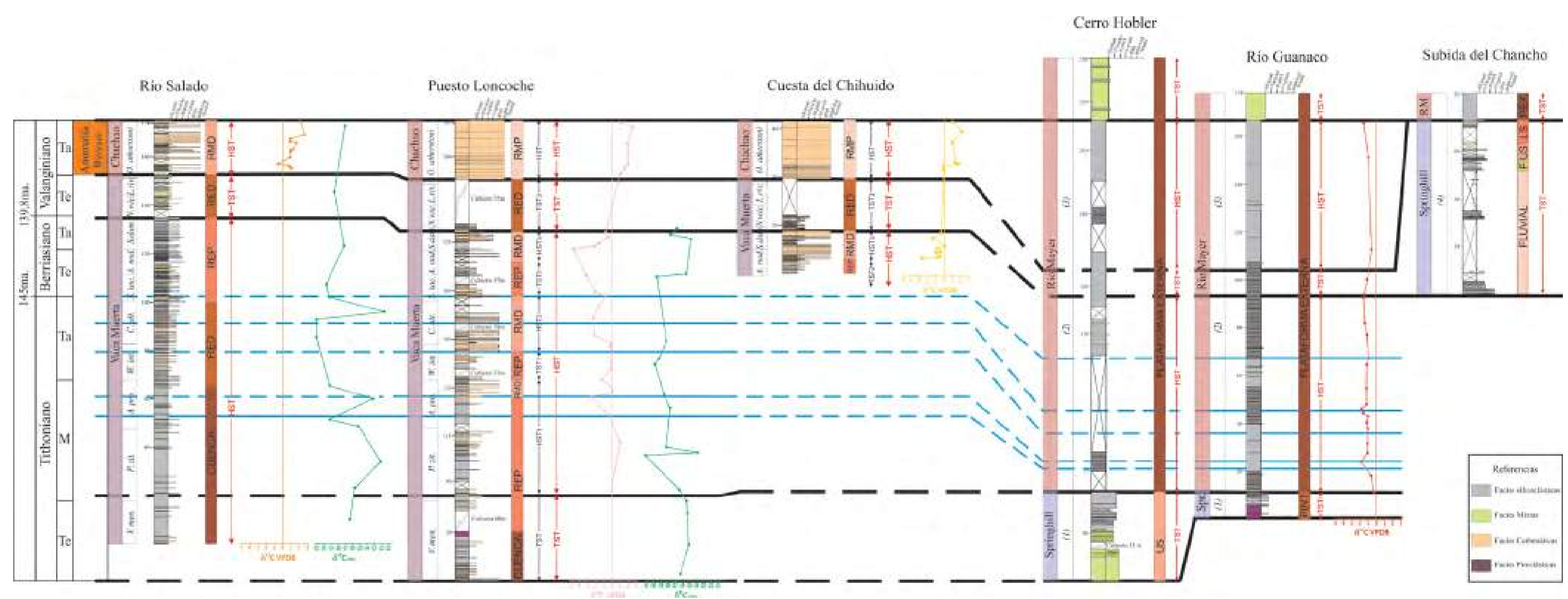

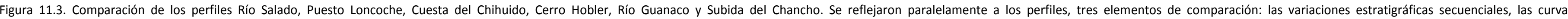

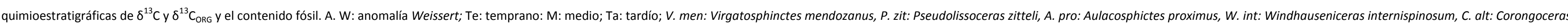

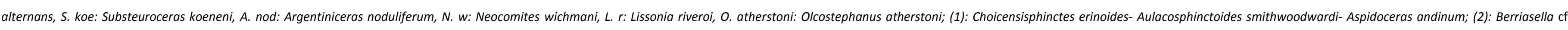

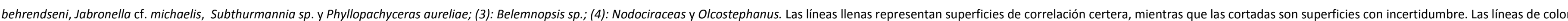
negro marcan correlaciones de mayor jerarquía y las de color azul de menor jerarquía. 


\section{Capítulo XII - Conclusiones}

En el siguiente capítulo se enumeran los resultados más sobresalientes del presente trabajo de tesis doctoral:

\section{Análisis ambiental}

1- Los depósitos del intervalo Tithoniano- Valanginiano de la Plataforma Mendocina (Cuenca Neuquina) y el sector entre los lagos Argentino y San Martin (Cuenca Austral) muestran importantes cambios faciales, que fueron estudiados mediante seis perfiles sedimentarios de detalle. En estas secciones se definieron un total de veintisiete facies sedimentarias, las cuales se agruparon según su relación vertical y lateral en diez asociaciones de facies, cinco correspondientes a la Cuenca Neuquina y cinco a la Cuenca Austral.

2- En la Cuenca Neuquina se definieron las asociaciones de facies de cuenca, rampa externa distal, rampa externa proximal, rampa media distal y rampa media proximal. A partir de ellas se interpretó como ambiente de depositación una rampa carbonática/mixta. En este sistema, las asociaciones de facies se agrupan en sucesiones somerizantes de decenas de metros de espesor. De base a techo, se observa composicionalmente una intercalación de niveles finos carbonáticos o silicoclásticos depositados por decantación, con niveles netamente bioclásticos cada vez más gruesos que son producto de corrientes hemipelágicas a tempestíticas. Hacia el tope se observa un potente bindstone carbonático que representa la máxima somerización.

3- En la Cuenca Austral se definieron las asociaciones de facies de plataforma externa, plataforma interna, shoreface, foreshore y fluvial. A partir de dichas asociaciones se proponen dos ambientes de acumulación: sistema de plataforma marina silicoclástica/mixta y sistema fluvial.

- En la plataforma marina, las asociaciones de facies silicoclásticas y mixtas se vinculan evidenciando condiciones cada vez más profundas hacia el tope. El registro comienza con depósitos de foreshore con evidencias de exposición subaérea, continúa con facies de shoreface depositadas por flujos unidireccionales bajo condiciones de alto régimen de flujo y termina con niveles de plataforma marina proximal y distal donde domina la decantación con episódicos depósitos generados por corrientes de turbidez concentradas a diluidas.

- El ambiente fluvial, por otro lado, se interpreta como el relleno de canales fluviales meandrosos intercalado con planicies de inundación. 
4- A partir del análisis estratigráfico secuencial se concluyó que existen cinco cortejos principales limitados por superficies estratigráficas que pueden ser reconocidas en ambas cuencas:

- Un cortejo transgresivo (TST) con el que da inicio la depositación de las formaciones Vaca Muerta en la Cuenca Neuquina y Springhill en las secciones Cerro Hobler y Río Guanaco, entre los lagos Argentino y Viedma (Cuenca Austral), y que puede ser ubicado hacia el final del Tithoniano temprano.

- Un cortejo de mar alto (HST) que representa la mayor parte del desarrollo de las Formación Vaca Muerta y las secciones inferior-media de la Formación Río Mayer inferior en la región entre los lagos Argentino y Viedma, de edad Tithoniano medio -Berriasiano.

- Nuevamente el desarrollo de un TST que se habría desarrollado hacia el comienzo del Valanginiano temprano. Este evento incluye el sector cuspidal de la Formación Vaca Muerta en la Plataforma Mendocina, un intervalo ubicado en el sector medio de la Formación Río Mayer inferior en los perfiles Cerro Hobler y Río Guanaco y la totalidad de la Formación Springhill en la Subida del Chancho.

- Un segundo episodio de HST durante el cual se depositan los sedimentos correspondientes a la Formación Chachao en la Cuenca Neuquina y que representa el sector cuspidal de la Formación Río Mayer inferior en los perfiles Cerro Hobler y Río Guanaco (región sur de la Cuenca Austral). Este evento fue acotado al final del Valanginiano temprano y comienzo del Valanginiano tardío.

- Un tercer evento transgresivo que da comienzo a la depositación de la Formación Agrio en la Plataforma Mendocina, los depósitos de la Formación Río Mayer medio entre los lagos Argentino y Viedma y de Río Mayer inferior en el Lago San Martín que se habría desarrollado hacia finales del Valanginiano tardío.

\section{Composición mineralógica}

4- A partir del análisis composicional de las rocas de la Cuenca Neuquina se pudo observar que:

- En la fracción pelítica, los minerales más abundantes son cuarzo y calcita, cuya suma siempre supera el $90 \%$ de la muestra. El incremento en el contenido de cuarzo en todos los casos coincide con una disminución en la calcita y viceversa. Entre los argilominerales predomina la illita y el interestratificado illita/esmectita (I/S) en los perfiles Río Salado y Puesto Loncoche, mientras que la esmectita es más abundante en la sección de la Cuesta 
del Chihuido. La caolinita se presenta en sectores aislados de los tres perfiles y la clorita posee sus mayores concentraciones en el perfil Río Salado.

- Las facies carbonáticas son íntegramente esqueletales. Mineralógicamente, están compuestas principalmente por calcita con bajo contenido de magnesio. En cuanto a la preservación tafonómica, es importante destacar que se reconocieron fragmentos de los mismos géneros fósiles desde totalmente fragmentados constituyendo wackestones hasta con las valvas articuladas y en posición de vida formando parte de bindstones.

- Las rocas mixtas se diferencian de las carbonáticas por la presencia de bajos porcentajes de elementos terrígenos, por esta razón, han sido clasificadas como areniscas mixtas fangosas carbonáticas (Río Salado) y fangolitas micríticas aloquímicas (Puesto Loncoche).

5- El análisis composicional de las sedimentitas de la Cuenca Austral arrojó los siguientes resultados:

- En la fracción pelítica, el mineral más abundante es el cuarzo, también existen cantidades escasas de calcita en los perfiles Cerro Hobler y Río Guanaco y arcillas en la Subida del Chancho. Entre los argilominerales presentes, predomina la illita y la clorita en los perfiles Cerro Hobler y Río Guanaco, con cantidades menos importantes de esmectita (en Cerro Hobler) e interestratificado I/S (en Río Guanaco). En la sección Subida del Chancho la caolinita es el argilomineral más abundante.

- Entre las psamitas se reconocieron arenitas líticas, y en menor proporción vaques líticos.

- Las psefitas fueron clasificadas como clasto ortoconglomerados líticos.

- Las rocas mixtas se diferencian de las silicoclásticas por la presencia de bivalvos no ostreidos, algas dasycladáceas y belemnites. Según la cantidad de componentes esqueletales fueron clasificadas en areniscas mixtas aloquímicas, areniscas mixtas fangosas silicoclásticas, areniscas fangosas silicoclásticas y fangolitas arenosas silicoclásticas.

\section{Procedencia}

6- En la Formación Vaca Muerta, los aportes detríticos provendrían del arco magmático que flanqueaba a la cuenca por el oeste, así como desde terrenos volcánicos triásicos y jurásicos tempranos ubicados en las regiones del margen pasivo (suroriental) de la cuenca. Tampoco se descarta la contribución desde los depósitos de la subyacente Formación Tordillo, incorporados durante el proceso transgresivo.

7- La fuente del material que compone a las formaciones Springhill y Río Mayer sería el Complejo vulcano- sedimentario El Quemado. 


\section{Diagénesis}

8- Gracias al estudio de la diagénesis en la fracción pelítica se determinó el origen detrítico o autigénico de los argilominerales illita e interestratificado I/S. Además, fue posible cuantificar el grado de alteración diagenética de acuerdo al porcentaje de capas expansivas.

- En las pelitas de la Formación Vaca Muerta (Cuenca Neuquina), una parte de la illita y los interestratificados I/S presentes son considerados autigénicos. De acuerdo al porcentaje de capas expansivas, los depósitos habrían experimentado una mesodiagénesis temprana.

- En las pelitas de las formaciones Springhill y Río Mayer (Cuenca Austral), los interestratificados $\mathrm{I} / \mathrm{S}$ y la mayor parte de la illita son autigénicas. A partir del estudio del porcentaje de capas expansivas, se puede concluir que la Formación Río Mayer alcanzó un estadio de mesodiagénesis tardía. En la Formación Springhill, por otro lado, no fue posible cuantificar el grado de alteración diagenética a partir de la mineralogía de arcillas.

9- En los niveles carbonáticos y mixtos de las Formaciones Vaca Muerta y Chachao, se identificaron rasgos diagenéticos correspondientes a los procesos de cementación, neomorfismo, piritización, fosfatización, disolución y compactación. Estos procesos corresponden a los estadios de eogénesis y mesogénesis temprana.

La diagénesis afecta de manera diferencial a las facies profundas y someras:

- Las facies profundas incluyen a los depósitos correspondientes a las asociaciones de facies de cuenca, rampa externa distal y rampa externa proximal de la base de la Formación Vaca Muerta. La diagénesis se caracteriza por el escaso desarrollo de los procesos de cementación marina y neomorfismo.

- Las facies someras incluyen a los depósitos correspondientes a las asociaciones de facies de rampa media distal y rampa media proximal del tope de la Formación Vaca Muerta y la Formación Chachao. Se caracterizan por la acción de procesos diagenéticos meteóricos, que se evidencian en rasgos tales como la abundancia de disolución y neomorfismo y la precipitación de cemento drusiforme.

10- En los niveles de psamitas silicoclásticas y mixtas de la Cuenca Austral, se reconocieron rasgos diagenéticos que corresponden a los procesos de: glauconitización, cementación carbonática marina, cementación cuarzosa, autigénesis de arcillas, cementación carbonática de soterramiento, disolución y compactación. Estos procesos se llevaron a cabo durante los estadios de eogénesis, mesogénesis temprana y mesogénesis tardía.

Para la Formación Springhill se han establecido tres trenes diagenéticos correspondientes a las facies fluviales, marinas mixtas y marinas silicoclásticas: 
- Las facies marinas mixtas incluyen parte de la asociación de facies de shoreface en los perfiles Cerro Hobler y Subida del Chancho. La diagénesis se caracteriza por el desarrollo de galuconitización y cementación carbonática marina y la ausencia de procesos de disolución.

- Las facies marinas silicoclásticas incluyen a las asociaciones de facies de shoreface del perfil Cerro Hobler, la plataforma interna del perfil Río Guanaco y los subambientes de upper shoreface y foreshore del perfil Subida del Chancho. Se caracteriza por la presencia de rasgos de cementación cuarzosa y la ausencia de rasgos eogenéticos.

- Las facies fluviales se reconocieron en el sector basal del perfil Subida del Chancho y están representados por vaques líticos con matriz fangosa. Los procesos diagenéticos que caracterizan a estas facies son compactación, disolución y autigénesis de arcillas.

11- En los fósiles de ostras y belemnites, la diagénesis afecta de manera diferencial a las distintas microtexturas que componen sus conchillas. Los ejemplares del género Aetostreon sp. reflejan una muy buena preservación en sus capas con crecimiento foliar, mientras que las de crecimiento "chalky" se ven alteradas. Los belemnites del género Belemnopsis sp. muestran una muy buena preservación de los rostros, pero poseen alta luminiscencia en sectores como la línea apical y el alveolo.

\section{Geoquímica}

12- Se efectuaron análisis de laboratorio con el objetivo de determinar elementos mayoritarios y minoritarios en ejemplares de ostras y belemnites de las cuencas Neuquina y Austral respectivamente. La mayoría de las muestras analizadas se encuentran dentro de los rangos estipulados para el taxón y la época, aunque existe una cantidad menor que presenta enriquecimientos o empobrecimientos diagenéticos.

13- No existen correlaciones positivas o negativas entre los elementos o relaciones elementales con los datos isotópicos que puedan ser vinculadas con la diagénesis. De esta forma, se concluye que los enriquecimientos y empobrecimientos diagenéticos que presentan ciertos elementos en muestras de las dos cuencas, no condicionaron los valores isotópicos.

14- Con los resultados isotópicos de $\delta^{18} O$ se calcularon paleotemperaturas y paleosalinidades.

- Los resultados de paleotemperaturas obtenidos para el agua de mar dan en promedio $25 \circ \mathrm{C}$ para la Cuenca Neuquina y $24{ }^{\circ} \mathrm{C}$ para la Cuenca Austral. Estos valores permiten caracterizar al mar como cálido en ambos casos. 
- Las paleosalinidades oscilan entre 31 y $35 \mathrm{~g} / \mathrm{l}$ para las formaciones estudiadas en ambas cuencas. Estos resultados ubican a las muestras dentro del campo de las aguas euhalinas o de salinidad normal.

15- Por medio del estudio de las tierras raras e itrio sobre restos fósiles se realizaron las siguientes observaciones sobre alteraciones diagenéticas, niveles de oxigenación y profundidad de las aguas.

- A partir del cálculo de enriquecimientos en las tierras raras medianas e itrio (MREY), se puede concluir que todas las muestras analizadas, exceptuando RS 237b, RS 248b, PL 110b, PL 116, PL 118, reflejan cantidades primarias en los patrones de REY normalizados, es decir, no existe enriquecimiento diagenético.

- Los resultados obtenidos reflejan, para todas las muestras, una anomalía negativa de Ce que se corresponde con condiciones óxicas del ambiente en el que las especies fósiles tuvieron su ciclo de vida.

- En el perfil Río Guanaco de la Cuenca Austral se observa un enriquecimiento superior en tierras raras pesadas e itrio (HREY) y mayores valores de la relación $\mathrm{Y} /$ Ho y las anomalías de La, Eu y Gd que en los perfiles de la Cuenca Neuquina. Estas tendencias, corroboran que los organismos de la Cuenca Austral vivieron y precipitaron sus conchillas en ambientes más profundos que los de la Cuenca Neuquina.

\section{Quimioestratigrafía}

16- A partir del análisis de las curvas quimioestratigráficas de $\delta^{13} \mathrm{C}$ se puede observar que:

- Existe una similitud en el comportamiento de las curvas quimioestratigráficas de $\delta^{13} \mathrm{C}$ de los perfiles sedimentarios Puesto Loncoche (Cuenca Neuquina) y Río Guanaco (Cuenca Austral).

- La curva de $\delta^{13} \mathrm{C}$ correspondiente a la sección Puesto Loncoche (Cuenca Neuquina) posee forma aserrada, con una fuerte oscilación en las cifras, desde $-4,9$ a 2,6\% VPDB. Por otro lado, la curva de $\delta^{13} \mathrm{C}$ del perfil Río Guanaco (Cuenca Austral) posee una forma similar pero con oscilaciones menos pronunciadas debido a que el rango de valores es más estrecho (desde $-1,7$ a $-0,56 \%$ vPDB).

- La diferencia en la amplitud de los valores de $\delta^{13} \mathrm{C}$ y la forma de las curvas observada entre los perfiles Puesto Loncoche y Río Guanaco, estaría vinculada con la profundidad en la cual los organismos precipitan su conchilla. 
17- Se conoce como anomalía Weissert a una excursión positiva de $\delta^{13} \mathrm{C}$ registrada en el Valanginiano medio. Este evento isotópico fue registrado en los afloramientos de ambas cuencas.

- En la Cuenca Neuquina se observó dicha anomalía positiva ( 2-3\% VPDB) en los niveles de la Formación Chachao (final del Valanginiano temprano y comienzo del Valanginiano tardío). Este evento fue restringido temporalmente sobre la base de la biozona de amonites de Olcostephanus atherstoni.

- En la Cuenca Austral la anomalía "positiva", es identificada hacia el tope del perfil Río Guanaco y se presenta con un valor máximo de apenas $-0,56 \%$ VPDB. Aunque no presenta valores anómalos, es reconocible gracias a la muy buena correlación entre las curvas de $\delta^{13} \mathrm{C}$ de ambas cuencas, razón por la cual se la definió como "anomalía fantasma". Este evento fue restringido temporalmente por su asociación faunística.

- Gracias al estudio de la anomalía Weissert, fue posible correlacionar las secciones estudiadas con otras contemporáneas en diferentes cuencas del mundo.

18- A partir del análisis de las curvas quimioestratigráficas de $\delta^{13} \mathrm{C}_{\mathrm{ORG}}$ se puede concluir que:

- En las secciones Río Salado y Puesto Loncoche los valores de $\delta^{13} \mathrm{C}_{\mathrm{ORG}}$ guardan una buena correlación con los resultados obtenidos con el material fosilífero, sobre todo hacia el sector de la curva correspondiente al Tithoniano.

\section{Integración de las cuencas}

19- La diagénesis afecta de manera diferencial a los distintos elementos que componen los depósitos sedimentarios de ambas cuencas, dependiendo de sus características texturales y estructurales. Así, es posible distinguir desde rocas carbonáticas y silicoclásticas con evidencias de múltiples procesos diagenéticos hasta sectores de fragmentos fósiles con excepcional preservación coexistiendo en los mismos niveles y habiendo experimentado la misma historia postdepositacional.

20- El análisis de las características del agua de mar permite inferir que:

- Los datos de temperatura, salinidad y oxigenación obtenidos en la Cuenca Neuquina reflejan las características del sector más somero del agua de mar, mientras que los de la Cuenca Austral corresponden a regiones más profundas.

- Las aguas de las dos cuencas en el intervalo temporal estudiado serían cálidas, óxicas y euhalinas. 
- Durante el periodo Tithoniano- Valanginiano se habría producido un "greenhouse" que habría elevado la temperatura global de las aguas. Este evento habría extendido el clima ecuatorial más allá de los trópicos, restringiendo las condiciones frías a unas pocas regiones polares y equilibrando la temperatura de las aguas en estas dos cuencas latitudinalmente tan distantes.

21- Con respecto al paleoclima se realizaron las siguientes observaciones:

- El clima durante el intervalo estudiado habría sido cálido y árido, con eventuales períodos con condiciones húmedas (ECA), hecho que se ve reflejado en las variaciones más importantes de las curvas quimioestratigráficas de $\delta^{13} \mathrm{C}$.

- No se encontraron evidencias suficientes para vincular los episodios de cambio ambiental (ECA) con cambios composicionales. Las variaciones en el contenido de caolinita estarían vinculadas a cambios relativos en el nivel del mar, al menos para los depósitos de la Formación Vaca Muerta. Por otro lado, la relación entre el contenido de componentes carbonáticos y silicoclásticos no habría estado controlada por los cambios en la humedad ni por los del nivel del mar.

22- Las cuencas estudiadas presentan historias depositacionales y diagenéticas distintas, pero pudieron ser correlacionadas por medio de tres elementos: curvas quimioestratigráficas, contenido fosilífero y superficies estratigráficas. Estos puntos en común permitieron establecer una evolución temporal comparada del periodo TithonianoValanginiano en las cuencas Neuquina y Austral. 


\section{Bibliografía}

Adatte, T., Stnnesbeck, W., Hubberten, H., Remane, J., Guadalupe L.O., 2001. Correlation of a Valanginian stable isotopic excursion in Northeastern Mexico with the European Tethys. En: Bartolini, C., Buffler, R.T., Cantu-Chapa, A. (Eds.), The Western Gulf of Mexico Basin: Tectonics, Sedimentary Basins, and Petroleum Systems. AAPG Memoir 75, 371-388.

Aguirre-Urreta, M.B., Rawson, P.F., 1997. The ammonite sequence in the Agrio Formation (Lower Cretaceous), Neuquén Basin, Argentina. Geological Magazine 134, 449-458.

Aguirre-Urreta, M.B., Rawson, P.F., 1998. The Early Cretaceous (Valanginian) ammonite Chacantuceras (gen. nov.), a link between the Neuquén and Austral basins. Revista de la Asociación Geológica Argentina 53 (3), 354-364.

Aguirre Urreta, M.B., Concheyro, A., Lorenzo, M., Ottone, E.G., Rawson, P.F., 1999. Advances in the biostratigraphy of the Agrio Formation (Lower Cretaceous) of the Neuquén Basin, Argentina: ammonites, palynomorphs and calcareous nannofossils. Palaeogeography, Palaeoecology and Palaeoclimatology 150, 33-47.

Aguirre-Urreta, M.B., Lazo, D.G., Griffin, M., Vennari, V.V., Parras, A.M., Cataldo, C., Garberoglio, R., Luci, L., 2011. Megainvertebrados del Cretácico y su importancia bioestratigráfica. En: Leanza, H.A., Arregui, C., Carbone, O., Danieli, J.C., Vallés, J.M. (Eds.), Geología y Recursos Naturales de la Provincia del Neuquén 465-488.

Aguirre-Urreta, M.B., Price, G.D., Ruffell, A.H., Lazo, D.G., Kalin, R.M., Ogle, N., Rawson, P.F., 2008. Southern Hemisphere Early Cretaceous (Valanginian-Early Barremian) carbon and oxygen isotope curves from the Neuquén Basin, Argentina. Cretac. Res. 29, 87-99.

Aguirre-Urreta, M.B., Rawson, P.F., Concheyro, G.A., Bown, P.R., Ottone, E.G., 2005. Lower Cretaceous (Berriasian-Aptian) biostratigraphy of the Neuquén Basin. En: Veiga, G.D., Spalletti, L.A., Howell, J.A., Schwarz, E. (Eds.), The Neuquén Basin, Argentina: a Case Study in Sequence Stratigraphy and Basin Dynamics. Geological Society, London, Special Publication 252, 57-81.

Álvarez- Trenttini, G., Schwarz, E., 2016. Ciclos carbonáticos-silicoclásticos de alta frecuencia (Fm. Mulichinco, Cuenca Neuquina Central, Argentina): identificación de cambios de la productividad carbonática en el tiempo y el espacio. VII Congreso Latinoamericano de Sedimentología -XV Reunión Argentina de Sedimentología, La Pampa 13.

Amorosi, A., 1995. Glaucony and sequence stratigraphy: a conceptual framework of distribution in siliciclastic sequences. Journal of Sedimentary Research 65, 419-425.

Anderson, T.F., Arthur, M.A., 1983. Stable isotopes of oxygen and carbon and their application 
to sedimentological and palaeoenvironmental problems. En: Arthur, M.A., Anderson, T.F., Kaplan, I.R., Veizer, J., Land, L.S. (Eds.), Stable Isotopes in Sedimentary Geochemistry. SEPM, Short Course Notes 10, 1-151.

Andersson, P.O.D., Worden, R.H., Hodgson, D.M., Flint, S., 2004. Provenance evolution and Chemostratigraphy of a Paleozoic submarine fan complex; Tanqua Karoo Basin, South Africa. Marine and Petroleum Geology 21, 555-577.

Arbe, H.A., 2002. Análisis estratigráfico del Cretácico de la Cuenca Austral. En: Haller, M.J. (Ed.), Geología y Recursos Naturales de Santa Cruz. Relatorio del Decimoquinto Congreso Geológico Argentino, 103-128.

Arbe, H.A., Fernández Bell Fano, F., 2002. Formación Springhill en el área costa afuera. En: Schiuma, M., Hinterwimmer, G., Vergani, G. (Eds.), Rocas Reservorio de las Cuencas Productivas Argentinas. V Congreso de Exploración y Desarrollo de Hidrocarburos, Mar del Plata, 75-89.

Arbe, H., Hechem J., 1984. Estratigrafía y facies de depósitos continentales, litorales y marinos del Cretácico superior, Lago Argentino. Actas IX Congreso Geológico Argentino, 7, 124158.

Arcila Gallego, P.A., 2010. Los depósitos sinorogénicos del sur de Mendoza y su relación con la faja plegada y corrida de Malargüe $\left(35^{\circ}-36^{\circ} \mathrm{S}\right)$, Mendoza. Argentina. Tesis doctoral. Universidad de Buenos Aires, 379 pp.

Asmerom, Y., Jacobsen, S.B., Knoll, A.H., Butterfield, N.J., Swett, K., 1991. Strontium isotopic variations of Neoproterozoic seawater: implications for crustal evolution. Geochimica et Cosmochimica Acta 55, 2883-2894.

Baldwyn, H.L., 1942. Nuevas observaciones sobre discordancias en Neuquén. Boletín de Informaciones Petroleras 19(214), 37-50.

Bartolini, A., 2003. Cretaceous radiolarian biochronology and carbon isotope stratigraphy of ODP Site 1149 (northwestern Pacific, Nadezhda Basin). En: Ludden, J.N., Plank, T., Escutia, C. (Eds.), Proceedings of the Ocean Drilling Program. Scientific Results 185, 117.

Bathurst, R.G.C., 1975. Carbonate Sediments and Their Diagenesis. Elsevier (2nd ed.), Amsterdam, $658 \mathrm{pp}$.

Beerling, D.J., 2000. Global terrestrial productivity in the Mesozoic era. En: Hart M.B. (Ed.), Climates: past and present. Geological Society of London Special Publication 181, 17-32.

Berner, R.A., 1984. Sedimentary pyrite formation: an update. Geochimica et Cosmochimica Acta 48, 605-615. 
Bianchi, J.L., 1967. Informe preliminar acerca de los perfiles estratigráficos realizados en el sector occidental de la Cuenca Austral, durante las campañas 1964-65 y 1965-66. Informe Inédito, Yacimientos Petrolíferos Fiscales (Y.P.F.), Buenos Aires.

Biddle, K., Uliana M., Mitchum R.J., Fitzgerald, M., Wright R., 1986. The stratigraphic and structural evolution of central and eastern Magallanes Basin, Southern America. En: Allen, P., Homewood, P. (Eds.), Foreland basins. International Association of Sedimentology, Special Publication 8, 41-61.

Biscaye P.E., 1965. Mineralogy and sedimentation of recent deep-sea clay in the Atlantic Ocean and adjacent seas and oceans. Bulletin of the Geological Society of America 76, 803831.

Blatt, H., 1992. Sedimentary Petrology, W.H. Freeman and company, New York, 514 pp.

Boggs, S., Krinsley, D., 2006. Application of Cathodoluminescence Imaging to the Study of Sedimentary Rocks. Cambridge University Press, New York, 176 pp.

Bonarelli, G., Nagera, J.J., 1921. Observaciones geológicas en las inmediaciones del Lago San Martin (Territorio de Santa Cruz). Ministerio Agricultura Dirección General de Minas, Geología e Hidrología 27, 1-39.

Borrello, A.V., 1956. Combustibles sólidos minerales. Museo Argentino de Ciencias Naturales Bernardino Rivadavia, Ciencias Geológicas 5, 26-66.

Borrello, A.V., 1967. Estado actual del conocimiento geológico del Flysch en la Argentina. Revista del Museo de La Plata 6 (Geología 44), 125-153.

Bowen, R., 1961. Palaeotemperature analysis of belemnoidea and Jurassic palaeoclimatology. Geology 69, 309-320.

Bowen, R., 1963. $\mathrm{O}^{18} / \mathrm{O}^{16}$ paleotemperature measurements on mesozoic Belemnoidea from Neuquén and Santa Cruz Provinces, Argentina. Journal Paleontology 37(3), 714-718.

Boyer, C., Clark, B., Jochen, V., Lewis, R., Miller, C.K., 2011. Shale gas: a global resource. Oilfield Review 23, 28-39.

Brand, U., Veizer, J., 1981. Chemical diagenesis of a multicomponent carbonate sistem: stable isotopes. Journal of Sedimentary Petrology 51 (3), 987-997.

Bridge, J.S., Demico, R.V., 2008. Earth Surface Processes, Landforms and Sediment Deposits. Cambridge University Press, Cambridge, 795 pp.

Brindley, G.W., 1961. Experimental Methods. En: Brown, G. (Ed.), The X-Ray identification and crystal structure of Clay Minerals. Mineralogical Society, 1-50.

Brown, G., 1980. Tables for the determination of $d$ in $\AA$ from $2 \theta$ for the $K \alpha$ and $K \beta$ radiations of cooper, cobalt and iron. En: Brindley, G.W., Brown G. (Eds.), Crystal Structures of Clay Minerals and their X-Ray identification. Mineralogical Society Monograph 5, 439-475. 
Buatois, L.A., Mángano, M.G., 2011. Ichnology. Organism-Substrate Interactions in Space and Time. Cambridge University Press, Cambridge, 358 pp.

Burley, S.D., Worden, R.H., 2003. Sandstones Diagenesis Recent and Ancient. Burley, S., Worden R. (Eds.). International Association of Sedimentologists Special Publication 4, 3-44.

Calderón, M., Fosdick, J.C., Warren, C., Massonne, H.J., Fanning, C.M., Fadel Cury, L., Schwanethal, J., Fonseca, P.E., Galaz, G., Gaytán, D., Hervé, F., 2012. The low-grade Canal de las Montañas Shear Zone and its role in he tectonic emplacement of the Sarmiento Ophiolitic Complex and Late Cretaceous Patagonian Andes orogeny, Chile. Tectonophysics 524-525, 165-185.

Canessa, N.D. Poiré, D.G., Doyle, P., 2005. Estratigrafía de las unidades cretácicas de la margen norte del Lago Viedma, entre el Cerro Pirámides y la Estancia Santa Margarita, Provincia de Santa Cruz, República Argentina. Actas del XVI Congreso Geológico Argentino, La Plata, 157-164.

Carozzi, A.V., Berkowski, F., Rodriguez, M., Sanckes, M., Vonesht, T., 1981. Estudio de microfacies de la Formación Chachao (Valanginiano), Provincia de Mendoza. Actas del VIII Congreso Geológico Argentino, San Luis 2, 545-565.

Catuneanu O., 2005. Principles of Sequence Stratigraphy. Elsevier, London, 376 pp.

Cecioni, G., 1955. Edad y Facies del Grupo Springhill en Tierra del Fuego. Universidad de Chile, Facultad de Ciencias Exactas, Físicas y Naturales, Anales 12, 243-256.

Celestino, R., Wohlwend, S., Reháková, D., Weissert H., 2017. Carbon isotope stratigraphy, biostratigraphy and sedimentology of the Upper Jurassic- Lower Cretaceous Rayda Formation, central Oman Mountains. Newsletters on Stratigraphy 50 (1), 91-109.

Cereceda, A., 2016. Sedimentología de los depósitos marinos de las formaciones Cerro Toro y Alta Vista, Cretácico Superior, Cuenca Austral. Tesis doctoral, Universidad Nacional de La Plata, $231 \mathrm{pp}$.

Chamley, H., 1989. Clay sedimentology. Springer, Berlín, 623 pp.

Champ, D.R., Gulens, J., Jackson, R.E., 1979. Oxidatio-reduction sequences in ground water flow systems. Canadian Journal of Earth Sciences 16, 12-23.

Charbonnier, G., Boulila, S., Gardin S., Duchamp-Alphonse S., Adatte T., Spangenberg J.E., Föllmi K.B., Colin C., Galbrun B., 2013. Astronomical calibration of the Valanginian "Weissert" episode: The Orpierre marlelimestone succession (Vocontian Basin, southeastern France). Cretaceous Research 45, 25-42.

Choquette, P.W., Pray, L., 1970. Geologic nomenclature and classification of porosity in sedimentary carbonates. American Association of Petroleum Geologists Bulletin 54, 
207-250.

Cloud, P.E., 1955. Physical limits of glauconite formation. American Association of Petroleum Geologists, Bulletin 39, 484-492.

Collinson, J.D., Mountney, N., Thompson, D., 2006. Sedimentary Structures. Terra Publishing (3 Ed.), Harpenden, 292 pp.

Concheyro, A., Palma, R.M., Lescano, M., López Gómez, J., Chivelet, J.M., Kietzmann, D.A., 2006. Nanofósiles calcáreos en los episodios de productividad y dilución de la Formación Vaca Muerta. IX Congreso Argentino de Paleontología y Bioestratigrafía, Córdoba, 218.

Cortiñas, J.C., Arbe, H.A., 1981. Un nuevo afloramiento fosilífero de la Formación Springhill, en el Noroeste de la provincia de Santa Cruz. Revista de la Asociación Geológica Argentina $36,212-214$.

Cotillon, P., Rio, M., 1984. Cyclic sedimentation in the Cretaceous of DSDP site 535 and 540 (Gulf of Mexico), 534 (central Atlantic) and the Vocontian Basin (France). En: Buffler, R.T., Schlager, W., Pisiotto, K.A. (Eds.), Initial Reports of the Deep Sea Drilling Project 77, 339-376.

Craig H., 1957. Isotopic standars for carbon and oxygen and correction Factor of Mass Spectrographic Analisys of carbon dioxide. Geochimica et Cosmochimica Acta 12, 133149.

Crame, J.A., 1991. Trophic structure. En: Briggs, D.E.G., Crowter, P.R. (Eds.), Palaeobiology. A Synthesis. Blacwell Scientific Publications, Oxford, 583 pp.

Cuitiño, J.I., 2011. Registro sedimentológico e isotópico de paleoambientes marinos y transicionales en el Patagoniano (Mioceno) del Lago Argentino. Tesis doctoral, Universidad de Buenos Aires, 229 pp.

Cuitiño, J.I., Ventura Santos, R., Alonso Muruaga P.J., Scasso, R.A., 2015. Sr-stratigraphy and sedimentary evolution of early Miocene marine foreland deposits in the northern Austral (Magallanes) Basin, Argentina. Andean Geology 42, 364-385.

Dalziel, I.W.D., 1981. Backarc extension in the southern Andes: a review and critical reappraisal. Philos. Trans. R. Soc. London 300, 319-335.

Decastelli, O.O., Iñiguez Rodríguez, A.M., 1984. Argilominerales en sedimentitas del Ciclo Cuyano de la cuenca Neuquina, su evolución diagenética. Actas IX Congreso Geológico Argentino, Bariloche 3, 300-316.

Derry, L.A., Kaufman, A.J., Jacobsen, S.B., 1992. Sedimentary cycling and environmental change in the Late Proterozoic: Evidence from stable and radiogenic isotopes. Geochimica et Cosmochimica Acta 56(3), 1317-1329. 
Dessanti, R.N., 1973. Descripción geológica de la Hoja 29b, Bardas Blancas, Provincia de Mendoza. Servicio Nacional de Minas y Geología Boletín 139, 1-70.

Dickinson, W., Breard, L., Brakenridge, G., Erjavec, J., Ferguson, R., Inman, K., Knepp, R., Lindberg, F., Ryberg, P., 1983. Provenance of North American Phanerozoic sandstones in relation to tectonic setting. Geological Society of America Bulletin 94, 222-235.

Digregorio, J.H., Uliana, M.A., 1979. Cuenca Neuquina. En: Turner, J.C.M. (Ed.), II Simposio de Geología Argentina, Córdoba 2, 985-1032.

Dott, R.H., 1964. Wacke, graywacke and matrix-what approach to immature sandstone classification. Journal of Sedimentary Petrology 34, 625-632.

Douglas, R.G., Savin, S.M., 1973. Oxygen and carbon isotope analyses of Cretaceous and Tertiary foraminifera from Central North Pacific. Initial Report Deep Sea Drilling Project 17, 591-605.

Doyle, P., Poiré, D.G., Spalletti, L.A., Pirrie, D., Brenchley, P., Matheos, S.D., 2005. Relative oxygenation of the Tithonian-Valanginian Vaca Muerta- Chachao formations of the Mendoza Shelf, Neuquén Basin, Argentina. En: Veiga, G.D., Spalletti, L.A., Howell, J.A., Schwarz, E. (Eds.), The Neuquén Basin, Argentina: a Case Study in Sequence Stratigraphy and Basin Dynamics. Geological Society, London, Special Publication 252, 185-206.

Duchamp-Alphonse, S., Fiet, N., Adatte, T., Maurice, P., 2011. Climate and sea-level variations along the northwestern Tethyan margin during the Valanginian C-isotope excursion: mineralogical evidence from the Vocontian Basin (SE France). Palaeogeography, Palaeoclimatology, Palaeoecology 302, 243-254.

Dumas, S., Arnott, R.W.C., 2006. Origin of hummocky and swaley cross-stratification - the controlling influence of unidirectional current strength and aggradation rate. Geology 34, 1073-1076.

Dunham, R.J., 1962. Classification of Carbonate Rocks according to Depositional Texture. En: Ham, W.E. (Ed.), Classification of Carbonate Rocks a symposium. American Association of Petroleum Geologists Memoir 1, 108-121.

Embry, A.F., Klovan, J.E., 1972. Absolute water depth limits of late Devonian paleoecological zones. Geologische Rundschau 61(2), 672-686.

Epstein, S., Buchsbaum, R., Lowenstam, H.A., Urey, H.C., 1953. Revised carbonate-water isotopic temperature scale. Geological Society of America Bulletin 64, 1315-1326.

Erba, E., Bartolini, A., Larson, R.L., 2004. Valanginian Weissert oceanic anoxic event. Geology $32,149-152$.

Esquevin, J., 1969. Influencié de la composition chimique des illites sur leer cristallinite. 
Bulletin Centre Recherche Pau 3(1), 147-153.

Fernández, M.S., 1998. Nuevo material de Caypullisaurus bonapartei Fernández (Reptilia: Ichthyosauridae) del Jurásico Superior de la cuenca Neuquina, Argentina. Ameghiniana 35, 21-24.

Fernández-Carmona, J., Riccardi, A.C., 1998. First record of Chitinoidella Doben in the Tithonian of Argentina. Actas del X Congreso Latinoamericano de Geología y VI Congreso Nacional de Geología Económica, Buenos Aires 1, 292.

Feruglio, E., 1938. El Cretáceo superior del Lago San Martín y de las regiones adyacentes. Physis 12, 293-342.

Feruglio, E. 1950. Descripción Geológica de la Patagonia. Y.P.F. Buenos Aires, Tomos I, II, III.

Fielding, C.R., 2006. Upper flow regime sheets, lenses and scour fills: extending the range of architectural elements for fluvial sediment bodies Sedimentary Geology 190, 227-240.

Fildani, A., Cope, T., Graham, S., Wooden, J., 2003. Initiation of the Magallanes foreland basin: Timing of the southernmost Patagonian Andes orogeny revised by detrital zircon provenance analysis. Geology 31(12), 1081-1084.

Flügel, E., 2004. Microfacies of Carbonate Rocks: Analysis, Interpretation and Application. Springer, New York, 976 pp.

Fluteau, F., Ramstein, G., Besse, J., Guiraud, R., Masse, J.P., 2007. Impacts of palaeogeography and sea level changes on Mid-Cretaceous climate. Palaeogeography, Palaeoclimatology, Palaeoecology 247, 357-381.

Folk, R.L., 1965. Some aspects of recrystallization in ancient limestones. En: Pray, L.C., Murray, R.C. (Eds.), Dolomitization and limestone diagenesis. SEPM, Special Publication 13, 1448.

Folk, R.L., Andrews, P.B., Lewis, D.W., 1970. Detrital sedimentary rock classification and nomenclature for use in New Zealand. New Zealand Journal of Geology and Geophysics 13, 937-968.

Föllmi, K.B., 2012. Early Cretaceous life , climate and anoxia. Cretaceous Research 35, 230-257.

Fossa Mancini, E., Feruglio, E., Yussen De Campana, J., 1938. Una reunión de geólogos de YPF y el problema de la Nomenclatura Estratigráfica. Boletín de Informaciones Petroleras 171, 3-95.

Franzese, J.R., Spalletti, L.A., 2001. Late Triassic-early Jurassic continental extension in southwestern Gondwana: tectonic segmentation and pre-break-up rifting. Journal of South American Earth Sciences 14, 257-270.

Franzese, J.R, Spalletti, L.A, Gomez Pérez, I., Macdonald, D., 2003. Tectonic and paleoenvironmental evolution of Mesozoic sedimentary basins along the Andes 
foothills of Argentina ( $3 \mathrm{U}-54^{\circ} \mathrm{S}$ ). Journal of South American Earth Sciences 16, 81-90.

Franzese, J.R., Veiga, G.D., Schwarz, E., Gómez Pérez, I., 2006. Tectonostratigraphic evolution of a Mesozoic graben border system: the Chachil depocentre, southern Neuquén Basin, Argentina. Journal of the Geological Society 163, 707-721.

Frimmel, H.G., 2009. Trace element distribution in Neoproterozoic carbonates as palaeoenvironmental indicator. Chemical Geology 258, 338-353.

Garbán, G., 2016. Curso de Quimioestratigrafía y Geoquímica del petróleo. Universidad de Buenos Aires, Junio de 2016.

Gasparini, Z., Spalletti, L.A., Fernández, M., De la Fuente, M., 1999. Tithonian marine reptiles from the Neuquén Basin: diversity and paleoenvironments. Revue de Paléobiologie 18, 335-345.

Gaucher, C., 2012. Curso de Quimioestratigrafía isotópica: aplicaciones geocronológicas, paleoclimatológicas y paleoambientales. Centro de Investigaciones Geológicas, Noviembre de 2012.

German, C.R., Elderfield, H., 1990. Application of the Ce anomaly as a paleoredox indicator: the ground rules. Paleoceanography 5, 823-833.

Ghiglione, M. C., Likerman, J., Barberón, V., Giambiagi, L.B., Aguirre-Urreta M.B., Suarez F., 2014. Geodynamic context for the deposition of coarse-grained deep-water axial channel systems in the Patagonian Andes. Basin Research 26, 726-745.

Ghiglione, M.C., Suarez, F., Ambrosio, A., Da Poian, G., Cristallini, E.O., Pizzio, M.F., Reinoso, R.M., 2009. Structure and evolution of the Austral basin fold- thrust belt, southern Patagonian Andes. Revista de la Asociación Geológica Argentina 65, 215-226.

Gluyas, J., Garland, C., Oxtoby, N.H., Hogg, A.J.C., 2000. Quartz cement: the Miller's tale. En: Worden, R.H., Morad, S. (Eds.) Quartz Cementation in Sandstones. International Association of Sedimentologists, Special Publication 29, 199-218.

Gómez Dacal, A.R., Gómez Peral, L.E., Spalletti, L.A., Poiré, D.G., Borya, A., 2014a. Petrología y diagénesis de las formaciones Vaca Muerta y Chachao en el Puesto Loncoche: resultados preliminares. XIV Reunión Argentina de Sedimentología, Puerto Madryn, 121-122.

Gómez Dacal, A.R., Sial, A.N., Gómez Peral, L.E., Spalletti, L.A., Poiré, D.G., 2014b. Isótopos estables de $\mathrm{C}$ y $\mathrm{O}$ de las formaciones Vaca Muerta y Chachao en sector mendocino de la Cuenca Neuquina: primeros resultados. XIV Reunión Argentina de Sedimentología, Puerto Madryn, 123-124.

Gómez Dacal, A.R., Sial, A.N., Gómez Peral, L.E., Spalletti, L.A., Poiré, D.G., 2016. Estudio comparado de isótopos estables de carbono en sucesiones sedimentarias del intervalo 
Tithoniano- Valanginiano de las Cuencas Neuquina y Austral. VII Congreso Latinoamericano de Sedimentología - XV Reunión Argentina de Sedimentología, Santa Rosa, 87.

Gómez Peral, L.E., 2008. Petrología y diagénesis de las unidades sedimentarias precámbricas de Olavarría, Provincia de Buenos Aires. Tesis, Universidad Nacional de La Plata, 619 pp.

Gómez Peral, L.E., Schwarz, E., Sial, A.N., Spalletti, L.A., 2012. Palaeo-proxies recording primary signature of $\mathrm{C}-\mathrm{O}$ isotope data from the Valanginian Mulichinco Formation, Neuquen Basin, Argentina: First results. 8 Simposio Sudamericano de Geología Isotópica, Medellín, Colombia, CD Actas.

González, L., Herrero, C., Kelm, U., 1998. Springhill Formation, Magellan Basin, Chile: formation water characteristics and mineralogy. Marine and Petroleum Geology 15, 661-666.

Gröcke, D.R., Price, G.D., Robinson, S.A., Baraboshkin, E.Y., Mutterlose, J., Ruffell, A.H., 2005. The upper Valanginian (Early Cretaceous) positive carbon-isotope event recorded in terrestrial plants. Earth and Planetary Science Letters 240, 495-509.

Groeber, P., 1946. Observaciones Geológicas a lo largo del meridiano 70. Asociación Geológica Argentina, Reimpresiones 1, 1-174.

Grousset, F., Latouche, C., Maillet, N., 1983. Clay minerals as indicators of wind and current contribution to post-glacial sedimentation on the Azores/Iceland ridge. Clay Minerals $18,65-75$.

Gulisano, C.A., Gutiérrez Pleimling, A., 1994. Field Guide to the Jurassic of the Neuquén Basin, province of Neuquén. Secretaría de Minería de la Nación, Dirección Nacional del Servicio Geológico, Publicación 158, 1-111.

Gulisano, C.A., Gutiérrez Pleimling, A.R., Digregorio, R.E., 1984. Análisis estratigráfico del intervalo Tithoniano-Valanginiano (Formaciones Vaca Muerta, Quintuco y Mulichinco) en el suroeste de la provincia de Neuquén. Actas del IX Congreso Geológico Argentino, Bariloche 1, 221-235.

Halle, T.G., 1913. Some Mesozoic plant-bearing deposits in Patagonia and Tierra del Fuego and their floras. Kungliga Svensa. Sv. Vetenskaps Akademien Handlingar 51(3), 3-58.

Hatcher, J.B., 1897. On the geology of Southern Patagonia. American Journal of Science 4(23), 327-354.

Hennig, S., Weissert, H., Bulot, L., 1999. C-isotope stratigraphy, a calibration tool between ammonite- and magnetostratigraphy: the Valanginian- Hauterivian transition. Geologica Carpathica 50, 91-96.

Hernández-Ocaña, M.I., Quiroz-Barroso S.A., Sour-Tovar F., 2015. Tafonomía y paleoecología 
de las ostras de la Formación San Juan Raya, Aptiense del sureste de Puebla, Mexico. Boletín Geológico y Minero 126(1), 37-62.

Herrero Ducloux, A., 1946. Contribución al conocimiento geológico del Neuquén extrandino. Boletín de Informaciones Petroleras 23(226), 1-39.

Hilting, A.K., Kump, L.R., Bralower, T.J., 2008. Variations in the oceanic vertical carbon isotope gradient and their implications for the Paleocene-Eocene biological pump. Paleoceanography, 23.

Hoefs, J., 1997. Stable isotope geochemistry. Springer (4ํㅡ. Ed.), New York, 1-201.

Holser, W.T., 1997. Evaluation of the application of rare-earth elements to paleoceanography. Palaeogeography, Palaeoclimatology, Palaeoecology 132, 309-323.

Howell, J.A., Schwarz, E., Spalletti, L.A., Veiga, G.D., 2005. The Neuquén Basin: an overview. En: Veiga, G.D., Spalletti, L.A., Howell, J.A., Schwarz, E. (Eds.), The Neuquén Basin, Argentina: a Case Study in Sequence Stratigraphy and Basin Dynamics. Geological Society, London, Special Publication 252, 1-14.

James, N.P., Choquette, P.W., 1990, Limestones- The sea-floor diagenetic environment. En:. Mcllreath, I.A., Morrow, D.W. (Eds.), Diagenesis. Geoscience Canada 4, 13-34.

Jarvis, I., 1980. Palaeobiology of Upper Cretaceous belemnites from the phosphatic chalk of the Anglo-Paris Basin. Palaeontology 23(4), 889-914.

Jones, C.E., Jenkyns, H.C., Hesselbo, S.P., 1994. Strontium isotopes in Early Jurassic sea water. Geochimica et Cosmochimica Acta 58, 1285-1301.

Kaufman, A.J., Knoll, A.H., Narbonne, G.M., 1997. Isotopes, ice ages, and terminal Proterozoic earth history. Proceedings of the National Academy of Sciences of the United States of America 94(13), 6600-6605.

Kemper, E., 1987. Das Klima der Kreide-Zeit. Geologisches Jahrbuch 96, 5-185.

Kershaw, S., 1994. Classification and geological significance of biostromes. Facies 31, 81-91.

Kidwell, S.M., 1991. Taphonomic Feedback (Live /Dead Interaction) in the Genesis of Biogenic Bed: Key to Reconstruction Sedimentary Dynamics. En: Einsele, G., Ricken, W., Seilacher, E. (Eds.) Cycles and Events in Stratigraphy, Springer Verlag, 268-282.

Kidwell, S.M., Bosence, D.W.J., 1991. Taphonomy and time-averaging of marine shelly faunas. En: Allison, A., Briggs, D.E.G. (Eds.) Taphonomy: Releasing the data locked in the fossil record, Plenum Press, Topics in Geobiology 9, 116-209.

Kielbowicz, A.A., Ronchi, D.I., Stach, N.H., 1983. Foraminíferos y ostrácodos Valanginianos de la Formación Springhill, Patagonia Austral. Revista de la Asociación Geológica Argentina 38, 313-339.

Kietzmann, D.A., Palma, R.M., 2009. Tafofacies y biofacies de Formación Vaca Muerta en el 
sector surmendocino de la Cuenca Neuquina: implicancias paleoecológicas, sedimentológicas y estratigráficas. Ameghiniana 46, 321-343.

Kietzmann, D.A., Vennari, V.V., 2013. Sedimentología y estratigrafía de la Formación Vaca Muerta (Tithoniano-Berriasiano) en el área del cerro Domuyo, norte de Neuquén, Argentina. Andean Geology 40, 41-65.

Kietzmann, D.A., Martín-Chivelet, J., Palma, R.M., López-Gómez, J., Lescano, M., Concheyro, A., 2011. Evidence of precessional and eccentricity orbital cycles in a Tithonian source rock: the mid-outer carbonate ramp of the Vaca Muerta Formation, Northern Neuquén Basin, Argentina. American Association of Petroleum Geologists Bulletin 95, 14591474.

Kietzmann, D.A., Palma, R.M., Bressan, G.S., 2008. Facies y microfacies de la rampa TithonianaBerriasiana de la Cuenca Neuquina (Formación Vaca Muerta) en la sección del Arroyo Loncoche - Malargüe, Provincia de Mendoza. Revista de la Asociación Geológica Argentina 63, 696-713.

Kietzmann, D.A., Palma, R.M., Paula, M., Llanos, I., 2015. Cyclostratigraphy of an orbitallydriven Tithonian-Valanginian carbonate ramp succession, Southern Mendoza, Argentina: Implications for the Jurassic-Cretaceous boundary in the Neuquén Basin. Sedimentary Geology 315, 29-46.

Kietzmann, D.A., Palma, R.M., Riccardi, A.C., Martín-Chivelet, J., López-Gómez, J., 2014. Sedimentology and sequence stratigraphy of a Tithonian - Valanginian carbonate ramp (Vaca Muerta Formation): A misunderstood exceptional source rock in the Southern Mendoza area of the Neuquén. Sedimentary Geology 302, 64-86.

Korte, C., Hesselbo, S.P., 2011. Shallow marine carbon and oxygen isotope and elemental records indicate icehouse-greenhouse cycles during the Early Jurassic. Paleoceanography 26, 1-18.

Korte, C., Hesselbo, S.P., Jenkyns, H.C., Rickaby, R.E.M., Spötl, C., 2009. Palaeoenvironmental significance of carbon and oxygen isotope stratigraphy of marine Triassic-Jurassic boundary sections in SW Britain. Journal of the Geological Society 166, 431-445.

Kozlowki, E., Manceda, R., Ramos, V.A., 1993. Estructura. En: Ramos V.A., (Ed.), Geología y recursos naturales de la provincia de Mendoza. Actas del XII Congreso Geológico Argentino y II Congreso de Exploración de Hidrocarburos, Mendoza 1, 235-256.

Kraemer, P.E., 1991. Estructura y Evolución de los Andes Patagónicos entre los 49 40` y 50은 40' latitud sur, Provincia de Santa Cruz. Argentina. Tesis doctoral, Universidad Nacional de Córdoba, 335 pp.

Kraemer, P.E., Riccardi, A.C., 1997. Estratigrafía de la región comprendida entre los lagos 
Argentino y Viedma $\left(49^{\circ} 40^{\prime}-50^{\circ} 10^{\prime}\right.$ LS), Provincia de Santa Cruz. Revista de la Asociación Geológica Argentina 52(3), 333-360.

Kraemer, P.E., Ploszkiewicz, J.V., Ramos, V.A., 2002. Estructura de la cordillera patagónica austral entre los 460 y $52^{\circ}$ S. En: Haller, M.J. (Ed.), Geología y Recursos Naturales de Santa Cruz. Relatorio del Decimoquinto Congreso Geológico Argentino 21(1), 1-12.

Kubler, B., 1967. La cristallinité de Illité et les zones tout á fair supérieures du métamorphisme. En: Etages Tectoniques-Colloque de Neuchâtel 1966, Université Neuchâtel, á la Baconnière, Suisse, 105-122.

Larriestra, C., Merino, R., 2014. High Resolution Non-Destructive Chemostratigraphy of Vaca Muerta Fm: New Evidences of Black Shale Sedimentology Features. American Association of Petroleum Geologists, Annual Convention and Exhibition, Houston, Article 1840115.

Lawrence, M.G., Greig, A., Collerson, K.D., Kamber, B.S., 2006. Rare earth element and yttrium variability in South East Queensland waterways. Aquatic Geochemistry 12, 39-72.

Lazo, D.G., Aguirre-Urreta, M.B., Price, G.D., Rawson, P.F., Ruffell, A.H., Ogle, N., 2008. Palaeosalinity variations in the Early Cretaceous of the Neuquén Basin, Argentina: Evidence from oxygen isotopes and palaeoecological analysis. Palaeogeography, Palaeoclimatology, Palaeoecology 260, 477-493.

Lazo, D.G., Cichowolski, M., Rodriguez, D.L., Aguirre-Urreta, M.B., 2005. Lithofacies, palaeoecology and palaeoenvironments of the Agrio Formation, Lower Cretaceous of the Neuquén Basin, Argentina. En: Veiga, G.D., Spalletti, L.A., Howell, J.A., Schwarz, E. (Eds.), The Neuquén Basin, Argentina: a Case Study in Sequence Stratigraphy and Basin Dynamics. Geological Society, London, Special Publication 252, 295-315.

Leanza, A.F., 1967. Anotaciones sobre los fosiles Jurásico-Cretácicos de Patagonia austral (Coleccion Feruglio) conservados en la Universidad de Bologna. Acta Geológica 9, 121187.

Leanza, H.A., 1972. Acantholissonia, nuevo género de Ammonites del Calangiano de Neuquén, República Argentina y su posición estratigráfica. Revista de la Asociación Geológica Argentina 27(1) 63-70.

Leanza, H.A., 1973. Estudio sobre los cambios faciales de los estratos limítrofes JurásicoCretácicicos entre Loncopué y Picún Leufú, Provincia del Neuquén, República Argentina. Revista de la Asociación Geológica Argentina 28, 97-132.

Leanza, H.A., 1981. Faunas de ammonites del Jurásico Superior y Cretácico Inferior de América del Sur, con especial consideración de la Argentina. En: Volkheimer, W., Musacchio, E. (Eds.), Cuencas sedimentarias del Jurásico y Cretácico de América del Sur 2, 559-597. 
Leanza, H.A., 1993. Estratigrafía del Mesozoico posterior a los Movimientos Intermálmicos en la comarca del Cerro Chachil, provincia del Neuquén. Revista de la Asociación Geológica Argentina 48, 71-84.

Leanza, H.A., Hugo, C.A., 1977. Sucesión de amonites y edad de la Formación Vaca Muerta y sincrónicas entre los paralelos $35^{\circ}$ y $40^{\circ}$ L. S. Cuenca Neuquina- Mendocina. Revista de la Asociación Geológica Argentina 32, 248-264.

Leanza H.A., Zeiss, A., 1990. Upper Jurassic Limestones from Argentina (Neuquén Basin): Stratigraphy and Fossils. Facies 22, 169-186.

Leanza H.A., Hugo, C.A., Repol, D., Salvarredy Aranguren, M., 2003. Miembro Huncal (Berriasiano Inferior): un episodio turbidítico en la Formación Vaca Muerta, Cuenca Neuquina, Argentina. Revista de la Asociación Geológica Argentina 58(2), 248-254.

Leanza, H.A., Marchese, H., Riggi, J., 1977. Estratigrafía del Grupo Mendoza con especial referencia a la Formación Vaca Muerta entre los paralelos 35 y 40 L.S., Cuenca Neuquina-Mendocina. Revista de la Asociación Geológica Argentina 32(3), 190-208.

Leanza, H.A., Sattler, F., Martinez, R., Carbone, O., 2011. La Formación Vaca Muerta y Equivalentes (Jurásico Tardío-Cretácico Temprano) en la Cuenca. Neuquina. En: Leanza, H.A., Arregui, C., Carbone, O., Daniela, J.C., Vallés, J.M. (Eds.), Geología y Recursos Naturales de la Provincia del Neuquén, 113-129.

Legarreta, L., Gulisano, C.A., 1989. Análisis estratigráfico secuencial de la Cuenca Neuquina (Triásico superior-Terciario inferior). En: Chebli, G., Spalletti L.A. (Eds.), Cuencas Sedimentarias Argentinas, Serie Correlación Geológica 6, 221-243.

Legarreta, L., Kozlowski, E., 1981. Estratigrafia y sedimentologia de la Formación Chachao, Provincia de Mendoza. Actas del VIII Congreso Geológico Argentino, San Luis 2, 521543.

Legarreta, L., Uliana, M.A., 1991. Jurassic- Cretaceous marine oscillations and geometry of back-arc basin fill, central Argentine Andes. Internacional Association of Sedimentology, Special Publication 12, 429-450.

Legarreta, L., Uliana, M., 1996. The Jurassic succession in west-central Argentina: stratal patterns, sequences and paleogeographic evolution. Palaeogeography, Palaeoclimatology, Palaeoecology 120, 303-330.

Legarreta, L., Gulisano, C.A., Uliana, M.A., 1993. Las Secuencias Sedimentarias JurásicoCretácicas. En: Ramos V.A. (Ed.), Geología y Recursos Minerales de Mendoza. Relatorio XII Congreso Geológico Argentino y II Congreso de Exploración de Hidrocarburos, Mendoza 87-114.

Legarreta, L., Kozlowski, E., Bol, A., 1981. Esquema estratigráfico y distribución de facies del 
Grupo Mendoza en el ámbito surmendocino de la Cuenca Neuquina. Actas del VIII Congreso Geológico Argentino, San Luis 3, 389-409.

Lescano, M., Kietzmann, D.A., 2010. Nanofósiles Calcáreos de la Formación Vaca Muerta (Tithoniano inferior- Valanginiano inferior) en la región sudoccidental de la Provincia de Mendoza. Actas del X Congreso Argentino de Paleontología y Bioestratigrafía y VII Congreso Latinoamericano de Paleontología, La Plata, 94.

Li, Q., McArthur, J.M., Doyle, P., Janssen, N., Leng, M.J., Müller, W., Reboulet, S., 2013. Evaluating $\mathrm{Mg} / \mathrm{Ca}$ in belemnite calcite as a palaeo-proxy. Palaeogeography, Palaeoclimatology, Palaeoecology 388, 98-108.

Liermann, L.J., Mathur, R., Wasylenki, L.E., Nuester, J., Anbar, A.D., Brantley, S.L. 2011. Extent an isotopic composition of Fe and $\mathrm{Mn}$ release from two Pennsylvania shales in the presence of organic ligands and bacteria. Chemical Geology 281, 167-180.

Lini, A., Weissert, H.L., Erba, E., 1992. The Valanginian carbon isotope event: a first episode of greenhouse climate conditions during the Cretaceous. Terra Nova 4, 374-384.

Lluch, J.J., Spalletti, L.A., 1976. Minerales de las arcillas en los sedimentos actuales de la región del Cerro San Lorenzo, provincia de Santa Cruz. Revista de la Asociación Geológica Argentina 31, 23-32.

Machel, H.G., 2000. Application of cathodoluminiscenceto carbonate diagenesis. En: Pagel, M., Barbin, V., Blanc, P., Ohnenstetter, D. (Eds.), Cathodoluminiscence in Geocience, Berlin, Springer-Verlag 271-301.

Marchese, H.G., 1971. Litoestratigrafía y variaciones faciales de las sedimentitas mesozoicas de la Cuenca Neuquina, Prov. de Neuquén, Rep. Argentina. Revista de la Asociación Geológica Argentina 26, 343-410.

Marshall, D.J., 1988. Cathodoluminiscence of Geological Materials. Unwin-Hyman, Londres, $146 \mathrm{pp}$.

Marshall, J.D., 1992. Climatic and oceanographic isotopic signals from the carbonate rock record and their preservation. Geological Magazine 129(2), 1-143.

Mc Arthur, J.M., Mutterlose, J., Price, G.D., Rawson, P.F., Ruffell, A.H., Thirlwall, M.F., 2004. Belemnites of Valanginian, Hauterivian and Barremian age: Sr-isotope stratigraphy, composition (87Sr/86Sr, $813 \mathrm{C}, 8180, \mathrm{Na}, \mathrm{Sr}, \mathrm{Mg}$ ), and palaeo-oceanography. Palaeogeography, Palaeoclimatology, Palaeoecology 202(3-4), 253-272.

Mc Arthur, J.M., Doyle, P., Leng, M.J., Reeves, K., Williams, C.T., Garcia-Sanchez, R., Howarth, R.J., 2007. Testing palaeo-environmental proxies in Jurassic belemnites: $\mathrm{Mg} / \mathrm{Ca}, \mathrm{Sr} / \mathrm{Ca}$, $\mathrm{Na} / \mathrm{Ca}, \delta^{18} \mathrm{O}$ and $\delta^{13} \mathrm{C}$. Palaeogeography, Palaeoclimatology, Palaeoecology 252, 464480. 
McDonald, D., Gómez-Pérez, I., Franzese, J.R., Spalletti, L.A., Lawver, L., Gahagan, L., Dalziel, I., Thomas, C., Trewin, N., Hole, M., Paton, D., 2003. Mesozoic break-up of SW Gondwana: implications for regional hydrocarbon potential of the southern South Atlantic. En: Golonka, J. (Ed.), Thematic Set on Paleogeographic Reconstruction and Hydrocarbon Basins: Atlantic, Caribbean, South America, Middle East, Russian Far East, Arctic. Marine and Petroleum Geology 20, 287-308.

McLennan, S.M., 1989. Rare earth elements in sedimentary rocks: Influence of provenance and sedimentary processes. Reviews in Mineralogy and Geochemistry 21, 169-200.

Meissner, P., Mutterlose, J., Bodin, S., 2015. Latitudinal temperature trends in the northern hemisphere during the Early Cretaceous (Valanginian-Hauterivian). Palaeogeography, Palaeoclimatology, Palaeoecology 424, 17-39.

Melinte, M., Mutterlose, J., 2001. A Valanginian (Early Cretaceous) Boreal nannoplankton excursion in sections from Romania. Marine Micropaleontology 43, 1-25.

Miall, A.D., 1978. Lithofacies types and vertical profile models in braided river deposits: a summary. En: Miall, A.D. (Ed.), Fluvial Sedimentology. Canadian Society of Petroleum Geologists Bulletin, Memoir 5, 579-604.

Mitchum, R.M., Uliana M.A., 1986. Seismic Stratigraphy of Carbonate Depositional Sequences, Upper Jurassic - Lower Cretaceous, Neuquén Basin, Argentina. En: Bero, B.R., Woolverton, D.G. (Eds.), Seismic stratigraphy: an integrated approach to hydrocarbon exploration. American Association of Petroleum Geologists, Memoir 39, 255-274.

Mombrú, C.A., Bettini, F., Vazquez, J., 1976. Significado estratigráfico y sedimentología de las acumulaciones biocarbonáticas del Cretácico inferior surmendocino. Actas del VI Congreso Geológico Argentino, Bahía Blanca 1, 685-700.

Mombrú, C.A., Uliana, M.A., Bercowski, F., 1978. Estratigrafía y sedimentología de las acumulaciones biocarbonáticas del Cretácico inferior Surmendocino. VII Congreso Geológico Argentino, Neuquén 1, 685-700.

Moore, D.M., Reynolds, R.C., 1989. X-Ray Diffraction and the Identification and Analysis of Clay Minerals. Oxford University Press, Oxford, 329 pp.

Moyano Paz, D., Tettamanti, C., Poiré, D.G., 2016. Análisis de facies, composición y procedencia de psamitas de la Formación La Anita (Cretácico tardio) en el Cerro Calafate, Santa Cruz. VII Congreso Latinoamericano de Sedimentología -XV Reunión Argentina de Sedimentología, La Pampa, 122.

Myrow, P.M., Southard, J.B., 1996. Tempestite deposition. Journal of Sedimentary Research $66,875-887$.

Nawratil, A., Gómez, H., Larriestra, C., 2012. Key tools for black shales evaluation: geostatistics 
and inorganic geochemistry applied to Vaca Muerta Formation, Neuquén Basin, Argentina. American Association of Petroleum Geologists, International Conference \& Exhibition, Singapur, Article 41028.

Nothdurft, L.D., Webb, G.E., Kamber, B.S., 2004. Rare earth element geochemistry of Late Devonian reefal carbonates, Canning Basin, Western Australia: confirmation of a seawater REE proxy in ancient limestones. Geochimica et Cosmochimica Acta 68, 263283.

Nullo, F.E., 1979. Descripción geológica de la Hoja 39c, Paso Flores. Servicio Geológico Nacional, Boletín 167, 1-70.

Nullo, F.E., Proserpio, C.A., Blasco de Nullo, G., 1981. El Cretácico de la Cuenca Austral entre el Lago San Martín y Río Turbio. En: Volkheimer, W., Mussachio, E.A. (Eds.), Cuencas Sedimentarías del Jurásico y Cretácico de América del Sur, 181-220.

Nullo, F.E., Stephens, G.S., Combina, A., Dimieri, L., Baldauf, P., Bouza, P., 2004. Descripción geológica de la Hoja Malargüe, provincia de Malargüe, escala 1:250000. SEGEMAR, (Inédito), 107 pp.

Nullo, F.E., Stephens G.S., Otamendi J., Baldauf, P.E., 2002. El volcanismo del Terciario superior del sur de Mendoza. Revista de la Asociación Geológica Argentina 57(2), 119-132.

Nunn, E.V., Price, G.D., 2010. Late Jurassic (Kimmeridgian-Tithonian) stable isotopes $\left(\delta^{18} \mathrm{O}, \delta^{13} \mathrm{C}\right)$ and $\mathrm{Mg} / \mathrm{Ca}$ ratios: new palaeoclimate data from Helmsdale, northeast Scotland. Palaeogeography, Palaeoclimatology, Palaeoecology 292, 325-335.

Odin, G.S., Matter, A., 1981. De glauconiarum irigine. Sedimentology 28, 611-641.

Olivo, M., 2016. Análisis sedimentológico y estratigráfico secuencial de los sistemas fluviales y eólicos del valanginiano en el sector central de la Provincia de Neuquén, Cuenca Neuquina, Argentina. Tesis doctoral, Universidad Nacional de La Plata, 234 pp.

Palma, R.M., Angeleri, M.A., 1992. Early Cretaceous serpulid limestones: Chachao Formation, Neuquén Basin, Argentina. Facies 27, 175-178.

Palma, R.M., Lanés, S., 2001. Shell bed stacking patterns in the Chachao Formation (Early Valanginian) in Malargüe area, Mendoza province, Neuquén Basin-Argentina. Carbonates and Evaporites 16, 168-180.

Palma, R.M., Bressan, G.S., Kietzmann, D.A., 2008. Diagenesis of a bioclastic oyster deposit from the Lower Cretaceous (Chachao Formation), Neuquén Basin, Mendoza Province, Argentina. Carbonates and Evaporites 23, 39-49.

Palma, R.M., Lanés, S., Miretzky, P., Fazio, A.M., 1999. Evidencias geoquímicas y neomorfismo en rocas de la Formación Chachao (Valanginiano)-anticlinal Malargüe, Mendoza. Revista de la Asociación Geológica Argentina 54, 248-256. 
Palma, R.M., Meléndez, M.N., Calvo, J.P., Lanés, S.G., 2000. Abultamiento biodetrítico en la Formación Chachao (Valanginiano): caracterísiticas y evolución ambiental, Malargue, Mendoza. Revista de la Asociación Geológica Argentina. 55(4), 300-308.

Pankhurst, R.J., Riley, T.R., Fanning, C.M., Kelley, S.P., 2000. Episodic silicic volcanism in Patagonia and Antarctic Peninsula: Chronology of magmatism associated with the break-up of Gondwana. Journal of Petrology 41, 605-625.

Panza, J.L., Nullo, F.E., De Barrio, R. , Franchi, M., Irigoyen, V., Lapido, O., Marín, G., Malumián N., Ramos, V., Anielli, C., Butrón, F., Genini, A., Jones, M., Cobos, J., Ragona, D., 1994. Mapa Geológico de la provincia de Santa Cruz, República Argentina, escala 1:750000. Dirección Nacional del Servicio Geológico, Secretaría de Minería de la República Argentina.

Pedrazzini, M., Cagnolatti, M., 2002. Los reservorios de la Formación Springhill en el territorio continental. En: Schiuma, M., Hinterwimmer, G., Vergani, G. (Eds.), Rocas Reservorio de las Cuencas Productivas de la Argentina. V Congreso de Exploración y Desarrollo de Hidrocarburos, Mar del Plata, 29-53.

Perillo, M.M., Best, J.L., García, M.H., 2014. A new phase diagram for combined-flow bedforms. Journal of Sedimentary Research 84, 301-313.

Peroni, G., Cagnolatti, M., Pedrazzini, M., 2002. Cuenca Austral: marco geológico y reseña histórica de la actividad petrolera. En: Schiuma, M., Hinterwimmer, G. Vergani, G. (Eds.), Rocas Reservorio de las Cuencas Productivas Argentinas. V Congreso de Exploración y Desarrollo de Hidrocarburos, Mar del Plata, 11-19.

Petschick, R., Kuhn, G., Gingele, F., 1996. Clay mineral distribution in surface sediments of the South Atlantic: sources, transport, and relation to oceanography. Marine Geology 130, 203-229.

Pettijohn, F.J., 1957. Sedimentary Rocks. Harper, New York, 718 pp.

Pettijohn, F.J., Potter, P.E., Siever, R., 1972. Sand and Sandstone. Springer, New York, 553 pp.

Pettijohn, F.J., Potter, P.E., Siever, R., 1987. Sand and Sandstone. Springer, New York 553 pp.

Pirrie, D., Marshall, J.D., Doyle, P., Riccardi, A.C., 2004. Cool early Albian climates; new data from Argentina. Cretaceous Research 25, 27-33.

Poiré, D.G., Cereceda, A., Arrouy, J., 2014. Los reservorios del relleno sedimentario de la Cuenca Neuquina en superficie, con especial énfasis en sus facies turbidíticas. Recorrido geológico de campo, provincia de Santa Cruz (Argentina) y Chile. Guía de Campo Inédita: Centro de Investigaciones Geológicas, La Plata, 83 pp.

Poiré, D.G., Franzese, J.R., Muravchik, M., 2006. Calizas, margas y pelitas fétidas asociadas a las vulcanitas del Complejo El Quemado, Jurásico de Cuenca Austral, Argentina. IV 
Congreso Latinoamericano de Sedimentología y XI Reunión Argentina de Sedimentología. Bariloche, 183.

Poiré, D.G., Franzese, J.R., Spalletti, L.A., Matheos, S.D., 2007. Estratigrafía de las rocas reservorios de la Cuenca Austral en el sector cordillerano, provincia de Santa Cruz, Argentina. Guía de Campo Inédita, 112 pp.

Poiré, D.G., Matheos, S.D., Canessa, N.D., 2002. Petrografía de las calizas algales del techo de la Formación El Quemado (Jurásico superior), Lago Argentino, provinca de Santa Cruz, Argentina. IX Reunión Argentina de Sedimentología, Córdoba, 122.

Potter, P., Maynard, B., Depetris, P., 2005. Mud and Mudstones: introduction and overview. Springer, New York, 297 pp.

Price, G.D., Mutterlose, J., 2004. Isotopic signals from late Jurassic -early Cretaceous ( Volgian Valanginian ) sub-Arctic belemnites, Yatria River, Western Siberia. Journal of the Geological Society 161, 959-968.

Price, G.D., Nunn, E.V., 2010. Valanginian isotope variation in glendonites and belemnites from Arctic Svalbard: Transient glacial temperatures during the Cretaceous greenhouse. Geology 38(3), 251-254.

Pucéat, E., Lécuyer, C., Sheppard, S.M., Dromart, G., Reboulet, S., Grandjean, P., 2003. Thermal evolution of Cretaceous Tethyan marine waters inferred from oxygen isotope composition of fish tooth enamels. Paleoceanography 18(2), 7-1--7-12.

Pufahl, P.K., Grimm, K.A., Abed, A.M., Sadaqah, R.M.Y., 2003. Upper Cretaceous (Campanian) phosphorites in Jordan: implications for the formation of a south Tethyan phosphorite giant. Sedimentary Geology 161, 175-205.

Raigemborn, M.S., 2007. Estudio Estratigráfico, Sedimentológico y Composicional de las Sedimentitas del Terciario Inferior (Grupo Río Chico) en el Sector Sudoriental del Chubut Extraandino. Tesis doctoral, Universidad Nacional de La Plata, 351 pp.

Raigemborn, M.S., Gómez-Peral, L.E., Krause, J.M., Matheos, S.D., 2014. Controls on clay minerals assemblages in an early Palaeogene nonmarine succession: implications for the volcanic and paleoclimatic record of extra-andean patagonia, Argentina. Journal of South American Earth Sciences 52, 1-23.

Railsback, L.B., Anderson, T.F., Ackerly, S.C., Cisne, J.L., 1989. Paleoceanographic modeling of temperature-salinity profiles from stable isotope data. Paleoceanography 4, 585-591.

Ramos, V.A., Niemeyer, H., Skarmeta, J., Muñoz, J., 1982. Magmatic evolution of the Austral Patagonian Andes. Earth-Science Reviews 18, 411-443.

Ramos, V.A., 1999. Evolución Tectónica de la Argentina. En: Caminos, R. (Ed.), Geología Argentina. Instituto de Geología y Recursos Minerales, Anales 29, 715-759. 
Ramos, V.A., 2002. Evolución tectónica. En: Haller, M.J. (Ed.), Geología y Recursos Naturales de Santa Cruz. Relatorio del XV Congreso Geológico Argentino, El Calafate 1.23, 365-387.

Reineck, H.E., Wunderlich F., 1968. Classification and origin of flaser and lenticular bedding. Sedimentology 11, 99-104.

Reynolds, J.R.C., 1980. Interestratified clay minerals. En: Brindles, G.W., Brown, G. (Eds.), Crystal Structures of Clay Minerals and Their X-ray Identification. Mineralogical Society, 249-303.

Riccardi, A.C., 1971. Estratigrafía en el oriente de la Bahía de la Lancha, Lago San Martín, Santa Cruz, Argentina. Revista del Museo de la Plata, Sección Geología 7, 245-318.

Riccardi, A.C., 1988. The cretaceous system of southern South America. Geological Society of America, Memoir 168, 1-116.

Riccardi, A.C., 1991. Jurassic and Cretaceous marine connections between the Southeast Pacific and Tethys. Palaeogeography, Palaeoclimatology, Palaeoecology 87, 155-189.

Riccardi, A. C., 2015. Remarks on the Tithonian-Berriasian ammonite biostratigraphy of west central Argentina. Volumina Jurassica 13, 23-52.

Riccardi, A.C., Rolleri, E.O., 1980. Cordillera Patagónica Austral. En: Turner, J.C.M., (Ed.), Segundo Simposio de Geología Regional Argentina. Academia Nacional de Ciencias 2, 1173- 1304.

Riccardi, A.C., Damborenea, S.E., Manceñido, M.O., 1999. El Jurásico y Cretácico de la Cordillera Principal y la Cuenca Neuquina. Bioestratigrafía. En: Caminos, R. (Ed.), Geología Argentina. Instituto de Geología y Recursos Minerales, Anales 29, 419-432.

Riccardi, A.C., Damborenea, S.E., Manceñido, M.O., Leanza, H.A., 2011. Megainvertebrados jurásicos y su importancia geobiológica. En: Leanza, H.A., Arregui, C., Carbone, O., Daniela, J.C., Vallés, J.M. (Eds.), Geología y Recursos Naturales de la Provincia del Neuquén, 441-464.

Richiano, S., 2012. Sedimentología e Icnología de la Formación Río Mayer, Provincia de Santa Cruz Argentina. Tesis doctoral, Universidad Nacional de La Plata, 278 pp.

Richiano, S., 2015a. Environmental factors affecting the development of the Zoophycos ichnofacies in the Lower Cretaceous Río Mayer Formation (Austral Basin, Patagonia). Palaeogeography, Palaeoclimatology, Palaeoecology 439, 17-26.

Richiano, S., Varela, A.N., Gómez Peral, L.E., Cereceda, A., Poiré, D.G., 2015b. Composition of the Lower Cretaceous source rock from the Austral Basin (Río Mayer Formation, Patagonia, Argentina): Regional implication for unconventional reservoirs in the Southern Andes. Marine and Petroleum Geology 66, 764-790.

Richiano, S., Varela, A.N., Poiré, D.G., 2016. Heterogeneous distribution of trace fossils across 
initial transgressive deposits in rift basins: an example from the Springhill Formation, Argentina. Lethaia 49, 524-539.

Ricken W., Eder, W., 1991. Diagenetic modification of calcareous beds - an overview. En: Einsele, G., Ricken, W., Seilacher, A. (Eds.). Cycles and Events in Stratigraphy, 430-449.

Robbiano, J.A., Arbe, A., Bangui, A.H., 1996. Cuenca Austral Marina. En: Ramos, V.A., Turic, M. (Eds.), Geología y Recursos Naturales de la Plataforma continental Argentina. XIII Congreso Geológico Argentino y III Congreso de Exploración de Hidrocarburos, Buenos Aires, 343- 358.

Rodríguez, J., Miller, M., 2005. Cuenca Austral. Frontera Exploratoria de la Argentina. VI Congreso de Exploración y Desarrollo de Hidrocarburos, Mar del Plata, 307-324.

Russo, A., Flores, M.A., 1972. Patagonia Austral Extraandina. En: Leanza A.F. (Ed.), Geología Regional Argentina. Academia Nacional de Ciencias, 707-725.

Sagasti, G., 2001a. Estudio Sedimentológico y de Estratigrafía Secuencial de las sedimentitas carbonáticas de la Formación Agrio (Cretácico inferior), en el sector surmendocino de la Cuenca Neuquina, República Argentina. Tesis doctoral, Universidad Nacional de La Plata, 280 pp.

Sagasti, G., 2001b. La suceción rítmica dela Formación Agrio (Cretácico inferior) en el sur de la Provincia de Mendoza, y su posible vinculación con los ciclos de Milancovich. Revisa de la Asociación Argentina de Sedimentología 7(1-2), 1-22.

Sagasti G. y Ballent, S. 2002. Caracterización microfaunística de una transgresión marina: Formación Agrio (Cretácico inferior), Cuenca Neuquina, Argentina. Geobios 35, 721734.

Scasso, R.A., Limarino, C.O., 1997. Petrología y diagénesis de rocas clásticas. Asociación Argentina de Sedimentología, Publicación Especial 1, 258 pp.

Scasso, R.A., Alonso, S.M., Lanés, S., Villar, H.J., Lippai, H., 2002. Petrología y geoquímica de una ritmita marga-caliza del Hemisferio Austral: El Miembro Los Catutos (Formación Vaca Muerta), Tithoniano Medio de la Cuenca Neuquina. Revista de la Asociación Geológica Argentina 57(2), 143-159.

Shackleton, N.J., Kennett, J.P., 1975. Paleotemperature history of the Cenozoic and the initiation of Antarctic glaciation: oxygen and carbon isotope analyses in DSDP sites 277, 279 and 281. En: Kennett, J.P., Houtz, R.E., et al. (Eds.), Initial Reports of the Deep Sea Drilling Project, 29, 743-755.

Schwarz, E., 2003. Análisis paleoambiental y estratigrafía secuencial de la Formación Mulichinco (Valanginiano), en el sector septentrional de la Provincia de Neuquén, Cuenca Neuquina, Argentina. Tesis Doctoral. Universidad Nacional de La Plata, 329 pp. 
Schwarz, E., Spalletti, L.A., Veiga, G.D., 2011a. La Formación Mulichinco (Cretácico Temprano) en la Cuenca Neuquina. Relatorio del XVIII Congreso Geológico Argentino, Neuquén, Argentina, 131-144.

Schwarz, E., Veiga, G.D., Spalletti, L.A., Massaferro, J.L., 2011b. The transgressive infill of an inherited-valley system: The Springhill Formation (lower Cretaceous) in southern Austral Basin, Argentina. Marine and Petroleum Geology 28, 1218-1241.

Silva-Tamayo, J.C., Ramirez, C., Lara, M., Sial, A.N., Trujillo, D., Salazar, E., 2016. Sedimentology and chemostratigraphy of a Valanginian carbonate succession from the Baja Guajira Basin, northern Colombia. Brazilian Journal of Geology 20(10), 1-18.

Silvestro, J., Kraemer, P., Achilli, F., Brinkworth, W., 2006. Evolución de las cuencas sinorogénicas de la Cordillera Principal entre $35^{\circ}-36^{\circ} \mathrm{S}$, Malargüe. Revista de la Asociación Geológica Argentina 60(4), 627-643.

Simpson, J., 1987. Mud-Dominated Storm Deposits From A Lower Carboniferous Ramp. Geological Journal 22, 191-205.

Soffia, C., Jose, M., Harambour, P., Salvador S., 1988, Estructuras en el cinturon plegado y fallado de Ultima Esperanza, Magallanes, Chile (Structures in the fold and fault belt of Ultima Esperanza, Magallanes, Chile): Serie Comunicaciones, Departamento de Geologia, Facultad de Ciencias Fisicas y Matematicas, Universidad de Chile 39, 1-36.

Southard, J.B., Boguchwal, L.A., 1990. Bed configurations in steady unidirectional water flows, Synthesis of flume data. Journal of Sedimentary Petrology 60, 658-679.

Spalletti, L.A., 1980. Paleoambientes Sedimentarios en Secuencias Silicoclásticas. Asociación Geológica Argentina. Serie “B”, Didáctica y Complementaria 8. Buenos Aires, 175 pp.

Spalletti, L.A., 1994. Evolución de los ambientes fluviales en el triásicos de la Sierra Pintada (Mendoza, Argentina): análisis sobre la influencia de controles intrínsecos y extrínsecos al sistema depositacional. Revista de la Asociacion Argentina de Sedimentología 1(2), 125-142.

Spalletti L.A., Franzese J.R., 2007. Mesozoic paleogeography and paleoenvironmental evolution of Patagonia (southern South America). En: Gasparini, Z., Salgado, L., Coria, R. (Eds.), Patagonian Mesozoic Reptiles. Bloomington: Indiana University Press, 29-49.

Spalletti, L.A., Franzese, J.R., Matheos, S.D., Schwarz E., 2000. Sequence stratigraphy in tidallydominated carbonate-siliciclastic ramp, the Tithonian of the Southern Neuquén Basin, Argentine. Journal of the Geological Society 157, 433-446.

Spalletti, L.A., Matheos, S.D., Sánchez, E., Oyarzábal, F., 2005. Análisis diagenético de la Formación Springhill (Santa Cruz, Argentina). VI Congreso de Exploración y Desarrollo de Hidrocarburos, Mar del Plata, CD Actas, 14 pp. 
Spalletti, L.A., Pirrie, D., Veiga, G.D., Schwarz, E., Rollinson, G., Shail, R., Haberlah, D., Butcher, A., 2015. Análisis mineralógico integrado (QEMSCAN y DRX) de lutitas negras: los depósitos tithonianos basales de la Formación Vaca Muerta (Cuenca Neuquina, Argentina). Latin American Journal of Sedimentology and Basin Analysis 22(1), 13-28.

Spalletti, L.A., Schwarz, E., Veiga, G.D., 2014. Geoquímica inorgánica como indicador de procedencia y ambiente sedimentario en sucesiones de lutitas negras: los depósitos transgresivos titonianos (Formación Vaca Muerta) de la Cuenca Neuquina, Argentina. Andean Geology 41, 401-435.

Steinke, S., Kienast, M., Groeneveld, J., Lin, L.C., Chen, M.T., Rendle-Bühring, R., 2008. Proxy dependence of the temporal pattern of deglacial warming in the tropical South China Sea: toward resolving seasonality. Quaternary Science Review 68, 8-70.

Steuber, T., Rauch, M., Masse, J.P., Graaf, J., Malkoc, M., 2005. Low-latitude seasonality of Cretaceous temperatures in warm and cold episodes. Nature 437(7063), 1341-1344.

Stipanicic, P.N., Rodrigo, F., Baulies, O.L., Martinez, C.G., 1968. Nota sobre las Formaciones presenonianas en el denominado Macizo Nordpatagrnico y regiones adyacentes. Revista de la Asociación Geológica Argentina 23(2), 67-98.

Stolley, E., 1912. Uber einige Cephalopoden aus der Unteren Kreide Patagoniens. Svenskavetenskaps-Akademien, Stockholm, Arkiv for Zoologi 7, 13-18.

Surdam, R.C., Crossey, L.J., Hagen, E.S., Heasler, H.P., 1989. Organic-inorganic interactions and sandstone diagenesis. American Association of Petroleum Geologists Bulletin 73, 1-23.

Talevi M., Fernandez M., 2012. Unexpected skeletal histology of an ichthyosaur from the Middle Jurassic of Patagonia: implications for evolution of bone microstructure among secondary aquatic tetrapods. Naturwissenschaften 99, 241-244.

Tarduno, J.A., Cottrell, R.D., Lippert, P., Friedman, M., 2002. Extreme climates recorded in the Cretaceous High Arctic: JOI/USSAC. Workshop on Cretaceous Climate and Ocean Dynamics, Colorado, 76.

Tessier, B., Archer, A.W., Lanier, W.P., Feldman, H.R., 1995. Comparison of ancient tidal rhythmites (Carboniferous of Kansas and Indiana, USA) with modern analogues (the Bay of Mont-Saint Michel, France). En: Flemming, B.W., Bartholomá A. (Eds.), Tidal signatures in modern and ancient sediments. International Association of Sedimentologists, Special Publication 24, 259-271.

Thomas, C.R., 1949. Geology and petroleum exploration in Magallanes Province, Chile. American Association of Petroleum Geologists Bulletin 33, 1553-1578. 
Tostevin R., Shields, G.A., Tarbuck, G.M., He, T., Clarkson, M.O., Wood, R.A., 2016. Effective use of cerium anomalies as a redox proxy in carbonate-dominated marine settings. Chemical Geology 438, 146-162.

Tucker, M.E., 1988. Techniques in Sedimentology. Blackwell Scientific Publications, Oxford, 394 pp.

Tucker, M.E., 2001. Sedimentary Petrology. Blackwell Science (3으. Ed.), Oxford, 262 pp.

Tucker, M.E., Bathurst, R.G.C., 1990. Carbonate Diagenesis. Reprint Series 1, International Association of Sedimentologysts Blackwell Science, Oxford, 312 pp.

Uliana, M.A., Mombrú, C.A., Bercowsky, F., 1978. Los abultamientos calcáreos del Cretácico inferior- sur mendocino. Actas del VII Congreso Geológico Argentino, Neuquén 2, 695709.

Uliana, M.A., Biddle, K.T., Cerdán, J., 1989. Mesozoic extension and the formation of argentine sedimentary basins. En: Tankard, A.J., Balkwill, H.R. (Eds.), Extensional Deformation and Stratigraphy of the North Atlantic Margins. American Association of Petroleum Geologists Memoir 46, 599-614.

Uliana, M.A., Legarreta, L., Laffitte, G.A., Villar, H., 1999. Estratigrafía y geoquímica de las facies generadoras de hidrocarburos en las Cuencas Petrolíferas de Argentina. Simposio de Sistemas Petroleros de las Cuencas Argentinas. IV Congreso de Exploración y Desarrollo de Hidrocarburos, Mar del Plata, 1-61.

Ullmann, C.V, Korte, C., 2015. Diagenetic alteration in low-Mg calcite from macrofossils: a review. Geological Quarterly 59, 3-20.

Ullmann, C.V., Frei R., Korte, C., Hesselbo, S.P., 2015. Chemical and isotopic architecture of the belemnite rostrum. Geochimica et Cosmochimica Acta 159, 231-243.

Vaamonde, C., Poiré, D.G., 2006. Algas dasycladáceas en calizas del Complejo El Quemado, Cuenca Austral, Argentina. IV Congreso Latinoamericano de Sedimentología y XI Reunión Argentina de Sedimentología, San Carlos de Bariloche, 233.

Vail, P.R., Mitchum, R.M., Tood, R.G., Widmer, J.M., Thompson, S., Sangree, J.B., Rubb, J.N., Hatleid, W.G., 1977. Seismic stratigraphy and global changes of see-level. En: Payton, C.E. (Ed.), Seismic Stratigraphy-Applications to hydrocarbon explotation. American Association of Petroleum Geologists Memoir 26, 49-212.

Van de Schootbrugge, B., Föllmi, K.B., Bulot, L.G., Burns, S.J., 2000. Paleoceanographic changes during the Early Cretaceous (Valanginian-Hauterivian): evidence from oxygen and carbon stable isotopes. Earth and Planetary Science Letters 181, 15-31.

Varela, A.N., 2011. Sedimentología y modelos deposicionales de La Formación Mata Amarilla, Cretácico De La Cuenca Austral, Argentina. Tesis Doctoral. Universidad Nacional de La 
Plata, 289 pp.

Veiga, G.D., Spalletti, L.A., 2007. The Upper Jurassic (Kimmeridgian) fluvial/aeolian systems of southern Neuquén Basin, Argentina. Gondwana Research 11, 286-302.

Veizer, J., 1983a. Trace elements and isotopes in sedimentary carbonates. En: Reeder, R.J. (Ed.), Carbonates: Mineralogy and Chemistry 11, 265-99.

Veizer, J., 1983b. Chemical diagenesis of carbonates: theory and application of trace element technique. Stable Isotopes. En: Arthur M.A., et al. (Eds.), Sedimentary Geology, 3-100.

Vergani, G.D., Tankard, A.J., Belotti, H.J., Welsink, H.J., 1995. Tectonic evolution and paleogeography of the Neuquén Basin, Argentina. En: Tankard, A.J., Suarez Soruco, R., Welsink, H.J. (Eds.), Petroleum Basins of South America. American Association of Petroleum Geologists Memoir 62, 383-402.

Villar de Seoane, L., 2001. Cuticular study of Bennettitales from the Springhill Formation, Lower Cretaceous of Patagonia, Argentina. Cretaceous Research 22, 461-479.

Weaver, C.E., 1931. Paleontology of the Jurassic and Cretaceous of West Central Argentina. University of Washington, Memoir 1, 1-469.

Weissert, H., Lini, A., Föllmi, K.B., Kuhn, O., 1998. Correlation of Early Cretaceous carbon isotope stratigraphy and platform drowning events: a possible link? Palaeogeography, Palaeoclimatology, Palaeoecology 137, 189-203.

Westermann, S., Föllmi, K.B., Adatte, T., Matera, V., Schnyder, J., Fleitmann, D., Fiet, N., Ploch, I., Duchamp-Alphonse, S., 2010. The Valanginian $\delta^{13} \mathrm{C}$ excursion may not be an expression of a global oceanic anoxic event. Earth Planet. Science Letters 290, 118-131.

Wierzbowski, H., Joachimski, M.M., 2007. Reconstruction of late Bajocian-Bathonian marine palaeoenvironments using carbon and oxygen isotope ratios of calcareous fossils from the Polish Jura Chain (central Poland). Palaeogeography, Palaeoclimatology, Palaeoecology 254, 523-540.

Wohlwend, S., Celestino, R., Reháková, D., Huck, S., Weissert, H., 2017. Late Jurassic to Cretaceous evolution of the eastern Tethyan Hawasina Basin (Oman Mountains). Sedimentology 64, 87-110.

Worden, R.H., Morad, S., 2000. Quartz cementation in oil field sandstones: a review of the key controversies. En: Worden, R.H., Morad, S. (Eds.), Quartz Cementation in Sandstones. International Association of Sedimentologists, Special Publication 29, 1-20.

World sea temperature. World wide web adress: https://www.seatemperature.org/

Wortmann, U.G., Weissert H., 2000. Tying platform drowning to perturbations of the global carbon cycle with a $\delta^{13} \mathrm{C}$ curve from the Valanginian of DSDP Site 416 . Terra Nova 12 , 289-294. 
Zakharov, Y.D., Shigeta, Y., Nagendra, R., Safronov, P.P., Smyshlyaeva, O.P., Popov, A.M., Velivetskaya, T.A., Afanasyeva, T.B., 2011. Cretaceous climate oscillations in the southern palaeolatitudes: New stable isotope evidence from India and Madagascar. Cretaceous Research 32, 623-645.

Zambrano, J.J., Urien, C.M., 1970. Geological outline of the Basins in Southern Argentina and their Continuation off the Atlantic shore. Journal of Geophysical Research 75(8), 13631396.

Zerfass, H., Ramos, V.A., Ghiglione, M.C., Naipauer, M., Belotti, H.J., Carmo, I.O., 2017. Folding, thrusting and development of push-up structures during the Miocene tectonic inversion of the Austral Basin, Southern Patagonian Andes (50 S). Tectonophysics 699, 102-120. 


\section{Agradecimientos}

Las siguientes líneas son para agradecer a todas las personas que me brindaron sustento afectivo y profesional durante estos cinco años. Estoy convencido de que no lo podría haber logrado sin el apoyo de tanta gente querida.

A mis padres que son mi ejemplo, a mis hermanos y cuñado que me apoyan siempre y creen en mí y a Agustina, mi compañera de todos los días, que con interminable amor y paciencia me hace olvidar de todo al llegar a casa.

Al Dr. Luis Spalletti porque desde el primer día estuvo a disposición para enseñarme, aconsejarme y trasmitirme su pasión por la geología.

A la Dra. Lucía Gómez Peral por convencerme de que era posible, por su predisposición y su trato maternal.

Al Dr. Daniel Poiré, por sus palabras de aliento, su apoyo y su optimismo.

A mis amigos con los que comparto la oficina: David, Manuel, Camila, Gastón y Damián por las charlas y lo momentos compartidos, por hacer tan entretenidos los días de trabajo.

A quienes me acompañaron durante las campañas. A Abril, por tantos buenos días de trabajo juntos y por darme los primeros consejos. A Ailen, por su ayuda y compañía. A mi amiga Manu, que sacrificó descanso para hacer geología con migo y Aron, que entre risas clasificó todos los fósiles.

A todas las personas que gentilmente nos hospedaron durante las tareas de campo tanto en Calafate como en Malargüe. Principalmente a Facundo, Dafne, Maia y Naroa, también a mi familia Dacal de Calafate que siempre nos recibió con afecto.

A todo el personal del laboratorio NEG-LABISE en la Universidad de Pernambuco en Brasil, por hacerme sentir como en casa. En especial a Val, Cristian, Natán, Doña Amira y al Dr. Alcides Nobrega Sial con quien compartí tantas charlas de isótopos y fútbol.

A mis compañeros de las Cátedras de Sedimentología y Rocas Sedimentarias: Ernesto, Sebastián, Augusto, Julia, Agustín, Abril, Lucía, Marina, Mariana, Damián y Jerónimo, por tantos viajes y clases compartidas en las que he aprendido muchísimo. También a tantos alumnos con los que compartí tan gratas experiencias.

A los directores del Centro de Investigaciones Geológicas, en la primera etapa el Dr. Carlos Rapela y actualmente el Dr. Juan Franzese, por avalar mi permanencia en el instituto, y por su incentivo durante el desarrollo de esta investigación.

A Victor Liegl, por la molienda de las muestras, a Pablo García y Daniel Mártire por la confección de los cortes delgados y a Neli, Mabel, Rita, Andrea y Mer por tenerme tanta paciencia y ayudarme siempre con tan buena predisposición.

A la Lic. Cecilia Genazzini y al Lic. Germán Kurten por su apoyo en la realización de los estudios de rayos X y a Martín Ruiz por su apoyo en informática. A los encargados del Laboratorio de 
Geoquímica: Lic. Claudia Cavarozzi, Lic. Claudia Di Lello y Dr. Marcos Pedemonte por los análisis de ICPMS.

A la Lic. Florencia Mari que dedicó tiempo y esfuerzo para la preparación de las muestras de carbono orgánico y a la Lic. Mariana Esteban por la confección de la portada.

A la Dra. María Sol Raigemborn, Dr. Sergio Matheos y Lic. Ailen Borya por ayudarme con el equipo de catodoluminiscencia. Al Dr. Sebastián Richiano, que me compartió todo su conocimiento sobre la Cuenca Austral y su amistad.

Al jurado, que con sus comentarios contribuyó a mejorar este trabajo: Dr. Sergio Matheos, Dr. Matías Ghiglione y Dr. Claudio Gaucher.

A mis abuelos, tíos y primos que siempre están atentos a mis pasos y a Soledad, por ayudarme cuando más lo necesitaba.

A mi Grupo Scout porque ser mi lugar de dispersión y mi segundo hogar. A todos los dirigentes y beneficiarios con los que comparto tantas aventuras.

A todos los amigos que me dio esta profesión, en especial al Tano y a Jose que estuvieron presentes en cada paso que di. También a Pablo, Manu, Romi y Guille que siempre tuvieron palabras de aliento.

A los amigos de la vida que siempre están a mi lado.

A todo el Centro de Investigaciones Geológicas, lugar en el que se aprende y se comprarte con grandes compañeros y excelentes profesionales.

AI CONICET, por otorgarme la beca para llevar a cabo mi trabajo de doctorado. A la Facultad de Ciencias Naturales y Museo por alojarme como alumno. A la educación pública argentina, por tantos años de aprendizaje gratuito y de calidad. 
Anexos 
Perfil Río Salado
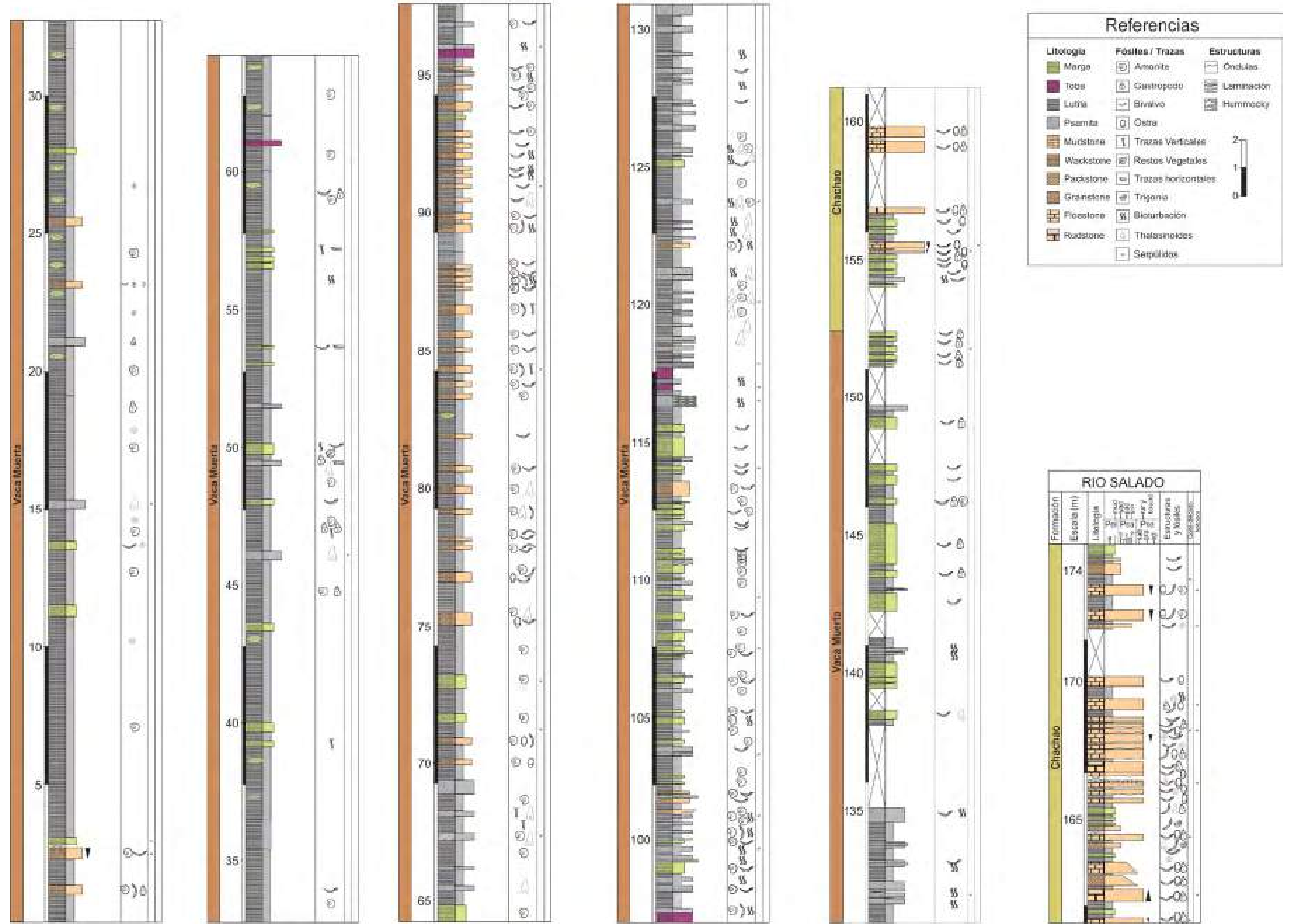
Perfil Puesto Loncoche
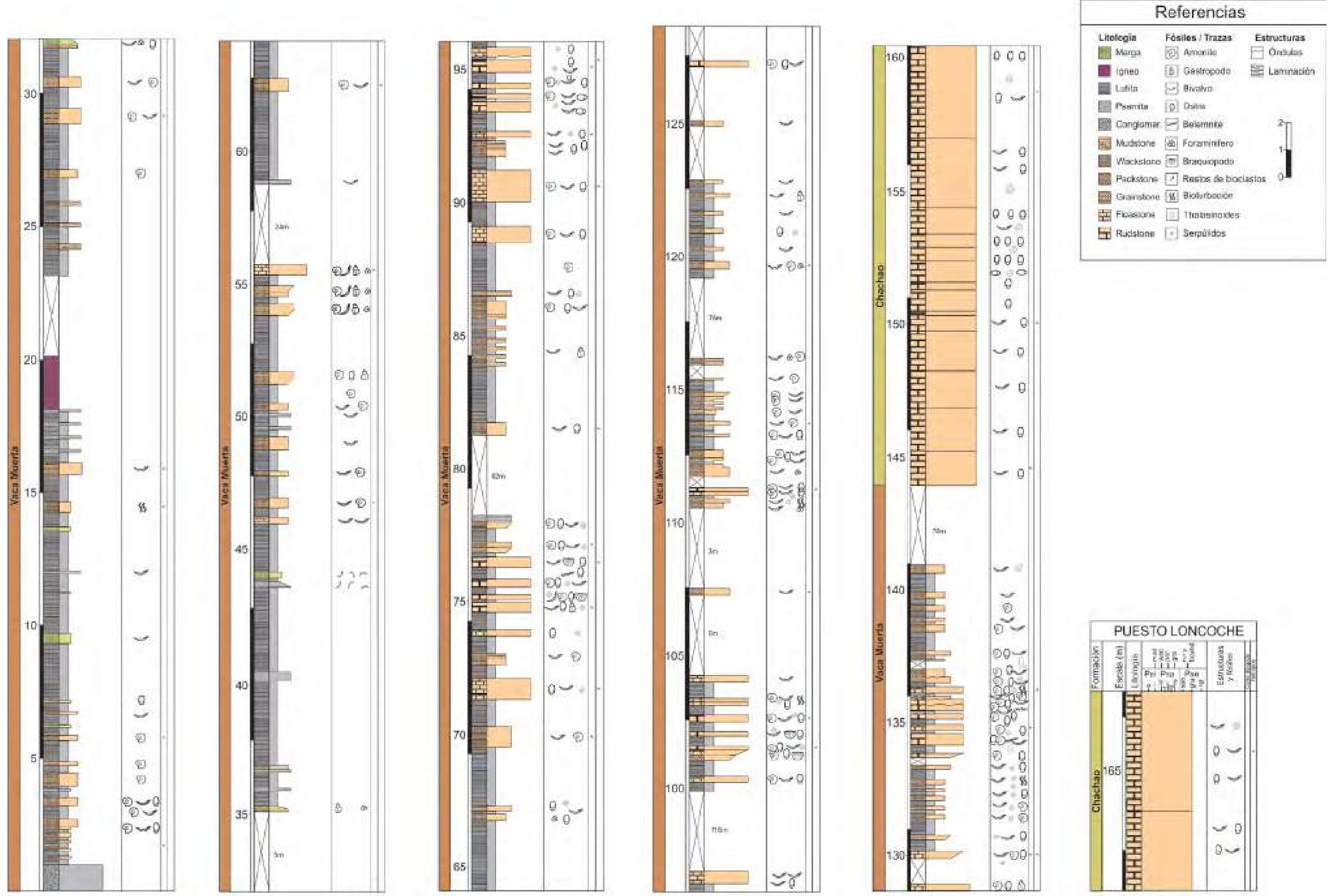


\section{Perfil Cuesta del Chihuido}
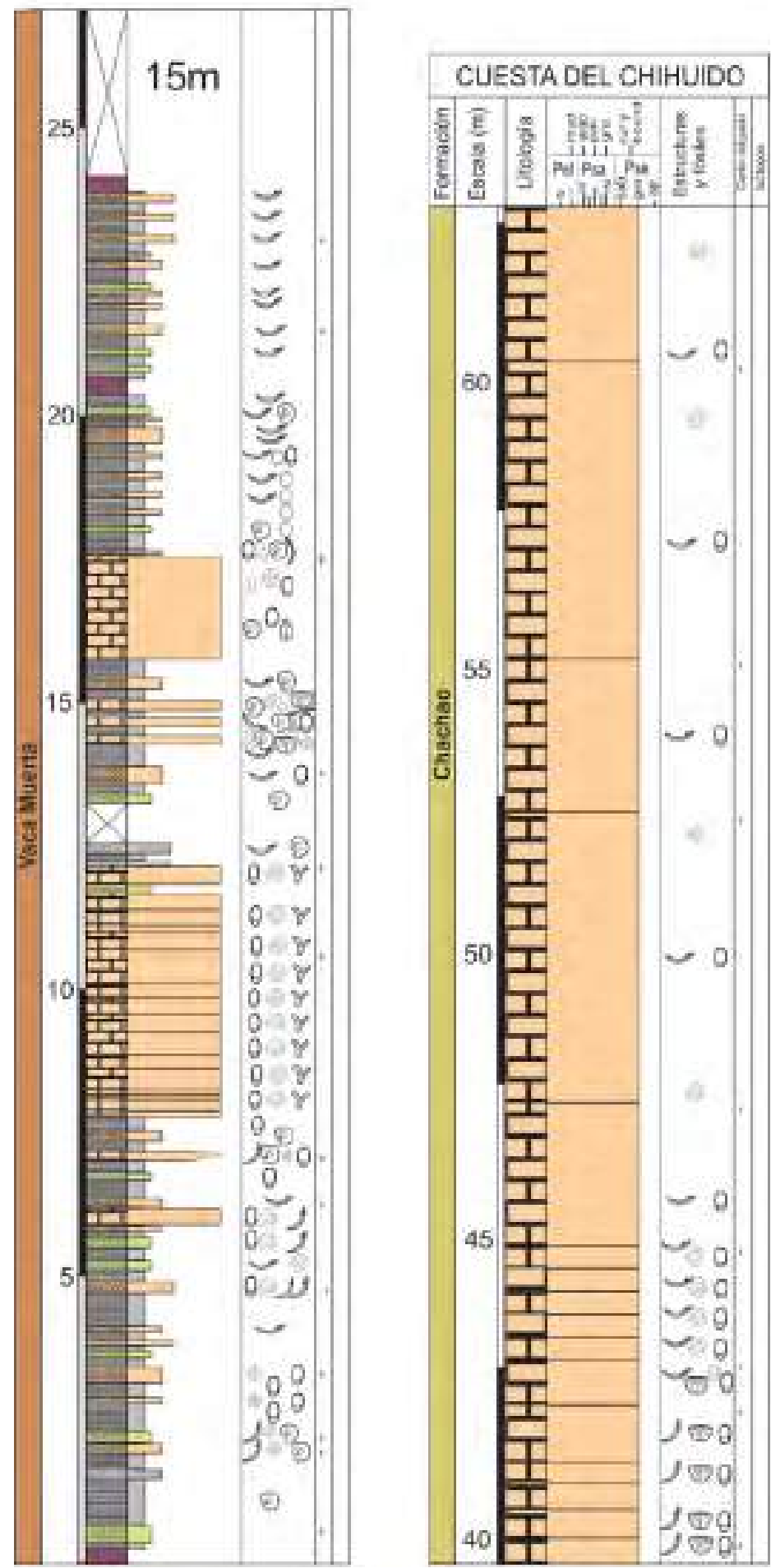

\begin{tabular}{|c|c|}
\hline \multicolumn{2}{|c|}{ Referencias } \\
\hline Litologia & Fosiles / Trazss \\
\hline 国 Mirgs & [1] Amorile \\
\hline tgnoo & [1] Gastropodo \\
\hline Lusta & Divalvo \\
\hline Psimita & [0] Data \\
\hline Heserollices & - Belemino \\
\hline Wacksore & (2) Foratrinilere \\
\hline Das Packicne & (2) Braquopodo \\
\hline 䚾 Flcasxone & M Enamos: \\
\hline II Russione & (0) Cutracodo \\
\hline${ }^{2} 7$ & [1] Tratainnidins \\
\hline & (7) Serpitidios \\
\hline & (1) Dohicnorpoa \\
\hline
\end{tabular}




\section{Perfil Subida del Chancho}

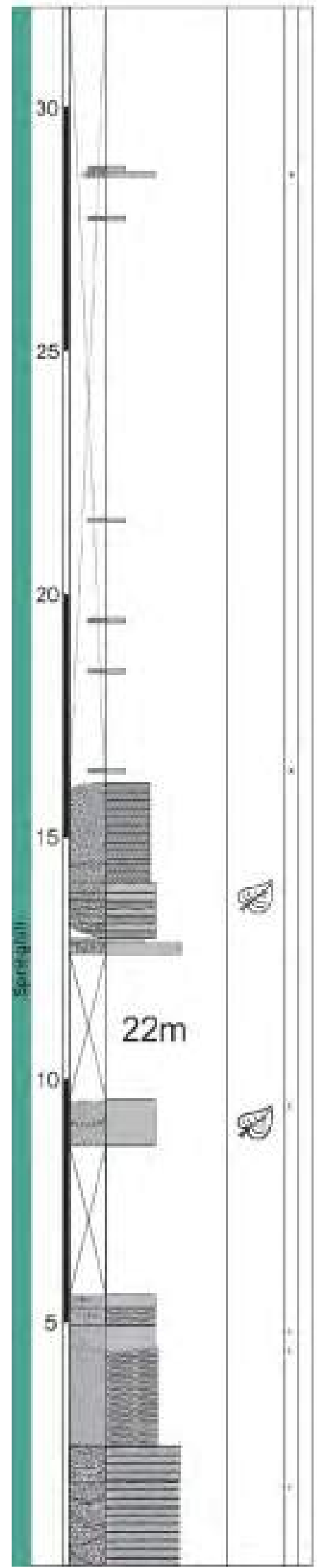

\begin{tabular}{|c|c|c|c|}
\hline \multicolumn{4}{|c|}{ Referencias } \\
\hline Litologia & Foshles $/$ Trazes & Eatructuran & \\
\hline D untas & [-] Bivalwo & \# Onduas & $2 \pi$ \\
\hline Fangolias & - Eeientriso & 园 Lamiracion Horizontas & \\
\hline Daside & (4) Euturthaciōn & 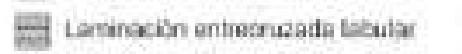 & ${ }^{1}$ \\
\hline 21. Conglemet. & 21. Brizns Vegetales & 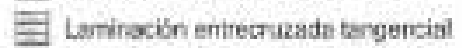 & 0 \\
\hline Dackstone & & & \\
\hline
\end{tabular}

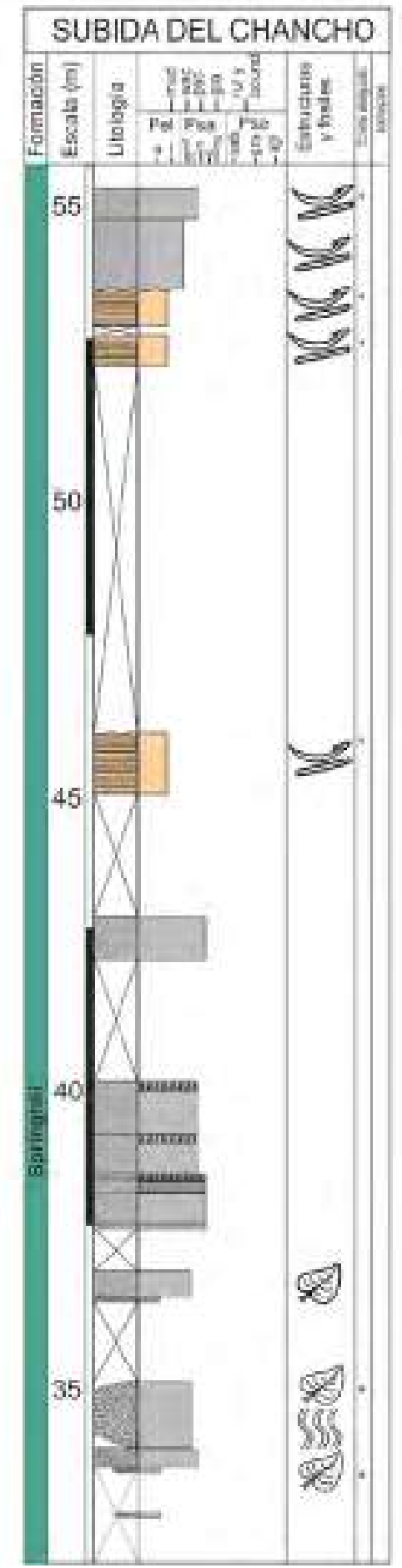


Perfil Río Guanaco

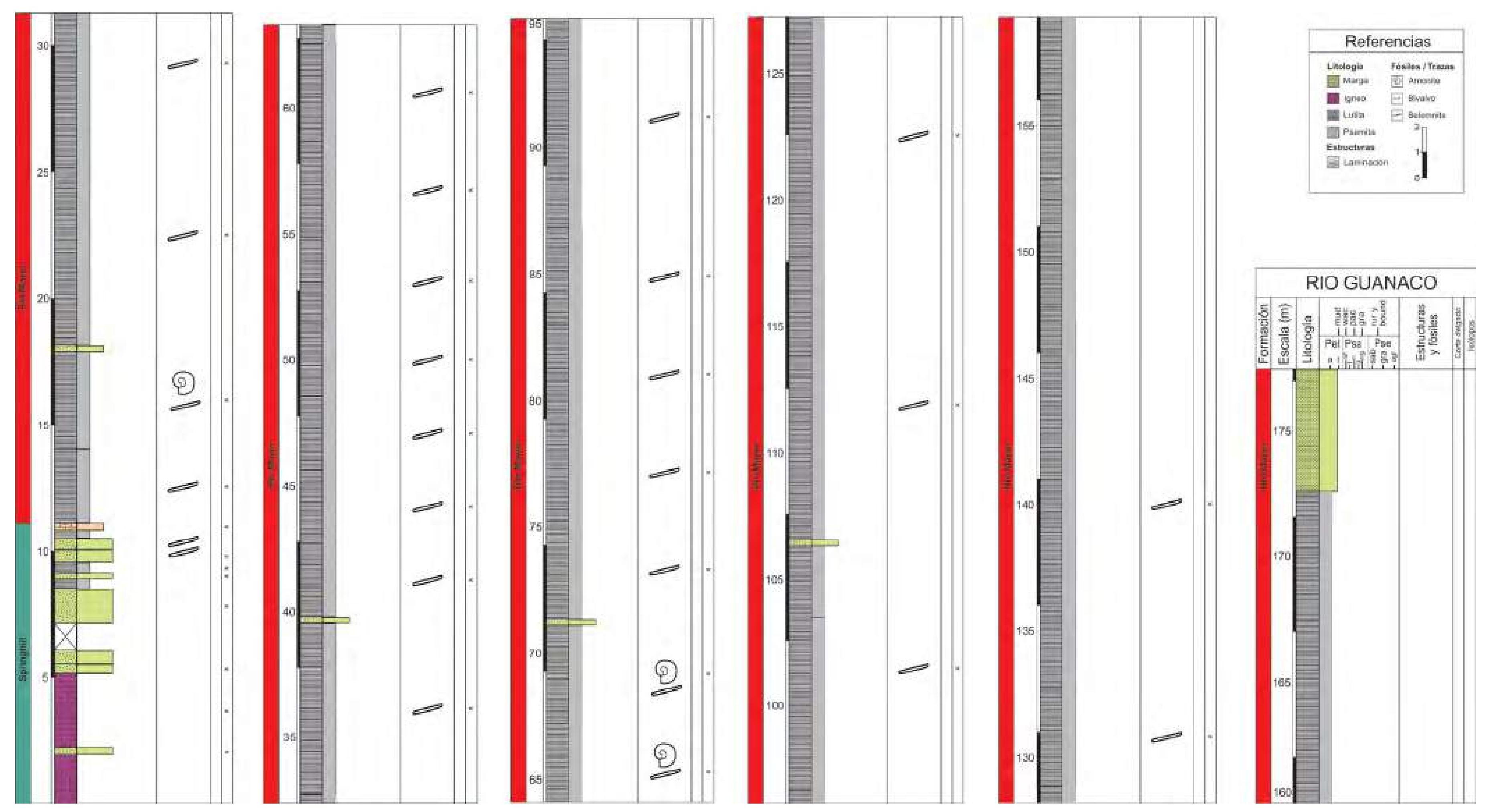



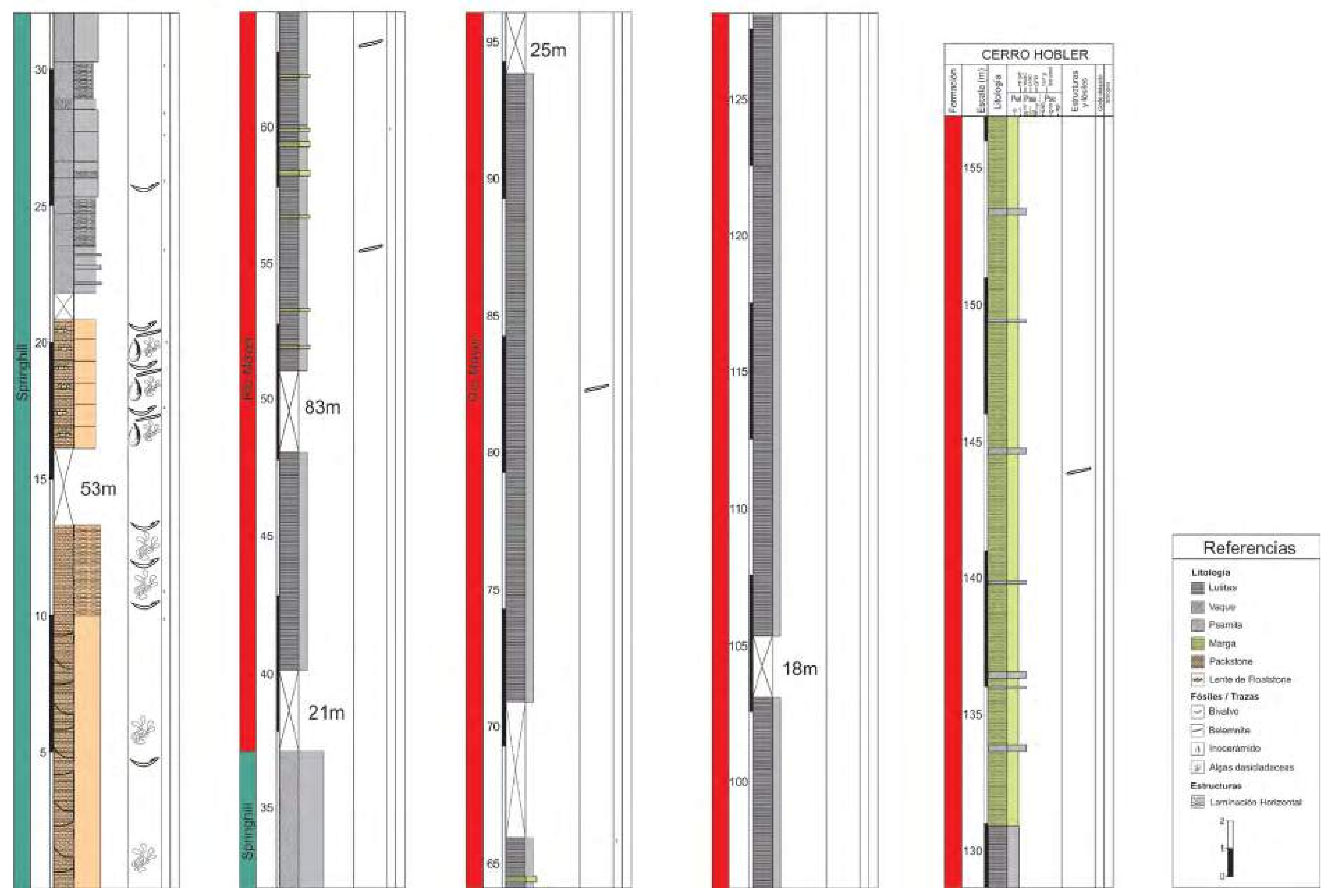